\title{
CATHODOLUMINESCENCE AND CHARACTERISATION OF DEFECT STRUCTURES IN QUARTZ WITH APPLICATIONS TO THE STUDY OF GRANITIC ROCKS
}

\author{
Dissertation \\ zur Erlangung des Doktorgrades \\ der Mathematisch-Naturwissenschaftlichen Fakultäten \\ der Georg-August-Universität zu Göttingen
}

vorgelegt von

Axel Müller

aus Dresden

Göttingen, Juni 2000 
D7

Referent: Prof. Dr. H.-J. Behr

Korreferent: Prof. Dr. K. Weber

Tag der mündlichen Prüfung: 21.06.2000 


\section{Summary}

The presented study contributes in solving the causes of cathodoluminescence (CL) of quartz. For this purpose a variety of quartzes from different geological environments has been systematically studied. The results have been applied to a number of granitic systems for the understanding of the textural evolution, intrusion mechanism, and the phasing of magmatic events of felsic igneous melts.

The spectral response of the CL of quartz in the range of visible light is characterised by emission bands between $1.7-2.2 \mathrm{eV}$ (red) and $2.4-3.1 \mathrm{eV}$ (blue) resulting in blue, violet, and red-brown colours. The emission bands with characteristic (relative) intensities, positions, and half-widths have been mathematically captured. The intensity of CL normally changes during electron radiation, whereby the blue emission decreases and the red emission increases, indicating that the luminescence centres are unstable. The decay and generation of luminescence centres during electron radiation have been quantified by recording timeresolved spectra and by using the kinetic law. The concentration of unstable luminescence centres is highest for quartz formed at low temperatures. In order to study the stability of luminescence centres at different temperatures a number of heating experiments have been carried out. Four emission bands $(1.73,1.85,1.96$, and $2.96 \mathrm{eV})$ are more intense after heating, whereas a band at $2.48 \mathrm{eV}$ disappears. Studies of samples with different polishing qualities show that the CL intensity is reduced for rough surfaces, but the time-dependent ratios of the emission bands remain unchanged. Besides radiation the CL intensity is influenced by the temperature (quenching) during the measurement. Also this correlation has been described here with the kinetic law.

A part of the study deals with the correlation between the CL properties and trace element contents (mainly Al, Ti, Li). Analytical conditions for EPMA, LA ICP-MS, SIMS were carefully chosen in order to achieve the highest possible sensitivity of these microanalytical methods applied to quartz analysis. Trace element line profiles explained the growth and alteration zones visible in CL. The average Fe concentration increases with the quartz formation temperature. Therefore, the Fe content can be used to distinguish magmatic and hydrothermal quartz. Substitutional incorporation of $\mathrm{Fe}^{3+}$ in the quartz lattice causes CL emission at $1.73 \mathrm{eV}$. The increase of the 1.85 and $1.96 \mathrm{eV}$ CL emissions during electron radiation is explained by the abundance of hydroxyl defects in the quartz lattice. Upon 
electron radiation $\mathrm{H}^{+}$diffuses away and forms non-bridging oxygen hole centres, resulting in higher CL intensity. This increase is steeper for hydrothermal and granitic ("wet") quartzes and is flatter for rhyolitic ("dry") quartz. The $2.15 \mathrm{eV} \mathrm{CL}$ emission (yellow) is characteristic for some granitic quartzes with high $\mathrm{Mn}(3-6 \mathrm{ppm})$. The $2.48 \mathrm{eV} \mathrm{CL}$ emission (turquoise) is typical for hydrothermal quartz, which shows a high Li-associated $3474 \mathrm{~cm}^{-1}$ IR absorption band. The $2.58 \mathrm{eV}, 2.68 \mathrm{eV}$ emissions occurring in spectra of all investigated quartzes may be caused by intrinsic defects such as oxygen vacancies. Hydrothermal quartz may contain high $\mathrm{Al}$ concentrations up to up to $5000 \mathrm{ppm}$; magmatic quartz shows $\mathrm{Al}$ concentrations up to 200 ppm. The hydrothermal quartz is characterised by a blue "flash" at initial electron radiation caused by the $2.79 \mathrm{eV} \mathrm{CL}$ emission. It is assumed that this CL emission is related to the positively charged interstitial cations $\mathrm{H}^{+}, \mathrm{Na}^{+}, \mathrm{Li}^{+}$and $\mathrm{K}^{+}$which compensate substitutional $\mathrm{Al}^{3+}$. However, the concentrations of these trace elements do not simply correlate with the CL intensity. Besides the unstable blue CL, we found also a more stable CL emission at a slightly different wavelength $(2.96 \mathrm{eV})$ in quartz phenocrysts in rhyolite and granite. This luminescence could be related with $\mathrm{Ti}$ (up to $130 \mathrm{ppm}$ ) and is responsible for the contrasting of growth zoning.

Based on the CL properties and trace elements, magmatic quartz has been subdivided into (1) euhedral quartz phenocrysts showing stable, dominantly blue CL and growth zoning related to Ti distribution and (2) anhedral matrix quartz with unstable red-brown CL and homogeneous trace element distribution. The red-brown $\mathrm{CL}$ is related to the concentration of $\mathrm{OH}^{-}$and molecular $\mathrm{H}_{2} \mathrm{O}$ in the crystal lattice. Rhyolitic and granitic quartz phenocrysts show similar growth textures and trace element signatures indicating a similar low to mid-crustal crystallisation environment. The phenocrysts are characterised by a fine-scale oscillatory zoning (2 - $20 \mu \mathrm{m}$ width), within super-ordinate stepped zoning (50 - $1000 \mu \mathrm{m}$ width), resorption surfaces, diffusion-induced wavy surfaces, and growth impediments. Except for the oscillatory zoning, formed by self-organising growth, all growth textures formed by external physico-chemical changes (temperature, pressure and magma composition) which result in abrupt changes of the $\mathrm{Ti}$ concentration in the quartz crystals. The Ti content in the quartz phenocrysts increases with increasing growth rate. Whereas the properties of the quartz phenocryst point at low to mid-crustal origin, the matrix quartz must have been formed during the conditions of magma emplacement.

Hydrothermal quartz shows similar growth patterns as magmatic quartz, but stepped zoning is dominant here. This indicates quartz crystallisation in a disturbed (open) system. A 
characteristic feature of hydrothermal quartz is the so-called sector zoning caused by different impurity concentrations dependant of the growth direction. The zoning patterns in hydrothermal quartz are explained by the distribution of Al-defects. The Al uptake is mainly controlled by the $\mathrm{pH}$ of the aqueous solution; high $\mathrm{pH}(=5)$ results in high $\mathrm{Al}$ concentrations in the quartz lattice. Additionally, the charge compensating ions $\mathrm{H}^{+}, \mathrm{Li}^{+}, \mathrm{Na}^{+}$, and $\mathrm{K}^{+}$ stimulates the $\mathrm{AP}^{3+}$ uptake.

Besides primary growth textures both magmatic and hydrothermal quartz mostly show a large variety of secondary structures, which formed during retrograde processes. These processes include (1) micro cataclasis, (2) healing, (3) diffusion, and (4) a-radiation. Based on the CL measurements, we proposed a classification in (a) secondary structures with reduced defects and (b) secondary structures with induced defects. Secondary structures with reduced defects are basically the result of healing, dissolution-precipitation and diffusion, typically occur in micro shear zones, along grain boundaries, and as halos around fluid inclusions. Decrepitometry studies of fluid inclusions with halos of secondary non-luminescent quartz showed they hold anomalous high fluid pressure on heating. The formation of secondary quartz around fluid inclusions indicates the healing of defect structures and are possibly initiated by the local increase of stress in part due to pressure gradients between fluid inclusion and host quartz. Structures with higher defect concentrations are the result of natural a-radiation and trace element diffusion and comprise bright CL halos around radioactive mineral inclusions, diffusion rims along grain boundaries, and radiation-induced nonluminescent spots. The radiation-induced spots are interpreted as aggregations of aqua complexes with a gel-like structure, i.e. regions with a high local concentration of $\mathrm{H}_{\mathrm{O}} \mathrm{O}$ and substitutional Al compensated by hydroxyl groups. Non-luminescent spots and secondary quartz around fluid inclusions are frequent in granitic matrix quartz and less common or lacking in phenocrysts.

Cathodoluminescence has been applied to granitic systems from 2 magmatic provinces: the Krušne Hory/Erzgebirge (Czech Republic/Germany) and the Eastern Lachlan Fold Belt (Australia). In this way, the reconstruction of petrogenetic processes during granitic melt generation, ascent and emplacement and related fractionation, could be achieved. The quartz phenocrysts occurring in the F-Li-enriched granites of the Krušne Hory/Erzgebirge show distinct contrasted growth zoning, being more common for phenocrysts in rhyolites. Similarities in grain size, grain shape and growth texture found for phenocrysts in different 
granite varieties of a intrusion complex proof a common history during the earliest stage of crystallisation. The CL properties of different quartz generations in granite reflect the change of the water content of the melt. During the early crystallisation stage the magma contained $<2.5 \mathrm{wt} \% \mathrm{H}_{2} \mathrm{O}$ and produced euhedral phenocrysts with stable CL and growth zoning. During magma evolution the water content of the melt increases until about $5 \mathrm{wt} \% \mathrm{H}_{2} \mathrm{O}$. At the latter stage anhedral matrix quartz was formed. The quartz phenocrysts from different complexes of F-Li-enriched granites may show different trace element contents (Ti/Al ratios). However, the magmatic rock textures, quartz generations, growth patterns observed in CL are very similar for all rocks. These similarities suggest that the magmatic quartz textures in the granite and the phenocryst growth patterns found in Krušne Hory/Erzgebirge province are typical for FLi-enriched melts which are related to $\mathrm{Sn}-\mathrm{W}$-mineralisations.

Snowball-textured quartz phenoblasts occur common in highly evolved F-Li-enriched granites and represent a late-magmatic solidification texture. Contrary to the rhyolitic quartz phenocrysts these snowball quartzes show red CL. A trigonal habit of the zoning in the phenoblasts indicates crystallisation temperatures $<600^{\circ} \mathrm{C}$ (at $<1 \mathrm{kbar}$ ). The irregular zoning is explained due to periodic degassing during melt cooling in the granite roof. We found that snowball quartz is a textural indicator for fluid-saturated, F-Li-enriched melts of alkali feldspar granites with sub-volcanic (shallow) emplacement. Furthermore, it serves as an indirect indicator for $\mathrm{Sn}-\mathrm{W}$-mineralisation.

The application of CL to greenschist facial deformed quartz of granites from the Eastern Lachlan Fold Belt, Australia showed that magmatic undeformed and deformed quartz can be easily distinguished based on CL properties. Deformed quartz exhibits structures of newly formed (secondary) quartz with weak red-brown CL whereas undeformed quartz shows blue to violet CL. The secondary quartz is depleted in trace elements. In deformed magmatic quartz the unstable 1.85 and $1.96 \mathrm{eV} \mathrm{CL}$ emissions related to water-bearing defects remain constant during electron radiation, indicating that the interstitial molecular water has been removed from the quartz lattice during deformation and subsequently was incorporated into muscovite micro flakes. 


\section{Acknowledgements}

First of all I like to thank all my co-workers from the Earth Science Institutes in Göttingen for their contribution to having a pleasant time throughout the last three years.

I would like to express my sincere thanks to Prof. Dr. H.-J. Behr and Dr. A.M. van den Kerkhof for setting up the project, their continuous, motivating support, and the numerous discussions we had during the course of study. They reviewed the whole manuscript critically and improved the quality of the thesis significantly. I also like to thank Prof. Dr. Weber for taking on the function of co-adviser.

I am extremely happy about the effective and smooth collaboration with Dr. R. Seltmann and Dr. R. Trzebski. I appreciate many fruitful scientific discussions with them.

I greatly appreciate the help of Dr. A. Kronz, Dr. K. Simon, T. Scherer, and Dr. M. Wiedenbeck with their tremendous technical knowledge they were instrumental for the progress of the present work.

Special thanks go to Dr. J. Götze, Dr. N. Stenina, Dr. K. Breiter, Dr. U. Hein, Dr. M. René, Dr. A. Vollbrecht, Dr. S. Siegesmund for invaluable advice, discussions which largely contributed to the success of this study.

Dr. P. Lennox is thanked for his introduction to the Australian geology and for the organisation of the field work in Australia.

For the correction of the English I wish to thank B. Peters-Kewitz, Dr. F. Wall, Dr. C.J. Stanley, Dr. C.T. Williams, Dr. R. Armstrong, and C. Gross.

Funding for the project was provided by the Collaborative Research Centre SFB 468 "Wechselwirkungen an geologischen Grenzflächen".

Above all, I thank my parents for their extraordinary support, both morally and financially. During all my university education they have been a constant source of encouragement. 


\section{Contents}

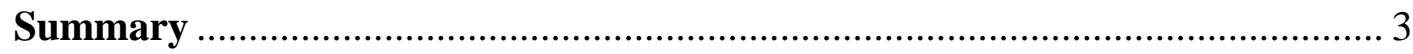

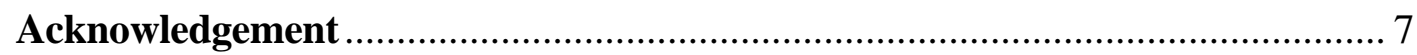

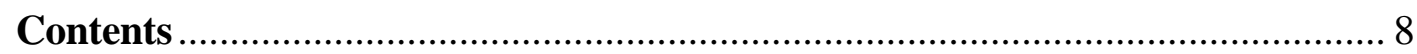

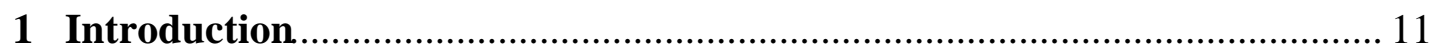

1.1 The application of cathodoluminescence to the study of quartz.................. 11

1.2 Aims of the study................................................................................... 15

Part I-CL properties and defect structures in quartz .............................. 15

Part II - CL applied to the study of granitic rocks .................................... 17

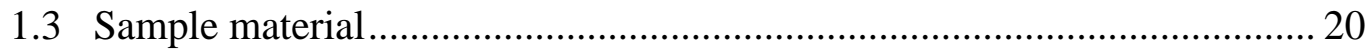

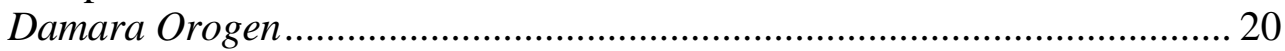

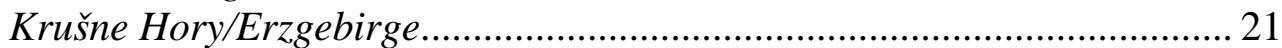

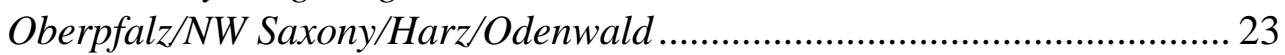

Eastern Lachlan Fold Belt .................................................................... 24

\section{PART I}

Cathodoluminescence properties and defect structures in quartz

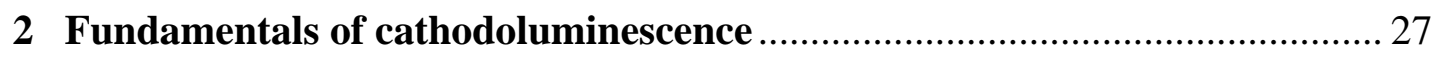

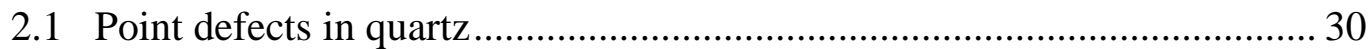

2.2 The state of water in quartz..................................................................... 32

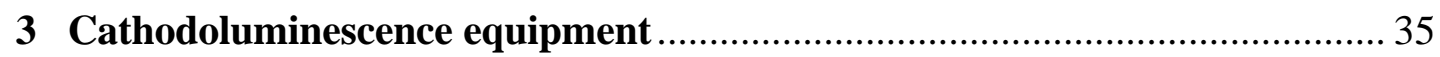

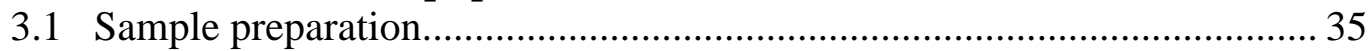

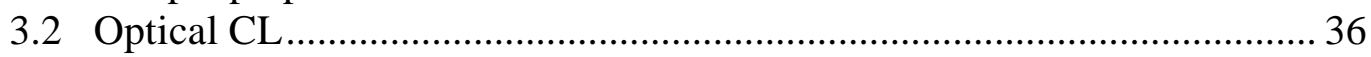

Cathodoluminescence microscope HC3-LM …………………………...... 36

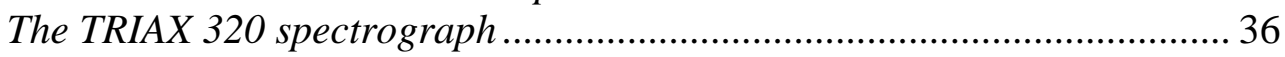

3.3 Scanning electron microscope (SEM) CL ................................................. 41

3.4 Mathematical treatment of CL spectra ........................................................ 43

4 Microanalysis of trace elements and defect centre characterisation in quartz

4.1 Electron probe microanalysis (EPMA),........................................................ 46

4.2 Laser ablation inductively coupled plasma mass spectrometry

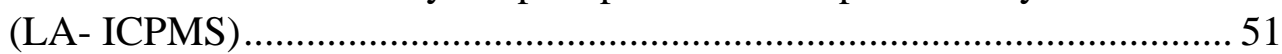

4.3 Secondary ion mass spectroscopy (SIMS) ……………………………..... 54

4.4 Fourier-transform infrared (FTIR) spectroscopy......................................... 57

4.5 Electron paramagnetic resonance (EPR) ……………………………....... 58

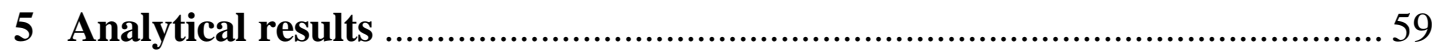

5.1 Characterisation of the cathodoluminescence of quartz..............................59

5.2 Instability of luminescence centres during electron bombardment ..............66 66

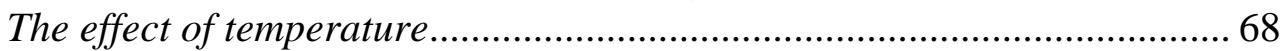

CL of thermally treated quartz................................................................... 73

The effect of sample preparation on the $C L$ of quartz................................. 73

Quantification of CL intensity change during electron radiation ................. 75 
5.3 Comparison of CL spectral and trace element analysis ............................ 77

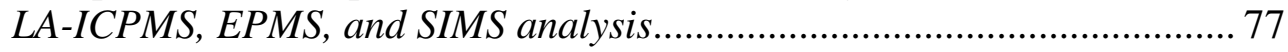

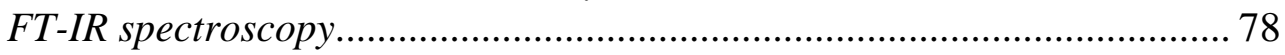

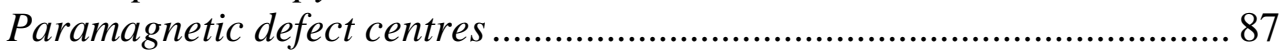

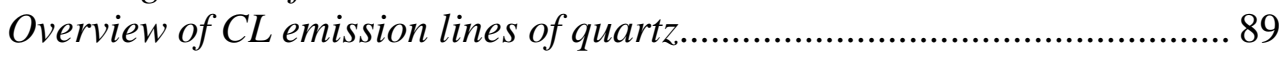

6 Genetic significance of CL structures and trace element distribution..........95

6.1 Impurity uptake during quartz crystallisation in silicate melts................... 95

6.2 Impurity uptake during quartz crystallisation in aqueous solution............. 102

6.3 Secondary CL structures and processes resulting in modification

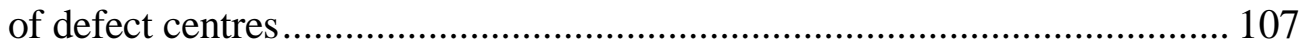

Secondary CL structures with reduced defect centres ............................... 107

Secondary CL structures with induced defect centres................................ 112

\section{PART II \\ Cathodoluminescence of quartz applied to the study of granitic rocks}

7 Application of Cathodoluminescence to Magmatic Quartz in a Tin Granite case study from the Schellerhau Granite Complex,

Eastern Erzgebirge, Germany

(co-authors: Seltmann R. and Behr H.-J.)........................................................ 114

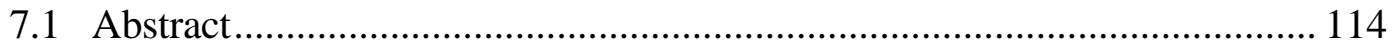

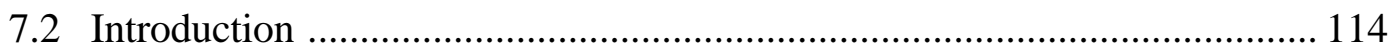

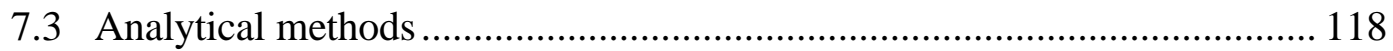

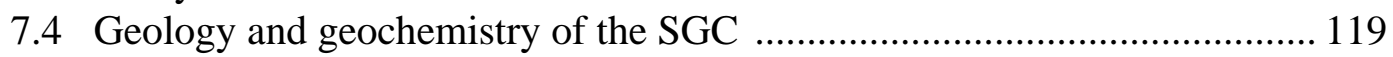

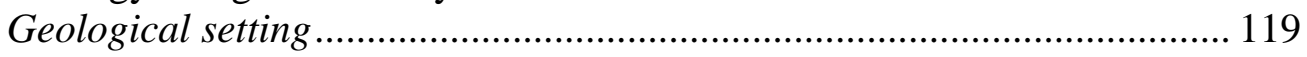

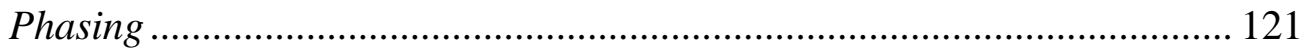

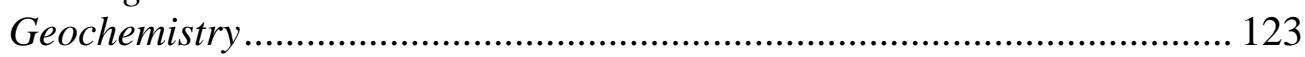

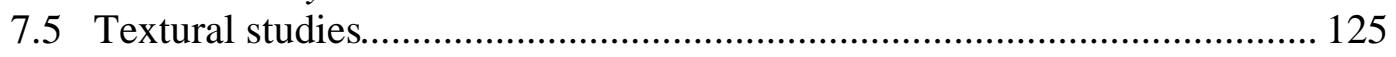

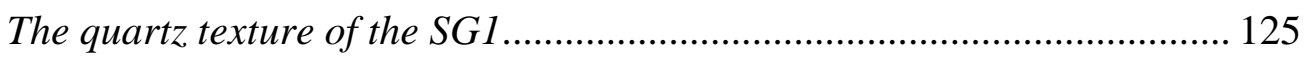

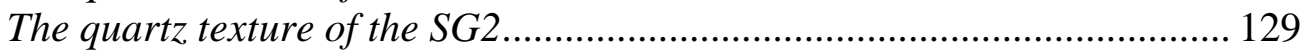

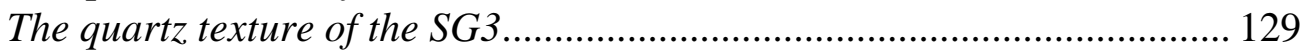

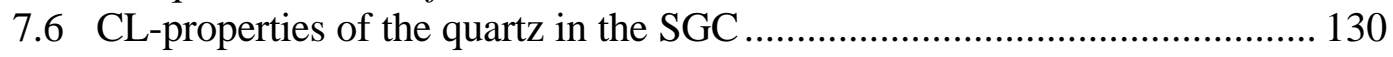

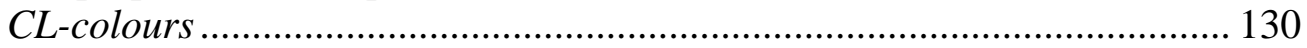

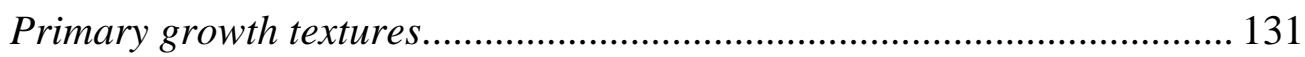

Secondary CL structures ................................................................... 137

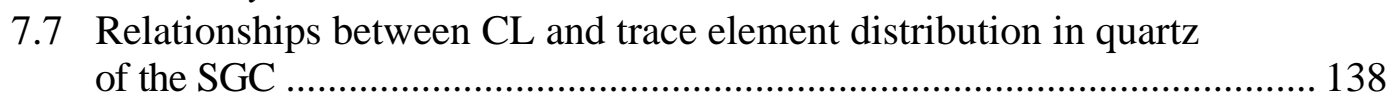

7.8 A multistage quartz crystallisation model of the SGC ............................ 142

Early phenocryst crystallisation ............................................................ 142

Melt separation, intrusion, and main crystallisation of SG1, SG2

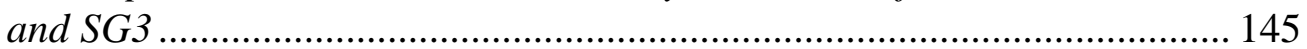

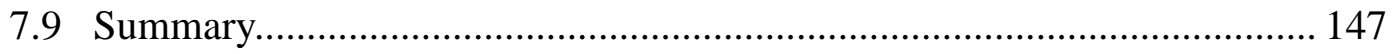

8 The genetic significance of snowball quartz in highly fractionated tin granites of the Krušne Hory/Erzgebirge

(co-author: and Seltmann R.).................................................................... 149

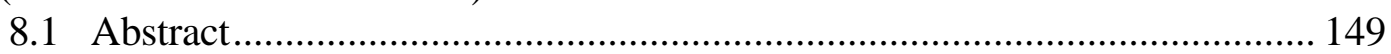

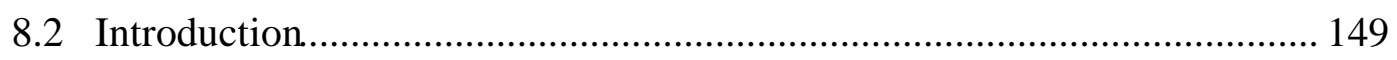

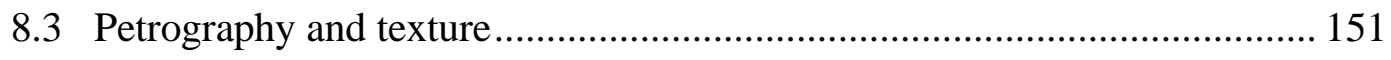




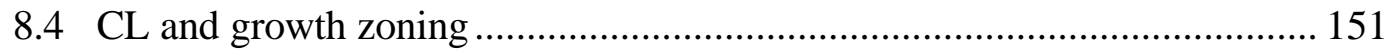

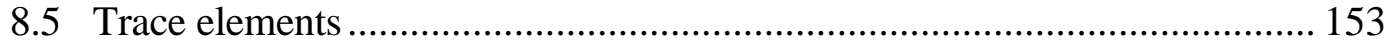

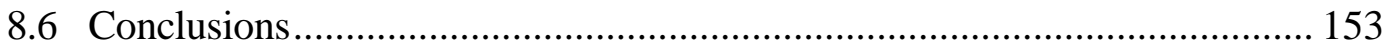

9 Cathodoluminescence (CL) of magmatic quartz: applications to topaz granites from the Hub Stock (Slavkovský Les Mts., Czech Republic)

(co-author: René M. and Behr H.-J.) .............................................................. 156

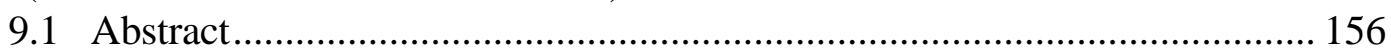

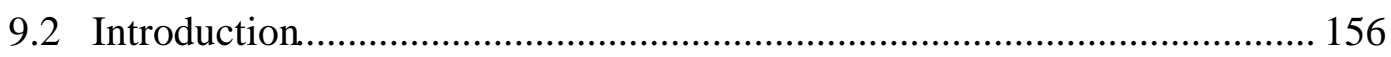

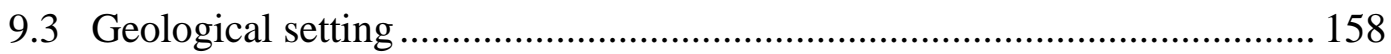

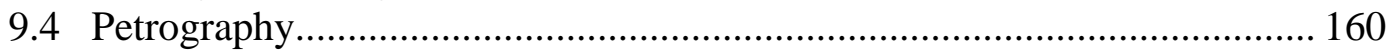

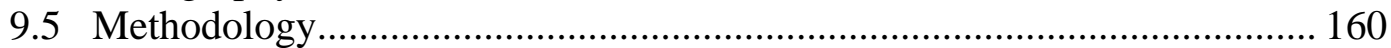

9.6 Quartz CL colours and growth patterns ................................................. 162

9.7 Quartz CL spectroscopy and trace element distribution............................ 162

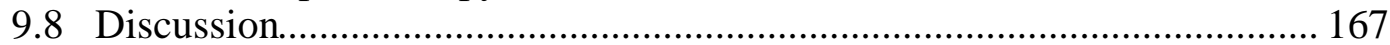

10 Magma crystallisation, emplacement and deformation of S- and I-type granites in the Eastern Lachlan Fold Belt (SE Australia) indicated by quartz texture, cathodoluminescence, and Al-in-hornblende barometry (co-authors: Lennox P., and Trzebski R.)......................................................... 171

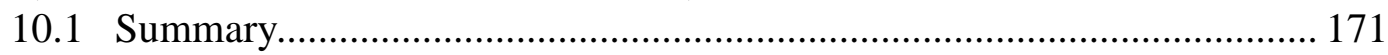

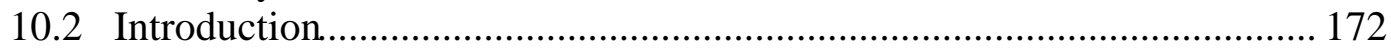

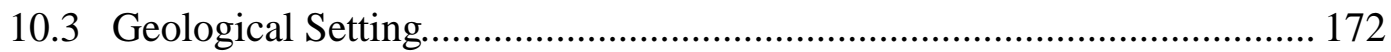

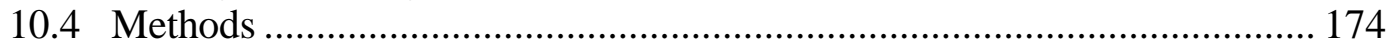

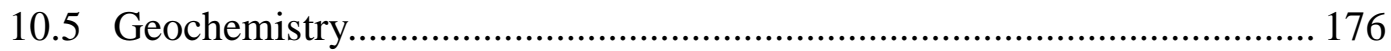

10.6 Quartz texture and foliation development ........................................... 177

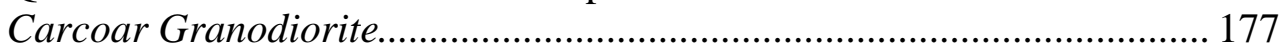

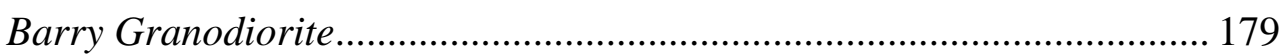

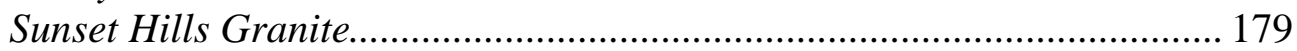

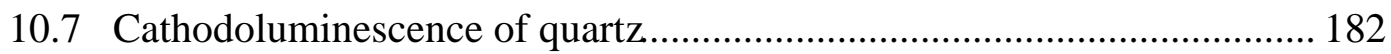

Primary magmatic CL textures …........................................................... 182

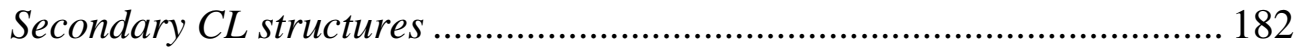

CL patterns and properties linked to trace elements in the quartz........... 183

10.8 Al-in-hornblende geobarometry on the Carcoar and Barry granodiorites. 188

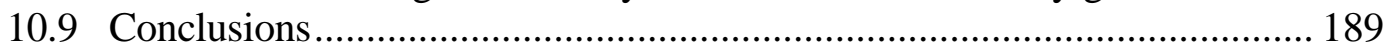

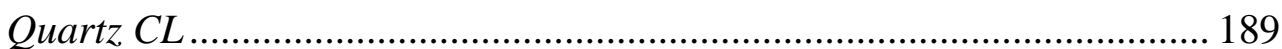

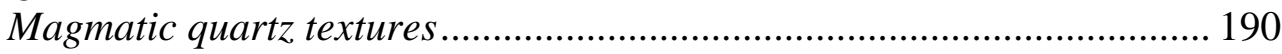

Geochemistry and Al-in-hornblende geobarometry............................... 191

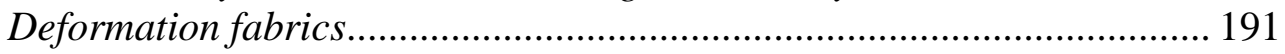

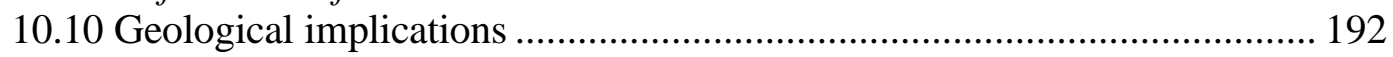

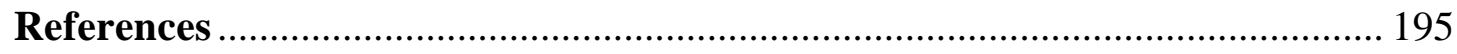

Appendix A

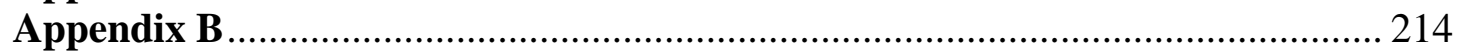

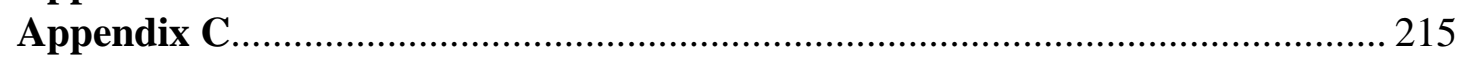

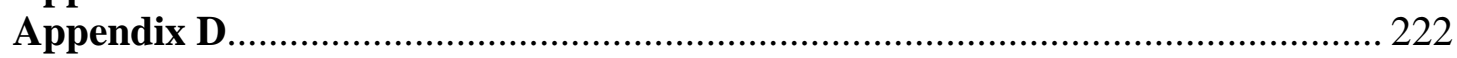

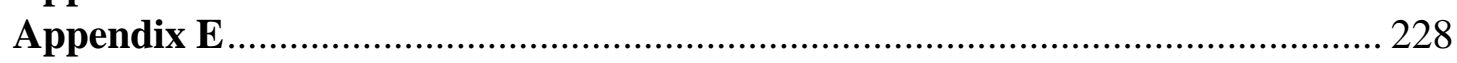




\section{Introduction}

\subsection{The application of cathodoluminescence to the study of quartz}

The electron-excited luminescence, or cathodoluminescence (CL), is an efficient technique for the visualisation of intra-granular growth textures and alteration structures in quartz. A distinction is made between growth textures such as zonation, resorption, incrustation, cementation, etc., and secondary, late-formed structures such as alteration halos along grain boundaries, healed microcracks formed by brittle deformation and healing structures around fluid inclusions (Behr and Frentzel-Beyme, 1988; Behr, 1989). In the following the term "primary CL textures" is used for intra-granular growth patterns developed during crystal growth which is in agreement with the general application of the term "growth textures" for crystal arrangements and zoning patterns in igneous rocks (e.g. Bard, 1986; Shore and Fowler, 1996; Watt et al., 1997). The term "secondary CL structures" is used for the wide variety of structures formed during alteration, healing, and retrograde processes.

These structures which become visible using CL are principally based on the distribution of trace elements and defects in the crystal lattice. The CL depends on the kind of chemical bond, lattice defects (vacancies), and impurity elements which can act as activators, sensitizers, and quenchers. Changes in the quantity and quality of defects in a mineral revealed by $\mathrm{CL}$ and complementary microanalytical methods reflect physico-chemical changes of melts and fluids (nature, concentration and oxidation state of trace elements, temperature and $\mathrm{pH}$ of solutions etc.) during crystal growth, deformation or alteration, or post-crystallisation dose rates of natural $\alpha$ - and $\gamma$-irradiation. However, the relationship between the CL emission and the defect structures of quartz are complex, most still not completely understood. Therefore, CL microscopy has been underused for the reconstruction of geological processes so far. The presented study contributes in solving the causes of the CL of quartz and uses CL for the interpretation of rock-forming processes.

The CL of minerals was studied more than a hundred years ago by Crookes (1879), who observed that "substances known to be phosphorescent shine with great splendour when subjected to the negative discharge in high vacuum". The first report about cathodoluminescence of quartz was given by Goldstein (1907). The possibilities afforded by the microscopic examination of minerals under electron bombardment was not explored until the 1960's when the luminescence was studied since introduction of the electron microprobe. 
Smith and Stenstrom (1965) and Long and Agrell (1965) independently made luminescence microphotographs by illuminating the surface of thin sections with a electron beam $(\sim 1 \mathrm{~mm}$ diameter). The results clearly showed the correlation between luminescence colour and brightness and the concentration of trace elements in quartz and zoned calcite. Sippel (1965) and Smith and Stenstrom (1965) used CL for the distinction of detrital quartz grains of igneous or metamorphic origin and cement quartz. During the last 30 years, the application of quartz CL in geosciences has grown in both extent and diversity. Major contributions pointing out the use of CL as a petrologic tool have been published by Smith and Stenstrom (1965), Remond (1977), Zinkernagel (1978), Hagni (1984, 1987), Walker (1985), Marshall (1988), Remond et al. (1992), and Pagel et al. (2000).

Applications of CL in geosciences with special emphasis to quartz and quartz-bearing rocks are summarised as follows:

1. CL facilitates the rapid characterisation of modal mineralogy and the identification of economic or pathfinder minerals. It is possible to distinguish mineral constituents by colour contrast, even in fine-grained rocks like sandstone or quartzite (e.g. Magnus and Götze, 1998).

2. CL is well suitable to distinguish between different mineral generations of quartz and carbonate. It enables the distinction of detrial quartz and cement quartz in siliciclastic rock (e.g. Sippel, 1968) or of different quartz generations in igneous rocks (D'Lemos et al., 1997; Müller et al., 2000). CL imaging clearly yields superior quantification of quartz cement volumes in siliciclastic rocks (e.g. Evans et al., 1988). It has been suggested that CL colours and structures visible in CL in detrial quartz grains may be used as provenance indicators in study of siliciclastic rocks (Matter and Ramseyer, 1985; Owen, 1991; Kennedy and Arikan, 1990; Milliken, 1994).

3. CL is a sensitive method for revealing growth zonation, twinning patterns, grain shapes and secondary overgrowths which are not distinguishable in transmitted or polarised light (e.g. D'Lemos et al., 1997; Watt et al., 1997). Zoning patterns result from the combination of progressive growth, boundary layer effects and episodes of crystal-melt/fluid disequilibria caused by fluctuations in temperature and melt/fluid composition during crystallisation. The intragranular growth textures yield important information about the nature and evolution of the crystal-forming melt/fluid.

4. The distribution of luminescence colours reveals alteration patterns in crystals, like grain boundary alteration. The knowledge of the alteration pattern is important, for instance, for the interpretation of oxygen isotope distribution in quartz crystals (Valley and Graham, 
1996). In ore exploration CL studies of alteration structures facilitates the delineation of the alteration zones affected by mineralising fluids and therewith of the size of ore bodies (Hagni, 1984; 1987).

5. Alteration and deformation (secondary) structures like healed micro-fractures and recrystallised phases can be easily detected in quartz by CL. This structures are indicators for the paleopermeability and paleoporosity of crustal rocks, which are of particular interest for oil exploration (e.g. Behr and Frentzel-Beyme, 1988; Laubach, 1997). Boiron et al. (1992) and Winslow et al. (1994) demonstrated that CL can be used to distinguish between different inclusion generations. Furthermore, CL investigations of secondary structures contribute in solving the problem of fluid loss and re-equilibration of fluid inclusions in quartz (e.g. Audétat and Günther, 1999).

6. CL spectroscopy provides information about the impurity and defect centre quality of a crystal. For example, in carbonate REE can be measured by CL analysis of carbonate at levels down to $0.1 \mathrm{ppm}$ (Habermann et al., 2000). In some cases, CL spectrometry allows the semi-quantitative analysis of trace elements (Townsend and Rowlands, 2000). Defect identification of silicates by $\mathrm{CL}$ are also of interest for material sciences e.g., semiconductor industry, silicate technique, optical industry, and for the protection of historical monuments i.e. the study of weathering of building materials like marble and limestone.

Despite considerable benefits of the phenomenological investigation of CL colours in quartz, the causes of CL have not been resolved. This is partly due to the complex CL spectrum, about 12 emission bands were detected in quartz (Kalceff and Phillips, 1995 and references therein), and partly to the fact that the incorporation of trace elements and natural irradiation causes a great number structural defects which strongly influence the quartz CL (e.g. Richter and Zinkernagel, 1975; Zinkernagel, 1978; Sprunt, 1981; Ramseyer et al., 1988; Owen, 1988; Ramseyer and Mullis, 1990; Perny et al., 1992; Kalceff and Phillips, 1995). The determination of trace element distribution is impeded by the general low trace element content of quartz which is in the range of the detection limits of micro analytical techniques. Furthermore, the structure of the defects in the quartz lattice is partly unknown.

Trace elements in quartz which substitute for $\mathrm{Si}^{4+}$ are $\mathrm{Al}^{3+}, \mathrm{Fe}^{3+}, \mathrm{Ti}^{4+}, \mathrm{Ge}^{4+}, \mathrm{P}^{5+}, 4 \mathrm{H}^{+}$and $\mathrm{Ga}^{3+}$ ordered of average frequency (e.g. Bambauer, 1961; Lehmann, 1975; Lehmann and Bambauer, 1973; Nuttall and Weil, 1980; Maschmeyer and Lehmann, 1983a and 1983b; Weil, 1984). Cations such as $\mathrm{H}^{+}, \mathrm{Li}^{+}, \mathrm{Na}^{+}, \mathrm{K}^{+}, \mathrm{Fe}^{2+}, \mathrm{Cu}^{+}$, and $\mathrm{Ag}^{+}$function as compensators of the electric charge at interstitial positions. It has been striven to obtain quantitative analysis of 
trace elements in quartz at the ppm level and with high spatial resolution. Variations in trace element concentrations proved to be useful as petrogenetic indicators. Earlier studies showed a large variation in the chemistry of quartz crystals from different environments (e.g. Suttner and Leininger, 1972; Schrön et al., 1988; Blankenburg et al., 1994 and references therein, Müller et al., 2000). Several authors have tried to relate specific trace elements and the related defect structures in quartz to the formation environment and to a genetic interpretation. Examples are given by Dennen et al. (1970), Siebers (1986), Ramseyer and Mullis (1990), Gerler (1990), and Perny et al. (1992) for hydrothermal quartz, and Suttner and Leininger (1972), Schrön et al. (1988), and Watt et al. (1997) for magmatic quartz. Dennen et al. (1970) proposed a geothermometer based on the incorporation of $\mathrm{Al}$ in hydrothermal quartz as a function of formation temperature. Using the electron paramagnetic resonance (EPR) technique, Agel and Petrov (1990) confirmed that the concentration of $\left[\mathrm{AlO}_{4}\right]^{0}$ centres in quartz increases with increasing crystallisation temperature. The concentration of paramagnetic $\mathrm{Ti}$ and Al-related defect centres created by natural irradiation can be used for rock dating (e.g Grün et al., 2000). Schrön et al. (1988) grouped pegmatitic, granitic, and rhyolitic quartz according their $\mathrm{Ge}-\mathrm{Ti}-\mathrm{Al}$ contents.

A number of trace elements have been found to activate CL in quartz: Ti (Sprunt, 1981; Kerkhof et al., 1996), Fe (Pott and McNicol, 1971; Sprunt, 1981; Gorobets et al., 1989), Al (Grant and White, 1978; Perny et al., 1992), H and Li (Matter and Ramseyer, 1985; Perny et al., 1992), Mn (Richter and Zinkernagel, 1975; Dudley, 1976), $\mathrm{OH}^{-}$and $\mathrm{H}_{2} \mathrm{O}$ (Behr, 1989; Kalceff and Phillips, 1995), Ge (Luff and Townsend, 1990), and Ga (Dudley, 1976). There are only a few studies about the CL of quartz in comparison with trace element studies which have been done to visualise intra-granular growth patterns, to distinguish different quartz generations and to explain crystallisation processes e.g. Sprunt (1981), Ramseyer and Mullis (1990), Perny et al. (1992), Demars et al. (1996), Bruhn et al. (1996), and Watt et al. (1997). The heterogeneous distribution of the trace elements (growth zoning) reflects the physicochemical variations of the fluid or the melt during crystal growth (e.g. Ramseyer and Mullis, 1990; Watt et al., 1997). Structural and/or chemical variations within crystals, which may relate to crystal growth zones, can be identified by spatial variations in wavelength and intensity of CL (e.g Waychunas, 1988; Marshall, 1988). CL-contrasted growth zoning are observed e.g., by Ramseyer et al. (1988), Ramseyer and Mullis (1990) and Perny et al. (1992) in hydrothermal quartz and e.g., by Schneider (1993) and Watt et al. (1997) in rhyolitic quartz phenocrysts. Retrograde processes (alteration) may change CL properties resulting in the creation of secondary CL structures may caused by the redistribution of defects. Most 
secondary structures represent migration pathways of fluids which migrate along grain boundaries, microcracks, or channelways by pore overpressure or tectonic strain (Behr and Frentzel-Beyme, 1988; Behr, 1989). In spite of the fact that quartz is one of the common rockforming minerals, yet the relation between its CL properties, trace element distribution, and petrogenesis is far from be solved.

\subsection{Aims of the study}

The aim of this study is to better explain the causes for the CL properties of quartz and to find the petrological significance of structures visible in CL. The study is subdivided in 2 parts. In the first part (chapters 2-6) defect structures of quartz are characterised and quantified by CL microscopy, spectroscopy and complementary micro-analytical studies. In the second part (chapters 7-10) CL-studies are applied of the results from the first part to mineralised granitic systems on the hand of examples from the magmatic provinces Krušne Hory/Erzgebirge (Czech Republic/Germany) and the Eastern Lachlan Fold Belt (Australia).

\section{Part I - CL properties and defect structures in quartz}

The first part of the study deals with the CL of quartz and its correlation with defect structures. The defect structures in quartz are characterised and their formation during crystallisation and re-distribution during retrograde processes are discussed. Quartz samples from Upper Carboniferous granite intrusions in Germany and related rhyolitic dykes, flows and domes of the Permian continental crust and hydrothermal quartzes of the Upper Proterozoic Damara Orogen of Namibia were taken for the studies of the CL of quartz. The main characteristics of the samples are summarised in table 1.1.

Defect structures in quartz are unstable under electron radiation bombardment resulting in changes of the CL. Looking at the problem of the mathematical capturing of CL parameters like beam energy, radiation time, and sample temperature have been considered. Timeresolved CL spectra with high resolution of the emitted wavelength were recorded to detect the intensity, position and half-width of the emission bands and their changes during electron radiation. In order to establish the parameters which may effect the CL of quartz the spectra were recorded using different beam currents, sample surface roughness, and also by the study of heat-treated samples. Temperature measurements were carried out to determine 
temperature changes of the sample during electron radiation. For the quantification of the CL emission spectra were resolved by best fitting with Gaussian curves.

A larger part of the study comprises the correlation between CL properties of quartz and trace element distribution. Electron probe micro analysis (EPMA), laser ablation - inductively coupled plasma mass spectrometry (LA ICP-MS), and secondary ion mass spectrometry (SIMS) were used for the determination of trace elements. Since the determination of trace elements in quartz is not a routine analysis, the sensitivities of the different microanalytical methods were investigated. Furthermore, the defect centres were characterised by using electron paramagnetic resonance spectroscopy (EPR). Fourier transform infra-red (FTIR) spectroscopy facilitates the qualitative characterisation of crystallographic bound water. Water occurs in quartz as different modifications: as hydroxyl groups related to different defect structures (e.g. with $\mathrm{Al}$ ), as molecular water in micropores and in fluid inclusions. During electron radiation and heating crystallographic bound water may change to molecular water which concentrates in micro pores. These processes are not completely understood and a main topic of this study.

After studying CL properties CL structures and processes responsible for trace element distribution and defect structure formation were discussed. At first quartz growth textures were classified. The rhyolites as well as a number of the granites contain euhedral quartz phenocrysts showing a CL-contrasted complex growth pattern The euhedral phenocrysts in granite are recognisable only by using CL because they are overgrown and embedded in homogeneous anhedral quartz. The euhedral quartz phenocrysts in granite showing CLcontrasted growth textures have been described in a few cases (Frentzel-Beyme, 1989; Seltmann, 1994; D’Lemos et al., 1997; Müller and Behr, 1997). The questions arise if these phenocrysts have the same origin and formed at similar conditions like phenocrysts in rhyolite. This important for the understanding Upper Carboniferous magma formation during the Variscan orogeny. The development of growth zoning during magmatic crystallisation is explained by a number of models (e.g. Sibley et al., 1976; Anderson, 1984; Fowler, 1990) that have been derived from the zoning pattern of plagioclase. We apply these models to the crystallisation of magmatic quartz having a similar growth pattern as plagioclase. The classification of growth zoning helps in distinguishing between zoning caused by selforganised growth and zoning caused by physico-chemical changes of external factors such as temperature, pressure and magma composition (Bottinga et al., 1966; Allègre et al., 1981; Shore and Fowler, 1996). The zoning caused by external factors is of interest for the reconstruction of the crystallisation history of felsic melts (magma storage, ascent, mixing, 
emplacement, and cooling rate). In a further step the zoning of magmatic quartz was compared with zoning observed in hydrothermal quartz. The differences between impurity uptake in quartz crystals in a melt and in aqueous solutions were discussed.

In CL quartz shows secondary structures which formed during retrograde processes. Typical secondary structures of quartz are healed veinlets and domains along micro shear zones, grain and subgrain boundaries, diffusion rims at grain boundaries, patchy halos of secondary quartz around fluid inclusions, radiation-induced non-luminescent spots, and halos around radioactive inclusions. Mostly, secondary quartz shows a weak luminescence and is therefore mostly easily distinguishable from the host crystal. The formation of secondary quartz may be stimulated by fluid activity. The CL properties of the secondary quartz in comparison with the host quartz indicate a redistribution of defect structures.

The study focuses on two types of secondary structures occurring in magmatic quartz: halos of secondary quartz around fluid inclusions and non-luminescent spots with gel-like defect structure. A wide variety of patchy halos around fluid inclusions have been observed by CL since about one decade (Frentzel-Beyme, 1989; Behr, 1989; Kerkhof and Müller, 1999). The CL-contrasted halos around fluid inclusions are assumed to be related to explosion and implosion-decrepitation at changing PT conditions and to healing processes resulting in volumetric and compositional changes of fluid inclusions. A better understanding of the physical and chemical conditions leading to formation of halos of secondary quartz around fluid inclusions is essential for a proper interpretation of fluid inclusion data. Nonluminescent spots (1-5 $\mu \mathrm{m})$ observed by SEM-CL become visible first in CL after a radiation time of some minutes. The spots may be associated with larger defect clusters containing structural water in the form of $\mathrm{H}^{+}, \mathrm{OH}^{-}$, and $\mathrm{H}_{2} \mathrm{O}$.

\section{Part II - CL applied to the study of granitic rocks}

In the second part of the study (chapters 7-10) CL is applied to the study of quartz in granitic rocks and comprises four papers. Two papers (chapter 7 and 8) have been published by Müller, Seltmann, and Behr (2000) in "Mineralum Deposita" (vol. 35: pp. 169-189) and by Müller and Seltmann (1999) in "Mineral Deposits: Processes to Processing" edited by Stanley et al. (pp. 409-412). The other two papers (chapter 9 and 10) have been submitted by Müller, René, and Behr to "Terra Nova" and by Müller, Trzebski, and Lennox to "Mineralogy and Petrology".

Samples were collected from two magmatic provinces, the Krušne Hory/Erzgebirge (Czech Republic/Germany) and the Eastern Lachlan Fold Belt (Australia). The sample material used 
for the studies is described in $\S 7.4,8.3,9.3$, and 10.3. Principally, in the four papers the results of quartz CL and trace element analysis are utilised to reconstruct interactions at the crystal-melt interface during crystal growth and the state and changes in chemistry and physics of the melt (mixing, differentiation, pulsation, degassing). Complimentary analysis of the magmatic textures (grain size distribution, grain shape, grain relationship) with special emphasis to fabrics influenced by late-magmatic volatiles will provide information about cooling rate of the melt, emplacement conditions, role of volatile. The studies links CL studies with micro-analytical studies and provide principally a new level in the knowledge about petrogenetic and metallogenetic processes in magmatic systems.

On the basis of field work, geochemical and textural investigations, and CL a model of the quartz crystallisation history of the Schellerhau granite melt is presented in chapter 7 (Müller et al., 2000a). The late-Variscan Schellerhau granite complex (Eastern Erzgebirge, Germany) is characterised by the intrusion sequence of porphyritic (SG1) to weakly porphyritic monzogranites (SG2) and mostly seriate albite granite containing snowball-textured quartz (SG3) (e.g. Seltmann, 1994; Schilka and Baumann, 1996). The intrusions are related to Sn-Wmineralisations. The source of magma and its physico-chemical evolution during ascent and fractionation is of particular interest for the formation of $\mathrm{Sn}-\mathrm{W}$-deposits. In the first step different quartz generations were distinguished based on CL studies and the grain size distribution. The SG1 and SG2 contain euhedral phenocrysts overgrown by an anhedral quartz phase (matrix quartz). The phenocrysts show distinct contrasted growth zoning, being normally more common for rhyolitic phenocrysts (Schneider, 1993). On the base of microthermometric studies of silicate melt inclusions, Thomas (1992) calculated the crystallisation depth of granitic quartz phenocrysts of the Erzgebirge granites (e.g. Eibenstock and Schellerhau granites) of up to $21 \mathrm{~km}$. Beside the Schellerhau granites a number of the other investigated granites (samples 6, 7, 8) show such quartz phenocrysts which are overgrown by a younger euhedral quartz generation (matrix quartz). The study of CL properties, growth zoning, and trace element distribution of the different quartz generations in Schellerhau granites answered the following questions: 1) Are granitic phenocrysts comparable with phenocrysts occurring in rhyolites and which crystallisation environment they represent? 2) Which crystallisation conditions cause the differences in CL and trace element distribution of quartz phenocrysts and anhedral matrix quartz? 3) Do the quartz CL and trace element distribution of different quartz generations reflect different crystallisation environments? 4) How does the volatile content of the melt effect the quartz CL and defect 
structure distribution? And 4) How can the analysis of growth zoning contribute to reconstruct the melt crystallisation history?

The fluid saturation textures of the SG3 Schellerhau granite are discussed in chapter 8 (Müller and Seltmann, 1999). This chapter contributes to solving the problem of the formation of snowball-textured alkali feldspar granites and their significance for genesis of $\mathrm{Sn}-\mathrm{W}$ deposits. Snowball-textured quartz occurring in highly evolved alkali feldspar granites worldwide are ellipsoidal phenoblasts up to $1 \mathrm{~cm}$ in size. They are characterised by zonal arrangement of entrapped matrix minerals (albite, K-feldspar, mica) alternating with inclusion free zones. Since long the origin and interpretation of snowball-texture are controversially discussed and lacked application of CL based arguments. It is considered to be either metasomatic (e.g. Beus et al., 1962; Sonyushkin et al., 1991), or magmatic origin (Kovlenko, 1977; Pollard, 1989; Yin et al., 1995; Renno, 1997; Poutiainen and Scherbakova, 1998). Snowball-textured quartz occurs also in the roof of late Variscan tin-bearing alkali feldspar granite stocks of the Krušne Hory/Erzgebirge. For textural, CL and trace element studies on snowball quartz were chosen the third intrusion stage SG3 of the Schellerhau Granite Complex (Eastern Erzgebirge/Germany) and the Podlesi dyke granite (Western Krušne Hory/Czech Republic). The problem of magmatic or metasomatic origin is discussed on the base of the analysis of the growth zoning visible by CL and the trace element distribution.

Chapter 9 discusses the significance of $\mathrm{Ti}$ distribution in quartz phenocrysts for the interpretation of growth patterns on the example of the topaz-bearing granites of Hub Stock, Slavkovsky Les Mountains, Czech Republic (Müller and René, 2000). The Hub Stock hosts the Sn-W deposit Krásno on the SE margin of the Krušné Hory/Erzgebirge Batholith. The trace element signature and growth patterns of quartz phenocryst of the different granite intrusions are compared. The study is focused on high-resolution CL spectroscopy of the quartz CL. Finally, similarities between quartz crystallisation history derivable from the quartz CL and trace element distribution of the Schellerhau and Hub stock tin granites are discussed.

In chapter 10 the significance of quartz CL for reconstruction of magma crystallisation, emplacement and deformation of S- and I-type granites in the Eastern Lachlan Fold Belt is discussed (Müller et al., 2000b). The samples were collected from Carcoar, Barry and Sunset Hills granites. In contrary to the investigated granites of Krušné Hory/Erzgebirge the three 
Australian granites are less fractionated and can be subdivided into the metaluminous I-type Carcoar and Barry granodiorites and the peraluminous S-type Sunset Hills Granite. They were intruded in the Late Ordivician-Early Silurian into Ordovician graywacke and volcaniclastic rocks and were subsequently repeatedly deformed. In this paper quartz CL has been applied to qualify and quantify the conditions of emplacement and deformation of the Carcoar and Barry granodiorites and the Sunset Hills Granite with special emphasis on the macro- and microtextures, trace element distribution of quartz, Al-in-hornblende barometry, and whole rock geochemistry. Structural analysis of granites with a polyphase deformation history often faces the difficulty in discriminating between generations of magmatic and deformation fabrics. The application of quartz CL enables easily the distinction between magmatic and deformation fabrics. Furthermore, the study demonstrates how the quartz CL properties and quartz textures reflect the temperature and pressure conditions during magmatic crystallisation and subsequent greenschist facial deformation. High-resolution spectroscopy is used to show differences in CL of deformed and undeformed magmatic quartz. The causes of this differences which may associated with crystallographic bound water in the quartz lattice are discussed.

\subsection{Sample material}

As study objects we have chosen samples for which an extensive state of knowledge based on mapping, chemical and petrographical data already exists but some petrogenetic questions are unsolved. The quartz samples and quartz-bearing rocks were taken from 4 regions (table 2.1).

\section{Damara Orogen}

The first sample group is represented by hydrothermal quartzes from the southern margin of the Upper Proterozoic Damara Orogen of Namibia. Previous fluid inclusion studies on this quartzes were done by Behr and Horn (1982), Behr et al. (1983), Schmidt-Mumm et al. (1986), and Behr and Schmidt-Mumm (1987) who contributed to the understanding of the formation and activity of tectonic brines during the Proterozoic Damara Orogen (Namibia).

The name "megaquartz" (sample 1) came from mega quartz crystals, which are outstanding, up to $60 \mathrm{~m}$ high monoliths in the Hakos Mountains. The quartz bodies are intergrown with dolomite and are emplaced tectonically during an early deformation event of the Damara Orogen. This event was characterised by thrusting of nappes over a fluvial-lacustrine and 
evaporitic metaplaya sequence (Behr and Schmidt-Mumm, 1987). The fluids forming this quartz-dolomite body are related to dehydration and leaching of evaporitic hydrate minerals of the metaplaya sequence and had salinities of up to $69 \mathrm{wt} \%$ total salt content revealed from fluid inclusion studies sequence (Behr and Schmidt-Mumm, 1987). The formation temperature, as determined in fluid inclusion studies, ranged from 150 to $250^{\circ} \mathrm{C}$. The clear fissile quartz (sample 2) representing a special variety of the megaquartz shows perfect cleavage parallel to the positive rhombohedral faces $\{1011\}$. The oil-bearing quartz (sample 3) is a pebble found in the gravel plain around the Geelkop Dome and contains fluid inclusions of higher hydrocarbons.

\section{Krušné Hory/Erzgebirge}

The second group of samples were taken from the magmatic province Krušne Hory/Erzgebirge (Czech Republic/Germany) forming. The study of the granitic rocks with special emphasis on quartz CL and textural analyses contributed to IGCP-373 project "Correlation, anatomy and magmatic-hydrothermal evolution of ore-bearing felsic igneous systems in Eurasia" (Seltmann et al., 2000). The project covers all aspects of the formation of silicic igneous systems (plutonic to volcanic) and their magmatic evolution. Our contribution is important for the understanding of textural evolution, physico-chemical balancing and intrusion mechanism, temporal scale and phasing of magmatic events of Li-F-enriched melts. The samples 4, 5, 6 represent felsic volcanics and subvolcanics of the Altenberg-Teplice caldera (ATC) of the Eastern Erzgebirge/Germany. Neoproterozoic gneisses of the metamorphic basement and volcano-sedimentary rocks form the host rocks of the $500 \mathrm{~km}^{2}$ large ATC. Late-collisional extensional tectonics and collapse of the Variscan orogen controlled during the Upper Carboniferous the block and graben tectonics in the area, caldera formation with pre-dominantly ignimbritic rhyolites (Schönfeld and Teplice rhyolite) and porphyritic microgranites (Altenberg microgranite), and finally the post-tectonic multiple intrusion of tin granites of the Schellerhau Granite Complex (SGC) into a subvolcanic level. The volcanogenic fill of the ATC is divided into four volcanic phases two of which have been sampled: The Schönfeld Rhyolite (sample 4) as the oldest phase and the effusive-subvolcanic Teplice Rhyolite (phase 2; TPR2), the youngest phase. The grey-greenish Schönfeld Rhyolite contains only a few quartz phenocrysts ( $<3$ vol.\%) showing an amoebic and skeletal shape. The Teplice Rhyolite (sample 5), volcanic fill of the ATC is the largest outcropping Carboniferous volcanic suite of the Bohemian Massif (Hoth et al., 1995). TPR2 displays hiatalporphyric texture with euhedral quartz $(2-3 \mathrm{~mm})$, anhedral alkalifeldspar and few biotite 
phenocrysts, sometimes also plagioclas. The caldera collaps was later followed also by a multiple intrusion of highly differentiated Schellerhau granites hosting Sn-W-mineralisations (Breiter et al., 1991). The subvolcanic Schellerhau Granite Complex (SGC) belongs to the highly evolved younger intrusion complex (YIC) of the Erzgebirge batholith (e.g. Tischendorf and Förster, 1990). The SGC is characterised by the intrusion sequence of porphyritic (SG1) to weakly porphyritic monzogranites (SG2) and mostly seriate albite granite (SG3). The SG1, SG2 and SG3 chemically represent the suite of P-poor, Li-F-enriched A-type series leucogranites. They are weakly peraluminous $(\mathrm{A} / \mathrm{CNK} \leq 1.2)$, enriched in HREE, Y, Th, Hf, $\mathrm{Zr}, \mathrm{Sc}, \mathrm{Nb}$, Ta, U and display from SG1 towards SG3 elevated abundances especially of Rb, $\mathrm{Li}, \mathrm{F}$, and Sn. There is only a moderate chemical contrast between SG1 and SG2. The SG3 is more highly evolved as to be seen also from fluid saturation textures. NW- and NE-striking faults with vertical dislocations of several hundred metres form the SGC as horst and as a result some deeper pluton parts are uncovered by erosion within the ATC. The granite variety SG2 (sample 6) was selected for investigations in part I (see also $§ 7.4$ and 7.5). The SG2 exhibits a weak hiatalporphyritic texture. Euhedral quartz phenocrysts with an average size of $2.6 \mathrm{~mm}$ are overgrown by an anhedral quartz phase with an average grain size of $0.7 \mathrm{~mm}$.

The Eibenstock granites (sample 7) are related to the younger intrusive complex (YIC) of the Krušné Hory/Erzgebirge Batholith in Western Erzgebirge (Lange et al., 1972; Fiala, 1968). The batholith extends over an area of about $6000 \mathrm{~km}^{2}$, belongs to the largest Variscan granite bodies of the Variscan Orogen. The sample 7 represents the first intrusion phase of the Eibenstock granites and is characterised by a coarse grained, perthitic texture with porphyritic kalifeldspars $(3 \mathrm{~cm})$. The porphyritic two mica Aue Granite (sample 8) which forms small satellite intrusions located northwestern of the Eibenstock Granite Massif belongs to the older intrusion complex (OIC) of the Krušné Hory/Erzgebirge Batholith.

In chapter 9 the study is focused on the topaz-bearing granites of the Hub Stock hosting the Sn-W deposit Krásno, Slavkovský Les Mountains, Czech Republic (Jarchovský et al., 1994; René, 1998). The Hub stock is situated at the SE margin of the Krušné Hory/Erzgebirge Batholith. The porphyritic topaz-albite granite (sample Ju-10) comprises fine-grained equigranular groundmass containing a phenocryst population dominated by quartz $(2-5 \mathrm{~mm})$, platy zinnwaldite, and sparse K-feldspar $(0.5-2 \mathrm{~cm})$. Topaz-albite microgranites (sample Ju20) found in the upper part of the Hub stock form the matrix to the intrusion breccias. The hydrothermal vein quartz (sample 9) originates from a post-Variscan mylonite zone situated in Hub stock granites. 


\section{Oberpfalz/NW Saxony/Harz/Odenwald}

The third group is represented by Permo-Carboniferous granites and rhyolites from different localities of the Variscan Orogen of Germany (Oberpfalz, NW Saxony, Harz, Odenwald). This group includes rocks which were investigated with CL by Schneider (1993). In our study the trace element analysis of these samples facilitates a better understanding of the phenomena described by Schneider (1993). Furthermore, this samples were chosen to compare the quartz properties of the magmatic rocks of the Krušné Hory/Erzgebirge with other magmatic provinces of the Variscan Orogen.

The Wachtelberg Rhyolite (sample 10) intruded metamorphic units of the Variscan Frankenberg - Hainichener Zwischengebirge at the Northern edge of the Erzgebirge. The Frankenberg - Hainichener Zwischengebirge is part of the SW-NE striking Central Saxonian Lineament. The intrusion marks the intersection of Central Saxonian Lineament with the Flöha Lineament.

The Beucha Rhyolite (sample 11) belongs to youngest subvolcanics of the PermoCarboniferous Volcanic Complex of Northwest Saxony. The rhyolite is characterised by the inhomogeneous occurrence of xenolithes and pyroxenes indicating assimilation of lower and mid-crustal rocks. Mineral framework indicates a strong whole rock alteration: discordant calcite veins, apatite in opaque biotites, sericitised and kaolinised orthoclas and plagioclas, and pyroxenes dulled by iron oxides.

The medium-grained two-mica Flossenbürg Granite (sample 12) intruded Moldanubian paragneisses of the Northern Oberpfalz/Germany. The anhedral quartz fills irregular cavities between the subhedral to euhedral feldspar and mica. Sample 21 is a clear, pegmatoid quartz lens (leucosome quartz) of migmatitic, Variscan HT-LP-paragneisses of the Northern Oberpfalz. During the Variscan peak metamorphism the Proterozoic educts were overprint at temperatures around $600^{\circ} \mathrm{C}$ and pressures between 2.5 and 4 kbar. The sample locality, the quarry Böhmischbruck, is about $15 \mathrm{~km}$ southern of the Flossenbürg Granite.

The subvolcanic Ramberg Granite (sample 14) is beside the Brocken Granite the most northern exposed Variscan granite in Germany situated in the Rhenoherzynian zone of the Harz Mountains. The sample represents the medium-grained variety of the locality Rosstrappe. The medium-grained variety occurs in the western and eastern part of the massif, whereas a porphyritic type forms the central part of the pluton.

The Weinheim Rhyolite (sample 15) is situated in the Southern part of the Odenwald Mountains/Germany, which forms part of the Mid-German Crystalline Rise (MGCR) within the Saxothuringian zone of the Variscan Orogen. The magma formation of the near-surface 
intruded rhyolite is explained by lower crustal anatexis and assimilation of upper crystal rocks. Secondary processes lead to the pneumatolytic hydrothermal alteration of the rhyolite (Flick, 1986; Arikas, 1964).

\section{Eastern Lachlan Fold Belt}

Granite samples collected from the Eastern Lachlan Fold Belt/Australia form the fourth group. The study of these samples contributes to the DFG project "Morphogenesis and tectonic setting of magma emplacement in the Eastern Lachlan Fold Belt, Australia" in cooperation with the University of New South Wales, Sydney, Australia (Trzebski et al., 1999). The northern part of the eastern Lachlan Fold Belt evolved in an island-arc setting during the lower Palaeozoic (Powell, 1984; Coney, 1992; Collins and Vernon, 1992; Gray et al., 1997). The Carcoar, Barry and Sunset Hills granites intruded the multiply deformed Ordovician metasedimentary and volcaniclastic rocks during the Silurian.

The I-type Carcoar Granodiorite is a fine- to medium-grained, enclave-containing, hornblende-biotite granodiorite to tonalite. The I-type Barry Granodiorite is a meridionally elongated body $(5 \times 12 \mathrm{~km})$, consisting mainly of hornblende and biotite granodiorite of tonalitic composition with minor microtonalite enclaves (Lennox et al., 1998). The Sunset Hills Granite shows an S-type aluminium saturation index (Wyborn and Henderson, 1996) and contains $40-50 \%$ quartz, 30-40\% plagioclase, $10-20 \%$ biotite and less than 10\% muscovite (Lennox et al., 1998). All three granites show a pervasive tectonic caused by the multiple deformation during the Early Devonian Bowning, late Middle Devonian Tabberabberan and Early Carboniferous Kanimblan events (Lennox et al., 1998; Trzebski et al., 1999). 
Table 1.1 Reference list of the sample material with origin and characteristics.

\begin{tabular}{|l|l|l|l|l|l|l|}
\hline \multicolumn{7}{|c|}{ Damara Orogen } \\
\hline No. & Sample name & Lokality & $\begin{array}{l}\text { Formation } \\
\text { process }\end{array}$ & Age & $\begin{array}{l}\text { Formation } \\
\text { temperature }\end{array}$ & Specific features \\
\hline 1 & megaquartz & $\begin{array}{l}\text { Hakos Mts./ } \\
\text { Namibia }\end{array}$ & $\begin{array}{l}\text { hydro- } \\
\text { thermal }\end{array}$ & $\begin{array}{l}\text { Upper } \\
\text { Proterozoic }\end{array}$ & $150-250^{\circ} \mathrm{C}$ & Megacrystals up to $60 \mathrm{~m}$ \\
\hline 2 & fissile quartz & $\begin{array}{l}\text { Hakos Mts./ } \\
\text { Namibia }\end{array}$ & $\begin{array}{l}\text { hydro- } \\
\text { thermal }\end{array}$ & $\begin{array}{l}\text { Upper } \\
\text { Proterozoic }\end{array}$ & $150-250^{\circ} \mathrm{C}$ & $\begin{array}{l}\text { perfect cleavage parallel to } \\
\text { the positive rhombohedral } \\
\text { faces }\{1011\}\end{array}$ \\
\hline 3 & $\begin{array}{l}\text { oil-bearing } \\
\text { quartz }\end{array}$ & $\begin{array}{l}\text { Geelkop } \\
\text { Dome/ } \\
\text { Namibia }\end{array}$ & $\begin{array}{l}\text { hydro- } \\
\text { thermal }\end{array}$ & $\begin{array}{l}\text { Upper } \\
\text { Proterozoic }\end{array}$ & $150-250^{\circ} \mathrm{C}$ & \begin{tabular}{l} 
oil-bearing inclusion \\
\hline
\end{tabular} \\
\hline
\end{tabular}

\begin{tabular}{|c|c|c|c|c|c|c|}
\hline \multicolumn{7}{|c|}{ Krušne Hory/Erzgebirge } \\
\hline No. & $\begin{array}{l}\text { Sample } \\
\text { name }\end{array}$ & Lokality & $\begin{array}{l}\text { Formation } \\
\text { process }\end{array}$ & Age & $\begin{array}{l}\text { Formation } \\
\text { temperature }\end{array}$ & Specific features \\
\hline 4 & $\begin{array}{l}\text { Schoenfeld } \\
\text { Rhyolite }\end{array}$ & $\begin{array}{l}\text { Eastern } \\
\text { Erzgebirge/ } \\
\text { Germany }\end{array}$ & magmatic & $310 \pm 5 \mathrm{Ma}$ & $>850^{\circ} \mathrm{C}$ & phenocysts \\
\hline 5 & $\begin{array}{l}\text { Teplice } \\
\text { Rhyolite } \\
\text { (TPR2) }\end{array}$ & $\begin{array}{l}\text { Eastern } \\
\text { Erzgebirge/ } \\
\text { Germany }\end{array}$ & magmatic & $\begin{array}{l}308 \pm 2 \mathrm{Ma} \\
\text { (Lobin } \\
1983)\end{array}$ & $>850^{\circ} \mathrm{C}$ & phenocysts \\
\hline SH22 & $\begin{array}{l}\text { SG1 } \\
\text { Schellerhau } \\
\text { Granite }\end{array}$ & $\begin{array}{l}\text { Eastern } \\
\text { Erzgebirge/ } \\
\text { Germany }\end{array}$ & magmatic & $300 \pm 5 \mathrm{Ma}$ & $>650^{\circ} \mathrm{C}$ & $\begin{array}{l}\text { phenocrysts overgrown by } \\
\text { matrix quartz }\end{array}$ \\
\hline $\begin{array}{l}6 ; \\
\text { SH16, } \\
\text { SH32 }\end{array}$ & $\begin{array}{l}\text { SG2 } \\
\text { Schellerhau } \\
\text { Granite }\end{array}$ & $\begin{array}{l}\text { Eastern } \\
\text { Erzgebirge/ } \\
\text { Germany }\end{array}$ & magmatic & $300 \pm 5 \mathrm{Ma}$ & $>650^{\circ} \mathrm{C}$ & $\begin{array}{l}\text { phenocrysts overgrown by } \\
\text { matrix quartz }\end{array}$ \\
\hline \multirow[t]{2}{*}{ SH18 } & $\begin{array}{l}\text { SG3 } \\
\text { Schellerhau } \\
\text { Granite }\end{array}$ & $\begin{array}{l}\text { Eastern } \\
\text { Erzgebirge/ } \\
\text { Germany } \\
\end{array}$ & magmatic & $300 \pm 5 \mathrm{Ma}$ & $>500^{\circ} \mathrm{C}$ & Snowball-textured quartz \\
\hline & $\begin{array}{l}\text { Podlesi } \\
\text { dyke granite }\end{array}$ & $\begin{array}{l}\text { Krušne Hory } \\
\text { / Germany }\end{array}$ & magmatic & $300 \pm 10 \mathrm{Ma}$ & $>500^{\circ} \mathrm{C}$ & Snowball-textured quartz \\
\hline 7 & $\begin{array}{l}\text { Eibenstock } \\
\text { Granite }\end{array}$ & $\begin{array}{l}\text { Western } \\
\text { Erzgebirge/ } \\
\text { Germany }\end{array}$ & magmatic & $300 \pm 10 \mathrm{Ma}$ & $\begin{array}{l}695 \pm 6{ }^{\circ} \mathrm{C}^{1} \\
\text { (Solidus- } \\
\text { temp.; } \\
\text { Thomas } \\
\text { 1994a) }\end{array}$ & $\begin{array}{l}\text { phenocrysts over-grown by } \\
\text { matrix quartz }\end{array}$ \\
\hline 8 & Aue Granite & $\begin{array}{l}\text { Western } \\
\text { Erzgebirge/ } \\
\text { Germany }\end{array}$ & magmatic & $\begin{array}{l}325 \pm 5 \mathrm{Ma} \\
\text { (Förster } \\
\text { and } \\
\text { Tischendor } \\
\text { f 1994) }\end{array}$ & $>650^{\circ} \mathrm{C}$ & $\begin{array}{l}\text { phenocrysts over-grown by } \\
\text { matrix quartz }\end{array}$ \\
\hline $\mathrm{Ju} 10$ & $\begin{array}{l}\text { Krásno } \\
\text { Granite }\end{array}$ & $\begin{array}{l}\text { Hub Stock, } \\
\text { Slavkovský } \\
\text { Les } \\
\text { Mts./Czech } \\
\text { Republic }\end{array}$ & magmatic & $\begin{array}{l}\text { Upper } \\
\text { Carbo- } \\
\text { niferous }\end{array}$ & $>650^{\circ} \mathrm{C}$ & $\begin{array}{l}\text { phenocrysts overgrown by } \\
\text { matrix quartz }\end{array}$ \\
\hline
\end{tabular}




\section{Krušne Hory/Erzgebirge}

\begin{tabular}{|l|l|l|l|l|l|l|}
\hline No. & $\begin{array}{l}\text { Sample } \\
\text { name }\end{array}$ & Lokality & $\begin{array}{l}\text { Formation } \\
\text { process }\end{array}$ & Age & $\begin{array}{l}\text { Formation } \\
\text { temperature }\end{array}$ & Specific features \\
\hline Ju14 & $\begin{array}{l}\text { Krásno } \\
\text { Micro- } \\
\text { granite }\end{array}$ & $\begin{array}{l}\text { Hub Stock, } \\
\text { Slavkovsý } \\
\text { Les } \\
\text { Mts./Czech } \\
\text { Republic }\end{array}$ & magmatic & $\begin{array}{l}\text { Upper } \\
\text { Carbo- } \\
\text { niferous }\end{array}$ & $>650^{\circ} \mathrm{C}$ & $\begin{array}{l}\text { phenocrysts overgrown by } \\
\text { matrix quartz }\end{array}$ \\
\hline 9 & vein quartz & $\begin{array}{l}\text { Hub Stock, } \\
\text { Slavkovsḱ } \\
\text { Les } \\
\text { Mts./Czech } \\
\text { Republic }\end{array}$ & $\begin{array}{l}\text { hydro- } \\
\text { thermal }\end{array}$ & $<300 \mathrm{Ma}$ & $<500^{\circ} \mathrm{C}$ & Berg crystals $(3 \mathrm{~mm})$ \\
\hline
\end{tabular}

\section{Oberpfalz/NW Saxony/Harz/Odenwald}

\begin{tabular}{|c|c|c|c|c|c|c|}
\hline No. & Sample name & Lokality & $\begin{array}{l}\text { Formation } \\
\text { process }\end{array}$ & Age & $\begin{array}{l}\text { Formation } \\
\text { temperature }\end{array}$ & Specific features \\
\hline 10 & $\begin{array}{l}\text { Wachtelberg } \\
\text { Rhyolite }\end{array}$ & $\begin{array}{l}\text { Frankenberg } \\
\text { Mts./German } \\
\text { y }\end{array}$ & magmatic & $\begin{array}{l}\text { Rotliegen- } \\
\text { des }\end{array}$ & $>850^{\circ} \mathrm{C}$ & phenocrysts \\
\hline 11 & $\begin{array}{l}\text { Beucha } \\
\text { Rhyolite }\end{array}$ & $\begin{array}{l}\text { NW Saxonia/ } \\
\text { Germany }\end{array}$ & magmatic & $\begin{array}{l}\text { Rotliegen- } \\
\text { des }\end{array}$ & $>850^{\circ} \mathrm{C}$ & phenocysts \\
\hline 12 & $\begin{array}{l}\text { Flossenbuerg } \\
\text { Granite }\end{array}$ & $\begin{array}{l}\text { Oberpfalz/ } \\
\text { Germany }\end{array}$ & magmatic & $\begin{array}{l}312 \pm 3 \mathrm{Ma} \\
\text { (Rb/Sr WR; } \\
\text { Siebel et al. } \\
1997)\end{array}$ & $>650^{\circ} \mathrm{C}$ & euhedral matrix quartz \\
\hline 13 & $\begin{array}{l}\text { leucosome } \\
\text { quartz }\end{array}$ & $\begin{array}{l}\text { Oberpfalz/ } \\
\text { Germany }\end{array}$ & pegmatitic & $\begin{array}{l}\sim 320 \mathrm{Ma} \\
\text { (Peak meta- } \\
\text { morphose) }\end{array}$ & $\sim 600^{\circ} \mathrm{C}$ & clear crystals \\
\hline 14 & $\begin{array}{l}\text { Ramberg } \\
\text { Granite }\end{array}$ & $\begin{array}{l}\text { Harz/ } \\
\text { Germany }\end{array}$ & magmatic & $\begin{array}{l}290-295 \\
\mathrm{Ma} \\
\text { (Rb/Sr WR; } \\
\text { Schust et } \\
\text { al. 1991) }\end{array}$ & $>650^{\circ} \mathrm{C}$ & $\begin{array}{l}\text { phenocrysts over-grown by } \\
\text { matrix quartz }\end{array}$ \\
\hline 15 & $\begin{array}{l}\text { Weinheim } \\
\text { Rhyolite }\end{array}$ & $\begin{array}{l}\text { Odenwald/ } \\
\text { Germany }\end{array}$ & magmatic & $\begin{array}{l}\text { Rotliegen- } \\
\text { des }\end{array}$ & $>850^{\circ} \mathrm{C}$ & phenocyst \\
\hline
\end{tabular}

\section{Eastern Lachlan Fold Belt}

\begin{tabular}{|l|l|l|l|l|l|l|}
\hline No. & $\begin{array}{l}\text { Sample } \\
\text { name }\end{array}$ & Lokality & $\begin{array}{l}\text { Formation } \\
\text { process }\end{array}$ & Age & $\begin{array}{l}\text { Formation } \\
\text { temperature }\end{array}$ & Specific features \\
\hline $\begin{array}{l}\text { AU4- } \\
\text { AU7 }\end{array}$ & $\begin{array}{l}\text { Barry } \\
\text { Granodiorite }\end{array}$ & $\begin{array}{l}\text { Eastern } \\
\text { Lachlan Fold } \\
\text { Belt/Australia }\end{array}$ & magmatic & $\begin{array}{l}\text { Early } \\
\text { Silurian }\end{array}$ & $752 \pm 37^{\circ} \mathrm{C}$ & $\begin{array}{l}\text { phenocrysts overgrown by } \\
\text { matrix quartz }\end{array}$ \\
\hline $\begin{array}{l}\text { AU9- } \\
\text { AU16 }\end{array}$ & $\begin{array}{l}\text { Sunset Hills } \\
\text { Granite }\end{array}$ & $\begin{array}{l}\text { Eastern } \\
\text { Lachlan Fold } \\
\text { Belt/Australia }\end{array}$ & magmatic & $\begin{array}{l}\text { Early } \\
\text { Silurian }\end{array}$ & $>700^{\circ} \mathrm{C}$ & $\begin{array}{l}\text { phenocrysts overgrown by } \\
\text { matrix quartz }\end{array}$ \\
\hline $\begin{array}{l}\text { AU28- } \\
\text { AU55 }\end{array}$ & $\begin{array}{l}\text { Carcoar } \\
\text { Granodiorite }\end{array}$ & $\begin{array}{l}\text { Eastern } \\
\text { Lachlan Fold } \\
\text { Belt/Australia }\end{array}$ & magmatic & $\begin{array}{l}\text { Early } \\
\text { Silurian }\end{array}$ & $766 \pm 36^{\circ} \mathrm{C}$ & euhedral matrix quartz \\
\hline
\end{tabular}




\section{Fundamentals of cathodoluminescence}

The term cathodoluminescence (CL) designates the luminescence induced by electron bombardment. The interaction of the electron beam with the sample gives rise to a number of effects: the emission of secondary electrons (SE), back-scattering of electrons (BSE), electron absorption ("sample current"), characteristic X-ray, and CL emission (Fig. 2.1). Most energy of the beam is converted into heat. The penetration depth of electrons and accordingly, the excitation depth depends on the energy of the electrons $(10-20 \mathrm{keV})$ and is in the range of 2-8 $\mu \mathrm{m}$ (e.g. Marshall, 1988).

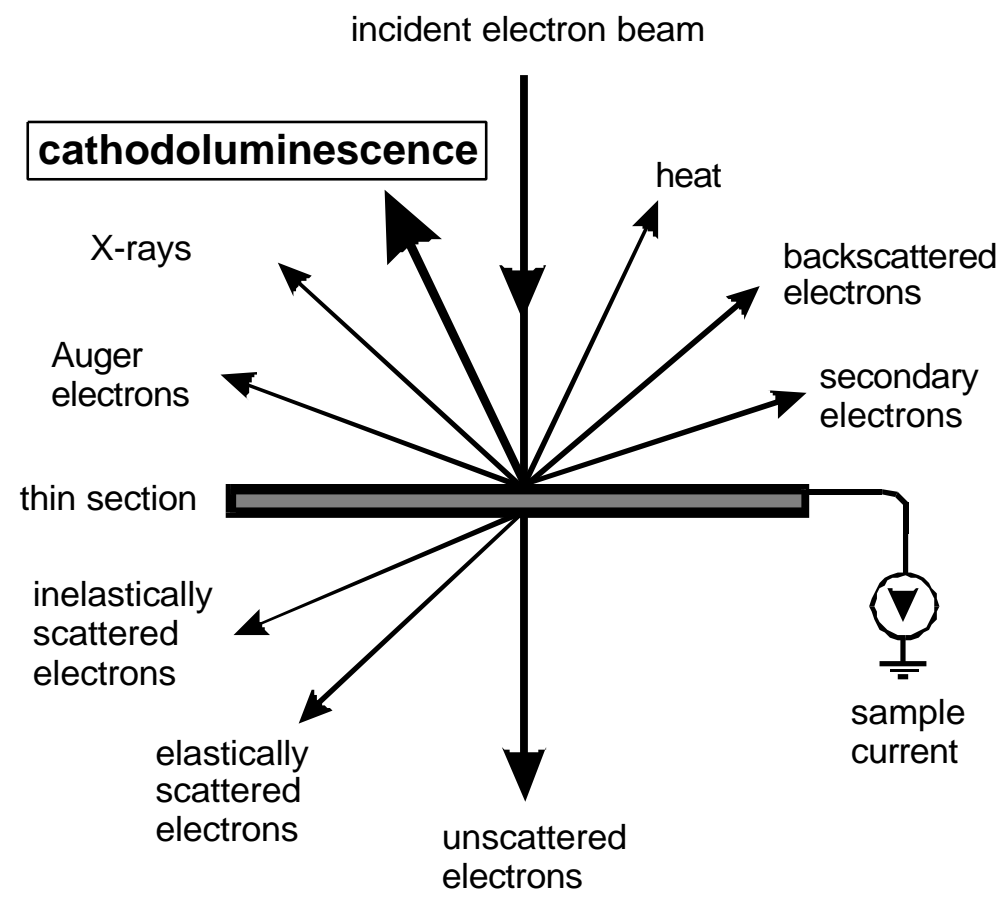

Fig. 2.1 Schematic representation of processes resulting from electron bombardment (modified after Potts et al., 1995). Note that the emissions come from different depths, e.g. CL and X-rays are emitted from deeper section levels than secondarv electrons.

Luminescence can be divided into two: intrinsic CL which is characteristic of the host lattice and extrinsic CL which results from impurities. Larger defects such as dislocations and clusters may also effect the CL.

Intrinsic luminescence is enhanced by non-stoichiometry (vacancies), structural imperfections (poor ordering, radiation damage, shock damage), and impurities (non-activators), which distort the crystal lattice. Some trace elements like Ti may provoke both intrinsic and extrinsic CL. However, the role of $\mathrm{Ti}$ in enhancing intrinsic CL is a matter of discussion. Ti-rich feldspar and quartz show blue CL, but the effective state of Ti charge and lattice position is 
not answered (Marshall, 1988). Both the use of the term "activator" and the term "intrinsic" have been used to characterise the CL of minerals containing Ti.

The impurities, responsible for the extrinsic luminescence, are called activators. Elements are referred to as sensitizers when their presence is necessary to create a luminescence centre with an activator. The latter is transferred into an excited state which results in a sensitized luminescence (e.g. Waychunas, 1988; Remond et al., 1992). The luminescence properties are mostly the result of luminescence-activating ions such as transition metals, rare-earth elements or actinides. Changes of the crystal field properties i.e., field strength, site symmetry, and coordination number, cause differences in the magnitude of the energy levels of the activator elements and also the splitting of closely spaced levels. Therefore the CL spectrum is not a characteristic property of the activator but a property of the mineral. The CL intensity generally increases with the concentration of the activator to a maximum and then decreases. This decrease is referred to as concentration quenching (self-quenching). It can be explained by the transfer of a part of the excitation energy to other activator ions which is more effective than luminescence emission. Some ions (quenchers) such as $\mathrm{Fe}^{3+}, \mathrm{Fe}^{2+}, \mathrm{Co}^{2+}$, and $\mathrm{Ni}^{3+}$ show broad and intense charge transfer bands in the absorption spectrum and cause quenching of the luminescence of activators with interfering emission bands. The quenching by ions with intense charge transfer bands especially influences the visible and near UV spectral ranges, whereas luminescence emissions in the IR are more or less unaffected. Apparently, the quenchers cause new closely-spaced energy levels so that the electron can easily return to the ground state with the emission of low-energy photons (IR) or by losing heat energy (Marshall, 1988).

Quenching due to lattice defects may occur if the crystal structure is damaged by mechanical processes, radiation, growth defects or impurities. These lattice defects create new energy levels between the conduction and the valence bands resulting in absorption of the excitation energy, non-luminescent energy transfer or low frequency emission.

Another process which may be responsible for lowering the luminescence intensity is thermal quenching. Principally, heating of a sample results in the release of electrons and accordingly in the excitation of thermoluminescence. During irradiation of a sample with high-energy particles (e.g., electrons, ions) a part of the energy can be transformed into heat which influences the energy transfer and non-luminescent transitions. As a consequence, the luminescence intensity decreases during electron bombardment and then stabilises. 
Cathodoluminescence is considered to form in 3 steps: (1) the absorption of excitation energy and stimulation of the atoms into an excited state, (2) transformation and transfer of the excitation energy, and (3) emission of light and relaxation to a non-excited state (Marfunin, 1995). The first two steps mainly depend on the mode of excitation, whereas the third step depends on the character of specific luminescence centres.

In crystals, complex interaction between atoms leads to the broadening of the energy levels into bands. In insulators like quartz, a broad gap, called the forbidden gap, exists between the valence band and the conduction band. A precondition for cathodoluminescence is the existence of activators (impurity ions, lattice defects), which cause and occupy discrete energy levels in this forbidden zone. Luminescence centres can be differentiated by their energy position within the forbidden gap and divided into into electron traps near the conduction band (donor level) and recombination sites in the vicinity of the valence band (acceptor level) (e.g. Marfunin, 1979).

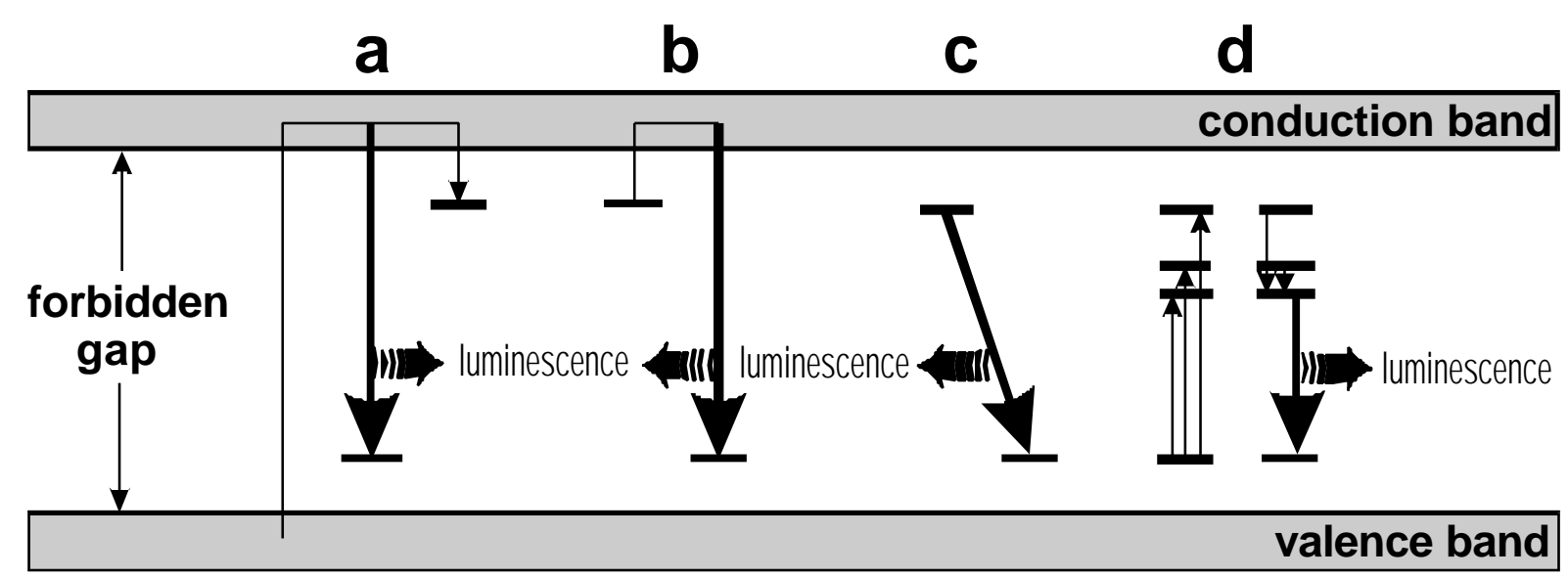

Fig. 2.2 Processes of charge transfer and luminescence production in crystals after Krbetschek et al. (1997).

CL involves electron radiation induced excitation of an electron from the ground state to an excited state. The following de-excitation leads to a state of lower energy within the forbidden gap. Excitation results in the trapping of an electron or in the recombination with a luminescent or a non-luminescent centre (Fig. 2.2a). In the case of a luminescent transition, a photon is emitted. If the atom or ion is placed in a crystal lattice, non-luminescent transitions are possible due to absorption or emission of lattice vibrations. A trapped electron can be excited again, transits into the conduction band and may recombine with an activator element level under emission of a photon (Fig. 2.2b). In the case of a small energy difference between electron trap and activator level, a direct luminescent transition of the electron to the 
recombination centre is possible (Fig. 2.2c). In figure 2.2d the excitation of several energy levels and the subsequent relaxation and luminescence emission of a single activator is shown.

\subsection{Point defects in quartz}

Quartz lattice defects can be grouped into three types according to their structure and size: 1) point defects (most important for luminescence studies), 2) dislocations, 3) inclusions and clusters of foreign minerals and volatiles. During crystallisation the impurity and lattice defects are generally incorporated as charge compensated, diamagnetic defect centres. Natural radioactivity as well as the electron radiation during experiments causes the transformation of diamagnetic precursor centres into paramagnetic centres. The irradiation changes the defects by trapping an electron or creating a hole at the site of a precursor defect. Additionally,

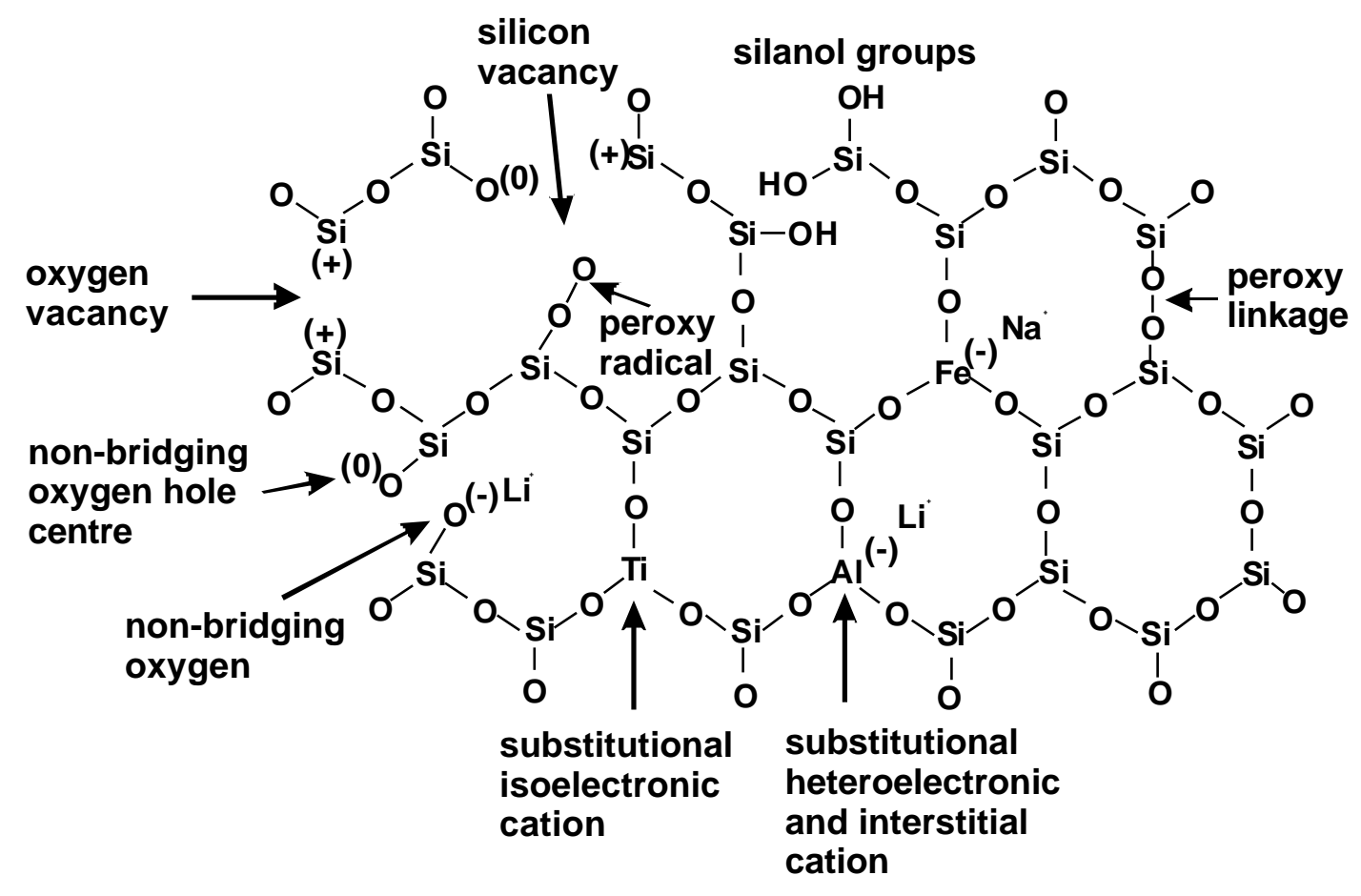

Fig. 2.3 Synopsis of the most common lattice defects in quartz modified after Götze (2000).

atomic displacements from the normal bonding (defect-free) sites may form by radiolysis processes (Kalceff and Phillips, 1995).

EPR studies have identified about 20 different paramagnetic defect centres in quartz which can be divided into 2 main types: 1) vacancy centres, which are subdivided into electron 
centres (oxygen vacancies) and hole centres (silicon vacancies) and 2) impurity centres which are subdivided into electron centres $\left(\mathrm{M}^{4+}+\mathrm{e}^{-}\right)$and hole centres $\left(\mathrm{M}^{3+}, \mathrm{M}^{2+}\right.$ ions, as well as atomic hydrogen). (e.g. Marfunin, 1979; Kostov and Bershov, 1987; Agel, 1992; table 2.1). The type 2 has different varieties, depending on the kind of ion-charge compensator in structural channels, such as $\mathrm{H}^{+}, \mathrm{Li}^{+}, \mathrm{Na}^{+}$, as well as on the position of the compensator.

The paramagnetic vacancy centres are represented by the frequent E' centre $\in \mathrm{Si} \cdot$ ), the peroxy radical ( $\equiv \mathrm{Si}-\mathrm{O}-\mathrm{O} \cdot)$, and the nonbridging oxygen hole centre $(\mathrm{NBOHC})(\equiv \mathrm{Si}-\mathrm{O} \cdot)$ (e.g. Weeks, 1956; Weil, 1984; Marfunin, 1979; Griscom, 1985; Kalceff and Phillips, 1995; Fig. 2.3). The non-paramagnetic oxygen vacancy $(\mathrm{Si}-\mathrm{Si})$ and the trapped electron centre $(\equiv \mathrm{Si}:)$ are possible precursors for an E' centre and the peroxy linkages ( $\mathrm{Si}-\mathrm{O}-\mathrm{O}-\mathrm{Si}$ ) for a peroxy radical and/or the NBOHC. The paramagnetic $\mathrm{O}^{-}$and $\mathrm{O}^{3-}{ }_{2}$ centres represent different types of NBOHC in tetrahedra with silicon vacancy (e.g. Bershov et al., 1978; Serebrennikov et al., 1982).

Table 2.1 Common paramagnetic centres of quartz after Plötze (1995).

\begin{tabular}{|c|c|c|c|c|c|}
\hline & \multicolumn{2}{|l|}{ Impurity centres } & \multicolumn{2}{|l|}{ Vacancies } \\
\hline & & $\mathrm{Si}^{4+}$ substitution & Interstitial & $\begin{array}{l}\text { Oxygen } \\
\text { vacancies }\end{array}$ & Silicon vacancies \\
\hline \multirow[t]{2}{*}{ Metastable } & $\begin{array}{l}\text { Electron centres } \\
\left(+\mathrm{e}^{-}\right)\end{array}$ & \begin{tabular}{|l}
{$\left[\mathrm{TiO}_{4}\right]^{-}$} \\
{$\left[\mathrm{TiO}_{4} / \mathrm{M}^{+}\right]^{0}$} \\
{$\left[\mathrm{GeO}_{4}\right]^{-}$} \\
{$\left[\mathrm{GeO}_{4} / \mathrm{M}^{+}\right]^{0}$}
\end{tabular} & $\begin{array}{l}\mathrm{M}^{+}=\mathrm{H}^{+}, \mathrm{Li}^{+} \\
\mathrm{M}^{+}=\mathrm{H}^{+}, \mathrm{Li}^{+}\end{array}$ & $\begin{array}{l}\text { E' centres: } \\
{\left[\mathrm{SiO}_{3}\right]^{3-}}\end{array}$ & \\
\hline & $\begin{array}{l}\text { Electron centres } \\
\left(-\mathrm{e}^{-}\right)\end{array}$ & $\begin{array}{l}{\left[\mathrm{AlO}_{4}\right]^{0}} \\
{\left[\mathrm{FeO}_{4}\right]^{0}}\end{array}$ & & & $\begin{array}{l}\mathrm{O}^{-} \text {centres: } \\
\mathrm{O}^{-}, \mathrm{O}_{2}{ }^{3-}, \mathrm{O}_{2}{ }^{3}-\mathrm{M}^{+}\end{array}$ \\
\hline \multicolumn{2}{|c|}{$\begin{array}{l}\text { Stable } \\
\text { (paramagnetic without } \\
\text { charge receive) }\end{array}$} & $\begin{array}{l}{\left[\mathrm{FeO}_{4} / \mathrm{M}^{+}\right]^{0}} \\
?\left[\mathrm{FeO}_{4}\right]^{-} \\
\text {(precursor for } \\
{\left[\mathrm{FeO}_{4}\right]^{0}}\end{array}$ & $\begin{array}{l}\mathrm{M}^{+}=\mathrm{Na}^{+}, \mathrm{Li}^{+}, \\
\mathrm{Fe}^{3+}\end{array}$ & & \\
\hline
\end{tabular}

Impurity ions enter either interstitial or substitutional positions in the quartz lattice depending on ion radius and charge. The number of ions which can substitute for the silicon atom in the quartz lattice is limited because of the small ionic radius of $\mathrm{Si}^{4+}$ compared to its 4-valency. Typical substitutes are $\mathrm{AP}^{3+}, \mathrm{Ti}^{4+}, \mathrm{Fe}^{3+}, \mathrm{Ge}^{4+}, \mathrm{P}^{5+}$, and $\mathrm{Ga}^{3+}\left(\mathrm{X}^{\mathrm{n+}}\right.$; order of average frequency) (e.g. Bambauer, 1961; Lehmann, 1975; Lehmann and Bambauer, 1973; Maschmeyer and Lehmann, 1983b; Weil, 1984). Nuttall and Weil (1980) and McLaren et al. (1983) reported a 
hydrogenic trapped hole-center with four hydrogen atoms on a silicon position. Large open channels (smallest O-O diameter 3.55 ?) thread through the quartz structure parallel to the caxis and offer locations for interstitial cations such as $\mathrm{H}^{+}, \mathrm{Na}^{+}, \mathrm{K}^{+}, \mathrm{Li}^{+}, \mathrm{Fe}^{2+}, \mathrm{Cu}^{+}, \mathrm{Co}^{2+}, \mathrm{Ag}^{+}$ ... $\left(\mathrm{M}^{\mathrm{n}+}\right.$; order of average frequency). They act as charge compensators for the substitutional $\mathrm{X}^{3+}$ and $\mathrm{X}^{5+}$ ions. The possible incorporation of other cations in interstitial position (e.g. $\mathrm{Ni}^{2+}$, $\mathrm{Al}^{3+}, \mathrm{Fe}^{3+}, \mathrm{Co}^{3+}, \mathrm{Cr}^{3+}, \mathrm{Ti}^{4+}$ ) is a matter of discussion (Lehmann and Bambauer, 1973a, b; Weil, 1984).

The paramagnetic impurity centres which are built by tetravalent ions (mostly $\mathrm{T}^{4+}$ and $\mathrm{Ge}^{4+}$ ) cause the formation of the diamagnetic $\left[\mathrm{XO}_{4}\right]^{0}$ centres. These centres act as a precursor for the paramagnetic $\left[\mathrm{XO}_{4}\right]^{-}$, which develops during ionisation irradiation (table 2.1). At room temperature these centres bind diffusing $\mathrm{M}^{+}$cations such as $\mathrm{H}^{+}, \mathrm{Li}^{+}, \mathrm{Na}^{+}$forming a paramagnetic $\left[\mathrm{XO}_{4} / \mathrm{M}^{+}\right]^{0}$ centre (Wright et al., 1963; Rinneberg and Weil, 1972; Mackey, 1963; Rakov et al., 1985; Agel, 1992; Weil, 1993). The trivalent ions build up diamagnetic $\left[\mathrm{YO}_{4} / \mathrm{M}^{+}\right]^{0}$ centres associated with an adjacent charge compensating cation $\mathrm{M}^{+}\left(\mathrm{H}^{+}, \mathrm{Li}^{+}, \mathrm{Na}^{+}\right)$. The paramagnetic defects are metastable and decay depending on the temperature. The closure temperature varies e.g. $55-82^{\circ} \mathrm{C}$ for the $\left[\mathrm{TiO}_{4} / \mathrm{M}^{+}\right]^{0}$ centre and $49-64^{\circ} \mathrm{C}$ for the $\left[\mathrm{AlO}_{4}\right]^{0}$ centre (Grün et al., 2000).

\subsection{The state of water in quartz}

Apart from $\mathrm{Al}$, bonded water in the quartz lattice in the form of $\mathrm{H}^{+}, \mathrm{OH}^{-}$and $\mathrm{H}_{2} \mathrm{O}$ is the most important impurity. Brunner et al. (1961) proposed that water can be incorporated into the quartz lattice according to the reaction: -Si-O-Si- $+\mathrm{H}_{2} \mathrm{O}=-\mathrm{Si}-\mathrm{OH}+\mathrm{HO}-\mathrm{Si}-$. This is a preferred stress-induced mechanism and referred to as "hydrolytic weakening" (e.g. Griggs and Blacic, 1965; Griggs, 1967; Fig. 2.4a). Calculations of total energy indicate that this reaction which uses an energy of $\sim 0.1 \mathrm{eV}$ is spontaneous for a $\mathrm{Si}-\mathrm{O}$ bond stretched beyond $4 \%$ of its normal bond length (Heggie, 1992). Another possible configuration is described by Nuttall and Weil (1980) and McLaren et al. (1983), who assumed that hydrogen is 
(a) hydrolytic (Griggs, 1967)

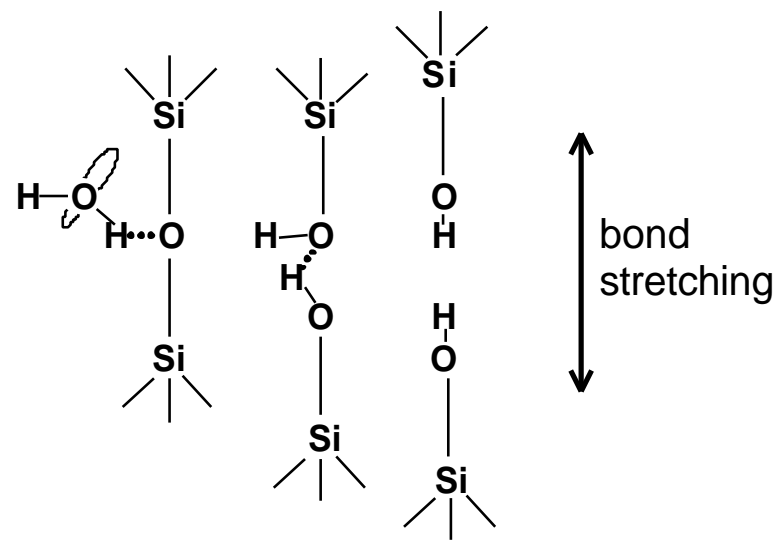

(b) $(4 \mathrm{H})_{\mathrm{Si}}$ - defects (McLaren et al., 1983)

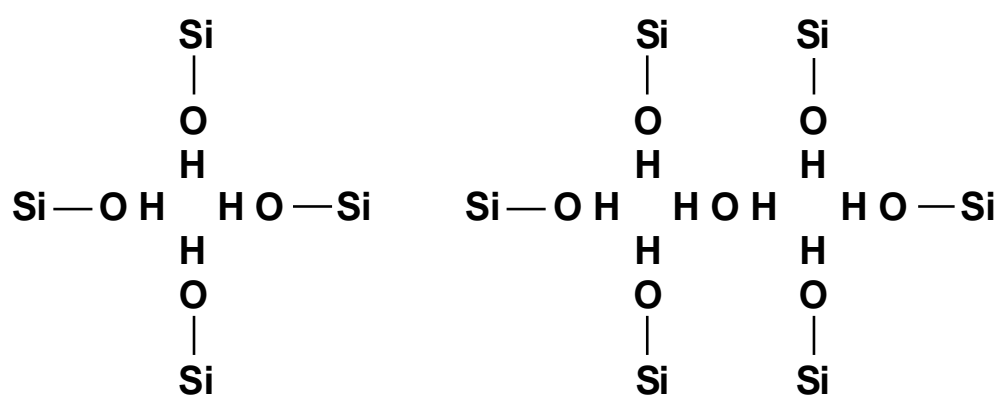

(C) $2 \mathrm{SiO}_{3}-\mathrm{H}_{2} \mathrm{O}-\mathrm{Me}^{\mathrm{n}+} 2 \mathrm{Me}^{\mathrm{m}+} \mathrm{O}_{4}$ aqua complexes (Stenina et al., 1988)
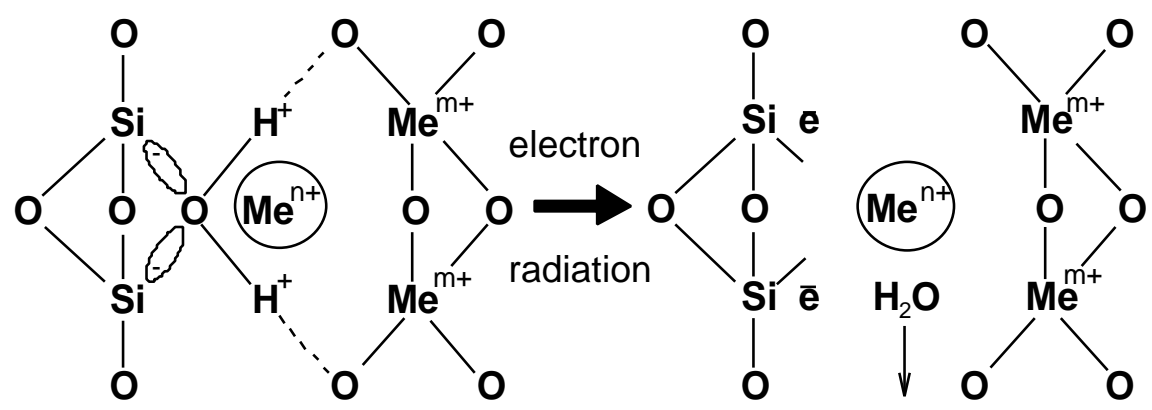

Fig. 2.4 Models of the structural state of water in the quartz lattice. a - hydrolytic weakening according to Griggs (1967); b - $(4 \mathrm{H})_{\mathrm{Si}}$ defects according to McLaren et al. (1983) where $4 \mathrm{H}^{+}$substitutes for $\mathrm{Si}^{4+}$; c- model of aqua complexes after Stenina et al. (1988). The incorporated water molecule forms weak donor-acceptor and hydrogen bonds with the surrounding matrix. This bonds break during electron radiation. 
incorporated in the quartz structure by means of $(4 \mathrm{H})_{\mathrm{Si}}$ defects where $4 \mathrm{H}^{+}$substitutes for $\mathrm{Si}^{4+}$ (Fig. 2.4b). The infrared absorption spectra of natural quartz crystals typically exhibit sharp absorption peaks between 3000 and $3700 \mathrm{~cm}^{-1}$ which are associated with hydrogen and hydroxyl acting as a charge compensator of $\mathrm{AP}^{3+} / \mathrm{M}^{\mathrm{n}+}$ (e.g. Brunner et al., 1961; Kats, 1962; Bambauer et al., 1963). Kronenberg et al. (1986) showed that the solubility of water in the quartz lattice depends on the Al content. Maschmeyer and Lehmann (1983a) proposed a model where two $\mathrm{OH}$ goups are neighbouring substitutional $\mathrm{X}^{3+}$ and interstitial $\mathrm{M}^{\mathrm{n}+}$. Based on transmission electron microscopy (TEM), X-ray microanalysis and EPR Stenina et al. (1988, 1995) showed that the trace substitutional $X^{3+}$ and related compensating $M^{n+}$ create parts of aqua complexes and clusters in the form of $2 \mathrm{SiO}_{3}-\mathrm{H}_{2} \mathrm{O}-\mathrm{M}^{\mathrm{n}+} 2 \mathrm{X}^{\mathrm{m}+} \mathrm{O}_{4}$, where $\mathrm{X}^{\mathrm{m}+}$ is mostly $\mathrm{AP}^{3+}$ and $\mathrm{Fe}^{3+}$ and $\mathrm{M}^{\mathrm{n}+}$ mostly $\mathrm{Li}^{+}$and $\mathrm{Na}^{+}$(Fig. 2.4c). The tetrahedrally charged water molecule is built between two defective positively charged $\mathrm{SiO}_{3}{ }^{+}$tetrahedra and the two defective negatively charged $\left[\mathrm{X}^{\mathrm{m}+} \mathrm{O}_{4}\right]$ tetrahedra. $\mathrm{M}^{\mathrm{p}}$ cations enter interstitial position as charged compensators. This scheme of heteroisomorphic substitution $\mathrm{M}^{\mathrm{n}+} \mathrm{X}^{\mathrm{m}+}$ for $\mathrm{Si}^{4+}$ is typical for quartz. The incorporated water molecule forms weak donor-acceptor and hydrogen bonds with the surrounding matrix. This tetrahedrally-charged water can be revealed in the IRspectrum as molecular water and hydroxyl. Under electron beam irradiation the aqua complexes become visible by TEM in form of several microns small, non-crystalline (gel like) micro-areas with diffuse boundaries. 


\section{Cathodoluminescence equipment}

\subsection{Sample preparation}

In this CL study thin sections with a thickness of $250 \mu \mathrm{m}$ were used so as to provide demountable thin sections on which to carry out LA-ICPMS, FTIR spectroscopy, EPMA, and CL on the same area of the quartz samples. The laser of the ICPMS ablated craters $100-150$ $\mu \mathrm{m}$ in depth and for the FTIR spectroscopy demounted thin sections polished on both sides are necessary.

The first stage of sample preparation consists of cutting the section, which was mounted on a glass slide with epoxy resin. Subsequent polishing was carried out with progressively finer grades of abrasive (carborundum). The final stage involves polishing with diamond paste with a grade of $0.3 \mu \mathrm{m}$. The samples were thoroughly cleaned. The polished surface was mounted on a standard glass slide $(48 \times 24 \times 2.8 \mathrm{~mm})$ with Akemi Mamorkitt 1000. The other glass slide was removed and the procedure of polishing was repeated until a section thickness of $250 \mu \mathrm{m}$ was reached. For sample temperature measurements during CL and FTIR spectroscopy the section was removed from the glass slide with Xylol. In addition, a number of thin sections were chemically polished with a OP-S suspension of different granularities (1 $\mu \mathrm{m}$ and $3 \mu \mathrm{m})$ in order to test the effect of the surface quality on the CL properties.

Quartz being a non-conductor, requires a conductive coating to prevent charging under electron bombardment. The preferred coating for CL studies is carbon. It is also the best choice for X-ray analysis, because has a minimal effect on the X-ray spectrum. However, it is not ideal for SEM imaging, owning to its low secondary electron field. The coating was done at standard conditions to a thickness of about $15 \mathrm{~nm}$ to avoid variations in CL-intensity. 


\subsection{Optical CL}

\section{Cathodoluminescence microscope HC3-LM}

The commercially produced hot-cathodoluminescence microscope (HC1-LM) after Neuser et al. (1995) is provided with a high-vacuum chamber $\left(<10^{-5} \mathrm{mbar}\right)$ and uses an acceleration voltage of $14 \mathrm{keV}$ (Fig. 3.1). The HC1-LM is a development of the prototype constructed at the IGDL Göttingen 1987 (Neuser, 1988) according to the model of Zinkernagel (1978). The electron gun operates as a "hot cathode", i.e. the electrons are emitted from a heated filament. In a "cold cathode" CL microscope the electron beam is generated during discharge between the cathode and anode in an ionised gas. The hot-cathode technique provides a considerably greater beam stability and CL intensity than the cold cathode instruments and thus is suitable for investigation of the weakly luminescent quartz. The electron gun directs a focused beam upwards onto an inverted thin section; the $\mathrm{CL}$ is viewed through the sample from above. The electron beam with a diameter of ca. $4.8 \mathrm{~mm}$ irradiates the thin section surface with a current density of ca. $10 \mathrm{~mA} / \mathrm{mm}^{2}$. The basis of the HC3-LM is a polarisation microscope model OLYMPUS BX30M with some modifications, for instance, the vacuum sample chamber is mounted in place of the sample stand. The polarisation objectives have a magnification/numerical aperture of $5 x / 0.15,10 x / 0.30,20 x / 0.40$. The high vacuum of the sample chamber is attained by a Diffstak oil diffusion pump combined with an Edwards rotary vane pump.

\section{The TRIAX 320 Spectrograph}

CL spectra were recorded with a triple-grating spectrograph TRIAX 320 provided with a liquid $\mathrm{N}_{2}$-cooled Charge Coupled Device (CCD) camera (Fig. 3.2). The system is well suited to applications with very low signals such as the CL of quartz. The spectrograph is attached to the CL microscope ocular with a quartz fibre guide of $1.5 \mathrm{~m}$ length (transmission range 200$900 \mathrm{~nm}$ ). The quartz fibre guide is coupled via a fibre optic interface to the entrance slit of the TRIAX 320. The system is controlled by an external PC using the software programs HWINIT for hardware initialisation and SpectraMax for Windows for data processing.

The triple-grating spectrograph is equipped with one ruled grating (100 lines/mm) and two blazed holographic gratings (1200 and 1800 lines/mm) which are mounted on a rotating triple grating turret. The higher spectral resolution obtained with the 1200 and 1800 lines/mm gratings results in small ranges of the recorded spectra, namely $70 \mathrm{~nm}$ and $40 \mathrm{~nm}$, respectively (Table 3.1). 


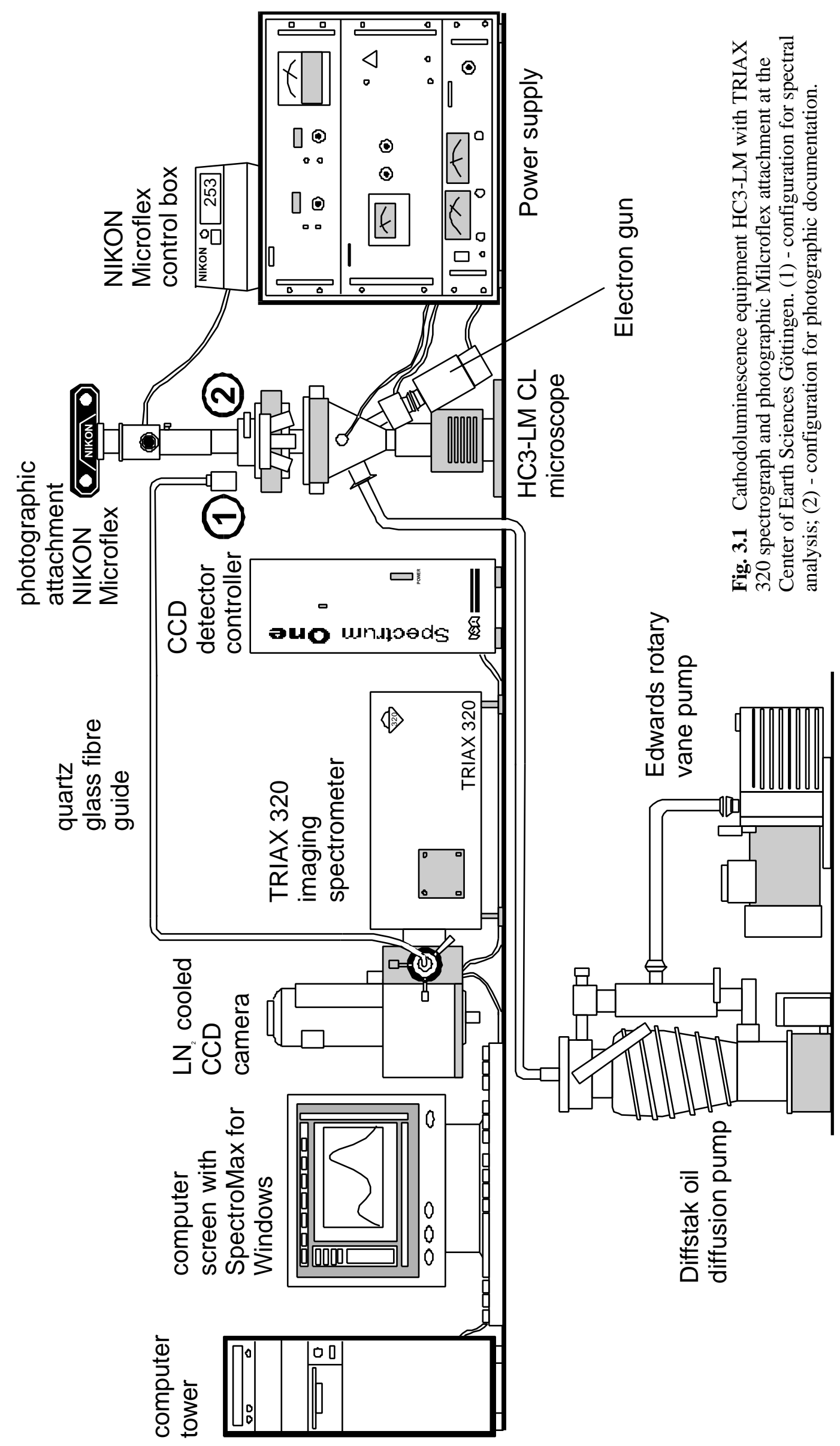


Table 3.1 Specification of the used optical gratings.

\begin{tabular}{llll}
\hline Grating & 100 lines $/ \mathrm{mm}$ & 1200 lines $/ \mathrm{mm}$ & 1800 lines $/ \mathrm{mm}$ \\
\hline Working range & $250-900 \mathrm{~nm}$ & $190-1200 \mathrm{~nm}$ & $250-900 \mathrm{~nm}$ \\
Scanning range per recording & $1000 \mathrm{~nm}$ & $70 \mathrm{~nm}$ & $40 \mathrm{~nm}$ \\
Spectral resolution & $0.5 \mathrm{~nm}$ & $0.06 \mathrm{~nm}$ & $0.02 \mathrm{~nm}$ \\
Wavelength position accuracy & $1 \mathrm{~nm}$ & $0.3 \mathrm{~nm}$ & $0.1 \mathrm{~nm}$ \\
\hline
\end{tabular}

The back-illuminated CCD camera with UV-AR-coating has a spectral response between 200 and $1050 \mathrm{~nm}$ (Fig. 3.3). The CCD detector array is built up of an area of silicon photodiodes divided into a 2-dimensional matrix of pixels. Each pixel integrates a charge arising from the photoelectric effect caused by the incident light. The charges of adjacent pixels are kept separated by a grid of electrodes that confine the changes by electrostatic force. The pixel charge is controlled and read out by the detector interface unit (DIU). The signal from the CCD is processed, amplified and converted to digital datapoints by electronics in the DIU and transferred to the host PC.

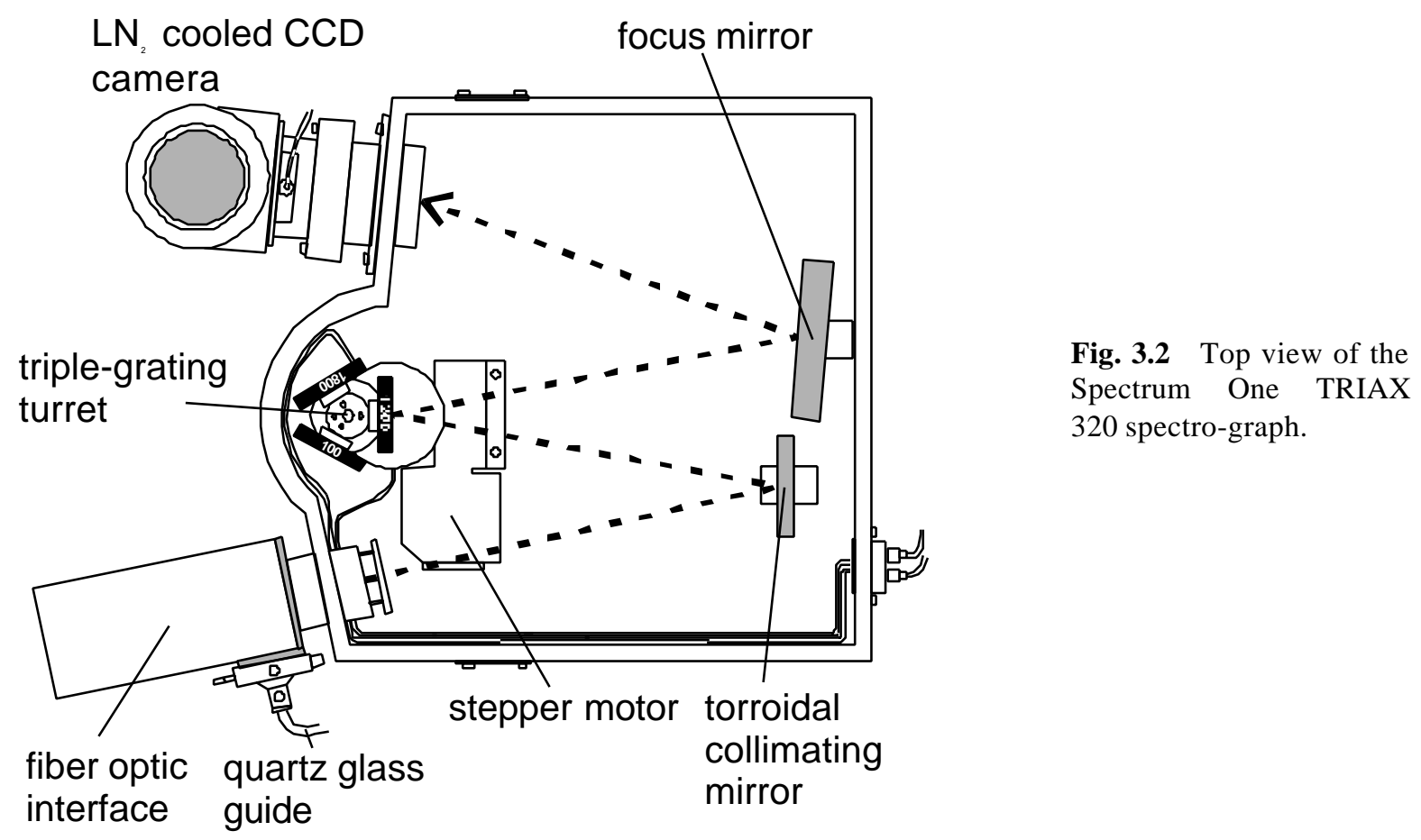

The CCD array head is cooled by liquid nitrogen which works with a temperature below $140^{\circ} \mathrm{C}$. The cooling is necessary to lowering the dark current and to obtain a better signal/noise ratio at low photon emission rates. 
A mercury lamp was attached to the entrance slit of the spectrometer in order to calibrate the wavelength. A difference between the position of the measured peak and the known mercury peak at $546.1 \mathrm{~nm}$ was corrected by setting the wavelength difference into the lines "MultiAUtoCaloffset $0=$ (1200 lines/mm grating), "MultiAUtoCaloffset $1=$ (1800 lines/mm grating), and "MultiAUtoCaloffset $2=$ " (100 lines/mm grating) of the file MONO1.ini.

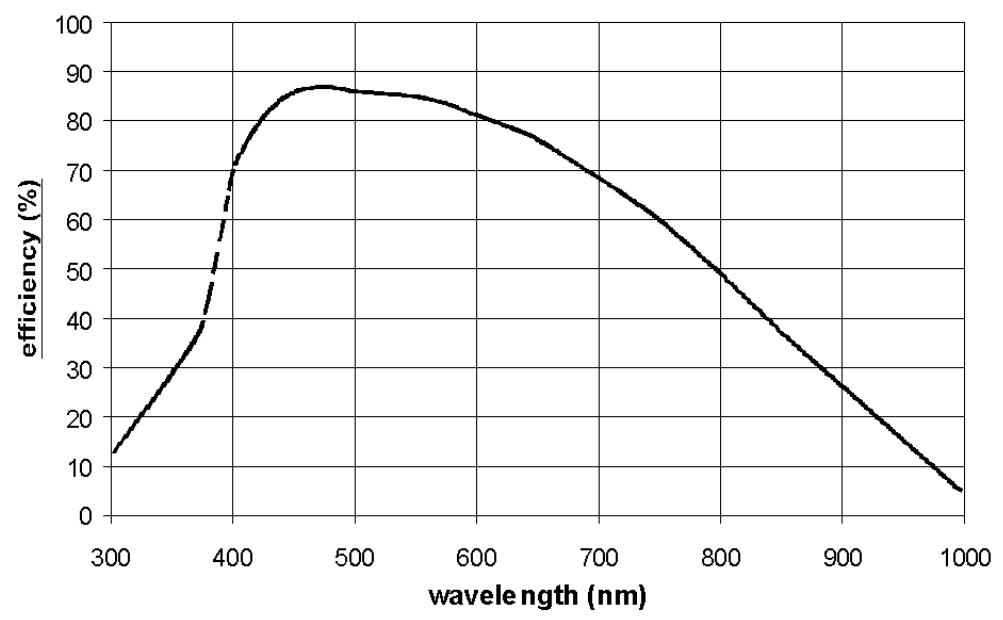

Fig. $\quad 3.3 \quad$ Spectral sensitivity of the TRIAX 320 CCD-camera

The CL spectra were recorded for the same instrumental setting: a filament current of $0.18 \mathrm{nA}$ using the objective 20x/0.40. The analysed area was $800 \mu \mathrm{m}$ in diameter. The 100 lines/mm grating was used to fully detect the emitted spectra of visible light between 400 and $900 \mathrm{~nm}$ (3.1 - $1.4 \mathrm{eV})$. The 1200 lines/mm grating provided high-resolution spectra of $70 \mathrm{~nm}$ width sectors. The high wavelength resolution obtained by using the 1800 lines/mm grating was not suitable as the half-width of the quartz CL bands varies between 20 and $100 \mathrm{~nm}$.

The time-resolved spectra were recorded within $40 \mathrm{~s}$ (100 lines/mm grating) and of $60 \mathrm{~s}$ (1200 lines/mm grating) using the maximum entrance slit width of $2 \mathrm{~mm}$ and an acquisition time of 20 and 30 s, respectively. The system needed twice the acquisition time to accumulate the low emission intensity and to measure the background. The intensities are integrated over the duration of exposure. The first spectrum was recorded immediately after the initialisation of the electron bombardment because of drastic CL change of quartz during the first seconds of radiation (Fig. 3.4). Subsequent spectra were recorded in steps of one minute or several minutes.

The change of the CL intensity of the 1.96 and $2.79 \mathrm{eV}$ emissions during electron radiation was measured with the $\mathrm{f} / 3.4$ Grating Monochromator at a speed of $10 \mathrm{~mm} / \mathrm{min}$ using the CL 
a) 100 lines/mm grating

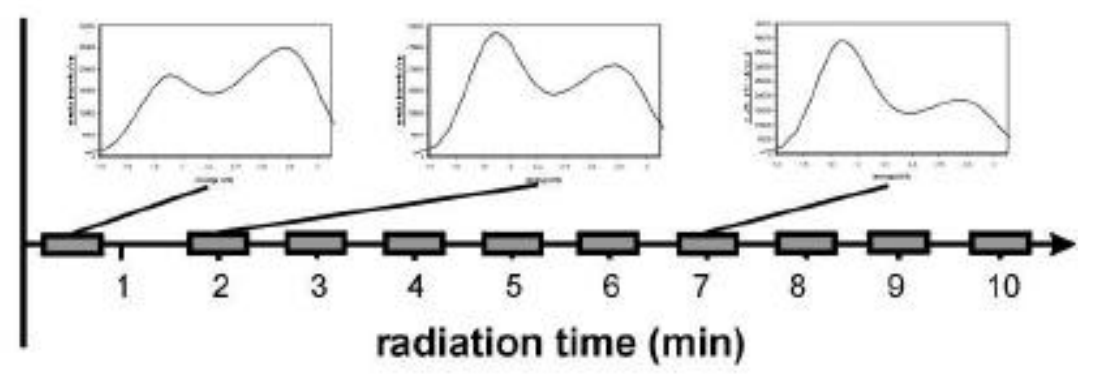

Fig. 3.4 Used time steps for time-resolved spectrum recording with the 100 lines/mm (a) and 1200 lines/mm grating (b). The grey squares represent the duration which is necessary for spectrum acquisition.

\section{b) 1200 lines $/ \mathrm{mm}$ grating}

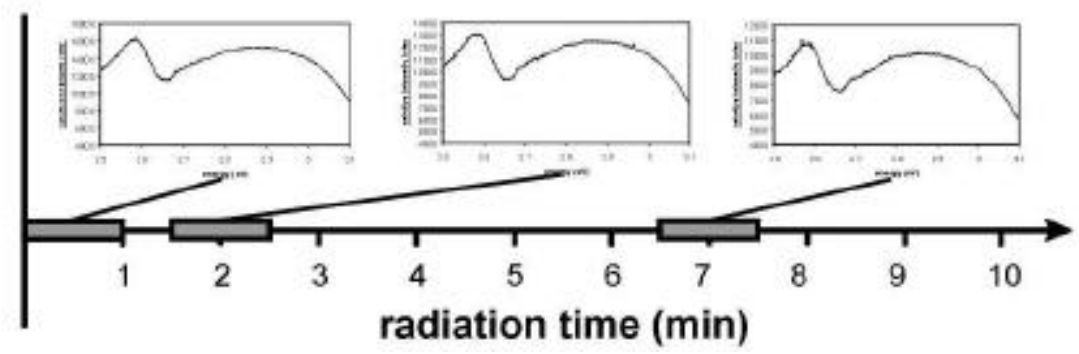

microscope after Zinkernagel (1978) at the University Göttingen (10 keV, $0.2 \mathrm{nA})$. In contrary to the TRIAX 320 the monochromator allows the record of the CL intensity change from time zero of electron radiation. The CL intensity drastically changes during the first seconds of electron radiation and its recording is of interest for solving the causes of CL.

The photographic documentation was carried out by a NIKON Microflex UFX-II system equipped with a NIKON FX-35A reflex camera (Fig. 3.1). Colour slides of the luminescent images were taken with high-sensitive films KODAK Ektachrome $400 \mathrm{HC}$ (400 ASA) and KODAK Ektachrome 1600 (1600 ASA). High-sensitive films were chosen because of the low CL intensities. The exposure times were of $100-250 \mathrm{~s}$ for the $400 \mathrm{HC}$ and of $10-30 \mathrm{~s}$ for the 1600 using the $10 x / 0.30$ objective. 


\subsection{The scanning electron microscope (SEM) CL}

The scanning electron microscope (SEM) is along with the light microscope the most important imaging instrument. The scanning electron microprobe utilises a scanned electron beam with a small spot size normally around $2 \mu \mathrm{m}$ in diameter. By scanning the electron beam, synchronized with the $\mathrm{X}, \mathrm{Y}$ deflection of a display oscilloscope, and modulating the display oscilloscope intensity with the photomultiplier output, a magnified map of the CL of the specimen is obtained. Total photomultiplier output intensities were used for the intensity function.

The SEM-CL offers advantages over the conventional (optical) CL microscopy for CL studies (Grant, 1978; Tovey and Krinsley, 1980). The main advantage is the larger spatial resolution of $\leq 1 \mu \mathrm{m}^{2}$. Other advantages are the higher magnification, the capability of combining CL and SEM investigations like back scattered electron (BSE) imaging and microanalytical analysis on the same area. The possibility of increasing the power density over small sample areas is useful for samples with low CL intensity like quartz. A disadvantage is the monochromatic (grey scale) image.

Two scanning electron microscopes equipped with different CL detectors, the Cambridge Instruments 250-MK3 with a S20-Extended photomultiplier and the JEOL JXA 8900 with a CLD40 R712 photomultiplier, were used for the study of internal growth patterns and secondary CL structures within individual quartz crystals. The voltage and sample current for both SEM was $15 \mathrm{keV}$ and 5-15 nA. A quartz glass lens in front of the S20-Extended detector collects the emitted light of the sample; the photomultiplier of the JEOL system works without additional lenses and mirrors. Images were collected from the JEOL system using slow beam scan rates of $20 \mathrm{~s}$ at processing resolution of 1024x860 pixels and 256 grey levels. The documentation of the CL images at the 250-MK3 were carried out with a photocamera with Agfapan APX 25 films and by using slow beam scan rates of $250 \mathrm{sec}$.

The detectable wavelength for both photomultipliers ranges from 380 to $850 \mathrm{~nm}$. The lower limit of detection is $380 \mathrm{~nm}$, which is determined by the absorption of the lead glass plate in front of the photomultipliers. The maximum wavelength responses are at $600 \mathrm{~nm}$ for the CLD40 R712 and at $420 \mathrm{~nm}$ for the S20-Extended photomultiplier. The spectral sensitivity of both photomultipliers are shown in the figure 3.5.

Remarkable differences between the images produced by the photomultipliers have been found (Fig. 3.6). The S20 Extended photomultiplier is more sensitive for blue emissions and was therefore used for imaging of samples with dominant blue luminescence, whereas the 
CLD40 R712 photomultiplier was preferred to contrast reddish luminescent secondary textures. Dark contrasted areas of quartz SEM-CL images always correspond to red to reddish

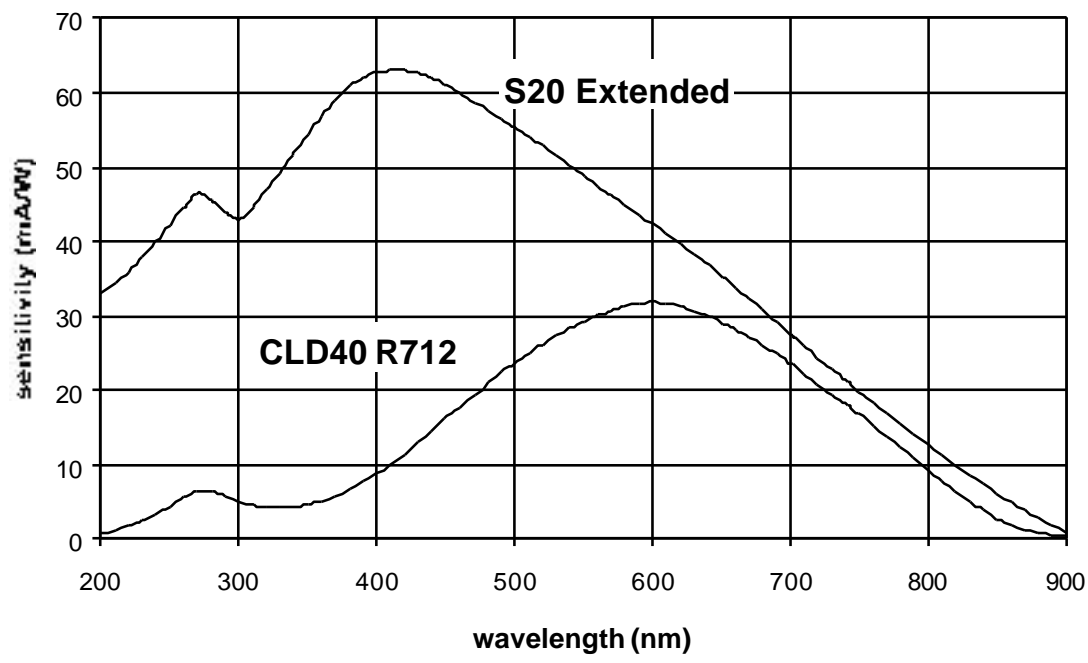

Fig. 3.5 The spectral sensitivity characteristics of the Cambridge Instruments S20 Extended and the JEOL CLD40 R712 photomultipliers.

brown CL-colours and bright areas correspond to blue to violet colours. The luminescence colours were checked by optical CL prior to or after SEM-CL investigations.

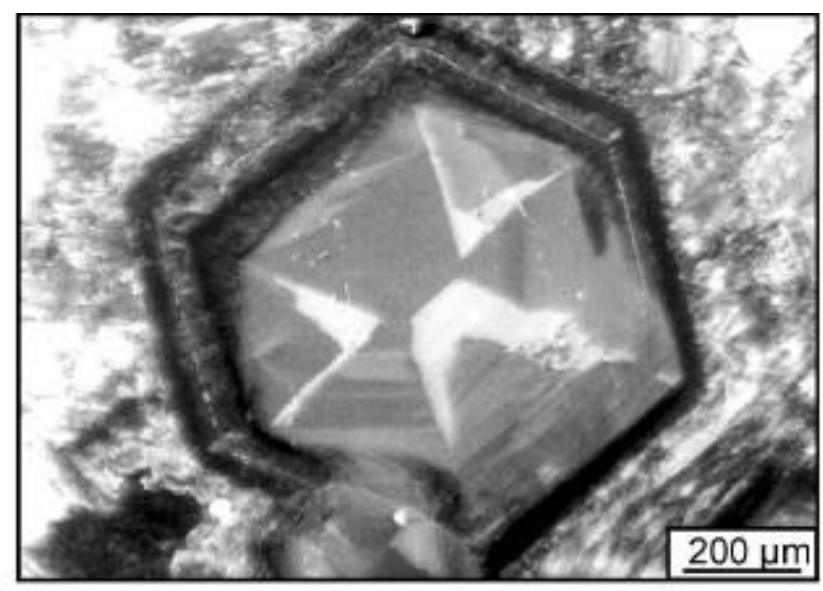

Fig. 3.6 Unprocessed SEM-CL images of a vein quartz (sample 9) using different photomultipliers. a Cambridge Instruments S20 Extended photomultiplier; b JEOL CLD40 R712 photomutliplier.

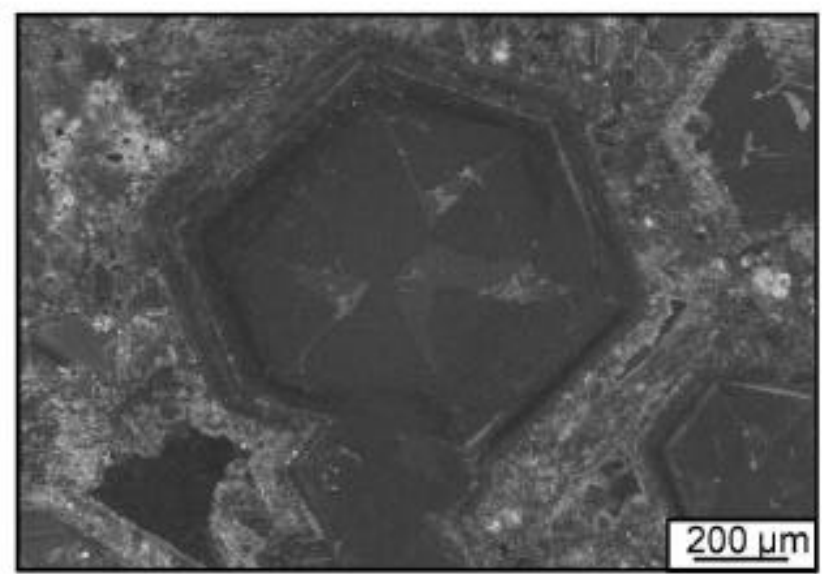


Image processing was carried out using the software Optimas 6.0 for Windows. Starting with an unprocessed CL image a typical sequence of processing steps was: (1) producing a grey level histogram (2) selection of the grey level range responsible for contrasting of structures within the quartz crystal (3) extension of the chosen grey level range to 256 grey levels (4) treatment of the image with several filters for sharpening and smoothing (5) determination of grey-scale profiles e.g. along trace element traverses of zoned quartz crystals, as shown in figure.

\subsection{Mathematical treatment of CL-spectra}

Spectral data acquisition was carried out by using the software SpectraMax for Windows. The emitted light was recorded in nanometer $(\mathrm{nm})$. The emission bands are not immediately obvious from visual inspection of the experimental data due to the close proximity of broad emission bands which results in complex peak overlapping. The asymmetry of the broad peaks and the shift in the different quartz samples suggests the presence of several bands. The processing steps for spectra analysis were the following:

1) For processing of the spectra the data were exported as ASCII data into the EXCEL program.

2) The spectra were corrected for the sensitivity of the spectrometer (Fig. 3.3). For that the measured intensities were multiplied by the factor of efficiency.

3) Spectral emission bands normally have a Gaussian shape if plotted in energy space (Kalceff and Phillips, 1995). Therefore, the data in nanometer (nm) were converted into electron volts $(\mathrm{eV})$ according: $E=1239.8 /$ ?, where $E$ is the energy $(\mathrm{eV})$, and ? the wavelength $(\mathrm{nm})$.

The shape of the intensity distribution of an emission band plotted versus the light energy is described by the Gaussian function. The emission intensity $\mathrm{I}(E)$ at the energy $E(\mathrm{eV})$ of an emission band centred at a is described by the following equation: 


$$
\mathrm{I}(E)=\mathrm{I}_{\mathrm{f}} \frac{1}{\mathrm{~s} \vee 2 \mathrm{p}} \mathrm{e}^{-(E-\mathrm{a})^{2} / 2 \mathrm{~s}^{2}}
$$

where $\mathrm{I}_{\mathrm{f}}=$ intensity factor; $E=$ energy $(\mathrm{eV}) ; \mathrm{a}=$ position of the maximum of the Gaussian curveand centre of symmetry; $\mathrm{s}=$ distance from a to the turning point of the Gaussian curve (Fig. 3.7).

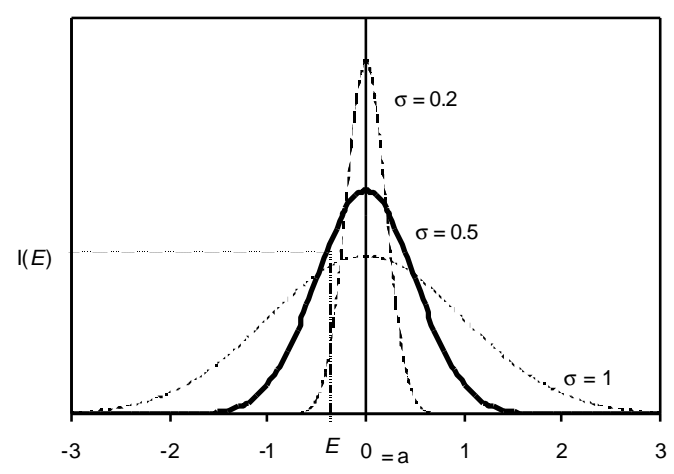

Fig. 3.7 Gaussian curves for $\mathrm{a}=$ $0, \mathrm{I}_{\mathrm{f}}=$ const., and different $\mathrm{s}(0.2$, 0.5 , and 1$)$.

The position (a), width (s), and size ( $\left.\mathrm{I}_{\mathrm{f}}\right)$ of the Gaussian curves were calculated and adjusted in such a way that the sum of the individual components equals the recorded spectrum. The band positions (a) were determined by manual setting of the peak configurations using the high-resolution spectra recorded with the 1200 lines/mm grating. The intensity factor If corresponds to the area under the Gaussian curve (the integral of Gaussian distribution from -8 to +8 is 1$)$. If was used to determine ratio and percentage of the individual emission bands of the total spectra between 1.4 and $3.1 \mathrm{eV}$ recorded with the 100 lines/mm grating. 


\section{Microanalysis of trace elements and defect centre characterisation in quartz}

Amongst the suite of microanalytical techniques commonly used for trace element determination, secondary ion mass spectrometry (SIMS), electron probe micro analysis (EPMA), and laser ablation inductively coupled plasma mass spectrometer (LA ICP-MS) can provide element analysis data with a high sensitivity and a high spatial resolution, which allows the determination of element zoning of crystals. Therefore, the three methods were chosen for the determination of the trace element distribution in quartz. The electron paramagnetic resonance (EPR) and the Fourier-transform infrared (FTIR) spectroscopy are powerful techniques available for the characterisation of defects centres in quartz. Clearly, no single instrument gives a complete characterisation of a mineral, but if the five techniques are employed in a complementary fashion, the chances for success are better.

The LA ICP-MS has the potential to determine most elements of the periodic system at the part-per-million level in solids with a spatial resolution down to $20 \mu \mathrm{m}$. The instrument allows fast and accurate analysis of most important trace elements in quartz ( $\mathrm{Li}, \mathrm{Al}, \mathrm{Ti}, \mathrm{Cr}$, $\mathrm{Mn}, \mathrm{Fe}$, and $\mathrm{Ge}$ ). A laser beam with larger diameter and higher energy ablates more material and results in lower detection limits. On the other hand the trace element distribution of zoned quartz crystals requires highest spatial resolution. Therefore a compromise between detection limit and spatial resolution has to be found. For a mean ablation crater size of about $20 \mu \mathrm{m}$ the detection limit for LA ICP-MS are comparable with those of EPMA.

The EPMA is based on X-ray emission of a solid bombarded with a focused electron beam. Characteristic X-rays are analysed according to their wavelength, the peak intensity counted relative to a standard. The main advantages of the EPMA are the high spatial resolution of $\sim 4$ $\mu \mathrm{m}$ and the capability of combining microanalytical analysis with CL and BSE imaging.

Trace and ultra-light elements (e.g. Li) which can not be measured by EPMA can measured by the ion microprobe. The SIMS instrument uses a focused primary ion beam to perform in situ microanalysis of minerals in samples prepared as gold coated polished thin sections. A very small percentage of the sample material sputtered from the polished surface of the sample is ionised, and these ions are accelerated into a mass spectrometer where they are separated according to their mass. Nearly all elements from $\mathrm{H}$ to $\mathrm{U}$ can be detected and many can be analysed quantitatively down to part-per-million levels, or lower. ${ }^{16} \mathrm{O}^{-}$beam currents 
are required for trace element analysis and beam diameters of $30 \mu \mathrm{m}$ allow the determination of the chemical zoning of minerals.

The $E P R$ is a powerful spectroscopic technique available for the detection and identification of paramagnetic defects. Paramagnetic defects arising from impurities (Al, Ti, Fe, Ge, H, P, $\mathrm{Cu}, \mathrm{Ag}$ ) and oxygen and silicon vacancies are induced by natural or artificial irradiation of the quartz lattice. EPR describes the interaction between an electronic spin submitted to the influence of crystal field and an external magnetic field. The technique based upon the resonance absorption of induced magnetic microwaves caused by the magnetic moment of unpaired electrons resulting from paramagnetic defects. The determination of centres were made using powders.

The FTIR spectroscopy of quartz allows the qualification of structural bounded water in form of $\mathrm{H}_{2} \mathrm{O}$ molecules, hydroxyl, hydrogen-compensated aluminium and lithium defects. Records of spectra of single points and along profiles through quartz crystals were used to determine variations of kind and quantity of water associated defects.

\subsection{Electron probe microanalysis (EPMA)}

Trace elements in quartz were determined by wavelength-dispersive Electron Probe Micro Analysis (EPMA) on the JEOL JXA 8900 operating at an accelerating potential of $15 \mathrm{keV}$, at a beam current of $120 \mathrm{nA}$ on the Faraday cup, and with a beam diameter of $7 \mu \mathrm{m}$. Analyses were performed for $\mathrm{Al}, \mathrm{Ti}, \mathrm{K}$, and $\mathrm{Fe}$. Raw intensities converted into concentrations, making appropriate matrix corrections after the phi-rho-z method by Armstrong (1991). Measurements were carried out as single point analysis, or as line scans, yielding distribution profiles. CL imaging was performed prior and after EPMA analysis. In this way the measurement points in relation to the CL textures can be exactly located.

Quartz contains trace elements of at such low concentrations that a quantification by EPMA poses a major difficulty. Therefore, particular attention had to be paid to a number of parameters: 1) long counting time, 2) high beam current, 3) precise background measurement, 4) high polishing quality of the sample surface, and 4) carbon coating with constant thickness. The most decisive and often underestimated is the effect of the sample surface quality on the sensitivity of the measurement (Fig. 4.1). The increase of the Al background between measurement 39 and 48 during sample change is caused by sample surface contamination, 

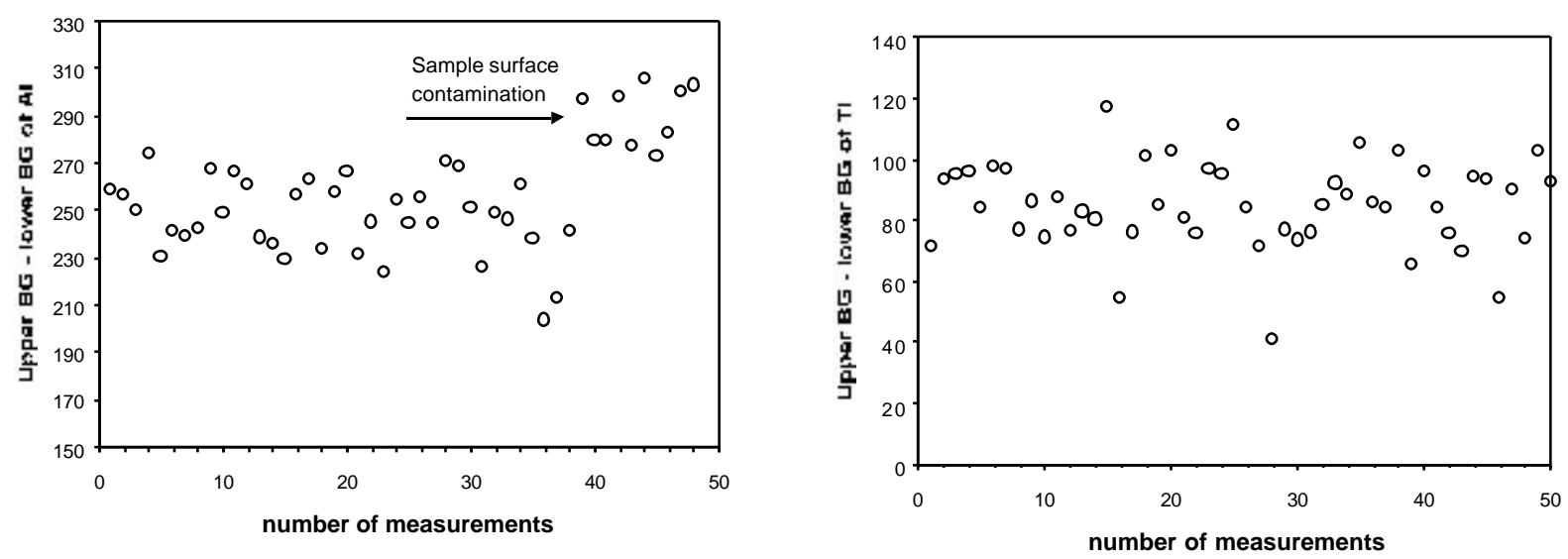

Fig. 4.1 Variation of brutto intensities of the $\mathrm{Al}$ and $\mathrm{Ti}$ background measurements (upper minus lower background) of three trace element profiles.

whereas the Ti background remains constant. This effect results in a decrease of the detection limit for $\mathrm{Al}$ from $27 \mathrm{ppm}$ to $50 \mathrm{ppm}$. Finally, for high precision and sensitivity, the high beam current of $120 \mathrm{nA}$, the beam diameter of $7 \mu \mathrm{m}$, and the counting rate of $10 \mathrm{~min}$ per shot means 180 s per element were chosen.

The determination of element concentrations in analytical chemistry is based on repetitive measurements and on the application of statistical methods (e.g. Miller and Miller, 1988; Miller, 1991). In EPMA, concentrations are calculated from the difference between the accumulated peak counts and the background $(\mathrm{BG})$ at the position of the X-ray line maximum. For extremely low concentrations only qualitative analysis is possible. The concentration at the detection limit, $\mathrm{C}_{\mathrm{DL}}$, as the lowest concentration of an analysed element that can be distinguished with reasonable confidence from zero concentration of the analysed element in a sample (blank). Ziebold (1967) suggested different definitions of the $\mathrm{C}_{\mathrm{DL}}$, and also Miller (1991) emphasises that a single, "correct", definition of the limit of detection, cannot be given and should be specified.

We used two definitions of the detection limit. The intensity (in counts) of the detection limit $\left(\mathrm{I}_{1 \mathrm{DL}}\right)$ is given in equation (4.1) (e.g. Merlet and Bodinier, 1990): 


$$
\mathrm{I}_{1 \mathrm{DL}}=3 \sigma_{\mathrm{BG}}
$$

where $\sigma_{\mathrm{BG}}=$ standard deviation of the background.

To reach a probability of $95 \%$ that a peak is present, the peak counts must exceed three times the standard deviation of the background, whereby the number of background measurements $\mathrm{n}$ must be $=5$. $\mathrm{I}_{1 \mathrm{DL}}$ was calculated for each trace element profile on the base of 12 background measurements.

A second method for determining of the intensity of the detection limit $\left(\mathrm{I}_{2 \mathrm{DL}}\right)$ is based on the level of significance applied to Student's t-distribution and the standard deviation obtained from background measurements (Plesch, 1982):

$$
\mathrm{I}_{2 \mathrm{DL}}=\mathrm{t}_{\mathrm{z}}(\mathrm{P} ; \mathrm{f}) \mathrm{s}_{\mathrm{BG}}
$$

where $s_{B G}=$ standard deviation of the mean of the background; $t(P ; f)=$ level of significance of the Student's t-distribution for binomial limitation determined by the confidence level $\mathrm{P}$ and the degrees of freedom $\mathrm{f}=$ number of background measurements $n-2$.

For each trace element profile both $\mathrm{I}_{1 \mathrm{DL}}$ and $\mathrm{I}_{2 \mathrm{DL}}$ were determined. For the latter a confidence level of $95 \%$ and 12 background measurements were used which result in the binomial level of significance $t_{z}(P ; f)$ of 2.228 (Table 4.1). The application of the equation (4.2) in this case results in a lowering of $\mathrm{I}_{\mathrm{DL}}$.

For the determination of the detection limit $\mathrm{C}_{\mathrm{DL}}$ the determination of the regression coefficients $\mathrm{a}$ and $\mathrm{b}$ are necessary, which represent the gradients of the regression line intensity vs. concentration of an element:

$$
\mathrm{C}_{\mathrm{DL}}=\mathrm{a}+\mathrm{b} \mathrm{I}_{\mathrm{DL}}
$$

where $a$ and $b=$ the regression coefficients of the regression line intensity vs. concentration. 
The regression coefficients $a$ and $b$ were determined by equation (4.4) and (4.5):

$$
\begin{aligned}
& \mathrm{a}=\frac{\text { ? } \text { ? }^{2}-? \mathrm{C} \text { I } ? \mathrm{I}}{\mathrm{n} ? \mathrm{I}^{2}-(? \mathrm{I})^{2}} \\
& \mathrm{~b}=\frac{\mathrm{n} ? \mathrm{C} \mathrm{I}-? \mathrm{I} ? \mathrm{C}}{\mathrm{n} ? \mathrm{I}^{2}-(? \mathrm{I})^{2}}
\end{aligned}
$$

where $\mathrm{I}=$ intensity; $\mathrm{C}=$ concentration of measurements; $\mathrm{n}=$ number of measurements.

The regression lines of intensity vs. concentration for the elements $\mathrm{Al}, \mathrm{Ti}, \mathrm{K}$, and $\mathrm{Fe}$ are illustrated in figure 4.2. The regression coefficients $\mathrm{a}$ and $\mathrm{b}$ were calculated from 273 measurements for each element. The coefficient a represents the concentration for zero counts and should be theoretically zero. But small systematic errors of the equipment result in a shift of the regression line (a ? 0) for $\mathrm{Al}$ at about $19 \mathrm{ppm}$. Consequently, the $\mathrm{Al}$ content calculated by the EPMA software is generally $19 \mathrm{ppm}$ to high. For the other elements a is about zero. The concentrations of the detection limit for $\mathrm{Al}, \mathrm{Ti}, \mathrm{K}$ and $\mathrm{Fe}$ calculated after the equations (4.2) and (4.3) are shown in figure 4.3 and listed in table 4.2.

Table 4.1 Level of significance of the Student's tdistribution for binomial limitation (Plesch, 1982).

\begin{tabular}{lll}
\hline $\mathrm{f}$ & \multicolumn{2}{c}{$\mathrm{t}_{\mathrm{z}}(\mathrm{P} ; \mathrm{f})$} \\
& $\mathrm{P}=95 \%$ & $\mathrm{P}=99 \%$ \\
\hline 1 & 12.710 & 63.660 \\
2 & 4.303 & 9.925 \\
3 & 3.182 & 5.841 \\
4 & 2.776 & 4.604 \\
5 & 2.571 & 4.032 \\
6 & 2.447 & 3.707 \\
7 & 2.365 & 3.499 \\
8 & 2.306 & 3.355 \\
9 & 2.262 & 3.250 \\
10 & 2.228 & 3.169 \\
12 & 2.179 & 3.055 \\
15 & 2.131 & 2.947 \\
20 & 2.086 & 2.845 \\
30 & 2.042 & 2.750 \\
50 & 2.009 & 2.678 \\
8 & 1.960 & 2.576 \\
\hline
\end{tabular}



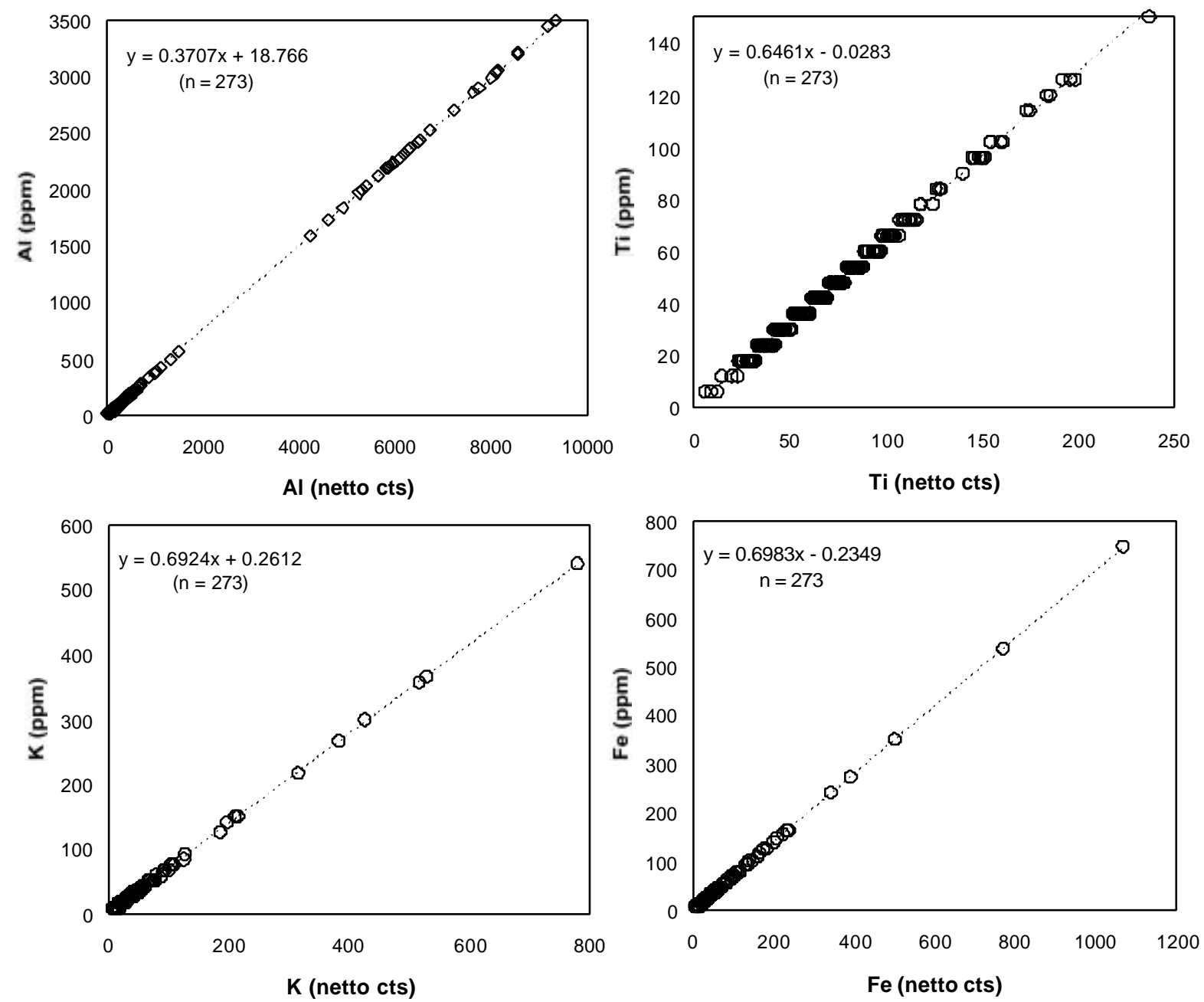

Fig. 4.2 Calculated regression coefficients a and b of regression lines of netto counts vs. element concentration. Under ideal conditions a should be zero, but systematic errors of the equipment cause a shifting of the regression line for $\mathrm{Al}$ at about $19 \mathrm{ppm}$.

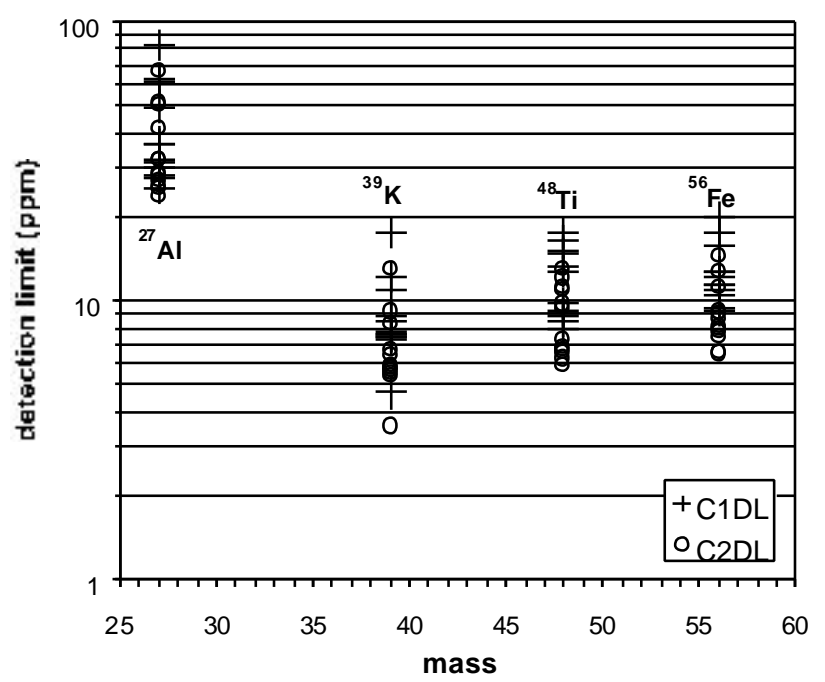

Fig. 4.3 Detection limits of trace elements in quartz for EPMA. The detection limit C1DL bases on the calculated intensity $\mathrm{I}_{\mathrm{DL}}$ after equation (4.1) and $\mathrm{C} 2 \mathrm{DL}$ on the intensity $\mathrm{I}_{2 \mathrm{DL}}$ after equation (4.2). In the case of the EPMA the C2DL is ca. $25 \%$ lower than C1DL caused by the level of significance which is lower than three standard deviations. 
Table 4.2 Detection limits $\mathrm{C}_{\mathrm{DL}}$ (ppm) of EPMA calculated after the equations (4.2) and (4.3) with a confidence level of $95 \%$.

\begin{tabular}{lllllll}
\hline $\begin{array}{l}\text { Profile } \\
\text { number }\end{array}$ & $\mathrm{n}$ & $\mathrm{f}$ & $\mathrm{Al}$ & $\mathrm{Ti}$ & $\mathrm{K}$ & $\mathrm{Fe}$ \\
\hline 1 & 12 & 10 & 41.8 & 10.9 & 9.1 & 9.1 \\
2 & 12 & 10 & 27.9 & 11.2 & 5.5 & 11.2 \\
3 & 12 & 10 & 51.3 & 7.3 & 13.0 & 14.5 \\
4 & 12 & 10 & 66.4 & 13.0 & 5.7 & 7.4 \\
5 & 12 & 10 & 32.2 & 6.8 & 5.6 & 8.0 \\
6 & 12 & 10 & 32.1 & 12.1 & 5.7 & 12.7 \\
7 & 12 & 10 & 28.6 & 9.5 & 5.4 & 7.7 \\
8 & 12 & 10 & 27.2 & 6.5 & 6.4 & 6.4 \\
9 & 12 & 10 & 26.0 & 5.9 & 5.8 & 8.6 \\
10 & 12 & 10 & 23.6 & 6.2 & 6.7 & 8.1 \\
11 & 12 & 10 & 50.2 & 9.7 & 3.6 & 6.6 \\
12 & 12 & 10 & 25.2 & 6.7 & 8.3 & 9.1 \\
\hline
\end{tabular}

\subsection{Laser ablation - inductively coupled plasma mass spectrometry (LA ICP-MS)}

The trace element composition of quartz grains has been determined using a Laser Ablation microsampler coupled to an Inductively Coupled Plasma Mass Spectrometer (LA ICP-MS) model FISONS PQ2+ with "S-option". A Nd:YAG UV-laser (266 nm) model FISONS UV Microprobe with a laser pulse repetition rate of $5 \mathrm{~Hz}$ was focused onto the surface of a polished sample. Using a laser beam energy of $2.25 \mathrm{~mJ}$, the middle aperture, and an acquisition time of $40 \mathrm{~s}$, the laser ablated craters 30 to $50 \mu \mathrm{m}$ in diameter and between 100 to $150 \mu \mathrm{m}$ deep. The ablated sample volume per shot amounted up to $300000 \mu \mathrm{m}^{3}$ of which approximately $80 \%$ reached the mass spectrometer and was analysed. The determination of the optimal laser configurations was carried out by several test measurements and varying counting rates, to reach very low detection limits, to avoid sample outbreak during ablation, and to get craters as small as possible for better spatial resolution of the trace element distribution (Fig. 4.4). A laser beam with larger diameter and higher energy ablates more material and results in lower detection limits which are inversely proportional to $3^{\text {rd }}$ root of the ablation volume (Potts et al., 1995). Nevertheless, the risk that micro-inclusions within this volume were also analysed cannot be avoided. 

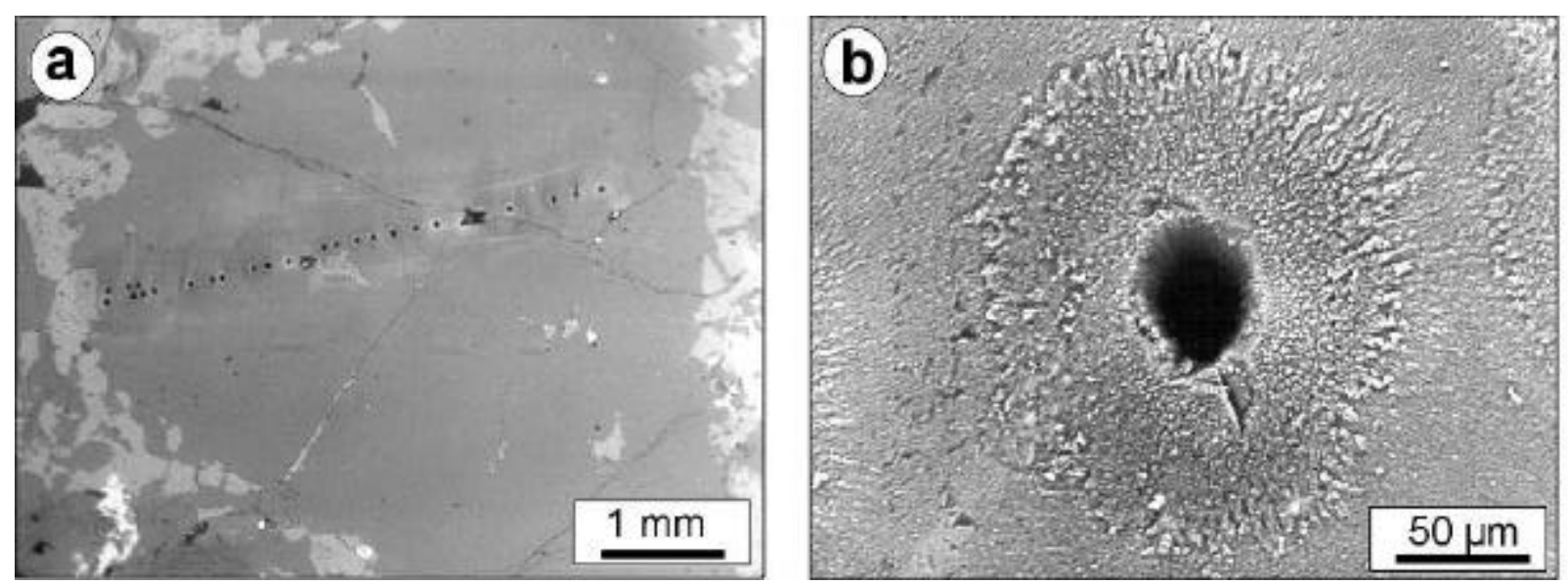

Fig. 4.4 BSE images of Nd-YAG laser ablation craters in quartz. a - Craters of a measurement profile through a quartz phenocryst of the Schellerhau Granite (sample 6). b - A close view shows that the craters are surrounded by wall of molten quartz glass.

The ablated material was swept by high purity $\mathrm{Ar}$ gas (flow rate $0.8-1.3 \mathrm{l} / \mathrm{min}$ ) into an inductively coupled plasma. Isotopic masses were analysed by an quadrupole mass filter. Time resolved measurements showed that the plasma needed about $3 \mathrm{~s}$ before reaching the mass spectrometer; during the following $5 \mathrm{~s}$ high count rates were detected. This may be caused by sample outbreak and sample surface contamination. After $8 \mathrm{~s}$ a stable count rate was reached, therefore, the counts of the first $8 \mathrm{~s}$ of the measurement were neglected.

Analyses were performed for the isotopes of ${ }^{7} \mathrm{Li},{ }^{23} \mathrm{Na},{ }^{27} \mathrm{Al},{ }^{29} \mathrm{Si},{ }^{30} \mathrm{Si},{ }^{44} \mathrm{Ca},{ }^{49} \mathrm{Ti},{ }^{53} \mathrm{Cr},{ }^{55} \mathrm{Mn}$, ${ }^{57} \mathrm{Fe}$, and ${ }^{72} \mathrm{Ge}$. The choice of the isotope of the element to be analysed depends on two criteria: (1) interferences with masses of other isotopes should be avoided, and (2) the ratio between intensity (peak) maximum of the isotope mass and the background should as high as possible. Figure 4.6 shows the detection limits for the different isotopes. Note the detection limit may highly vary for different isotopes of one element. For example, ${ }^{7} \mathrm{Li}$ isotope has a higher peak maximum/background ratio than ${ }^{6} \mathrm{Li}$ resulting in a lower detection limit.

The data were calibrated against the NBS610 glass standard (external standard) and the internal standard of the $\mathrm{Si}$ value $\left(4.67 \times 10^{5} \mathrm{ppm}=\right.$ stoichiometric concentration of $\mathrm{Si}$ in quartz). The element abundance of LA ICP-MS measurements were calculated by the equation (4.6): 


$$
\mathrm{c}_{\text {sample }}^{\text {elem }}=\frac{\mathrm{cps}_{\text {sample }}^{\text {elem }} * \mathrm{c}_{\text {sample }}^{\mathrm{Si} 29} * \mathrm{cps}^{\mathrm{Si} 29}{ }_{\text {NSB }}}{\mathrm{cps}^{\mathrm{Si} 29}{ }_{\text {sample }} * \mathrm{c}^{\mathrm{Si} 29}{ }_{\mathrm{NSB}} * \mathrm{cps}^{\text {elem }}{ }_{\text {NSB }}^{\text {elem }}} \mathrm{NSB}
$$

where $\mathrm{c}^{\text {elem }}$ sample $=$ the concentration of the element of interest in the sample; $\mathrm{cps}^{\text {elem }}{ }_{\text {sample }}=$ count rate of mass of element of interest in the sample; $\mathrm{c}^{\mathrm{Si29}}$ sample $=$ assumed concentration of the ${ }^{29} \mathrm{Si}$ isotope in the sample $(21980 \mathrm{ppm}) ; \mathrm{cps}^{\mathrm{Si} 29}{ }_{\mathrm{NSB}}=$ count rate of mass of the ${ }^{29} \mathrm{Si}$ isotope in the standard; $\mathrm{cps}^{\mathrm{Si} 29}$ sample $=$ count rate of the ${ }^{29} \mathrm{Si}$ isotope in the sample; $\mathrm{c}^{\mathrm{S} 229}{ }_{\mathrm{NSB}}=$ concentration of the ${ }^{29} \mathrm{Si}$ isotope in the standard $(15305 \mathrm{ppm}) ; \mathrm{cps}^{\mathrm{elem}}{ }_{\mathrm{NSB}}=$ count rate of mass of element of interest in the standard; $c^{\text {elem }}{ }_{\mathrm{NSB}}=$ concentration of the element of interest in the standard.

The detection limit is influenced by the acquisition time, the volume of ablated sample material, the flow rate of the Ar gas, and the isotope of the element. Furthermore, the sensitivity of the ICP-MS may change during the course of one measurement day. This drift found by standard and background measurements in regular time intervals was not a linear function of time (Fig. 4.5). Therefore, the measurements were done in the sequence: five background measurements - one standard measurements - ten sample analysis measurements.
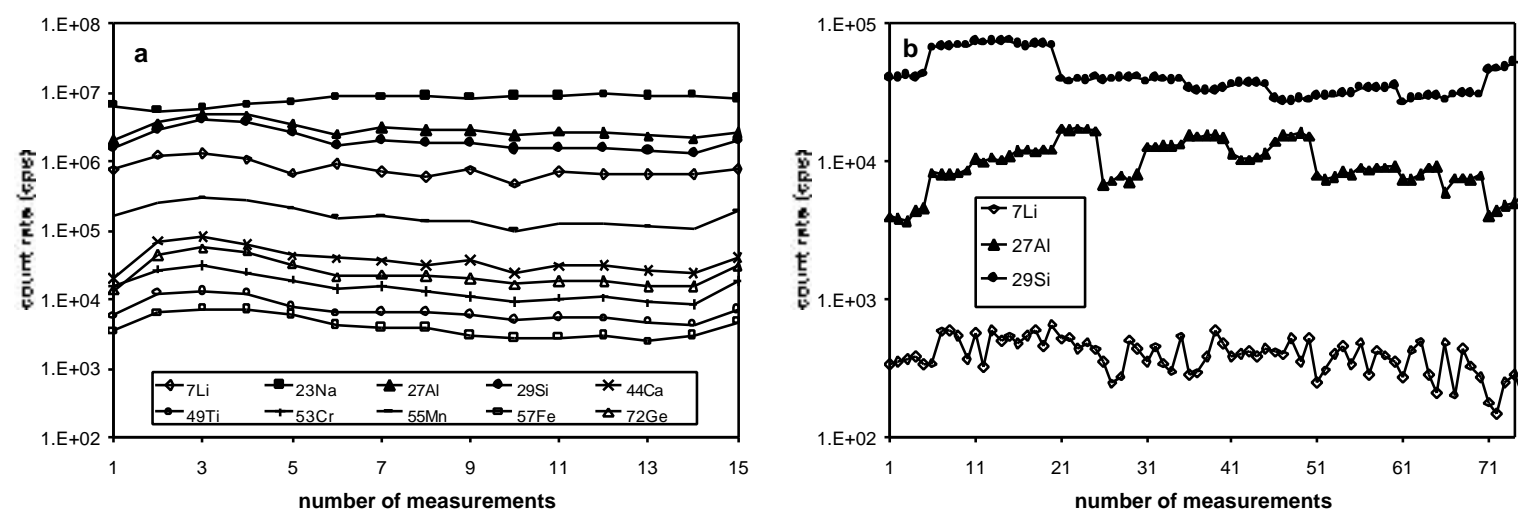

Fig. 4.5 Fluctuation of standard (a) and background (b) count rates of LA ICP-MS measurements during one measure day.

The mean and the standard deviation $\left(\sigma_{\mathrm{BG}}\right)$ were calculated for each sequence of background measurements. These values were then used to calculated the intensity of the detection limits ( $\left.\mathrm{I}_{\mathrm{DL}}\right)$ in accordance with the equations (4.1) and (4.2). The regression coefficient $\mathrm{b}$ was determined from a single point calibration, assuming a linear calibration line which passes through the origin of the intensity vs. concentration plot (Table 4.3). It follows from equation (4.7): 


$$
\mathrm{C}_{\mathrm{DL}}=\mathrm{C}_{\mathrm{STD}} \mathrm{I}_{\mathrm{DL}} / \mathrm{I}_{\mathrm{STD}}
$$

where $\mathrm{I}_{\mathrm{STD}}=$ intensity of the standard measurement; $\mathrm{C}_{\mathrm{STD}}=$ given concentration of the element in the standard.

The high sensitivity of the ICP-MS for most trace elements in quartz leads to very low detection limits shown in figure 4.6 and listed in table 4.3. Ca and Na cannot be measured because the high detection limit. For $\mathrm{Na}$ it is mainly caused by molecular interferences with ${ }^{12} \mathrm{C}^{32} \mathrm{O}_{2}$ which is present in small amounts in the sample chamber. The determination of $\mathrm{Na}$ is general problem of micro beam analysis because its high volatility and frequency leads to a omnipresent Na contamination.

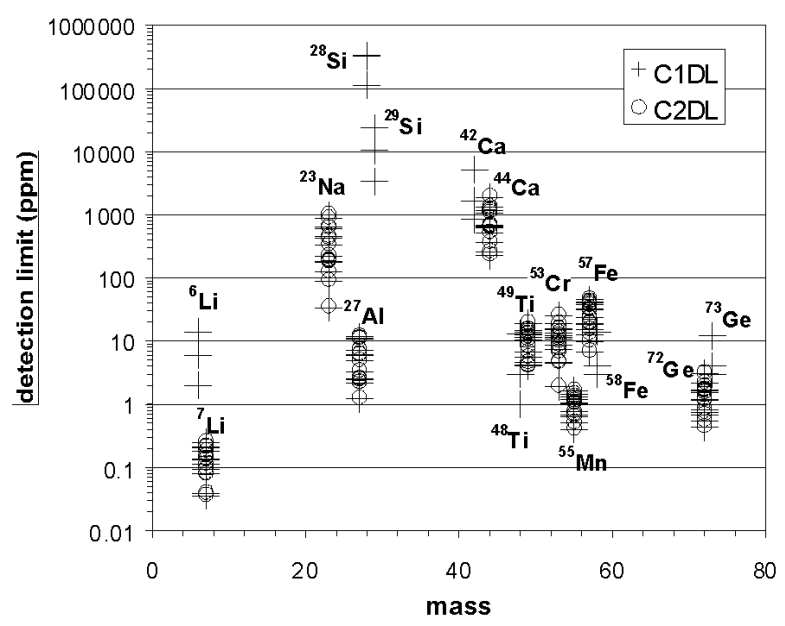

Fig. 4.6 Detection limits of trace elements in quartz for LA ICP-MS. The detection limit C1DL bases on the calculated intensity $\mathrm{I}_{1 \mathrm{DL}}$ after equation (4.1) and C2DL on the intensity $\mathrm{K}_{\mathrm{DL}}$ after equation (4.2). In the case of the EPMA the C2DL is ca. $25 \%$ lower than C1DL caused by the level of significance which is lower than three standard deviations.

\subsection{Secondary ion mass spectrometry (SIMS)}

The SIMS analyses were performed on a Cameca IMS-6f magnetic sector ion microprobe at the GeoForschungsZentrum Potsdam by M. Wiedenbeck. The mass filtered beam had a impact energy of $12.5 \mathrm{keV}$, a $40 \mathrm{nA}$ primary current and was focused to a spot size of $25 \mu \mathrm{m}$. The gold-coated polished samples were embedded in rings of one inch in diameter with a vacuum compatible medium. During analysis, the material was gradually removed from the sample surface by the incident primary ${ }^{16} \mathrm{O}^{-}$beam in a process termed "sputtering". After selecting a position to analyse, a 50x50 $\mu \mathrm{m}$ area was pre-sputtered with the rastered primary beam for $240 \mathrm{~s}$ to remove the gold coating and any surface contamination. Within any one set 
Table 4.3 Detection limits $\mathrm{C}_{\mathrm{DL}}(\mathrm{ppm})$ of LA ICP-MS calculated after the equations (4.2) and (4.7) with a confidence level of $95 \%$.

\begin{tabular}{llllllllllll}
\hline $\begin{array}{l}\text { Number of } \\
\text { Sequence }\end{array}$ & $\mathrm{n}$ & $\mathrm{f}$ & $\mathrm{Li}$ & $\mathrm{Na}$ & $\mathrm{Al}$ & $\mathrm{Ca}$ & $\mathrm{Ti}$ & $\mathrm{Cr}$ & $\mathrm{Mn}$ & $\mathrm{Fe}$ & $\mathrm{Ge}$ \\
\hline 1 & 6 & 4 & 0.04 & 446 & 6.3 & 1383 & 13.8 & 16.3 & 0.66 & 32.9 & 0.46 \\
2 & 6 & 4 & 0.12 & 189 & 2.3 & 239 & 4.4 & 2.0 & 0.42 & 24.9 & 1.59 \\
3 & 6 & 4 & 0.10 & 95 & 2.7 & 382 & 4.2 & 7.8 & 0.72 & 7.2 & 0.57 \\
4 & 6 & 4 & 0.10 & 132 & 1.3 & 273 & 4.8 & 4.8 & 0.80 & 13.6 & 0.87 \\
5 & 6 & 4 & 0.08 & 190 & 2.5 & 1292 & 8.5 & 7.0 & 1.20 & 38.3 & 1.65 \\
6 & 6 & 4 & 0.14 & 475 & 7.6 & 542 & 12.2 & 9.0 & 0.53 & 20.2 & 1.27 \\
7 & 6 & 4 & 0.16 & 200 & 2.3 & 706 & 16.0 & 10.4 & 1.29 & 23.6 & 2.00 \\
8 & 6 & 4 & 0.26 & 194 & 2.6 & 684 & 5.8 & 14.1 & 1.72 & 15.9 & 1.77 \\
9 & 6 & 4 & 0.04 & 236 & 6.5 & 716 & 11.1 & 26.8 & 1.28 & 10.4 & 1.73 \\
10 & 6 & 4 & 0.19 & 36 & 11.3 & 661 & 14.9 & 19.8 & 1.28 & 48.0 & 0.78 \\
11 & 6 & 4 & 0.14 & 686 & 5.1 & 1133 & 15.6 & 11.3 & 1.12 & 34.4 & 1.22 \\
12 & 6 & 4 & 0.14 & 352 & 3.5 & 712 & 20.2 & 13.0 & 1.52 & 44.0 & 1.78 \\
13 & 6 & 4 & 0.22 & 647 & 12.4 & 1219 & 13.5 & 16.6 & 1.08 & 42.8 & 3.26 \\
14 & 6 & 4 & 0.22 & 922 & 11.7 & 2017 & 7.0 & 12.2 & 1.38 & 40.6 & 2.27 \\
15 & 6 & 4 & 0.08 & 1061 & 7.6 & 546 & 13.5 & 5.0 & 0.71 & 19.7 & 0.71 \\
16 & 6 & 4 & 0.14 & 391 & 5.7 & 833 & 11.0 & 11.7 & 1.05 & 27.8 & 1.46 \\
17 & 6 & 4 & 0.06 & 301 & 3.6 & 468 & 4.8 & 6.2 & 0.37 & 12.8 & 0.72 \\
\hline
\end{tabular}

of analyses, the energy distribution stayed constant $( \pm 1 \mathrm{eV})$. The total counting time of one analysis was $1240 \mathrm{~s}$, composed of 20 cycles of $10 \mathrm{~s}$ for each isotope, except for $\mathrm{Si}$ with $2 \mathrm{~s}$. $\mathrm{Li}, \mathrm{Na}, \mathrm{Al}, \mathrm{Si}, \mathrm{K}, \mathrm{Ti}$, and $\mathrm{Fe}$ were measured on masses $6,23,27,30,39,48$, and 54, respectively. These masses were selected either because they represent an abundant isotope of the element in question or because interferences by molecular complexes would be at a
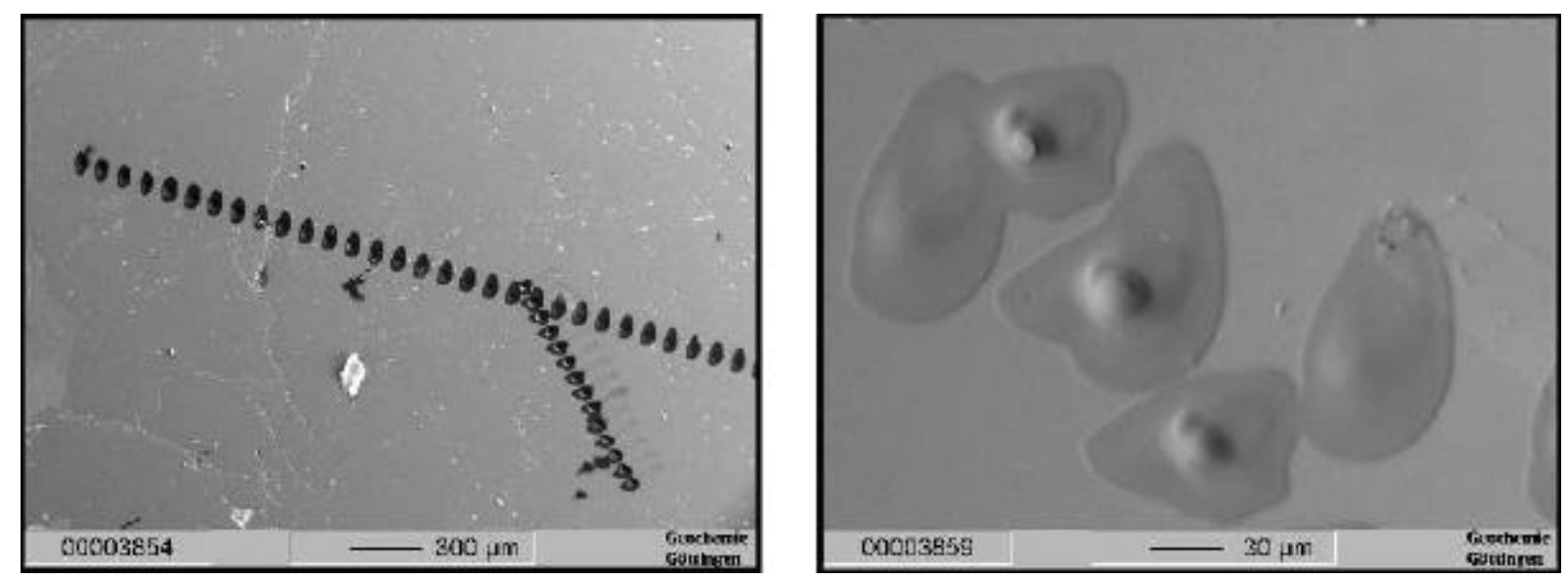

Fig. 4.7 BSE images of microcraters in quartz produced by primary ${ }^{16} \mathrm{O}^{-}$beam. a -Measurement profile through a quartz phenocryst of the Aue Granite (sample 8). b-Closer view of microcraters. 

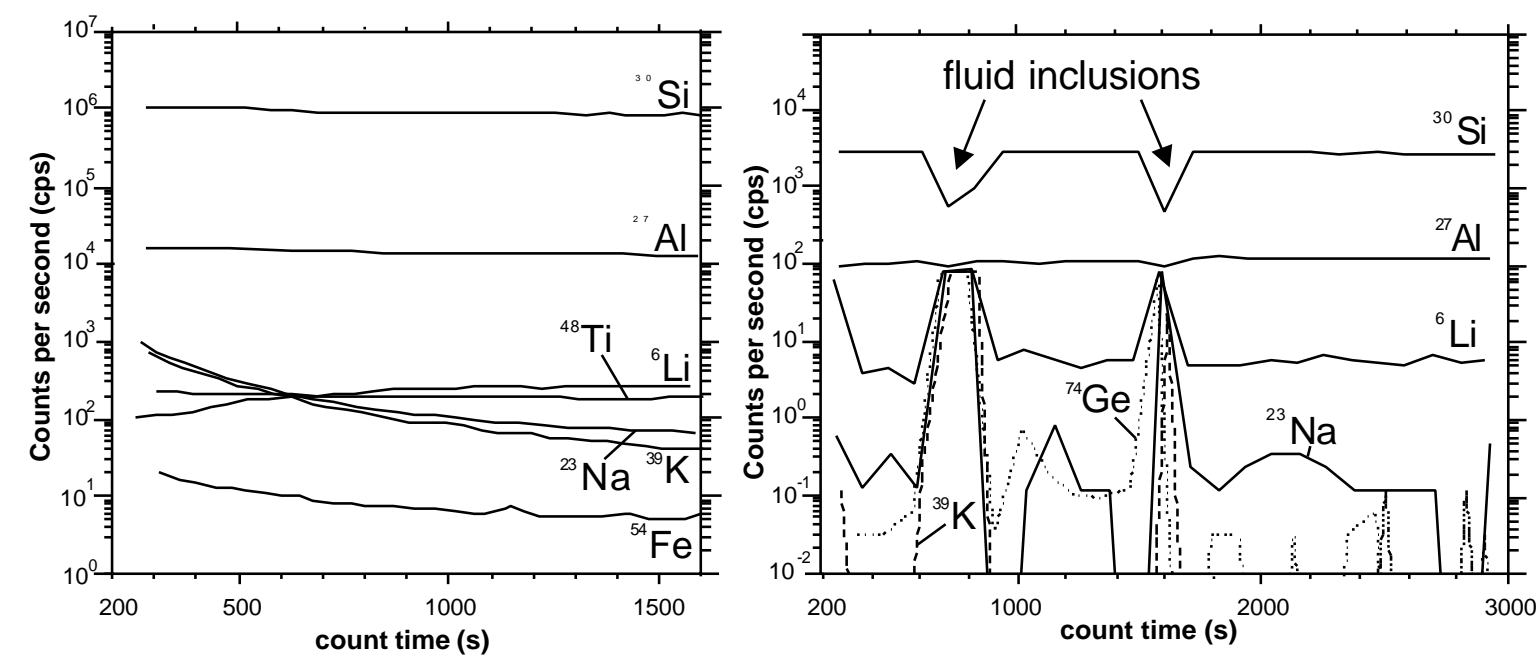

Fig. 4.8 Plots of secondary ion intensity as a function of sputter time. a - Analysis of sample 8 (Aue Granite) where a slight initial increase in ${ }^{7} \mathrm{Li}$ and a decrease in ${ }^{23} \mathrm{Na},{ }^{39} \mathrm{~K}$, and ${ }^{54} \mathrm{Fe}$ intensity with time have been observed. This intensity change is a general phenomena of the measurements. $b$ - Analysis of recrystallised quartz along a fluid inclusion trail in sample 1 (megaquartz). Extreme changes of $\mathrm{X} /{ }^{30} \mathrm{Si}$ ratios reflect analysed fluid or mineral inclusions.

minimum. The beam produces a microcrater $25 \mu \mathrm{m}$ in diameter and a depth ranging $5-20 \mu \mathrm{m}$ which allows subsequent verification of the spot location (Fig. 4.7). CL observations were performed prior and after SIMS analysis. Measurements were carried out as single point analysis and point traverses, yielding distribution profiles. The plot of secondary ion intensity as a function of sputter time facilitated the quality control of the analysis. Figure $4.8 \mathrm{~b}$ shows a time resolved analysis in recrystallised quartz of a fluid inclusion trail in sample 1 (megaquartz). Extreme changes of $\mathrm{X} /{ }^{30} \mathrm{Si}$ ratios reflect analysis of a fluid or mineral inclusion. A slight initial increase in ${ }^{7} \mathrm{Li}$ and a decrease in ${ }^{23} \mathrm{Na},{ }^{39} \mathrm{~K}$, and ${ }^{54} \mathrm{Fe}$ intensity with time have been observed in most measurements (Fig 4.8a; Aue Granite 8). $\mathrm{Li}^{+}, \mathrm{K}^{+}, \mathrm{Na}^{+}$, and $\mathrm{Fe}^{2+}$ are beside $\mathrm{H}^{+}$frequent and relative mobile interstitials in the quartz lattice. The cause of this often observed phenomena during SIMS analysis is controversial, and may be a consequence of electromigration due to sample charging and heating and/or sample surface contamination (e.g. Hughes et al., 1972; Wilson et al., 1989; Hervig and Peacock, 1989; Perny et al., 1992). In our case, the previous treatment of the sample with an electron beam during CL investigations may also result in a change of the element distribution at the sample surface. The electron radiation during CL investigations causes radiation-induced bond breaking resulting in impurity diffusion of interstitial ions which is additionally triggered by the sample charging and heating (e.g. Remond et al., 1979). The diffusion direction of a given impurity 
from the bulk to the surface or vice versa is controlled by the surface potential distribution. Nevertheless, the observed change in the line intensity with exposure time of alkalis and $\mathrm{Li}$ is an often observed phenomena during SIMS measurements (e.g. Shimizu et al., 1978). The electromigration near the surface will give low results for the $\mathrm{Na}, \mathrm{K}$, and $\mathrm{Fe}$ and high results for Li. After ca. $500 \mathrm{~s}$ the count rates are nearly stabilised. Therefore, counts from the first 8 analytical cycles (496 s) were neglected. Because no standard was available the relative intensities were given in $\mathrm{X} /{ }^{30} \mathrm{Si}$ ratios.

\subsection{Fourier-transform infrared (FTIR) spectroscopy}

Transmission FTIR spectra of quartz were obtained using the Perkin Elmer 1760-X FTIR spectrometer by S. Vaupel at the University Göttingen. The spectrometer can operate with an internal ray path and a triglycine-sulphate-detector or an external microscope with a separate mercury-cadmium-telluride-detector. The change between the two configurations is effected by a swivelling mirror. The external microscope is supplemented with a vacuum sample chamber (Dewar K-770-T) which is required for liquid $\mathrm{N}_{2}$-cooling of the sample and ray path $\left(-190--194^{\circ} \mathrm{C}\right)$ to avoid interference with atmospheric $\mathrm{H}_{2} \mathrm{O}$ and $\mathrm{CO}_{2}$. The cooling resulted in a maximal signal/noise ratio of the detected spectra.

FTIR spectroscopy is the only method for the determination of the distribution and specification of structural water in quartz crystals. The quartz wafer is penetrated by an electromagnetic UV beam (wavelength $=2-25 \mu \mathrm{m}$ ). The radiation excites the vibration of the atoms which lead to the absorption of distinct wavelengths depending on the kind of atoms and their bonds.

The analysis were carried out on doubly polished wafers $250 \mu \mathrm{m}$ in thickness. Prior to the measurement the wafers were cleaned with acetone and dried for $10 \mathrm{~h}$ at $110^{\circ} \mathrm{C}$. The spectra were acquired in a range of wave numbers between 5000 to $2000 \mathrm{~cm}^{-1}$ with 200 scans in the transmission modus. The resolution of the measurements was $4 \mathrm{~cm}^{-1}$. The spot size of the beam on the sample was $40 \mu \mathrm{m}$ in diameter which allows the recording of several spectra along a traverse within one grain. Background were taken after each spectra. The spectrum processing was carried out on a PC for baseline correction, sample thickness correction and converting of the transmission spectrum to the absorption spectrum. 


\subsection{Electron paramagnetic resonance (EPR)}

The paramagnetic defect centres of the quartz samples were investigated by EPR at frequencies of the X-band $(9.5 \mathrm{GHz})$ at 20, 70, and $295 \mathrm{~K}$ using a Varian E-line spectrometer at the Department of Mineralogy, University of Marburg. The measurements were carried out by T. Scherer. The influence of technical parameters such as modulation amplitude, microwave power, temperature, scan time, etc. on the spectra were checked for the optimal settings for recording the spectra. These settings (modulation field $\mathrm{H}_{\mathrm{M}}=1 \mathrm{G}$, temperature $\mathrm{T}=$ $295 \mathrm{~K}$, microwave power $\mathrm{p}=0.2 \mathrm{~mW}$ for $\mathrm{E}^{\prime}$ and $\mathrm{H}_{\mathrm{M}}=1 \mathrm{G}, \mathrm{p}=7 \mathrm{~mW}, \mathrm{~T}=70 \mathrm{~K}$ for $\left[\mathrm{AlO}_{4}\right]^{0}$ centres) were kept constant throughout all the measurements to allow correct comparison between the signal intensities of the different spectra.

The samples were crushed and quartz crystals were separated from the parent rock material by hand-picking under binocular microscope. Isolated quartz was sieved to obtain the $63-125 \mu \mathrm{m}$ fraction, followed by a HF acid treatment at room temperature to remove feldspar (not necessary for the hydrothermal quartz). Finally the fraction was treated with distilled water and then air dried.

The specific peak positions of the paramagnetic centres were drawn from simulated spectra and from literature data. The centres were calculated in relative intensities. For the calculation of the relative intensity of the paramagnetic defect centres the following equation was used:

$$
\mathrm{I}_{\mathrm{rel}}=\frac{\mathrm{I}_{\mathrm{s}} * 10000}{\mathrm{G}_{\mathrm{s}} * \mathrm{~m}_{\mathrm{s}}}
$$

where $I_{s}=$ measured intensity of the EPR signal, $G$ = intensification factor used during spectrum recording, and $\mathrm{m}_{\mathrm{s}}=$ mass of the sample. 


\section{Analytical results}

\subsection{Characterisation of the cathodoluminescence of quartz}

The quartz CL spectra in the range of 1.4 to $3.1 \mathrm{eV}$ generally consist of two broad emission peaks at $1.7-2.2 \mathrm{eV}$ (red emission) and $2.4-3.1 \mathrm{eV}$ (blue emission; Fig. 5.1). The CL colour, mostly shades of blue, violet, and red-brown is dependent on the ratio of the two main emission peaks (Table 5.1). The peak ratio changes with the exposure time of electron radiation, whereby the blue emission generally decreases and the red emission increases (Fig. 5.2). The maximum of the two peaks shifts for different quartz types indicating that the peaks are built up of different emission bands of different stability. Nine emission bands have been detected in all the spectra by fitting the spectra with Gaussian curves. Three emission bands can be distinguished in the red emission range $(1.73,1.84$, and $1.96 \mathrm{eV})$ and five bands in the blue emission range $(2.47,2.58,2.68,2.79$, and $2.96 \mathrm{eV})$ (Fig. 5.3). Additionally, a broad band has been observed in the yellow range of the spectrum at $2.15 \mathrm{eV}$. Depending on the quartz sample the emission bands show different intensities, half-width, and different stability during irradiation. The parameters of CL emission bands obtained from best-fit listed in Appendix A. Most CL band positions are consistent with the values reported in the literature (e.g. Remond et al., 1992; Gorton et al., 1996; Kalceff et al., 2000 and references therein; Table 5.2). Characteristics of the spectra can be summarised as follows (Fig. 5.1, 5.2, 5.3):

1. Nine emission bands are developed in the CL spectra of all samples.

2. The intensity of the blue emissions decreases whereas the intensity of red emission generally increases during electron radiation. A frequently observed bright blue "flash" at initial electron radiation is caused by the unstable blue emission at $\sim 2.79 \mathrm{eV}$.

3. Dominant emission bands of rhyolitic quartz (samples $4,10,11,15$ ) are the 1.96, 2.58, $2.68,2.79$, and $2.96 \mathrm{eV}$ band. The spectra are very similar although they originate from different volcanic provinces. An exception is the quartz of the Teplice Rhyolite showing a dominant $1.73 \mathrm{eV}$ emission. The blue and red luminescent growth zones in quartz phenocrysts are caused by the variation of the blue CL emission whereas the red CL remains essentially constant (sample $10,11,15$ ).

4. The 1.73 and $2.15 \mathrm{eV}$ bands are characteristic for the granitic quartz and some rhyolites (sample 5). The $2.15 \mathrm{eV}$ emission is dominant in the quartz of the Aue and Eibenstock granites form the Western Erzgebirge. 
5. Hydrothermal quartz (sample 1, and 3) exhibit a distinctive $2.47 \mathrm{eV}$ band and sample $9 \mathrm{a}$ dominant $2.79 \mathrm{eV}$ band. The bands are characterised by a fast intensity decrease during electron exposure. The $2.47 \mathrm{eV}$ emission causes a turquoise $\mathrm{CL}$ at initial electron radiation (sample 1 and 3).

6. The 2.68 and $2.58 \mathrm{eV}$ emission bands are developed with about constant peak area ratios in all samples: $1: 0.34 \pm 0.08$. Similar observations were made for the 1.96 and $1.84 \mathrm{eV}$ red emission bands which show ratios of $1: 0.51 \pm 0.17$. The $2.58 \mathrm{eV}$ and $2.68 \mathrm{eV}$ emission are not immediately obvious from visual inspection of the other $100 \mathrm{~mm}$-grating spectra due to the close proximity of more intense emissions, but the bands are detectable in spectra recorded with the 1200 line/mm grating (Fig. 5.3).

Table 5.1 CL colours and structures revealed by CL.

\begin{tabular}{|c|c|c|c|c|c|c|}
\hline No. & Sample name & $\begin{array}{l}\text { Initial CL } \\
\text { colour }\end{array}$ & $\begin{array}{l}\text { Duration of } \\
\text { initial } \\
\text { colour (s) }\end{array}$ & Final CL colour & Primary CL structures & $\begin{array}{l}\text { Secondary CL } \\
\text { structures }\end{array}$ \\
\hline 1 & megaquartz & intense turquoise & 60 & orange-brown & - & 3,5 \\
\hline 2 & fissile quartz & bright blue & 30 & red-brown & - & - \\
\hline 3 & oil-bearing quartz & intense turquoise & 60 & red-brown & - & - \\
\hline 4 & Schoenfeld Rhyolite & bright blue & 120 & blue-violet & zoned phenocrysts & 3,4 \\
\hline 5 & Teplice Rhyolite (TPR2) & $\begin{array}{l}\text { bright blue } \\
\text { weak blue }^{2)}\end{array}$ & $\begin{array}{l}30^{1)} \\
10^{2)}\end{array}$ & $\begin{array}{l}\text { violet-blue } \\
\text { dark red }^{1)}\end{array}$ & zoned phenocrysts & $2,3,4,5$ \\
\hline 6 & Schellerhau Granite & $\begin{array}{l}\text { bright blue } \\
\text { weak blue }^{2)} \\
\text { bright blue }^{3 \text { ) }}\end{array}$ & $\begin{array}{l}30^{1)} \\
5^{2)} \\
20^{3)}\end{array}$ & $\begin{array}{l}\text { violet-blue }^{1)} \\
\text { red-brown } \\
\text { red-brown }^{3)}\end{array}$ & zoned phenocrysts & $1,2,3,5$ \\
\hline 7 & Eibenstock Granite & $\begin{array}{l}\text { bright blue } \\
\text { bright blue }^{3 \text { ) }}\end{array}$ & $\begin{array}{l}30^{11} \\
20^{3)}\end{array}$ & $\begin{array}{l}\text { violet-red-brown }{ }^{1)} \\
\text { red-brown }\end{array}$ & zoned phenocrysts & $1,2,3,5$ \\
\hline 8 & Aue Granite & bright blue & 20 & orange-brown & zoned phenocrysts & $1,2,3,5$ \\
\hline 9 & vein quartz & intense blue & 300 & dark blue & - & - \\
\hline 10 & Wachtelberg Rhyolite & $\begin{array}{l}\text { bright blue } \\
\text { weak blue }^{2)}\end{array}$ & $\begin{array}{l}30^{1)} \\
10^{2)}\end{array}$ & $\begin{array}{l}\text { violet }^{1)} \\
\text { red-brown }\end{array}$ & zoned phenocrysts & 3,4 \\
\hline 11 & Beucha Rhyolite & $\begin{array}{l}\text { bright blue } \\
\text { bright blue }^{2)}\end{array}$ & $\begin{array}{l}120^{1)} \\
10^{2)}\end{array}$ & $\begin{array}{l}\text { blue-violet }^{1)} \\
\text { red-brown }\end{array}$ & zoned phenocrysts & $2,3,4,5$ \\
\hline 12 & Flossenbuerg Granite & bright blue & 60 & red-brown & - & $1,2,3,5$ \\
\hline 13 & leucosome quartz & bright blue & 20 & red-brown & - & - \\
\hline 14 & Ramberg Granite & bright blue & 30 & red-brown & zoned phenocrysts & $1,2,3,5$ \\
\hline 15 & Weinheim Rhyolite & $\begin{array}{l}\text { bright blue } \\
\text { bright blue }^{2)}\end{array}$ & $\begin{array}{l}120^{1)} \\
10^{2)}\end{array}$ & $\begin{array}{l}\text { violet-blue }{ }^{1)} \\
\text { red-brown }\end{array}$ & zoned phenocrysts & 3,4 \\
\hline
\end{tabular}

Secondary CL textures (see chapter 7.3): 1 - micropores; 2 - patchy halos of secondary quartz around fluid inclusions; 3 - veinlets of recrystallised quartz; 4 - diffusion rims along grain boundaries; 5 - bright halos caused by radioactive inclusions and fluids;

1) Blue luminescent growth zones in magmatic phenocryst

${ }^{2)}$ Red luminescent growth zones in magmatic phenocryst

3) Magmatic matrix quartz 
Table 5.2 Comparison of frequently reported $\mathrm{CL}$ emissions of $\mathrm{SiO}_{2}$ and proposed associations and identification $\left(\mathrm{a}-\mathrm{SiO}_{2}=\right.$ amorphous $\left.\mathrm{SiO}_{2}\right)$.

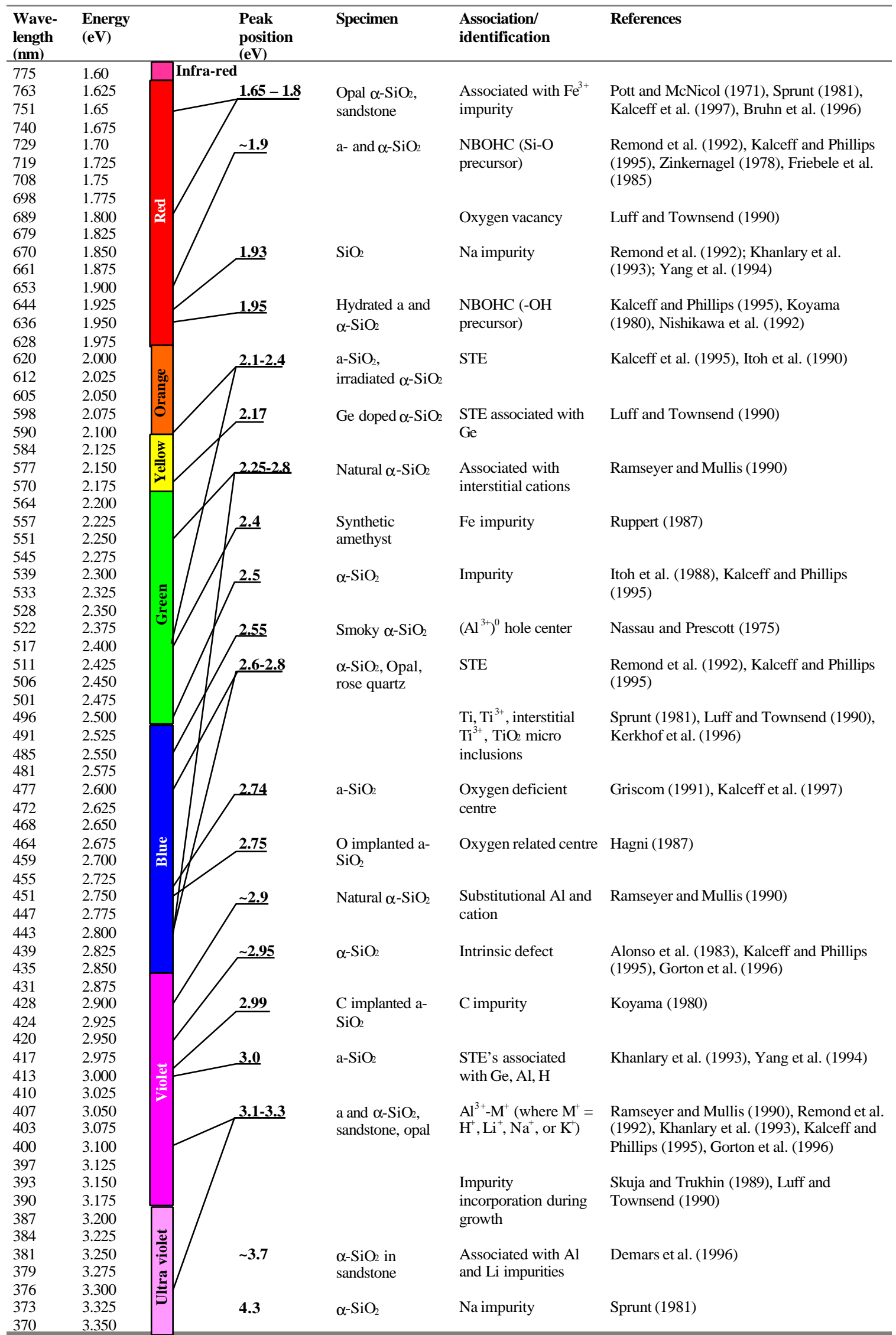



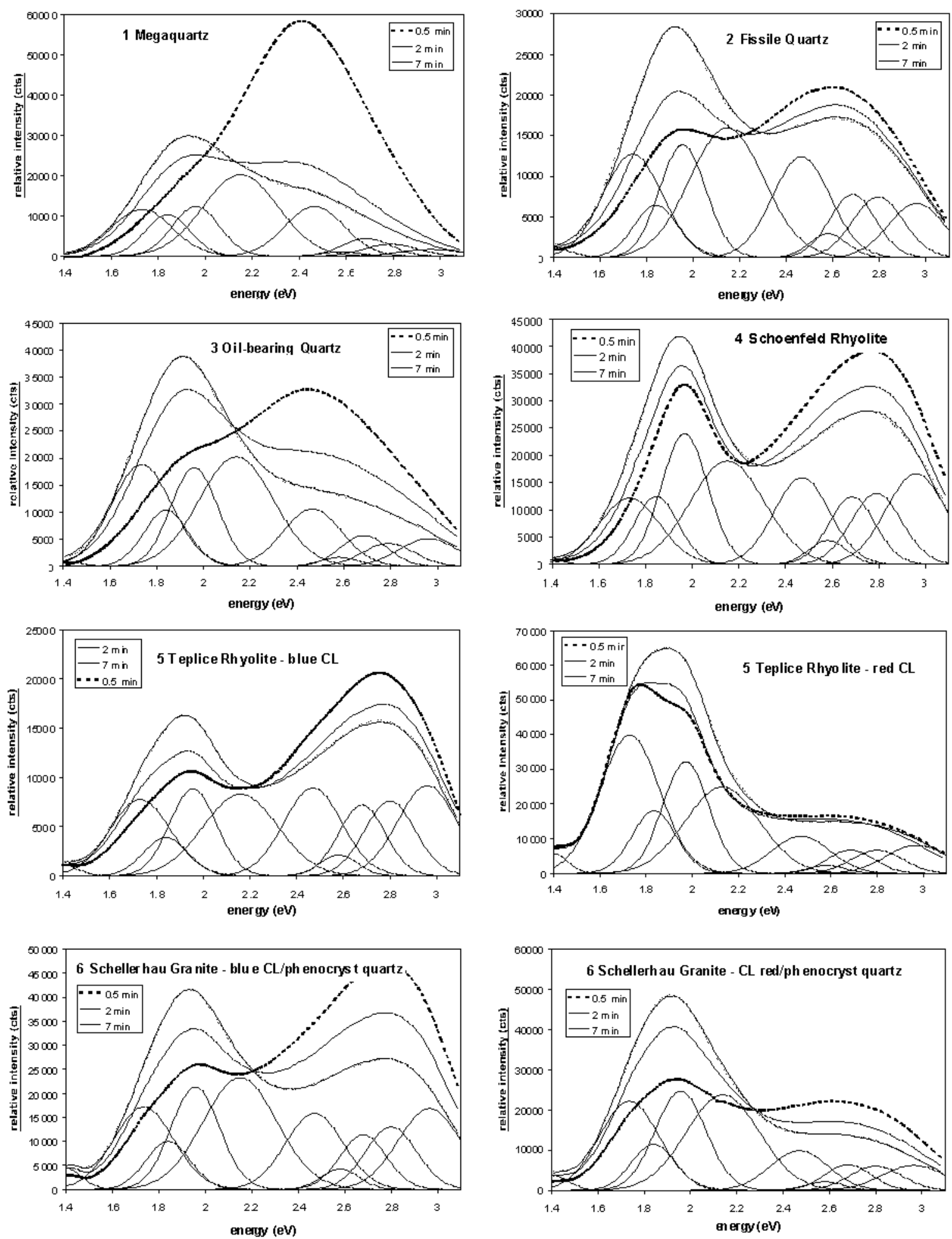

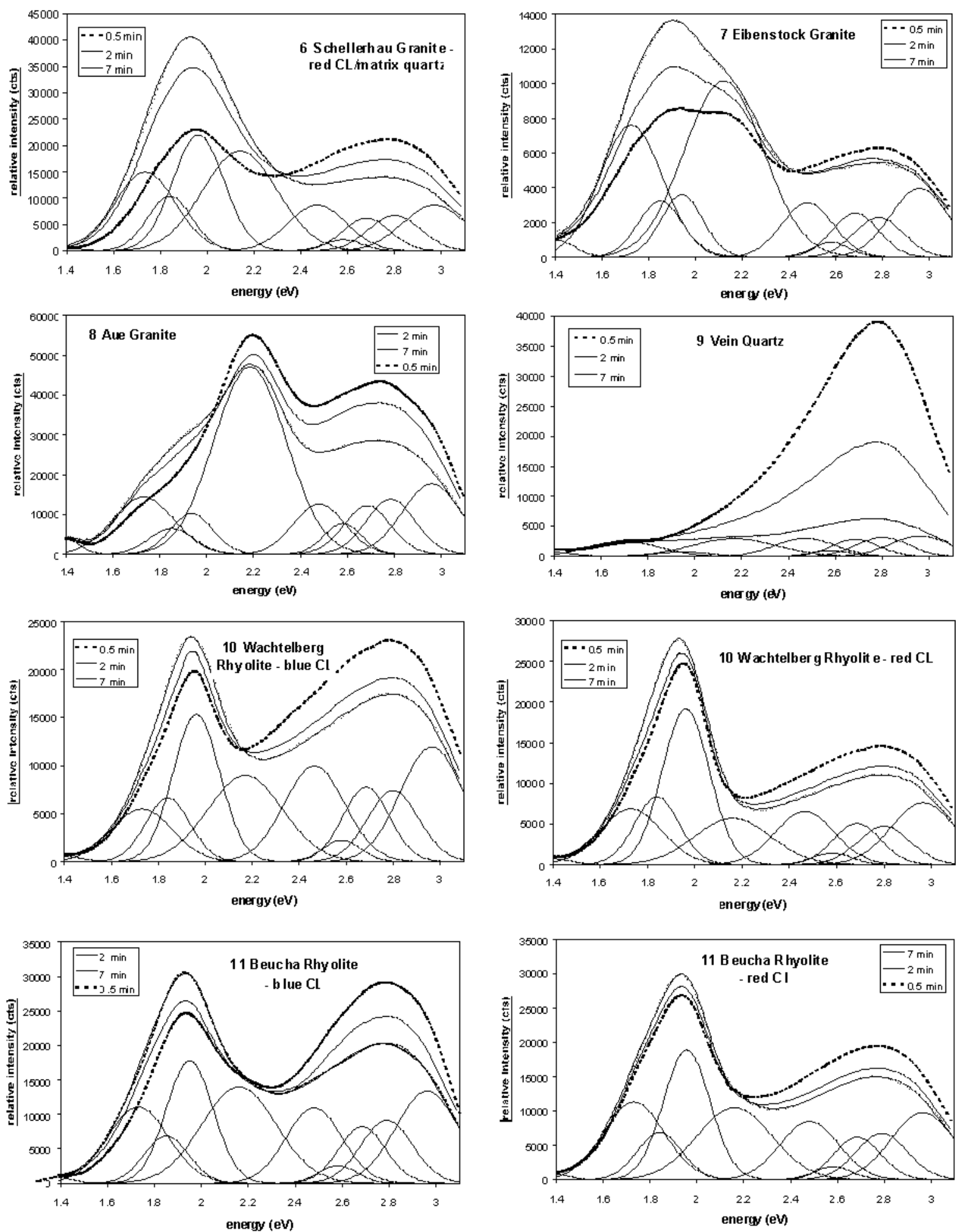

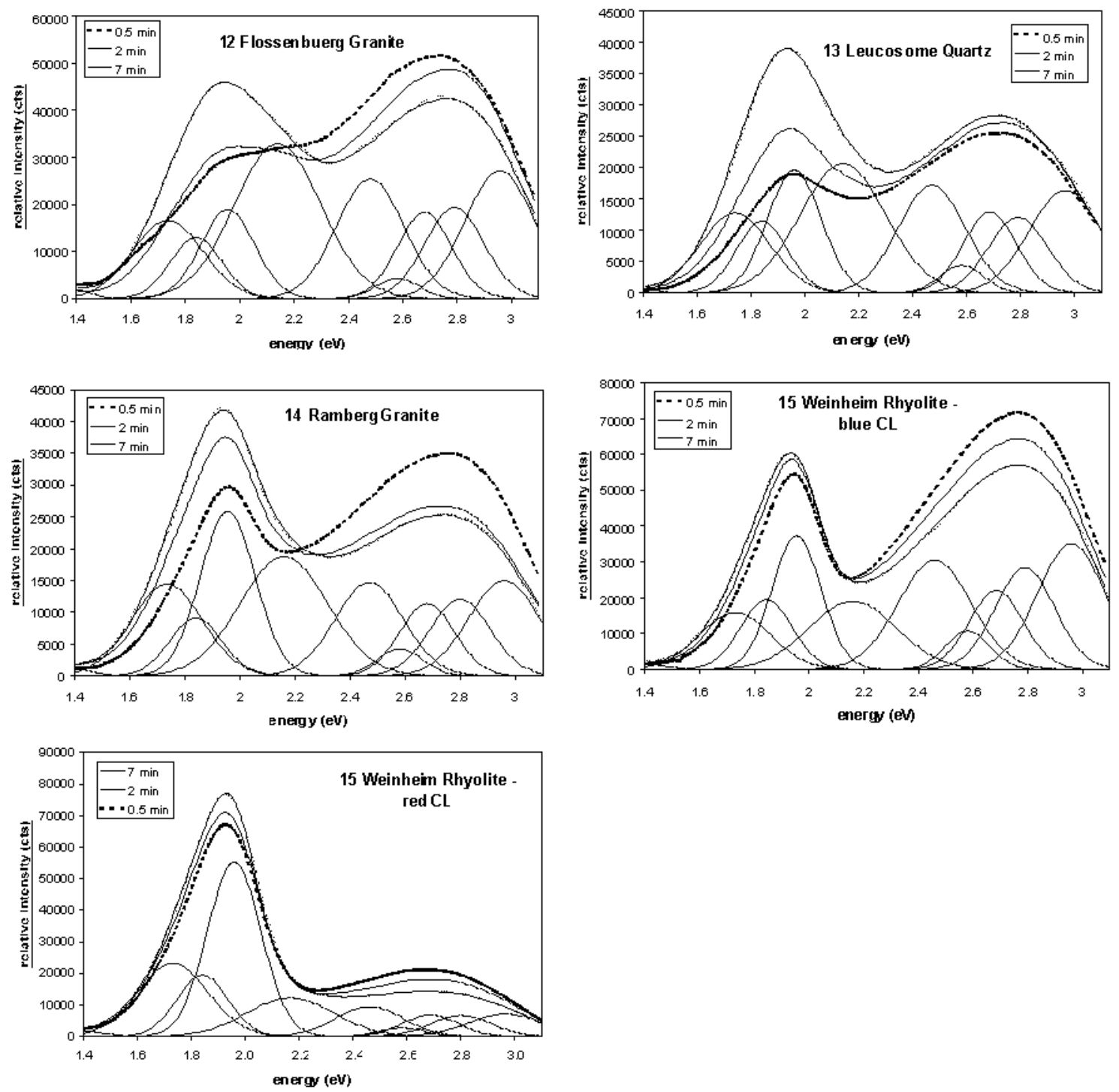

Fig. 5.1 Quartz CL spectra recorded with the 100 lines/mm grating after 0.5, 2, and 7 min electron radiation. The 7-min-spectrum is fitted in Gaussian curves so that the sum of the Gaussian curves corresponds the recorded spectra. 

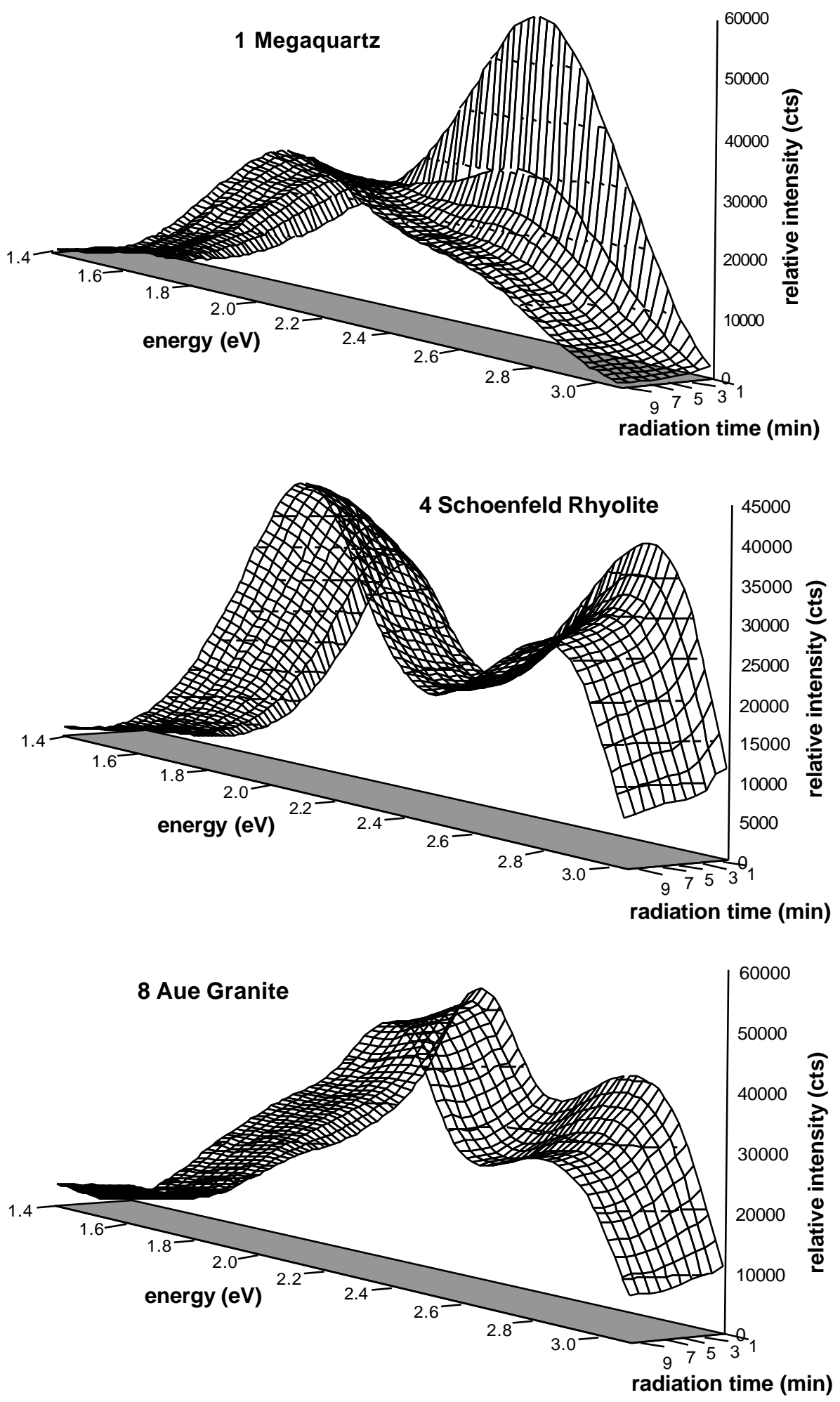

Fig. 5.2 CL intensity change during $10 \mathrm{~min}$ electron radiation of the samples 1 , 4, and 8 . Note the high instability of the blue emission of sample 1 and the dominance of the relative constant intensity of the yellow $2.15 \mathrm{eV}$ band of sample 8 . 


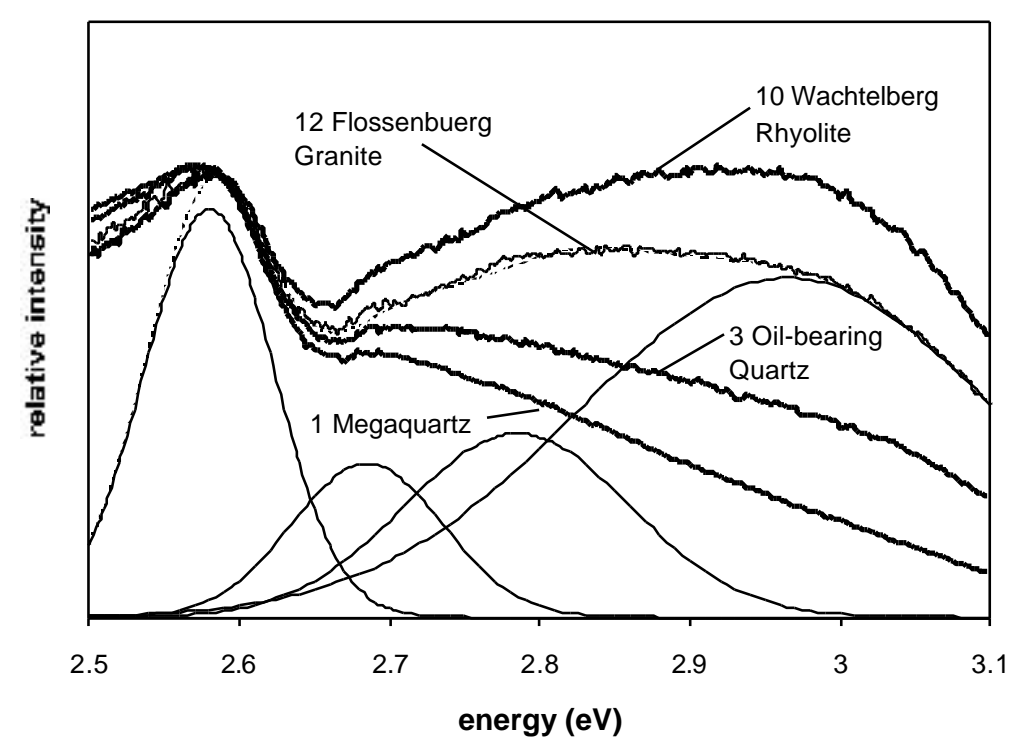

Fig. 5.3 Blue CL emission range of several quartzes recorded 1200 lines/mm grating after $7 \mathrm{~min}$ electron radiation. The spectrum of the sample 12 is fitted in Gaussian curves.

\subsection{Instability of CL during electron bombardment}

The blue emission $(2.6-3.1 \mathrm{eV})$ is characterised by high intensity at initial electron bombardment visible as a blue "flash". The initial intensity of this blue emission, mostly centred at $\sim 2.8 \mathrm{eV}$ may drop by $1 / 2$ to $1 / 3$ after a few seconds. The intensity is stabilised after 30 to $100 \mathrm{~s}$ of electron bombardment (Fig. 5.4). The steady state of CL-changes during electron radiation points at a saturation effect. The saturation status is reached faster with higher electron radiation dose. Figure 5.5 shows CL spectra of sample 12 after 2 minutes electron beam exposure using different beam currents. Note that the intensity of blue emission remains constant after 2-minutes spectra at beam currents $=0.18 \mathrm{~mA}$ indicating a saturation status. In the case of the megaquartz (sample 1) and oil-bearing quartz (sample 3) the initial blue emission is centred at $\sim 2.5 \mathrm{eV}$ which causes turquoise $\mathrm{CL}$ at initial electron radiation.

In contrast to the blue emission, the red emission $(1.75-2.2 \mathrm{eV})$ generally shows an intensity minimum at initial electron bombardment followed by a steep parabolic increase during first minute of electron radiation followed by a slight increase until saturation is reached. The intensity increase of red CL together with the decrease of the blue CL causes a change from initial blue/violet to red/red-brown CL. However, the decrease of blue and the increase of red emission behave independently: in the case of the deformed magmatic quartz form the Eastern Lachlan Fold Belt (see $\S 10.7$ ) the red emission remains constant whereas the blue one decreases. 

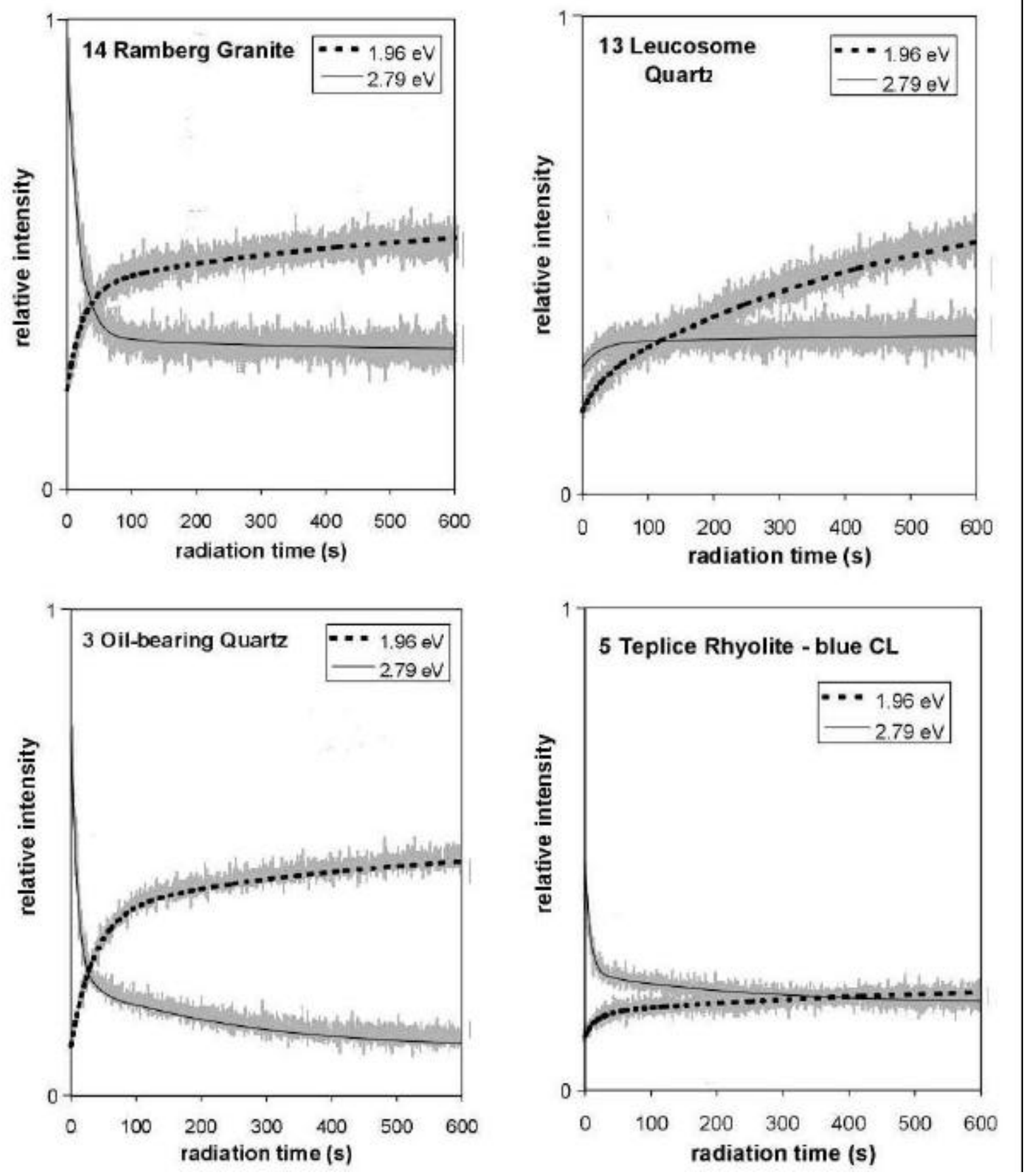

Fig. 5.4 Intensity change of the 1.96 and $2.79 \mathrm{eV}$ emission of some characteristic samples during the radiation time of $10 \mathrm{~min}$ recorded with the f/3.4 Grating Monochromator using the CL microscope after Zinkernagel (1978) at the University Göttingen $(10 \mathrm{keV}, 0.25 \mathrm{~mA})$. The experimental curves are grey and the fitted curves are black lines. 


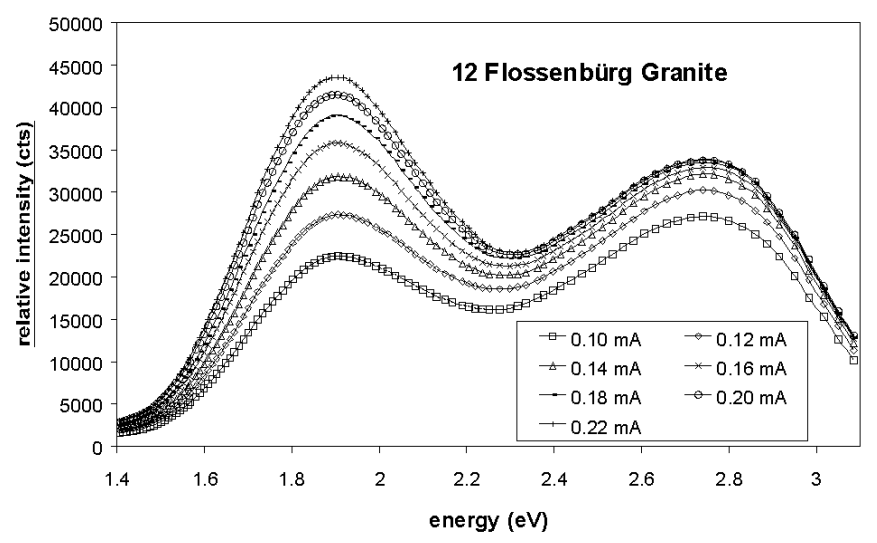

Fig. 5.5 CL spectra of sample 12 after 2 min electron beam exposure using different beam currents.

\section{The effect of temperature}

Most of the energy of the electron beam is converted into heat in the sample near the surface (e.g. Remond et al., 1992). After Reimer (1985) the portion of the converted beam energy into heat amounts between $f=40-80 \%$ ( $f=$ degree of effectiveness); Castaing (1951) assumed an average portion of $f=70 \%$ which transforms into heat. The energy $\mathrm{Q}=f * \mathrm{U} * \mathrm{I} * \mathrm{t}$ which effects the samples measured here reaches $\mathrm{Q}=2.016 \mathrm{~J}$ using a beam voltage $\mathrm{U}=1.410^{4} \mathrm{~V}$, current $\mathrm{I}=1.810^{-4} \mathrm{~A}$ and $f=0.8$.

The heat production at the irradiated spot was calculated by several authors and several types of equipment (Castaing, 1951; Friskney and Haworth, 1967; Dudek, 1970; Reimer, 1985). These calculations, which give an idea about the maximum temperature of the sample, assume, that firstly, the electron beam radius $\mathbb{1}_{b}$ corresponds to the interaction depth of the electron beam $r_{e}$ in the sample. Secondly, the radius of the sample $r_{s}$ should be so large that the external surface of the sample remains at ambient temperature $(\Delta \mathrm{T}=0)$ meaning that $\mathrm{r}_{\mathrm{S}} \gg$ $\mathrm{r}_{\mathrm{b}}$. Both conditions are not fulfilled for the used CL microscope: the electron beam radius $\mathfrak{r}_{b}$ $(2.4 \mathrm{~mm})$ is ca. 500 times larger than the penetration depth of the electrons $\left(\mathrm{r}_{\mathrm{e}} \sim 5 \mu \mathrm{m}\right)$ and the beam radius is so large that the temperature at the external sample surfaces rises considerably. As a consequence the thin section turns hot after same minutes of electron radiation.

The heat developed in a cylindrical interaction volume is controlled by the thermal conductivity of the sample (e.g. $\lambda_{\text {quartz }}=1.38 \mathrm{~W} \mathrm{~m}^{-1} \mathrm{~K}^{-1}$ or $\lambda_{\text {granite/rhyolite }}=2.1-2.9 \mathrm{~W} \mathrm{~m}^{-1} \mathrm{~K}^{-1}$ ), of the carbon coating $\left(\lambda_{\text {graphite }}=169 \mathrm{~W} \mathrm{~m}^{-1} \mathrm{~K}^{-1}\right)$, of the glass slide of the thin section $\left(\lambda_{\text {window }}\right.$ glass $\left.=0.7 \mathrm{~W} \mathrm{~m}^{-1} \mathrm{~K}^{-1}\right)$, and of the sample holder $\left(\lambda_{\text {brass }}=111 \mathrm{~W} \mathrm{~m}^{-1} \mathrm{~K}^{-1}\right)$. The heat flow problem is very complex due to the different thermal conductivities and thermal transition coefficients, and the heterogeneous heat transmission. Therefore, temperature measurements 
were carried out to know the thermal changes of the sample during electron radiation. The temperatures were measured with a sensor on the reverse of demounted thin sections about $250 \mu \mathrm{m}$ away from the incident beam and by using different beam currents (Fig. 5.6a, b, c). The measurements were corrected by the maximal temperature difference $\Delta \mathrm{T}$ between the target of the incident electron beam and the sensor:

$$
\Delta \mathrm{T}=f * \mathrm{U} * \mathrm{I} * l / \lambda_{\text {sample }} \pi \mathrm{r}_{\mathrm{b}}^{2}
$$

where $l=$ distance between temperature measure point and incident beam on the thin section surface, $\lambda_{\text {sample }}=$ thermal conductivity of the sample, and $\pi r^{2}=$ area of the incident beam.

The temperature difference $\Delta \mathrm{T}$ amounts $19.7 \mathrm{~K}$ by taking the electron beam voltage is $\mathrm{U}=1.4$ $10^{4} \mathrm{~V}$, the current $\mathrm{I}=1.810^{-4} \mathrm{~A}, f=0.8$, the distance $2.4410^{4} \mathrm{~m}$, the beam radius $\mathrm{r}_{\mathrm{b}}=2.410^{3}$ $\mathrm{m}$, and $\lambda_{\text {quartz }}=1.38 \mathrm{~W} \mathrm{~m}^{-1} \mathrm{~K}^{-1}$.

Figures 5.6a, f, and k show the temperature increase in the target of the electron beam for the samples 1, 4 and 8 during 600 seconds. The temperature increase is an exponential function of the radiation time and shows a linear correlation with the beam current (Fig. 5.7). The plots 5.6b, g, and 1 show the CL intensity change of the single emission bands during the first electron exposure and the plots 5.6d, i, and n during the second electron exposure of the same sample area after $24 \mathrm{~h}$. The emission band areas and their change were determined from timeresolved spectra recorded with the 100 lines/mm grating of the TRIAX 320. Note, that the spectrum recording with the TRIAX 320 does not allow the determination of the fast intensity change during the first $30 \mathrm{~s}$ of electron beam exposure. The intensity change during the second electron exposure is much lower than the change during the first electron exposure indicating that 1) the CL is mainly caused by the electron radiation, 2) the temperature has a low influence of the CL, 3) the electron exposure causes a permanent modification of luminescence centres, and 4) the creation and destruction of luminescence centres take place mainly during the first three minutes of electron radiation. In the plots showing CL intensity change versus temperature (5.6c, e, h, j, m, and o) a clear mathematical correlation does not exist demonstrating a low dependence of CL on the temperature.

However, thermoluminescence bands may have identical positions as the CL bands. Characteristic thermoluminescence bands are the 2.95-2.85 eV, 2.21-2.14 eV and 2.00-1.98 eV bands (e.g. Jani et al., 1983; Yang et al., 1994; Zhang et al., 1994; Rink et al., 1993). 
Especially the latter is a frequent and intensive thermoluminescence band of natural quartz (e.g. Rink et al., 1993). The intensity maximum of the 2.21-2.14 eV and 2.00-1.98 eV bands is in the temperature range of the CL measurements. Therefore, the temperature should have a secondary influence on the CL intensity and its change.

\section{Sample heating during electron exposure}

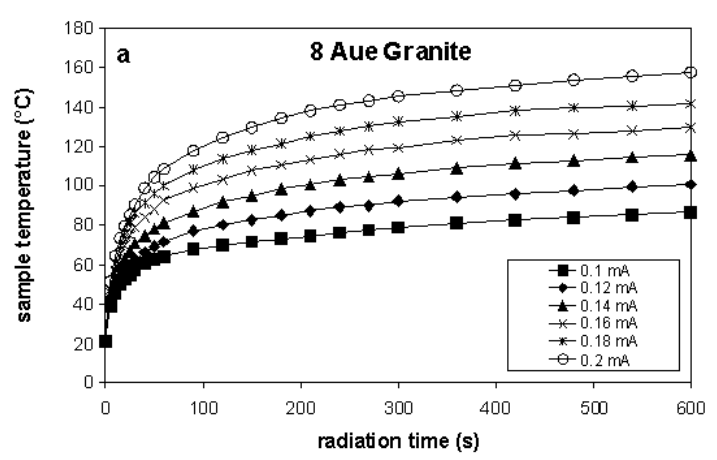

$\mathrm{CL}$ intensity change during the first electron exposure
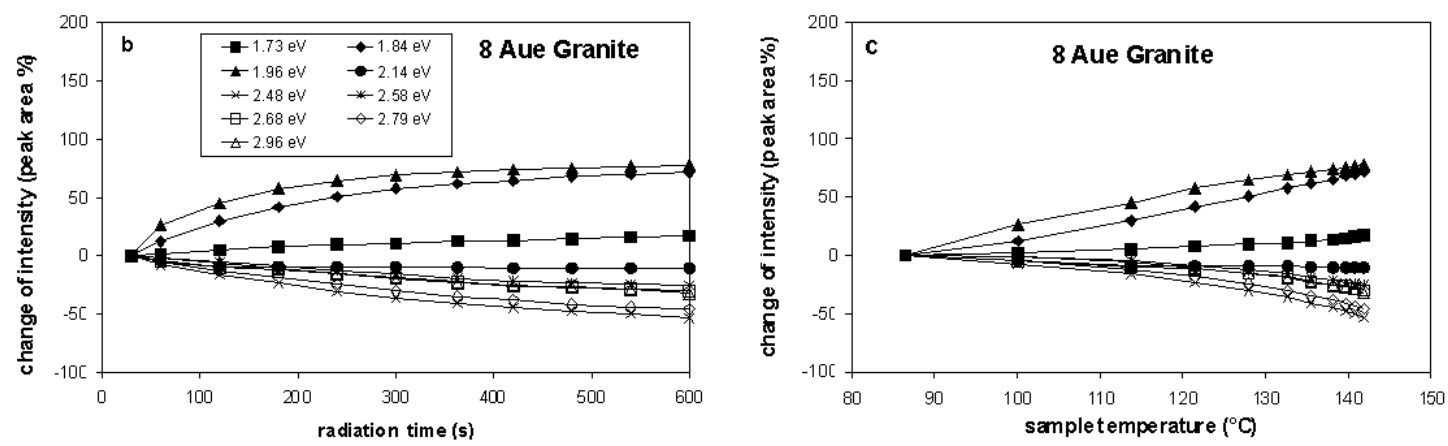

$\mathrm{CL}$ intensity change during the second electron exposure after $24 \mathrm{~h}$
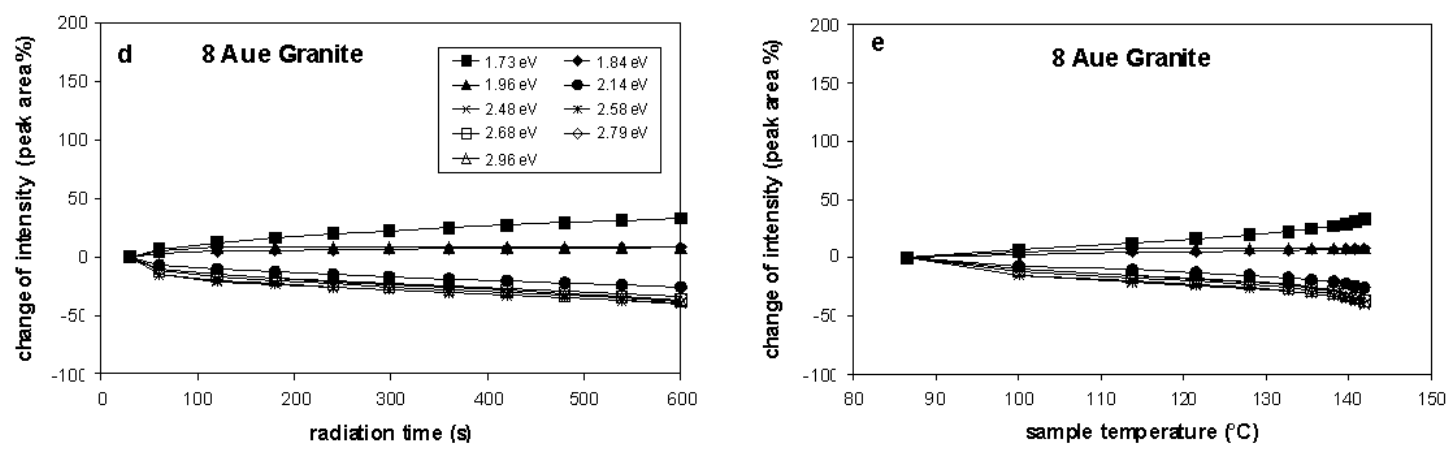

Fig. 5.6a-e Plots of radiation time versus sample temperature and CL intensity change of the sample 8 . a Change of the sample temperature in the target of the electron beam using different beam currents; $b-C h a n g e$ of CL band intensities given in percentage emission band area during the first electron exposure of 10 min using the beam current of $0.18 \mathrm{~mA}$; $\mathrm{c}-$ Plot of emission band area change versus sample temperature rise; $\mathrm{d}$ - Change of CL band intensities given in percentage emission band area during the second electron exposure after $24 \mathrm{~h}$ using the beam current of $0.18 \mathrm{~mA}$; e - Plot of emission band area change versus sample temperature rise. 


\section{Sample heating during electron exposure}

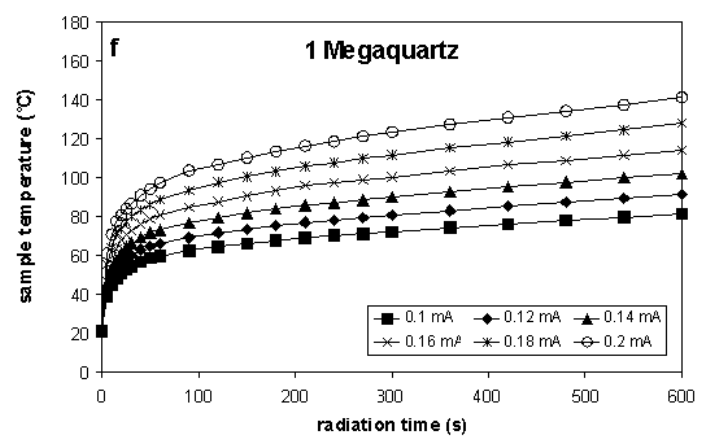

$\mathrm{CL}$ intensity change during the first electron exposure
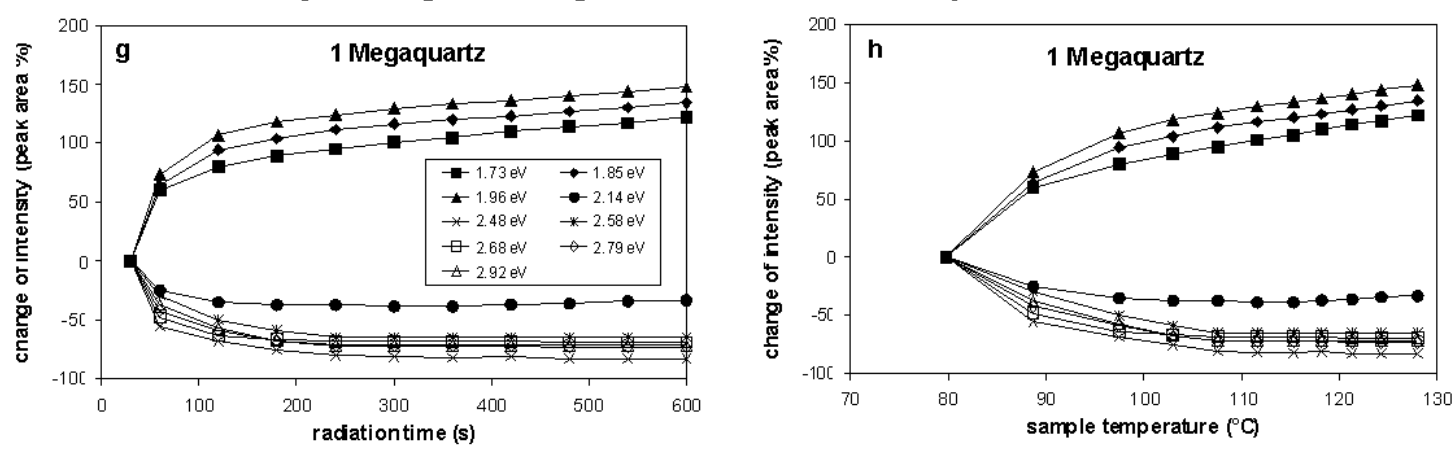

$\mathrm{CL}$ intensity change during the second electron exposure after $24 \mathrm{~h}$
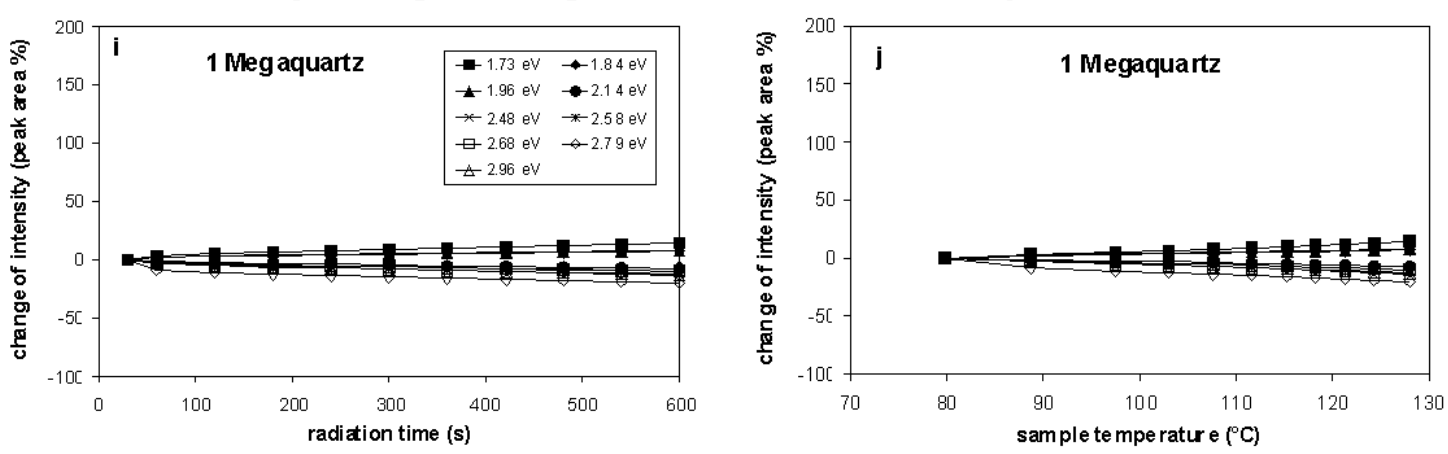

Fig. 5.6f-j Plots of radiation time versus sample temperature and CL intensity change of the sample 1 . f Change of the sample temperature in the target of the electron beam using different beam currents; $\mathrm{g}-\mathrm{Change}$ of CL band intensities given in percentage emission band area during the first electron exposure of $10 \mathrm{~min}$ using the beam current of $0.18 \mathrm{~mA} ; \mathrm{h}-$ Plot of emission band area change versus sample temperature rise; $\mathrm{i}$ - Change of CL band intensities given in percentage emission band area during the second electron exposure after $24 \mathrm{~h}$ using the beam current of $0.18 \mathrm{~mA} ; \mathrm{j}$ - Plot of emission band area change versus sample temperature rise. 


\section{Sample heating during electron exposure}

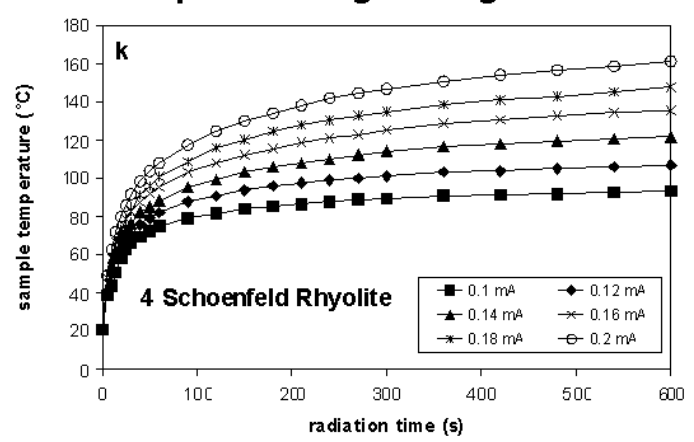

\section{CL intensity change during the first electron exposure}
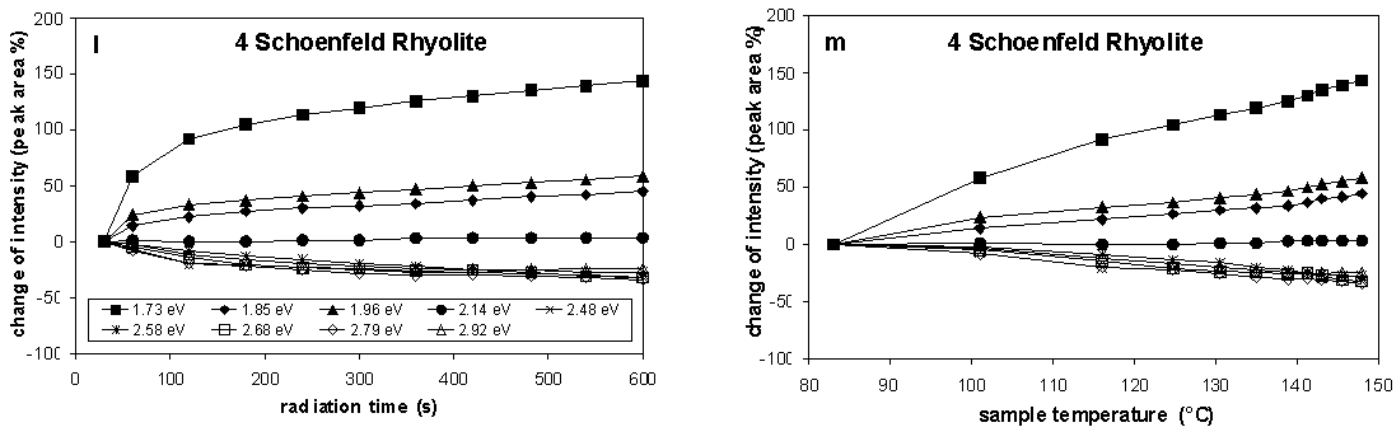

\section{$\mathrm{CL}$ intensity change during the second electron exposure after $24 \mathrm{~h}$}
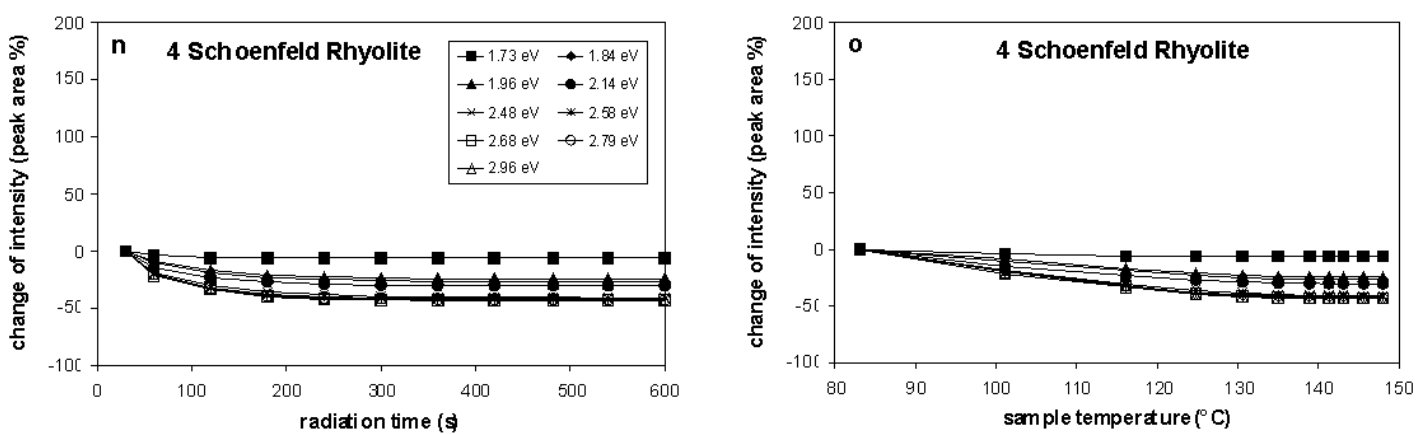

Fig. 5.6k-o Plots of radiation time versus sample temperature and CL intensity change of the sample 4 . k Change of the sample temperature in the target of the electron beam using different beam currents; 1 - Change of CL band intensities given in percentage emission band area during the first electron exposure of 10 min using the beam current of $0.18 \mathrm{~mA} ; \mathrm{m}$ - Plot of emission band area change versus sample temperature rise; $\mathrm{n}$ - Change of CL band intensities given in percentage emission band area during the second electron exposure after $24 \mathrm{~h}$ using the beam current of $0.18 \mathrm{~mA}$; o - Plot of emission band area change versus sample temperature rise. 


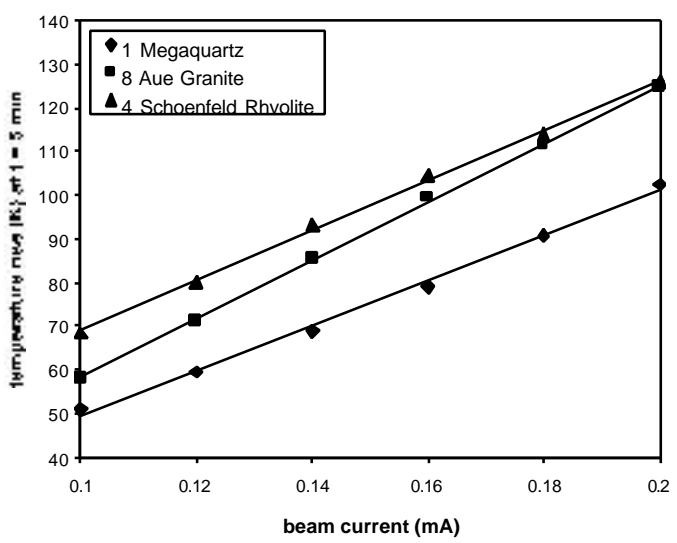

Fig. 5.7 Linear correlation of sample temperature increase in the target of the electron beam versus electron beam current.

\section{CL of thermally treated quartz}

The samples 1,14 , and 15 were thermally treated at $300^{\circ} \mathrm{C}$ and at $600^{\circ} \mathrm{C}$ for 24 hours. The spectra of the thermally treated quartzes show the following changes in the emission properties (Fig. 5.8, 5.9):

1) The treatment generally results in a significant increase of the $1.73 \mathrm{eV}$ band after $300^{\circ} \mathrm{C}$ heating from room temperature and a sligth increase of both the 1.85 and 1.96 eV bands.

2) The initial peak observed at $2.48 \mathrm{eV}$ is destroyed at $>600^{\circ} \mathrm{C}$.

3) All three samples show a more or less intensive shift of the blue peak to higher energy after $600^{\circ} \mathrm{C}$ heat-treatment, caused by the intensification of the $2.96 \mathrm{eV}$ (sample 1,14 , 15 ) and of the $2.79 \mathrm{eV}$ bands (sample 14).

The intensification of the $2.96 \mathrm{eV}$ band in all three samples may indicate that this peak is characteristic for quartz formed at high temperature, whereas the $2.48 \mathrm{eV}$ band is typical for hydrothermal quartz.

\section{The effect of sample preparation on the CL of quartz}

The method of specimen preparation (polishing) may affect the concentration of defects participating in radiative and non-radiative processes in the surface regions (Ruppert, 1987). The influence of specimen preparation and surface roughness on the CL signal of $\mathrm{SiO}_{2}$ has been mentioned in Sprunt (1981) and Ruppert (1987). In order to study the effect of sample preparation spectra were recorded for (a) unpolished thin sections using different granularities of carborundum $(1 \mu \mathrm{m}$ and $3 \mu \mathrm{m})$ and (b) thin sections polished chemically (OP-S suspension) and compared with (c) the normally used polishing with diamond paste $(0.3 \mu \mathrm{m})$. As a result we found systematic lower CL intensities for rougher surfaces. However, the peak area ratios of the emission bands and the stability of the CL-activator centres remained unchanged. 

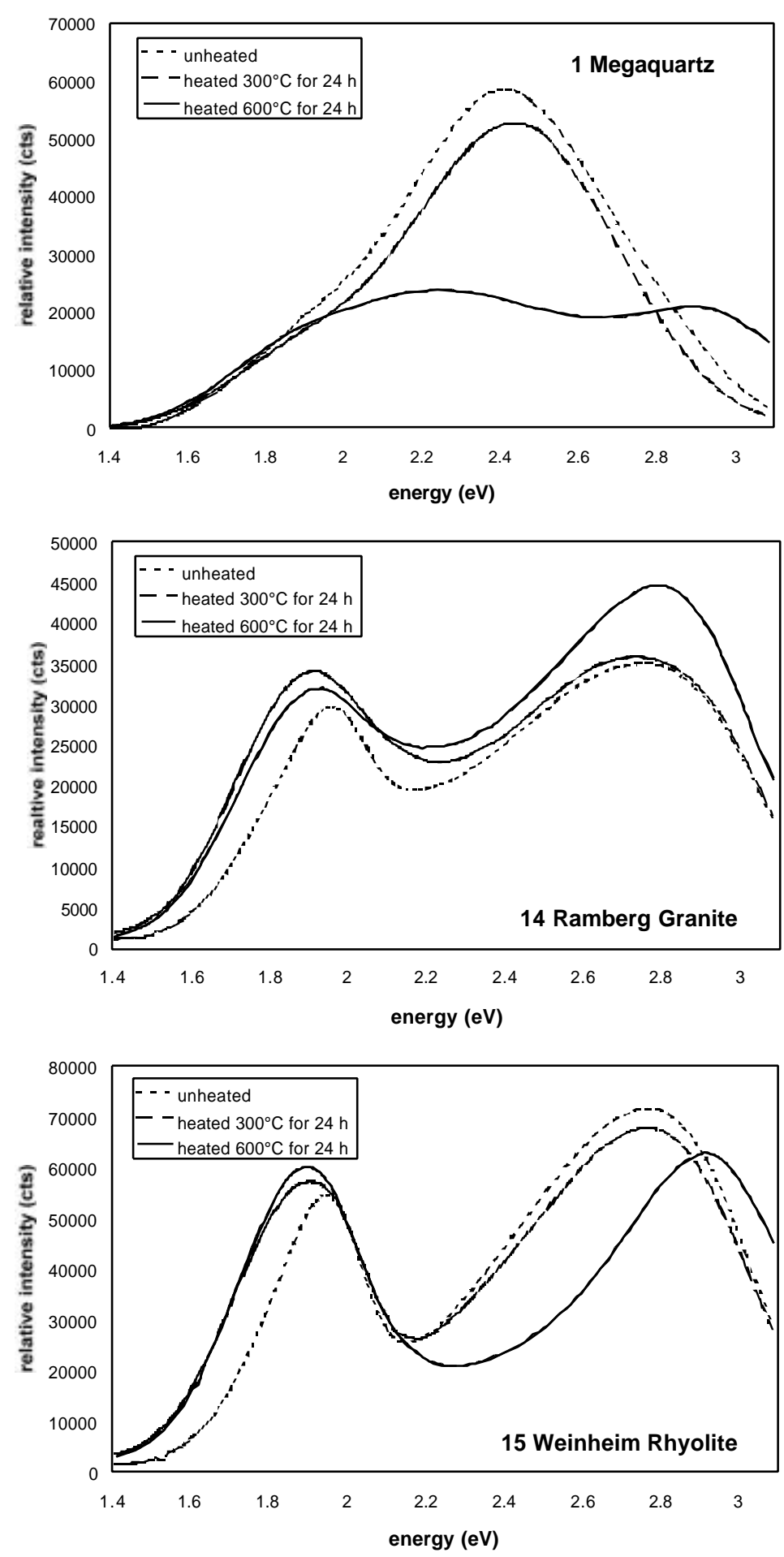

Fig. 5.8 Initial CL spectra (after $30 \mathrm{~s}$ electron radiation) of unheated, and at 300 and $600^{\circ} \mathrm{C}$ for $24 \mathrm{~h}$ treated quartzes. 


\section{Quantification of CL intensity change during electron radiation}

The kinetic of physicochemical reactions in natural systems can be generally described by the kinetic law $\mathrm{c}=\mathrm{c}_{0} \exp (-\mathrm{kt})$, where $\mathrm{c}=$ concentration of the component at time $\mathrm{t}, \mathrm{c}_{0}=$ concentration of the component at time $\mathrm{t}=0$, and $\mathrm{k}=$ velocity (equilibrium) constant. The equation is the base for the determination of velocity constants (e.g. diffusion coefficients, thermal conductivity). The equation was applied to quantify the decay of the blue intensity and the simultaneously increase of the red emission intensity during electron radiation. The

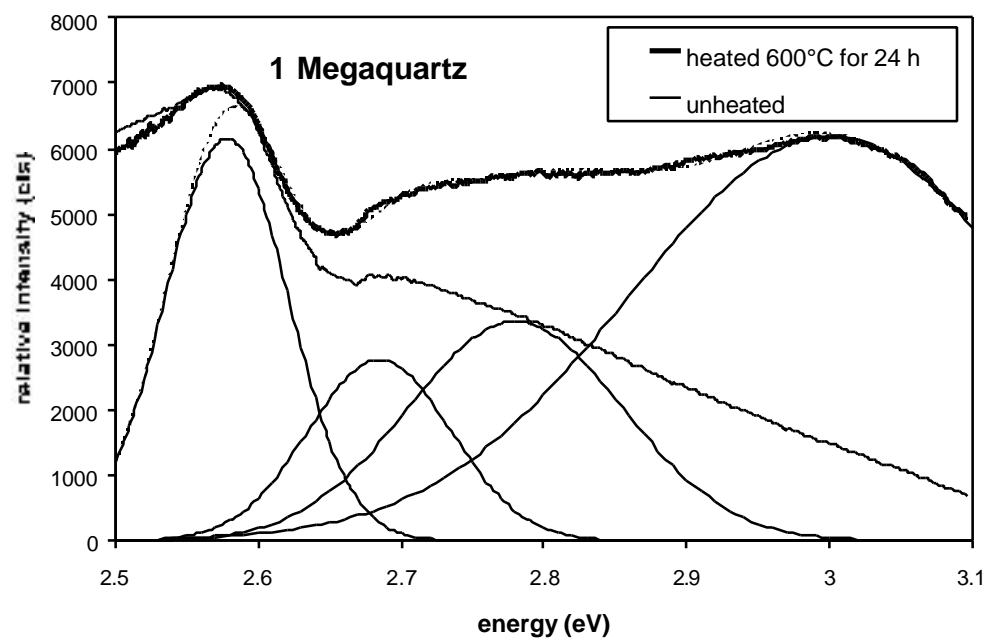

Fig. 5.9 CL spectra of the blue emission range of unheated and heated quartz of the megaquartz. The spectrum of the heated quartz were fitted with Gaussian curves.

latter may be described by the reverse equation of the kinetic law. Application of the equation resulted in an approximate quantification of the intensity change as a function of time. A complicating factor is the composite character of the blue emission intensities, which subdivides into a fast decaying component and a slowly decaying component. Picouet (1999) suggested an equation being the sum of two kinetic law equations:

$$
\mathrm{I}_{\mathrm{b}}=\mathrm{I}_{\mathrm{bs}}+\mathrm{I}_{\mathrm{b} 1} * \exp \left(-\mathrm{t} / \mathrm{k}_{\mathrm{b} 1}\right)+\mathrm{I}_{\mathrm{b} 2} * \exp \left(-\mathrm{t} / \mathrm{k}_{\mathrm{b} 2}\right)
$$

where $\mathrm{I}_{\mathrm{b}}=$ intensity of blue $\mathrm{CL}$ at the radiation time $\mathrm{t} ; \mathrm{I}_{\mathrm{bs}}=$ intensity of stable blue CL; $\mathrm{I}_{\mathrm{b} 1}=$ intensity of the slow decreasing CL component at $\mathrm{t}=0 ; \mathrm{k}_{\mathrm{b} 1}=$ velocity constant of the slow decreasing CL component; $\mathrm{I}_{\mathrm{b} 2}=$ intensity of the fast decreasing CL component at $\mathrm{t}=0 ; \mathrm{k}_{\mathrm{b} 2}=$ velocity constant of the fast decreasing CL component; $\mathrm{t}=$ radiation time. 
This equation fits very well with the measured time-dependent intensity change (Fig. 5.4). The increase of red emission between 1.75 to $2.2 \mathrm{eV}$ may be described by the following equation which is the reverse function of equation 5.2:

$$
\mathrm{I}_{\mathrm{r}}=\mathrm{I}_{\mathrm{rs}}-\mathrm{I}_{\mathrm{r} 1} * \exp \left(-\mathrm{t} / \mathrm{k}_{\mathrm{r} 1}\right)-\mathrm{I}_{\mathrm{r} 2} * \exp \left(-\mathrm{t} / \mathrm{k}_{\mathrm{r} 2}\right)
$$

where $I_{r}=$ intensity of red CL at the radiation time $t ; I_{r s}=$ intensity of red CL for $t ? \quad 8$; $\mathrm{I}_{\mathrm{r} 1}=$ intensity of the slow increasing CL component for $\mathrm{t} ? 8 ; \mathrm{k}_{\mathrm{r} 1}=$ velocity constant of the slow increasing CL component; $\mathrm{I}_{\mathrm{r} 2}=$ intensity of the fast increasing CL component for $\mathrm{t}$ ? $8 ; \mathrm{k}_{\mathrm{r} 2}=$ velocity constant of the fast increasing $\mathrm{CL}$ component; $\mathrm{t}=$ radiation time.

The red CL emission is composed of a fast increasing component during the first minute of electron radiation and a slowly increasing component. Figure 5.4 shows the intensity change of the 1.96 and $2.79 \mathrm{eV}$ emissions during 10 min electron beam exposure. The curves were fitted using the equations 5.3 and 5.2, respectively. The samples 9 and 13 show a reverse time -dependent behaviour of the CL signal.

The fitted parameters of the radiation-time-dependent intensities at 1.96 and $2.79 \mathrm{eV}$ are given in Appendix B. The velocity constants $\mathrm{k}_{\mathrm{r} 1}, \mathrm{k}_{\mathrm{r} 2}, \mathrm{k}_{\mathrm{b} 1}$, and $\mathrm{k}_{\mathrm{b} 2}$ are similar for all samples: namely $502 \pm 16,24 \pm 11,252 \pm 9$, and $14 \pm 5$, respectively. The lower the velocity constant the faster the decay and formation of CL activator centres. That implies that the decay of the centres causing blue CL is about 2 times faster than the formation of the activator centres causing red CL.

The emission intensities I represent the concentration of luminescence centres in the interaction volume of the electron beam. The parameters $\mathrm{I}_{\mathrm{rs}}, \mathrm{I}_{\mathrm{r} 1}, \mathrm{I}_{\mathrm{r} 2}, \mathrm{I}_{\mathrm{bs}}, \mathrm{I}_{\mathrm{b} 1}$, and $\mathrm{I}_{\mathrm{b} 2}$ are intensity portions of the respective emission, whereby $\mathrm{I}_{1}, \mathrm{I}_{\mathrm{r} 2}, \mathrm{I}_{\mathrm{b} 1}$, and $\mathrm{I}_{\mathrm{b} 2}$ are intensity portions which compose the changeable CL. These parameters are proportional to the concentration of luminescence centres. The rhyolitic quartz has a low $\mathrm{I}_{\mathrm{r} 2}$ and $\mathrm{I}_{\mathrm{b} 2}$ indicating a more stable CL (Fig. 5.10). The granitic and hydrothermal quartz exhibit a wide scattering of intensity parameters which corresponds to unstable and highly variable CL. Particularly the high $\mathrm{I}_{\mathrm{r} 1}$ and $\mathrm{I}_{\mathrm{r} 2}$ of granitic quartz demonstrates the high instability of the red CL. Generally, we conclude that the higher the quartz formation temperature and pressure the lower is the concentration of unstable luminescence centres. 

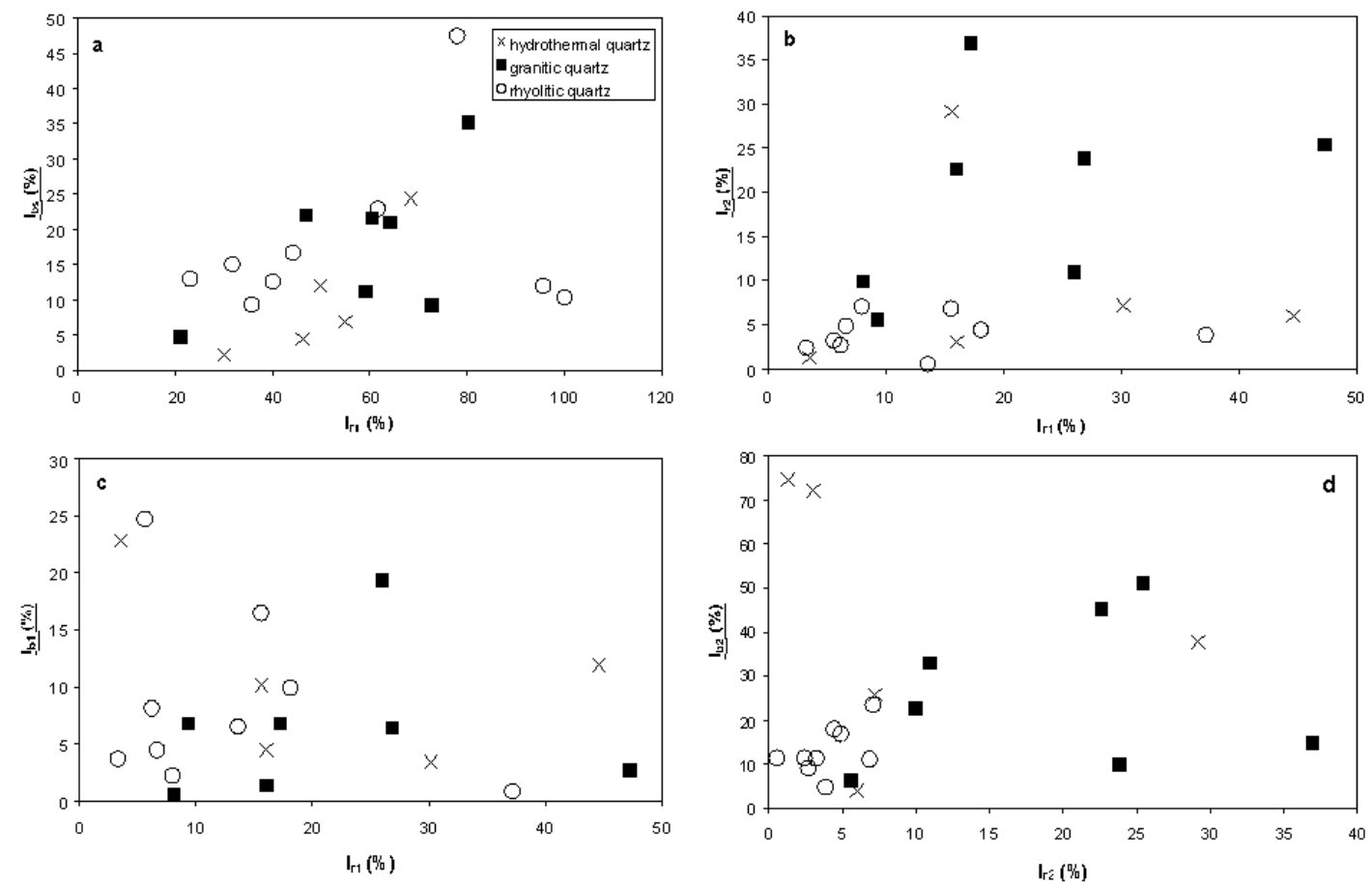

Fig. 5.10 Plots of fitted parameters $\mathrm{I}_{\mathrm{rs}}, \mathrm{I}_{\mathrm{r} 1}, \mathrm{I}_{\mathrm{r} 2}, \mathrm{I}_{\mathrm{bs}}, \mathrm{I}_{\mathrm{b} 1}$, and $\mathrm{I}_{\mathrm{b} 2}$ of the equation 5.2 describing the decrease of 2.79 $\mathrm{eV}$ (blue) $\mathrm{CL}$ emission and of the equation 5.3 describing the increase of $1.96 \mathrm{eV}$ (red) CL emission during electron exposure. $\mathrm{a}-$ Plot of the stable blue CL intensity $\mathrm{I}_{\mathrm{bs}}$ versus the intensity of red CL $\mathrm{I}_{\mathrm{rs}}$ for radiation time $\mathrm{t}$ ? 8 showing that samples with high intensity of blue CL exhibit also a high intensity of red CL; b - Plot of the fast increasing red CL component $\mathrm{I}_{\mathrm{r} 2}$ versus the slow increasing red CL component $\mathrm{I}_{\mathrm{r} 1}$. There is no correlation between the two components; $\mathrm{c}$ - Plot of the slow changing CL components of the blue CL $\mathrm{I}_{\mathrm{b} 1}$ and red CL $\mathrm{I}_{\mathrm{r} 1}$; $\mathrm{d}$ Plot of the fast changing CL components of the blue CL $\mathrm{I}_{\mathrm{b} 2}$ and red CL $\mathrm{I}_{22}$. Note, that rhyolitic quartz has a low no fast changing CL.

\subsection{Comparison of CL spectral and trace element analysis}

EPMA, LA-ICPMS, and SIMS analysis

In order to measure trace element distributions complementary to the CL colours and spectra, quartz has been analysed by LA-ICPMS and EPMA. SIMS analysis were carried out on a selection of samples (megaquartz; Aue Granite; and Weinheim Rhyolite). The analysis were performed by EPMA for Al, Ti, Fe, Mn, by LA-ICPMS for Al, Ti, Li, Ge, Fe, and by SIMS for $\mathrm{Li}, \mathrm{Na}, \mathrm{K}, \mathrm{Al}, \mathrm{Ti}$, and $\mathrm{Fe}$. Trace element profiles traversing different growth and alteration zones were measured (Fig. 5.11a, b, c; see also chapter 7, 8, 9, 10).

Quartz formed at high temperatures $\left(=600^{\circ} \mathrm{C}\right)$ such as rhyolitic quartz shows an average high Ti concentration up to $130 \mathrm{ppm}$ (Fig. 5.11, 5.12a, 5.13). The growth zones are mainly characterised by variations in $\mathrm{Ti}$. The $\mathrm{Ti}$ concentration correlates exponentially with the 
intensity of the $2.96 \mathrm{eV}$ emission (Fig. 5.14). The content of $\mathrm{Ti}$ in hydrothermal quartz is always below 40 ppm. Magmatic quartzes show a maximal Al content of $200 \mathrm{ppm}$, whereas hydrothermal quartz may contain much more $\mathrm{Al}$ e.g. up to $5000 \mathrm{ppm}$ in vein quartz. The vein quartz shows unstable $\mathrm{CL}$ at $2.79 \mathrm{eV}$ of very high intensity, suggesting that this luminescence is associated with $\mathrm{Al}$ defect structures. Large variations in $\mathrm{Al}$ between adjacent growth zones of hydrothermal quartz have been found. Furthermore, Al concentration differs for the rhombohedral faces $\mathrm{z}$ to $\mathrm{r}$ of the zoned hydrothermal $\alpha$-quartz (Fig. 5.11b). The sum of Li, $\mathrm{Na}, \mathrm{K}$, and Fe shows a good correlation with Al (Fig. 5.13). This confirms the general assumption that $\mathrm{Li}, \mathrm{Na}, \mathrm{K}$, and $\mathrm{Fe}$ act as interstitial charge compensators for substitutional $\mathrm{Al}$ (e.g., Dennen, 1965; Smith and Steele, 1984).

Hydrothermal quartz exhibits elevated Ge concentrations, between 3-16 ppm (Fig. 5.12.). The LA-ICPMS analysis shows a strong enrichment in $\mathrm{Mn}, \mathrm{Fe}, \mathrm{Ge}$, and $\mathrm{Cr}$. The enrichment of all these element may caused by micro inclusions situated in the measured sample volume.

The quartz of the Erzgebirge Batholite (Eibenstock and Aue Granite) exhibits high Fe and Mn. The CL spectra of these samples show a characteristic stable $2.15 \mathrm{eV}$ band which is possibly associated with $\mathrm{Mn}$.

The average Fe concentration increases with the quartz formation temperature. Therefore, the Fe content of quartz is a good criteria to distinguish quartz of different genesis. Pott and McNicol (1971) and Kempe et al. (1999) found that high $\mathrm{Fe}^{3+}$ causes the $1.73 \mathrm{eV} \mathrm{CL}$ emission. However, in our samples we found no correlation between the Fe concentration and the $1.73 \mathrm{eV}$ band intensity. The lack of correlation may be explained by the fact that Fe occurs as divalent and trivalent ions. It was frequently observed that Fe increases towards the grain boundary indicating a high diffusion rate of Fe in the quartz lattice (Fig. 5.11a, see also $\S$ 10.7). The preferred diffusing ion is likely to be the $\mathrm{Fe}^{2+}$ due to its smaller ion radius. Weak or non-luminescent secondary quartz in healed microcracks, or formed around fluid inclusions is typically depleted in all trace elements (Fig. 5.11c).

\section{FT-IR spectroscopy}

Spectra of quartz containing structural water in the form of $\mathrm{H}^{+}, \mathrm{OH}^{-}$, and $\mathrm{H}_{2} \mathrm{O}$ show characteristic absorption bands between $3000-3700 \mathrm{~cm}^{-1}$. The absorption bands are caused by stretching vibrations of H-related chemical bonds excited by electromagnetic UV radiation. Generally two classes of absorption occur in the IR spectra: sharp absorption bands (low half width) at 3305, 3365, 3425, and $3470 \mathrm{~cm}^{-1}$ and broad absorption bands (high half-width) at $3440 \mathrm{~cm}^{-1}, 3220 \mathrm{~cm}^{-1}$ and $3110 \mathrm{~cm}^{-1}$ (Brunner, 1961; Kats, 1962; Aines and Rossman, 1984). 


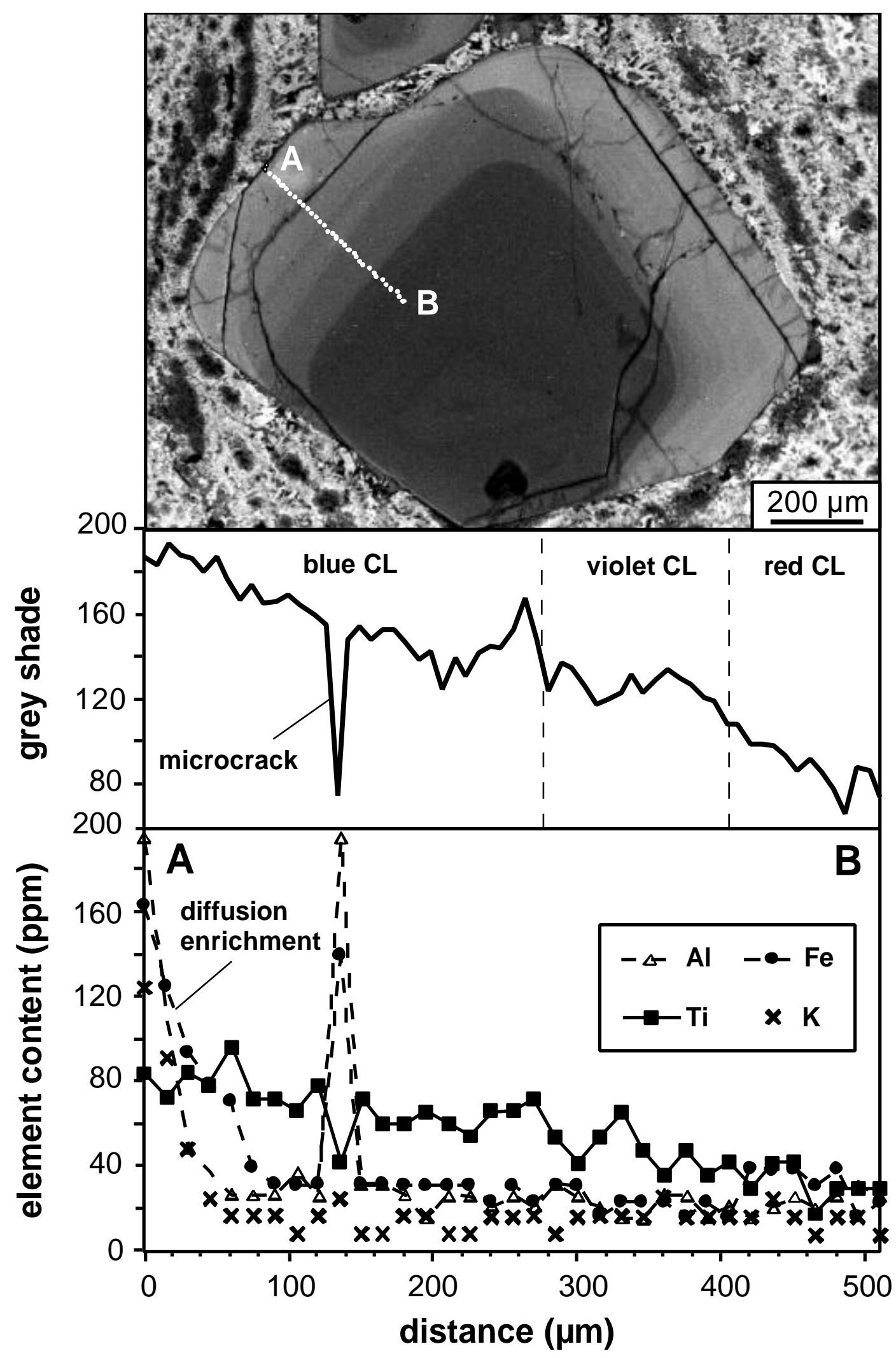

Fig. 5.11a Trace element profile of a quartz phenocryst of the Wachtelberg Rhyolite (sample 12) determined by EPMA and compared with relative CL intensity (grey shade). 


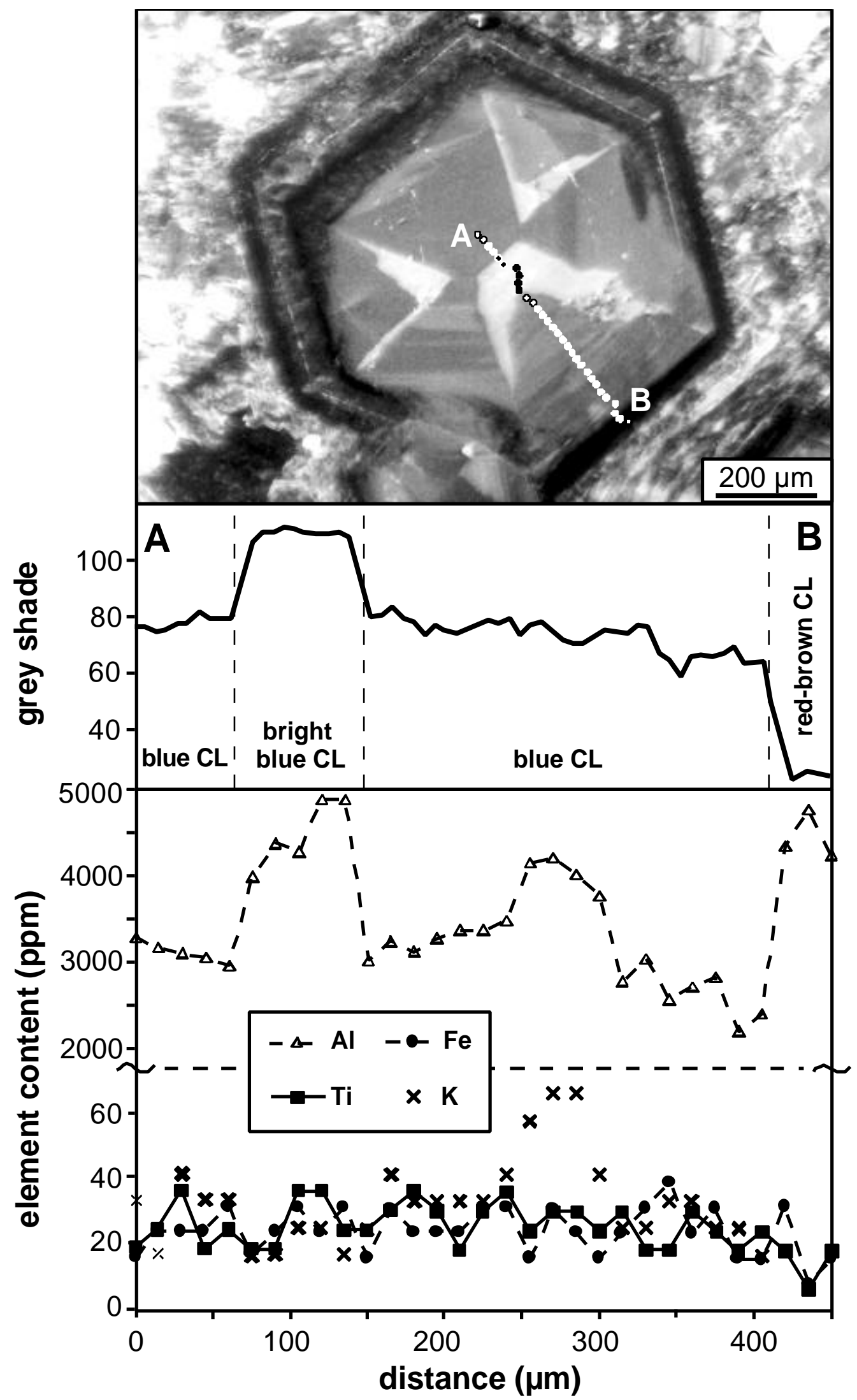

Fig. 5.11b Trace element profile of a Berg crystal (vein quartz; sample 9) determined by EPMA compared with relative CL intensity (grey shade). 


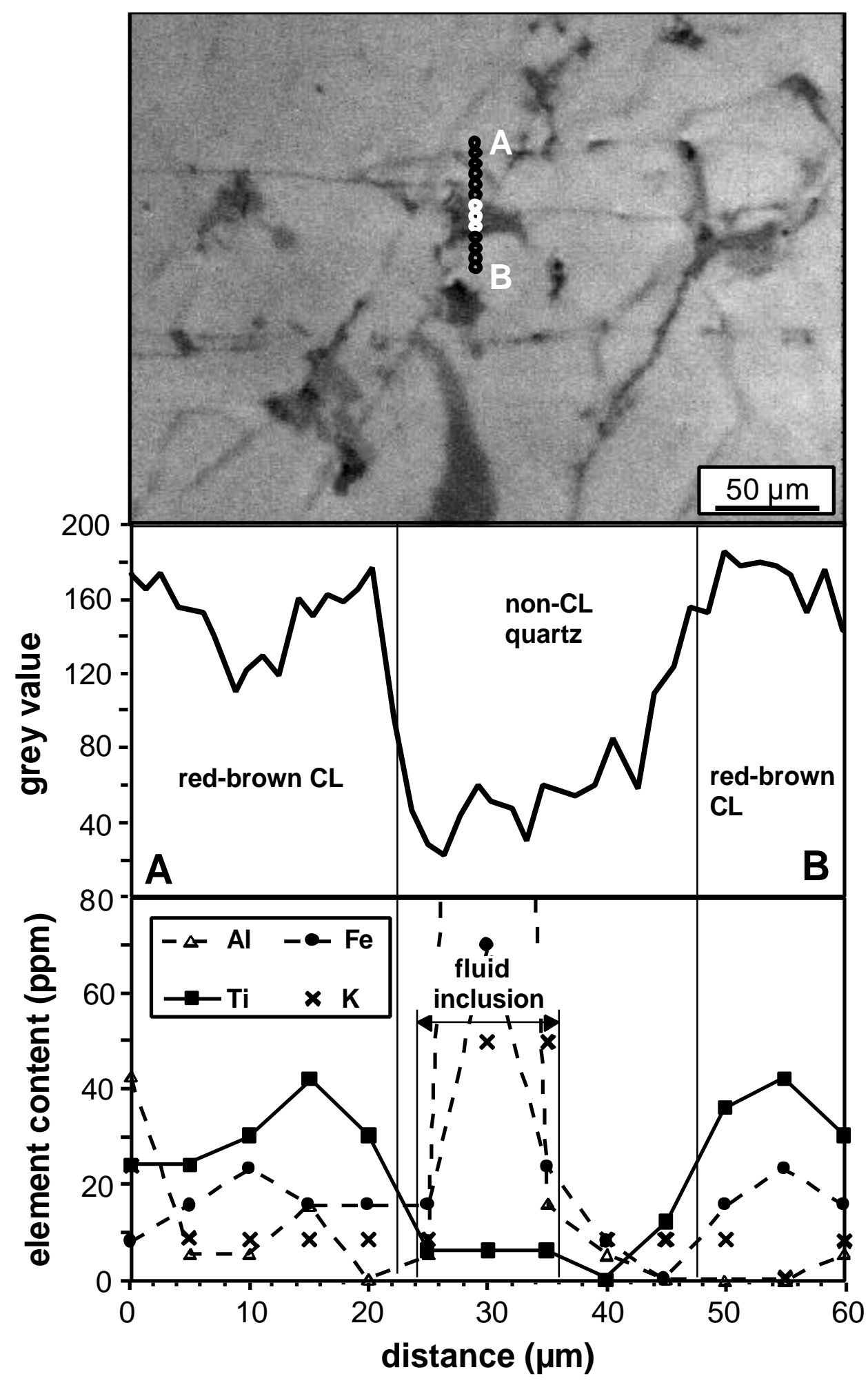

Fig. 5.11c Trace element profile of a quartz crystal of the Flossenbürg Granite (sample 12) determined by EPMA compared with relative CL intensity (grey shade). The microprofile cuts a weak luminescent secondary quartz (dark grey) around a fluid inclusion. The secondary quartz is depleted in trace elements. 

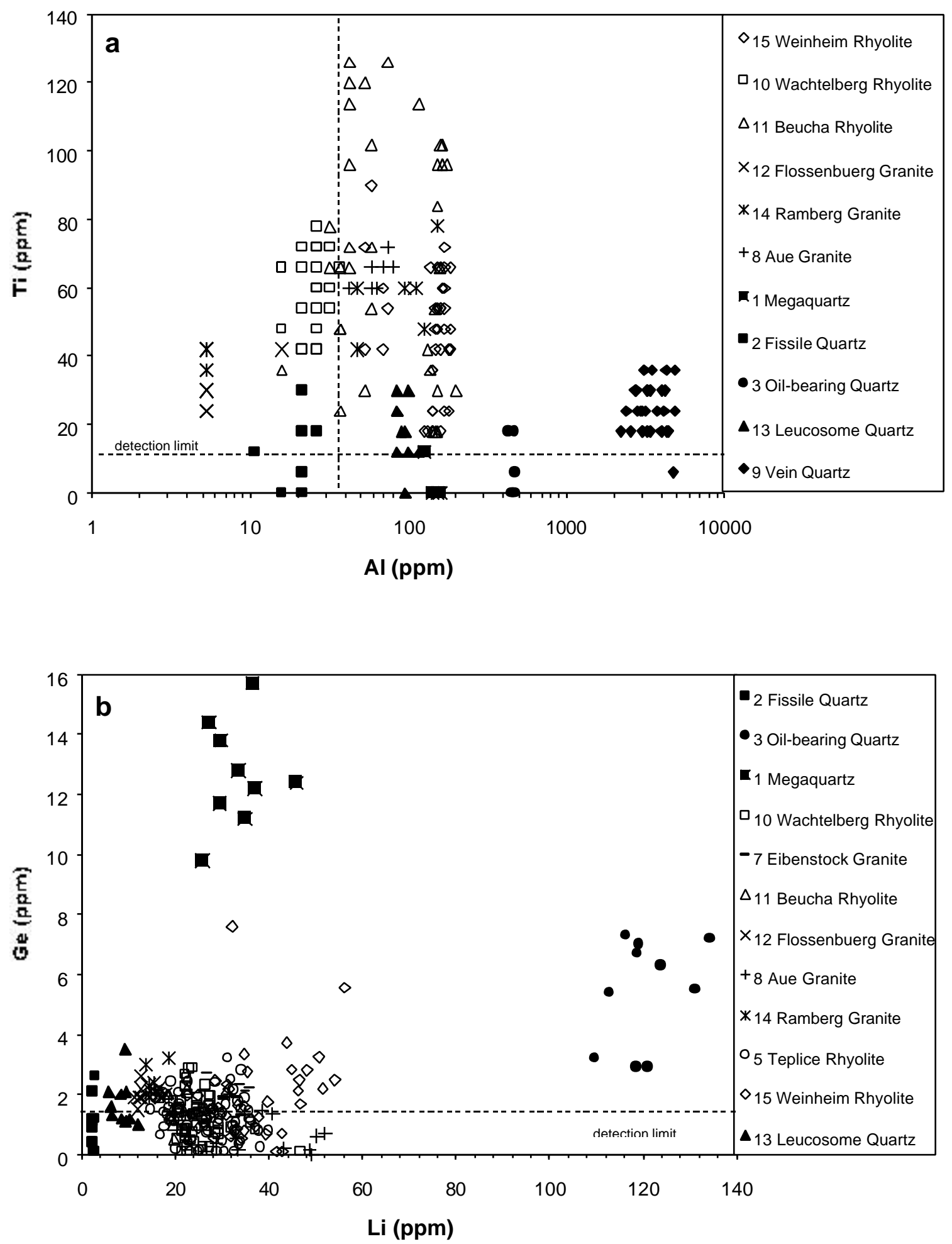

Fig. 5.12a, b Plots of trace element concentration of quartz. a - Al vs Ti determined by EPMA. b - Li vs. Ge determined by LA-ICPMS. 

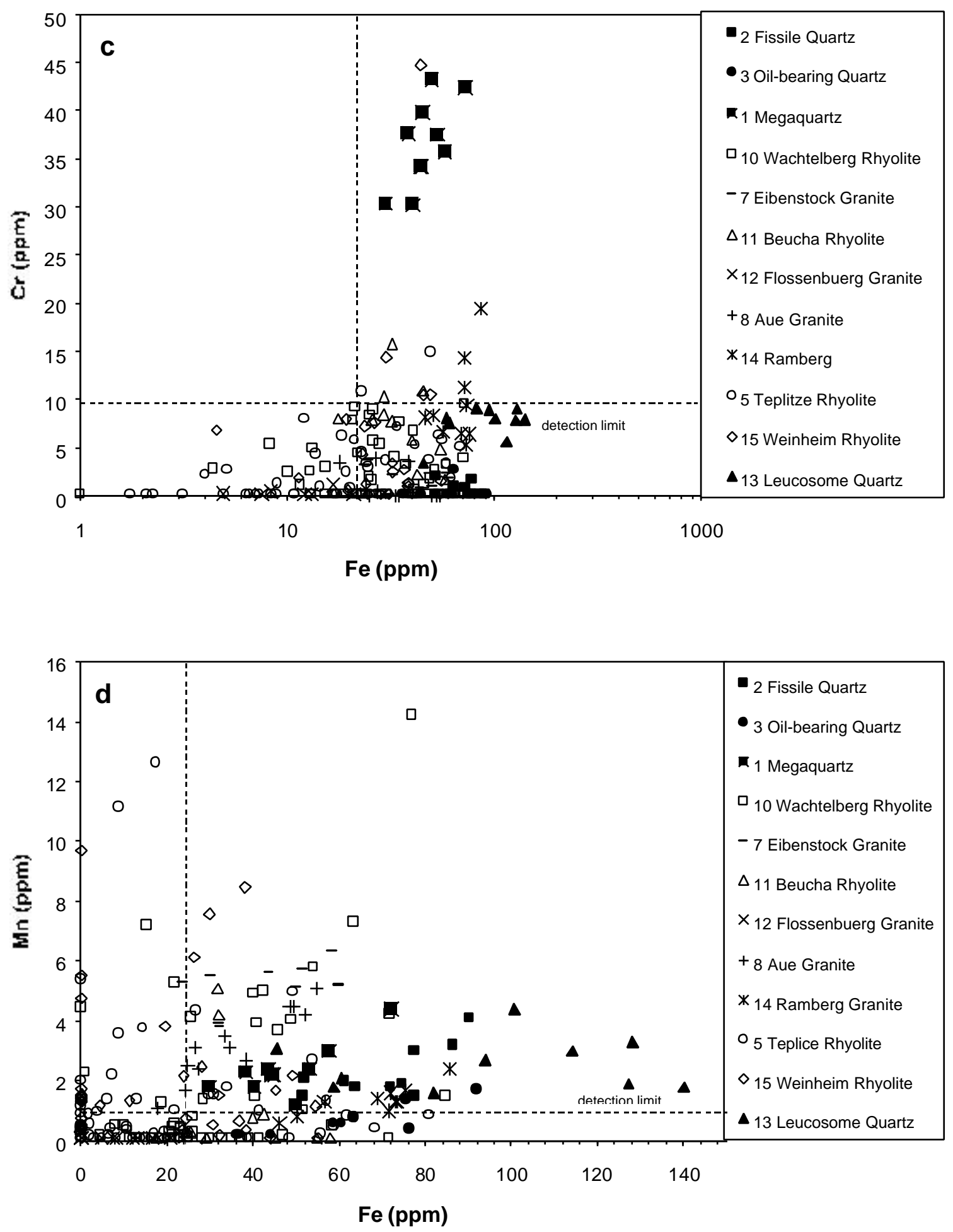

Fig. 5.12c, $d$ Plots of trace element concentration of quartz. c - Fe vs. Cr determined by LA-ICPMS. d - Fe vs. Mn determined by LA-ICPMS. 

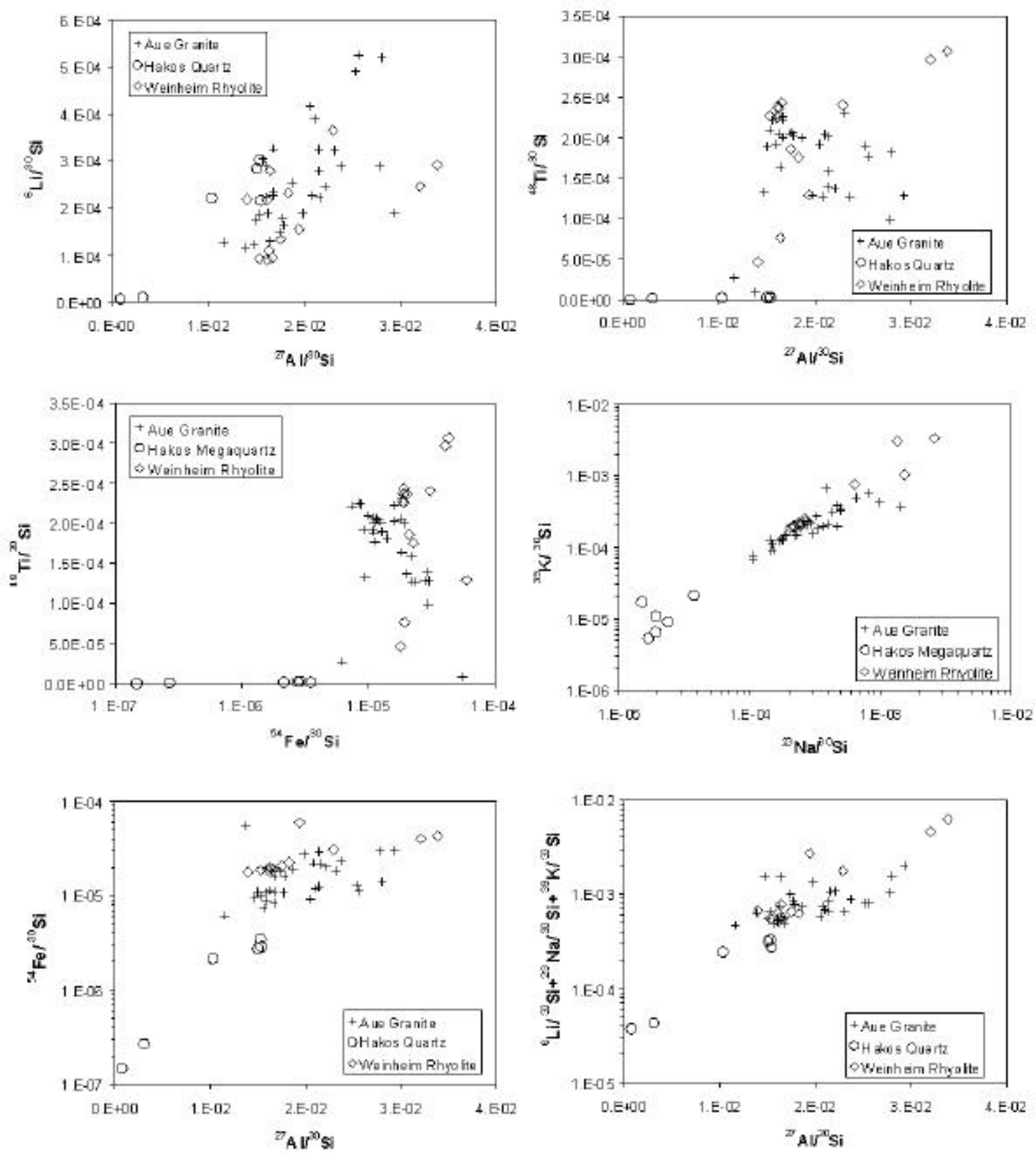

Fig. 5.13 Variation diagrams of relative concentrations $\left(\mathrm{X} /{ }^{30} \mathrm{Si}\right.$, where $\left.\mathrm{X}={ }^{6} \mathrm{Li},{ }^{23} \mathrm{Na},{ }^{27} \mathrm{Al},{ }^{39} \mathrm{~K},{ }^{54} \mathrm{Fe},{ }^{48} \mathrm{Ti}\right)$ of trace elements determined by SIMS. 


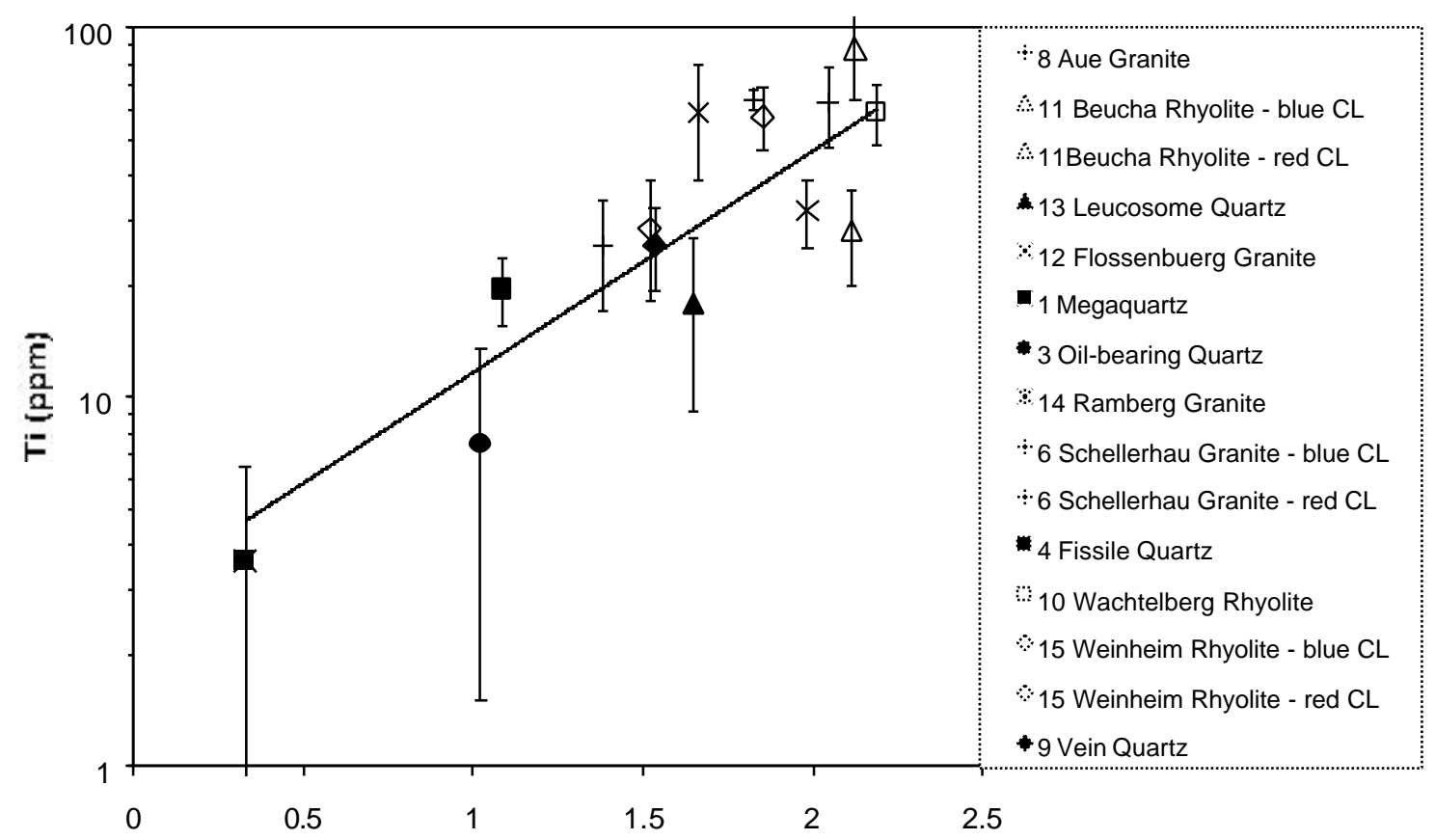

$2.96 \mathrm{eV} / 2.68 \mathrm{eV}$-peak area ratio after $7 \mathrm{~min}$ electron radiation

Fig. 5.14 Correlation of average Ti concentration with the peak area of the $2.96 \mathrm{eV}$ emission.

A band with low half-width indicates a well definite bond, which is not effected by other bond vibrations. Sharp bands are developed if H-related bonds are isolated and have a sufficient large distance to similar bonds. The sharp peaks at 3365 and $3305 \mathrm{~cm}^{-1}$, attributed to protoncompensated aluminium defects, are the most significant peaks in the hydroxyl band. The Al$\mathrm{H}$-defects $\left(\left[\mathrm{AlO}_{4} / \mathrm{H}^{+}\right]^{0}\right.$ centres) are very stable up to temperatures of $1000^{\circ} \mathrm{C}$ (Kats, 1962 ; Schneider, 1993). The peak at $3474 \mathrm{~cm}^{-1}$ was assigned by Kats (1962) to proton-compensated aluminium defect perturbed by $\mathrm{Li}^{+}$(marked as "Li-H" in Fig. 5.15). This absorption band was absent after $>450^{\circ} \mathrm{C}$ quartz heating (Schneider, 1993).

Molecular water exists in the quartz lattice as micropores and fluid inclusions as well as structural bound water. The vibrations of the water molecules affect one another which results in broader absorbed wavelength ranges. At room temperature the broad absorption bands at $3440 \mathrm{~cm}^{-1}$ are caused by the asymmetrical stretching vibrations and the $3220 \mathrm{~cm}^{-1}$ and 3110 $\mathrm{cm}^{-1}$ bands by the symmetrical stretching vibrations of molecular water (Aines and Rossman, 1984). To distinguish fluid water from crystallographic bounded water, spectra are obtained at cryogenic temperatures between -190 and $-194^{\circ} \mathrm{C}$. The change of the state from the water to ice during sample cooling results in the quenching of the asymmetrical vibrations $\left(3440 \mathrm{~cm}^{-1}\right)$ in the crystal lattice and the rise of the symmetric vibrations $\left(3220 \mathrm{~cm}^{-1}\right.$ and $\left.3110 \mathrm{~cm}^{-1}\right)$. 
Structural bounded $\mathrm{OH}$-groups can not change into solid $\mathrm{H}_{2} \mathrm{O}$ (ice). The change into the solid state of water presupposed, that the water molecules are able to built hydrogen bonds which can be problematic if the number of water molecules is small (Aines and Rossman, 1984).

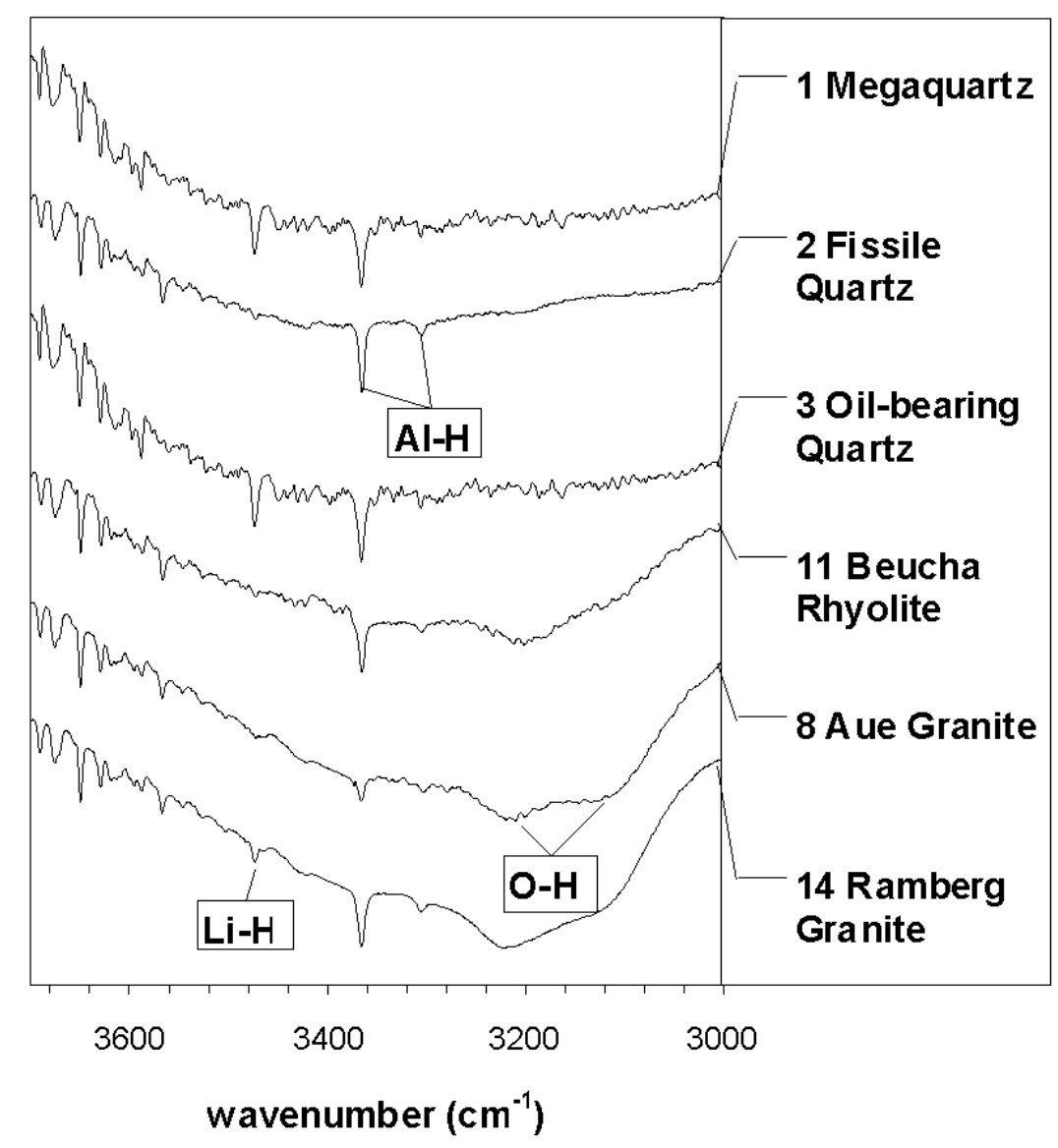

Fig. 5.15 Representative IR-absorption spectra of different quartz types measured at $\sim 190^{\circ} \mathrm{C}$.

The IR absorption spectra of one sample recorded along profiles are very homogeneous. There is no variation of $\mathrm{Al}-\mathrm{H}-$ and $\mathrm{Li}-\mathrm{H}-$ defect concentrations found in different growth zones of the rhyolitic phenocrysts (sample 11). The lack of correlation between spectroscopic data and growth zoning in the quartz phenocrysts shows that neither proton-compensated Al nor Li-defect concentrations control the luminescence contrast of this growth zones. Similar observations were made by Liebetrau (1991) and Schneider (1993) in rhyolitic quartz phenocrysts.

The associated 3365 and $3305 \mathrm{~cm}^{-1}$ absorption bands are found in all spectra and are indicative for proton-compensated $\mathrm{Al}$ defects (Fig. 5.15). The bands are most intense in 
hydrothermal quartz (samples 1, 2, 3). However, the relative absorption intensities (integrated peak areas) do not correlate with the $\mathrm{Al}$ concentrations.

Hydrothermal quartz (Fig. 5.12a) shows a high intensity of the Li-associated $3474 \mathrm{~cm}^{-1}$ band. This quartz is characterised by a high intensity of the $2.48 \mathrm{eV} \mathrm{CL}$ emission (Fig. 5.1, 5.2). The $3474 \mathrm{~cm}^{-1}$ absorption band is thermally unstable at temperatures $=450^{\circ} \mathrm{C}$ (Schneider, 1993). The characteristics of the $2.48 \mathrm{eV} \mathrm{CL}$ band and of the Li-associated $3474 \mathrm{~cm}^{-1}$ absorption band suggest an association with Li-defects.

Granitic (sample 8, 14) and rhyolitic quartz (sample 11) is characterised by high absorption bands at $\sim 3110$ and $3220 \mathrm{~cm}^{-1}$. Granitic quartz shows a high number of small fluid inclusions mostly $<1 \mu \mathrm{m}$ in the measured area. The quartz samples of the Beucha Rhyolite do not contain fluid inclusions. However, the 3110 and $3220 \mathrm{~cm}^{-1}$ absorption bands indicate the presence of molecular water in lattice.

\section{Paramagnetic defect centres}

The paramagnetic $\mathrm{E}^{`}, \mathrm{O}_{2}{ }^{3-},\left[\mathrm{AlO}_{4}\right]^{0},\left[\mathrm{TiO}_{4} / \mathrm{Li}^{+}\right]^{0}$, and $\left[\mathrm{TiO}_{4} / \mathrm{H}^{+}\right]^{0}$ centres were studied at the University Marburg by T. Scherer using EPR spectroscopy. The relative intensities of the defect centre concentration are listed in Table 5.3. The concentration of the paramagnetic defect centres in quartz depends on the number of precursor defects, the post-crystallisation dose rate and the duration of the natural radiation. The centres decay under UV radiation and are stable at temperatures $<100^{\circ} \mathrm{C}$. The closing temperature varies between 55 and $82^{\circ} \mathrm{C}$ for the $\left[\mathrm{TiO}_{4} / \mathrm{Li}^{+}\right]^{0}$ centre and between 49 and $64^{\circ} \mathrm{C}$ for the $\left[\mathrm{AlO}_{4}\right]^{0}$ centre (e.g. Grün et al., 2000). The relative intensities of $\left[\mathrm{AlO}_{4}\right]^{0}$ as well as $\left[\mathrm{TiO}_{4} / \mathrm{Li}^{+}\right]^{0}$ centres systematically increase for hydrothermal quartz (samples 1, 2, 3, 13) granitic quartz (samples 6, 8, 12, 14) and rhyolitic quartz (samples 10, 11, 15), respectively (Fig. 5.16a). The Ti concentration correlates with the absorption intensity of the $\left[\mathrm{TiO}_{4} / \mathrm{Li}^{+}\right]^{0}$ centre but there is no correlation between the $\mathrm{Al}$ concentration and the intensity of the $\left[\mathrm{AlO}_{4}\right]^{0}$ centres. High concentrations of $\left[\mathrm{TiO}_{4} / \mathrm{Li}^{+}\right]^{0}$ centres are typical for magmatic quartz (Rakov et al., 1991; Agel, 1992; Plötze, 1995). The lack of correlation between $\mathrm{Al}$ concentration and paramagnetic Al-defects may due to the fact that paramagnetic Al-centres are less stable. The $\left[\mathrm{TiO}_{4} / \mathrm{H}^{+}\right]^{0}$ centres could not detected. They are typical for metamorphic quartz (Rakov et al., 1991; Agel, 1992; Plötze, 1995).

The relative concentration of $\left[\mathrm{AlO}_{4}\right]^{0}$ centres in magmatic quartz shows a positive correlation with the slow decaying component $\left(\mathrm{I}_{\mathrm{b} 1}\right.$; see $\left.\S 5.2\right)$ of the blue $2.79 \mathrm{eV}$ CL emission (Fig. 5.17a). The abundance of $\mathrm{O}_{2}{ }^{3-}$ centres exhibits a association with the fast increasing 
component ( $\mathrm{I}_{\mathrm{r} 2}$; see $\S 5.2$ ) of the red $1.96 \mathrm{eV} \mathrm{CL} \mathrm{emission} \mathrm{(Fig.} \mathrm{5.17b).} \mathrm{This} \mathrm{corresponds} \mathrm{with}$ the general observation, that the $1.96 \mathrm{eV}$ emission is associated with non-bridging oxygen hole centres (NBOHC) with OH-precursor (e.g. Kalceff and Phillips, 1995). The paramagnetic $\mathrm{O}_{2}{ }^{3-}$ centre is a kind of $\mathrm{NBOHC}$ (see chapter 2$)$. Silanol groups $(=\mathrm{Si}-\mathrm{O}-\mathrm{H})$ are favourable precursors $\mathrm{O}_{2}{ }^{3-}$ centres in quartz. Upon irradiation $\mathrm{H}^{+}$diffuses away and $\mathrm{NBOHC}$ are formed (e.g. $\mathrm{O}^{-}, \mathrm{O}_{2}{ }^{3-}$ ) resulting in an increase of the $1.96 \mathrm{eV} \mathrm{CL}$ emission.

Table 5.3 List of relative intensity of paramagnetic defect centres determined by EPR spectroscopy.

\begin{tabular}{|c|c|c|c|c|c|c|}
\hline \multirow{2}{*}{$\begin{array}{l}\text { No } \\
\text {. }\end{array}$} & \multirow[t]{2}{*}{ Sample name } & \multirow[t]{2}{*}{ Quartz type } & \multicolumn{4}{|c|}{ ESR intensity of paramagnetic defect centres (a.u.) } \\
\hline & & & {$\left[\mathrm{AlO}_{4}\right]^{0}$} & {$\left[\mathrm{TiO}_{4} / \mathrm{Li}^{+}\right]^{0}$} & $\mathbf{O}_{2}^{3-}$ & E'-centre \\
\hline 1 & megaquartz & hydrothermal & 0.38 & 0 & 0.422 & 0.068 \\
\hline 2 & fissile quartz & hydrothermal & 0 & 0 & 0 & 0 \\
\hline 3 & oil-bearing quartz & hydrothermal & 0.691 & 0 & 0.68 & 0.68 \\
\hline 4 & Schoenfeld Rhyolite & rhyolitic & n.d. & n.d." & n.d. & n.d. \\
\hline 5 & Teplice Rhyolite (TPR2) & rhyolitic & 12.77 & 0.221 & 1.128 & 0.719 \\
\hline 6 & Schellerhau Granite & granitic & 11.689 & 0.948 & 0.906 & 0.329 \\
\hline 7 & Eibenstock Granite & granitic & 3.124 & 0.516 & 1.57 & 0.287 \\
\hline 8 & Aue Granite & granitic & 5.003 & 0.95 & 1.177 & 0.171 \\
\hline 9 & vein quartz & hydrothermal & n.d. ${ }^{*}$ & n.d. & n.d. ${ }^{*}$ & n.d. \\
\hline 10 & Wachtelberg Rhyolite & rhyolitic & 27.94 & 1.27 & 0.749 & 0.439 \\
\hline 11 & Beucha Rhyolite & rhyolitic & 14.03 & 1.499 & 0.302 & 0.801 \\
\hline 12 & Flossenbuerg Granite & granitic & 8.933 & 0.414 & $0.604 / 0.682$ & 0.141 \\
\hline 13 & leucosome quartz & pegmatoid & 0.244 & 0.159 & 0 & 0 \\
\hline 14 & Ramberg Granite & granitic & 5.195 & 0.445 & 1.365 & 0.058 \\
\hline 15 & Weinheim Rhyolite & rhyolitic & 11.87 & 1.505 & 0.435 & 0.111 \\
\hline
\end{tabular}
n.d." - not determined
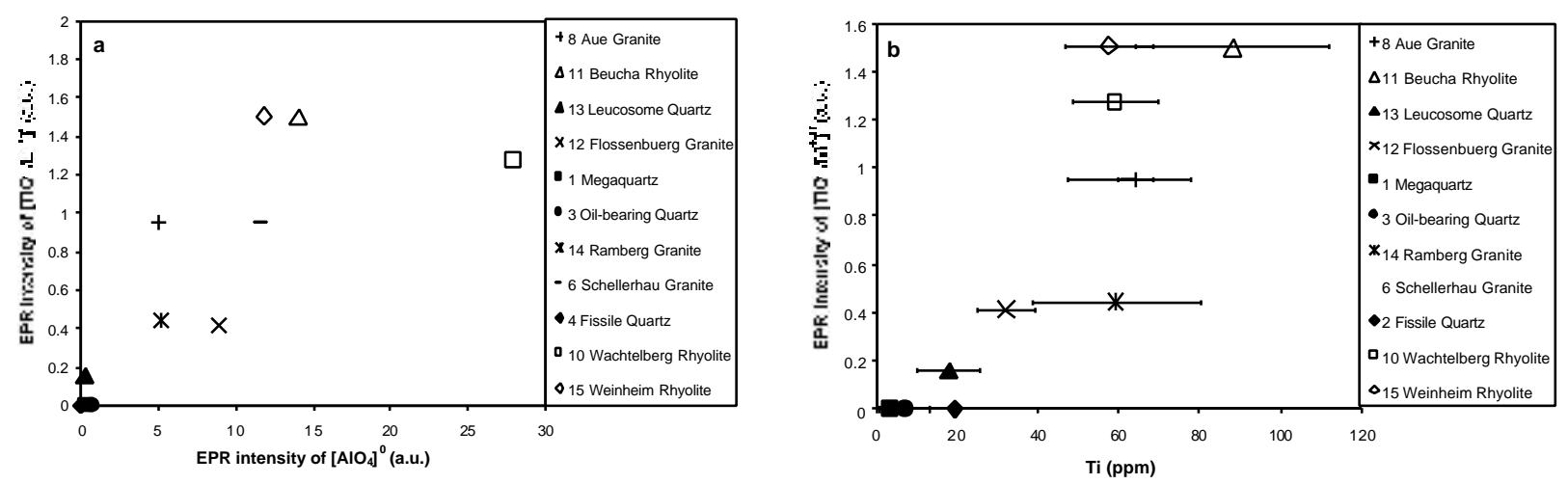

Fig. 5.16 Results of EPR spectroscopy. a - EPR intensity of the $\left[\mathrm{AlO}_{4}\right]^{0}$ vs the $\left[\mathrm{TiO}_{4} / \mathrm{Li}^{+}\right]^{0}$ centre of different quartz types. High temperature formed quartzes exhibit the highest concentrations. $\mathrm{b}-\mathrm{Ti}$ concentration vs EPR intensity of the $\left[\mathrm{TiO}_{4} / \mathrm{Li}^{+}\right]^{0}$ centre. Quartzes with high Ti content show a high the $\left[\mathrm{TiO}_{4} / \mathrm{Li}^{+}\right]^{0}$ defect concentration. 

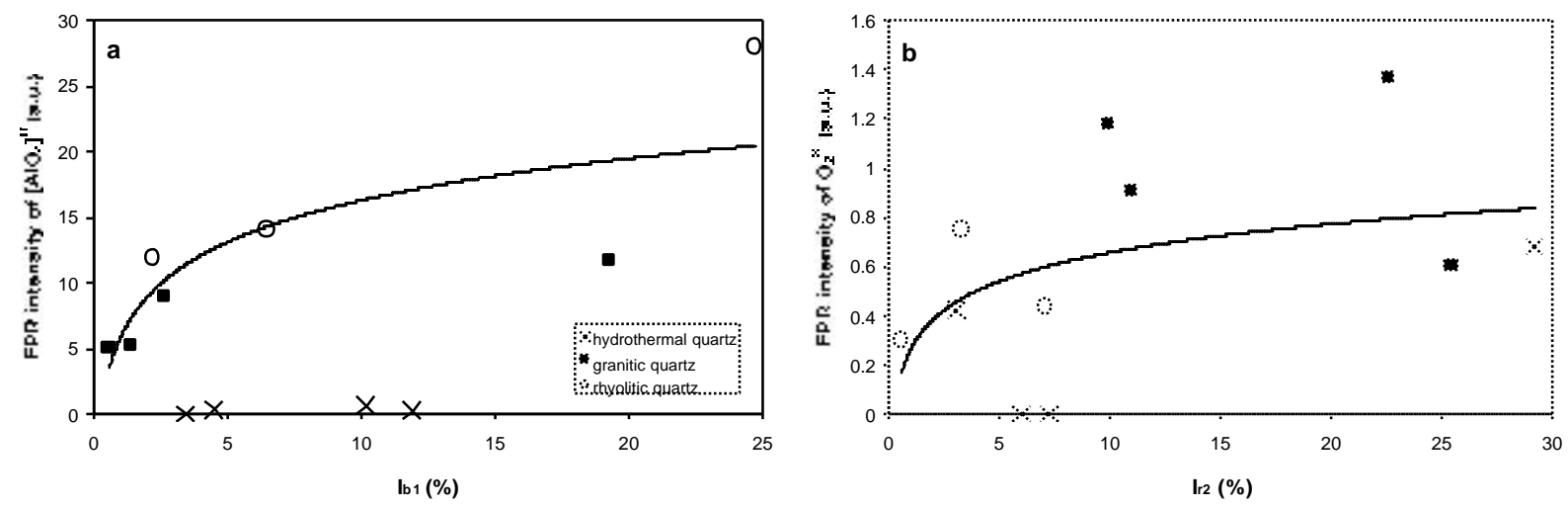

Fig. 5.17 Comparison of intensities of paramagnetic defects and intensity parameters of the $1.96 \mathrm{eV}$ and 2.79 eV CL emission. a - EPR intensity of the $\left[\mathrm{AlO}_{4}\right]^{0}$ vs the slow decaying component $\left(\mathrm{I}_{\mathrm{b} 1}\right.$; see $\left.\S 5.2\right)$ of the blue $2.79 \mathrm{eV}$ CL emission. The regression line was calculated for the magmatic quartzes. $\mathrm{b}-\mathrm{EPR}$ intensity of the $\mathrm{O}_{2}{ }^{3-}$ vs the fast increasing component $\left(\mathrm{I}_{\mathrm{r} 2}\right.$; see $\left.\S 5.2\right)$ of the red $1.96 \mathrm{eV} \mathrm{CL}$ emission.

\section{Overview of CL emission lines of quartz}

\section{$\underline{1.73 \pm 0.1 \mathrm{eV} \text { emission }}$}

The dominance of the $1.73 \mathrm{eV}$ band may be responsible for reddish luminescence (instead of the frequent red-brown CL). The CL typically increases during radiation time. Thermal treatment of some samples results in a significant increase of the intensity at $300^{\circ} \mathrm{C}$ for $24 \mathrm{~h}$ (Fig. 5.8) indicating that the emission can be excited thermally.

The $1.73 \mathrm{eV}$ emission line is caused by the substitutional incorporation of $\mathrm{Fe}^{3+}$ into the quartz lattice (Pott and McNicol, 1971; Gorobets et al., 1989; Kempe et al., 1999). $\mathrm{Fe}^{3+}$ is an important $C L$ activator even when it is present in low concentration $(<50 \mathrm{ppm})$ in the crystal lattice (Marshall, 1988). The average Fe concentration increases with the quartz formation temperature (Fig. 5.13). It was frequently observed that Fe increases at the grain boundary of magmatic quartz which indicates a high diffusion rate of $\mathrm{Fe}$ in the quartz lattice at high temperatures (Fig. 5.11a). However, a correlation between the Fe concentration and the 1.73 $\mathrm{eV}$ emission intensity could not be proofed. There are several 3 explanations: 1) the $\mathrm{Fe}$ concentration lies mostly near the detection limit and inaccuracies do not allow any correlation, 2) $\mathrm{Fe}$ occurs also as a divalent ion which enters interstitial positions (e.g. Lehmann, 1975), 3) the $\mathrm{Fe}^{3+}$ can be incorporated into quartz structure also in interstitial positions (e.g. Scala and Hutton, 1976). 


\section{$\underline{1.85 \pm 0.1 \text { and } 1.96 \pm 0.2 \mathrm{eV} \text { emission }}$}

The dominant peak of the red emission range of most quartzes is given by the $1.96 \mathrm{eV}$ band. The weak $1.85 \mathrm{eV}$ emission is associated with the $1.96 \mathrm{eV}$ band as both emissions show a constant peak area ratio $(1.96: 1.84 \mathrm{eV}=1: 0.51 \pm 0.17)$. The emissions are characterised by an parabolic increase during electron radiation. The only exception is the vein quartz (sample 9), for which no red CL emission was observed. The intensity increase is generally steeper in quartz formed at low temperature and flatter in quartzes in rhyolite, where these lines show already a high initial intensity. The 1.96 and $1.85 \mathrm{eV}$ bands of the rhyolitic quartzes are often very distinct as the neighbouring 1.73 and $2.15 \mathrm{eV}$ emissions normally have low intensities. The emission is slightly influenced by the sample warming during electron radiation (Fig. 5.6). Furthermore the heating at $300^{\circ} \mathrm{C}$ for $24 \mathrm{~h}$ results in an intensity increase of both 1.85 and $1.96 \mathrm{eV}$ bands (Fig. 5.8). This is in agreement with Rink et al. (1993) who observed that radiated rhyolitic quartz phenocrysts show an intense red thermoluminescence band centred at 1.96-2.0.

The concentration of $\mathrm{O}_{2}{ }^{3-}$ centres shows a weak association with the unstable component of the $1.96 \mathrm{eV}$ emission (Fig. 5.17b). This corresponds with the general observation, that the 1.96 $\mathrm{eV}$ emission is associated with non-bridging oxygen hole centres ( $\mathrm{NBOHC}$ ) like $\mathrm{O}_{2}{ }^{3-}$ and $\mathrm{O}^{-}$ centres (e.g. Siegel and Marrone, 1981; Kalceff and Phillips, 1995). OH-precursors are the proposed cause for the creation of this NBOHC (e.g. Griscom, 1985; Friebele et al., 1985; Kalceff and Phillips, 1995). Upon irradiation $\mathrm{H}^{+}$diffuses away and NBOHC are formed resulting in an increase of the $1.96 \mathrm{eV}$ CL emission. According to Griscom (1985) the paramagnetic E'centre $(\equiv \mathrm{Si} \cdot)$ and/or the diamagnetic trapped-electron center $(\equiv \mathrm{Si}:)$ are important causes for the emission at $1.96 \mathrm{eV}$ besides the NBOHC. Defects related to structural water have been assumed as possible precursor centres. Koyama (1980) assumed that this emission may originate from hydrogen in the form of $\mathrm{OH}$ or adsorbed $\mathrm{H}_{2} \mathrm{O}$ in the quartz lattice. The $1.85 \mathrm{eV}$ band is similarly associated with NBOHC (Griscom, 1985; Kalceff and Phillips, 1995). Possible precursors of the NBOHC are peroxy linkages, "strained" silicon-oxygen bonds, and/or hydroxyl groups.

Greenschist facial deformed granitic quartz from the Lachlan Fold Belt (see $\S 10.7$ ) show a constant or decreasing $1.96 \mathrm{eV}$ and $1.85 \mathrm{eV}$ emissions during electron bombardment. This quartz contains finely dispersed muscovite flakes of up to $0.5 \mu \mathrm{m}$ in diameter, which are arranged on micro-sliding planes. The flakes are interpreted as products of deformation. They incorporated the stress-induced mobilised structural water of the quartz lattice. Therefore, 
nearly no interstitial bonded water occurs in the quartz lattice, which would have caused the rise of red intensity during electron radiation due to the radiolysis of hydroxyl bonds.

Both 1.96 and $1.85 \mathrm{eV}$ emissions do not generally correlate with the $\mathrm{Al}$ distribution. High $\mathrm{Al}$ concentrations (>1000 ppm) are associated with the $2.79 \mathrm{eV}$ emission (see below) and the 3.26 eV emission (Alonso et al., 1983; Luff and Townsend, 1990; Perny et al., 1992; Gorton et al., 1996). This lack of correlation may explained as follows: 1) the substitutional position compensated by hydroxyl defects may be occupied also by other ions like $\mathrm{Fe}^{3+}, 2$ ) $\mathrm{Al}$ may occur also in interstitial sites (Cohen, 1960), and 3) $\mathrm{Al}$ is in part present in the form of microinclusions (Blankenburg et al., 1994; Götze et al., 1999).

\section{$\underline{2.15 \pm 0.2 \mathrm{eV} \text { emission }}$}

The $2.15 \mathrm{eV}$ emission band (yellow) is dominant for granitic quartz (samples 7, 8, 12). It is the only emission band whose intensity remains relatively constant during electron radiation implying a stable luminescence centre. The quartz of the Eibenstock and Aue Granite showing high-intensity $2.15 \mathrm{eV}$ emission exhibit high Mn suggesting that the emission may caused by Mn.

According to Lysakov (1978) Mn in quartz has characteristic CL at 1.92, 2.23, and 2,6 eV in quartz. The latter peak is caused by the trivalent ion and the other two by the bivalent ion. The $2.15 \mathrm{eV}$ band was observed by Itoh et al. (1990), Remond et al. (1992), Fuchs and Götze (1996) and Götze et al. (1999). Rink et al. (1993) described a thermoluminecence peak centred between $2.14 \mathrm{eV}-2.21 \mathrm{eV}$ in natural quartz of hydrothermal origin. Itoh et al. (1990) proposed that electron radiation of $\alpha$-quartz generates pairs of E' centres $€ \mathrm{Si}$.) and peroxy radicals ( $\equiv \mathrm{Si}-\mathrm{O}-\mathrm{O} \cdot$ ) showing luminescence at $2.1 \mathrm{eV}$ as well as self trapped excitons (STE) showing luminescence at $2.8 \mathrm{eV}$. However, an association of the the $2.15 \mathrm{eV}$ and $2.79 \mathrm{eV}$ emission could not be detected. According to Fuchs and Götze (1996) and Götze et al. (1999) the predominance of the $2.15 \mathrm{eV}$ emission of some agates and of hydrothermal quartz is associated with the high concentration of E' centres. In this study a correlation between EPR intensity of the E' centre and the peak area of the $2.15 \mathrm{eV}$ band has not been found.

\section{$\underline{2.48 \pm 0.2 \mathrm{eV} \text { emission }}$}

Hydrothermal quartz (megaquartz and oil-bearing quartz) exhibit a significant $2.48 \mathrm{eV}$ peak at initial electron bombardment causing a turquoise CL at initial radiation. This emission rapidly decays during the first minute of electron bombardment. The emission is thermally stable up to $300^{\circ} \mathrm{C}$, however it is destroyed after heating at $600^{\circ} \mathrm{C}$ for $24 \mathrm{~h}$. The samples of 
hydrothermal quartz (Fig. 5.12a) show a high intensity of the Li-associated $3474 \mathrm{~cm}^{-1}$ band. The decrease or disappearance of the $\mathrm{Li}-\mathrm{H}$ absorption band after heating at $500^{\circ} \mathrm{C}$ (Schneider, 1993 ) is in accordance with the presently observed disappearance of the CL emission after $600^{\circ} \mathrm{C}$ heating (Fig. 5.8). The properties of the $2.48 \mathrm{eV}$ band and of the Li-associated 3474 $\mathrm{cm}^{-1}$ absorption bands imply an association of this CL emission with Li-defects (Table 5.4).

Demars et al. (1996) established that the UV emission between 3.65 and $3.76 \mathrm{eV}$ correlates with high Al and Li concentrations. Pott and McNicol (1971), Itoh et al. (1988), and Luff and Townsend (1990) proposed that the $2.48 \mathrm{eV}$ band is caused by an impurity defect, but they give different answers about the kind of impurity. Itoh et al. (1988) assumed the $2.5 \mathrm{eV}$ emission band is extrinsic due to the substitutional incorporation of impurity ions; according to Pott and McNicol (1971) the intensity of the band is associated with $\mathrm{Mn}^{2+}$-defects, whereas Luff and Townsend (1990) showed that Ge-doped quartz exhibits a thermoluminescence band at $2.43 \mathrm{eV}$.

\section{$\underline{2.58 \mathrm{eV} \text { and } 2.68 \mathrm{eV} \text { emissions }}$}

The narrow $2.58 \mathrm{eV}$ emission and the $2.68 \mathrm{eV}$ and the $2.79 \mathrm{eV}$ bands show constant peak area ratios, i.e. $2.68 \mathrm{eV}: 2.58 \mathrm{eV}=1: 0.34 \pm 0.08$. The two emission bands are characterised by intensity decay during electron radiation and cause beside the $2.79 \mathrm{eV}$ emission the blue "flash" at initial electron radiation. Contrary to our findings, Gorton et al. (1996) suggested that the $3.26 \mathrm{eV}$ band is responsible for the high initial blue intensity that is visible as a blue "flash". The $2.68 \mathrm{eV}$ band was observed in crystalline quartz by Kalceff and Phillips (1995) who assume an association of the emission with a STE combined with an E' center. However, the occurrence of the two emissions in all investigated quartzes points to an intrinsic cause.

\section{$\underline{2.79 \pm 0.2 \mathrm{eV} \text { emission }}$}

This emission shows a strong intensity decay during the electron radiation and is mainly responsible for the blue "flash" during the first seconds of electron radiation. Heat treatment sometimes leads to the intensification of the blue emission band (Fig. 5.8; sample 14). Vein quartz showing an intense unstable $2.79 \mathrm{eV}$ emission has extremely high $\mathrm{Al}$ concentrations. However, no significant correlation between $\mathrm{Al}$ concentration and peak area has been found. According to Ramseyer and Mullis (1990) the blue luminescence is related to the positively charged interstitial cations $\mathrm{H}^{+}, \mathrm{Na}^{+}, \mathrm{Li}^{+}$and $\mathrm{K}^{+}$, which compensate $\mathrm{Al}^{3+}$. Ramseyer and Mullis (1990) show that areas with a high Al content (>1000 ppm Al) always exhibit unstable blue luminescence. This luminescence is absent for $\mathrm{Al}<50 \mathrm{ppm}$. However, they did not find a 
simple correlation between the $\mathrm{Al}$ content and CL intensity. The relative concentration of $\left[\mathrm{AlO}_{4}\right]^{0}$ centres in magmatic quartz show a positive correlation with the unstable component of the blue $2.79 \mathrm{eV}$ emission. This observation is in agreement with Nassau and Prescott (1975) who assumed that the $\left[\mathrm{AlO}_{4}\right]^{0}$ centre is associated with the emission band at $2.85 \mathrm{eV}$. The general absence of a significant correlation between the $\mathrm{Al}$ and the emission intensity of the $2.79 \mathrm{eV}$ band can explained by the occurrence of $\mathrm{Al}$ also in interstitial sites (Cohen, 1960) and/or in form of microinclusions lattice (Flicstein and Schieber, 1974; Blankenburg et al., 1994; Götze and Plötze, 1997). However, the decay of the blue $2.79 \mathrm{eV}$ emission can explained by radiation-induced release of interstitial cations accelerated by sample warming and charging. Possibly the emission is associated with charge compensating ions of substitutional $\mathrm{Al}^{3+}$.

Table 5.4 Detected CL emission bands of quartz and their possible association with trace elements and defect centres.

\begin{tabular}{|c|c|c|c|}
\hline $\begin{array}{l}\text { Position } \\
(\mathrm{eV})\end{array}$ & $\begin{array}{l}\text { Half width } \\
(\mathrm{eV})\end{array}$ & Association with trace elements & $\begin{array}{l}\text { Association with defect } \\
\text { centres }\end{array}$ \\
\hline $1.73 \pm 0.02$ & $0.3 \pm 0.02$ & Associated with Fe-defects (?) & - \\
\hline $1.84 \pm 0.01$ & $0.22 \pm 0.01$ & $\begin{array}{l}\text { Associated with structural water in form of } \mathrm{H}^{+} \text {, } \\
\mathrm{OH}^{-} \text {, and } \mathrm{H}_{2} \mathrm{O} \text { (especially the unstable } \\
\text { component) (?) } \\
\text { and partly associated with Al-defects and their } \\
\text { interstitial charge compensators }\left(\mathrm{H}^{+}, \mathrm{Li}^{+}, \mathrm{Na}^{+} \text {, }\right. \\
\left.\mathrm{K}^{+}, \mathrm{Fe}^{2+}\right)(?)\end{array}$ & Associated with $\mathrm{O}_{2}{ }^{3-}$ centres (?) \\
\hline $1.96 \pm 0.02$ & $0.22 \pm 0.02$ & $\begin{array}{l}\text { Associated with structural water in form of } \mathrm{H}^{+} \text {, } \\
\mathrm{OH} \text {, and } \mathrm{H}_{2} \mathrm{O} \text { (especially the unstable } \\
\text { component) } \\
\text { and partly associated with } \mathrm{Al} \text {-defects and their } \\
\text { interstitial charge compensators }\left(\mathrm{H}^{+}, \mathrm{Li}^{+}, \mathrm{Na}^{+} \text {, }\right. \\
\left.\mathrm{K}^{+}, \mathrm{Fe}^{2+}\right)\end{array}$ & Associated with $\mathrm{O}_{2}{ }^{3-}$ centres \\
\hline $2.15 \pm 0.02$ & $0.38 \pm 0.01$ & Associated with Mn-defects (?) & - \\
\hline $2.47 \pm 0.02$ & $0.30 \pm 0.03$ & Associated with Li-defects & Associated with Li-H defects \\
\hline $2.58 \pm 0.01$ & $0.18 \pm 0.005$ & - & Intrinsic defect (?) \\
\hline $2.68 \pm 0.01$ & $0.23 \pm 0.01$ & - & Intrinsic defect (?) \\
\hline $2.79 \pm 0.01$ & $0.26 \pm 0.01$ & $\begin{array}{l}\text { Associated with Al-defects and their interstitial } \\
\text { charge compensators }\left(\mathrm{H}^{+}, \mathrm{Li}^{+}, \mathrm{Na}^{+}, \mathrm{K}^{+}, \mathrm{Fe}^{2+}\right)\end{array}$ & Associated with $\left[\mathrm{AlO}_{4}\right]^{0}$ centres \\
\hline $2.96 \pm 0.015$ & $0.30 \pm 0.02$ & Associated with Ti-defect structures & $\begin{array}{l}\text { Associated with }\left[\mathrm{TiO}_{4} / \mathrm{Li}^{+}\right]^{0} \\
\text { centres }\end{array}$ \\
\hline
\end{tabular}




\section{$\underline{2.96 \pm 0.2 \mathrm{eV} \text { emission }}$}

This band represents the more stable part of the blue CL emission and is characteristic for rhyolitic quartz (sample 5, 15) as well as for granitic quartz (sample 7, 12, 14; Fig. 5.1, 5.3). A good correlation between the emission intensity and Ti distribution was found (Fig. 5.14). Heating at $600^{\circ} \mathrm{C}$ for $24 \mathrm{~h}$ results in the intensification (sample 15) as well as the creation (sample 1) of the $2.96 \mathrm{eV}$ band after (Fig. 5.8, 5.9).

Rink et al. (1993) observed thermoluminescence emission at 2.85-2.95 eV for magmatic quartz. Kalceff and Phillips (1995) assumed that the origin of the $2.95 \mathrm{eV}$ emission is possibly related to irradiation producing intrinsic defects. Koyama (1980) observed blue CL in carbon-

implanted $\mathrm{SiO}_{2}$. Like $\mathrm{Ti}^{4+}$ carbon enter the substitutional position in the $\mathrm{SiO}_{4}$ tetrahedra. Although the Ti content closely correlates with the $2.96 \mathrm{eV}$ emission, it is not clear whether $\mathrm{Ti}$ is a CL activator or sensitizer (Table 5.4). 


\section{Genetic significance of $C L$ structures and trace element distribution}

\subsection{Impurity uptake during quartz crystallisation in silicate melts}

The rhyolites (samples 4, 5, 10, 11, 15) as well as a number of the sampled granites (samples $6,7,8,14)$ contain euhedral quartz phenocrysts showing a CL-contrasted complex growth pattern (Fig. 5.11, 6.1, 6.2a-f, 7.6; Plate 1). The euhedral phenocrysts of granites are recognisable only by using CL because they are overgrown and embedded in a homogeneous anhedral quartz phase. The existence of euhedral quartz phenocrysts in granites showing CLcontrasted growth textures is currently not known to be common and was described in only a few cases (Frentzel-Beyme, 1989; Seltmann, 1994; D’Lemos et al., 1997; Müller and Behr, 1997). The questions arises if this granitic phenocrysts are comparable phenocrysts occurring in rhyolites and if they represent a similar crystallisation environment.

A main result of the trace element analysis is that the stable blue CL of the phenocrysts correlates with high $\mathrm{Ti}$ concentrations and that the variation of $\mathrm{Ti}$ is mainly responsible for the contrasting of the magmatic zoning of the quartz phenocrysts (see chapter 7 and 9). Caused by its high field strength $(\mathrm{F}=1.04) \mathrm{T}^{4+}$ can substitute $\mathrm{Si}$ only at high temperatures. High $\mathrm{Ti}$ concentrations in macroscopically rutile-free quartz generally indicate formation temperatures $=500^{\circ} \mathrm{C}$ (Blankenburg et al., 1994). High Ti concentrations are also typical for quartz in granulites (Kerkhof and Müller, 1999). To understand the variation of the Ti concentration in quartz phenocrysts the growth textures were classified according their structure. The classification of growth zoning is necessary to distinguish between zoning caused by selforganised growth and zoning caused by physico-chemical changes of external factors such as temperature, pressure and magma composition (e.g. Bottinga et al., 1966; Allègre et al., 1981; Shore and Fowler, 1996). The zoning caused by external factors is of great interest for the reconstruction of the crystallisation history of felsic melts (magma storage, ascent, mixing, emplacement, and cooling rate) which will applied in the in the chapters 7-10. 

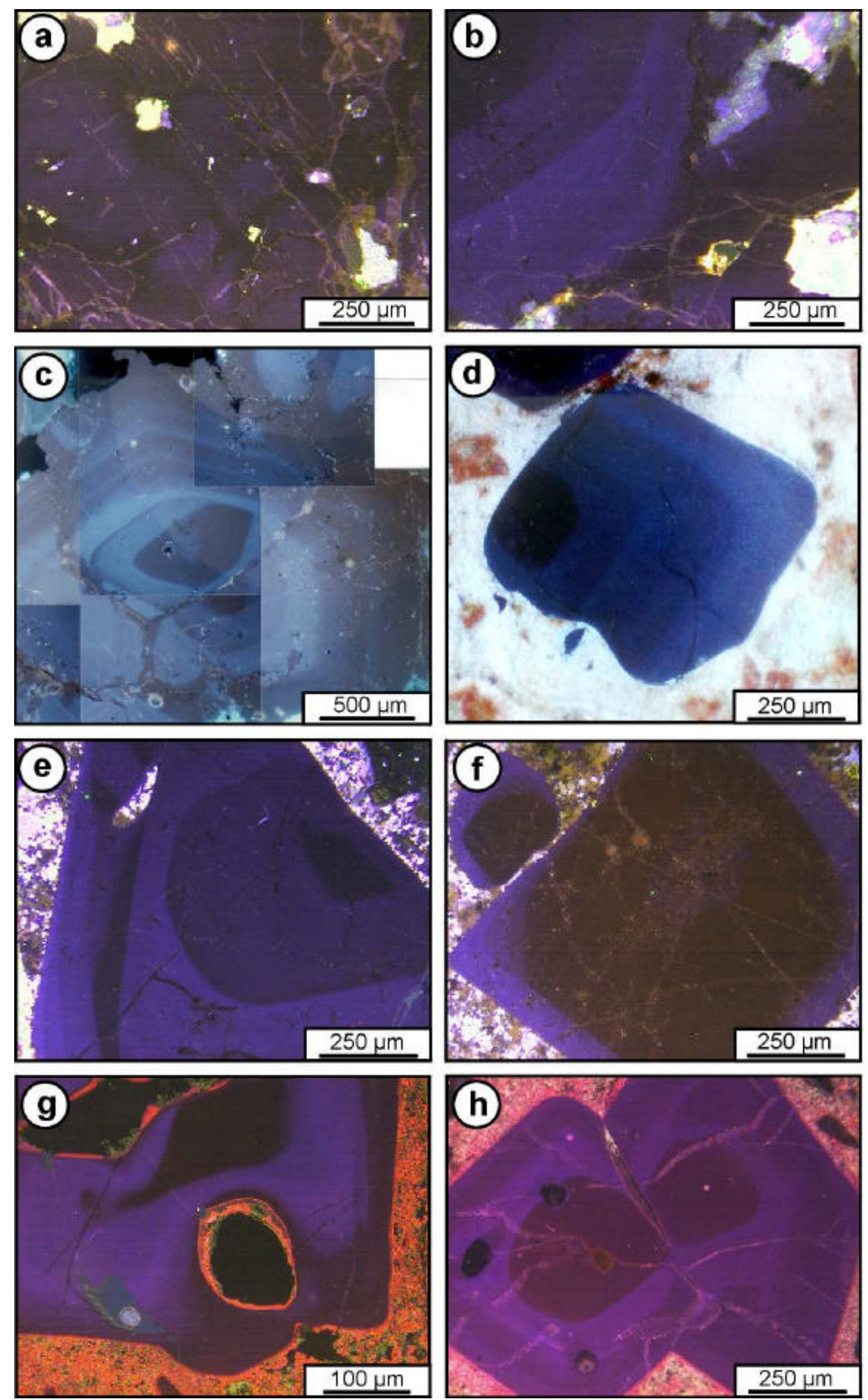
Plate 1 CL images of magmatic quartz. a - Quartz of the Flossenbuerg Granite (sample 12) showing a weak red-brown CL and a dense network of healed cracks. b - Edge of a zoned quartz phenocryst with blue CL overgrown by red-brown luminescent matrix quartz (Schellerhau Granite, sample 6). c - Quartz phenocryst of the Schellerhau Granite with complex growth pattern overgrown by red-brown luminescent anhedral matrix quartz. d - Zoned quartz phenocryst of the Teplice Rhyolite (sample 5). Resorption of the phenocryst surface causes the truncation of pre-existing growth zones. Note the small quartz fragments around the phenocryst which indicate a mechanical abrasion during transport in the melt. e - Zoned quartz phenocryst of the Teplice Rhyolite. f - Zoned quartz phenocryst of the Teplice Rhyolite with red-brown luminescent core. g - Edge of a zoned quartz phenocryst of the Weinheim Rhyolite (sample 15) with a melt inclusion. The zoning fits the shape of the melt inclusion (black with red rim). h - Zoned quartz phenocryst twin of the Weinheim Rhyolite which exhibits resorpted red-brown luminescent cores, melt inclusions (black), and healed cracks (pink lines).
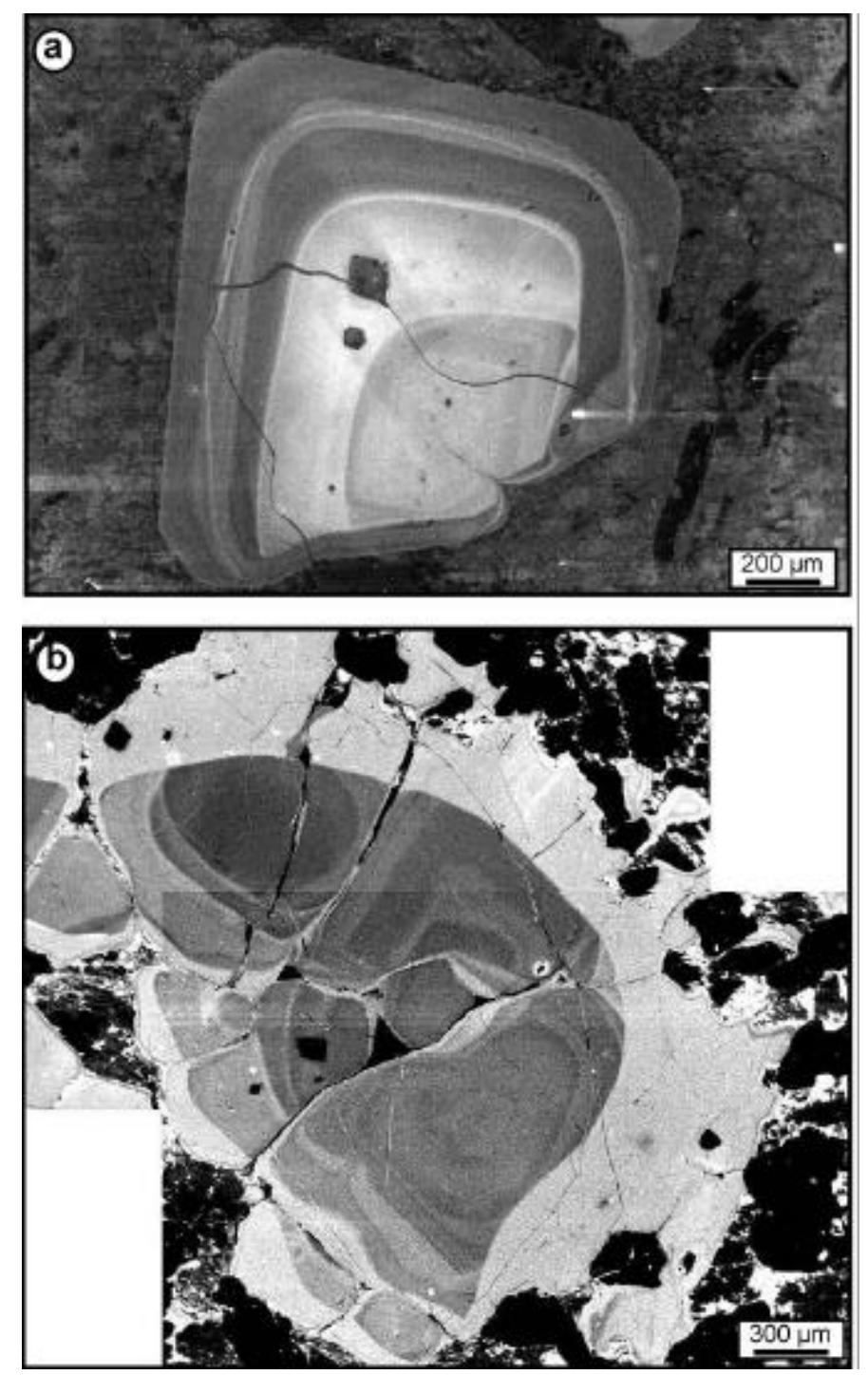

Fig. 6.1 CL images of rhyolitic quartz phenocrysts recorded with a JEOL CLD40 R712 detector. a - Phenocryst from the Weinheim Rhyolite (sample 15). b - Phenocryst from the Beucha Rhyolite (sample 11). Note the anhedral, unzoned, bright quartz phase which overgrows the resorpted core with complex zoning pattern. 

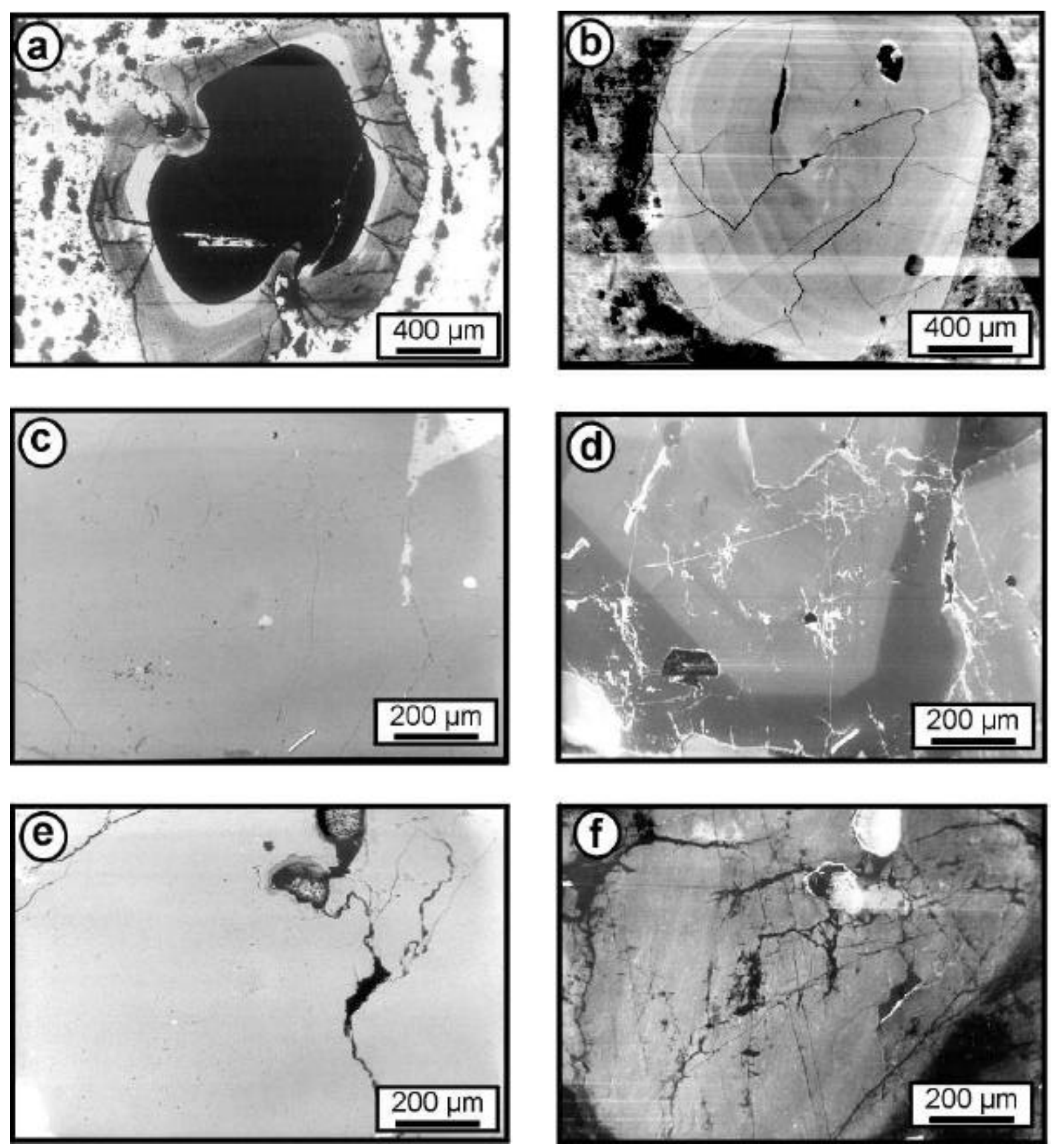

Fig. 6.2 CL and BSE images of magmatic quartz. The CL images were recorded with the S20 Extended detector. a - Phenocryst of the Wachtelberg Rhyolite showing a red-brown, Ti-depleted core. b - Phenocryst of the Schoenfeld Rhyolite with bright blue CL. c - BSE image of quartz in the Eibenstock Granite. d - CL image of the same area as (c) showing an euhedral zoned core overgrown by an anhedral, red luminescent quartz phase without zoning. The CL intensity of secondary quartz have been turned from low CL intensity to high CL intensity after 5 min electron radiation (bright patchy areas within the crystal). e - BSE image of quartz in the Ramberg Granite. f - CL image of the same area as (e) showing a very weakly contrasted phenocryst (bright) with faint growth zoning. The granitic quartz in figures $\mathrm{d}$ and $\mathrm{f}$ exhibits a number of secondary CL structures. 
The development of growth zoning during magmatic crystallisation is described by a number of models (e.g. Sibley et al., 1976; Anderson, 1984; Fowler, 1990) that have been derived from the growth zoning of plagioclase. We apply these models to the crystallisation of magmatic quartz having a very similar growth zoning as plagioclase. Below an interpretation of growth textures in quartz phenocrysts is given, based on our observations and the present level of knowledge, to explain the variations of impurity uptake in magmatic quartz. The compilation of growth textures is illustrated in Fig. 7.1 (chapter 7).

During crystallisation of a mineral four processes are competing and the overall growth ratecontrolling process is the slowest one: 1) the reactions occurring at the crystal-melt interface, 2) the bulk diffusion of components in the melt close to the interface, 3) the production and dissipation of the latent crystallisation heat at the interface, and 4) the relative flow of the melt with respect to the interface. The latter two are not critical since heat diffusivities are one to several orders of magnitude higher than mass diffusivities (Dowty, 1980) and the crystal settling effects in a magma chamber are small for viscous silicate melts. Therefore, processes 1) and 2) control are the main parameters controlling the crystal growth rate. A crystal can grow only if the thermodynamic variables for the formation of that phase exceed the equilibrium conditions. This overstepping (undercooling, overheating, supersaturation) provides energy by which nuclei are formed and crystal growth is sustained. The nuclei provide sinks to which the crystallising components diffuse. The distance over which elements are transported by diffusion depends on the diffusion rate and time.

The microscopic topography of individual growth zones is a relic crystal-melt interface and is indicative for disturbances of growth and diffusion rates during crystallisation. These parameters depend on the melt composition, crystal transport in the melt (e.g., convection), the ascent velocity of the melt, and pressure- and temperature variations. These criteria regulate the type and quantity of trace elements, few of which are CL-activators. Thickness and frequency of the zones are directly related to the physical and chemical melt properties. The diffusion rate in the melt controls the compositional variation and width of the zoning. The higher the diffusion rates, the less are the compositional differences in trace element content in the quartz. Concentration gradients develop in the melt when the growth rate exceeds the diffusion rate, and in the solid when the reaction rate of crystals with the liquid is lower than the growth rate (Sibley et al., 1976). The development of growth zoning during magmatic crystallisation was described by a number of models (e.g. Sibley et al., 1976; Anderson, 1984) that have been derived from the zonal structure of plagioclase. We apply 
these models to the crystallisation of magmatic quartz, which shows very similar zonal growth as plagioclase.

Major discontinuities in the zoning (50 - $1000 \mu \mathrm{m}$ width) being non-periodic and showing a significant change of the luminescence colours result in physico-chemical changes of external factors ("extrinsic" according to Shore and Fowler, 1996) such as temperature, pressure and magma composition (Bottinga et al., 1966; Allègre et al., 1981). Bottinga et al. (1966) defined the non-periodic zones as compositional zoning, and Allègre et al. (1981) called them stepped zoning. Depending on the type of the physico-chemical change (degassing, magma mixing or ascent) the trace element concentrations, mostly represented by variations of $\mathrm{Ti}$ and sometimes of $\mathrm{Al}$, show an abrupt change (see chapter 7).

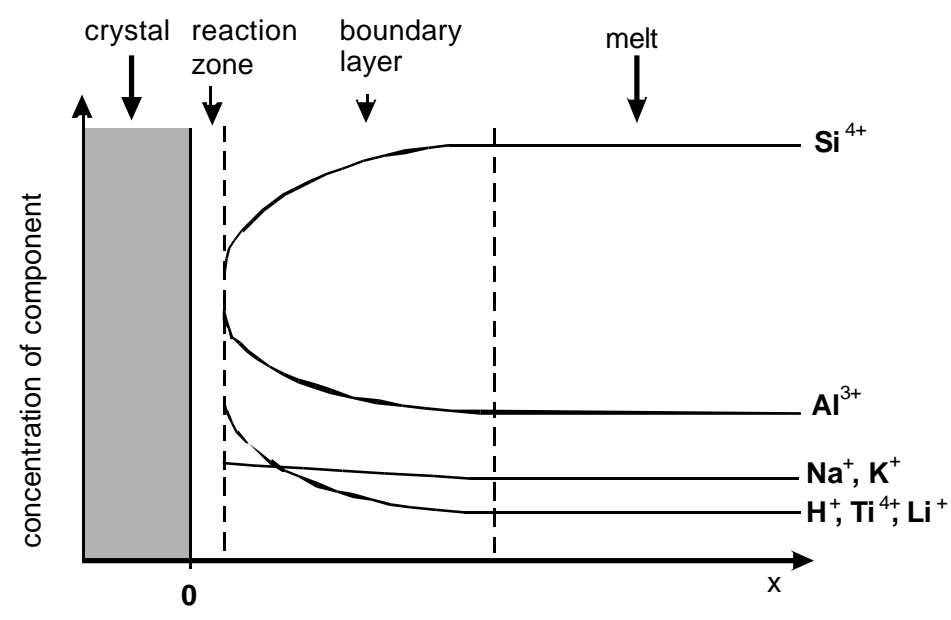

Fig. 6.3 Model system showing schematic concentrations of relevant species versus distance from the surface of quartz crystal in melt. The very low $\mathrm{Na}^{+}$and $\mathrm{K}^{+}$ gradient is due to its high diffusion coefficient (after Hess 1989).

The fine oscillatory zoning ( 2 - $20 \mu \mathrm{m}$ width) within the step zones can be explained by a selforganised ("intrinsic" according to Shore and Fowler, 1996) diffusion-controlled mechanism on the crystal-melt boundary layer and plays a role exists in a number of models proposed by several authors (Sibley et al., 1976; Haase et al., 1980; Allègre et al., 1981; Loomis, 1982; Simakin, 1984; Pearce, 1993). Oscillatory growth zones form very slowly, at low degrees of undercooling and oversaturation under near-equilibrium conditions. This is possible only when the crystallising system on the solid-liquid interface is not disturbed, i.e. thus the melt should not convect (Allègre et al., 1981). The self-organisation in the crystal-melt reaction zone and boundary layer can be explained by the following model (e.g. Allègre et al., 1981; Fig. 6.3): Saturation of silica in the reaction zone increases the quartz growth rate. The increasing growth rate results in the decrease of silica concentration if the growth rate exceeds the diffusion rate of silica. Simultaneously, quartz-foreign elements are accumulated in the reaction zone and boundary layer. The high growth rate favours the incorporation of impurities due to the change of planar to the cellular interfaces with rather high specific free 
energy. The growth rate will slow down when quartz growth is so fast that silica becomes depleted in the reaction zone and boundary layer. Consequently, the diffusion rate becomes the dominant crystal growth controlling process. The growth rate starts to rise again as soon as the silica in the reaction zone has been recovered. Investigations on natural plagioclase by Greenwood and McTaggart (1957) and Wiebe (1968) confirm that oscillation zones of crystals grown from the same melt and formed by self-organising character of processes cannot be correlated. Physical or chemical changes in the bulk magma are not required to develop oscillation zones. The self-organised growth causes only slight variations of $\mathrm{Ti}$ upatke.

Wavy surfaces are sometimes observed between the straight-bordered growth zones. They are characterised by convex inlets which are opposed to the growth direction. In contrast to resorption surfaces which are resulted in sharp truncation of the regular zoning and rounded crystal corners (e.g. Shore and Fowler, 1996) the inlets of the wavy surface are much smaller and extend maximal $20 \mu \mathrm{m}$ in the growth zones and do not cut older zones or round-off corners. The subsequent growth zones are rectilinear bordered again and parallel to the euhedral crystal habit. This feature is in contrast to the wavy zoning which is described for plagioclase by Pearce and Kolisnik (1990), where the subsequent growth zones keep the wavy structure. The wavy zones of quartz are interpreted as a small scale diffusion front caused by rapid variation of the melt temperature and/or composition leading to changes of CL properties developed during crystal growth.

Discussions about the distinction of resorption surfaces and growth impediments in quartz phenocrysts have been controversial (Kozlowski, 1981; Harris and Anderson, 1984). Laemmlein (1930) first recognised and described lobate depressions at the quartz crystal surface as growth impediments. This result is in accordance with our CL observations which show clearly that the zoning around lobate depressions, mineral-, and melt inclusions adapts to the shape of the impediments. In contrast, resorption surfaces cut pre-existing growth zones. Growth impediments are caused by immiscible liquids, vapor bubbles, molten sulfide or fluid-rich melt droplets which stick on the crystal surface, hinder the crystal growth and result in lobate depressions and entrapments (Kozlowski, 1981; Donaldson and Henderson, 1988; Lowenstern, 1995). The resorption (melting) of quartz surfaces is due to $\mathrm{SiO}_{2}$ undersaturation of the melt that may be caused by increase in temperature, isothermal depressurisation or magma mixing. Crystals may undergo rounding due to chemical interaction (melting) and mechanical abrasion during transport in the melt. The occurrence of resorption which results in strong rounding of the quartz crystals is in accordance with the 
rapid ascent of granitic melts by dyke formation as found by Holtz and Johannes (1994) and Johannes and Holtz (1996).

The presence of skeletal (dendritic) growth indicates supercooling and the consequent decrease of the diffusion/growth rate. Here, the compositional gradient on the crystal-melt interface develops, but the planar crystal-melt interface becomes unstable and changes to cellular and dendritic growth. This type of crystal growth results in skeletal (dendritic) crystal morphologies (Kirkpatrick, 1981; Fowler, 1990).

The growth pattern in rhyolitic and granitic quartz phenocrysts are similar indicating a similar crystallisation environment. Flick $(1984 ; 1987)$ describes rhombohedral a-quartz phenocrysts from the Weinheim Rhyolite (sample 15). Assuming a typical solidus of a rhyolitic melt of $900-950^{\circ} \mathrm{C}$, a crystallisation pressure of at least 13 kbar is necessary for a-quartz crystallisation (Flick 1987). This pressure corresponds with a formation depth of phenocrysts in this rhyolite of about $40 \mathrm{~km}$ assuming a geothermal gradient of $20 / 25^{\circ} \mathrm{C} / \mathrm{km}$. Thomas (1992) calculated the depth of quartz phenocryst crystallisation of granites of the Erzgebirge (e.g. Eibenstock Granite) of up to $21 \mathrm{~km}$ provided by microthermometric studies of silicate melts. Our observations and the two calculations of the crystallisation depth show that euhedral quartz phenocrysts in rhyolites as well as granites exhibiting blue CL-contrasted growth zoning represent a low to mid-crustal crystallisation environment.

Like shown above except for the oscillatory zoning all growth textures are caused by physicochemical changes of external factors such as temperature, pressure and magma composition which result in the abruptly change of Ti concentration. In $\S 9.8$ is shown that the Ti content in quartz phenocrysts increases with increasing growth rate. Quartz phenocrysts frequently show a Ti depletion in the red/red-brown luminescent crystal core (sample 5, 6, 10, 15) indicating a slow growth rate during the early crystallisation stage (Fig. 6.2a).

\subsection{Impurity uptake during quartz crystallisation in aqueous solution}

Hydrothermal quartz shows similar growth patterns as magmatic quartz but the compositional zoning is more dominant than the self-organised oscillatory zoning. This indicates crystallisation in a more frequently disturbed (open) system. Resorption (solution) surfaces observed in magmatic quartz and cutting pre-existing growth zones do not occur in hydrothermal quartz. This observation can be explained by the low solubility of $\mathrm{Si}_{2} \mathrm{O}$ in water which results only in weakly resorbed (solved) crystal surfaces that can not be distinguished 
from unsolved surfaces. A matter of discussion is, if a crystal surface represents generally a solution surface. A characteristic feature of hydrothermal quartz is the so-called sector zoning (e.g., Siebers, 1986) which has been not observed in magmatic quartz.

As shown in chapter 6 the contrasted zoning of hydrothermal quartz was explained by the distribution of Al-defects. Therefore, the present discussion focuses on the incorporation and distribution of $\mathrm{Al}^{3+}$ (and to lesser extend also $\mathrm{Fe}^{3+}$ ) and their charge compensating ions $\mathrm{Li}^{+}$, $\mathrm{H}^{+}, \mathrm{Na}^{+}, \mathrm{Fe}^{2+}, \mathrm{K}^{+}$. Ti, which may cause CL zoning of magmatic quartz phenocrysts is nearly absent in hydrothermal quartz. This can be explained by the following considerations: 1) The high field strength of $\mathrm{T}_{1}^{4+}$ allows the to substitution of $\mathrm{Si}^{4+}$ only at temperatures $>500^{\circ} \mathrm{C}$ (Blankenburg et al., 1994), 2) the supply of Ti is very low in natural hydrothermal solutions, and 3) the uptake of Ti of $>50 \mathrm{ppm}$ is limited by the stability PT-field of the a-quartz.

Generally, the incorporation of trace elements in hydrothermal quartz depends on the growth direction, growth velocity, the solution chemistry, and the crystallisation pressure and temperature (Brown and Thomas, 1960; Cohen, 1960; Bambauer, 1961; Poty, 1969; Siebers et al., 1984; Siebers and Klapper, 1984; Siebers, 1986; Pankrath 1988). The quartz growth kinetic in an aqueous solution is similar to the processes in silicate melt and can be divided into 5 stages:

1) Solution of silica in the form of complexes

2) Transport of the complexes into the crystal boundary layer and reaction zone of the growing crystal by diffusion and convection

3) Dissociation of the complexes, and adsorption of the complex components on the crystal surface; desorption and removal of water and quartz-foreign elements from the reaction zone

4) Surface diffusion of the components to energetically favourable places

5) Incorporation (reaction) into the crystal and diffusion of the reaction heat.

In order to understand the processes in the crystal-fluid reaction zone and boundary layer in aqueous solutions Siebers (1986) proposed the following model: At the crystal surface a equilibrium develops between diffusion and boundary layer processes (Fig. 6.4). The thickness of the boundary layer depends on the diffusion coefficient of the reaction partners at the crystal surface. The thermal diffusion coefficient of the heat which is produced in the reaction zone is much higher than the diffusion coefficients of the substances. Therefore, the reaction heat does not effect reaction and growth processes. The oversaturation of the reaction partners increases with the distance from the reaction zone. The concentration gradient in the boundary layer is the driving force of the reaction and growth rate. Therefore, the height of 
growth mounds at the basis c (0001) corresponds to the thickness of the boundary layer which can reach several millimetres (Jackson, 1979). In comparison to the crystal-melt interface the crystal-liquid interface is generally more sensitive for concentration variations than temperature variations (Siebers, 1986).

Precondition for impurity incorporation in quartz is that the impurity element is dissolved in the aqueous solution as a complex which can be transported. The dissolution rate and the ability of forming complexes depend on the element concentration of the solution, the pressure, temperature, redox potential, and $\mathrm{pH}$ (e.g. Siebers, 1986). Al can be fixated on the quartz surface if it is represent as aqueous tetrahedrally coordinated species $\left[\mathrm{Al}(\mathrm{OH})_{4}\right]^{-}$ (Merino et al., 1989). This species occurs in aqueous solutions with $\mathrm{pH}>5$ (for $=100^{\circ} \mathrm{C}$ ). According to Merino et al. (1989) and Pankrath (1988) high amounts of Al (>2000 ppm), Li, $\mathrm{Na}$ and low $\mathrm{H}$ concentrations in hydrothermal quartz may result from crystallisation in a high$\mathrm{pH}$ aqueous solution. These authors assumed that the $\mathrm{pH}$ of the solution is beside the crystal growth rate the main controlling factor in the uptake of $\mathrm{Al}$ and responsible for the large variation of $\mathrm{Al}$ in hydrothermal quartz.

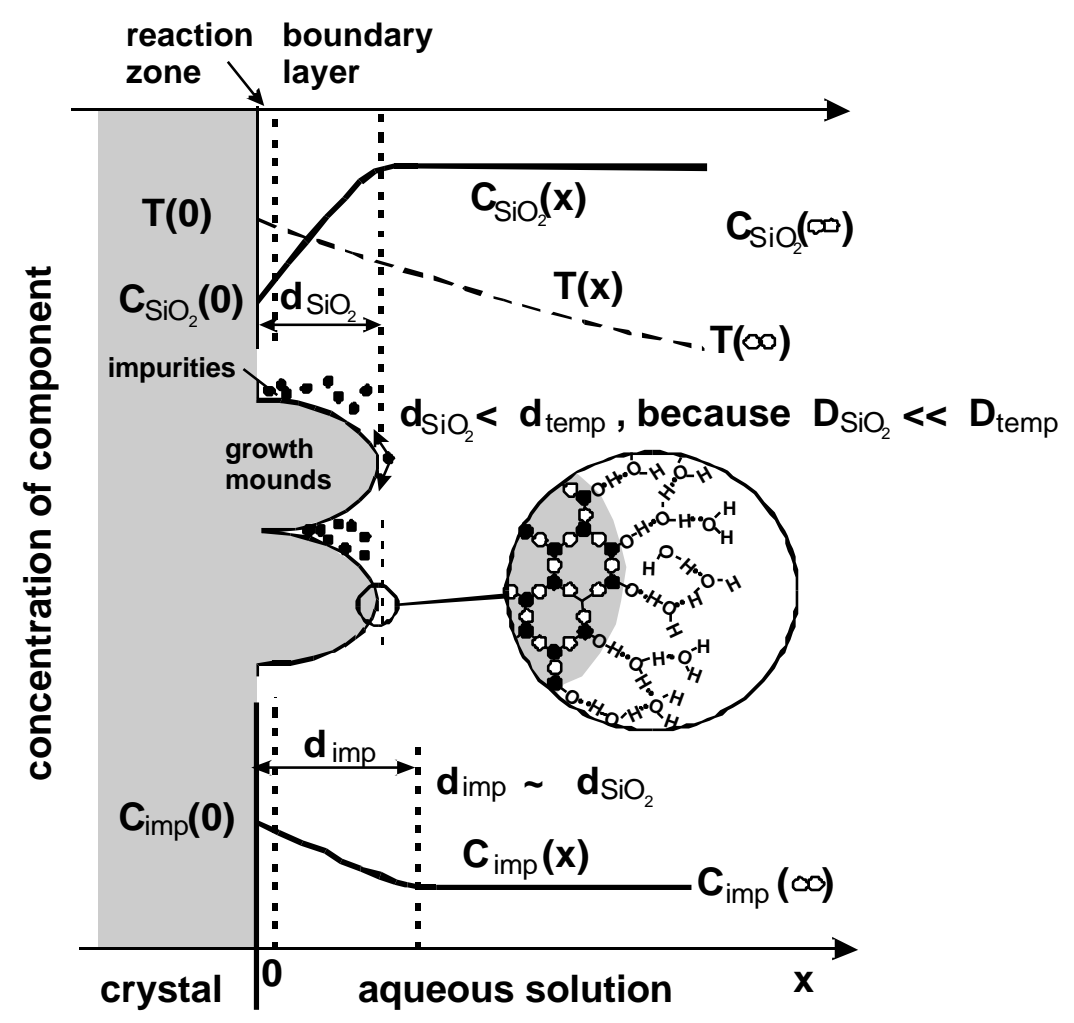

Fig. 6.4 Model system (modified after Siebers 1986) showing schematic concentrations c of relevant components versus distance from the surface of quartz crystal in solution during diffusion-controlled growth. The relative thickness of the boundary layer $\mathrm{d}$ of component is controlled by its diffusion coefficient $\mathrm{D}$. The development of growth mounds favours the impurity segregation. The sketch in the cycle show the idealised crystal-fluid reaction zone in pure water. 
The Al concentration of the hydrothermal quartz (sample 9) differs between the rhombohedral faces z ( 4500 ppm) and r ( 3300 ppm). The different Al concentrations of different growth directions cause the sector zoning observed by CL (Fig. 6.11c). The probability of $\mathrm{AP}^{3+}$ uptake is controlled by different crystal structural and crystal chemical properties of the surfaces of the growing crystal. For these different surfaces, the probability of $\mathrm{Al}$ uptake is higher for $\mathrm{z}$ (0111) faces and lower in r (1011) faces. According to the Periodic-Bond-Chain (PBC) theory after Hartmann (1978) the crystal faces of quartz can be distinguished into K-(kinked) and F(flat) faces. Atomic flat F-faces are the m (1010), r (1011), and z (0111) faces. The basis c (0001) is an atomic rough K-face. The PBC theory can not differentiate between the surfaces of $\mathrm{r}$ (1011) and $\mathrm{z}$ (0111). The K-face is more reactive because of the high number of free bonds. At this face foreign ions are preferably adsorbed. The F-faces remains flat during higher growth rate whereas the roughness of the K-face c (0001) increases. An increasing growth rate results in a drastic increase of the impurity uptake at the rough K-face c (0001) (e.g., Martin and Armington, 1983). The increase of Al uptake on the F-face z (0111) with increasing growth rate occurs at temperatures above $400^{\circ} \mathrm{C}$. Below $400^{\circ} \mathrm{C}$ the relationship between Al uptake and growth rate becomes inverted (Tsinober and Kamentsev, 1964; Rumyantsev and Novozhilov, 1980). Siebers (1986) proofed that the impurity concentration decreases from c (0001), m (1010), r (1011), to z (0111). The PBC theory cannot explain the different distribution coefficients of foreign ions at $\mathrm{m}$ (1010), $\mathrm{r}$ (1011), and z (0111). The distribution coefficient of foreign ions on the different faces depends also on the growth rate, temperature, degree of saturation, and growth mechanism (Siebers, 1986). The compositional differences between $\mathrm{F}$ and $\mathrm{K}$-faces disappear at higher temperatures near the solidus. During high temperature crystallisation the crystal-fluid interface undergoes a drastic increase of roughness. Close to the melting temperatures all faces becomes rough and take up foreign ions in similar portions. That explains why sector zoning is not observed in magmatic quartz. The extremely high Al in hydrothermal quartz up to $5000 \mathrm{ppm}$ (sample 9) gives reason to assume that $\mathrm{Al}$ is not only structurally incorporated, but also as impurity clusters or inclusions (Flicstein and Schieber, 1974; Blankenburg et al., 1994). Götze et al. (1999) showed that the content of bulk trace $\mathrm{Al}$ is higher than the structurally incorporated $\mathrm{Al}$ calculated from saturated paramagnetic Al centres. Mullis and Ramseyer (1999) determined up to $12000 \mathrm{ppm}$ $\mathrm{Al}$ in fissure quartz form the Alps. Caused by the larger ion radius of $\mathrm{AP}^{3+}$ in comparison to $\mathrm{Si}^{4+}$ such high amounts of structurally incorporated $\mathrm{Al}^{3+}$ should cause an extreme deformation and weakening of the quartz lattice. Pfenninger (1961) described impurity entrapment in the form of micro-inclusions and gave the following explanation: The oversaturation of silica 
results in diffusion-controlled crystal growth and higher growth rates. At these rates the surface diffusion is too low to organise a planar face growth and cellular growth becomes dominant. Cellular growth results in the development of defect channels which may be filled with foreign elements. These defect channels, 20 - $50 \mathrm{~nm}$ in diameter, are parallel to the c-axis and surrounded by disordered $\mathrm{SiO}_{2}$ boundary layers (Fig. 6.5). They start to grow at the structural channels due to the stepwise bond lacking between the tetrahedra. The competition between impurity segregation and lateral diffusion results in a broadening of the defect channels which finally may result in dendritic growth.

The dynamics of processes at the atomic boundary layer (4-6) are not fully explained, because the structure of the quartz surface is unknown. It has been assumped that free bonds of the surface oxygen are compensated by $\mathrm{H}^{+}$(e.g., Anderson and Wickersheim 1964, Gallei and Parks 1972, Kuznetsov and Lobachev 1973). $\mathrm{H}_{2} \mathrm{O}$ is removed during the uptake of dissolved $\mathrm{SiO}_{2}$ complexes. The $\mathrm{Si}-\mathrm{OH}$ bond layer is followed by polymolecular adsorbed $\mathrm{H}_{2} \mathrm{O}$ molecules (Fig. 6.4). This "quasi-crystalline" layer interacts with the dissolved complexes.

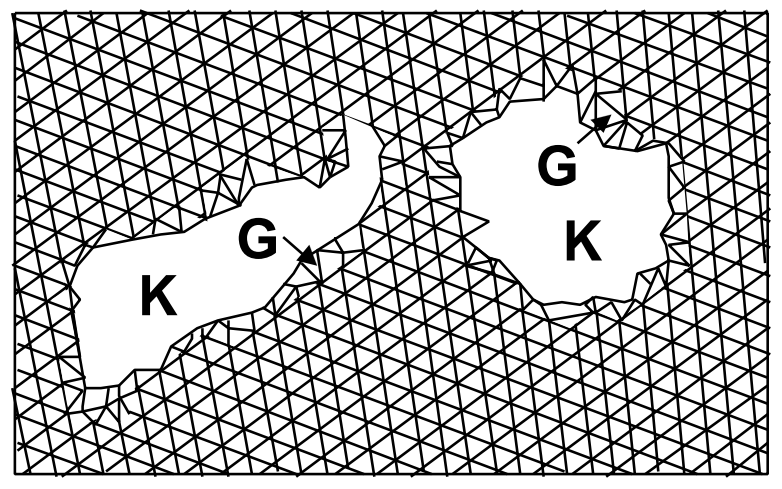

Fig. 6.5 Idealised model of hollow defect channels $\mathrm{K}$ and the disordered boundary layer $\mathrm{G}$ according to Pfenninger (1961). Section vertical to c-axis.

The criteria which control the uptake of $\mathrm{Al}^{3+}$ and $\mathrm{Fe}^{3+}$ and its charge compensating ions $\mathrm{Li}^{+}$, $\mathrm{H}^{+}, \mathrm{Na}^{+}, \mathrm{Fe}^{2+}, \mathrm{K}^{+}$into the lattice of hydrothermal quartz can be summarised as follows:

1) Impurity concentration differs systematically between growth directions and decreases from c (0001), m (1010), r (1011), to z (0111).

2) The increase of the growth rate stimulates the impurity uptake at the K-face c (0001). This is valid only at temperatures $>400^{\circ} \mathrm{C}$ for the F-face $\mathrm{z}(0111)$. Below $400^{\circ} \mathrm{C}$ the impurity concentration decreases with increasing growth rate.

3) Impurity uptake is controlled by the $\mathrm{pH}$ of the aqueous solution. High $\mathrm{pH}(=5)$ of an aqueous solution results in high $\mathrm{Al}$ concentrations in quartz.

4) The presence of the charge compensating ions $\mathrm{H}^{+}, \mathrm{Li}^{+}, \mathrm{Na}^{+}$, and $\mathrm{K}^{+}$stimulates the $\mathrm{Al}^{3+}$ and $\mathrm{Fe}^{3+}$ uptake. 
Dennen et al. (1970) proposed a geothermometer based on the incorporation of $\mathrm{Al}$ in hydrothermal quartz as a function of the formation temperature. However, the multiple criteria which control the $\mathrm{Al}$ uptake show that the $\mathrm{Al}$ concentration cannot be directly used as a geothermometer.

\subsection{Secondary CL structures and processes resulting in modification of defect centres}

Quartz may show a number of secondary structures made visible in CL which formed after growth of the host crystal by retrograde processes. The secondary CL structures are principally formed by a number of processes: 1) micro-cataclasis followed by healing (dissolution-precipitation), 2) diffusion, and 3) a-radiation. These processes result in the modification of defect centres in the quartz lattice or in the formation of new quartz. The secondary structures may show reduced or lower defect centre contents or reversely defect centres are induced. The secondary CL structures have been grouped according their defect centre content.

\section{Secondary CL structures with reduced defect centres}

Secondary structures with reduced defect centre content are healed veinlets, healed irregular domains, and patchy halos of secondary quartz around fluid inclusions. They are distinguished by weak red-brown or no CL. This weak CL is indicative of lower contents of activator elements and/or intrinsic defects.

Trans-granular veinlets and irregular domains of up to several hundreds micrometres wide have been observed. The veinlets are completely healed, or they contain fluid inclusions. Some samples (Megaquartz, Schellerhau Granite) show different veinlet generations of (Fig. 6.6e, f). Thin concentric and radial, healed micro-cracks are typical for rhyolitic quartz phenocrysts (Fig. 6.2a, b). In this case the cracks are interpreted as thermally induced contraction cracks formed due to rapid cooling during effusion. Dissolution-precipitation (healing) results in veinlets and domains of secondary quartz along micro shear zones, grain edges, grain and subgrain boundaries $(\S 10.7)$. 

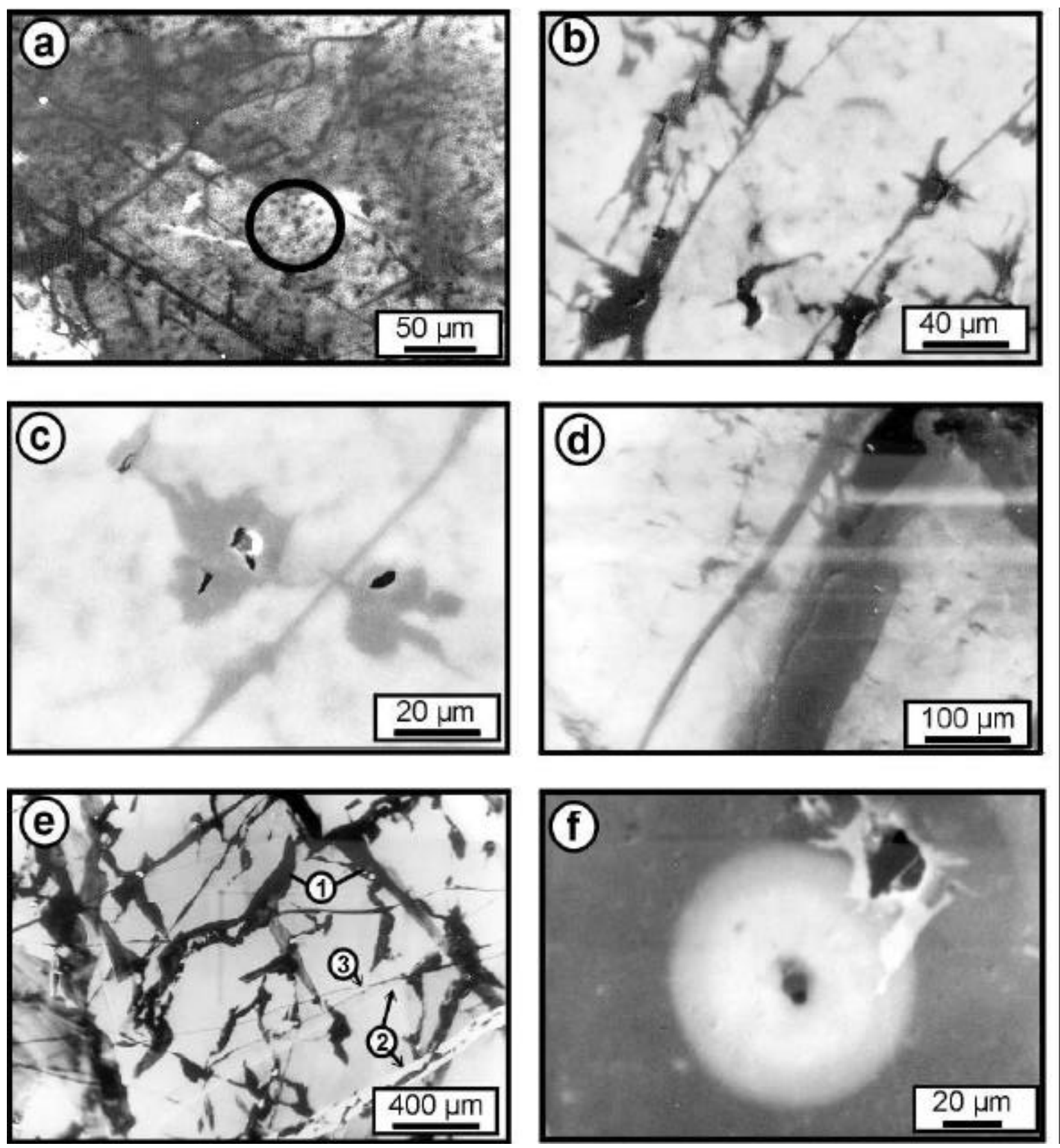

Fig. 6.6 SEM-CL images of secondary CL structures in quartz. a - Non-luminescent spots (easily visible in the cycle) in quartz of the Flossenbuerg Granite. b - Patchy halos of secondary quartz around fluid inclusions connected by sub-parallel healed micro cracks (Flossenbuerg Granite). c - Combination of SEM-CL and BSE images showing the residual porosity of the former fluid inclusions (black "holes"; Flossenbuerg Granite). d Healed veinlet in the quartz of the Sunset Hills Granite/Lachlan Fold Belt (see chapter 10). The wider veinlet is not completely healed. e - The hydrothermal megaquartz shows a dense network of healed cracks and domains of different ages. Three populations can be distinguished: 1) healed domains with weak CL following fluid inclusion trails. 2) Bright luminescent, linear trails some of which overprint the population (1). 3) Linear, thin cracks healed with weak luminescent quartz. f - Light circular halo around a zircon. The radius of halo is $\sim 40$ $\mu \mathrm{m}$. The halo is subdivided into a brighter inner zone $(\sim 25 \mu \mathrm{m})$ and a outer zone $(\sim 15 \mu \mathrm{m})$ (Schellerhau Granite). 
Particularly in quartz formed at high temperatures patchy halos of secondary quartz around fluid inclusions were observed. These and similar structures have been observed since about one decade (Frentzel-Beyme, 1989; Behr, 1989; Kerkhof and Müller, 1999). In the following part the characteristics and formation mechanics of the halos are discussed in more detail. The understanding of the formation of this structures is important for the interpretation of fluid inclusion data. Magmatic quartz crystals typically contain red to red-brown luminescent, patchy halos of secondary quartz around fluid inclusions, connected by healed sub-parallel trans-granular micro-cracks of $<5 \mu \mathrm{m}$ wide (Fig. 6.6c). This structures are frequent in granitic quartz and less common in rhyolitic phenocrysts. The secondary quartz has the same crystallographic orientation as the host quartz indicating. The CL intensity of the secondary quartz increases during 2-10 min electron radiation using high beam power densities $>10^{+4}$ $\mathrm{W} / \mathrm{cm}^{2}$ (Fig. 6.2d). The halos of secondary quartz are depleted in trace elements ( $\mathrm{Li}, \mathrm{Al}, \mathrm{K}$, and $\mathrm{Ti}$ ) compared to the host quartz (see $\S 10.7$ ). Sometimes, the host crystal around the secondary quartz is enriched particularly in Fe and $\mathrm{Ti}$ (Fig. 5.11c). These elements are probably released from the secondary quartz.

Decrepitation experiments of fluid inclusions with halos of secondary quartz showed that they hold anomalously high fluid pressures on heating (Müller, 1995). Bodnar et al. (1989) showed that the internal pressure required to initiate decrepitation of fluid inclusions in quartz is inversely related to inclusion size according to the equation: internal pressure $(\mathrm{kbar})=4.26$ • $\mathrm{D}^{-0.423}$, where $\mathrm{D}$ is the inclusion diameter in microns. Figure 6.7 shows this relationship between decrepitation pressure and fluid inclusion diameter (line) within a range (hatched area) after Bodnar et al. (1989). The data measured for the pegmatite quartz of Pleystein and Kreuzstein and Pfahl quartz (Oberpfalz, Germany) plot in the hatched area. On the other hand the data of the Rozvadov Granite (Oberpfalz, Germany) show extremely high decrepitation pressures. The fluid inclusions of this rock exhibit halos of secondary quartz, whereas the pegmatites and Pfahl quartz do not.

The specific features of secondary quartz around fluid inclusions allow us to establish a model for the mechanism of fluid inclusion decrepitation and modification, whereby three stages can be distinguished (Fig. 6.8). 


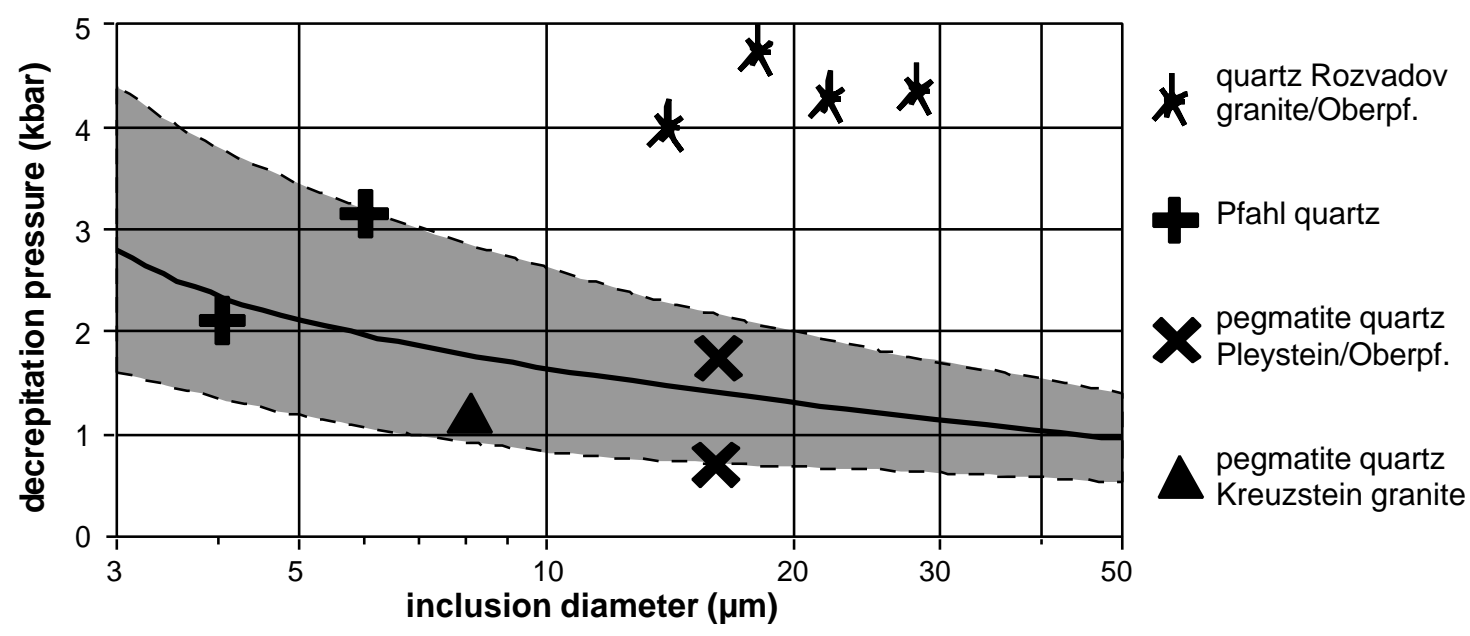

Fig. 6.7 Relationship between decrepitation pressure and inclusion diameter after Bodnar et al. (1989). According to Bodnar et al. (1989) data should plot in the hatched area like the fluid inclusions of the pegmatites and the Pfahl quartz form the Oberpfalz/Germany. The fluid inclusions in the quartz of the Rozvadov Granite showing halos of secondary quartz around fluid inclusions hold anomalously high fluid pressures on heating (Müller, 1995).

In the first stage mass decrepitation of fluid inclusions (micro-crack formation) may occur. Simultaneous decrepitation of fluid inclusions is assumed, because in the present samples the halos are connected with one generation of healed micro-cracks. Mass decrepitation may be induced by differences between fluid pressure and lithostatic pressure e.g. during uplift (isothermal decompression). The $\alpha / \beta$-transition causes an anisotropic contraction of 0.86 vol.\% vertical to the c-axis and $1.3 \mathrm{vol} \%$ parallel to the c-axis and induces stress within individual grains (e.g. Blankenburg et al. 1994) and subsequently may also trigger mass decrepitation. Dissolution-precipitation initiated by shearing leads to the healing of the micro cracks.

In the second stage the defect-poor quartz grows at the cost of the host quartz and releases or replaces defect centres. The formation of defect-poor quartz at the cost of the defect-rich host quartz is explained by the displacing of atoms along the phase boundary of the quartz with higher defect density so that the atoms fit to the lattice of the quartz with low defect density (e.g. Passchier and Trouw, 1998; Stünitz, 1998). This results in local displacement of the phase boundary (between the new quartz and the host quartz) and the growth of the more pure crystal at the cost of more disordered neighbour. The process reduces the internal free energy of the crystals involved and causes the release and replacement of defect centres, which are enriched in the grow front. 
In conclusion, the formation of secondary quartz around fluid inclusions is explained by a reconstituting process of the host crystal and represents a structural transformation, whereby the crystallographic orientation is preserved.
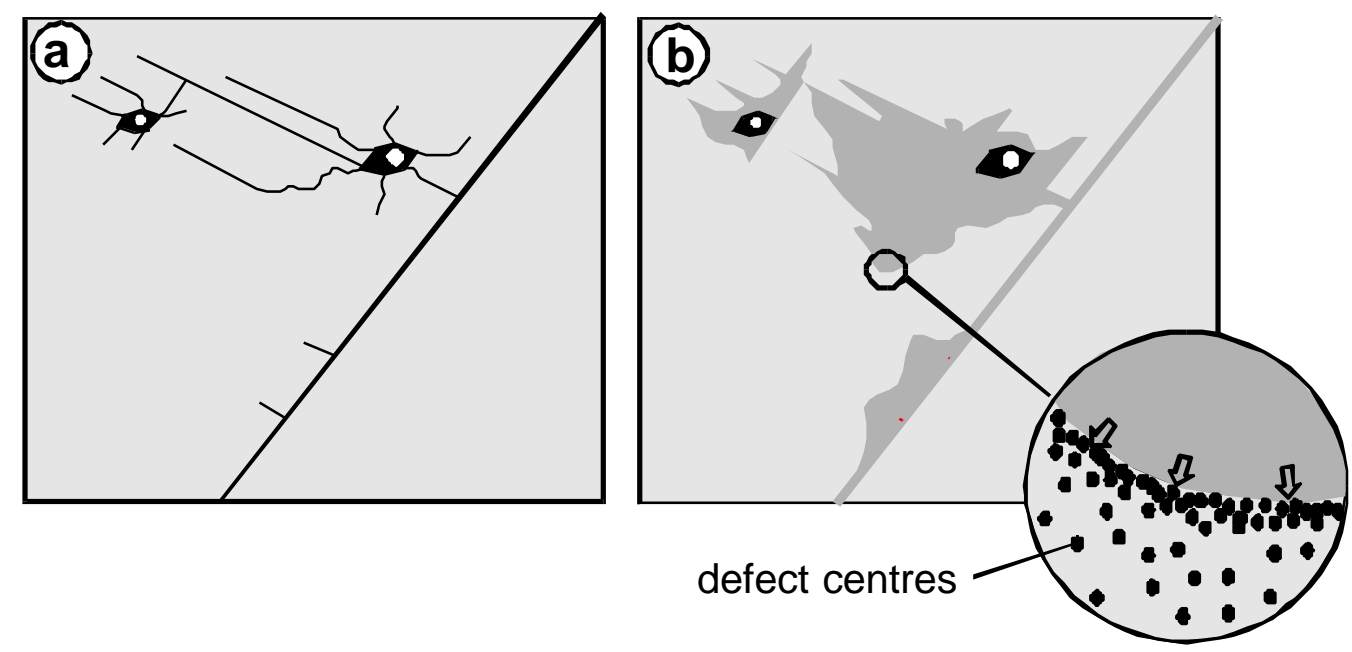

Fig. 6.8 Model of formation of halos of secondary quartz around fluid inclusions. a - first stage: mass decrepitation of fluid inclusions (micro-crack formation). $b$ - second stage: defect-poor quartz grows at the cost of the host quartz and releases or replaces defect centres.

\section{Secondary CL structures with induced defect centres}

Secondary CL structures with induced defect centres are halos around radioactive inclusions, diffusion rims along grain boundaries and micro-cracks, and non-luminescent spots in granitic quartz. Natural a-radiation and trace element diffusion cause the modification and formation of defect centres in quartz.

Some samples show round halos around radioactive inclusions with pinkish/yellowish white CL (Fig. 6.6b). Natural a-radiation of radioactive micro-inclusions (zircon, monazite) results in damage of the crystal structure (metamictisation). The radius of halos is typically $\sim 40 \mu \mathrm{m}$. Each halo is subdivided into a brighter inner zone $(\sim 25 \mu \mathrm{m})$ and an outer zone $(\sim 15 \mu \mathrm{m})$. The radius of $\sim 40 \mu \mathrm{m}$ corresponds to the interaction radius of the a-particles in quartz (Owen, 1988). Similar bright CL was also observed in hydrothermal quartz (sample 1) along opeb cracks, indicating that quartz lattice damage was produced by a-radiation from radioactive components of the migrating fluid.

In magmatic quartz diffusion rims at grain boundaries (grain boundary alteration) frequently occur at the grain contacts between quartz and plagioclase or biotite (see $\S 10.7$ ). The diffusion rims show the enrichment of $\mathrm{Fe}, \mathrm{Al}$, and $\mathrm{K}$. Fe may diffuse up to $400 \mu \mathrm{m}$ into the 
quartz. The Fe enrichment at the grain boundaries not always results in the change of the CL colour (Fig. 5.11c). This observation may be explained by the fact that Fe occurs as divalent and trivalent ions. The diffusion rims in magmatic quartz are explained by solid state diffusion of trace elements at high (sub-solidus) temperatures.

Particularly in granitic quartz radiation-induced non-luminescent spots were observed. Weak luminescent spots up to $5 \mu \mathrm{m}$ in size developed during electron radiation in granitic quartz (sample 7, 8, 12, and 14; Fig. 6.6a). The radiation-induced spots are interpreted as aggregations of aqua complexes with a gel-like disordered structure, i.e. regions with a high local concentration of $\mathrm{H}_{2} \mathrm{O}$ and substitutional $\mathrm{Al}$ with one or more $\mathrm{OH}$ groups attached in a locally disordered network. Stenina et al. (1984) described similar spots developed during electron radiation and identified these structures as amorphous (non-crystalline) micro-areas using TEM imaging. The electron radiation results in the release of molecular water from the aqua complexes (see $\S 2.2$ ). $\mathrm{H}^{+}$ions migrate along weak donor-acceptor and hydrogen bonds of the aqua complex defects. As a consequence oxygen may migrate due to the radiationtriggered redistribution of $\mathrm{Si}-\mathrm{O}$ and $\mathrm{M}^{\mathrm{m}+}-\mathrm{O}$ bonds (Stenina et al., 1984; Gritsenko and Lisitsyn, 1985). At the defective places the following reaction occurs: $\mathrm{O}^{2-}+2 \mathrm{H}^{+}$? $\mathrm{H}_{2} \mathrm{O}$. Here water bubbles may develop. Heggie (1992) showed that microcracks by producing radicals facilitate the migration of water. In this case "water" moves through $\mathrm{SiO}_{2}$ matrix in the dissociated form. Heat-treatment experiments $\left(500^{\circ} \mathrm{C}\right.$ for several hours) showed that the aqua complexes homogenised into the lattice and structural water converts to non-bound form and creates micro bubbles (e.g. Griggs, 1967; Brunner et al., 1961; Bambauer et al., 1969; McLaren et al., 1983; Stenina et al., 1984). These bubbles of heat-treated quartz arise as a result of the thermal-induced break down of $2\left[\mathrm{SiO}_{3}\right]---\mathrm{O}-\mathrm{H}-\mathrm{H}$ bonds and the following $\mathrm{H}^{+}$ migration along the weak bonds of the lattice. The gel like defect structures were incorporated during crystallisation. The frequent occurrence of these spots in anhedral granitic quartz (matrix quartz) reflects "wet" conditions during crystallisation whereas rhyolitic and granitic quartz phenocrysts does not show spots indicating "dry" crystallisation conditions.

In summary, trace elements in quartz are largely redistributed during retrograde processes. Non-luminescent spots and secondary quartz around fluid inclusions are frequently in granitic matrix quartz and less common or lacking in rhyolitic phenocrysts. The frequent occurrence of spots caused by gel-like defect structures in anhedral granitic matrix quartz reflects "wet" conditions during crystallisation, whereas rhyolitic and granitic quartz phenocrysts does not show spots indicating "dry" crystallisation conditions. Rhyolitic phenocrysts are mostly fluid 
inclusion free, whereas granitic phenocrysts frequently show halos of secondary quartz around fluid inclusions as a result of a overprinting by late-magmatic voliatiles. 


\section{Application of Cathodoluminescence to Magmatic Quartz in a Tin Granite - Case Study from the Schellerhau Granite Complex, Eastern Erzgebirge, Germany}

(this chapter has been published in Mineralium Deposita, vol. 35, pp. 169-189, 2000, co-authors: R. Seltmann and H.-J. Behr)

\subsection{Abstract}

A model of the cooling history of tin-bearing granitic magma forming the Schellerhau granites (Eastern Erzgebirge, Germany) is shown on the basis of quartz textures. Similar grain size, similar grain habit and correlatable growth textures of phenocrysts in different granite varieties give proof of a common crystallisation history before the melts of the Schellerhau granite varieties were intruded. Four nucleation events occurred during crystallisation in different crustal levels between about 20 and $1 \mathrm{~km}$ depth. The parental melt of the Schellerhau granites is interpreted to have contained $<2.5 \mathrm{wt} . \% \mathrm{H}_{2} \mathrm{O}$ originally. The water content of the melt during the subvolcanic intrusion stage amounted to more than $5 \mathrm{wt} \%$ and characterises highly evolved residual melts that enable the formation of tin deposits. This paper contributes to a better understanding of the development and behaviour of fractionated tin-bearing granitic melts, and links quartz cathodoluminescence (CL) with microanalytical studies.

\subsection{Introduction}

MacLellan and Trembath (1991) developed a quantitative model for evaluating the cooling history of a granitic magma on the basis of quartz textures. The relative chemical and structural stability of quartz is responsible for the conservation of quartz generations of different size, habit and structural state in granites and rhyolites. In contrast the chemical composition of feldspar changes during cooling because it is in equilibrium with melt. Therefore quartz morphology provides reliable information about the cooling history of granitic melts.

In this paper we report about the application of cathodoluminescence (CL) microscopy to distinguish different quartz generations in the Schellerhau tin granites. CL is used to illustrate 
the growth textures of quartz. However, it is not the aim of this paper to provide a detailed explanation of the complex causes of luminescence in quartz. The CL of quartz results from substitutional and interstitial incorporation of trace elements and from different types of intrinsic and extrinsic defect centres in the quartz lattice (e.g. Ramseyer et al., 1988). Consequently, the luminescence behaviour is a complex function of the concentration of trace elements which may act as CL activators, like $\mathrm{Al}, \mathrm{Fe}$ and $\mathrm{Ti}$, or as quenchers. The $\mathrm{CL}$ is related to the conditions of mineral crystallisation, and alteration and of natural $\gamma$ - and $\alpha$ radiation. The analysis of the luminescence spectra makes it possible to quantify the emission properties of single grains. The scanning electron microscope cathodoluminescence (SEMCL) facilitates high resolution of intragranular growth textures of magmatic quartz. Zoning within quartz is normally invisible by conventional optical microscopy and rarely documented by quantitative analysis. We also determined trace element concentrations in quartz using the electron microprobe. In addition, the detailed analysis of quartz texture and size distribution was carried out. The intragranular growth textures, the quartz framework and the grain size distribution yield important information on the nature and evolution of the melt from which the crystal grew. Plots of maxima of grain size distributions for a single mineral indicate bursts of nucleation which are caused by a high degree of melt undercooling (Dowty, 1989).

In the following is given a short introduction in the general interpretation of growth textures, based on the present level of knowledge. A general compilation of observable growth and resorption textures is illustrated in Fig. 7.1.

The different primary growth textures represent disturbances of growth and diffusion rates during crystallisation. Growth and diffusion rates depend on melt composition, crystal transport in the melt (e.g., convection) and ascent velocity of the melt and related pressure and temperature changes. These criteria regulate type and quantity of defects, few of which are luminescent active and incorporated into the quartz lattice. Wavelength and amplitudes of individual zones are directly related to the physical and chemical melt properties. The 


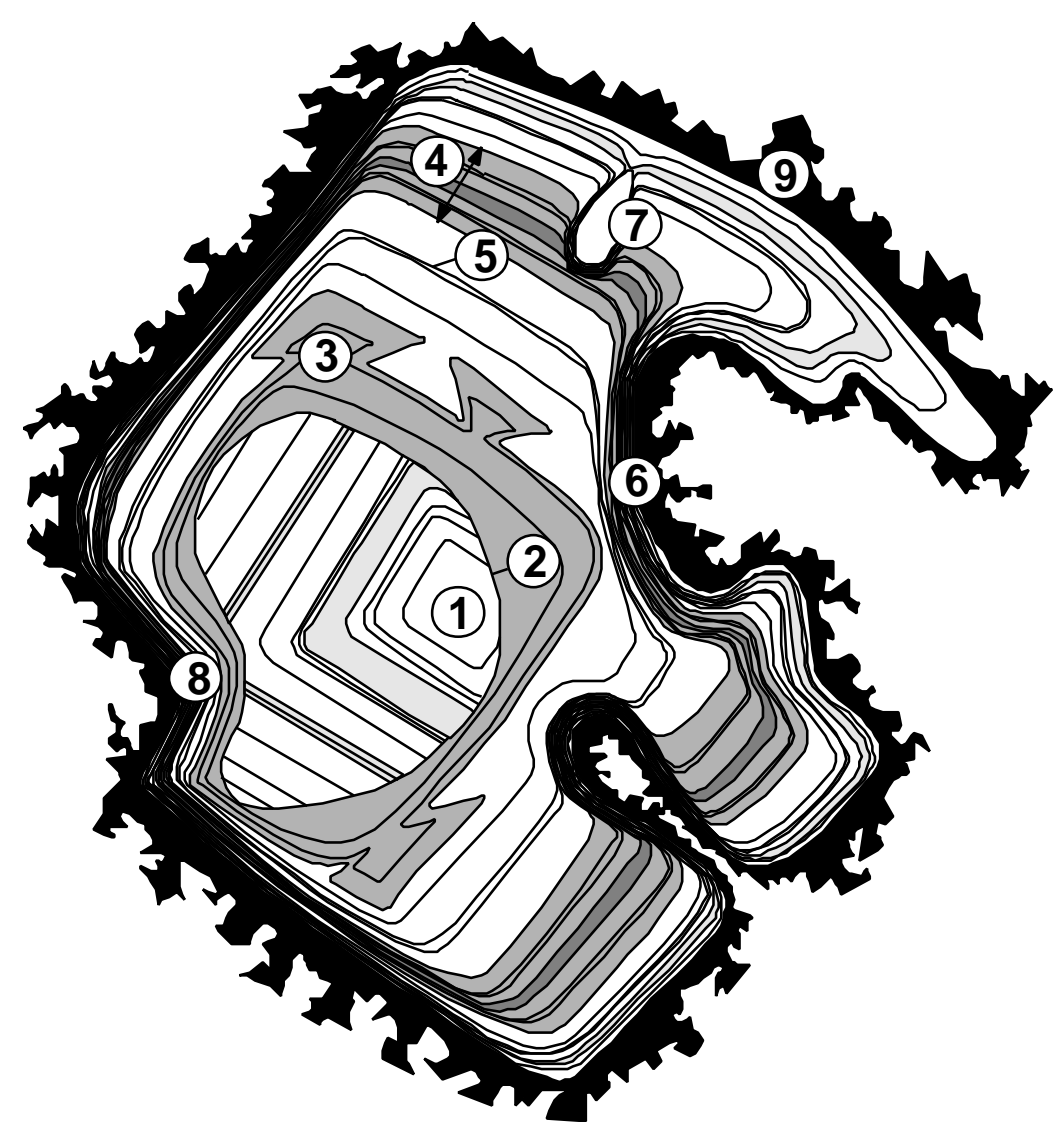

Fig. 7.1 Synoptical scheme of primary growth textures in magmatic quartz phenocrysts with a diameter of 1 to $5 \mathrm{~mm}$ contrasted by SEM-CL. 1 - Nucleation of hexagonal $\beta$-quartz or rhombohedral $\alpha$-quartz; 2 - Resorped surface; 3 - Skeletal growth; 4 - Step zoning (50 - $1000 \mu \mathrm{m}) ; 5$ - Oscillation zoning (2 - $20 \mu \mathrm{m})$; 6 - Growth impediment; 7 - Inclusion (entrapment) of melt or a bubble; 8 - Growth impediment caused by adjacent phenocrysts; 9 - Rim of anhedral quartz of the final magmatic crystallisation.

diffusion rate in the melt controls the compositional variation and width of the zoning. The higher the diffusion rates, the less compositional differences occur in the quartz. Concentration gradients develop in the melt when the growth rate exceeds the diffusion rate, and in the solid when the reaction rate of crystals with the liquid is lower than the growth rate (Sibley et al., 1976).

The development of growth zoning during magmatic crystallisation is described by a number of models (e.g. Sibley et al., 1976; Anderson, 1984) that have been derived from the zonal structure of plagioclase. We apply these models to the crystallisation of magmatic quartz having a very similar zonal growth as plagioclase.

Major discontinuities in the zoning (50 - $1000 \mu \mathrm{m}$ width) being non-periodic and showing a significant change of the luminescence colours result in physicochemical changes of external factors ("extrinsic" acc. to Shore and Fowler, 1996) such as temperature, pressure and magma 
composition (Bottinga et al., 1966; Allègre et al., 1981). Bottinga et al. (1966) defined those zones as compositional zoning, and Allègre et al. (1981) called them stepped zoning.

The fine oscillatory zoning $(2-20 \mu \mathrm{m}$ width) within the step zones is explained by a selforganised ("intrinsic" acc. to Shore and Fowler, 1996) diffusion controlled mechanism on the crystal-melt boundary layer and exists in a number of recent models (Sibley et al., 1976; Haase et al., 1980; Allègre et al., 1981; Loomis, 1982; Simakin, 1984; Pearce, 1993). Oscillatory growth happens very slowly at low degrees of undercooling and oversaturation. It may only take place when the crystallising system is not disturbed on the solid-liquid interface, thus the melt should not convect (Allègre et al., 1981). Investigations on natural plagioclases by Greenwood and McTaggart (1957) and Wiebe (1968) confirm that oscillation zones of crystals grown from the same melt cannot be correlated due to the self-organising character of the process. To develop oscillation zones physical or chemical changes in the bulk magma are not required.

Discussions about the distinction of resorption structures and growth impediments in quartz phenocrysts have been controversial (Kozlowski, 1981; Harris and Anderson, 1984). Laemmlein (1930) first recognised and described lobate depressions at the crystal surface as growth embayments. The fact that these are growth impediments may be recognised because the zonation adapts to the shape of the embayments. In contrast, resorption surfaces cut preexisting zones. Growth impediments are caused by immiscible liquids, vapor bubbles, molten sulfide or fluid-rich melt droplets which stick on the crystal surface, hinder the crystal growth and result in lobate depressions and entrapments (Kozlowski, 1981; Donaldson and Henderson, 1988; Lowenstern, 1995). The resorption (melting) of quartz surfaces is due to $\mathrm{SiO}_{2}$-undersaturation of the melt which may be caused by increase in temperature, isothermal depressurisation or magma mixing. Crystals may undergo a rounding due to thermal weakening, chemical interaction and mechanical abrasion even during transport in the melt. The occurrence of resorption which results in strong rounding of the quartz crystals is in accordance with the rapid ascent of granitic melts by dyke formation as found by Holtz and Johannes (1994) and Johannes and Holtz (1996).

The presence of skeletal growth indicates supercooling and a related decrease of the ratio of diffusion rate/growth rate. In such cases compositional gradients on the crystal-melt interface develop, planar crystal/melt interfaces become unstable and the growth results in skeletal morphology (Kirkpatrick, 1981; Fowler, 1990). 
As object of studies we have chosen the Schellerhau Granite Complex (SGC) in the Eastern Erzgebirge/Germany. It has been studied by Pälchen and Ossenkopf (1967), Helbig and Beyer (1970), Seim et al. (1982), Just et al. (1987), and Schilka and Baumann (1996) so that an extensive state of knowledge based on mapping, availability of drill cores and resulting chemical and petrographical data exists. The pluton was studied by the authors across a vertical sampling profile of about $1000 \mathrm{~m}$ using the relief differences of up to $300 \mathrm{~m}$ caused by erosion and dislocations, and available drill cores of depths of up to $1000 \mathrm{~m}$ (drilling Niederpöbel 1/58, Helbig and Beyer, 1970). On the basis of the collected data, we present a model of the quartz crystallisation history of the Schellerhau granite magma.

\subsection{Analytical methods}

Cathodoluminescence (CL) microscopy has been used to visualise growths and alteration structures in quartz. Two instruments for CL studies of polished thin sections were used. The analyses of the luminescence colours (optical CL) were carried out on a hot-cathodeluminescence-microscope (Neuser et al., 1995) at the University of Göttingen. Thin sections were coated with a carbon layer and were bombarded with electrons with an energy of $14 \mathrm{keV}$ and a filament current of $0.17 \mathrm{~mA}$. The electron beam (4 mm cross section) and the sample were maintained in vacuum conditions of $10^{-5}$ mbar. The spectral response of the luminescence was recorded by a TRIAX 320 spectrometer with a 100 lines/mm grating for the emission spectra from 1.3 to $3.1 \mathrm{eV}$. The single emission bands $2.79 \mathrm{eV}$ and $1.96 \mathrm{eV}$ were measured with the Monochromator at a speed of $10 \mathrm{~mm} / \mathrm{min}$ using the CL-microscope after Zinkernagel (1978) (10 keV, $0.25 \mathrm{~mA})$. The scanning electron microscope model Geoscan 250-MK3 with a CL detector (SEM-CL) was used for black-and-white images of the internal growth and secondary structures of the quartz grains. The voltage was $15 \mathrm{keV}$ and the current 5 to $15 \mathrm{nA}$. Dark contrasted areas in quartz produced by SEM-CL correspond to red to reddish brown CL-colours of the optical CL. Light areas correspond to blue to violet colours.

The trace element concentrations in quartz were determined by wavelength-dispersion analysis on the JEOL JXA 8900 electron microprobe operating at $15 \mathrm{kV}$ and $70 \mathrm{nA}$ with a beam diameter of $5 \mu \mathrm{m}$. Analyses were performed for $\mathrm{Al}, \mathrm{Ti}, \mathrm{Mn}$ and $\mathrm{Fe}$. The calculated detection limits ranged from $<25 \mathrm{ppm}$ for $\mathrm{Al},<17 \mathrm{ppm}$ for $\mathrm{Ti}$, $<26 \mathrm{ppm}$ for $\mathrm{Mn}$ to $<23 \mathrm{ppm}$ for Fe with a confidence level of $95 \%$. 
The application of the lacquer peel method (Behr, 1966) enables detailed analyses of the quartz framework (Müller and Behr, 1997). This technique, usually applied to carbonates, is used here to visualise the quartz textures. The peels are produced by treating the surfaces of polished samples with a $40 \%$ HF solution. The corroded surface is covered with several lacquer layers. After drying, the lacquer film is pulled off and used as a negative for blackand-white photos. Quartz appears black and feldspar and mica white or grey on the photos.

Grain size analyses were carried out in thin sections and in hand specimen. The length and width of quartz grains $(\leq 1 \mathrm{~mm})$ in the thin sections was measured using a defined raster, determined through the grain size. The distance between the points of the raster corresponds to the average grain diameter. Quartz grains larger than $1 \mathrm{~mm}$ were measured by micrometer on polished hand specimens $(15 \times 15 \mathrm{~cm})$. The grain size was calculated from the average of its length and width.

\subsection{Geology and geochemistry of the SGC}

\section{Geological setting}

The SGC belongs to the highly evolved younger granite group of the Erzgebirge batholith (Tischendorf and Förster, 1990; Stemprok, 1993; Förster and Tischendorf, 1994; Seltmann, 1994). Neoproterozoic gneisses of the metamorphic basement and volcano-sedimentary rocks of the Altenberg-Teplice caldera form the host rocks (Fig. 7.2).

Late-collisional extensional tectonics and collapse of the Variscan orogen controlled during the Upper Carboniferous the block and graben tectonics in the area, caldera formation with pre-dominantly ignimbritic rhyolites and porphyritic microgranites, and finally the posttectonic multiple intrusion of tin granites of the SGC into a subvolcanic level. Uplift, faulting, block tilting and erosion took place mostly in Permo-Silesian and Cenozoic times and formed the recent morphology. NW- and NE-striking faults with vertical dislocations of several hundred metres form the SGC as horst and as a result some deeper pluton parts are uncovered by erosion. The SGC crops out at about $13 \mathrm{~km}^{2}$ as a NW-SE elongated body roughly bounded in the north-eastern part by the Weisseritztal fault and in the south-western part by the 


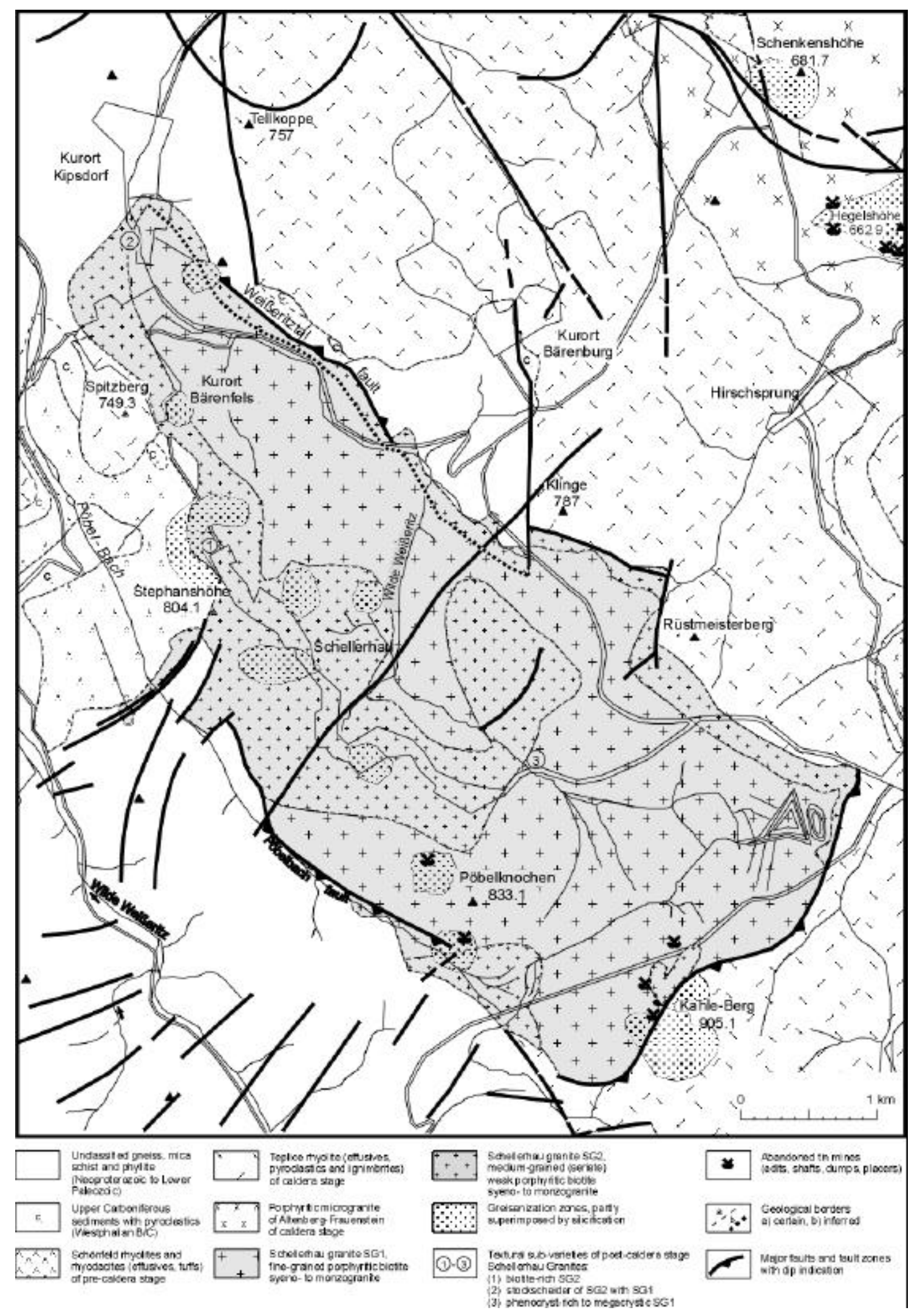

Fig. 7.2 Geological sketch map of the Schellerhau granite massif and its geological setting in the AltenbergTeplice caldera, Eastern Erzgebirge (without Cenozoic). 
Pöbelbach fault (Schilka and Baumann, 1996). These marginal fault zones indicate within the structural pattern of the Altenberg-Teplice caldera a NW-striking sinistral strike-slip movement and north-east directed extension controlling in the post-caldera stage the posttectonic SGC intrusion. Faults intersecting the SGC are either post-intrusively reactivated or newly formed as indicated by their hydrothermal mineralisation of diffent ages ranging from Upper Carboniferous to Cenozoic.

According to gravimetry data and geochemical studies of drill cores, granites of the SGC type form the mostly hidden Eastern Erzgebirge partial pluton (Tischendorf, 1964). This NNWstriking hidden granite ridge reaches from Dippoldiswalde in the north to Zinnwald in the south with ca. $10 \mathrm{~km}$ east-west extension. To the south, in the Czech part of the Erzgebirge, the chemically and texturally similar Preisselberg-Cinovec granite (Stemprok et al., 1994) forms the continuation of this granite ridge.

\section{Phasing}

The SGC is characterised by the intrusion sequence of porphyritic (SG1) to weaklyporphyritic (SG2) biotite syeno- to monzogranites, and mostly seriate albite granites (SG3). The SG1, SG2 and SG3 rocks of the SGC represent individual stages (phases) of a multiple granite intrusion as indicated by field evidence.

The SG1 forms the central and upper part of the SGC and occupies about 2/3 of the SGC at the recent surface. Locally, the SG1 exhibits a marginal facies characterised by the most primitive composition within the SGC that is due to porphyritic texture and muscovitebearing similar to the "intermediate granites" (IG, "Zwischengranite" type Walfischkopf, Lange et al., 1972; Stemprok, 1986) of the Western Erzgebirge. Pendants of that SG1 variety of the SGC also occur in the multiple intrusions of tin granites at Sadisdorf and Sachsenhöhe. The textural variability of the marginal facies of the SGC also includes so-called two-phase textures (Cobbing et al., 1992; Seltmann and Stemprok, 1994) where crystals/crystal mush of an earlier SGC intrusion and cooling stage either underwent fluidisation at intrusive contacts or were infiltrated along grain margins but not resorbed by low-viscosity melt batches of a subsequent intrusion stage. The older phenocrysts exhibit sharp contacts to the surrounding groundmass of that second stage.

The SG2 intruded the SG1 along its margins probably due to cauldron subsidence effects in the post-caldera stage of the Altenberg-Teplice crustal unit. The SG2 occupies about 1/3 of the SGC surface. There is field evidence that SG1 enclaves occur in SG2 (locality ParadiesFundgrube), SG2 dykes cross-cut SG1, and there are sharp intrusive contacts with 
stockscheiders and chilled margins of the younger phase against the earlier phase (northern SGC flank at Kipsdorf SG2/SG1, southern SGC flank at Kahleberg SG2/SG1, drill cores SG3/SG1 and SG3/SG2).

The albite granites (SG3) occur as fine- to medium-grained porphyritic and seriate varieties. They were found in most of the drillings as flat igneous layers of up to several ten metres thickness intercalated with SG1 and SG2 units characterising the SGC as sheeted laccolite body. Small SG3 dykes cross-cutting the earlier granite phases SG1 and SG2 provide evidence for magmatic origin of SG3 and against its interpretation as metasomatic zones. Exploratory excavations near the former New Galgenteich quarry exposed a small SG3 dyke with sharp igneous contacts to the SG2 (F. Schiemenz, pers. comm.). The occurrence of fluid saturation textures (miarolitic cavities, micrographic quartz/K-feldspar intergrowth) reflects the high fractionation degree of the SG3 melt.

The genetical position of alkali feldspars, especially the occurrence of sugar-grained albites, remains unsolved and is controversially discussed for similar rocks (Beus et al., 1962; Schwartz, 1992; Stemprok, 1993). Regardless of many subsolidus features caused by deuteric alteration and post-magmatic fluid-rock reactions, we classify the SG3 rocks as to be of predominantly magmatic origin (Just et al., 1987; Seltmann et al., 1992) as they are characterised by snowball quartz that is bearing melt inclusions (R. Thomas, pers. comm.). These melt inclusions show features of trapped silicate melt similar to those studied in topazbearing granites from Karelia (Poutiainen and Scherbakova, 1998) and do not link to the interpretation of crystallised silica colloid trapped as a hydro gel during greisenisation as described from a Cornish topaz granite (Williamson et al., 1997). The snowball quartz contains also inclusions of late-magmatic matrix albite. Many SGC samples underwent supplementary metasomatic albitisation (Haapala, 1997) and therefore only relics of the primary texture and structural relationships allow to identify the original granite type.

Within the Eastern Erzgebirge, marginally to the SGC, a series of stock-like granites (Altenberg, Sadisdorf, Sachsenhöhe, Zinnwald, Preisselberg), each with 1-5 $\mathrm{km}^{2}$ outcrop size at the recent surface, form as multiple intrusions cupola-shaped elevations of the hidden pluton. These stocks we interprete as channelised products of evolved melt batches and the accompanying ore-forming greisen fluids as originated from deeper parental magmas. They are, similar to the SG1 to SG3 sequence, composed of rock types with fine-grained porphyritic via medium-grained equigranular syeno- to monzogranites to seriate albite granites. The granite elevations represent the country rocks for endocontact tin mineralization of the greisen type. Numerous drillings made in the area between Cinovec (Zinnwald) and 
Krupka on the Czech side where granites were continuously followed in the drill cores appear equivalent to those found in the SGC. Our studies confirm the evolution series of protolithionite, zinnwaldite and lepidolite granites such as decribed as upward sequence from the deep drilling at Cinovec (Stemprok and Sulcek, 1969; Rub et al., 1997).

Due to the recent erosion level of the SGC of estimated ca. 500-1000 m (Schust, 1980, Spengler, 1949), any mineralised cupolas or elevations over the Schellerhau granite body were eroded. Greisen occurrences within the SG1 (Fig. 7.1) represent either the root zones of eroded tin mineralization or are exogreisens of hidden intrusions of SG2 and SG3 intruding at depth the SG1.

\section{Geochemistry}

The SG1, SG2 and SG3 rocks chemically represent the suite of P-poor, Li-F-enriched series of leucogranites that exhibit some distinct A-type tendency (Förster et al., 1995; Breiter et al., 1999). The latter are weakly peraluminous (A/CNK $\leq 1.2$ ), enriched in HREE, Y, Th, Hf, Zr, Sc, Nb, Ta, and U and display elevated abundances of Rb, Li, F, and Sn (Förster et al., 1996) increasing from SG1 to SG3. There is only a moderate chemical contrast between the SG1 and SG2 rocks. The SG3, however, exhibits in distinction to the SG1 and SG2 the chemical and petrographic patterns of alkali feldspar leucogranites (Table 7.1). The SG3 rocks are more highly evolved as also shown by the decreased $\mathrm{Zr} / \mathrm{Hf}$ and $\mathrm{Y} / \mathrm{Ho}$ values. Its modal composition (Table 7.2) is due to feldspathisation different to that of the SG1 and SG2 rocks. Topaz occurs mostly poikiloblastic and was classified in Table 7.2 as of secondary nature but in few cases primary magmatic topaz exists in the SGC rocks ( $\mathrm{R}$. Thomas, pers. comm.).

The SG1, SG2 and SG3 rocks are interpreted as products of in-situ fractionation of a magma derived from a common deep-crustal parental magma. The chemical and textural specifics of the SG3 rocks were produced when the rock underwent deuteric alteration, and only in few cases (drill cores) the primary textural and chemical features were preserved. 
Table 7.1 Chemical analyses of major and trace elements from representative SGC samples.

\begin{tabular}{|c|c|c|c|c|}
\hline $\begin{array}{l}\text { Number, } \\
\text { Granite }\end{array}$ & Sh-22 (SG1) & \# 16 (SG2) & Sh-32 (SG2) & Sh-18 (SG3) \\
\hline Locality & $\begin{array}{r}\text { Abandoned } \\
\text { mine Paradies- } \\
\text { Fdgr. }\end{array}$ & $\begin{array}{l}\text { Abandoned mine } \\
\text { Paradies-Fdgr. }\end{array}$ & $\begin{array}{r}\text { From drill core near } \\
\text { Kipsdorf }\end{array}$ & $\begin{array}{l}295 \mathrm{~m} \text { depth, drill } \\
\text { core at Kipsdorf }\end{array}$ \\
\hline Texture & $\begin{array}{r}\text { Very fine- } \\
\text { grained, weakly } \\
\text { porphyritic, } \\
\text { phenocryst-poor }\end{array}$ & $\begin{array}{r}\text { Medium-grained } \\
\text { (altered), seriate, } \\
\text { weakly } \\
\text { porphyritic, }\end{array}$ & $\begin{array}{c}\text { Medium-grained } \\
\text { equigranular } \\
\text { (slightly altered) }\end{array}$ & $\begin{array}{r}\text { Fine- to medium- } \\
\text { grained seriate, } \\
\text { albitized }\end{array}$ \\
\hline $\mathrm{SiO}_{2}$, wt. $\%$ & 75.13 & 72.93 & 71.91 & 69.29 \\
\hline $\mathrm{TiO}_{2}$ & 0.057 & 0.094 & 0.068 & 0.022 \\
\hline $\mathrm{Al}_{2} \mathrm{O}_{3}$ & 12.60 & 13.84 & 14.64 & 16.97 \\
\hline $\mathrm{Fe}_{2} \mathrm{O}_{3}$ & 0.89 & 1.69 & 1.25 & 0.74 \\
\hline $\mathrm{MnO}$ & 0.02 & 0.05 & 0.033 & 0.09 \\
\hline $\mathrm{MgO}$ & 0.06 & 0.17 & 0.07 & 0.02 \\
\hline $\mathrm{CaO}$ & 0.50 & 0.71 & 0.92 & 0.11 \\
\hline $\mathrm{Na}_{2} \mathrm{O}$ & 3.31 & 3.47 & 3.91 & 6.96 \\
\hline $\mathrm{K}_{2} \mathrm{O}$ & 5.33 & 5.09 & 4.64 & 4.09 \\
\hline $\mathrm{P}_{2} \mathrm{O}_{5}$ & 0.02 & 0.04 & 0.036 & 0.03 \\
\hline $\mathrm{H}_{2} \mathrm{O}^{+}$ & 0.86 & 0.72 & 0.98 & 0.87 \\
\hline $\mathrm{CO}_{2}$ & 0.05 & 0.10 & 0.12 & 0.15 \\
\hline $\mathrm{Li}_{2} \mathrm{O}$ & 0.037 & 0.075 & 0.164 & 0.016 \\
\hline $\mathrm{F}$ & 0.51 & 0.82 & 1.41 & 0.12 \\
\hline$-\mathrm{O}=\mathrm{F}$ & -0.21 & -0.34 & -0.59 & -0.05 \\
\hline Total & 99.16 & 99.45 & 99.56 & 99.43 \\
\hline Sn, ppm & 18 & 402 & 164 & 42 \\
\hline $\mathrm{Nb}$ & 51 & 40 & 75 & 72 \\
\hline $\mathrm{Rb}$ & 782 & 929 & 1297 & 1115 \\
\hline $\mathrm{Sr}$ & 8.53 & 34.0 & 32.1 & 19.2 \\
\hline $\mathrm{Ba}$ & 86.9 & 798 & 105 & 83.8 \\
\hline Cs & 29.7 & 40.2 & 62.4 & 16.7 \\
\hline $\mathrm{Zr}$ & 140 & 121 & 84.2 & 40.1 \\
\hline Hf & 8.11 & 7.53 & 6.71 & 8.28 \\
\hline $\mathrm{Pb}$ & 39 & 413 & 18 & 6.9 \\
\hline Th & 58.1 & 39.5 & 24.9 & 9.29 \\
\hline $\mathrm{U}$ & 15.0 & 17.6 & 20.8 & 3.33 \\
\hline $\mathrm{Y}$ & 103 & 89.6 & 44.5 & 1.55 \\
\hline $\mathrm{La}$ & 15.8 & 35.5 & 26.1 & 1.14 \\
\hline $\mathrm{Ce}$ & 32.4 & 85.3 & 69.0 & 2.44 \\
\hline $\operatorname{Pr}$ & 5.22 & 11.2 & 8.55 & 0.26 \\
\hline $\mathrm{Nd}$ & 19.0 & 37.4 & 25.3 & 0.70 \\
\hline $\mathrm{Sm}$ & 6.11 & 10.3 & 6.85 & 0.24 \\
\hline $\mathrm{Eu}$ & 0.063 & 0.195 & 0.12 & $<0.02$ \\
\hline $\mathrm{Gd}$ & 8.47 & 10.7 & 6.01 & 0.24 \\
\hline $\mathrm{Tb}$ & 1.94 & 2.27 & 1.36 & 0.06 \\
\hline Dy & 14.3 & 15.4 & 9.54 & 0.38 \\
\hline Ho & 3.24 & 3.25 & 1.99 & 0.08 \\
\hline $\mathrm{Er}$ & 10.6 & 10.5 & 6.95 & 0.30 \\
\hline $\mathrm{Tm}$ & 1.73 & 1.89 & 1.42 & 0.08 \\
\hline $\mathrm{Yb}$ & 12.0 & 12.8 & 11.4 & 0.93 \\
\hline $\mathrm{Lu}$ & 1.80 & 1.97 & 1.71 & 0.15 \\
\hline Y/Ho & 31.7 & 27.5 & 22.4 & 20.7 \\
\hline $\mathrm{Zr} / \mathrm{Hf}$ & 17.2 & 16 & 12.5 & 4.8 \\
\hline
\end{tabular}

Notes on analytical methods: Oxides, $\mathrm{Nb}, \mathrm{Sn}$ by XRF, Li by ICPAES, $F$ by ISE, other trace elements by ICPMS. Details on analytical conditions and accuracy are available on request from $\mathrm{RS}$. $\mathrm{H}_{2} \mathrm{O}^{-}$not determined. Sample \#16 bears little galena. 
Table 7.2 Modal mineral composition of representative samples of the SGC.

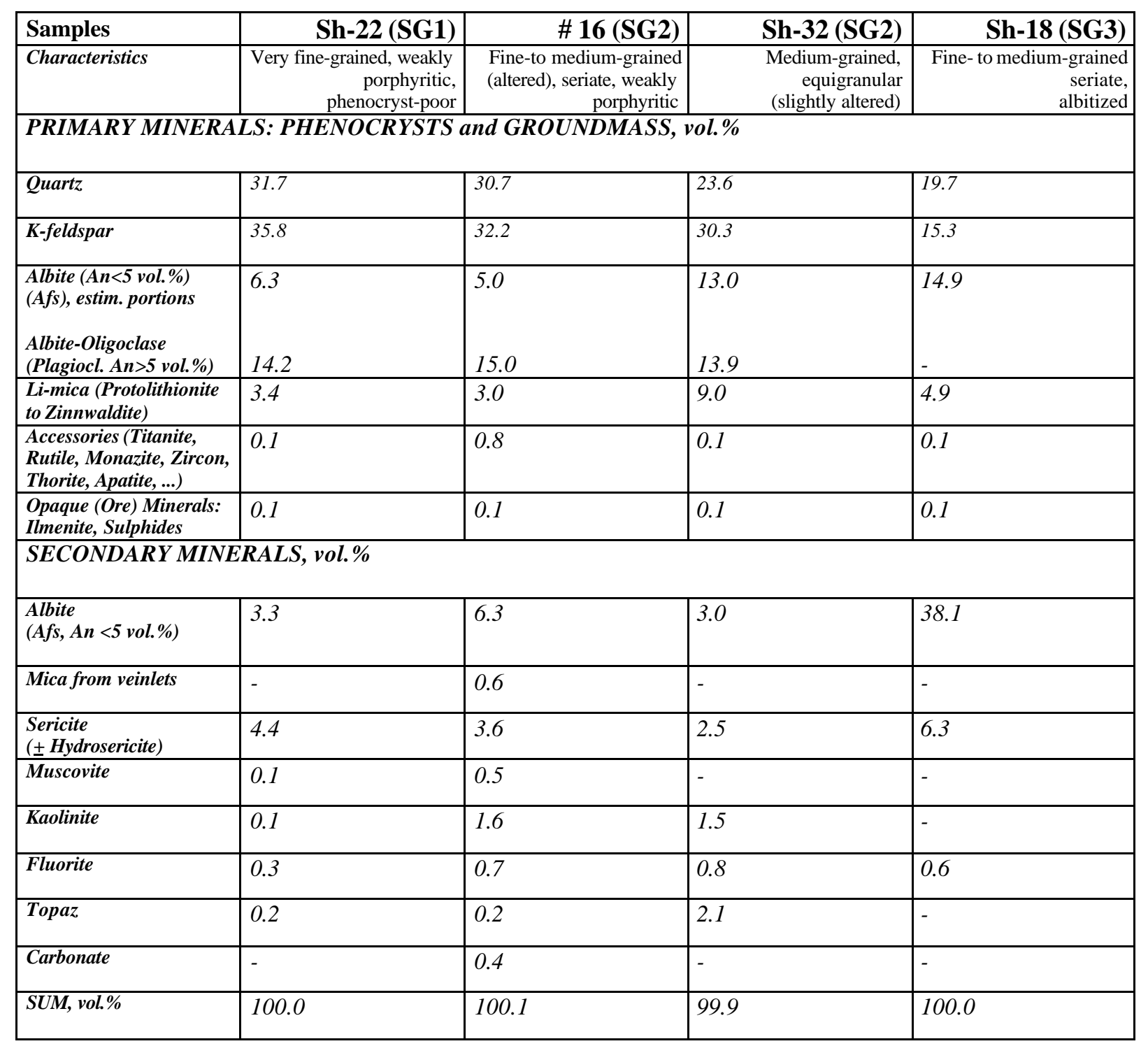

\subsection{Textural studies}

\section{The quartz texture of the SG1}

The grain size maxima of quartz in the phases and varieties of the Schellerhau granite massif (Figs. 7.3 and 7.4) help to reconstruct the multiphase intrusion and crystallisation history of the pluton. We focussed in our study on SG1 and SG2 phases of the SGC since these are the only ones well exposed at the surface, whereas the afs-rich SG3 varieties are predominantly represented by a few drill cores and are mainly characterised by secondary (recrystallisation) structures which overprint and remove the primary ones. 


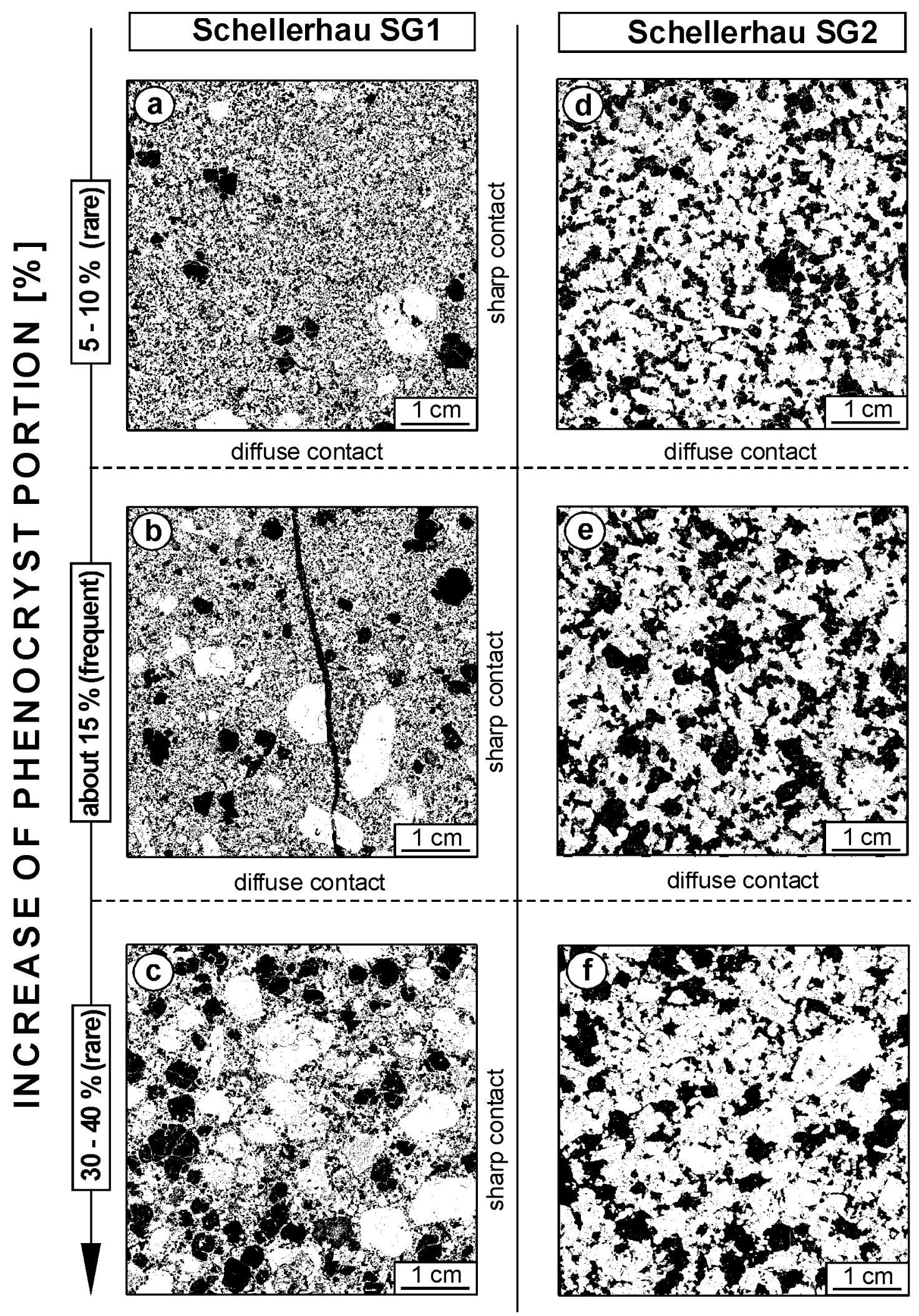

Fig. 7.3 The phenocryst portion of textural varieties of the SG1 and SG2, illustrated by black-and-white prints of lacquer peels. Quartz appears black and feldspars grey or white. The phenocryst portion varies between 5 to $40 \%$; the portion of $15 \%$ is most frequent and common. 


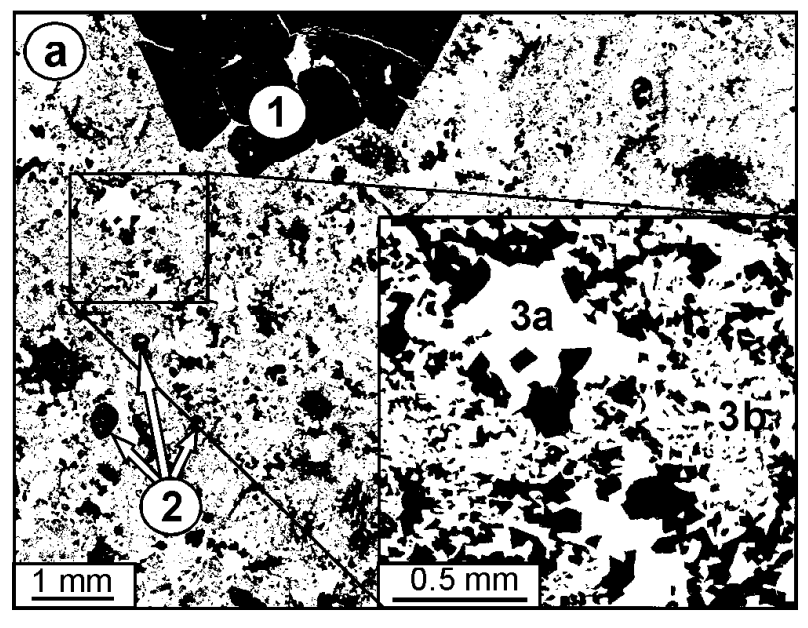

porphyritic SG1 with microgranophyric matrix quartz and interconnected miarolitic texture
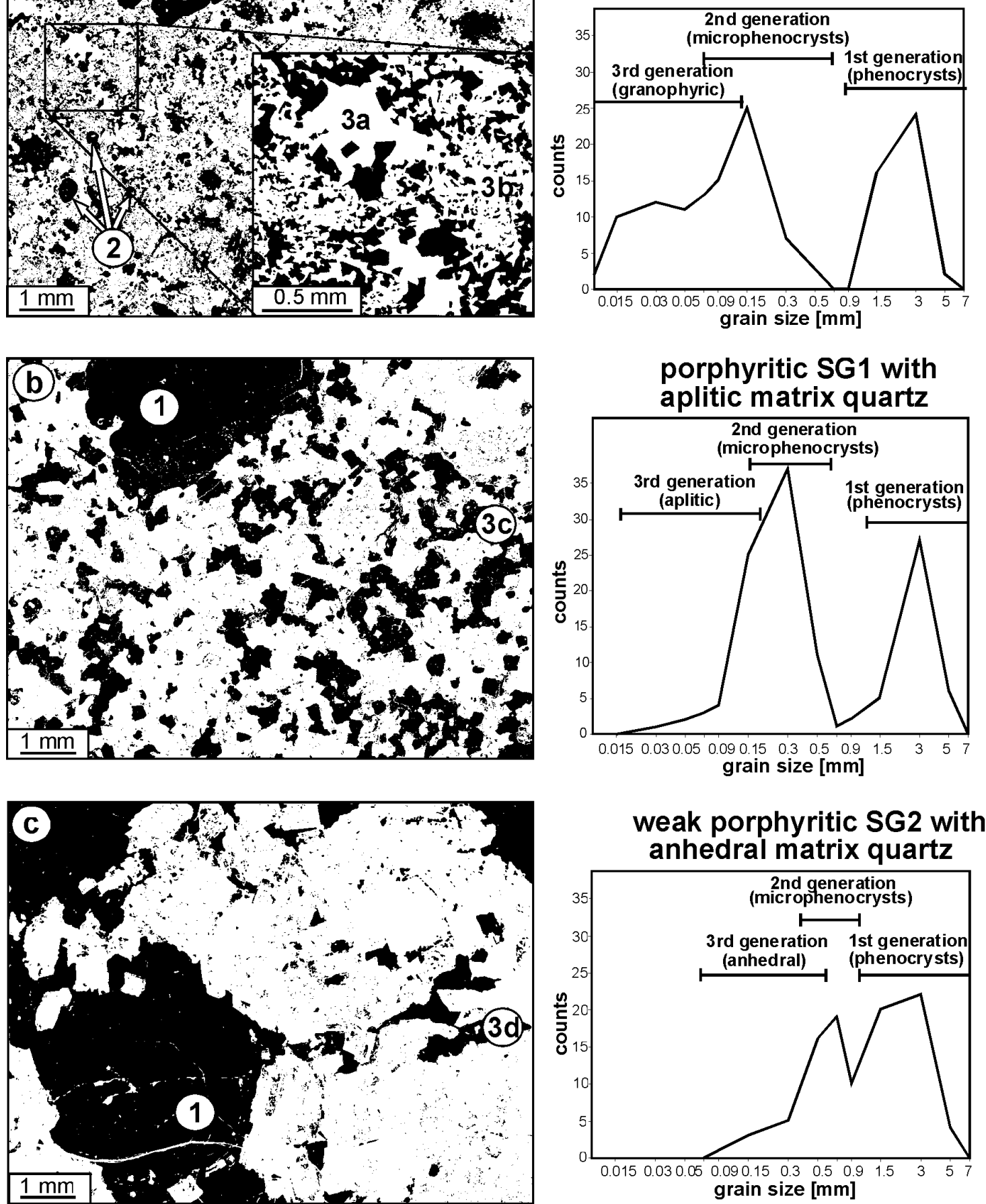

Fig. 7.4 Grain size maxima, shapes and distributions of quartz crystals in the SG1 and SG2. A maximum in the grain size distribution in a magmatic rock indicates a burst of nucleation caused by a high degree of melt undercooling. The texture is contrasted by black-and-white prints of laquer peels. The quartz appears black and the feldspar grey or white. 1 - quartz phenocrysts $\left(1^{\text {st }}\right.$ generation $) ; 2$ - quartz microphenocrysts $\left(2^{\text {nd }}\right.$ generation); $3 \mathrm{a}$ - granophyric quartz in miaroles; $3 \mathrm{~b}$ - microgranophyric quartz ( ${ }^{\text {rd }}$ generation); $3 \mathrm{c}$ - isometric aplitic quartz ( $3^{\text {rd }}$ generation); $3 \mathrm{~d}$ - anhedral quartz ( $3^{\text {rd }}$ generation). 
The phenocrysts of the early quartz generation $\left(1^{\text {st }}\right.$ generation) are large, 1.5 to $6 \mathrm{~mm}$ idiomorphic hexagonal dipyramidal crystals with hexagonal prism faces ( $\beta$-quartz). The median grain size of SG1 quartz phenocrysts is $2.3 \mathrm{~mm}$. The large feldspar phenocrysts (up to $2 \mathrm{~cm}$ long) are surrounded by microgranophyric intergrowths with quartz. The "typical" SG1 rocks contain a portion of ca. 15 vol. $\%$ phenocrysts $(5 \%$ quartz $+10 \%$ feldspar, less than $1 \%$ mica). Phenocryst portions below 12 vol.\% and more than 18 vol.\%, resp., are rarely represented and occur only in the southern part of the Schellerhau granite (Pöbelknochen and Seifenbusch area, Schilka and Baumann, 1996). The Pöbelknochen (elevation $833 \mathrm{~m}$ ) represents the uppermost part of the Schellerhau granite massif in the studied vertical profile. The matrix quartz, we call it later $3^{\text {rd }}$ generation, exhibits variable shape. The major portion of the granite is characterised by aplitic matrix quartz which contains small crystals $(0.02-0.2$ $\mathrm{mm}$ ) that are anhedral and more or less isometric. They surround the small euhedral feldspar crystals as clusters or networks or occur as overgrowths on quartz phenocrysts. Crystals $(<0.1$ $\mathrm{mm}$ ) are often in granophyric intergrowths with feldspar. The matrix quartz is in a microgranophyric intergrowth with feldspar especially in the upper $30 \mathrm{~m}$ of the cupola region of the locality Pöbelknochen. This texture is superimposed by interconnected miarolitic texture (IMT, Candela and Blevin, 1995). The IMT consists of micropegmatitic miaroles that form 3-dimensional interconnected networks (Fig. 7.4). The size of the druses and miaroles ranges from $0.2 \mathrm{~mm}$ to pegmatitic cavities of several $\mathrm{cm}$ size. Below $800 \mathrm{~m}$ elevation the microgranophyric texture of the matrix quartz continuously changes into aplitic texture and the IMT disappears. In the deeper parts, the IMT occurs only rarely and is developed 2dimensionally exclusively along early fractures that were filled by residual melt portions (locality Paradies-Fundgrube).

Supported by the small grain size of the miarolitic matrix, another quartz type could be detected at the Pöbelknochen locality. However in contrast to the phenocrysts, these microphenocrysts are euhedral, hexagonal dipyramids of only 0.1 to $0.5 \mathrm{~mm}$ size, and are homogeneously distributed within the matrix. They are mantled by matrix quartz, similar to the phenocrysts, and are classified as $2^{\text {nd }}$ quartz generation. The percentage of this frequent grain generation is difficult to determine. For example, the miarolitic SG1 rocks contain 5 to $7 \mathrm{vol} \%$ of this $2^{\text {nd }}$ quartz generation. It may be assumed that this generation is represented also within the aplitic type. However, due to the small grain size it is not distinguishable from the aplitic grains in studies of the lacquer peels and thin sections.

Hydrothermal quartz is well distinguishable from the above described primary magmatic quartz. Based on postsolidus recrystallisation textures (metasomatic overprint and blasteses), 
visible CL zonation, and dark red-brown luminescence, those metasomatic quartz textures formed by hydrothermal processes could be excluded from this study.

\section{The quartz texture of the SG2}

The SG2 exhibits a weak hiatalporphyritic texture (Figs. 7.3 and 7.4) that was described in the past as homophan (Pälchen, 1968) or equigranular (Schilka and Baumann, 1996). However, the grain size distribution shows a significant hiatus between the both maxima at $0.7 \mathrm{~mm}$ and $3 \mathrm{~mm}$. The median grain size of the SG2 quartz phenocrysts ( $1^{\text {st }}$ generation) is $2.6 \mathrm{~mm}$ (the corresponding value in the SG1 for the $1^{\text {st }}$ quartz generation is $2.3 \mathrm{~mm}$ ). The most frequent phenocryst portion amounts to 15 vol. $\%$ as in SG1 (5 \% quartz $+10 \%$ feldspar). Variations in comparison to the "normal" type are situated only in the southern part of the granite massif near the locality of Seifenbusch. The mine dumps of the abandoned "Paradies-Fundgrube" contain SG2 varieties with up to 35 vol.\% phenocryst portions (quartz + feldspar), and others with less than $10 \mathrm{vol} . \%$. The role of the $2^{\text {nd }}$ quartz generation may be similar to that in the SG1. The anhedral matrix quartz ( $3^{\text {rd }}$ generation) of the SG2 was feeding the irregular cavities between the subhedral to euhedral feldspar crystals and envelopes the quartz phenocrysts.

\section{The quartz texture of the SG3}

The textures of the granite phases succeeding SG1 and SG2, in the following summarized as SG3, are heterogeneous, aberant and show no or only few similarities to the previously described textural types (Fig. 7.5). Numerous leucocratic SG3 phases and varieties, hiatalporphyritic, seriate, equigranular and aplitic ones, are, in general, characterised by an alkali feldspar-rich matrix. Within the matrix composed of euhedral, microcrystalline albite plates $(20-600 \mu \mathrm{m})$ occur micropoikilitic, amoebic and snowball-like quartz phenoblasts of different size $(0.3-5 \mathrm{~mm})$. These belong to magmatic-hydrothermal transition processes and form a $4^{\text {th }}$ quartz generation that is grown in a highly viscous crystal mush with a low portion of residual melt in coexistence with fluids exsolved from the melt. Albite has been clearly determined as the liquidus mineral as it forms inclusions in all the other rock-forming minerals. Small isolated K-feldspar phenocrysts have irregular grain boundaries. The quartz crystals contain numerous euhedral albite crystals that also typically occur in the matrix. The irregular grain boundaries of the quartz, surrounding the albite crystals of the matrix, support the idioblastic growth. Partially, the quartz grains show euhedral shape due to occurrence of idioblastic growth creating textures characteristic of highly fractionated Sn-bearing granites (Cobbing et al., 1992; Müller and Behr, 1997; Beskin et al., 1994). 

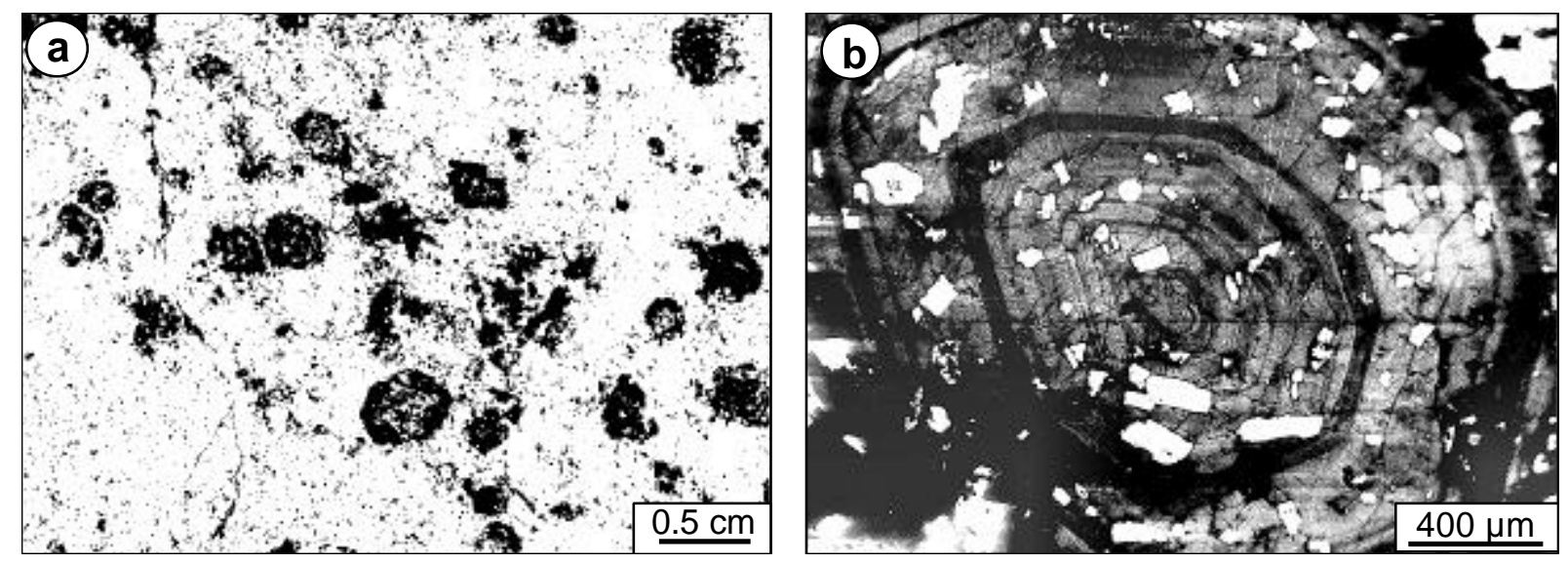

Fig. 7.5 The quartz phenoblasts ( $4^{\text {th }}$ generation) of the SG3. a - Porphyroblastic texture of the SG3. Quartz is black and feldspar white; $b$ - SEM-CL image of the idioblastic, micropoikilitic snowball quartz of the SG3. The $\mathrm{CL}$ and the growth textures are different from that of the phenocrysts and microphenocrysts. The zoning follows the shape of trigonal $\alpha$-quartz (combination of the hexagonal prism $\mathrm{m}$ and the rhombohedrons $\mathrm{r}$ and $\mathrm{z}$ ).

\subsection{CL properties of the quartz in the SGC}

\section{CL colours}

The detected emission spectra $(1.3-3.1 \mathrm{eV})$ of the SGC quartz generations are composed of two broad emission bands: blue $(2.6-3.1 \mathrm{eV})$ and red $(1.75-2.2 \mathrm{eV})$. In addition, an infra-red emission band with low intensity occurs between 1.3 to $1.5 \mathrm{eV}$. The blue emission $(2.6-3.1$ $\mathrm{eV}$ ) centred around $2.79 \mathrm{eV}$ is characterised by very high intensity at initial electron bombardment being a typical feature of natural quartz (e.g., Ramseyer and Mullis, 1990). The initial intensity drops by $1 / 2$ to $1 / 3$ after a few seconds (unstable CL) and is stabilised after 30 to $120 \mathrm{~s}$ of electron bombardment (stable CL). A slight decrease or nearly constant intensity was observed. The removal of those defects that are luminescence active in the blue emission range is forced in the crystal lattice caused by electron bombardment ( $\gamma$-radiation) and the related warming of the sample to $70^{\circ}$ to $90^{\circ} \mathrm{C}$. Alonso et al. (1983) and Gorton et al. (1996) detected three $(2.82,2.92,3.26 \mathrm{eV})$ and four $(2.48,2.76,2.95,3.18 \mathrm{eV})$ bands in the blue emission range, respectively. Gorton et al. (1996) suggested that the $3.26 \mathrm{eV}$ band is responsible for the high intial blue intensity that is visible as a blue "flash".

In contrast to the blue emission, the red emission $(1.75-2.2 \mathrm{eV})$ is centred around $1.96 \mathrm{eV}$ and shows an intensity minimum at initial electron bombardment that is flat or exhibits a steep parabolic increase during radiation duration of several minutes. However, the decrease of blue and the increase of red emission are two independent processes because it was observed in 
deformed quartz that the red emission remained constant whereas the blue one decreased (authors' unpubl. data).

After subsidence of the initial blue emission, the morphologically-distinct quartz generations of the SGC show different luminescence colours from bright blue to violet to dark red-brown. There are three different luminescence types of quartz in SG1 and SG2 rocks. Nearly all phenocrysts in the SG1 and SG2 sections, exhibit a weak luminescent, dark red-brown phenocryst core. This is surrounded by $100-1000 \mu \mathrm{m}$ broad, in shades of a blue and violet luminescent phenocryst ongrowth zone. The phenocrysts show an outermost ongrowth zone formed by homogeneous matrix quartz with unstable red-brown luminescence. The spectral analysis of the red-brown luminescent phenoblasts of the SG3 was not feasible due to the high density of feldspar inclusions.

The luminescence spectra at 1.3 to $3.1 \mathrm{eV}$ of these three types show different ratios of red versus blue emission peak areas. The ratio in the phenocryst core is 3.5 , in the blue zone 1.4 , and in the matrix quartz 2.8. The red-brown luminescent phenocryst core is characterized by a minor concentration of stable blue luminescent defect structures and accompanied by a low red emission intensity, that only slightly increases during continued radiation. In contrast, the blue luminescent quartz exhibits a much higher stable blue luminescence and also a low and slightly increased red emission. The intensity of the blue luminescence of the matrix quartz lies near those of the red core, but the high red intensity is characterised by a steep rise. Consequently, the CL of the two phenocryst luminescence types is more stable during electron radiation than the $\mathrm{CL}$ of the matrix quartz.

The infra-red emission between 1.3 to $1.5 \mathrm{eV}$ behaves similar to the red emission, the intensity increases with treatment (electron bombardment) time. The intensity of this emission peak is lower than the blue and red emissions, and it varies strongly within quartz grains that are visible as homogeneous.

\section{Primary growth textures}

The phenocrysts and microphenocrysts of the SG1 and SG2 show distinctive growth zonations (Figs. 7.6, .7.7 and 7.8), as is normally more common for rhyolitic phenocrysts (e.g. 


\begin{tabular}{|l|}
\hline $\begin{array}{l}\text { 1st generation } \\
\text { (phenocrysts) }\end{array}$ \\
\hline
\end{tabular}
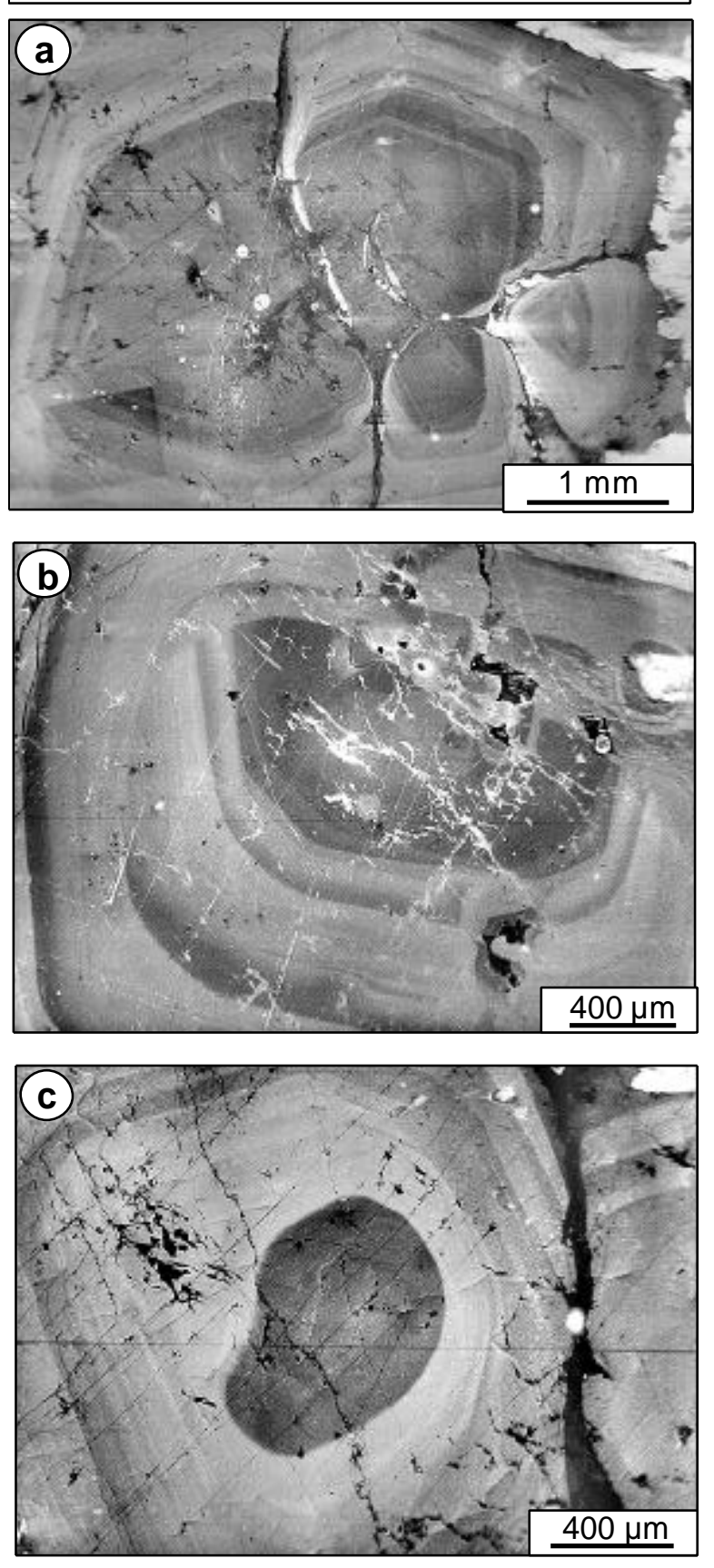
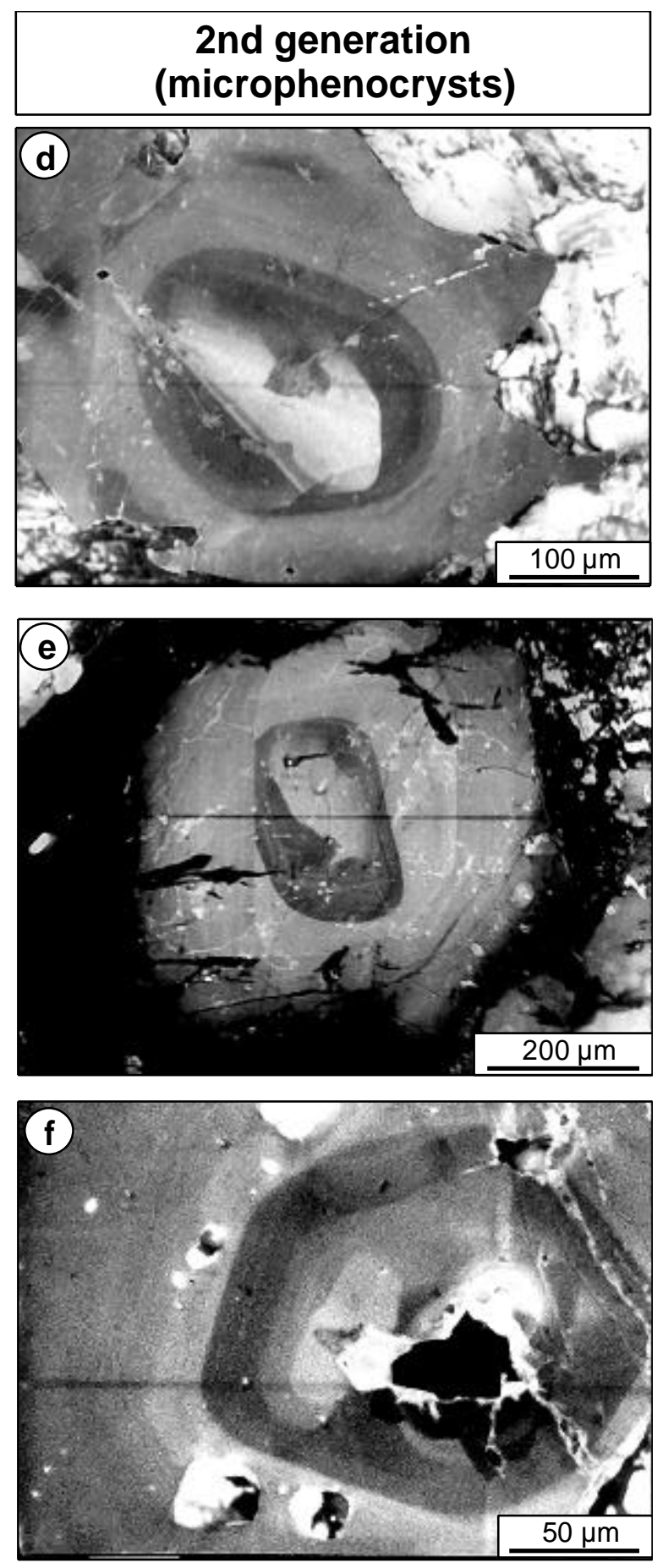

Fig. 7.6 Quartz growth textures contrasted by SEM-CL in the $1^{\text {st }}$ generation (phenocrysts) and in the $2^{\text {nd }}$ generation (microphenocrysts) of the SG1 and SG2; a - hexagonal dipyramidal phenocryst with hexagonal prism faces ( $\beta$-quartz) (SG1); b - microphenocryst (SG1) with anhedral ongrowth rim; c - phenocryst (SG2) with different resorbed surfaces; d - microphenocryst (SG2); e - phenocryst with rounded (resorbed) core (SG2); f microphenocryst nucleation on K-feldspar (black) (SG2). 
Laemmlein, 1930; Schneider, 1993; Watt et al., 1997). The existence of euhedral quartz phenocrysts in granites showing CL-contrasted growth textures is currently not known to be common and was described in only a few cases (Frentzel-Beyme, 1989; Seltmann, 1994; D'Lemos et al., 1997; Müller and Behr, 1997). The detailed analysis and comparison of growth textures of ca. 40 phenocrysts and 50 microphenocrysts in SG1 and SG2 allow the correlation of significant growth textures indicating a common crystallisation history.

All phenocrysts of the SG1 and SG2 exhibit a dark red-brown luminescent rounded or globular core (zone 1). Internally, the dark core zone does not show contrasted growth textures. Weakly contrasted growth zones occur exclusively in the marginal zone (zone 1a). The crystals used tiny mica, albite or orthoclase crystals as nuclei. Large crystal nuclei (e.g., mica and K-feldspar) often serve as growth centers for two to five quartz crystals simultaneously, and growth impediments are typical (Fig. 7.6a). Such grain clusters may break up during magma flow, leading to single grains, showing different growth rates in the various growth directions. In the case of small nuclei, isolated crystals develop.

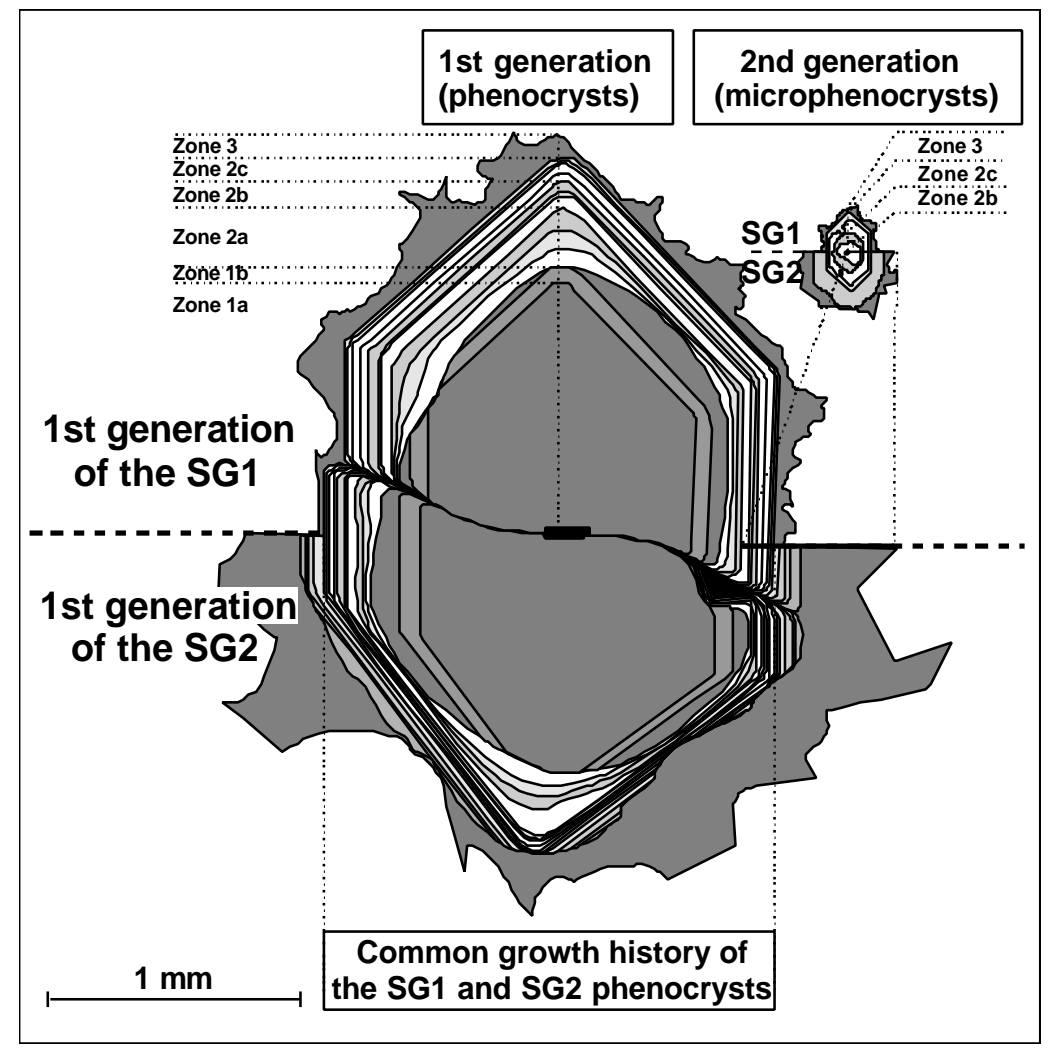

Fig. 7.7 Schematic representation of quartz growth textures contrasted by SEM-CL and their correlation with the $1^{\text {st }}$ generation (phenocrysts) of the SG1 and SG2. Two different euhedral quartz generations continue to grow simultaneously with the beginning of microphenocryst growth in the step zone $2 \mathrm{~b}$. The subordinate zones $2 \mathrm{a}$, b and $\mathrm{c}$ are characterised by a gradual change from bright blue to violet luminescence. Both the phenocrysts and microphenocrysts are hexagonal dipyramidal $\beta$-quartz crystals with hexagonal prism faces. 


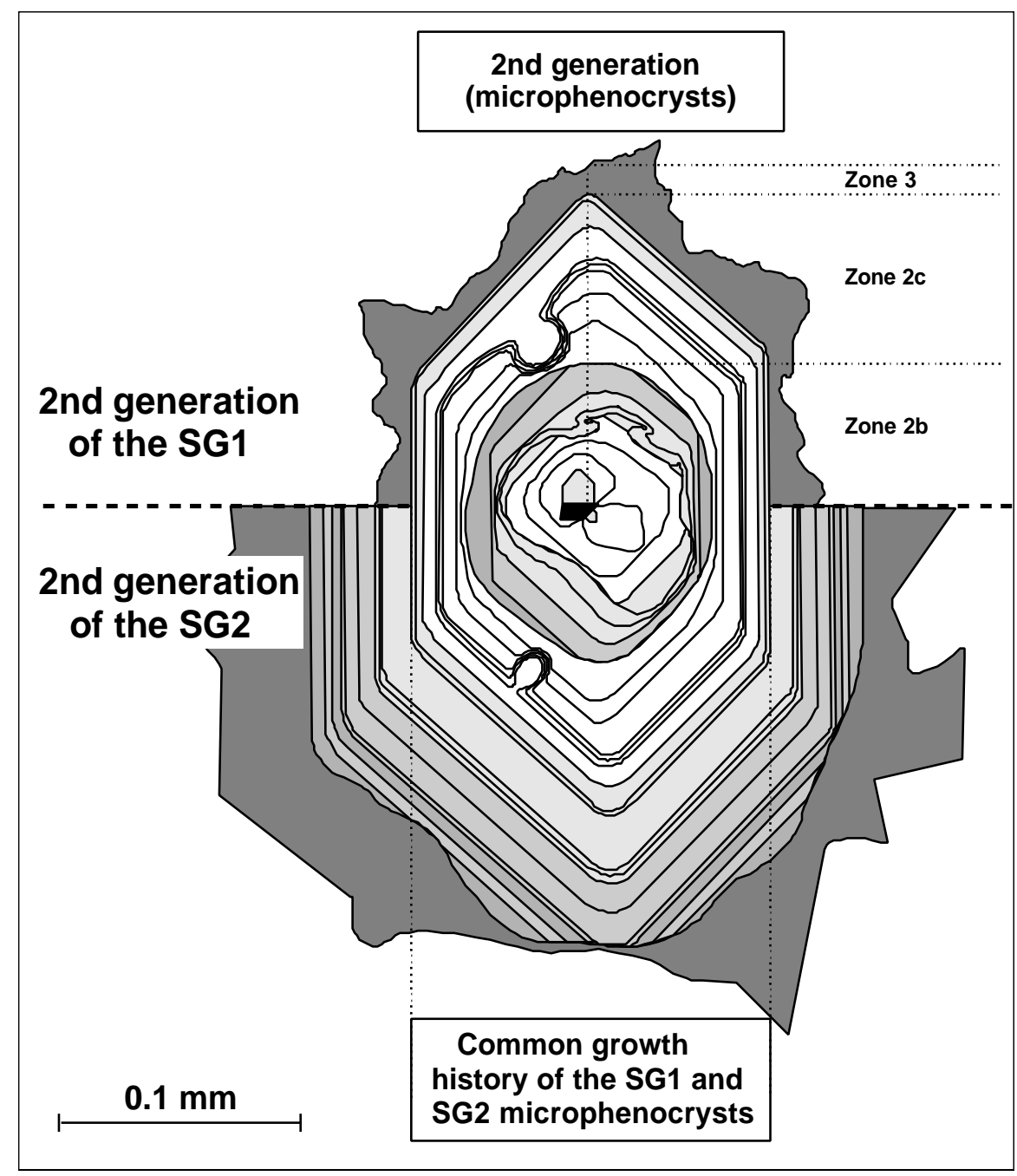

Fig. 7.8 Schematic representation of quartz growth textures contrasted by SEM-CL and their correlation with the $2^{\text {nd }}$ generation (microphenocrysts) of the SG1 and SG2. The frequent impediments of the zone $2 \mathrm{c}$ were caused by vapour bubbles that stuck to the crystal surface and hindered the growth.

The stage of red-brown growth ends with resorption (rounding) (Figs. 7.6b, c). The evidence of resorption is the cutting of zonations of zone 1a. The degree of resorption differs strongly in the individual crystals, and most of the euhedral crystals develop a globular shape. This is succeeded by a blue to violet growth zone (zone 2) that may be subdivided into three subzones $(2 \mathrm{a}, \mathrm{b}$ and $\mathrm{c})$. Internally, these sub-zones show a gradual transition from bright blue to violet. Within the sub-zones are oscillatory zonations of 2 to $20 \mu \mathrm{m}$ thickness. Zone 2 may have up to three subordinated resorption phases, where the resorption is only slightly developed and is not detectable in each crystal. The oscillatory zonation of zone 2 in the SG1 phenocrysts disappears in the direction of the red-brown luminescent rim $\left(3^{\text {rd }}\right.$ generation, zone 
3). In contrast, zone 2 in the SG2 phenocrysts is disturbed by resorption. This is followed by a homogeneous red-brown anhedral growth rim.

In addition to the $1^{\text {st }}$ generation of quartz phenocrysts, the $2^{\text {nd }}$ generation of euhedral quartz (microphenocrysts) occurring in the miarolitic SG1 (Figs. 7.4 and 7.8) exhibits clearlycontrasted growth textures with oscillatory zones of $\geq 2 \mu \mathrm{m}$. The growth textures belonging to different crystals may be correlated as genetically-linked generations. The nucleation of the second generation can be reconstructed in detail (Fig. 7.6d-f). Exclusively, tiny K-feldspar crystals serve as crystallisation centre for quartz that started growing simultaneously at many places on the feldspar surfaces. With increasing size the growing crystals touch and unify to a single crystal. It is significant that these crystals of the $2^{\text {nd }}$ generation do not show the growth impediments that usually develop during growth of neighbouring crystals (such as phenocrysts of $1^{\text {st }}$ generation). The crystals of the $2^{\text {nd }}$ generation could grow in the melt unimpeded and have only few small lobate impediments. Consequently, the crystals accumulated in a later crystallisation stage to intergranular clusters that are situated among the feldspars and form net-like envelopes around the feldspar crystals as visible by CL (Fig. 7.9). The crystal growth begins with bright blue luminescent quartz which merges into violet during further growth. This growth stage is accompanied by an early simultaneous resorption and by a subsequent distinct resorption stage (Fig. 7.6d-f). The overgrowth zone changes from bright blue to violet again. Within this zone lobate impediments often occur. Such structures could not be observed in large phenocrysts of the $1^{\text {st }}$ generation. Marginally, the SG1 microphenocrysts lose their zonal structure and merge into homogeneous, dark red luminescent, anhedral growth rims. In contrast, the marginal zone of the SG2 quartz concludes with resorption, similarly to the SG2 phenocrysts. Finally, the SG2 microphenocrysts show ongrowth of a homogeneous, red-brown luminescent anhedral generation $\left(3^{\text {rd }}\right.$ generation, zone 3$)$.

The average grain size of the microphenocrysts $(0.07-0.6 \mathrm{~mm}$, Fig. 7.4$)$ is lower in the SG1 than in the SG2 $(0.3-0.9 \mathrm{~mm})$. The comparison of grain size maxima of the miarolitic SG1 $(0.15 \mathrm{~mm})$ with the aplitic SG1 $(0.3 \mathrm{~mm})$ shows that the grain size of this generation increases in the aplitic SG1. The CL observations allow the conclusion that this increase of grain size is caused by a broader anhedral growth rim in the aplitic facies. In contrast, the grains of the miarolitic variety exhibit either no or very thin growth rims. Thus, the measured average grain size of the miarolitic variety represents the "true" size of the SG1 microphenocrysts. 


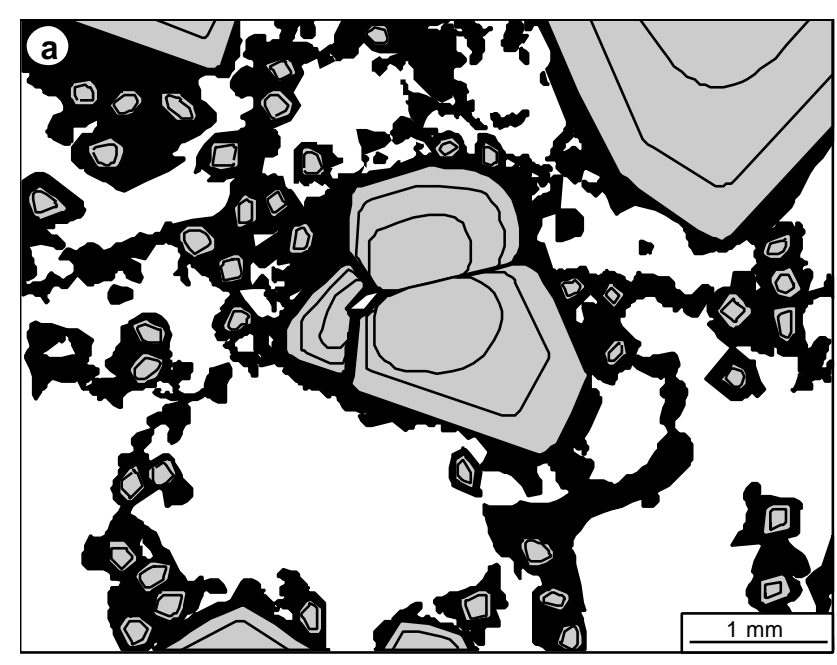

Fig. 7.9 Distribution of the $1^{\text {st }}$ (large grey grains), $2^{\text {nd }}$ (small grey grains) and $3^{\text {rd }}$ generation (black) in the quartz framework a) of the SG1 and b) of the SG2 in thin section images.

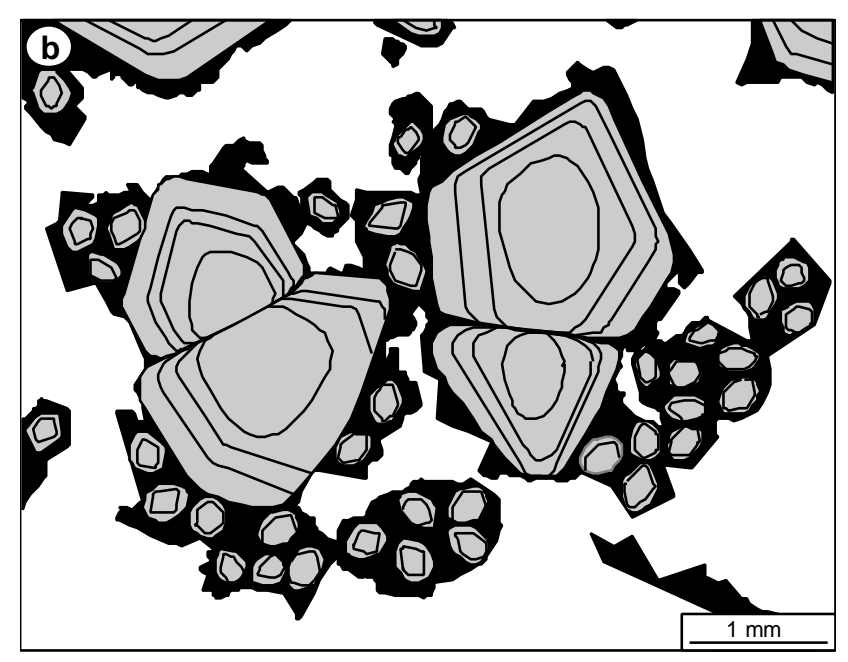

Although the euhedral $1^{\text {st }}$ and $2^{\text {nd }}$ generations show different grain size range, it is justified to correlate their growth textures. The microphenocrysts have initial growth during the growth of zone $2 \mathrm{~b}$ of the phenocrysts. Both exhibit the same resorption events, but the resorption is more strongly developed in the microphenocrysts. In exceptional cases, individual crystals form sub-generations between 1 st and 2 nd generations. These are phenocryst fragments that formed by brittle failure during magma flow and that later continued to grow separately (Fig. 7.6a). According to habits, internal zonation and luminescence behaviour, the $1^{\text {st }}$ and $2^{\text {nd }}$ generations of quartz phenocrysts are similar or identical to those in rhyolites (Schneider, 1993). This observation characterises the original SGC melt as dry felsic (rhyolitic) magma.

The growth zoning of phenoblasts of the SG3 $\left(4^{\text {th }}\right.$ generation, Fig. 7.5$)$ shows no similarities to the zoning in the phenocrysts and microphenocrysts of the SG1 and SG2 and develops obviously under magma-hydrothermal transitional conditions when the melt is degassing. It is clearly distinguishable from the postsolidus rearrangements by hydrothermal fluids as outlined above. The phenoblasts consist of sharp-bordered, homogeneous, bright grey and 
dark grey contrasted zones $(2 \mu \mathrm{m}$ to $200 \mu \mathrm{m})$. Resorption surfaces which resulted in rounding of the crystals cannot be detected. The zoning follows the shape of trigonal $\alpha$-quartz (combination of the hexagonal prism $\mathrm{m}$ and the rhombohedrons $\mathrm{r}$ and $\mathrm{z}$ ). Growth impediments occur around the feldspar inclusions, but the impediments do not form large lobate textures like those in the microphenocrysts.

\section{Secondary CL structures}

Primary growth textures and secondary CL structures are distinguished by characteristic features because primary textures were developed during crystallisation and secondary strucutres formed after growth. Secondary structures overprint and delete primary ones. Cataclasis of crystals (cracks, decrepitated inclusions) cause recrystallisation of quartz that shows different CL characteristics due to formation under different conditions.

Almost all quartz crystals contain dark red-brown luminescent, star-like structures along thin microcracks $(<3 \mu \mathrm{m})$. These strucutres are healed decrepitation traces of micro-inclusions. The ruptures that connect the decrepitation halos can be explained by cooling-induced thermal stresses at grain scales, especially during incoherent $\beta$-/ $\alpha$-transition and isothermal uplift (Sprunt, 1979; Behr, 1989). In the case of dense networks of microcracks a fracture pattern of dark contrasted polygons develops (Figs. 7.6e and 7.10).

White to light gray contrasted structures veining the grains in high intensity are conspicious in these samples (Fig. 7.6b). Their distribution is inhomogeneous; some single grains are extremely veined and others not. These structures are stable at extended electron bombardment and are rooted in inclusions and neighboured crystals of K-feldspar. The quartz develops white rims at its grain boundaries with K- feldspar. The veins use the decrepitation structures and partially overprint them. All quartz types show light halos around radioactive inclusions.

In addition to thin CL contrasted microcracks $(<3 \mu \mathrm{m})$ that connect the decrepitation traces, larger transgranular microshear zones (to $100 \mu \mathrm{m}$ ) showing distinct brecciation of the host quartz occur (Fig. 7.6c). The healed cracks, that are only visible by CL are related to heat generated by friction of crystals in the melt and to post-magmatic deformation. 


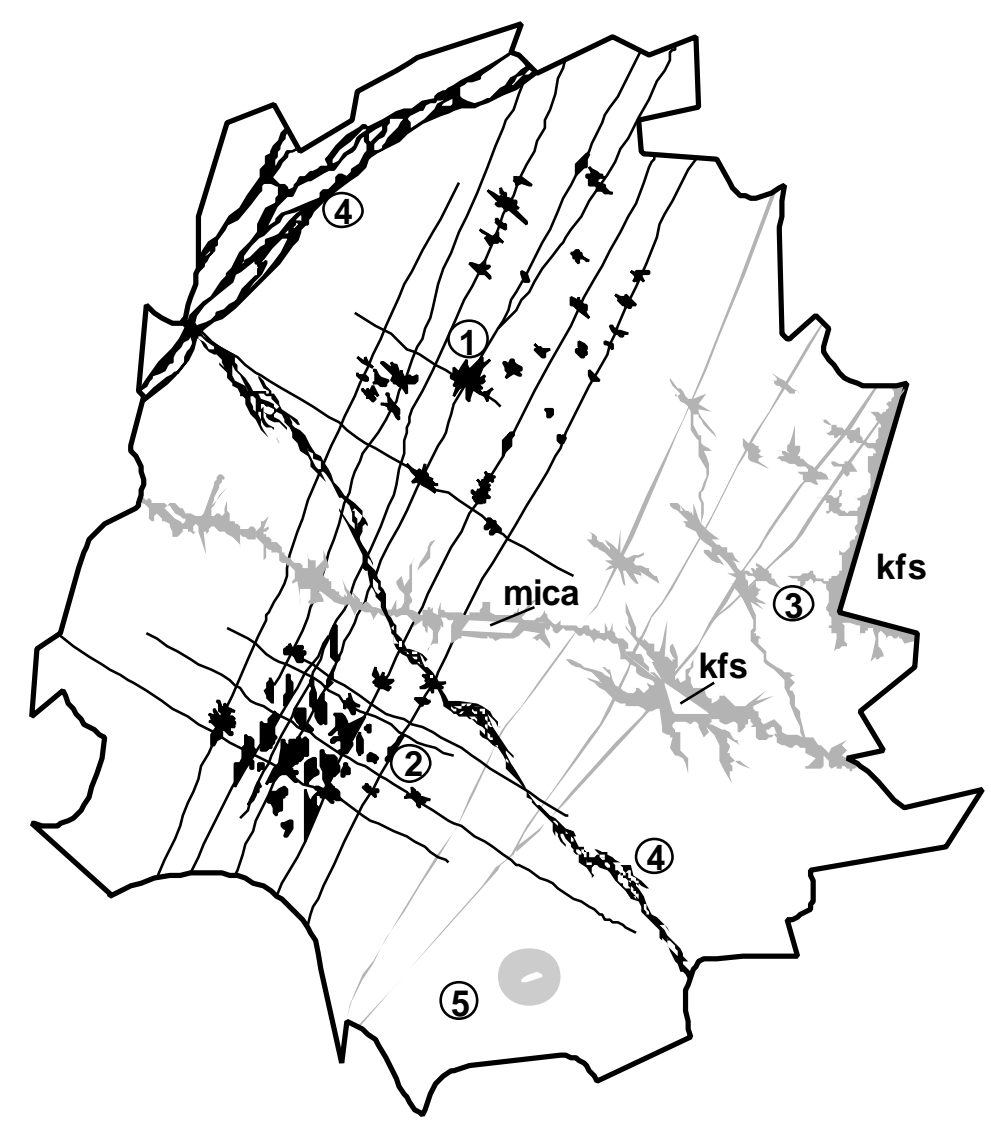

Fig. 7.10 Synoptical scheme of secondary structures contrasted by SEM-CL. 1 - star-like decrepitation traces around fluid inclusions connected with microcracks; 2- pattern of polygons associated with a dense network of microcracks; 3 - light grey contrasted structures rooted in inclusions and neighboured crystals of K-feldspar; 4 microshear zones; 5 - round halos around radioactive inclusions.

\subsection{Relationships between CL and trace element distribution in quartz of the SGC}

Different trace element contents in the quartz generations and the heterogeneous incorporation of trace elements in zoned crystals reflect changes of growth conditions like temperature, pressure and composition of the melt. One aim of this work was to determine the traceelement contents of the different quartz generations and their distribution in the zoned phenocrysts, to search for correlations between the CL behaviours and $\mathrm{Al}, \mathrm{Ti}, \mathrm{Fe}$ and $\mathrm{Mn}$.

High Al concentrations occur in the red brown luminescent matrix quartz as a short-lived, intensive initial blue (Figs. 7.11a, c and 7.12). In contrast, the quartz phenocrysts and the quartz of the healed microcracks with blue CL and relative stable red-brown, respectively, contain low Al concentrations. Alonso et al. (1983), Perny et al. (1992), Kalceff and Phillips (1995) and Gorton et al. (1996) suggested that the 3.1 - 3.25 eV emission band correlates with $\mathrm{Al}$ of the compensated centres and causes the unstable portion of the blue CL. However, the 
investigated quartz shows a decrease of the entire measured blue emission range $(2.6-3.1$ $\mathrm{eV}$ ) with maximum at $2.79 \mathrm{eV}$.
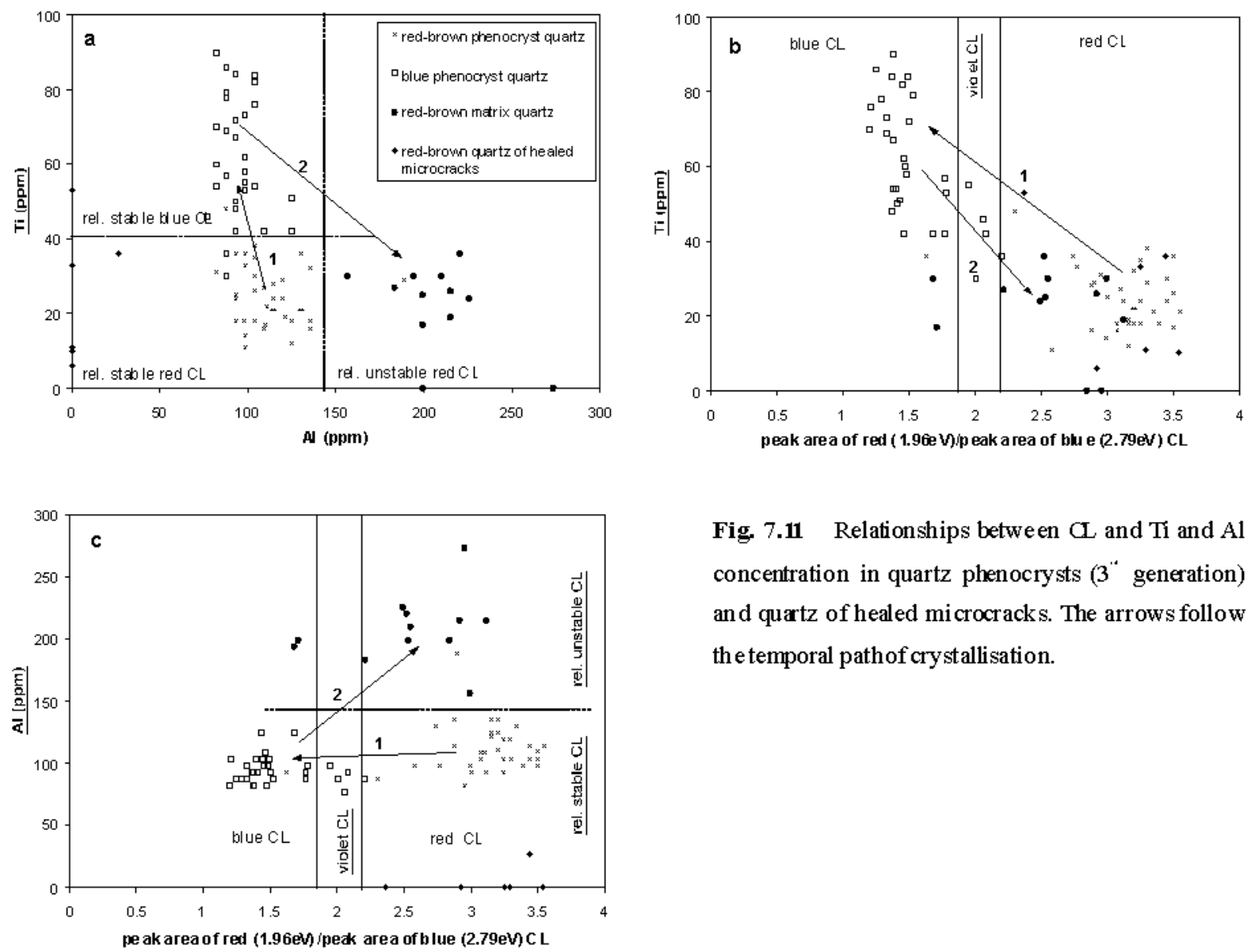

Fig. 7.11 Relationships between $\mathrm{C}$ and $\mathrm{Ti}$ and $\mathrm{Al}$ concentration in quartz phenocrysts ( $3^{\text {" generation) }}$ and quartz of healed microcracks. The arrows follow the temporal pathof crystallisation.

Numerous studies of natural and synthetic quartz by electron paramagnetic resonance (EPR) and optical absorption showed that $\mathrm{Al}^{3+}\left(\mathrm{M}^{3+}\right)$ as the most characteristic impurity element of quartz substitutes $\mathrm{Si}^{4+}$ in the silicon-oxygen tetrahedra of the regular lattice and $\mathrm{Li}^{+}, \mathrm{Na}^{+}, \mathrm{K}^{+}$, $\mathrm{Fe}^{2+}$ and $\mathrm{H}^{+}\left(\mathrm{M}^{\mathrm{n}+}\right)$ as ion-compensators enter interstitial positions. The infrared absorption spectra of natural quartz crystals often exhibit sharp, dichroic absorption peaks between 3000 and $3740 \mathrm{~cm}^{-1}$ which are associated with hydrogen and hydroxyl acting as a charge compensator of $\mathrm{Al}^{3+}$ and of $\mathrm{M}^{\mathrm{n}+}$ (e.g. Brunner et al., 1961; Kats, 1962; Bambauer et al., 1963). Maschmeyer and Lehmann (1983) gave a first model for the association of Al and hydroxyl in quartz where two $\mathrm{OH}$ groups are neighbouring the substitional $\mathrm{M}^{3+}\left(\mathrm{Al}^{3+}, \mathrm{Fe}^{3+} \ldots\right)$ and interstitial $\mathrm{M}^{\mathrm{n}+}$. Stenina et al. (1988) showed on the basis of transmission electron microscopy, X-ray microanalysis and EPR that the trace $\mathrm{M}^{3+}$ cations replacing $\mathrm{Si}^{4+}$ in oxygen tetrahedra are related to compensating $\mathrm{M}^{\mathrm{n}+}$ ions and form parts of aqua complexes and clusters as follows: 
Scheme 1

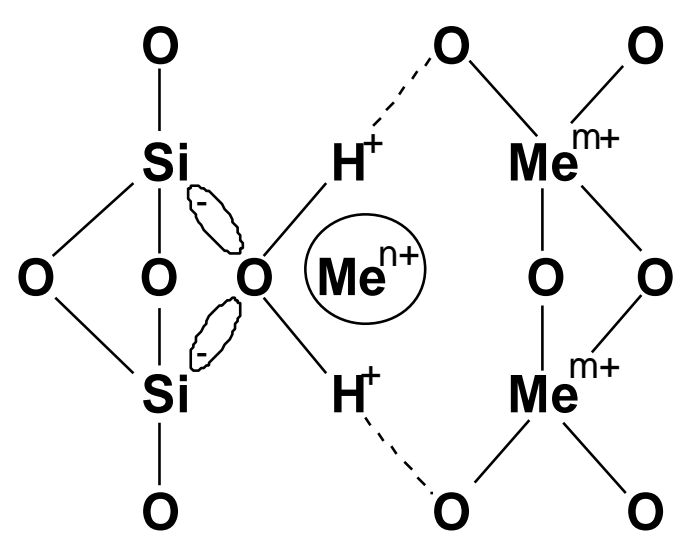

The greater part of the structural water, Al-, Li- and Na-ions of hydrothermal and magmatic quartz are incorporated in such aqua complexes. These defect structures are primary and are built into the lattice during crystallisation. Consequently the uptake of $\mathrm{M}^{\mathrm{p}^{+}}$and $\mathrm{M}^{\mathrm{n}+}$ in magmatic quartz is controlled by the presence of water in the melt. The structural water bounded as $\mathrm{Si---O}-\mathrm{H}-\mathrm{H}$ traps scattered electrons during radiation and the bounds are ruptured (McLaren and Phakey, 1966; Maschmeyer and Lehmann, 1983; Stenina et al., 1984). The radiation-induced reaction results in the development of paramagnetic E' centres ( $\equiv \mathrm{Si} \cdot$ ) and/or diamagnetic trapped electron centres $(\equiv \mathrm{Si}$ :) which are beside the non-bridging oxygen hole centres (Si-O) the cause for the emission at $1.96 \mathrm{eV}$ (Griscom, 1985). This process is visible by $\mathrm{CL}$ where the formation of point defects of red-brown CL $(<1 \mu \mathrm{m})$ takes place in water-rich pegmatitic and granitic quartz during electron bombardment (e.g. Behr, 1989; Schneider, 1993). Nevertheless, the mechanism of transformation is not clearly yet. The higher the content of interstitial molecular water and of associated $\mathrm{Me}^{\mathrm{n}+}$ and $\mathrm{M}^{3+}$ ions in the magmatic quartz the steeper is the intensity increase of red CL during the electron bombardment. Furthermore, the different quartz luminescence types of the SGC reflect the water content of the melt: dry ("rhyolitic") conditions during the nucleation and growth of the red-brown phenocryst core, more wet conditions during the blue phenocryst growth and, finally, wet ("granitic") conditions during the granite emplacement and crystallisation of the $3^{\text {rd }}$ generation. The low Al concentration in the phenocrysts is presumedly caused by the limited water supply in the melt. This conclusion confirms Thomas (1994) who determined water contents of melt inclusions of Erzgebirge granites in the range of 2.9 to 8.0 eq. wt. \%. These melt inclusions represent the early and late stages of quartz crystallisation, respectively. 


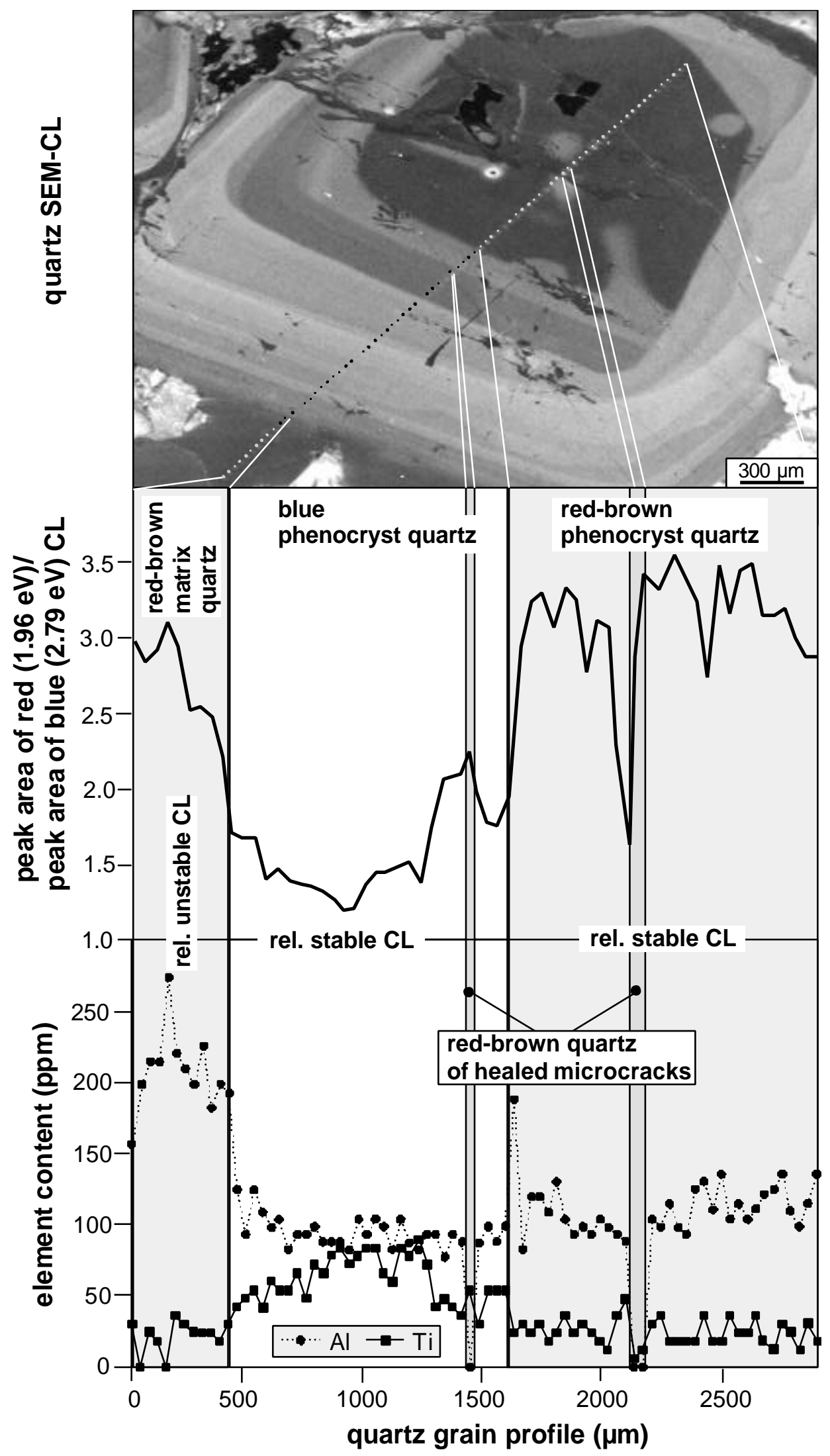

Fig. 7.12 SEM-CL profile across a zoned quartz phenocryst showing the $\mathrm{Al}$ and Ti concentration and the ratio of the red and blue emission peak areas. 
In contrast to the $\mathrm{M}^{3+}$ and $\mathrm{M}^{\mathrm{n}+}$ the substitional $\mathrm{M}^{4+}$ ions (mostly $\mathrm{Ti}^{4+}$ ) create relatively stable defect centres without interstitial charge compensators. The blue luminescent quartz of the phenocrysts and microphenocryst shows a strong enrichment of Ti. In contrast the stable redbrown CL of the phenocryst and crackling structures and the unstable red-brown CL of matrix quartz exhibit low $\mathrm{Ti}$ concentrations. The high intensity of the stable blue luminescence correlates with Ti-related defect centres (Figs. 7.11a, b and 7.12). These observations are also supported by Kerkhof et al. (1996) and Bruhn et al. (1996). It remains unsolved if the Ti functioned as CL activator or sensitizer (J. Götze, pers. comm.). The dark red-brown luminescent quartz of the healed microcracks and of the decrepitation halos is depleted in $\mathrm{Al}$ and Ti (Figs. 7.11a-c and 7.12).

Iron and manganese concentrations of all CL types are below the detection limit of 23 and 26 ppm, respectively.

\subsection{A multistage quartz crystallisation model of the SGC}

\section{Early phenocryst crystallisation}

Initially, nuclei developed in the melt during growth as hexagonal dipyramids ( $\beta$-quartz). Such crystals are formed at low values of undercooling $\Delta \mathrm{T}_{\mathrm{i}}$ (Kirkpatrick, 1975; Allègre et al., 1981; Swanson and Fenn, 1986; MacLellan and Trembath, 1991). The value of $\Delta T_{i}$ is the difference between the liquidus temperature and crystallisation temperature. At such conditions, the nucleation rate is low (Swanson, 1977), and only a limited number of nuclei may be formed in the melt.

The nucleation of quartz crystals of the $1^{\text {st }}$ generation, and $2^{\text {nd }}$ generation, as well took place in few cases on growth centres that are formed by tiny K-feldspar, albite and mica crystals. Their joint occurrence allows to interpret them as microenclaves that are in disequilibrium with the melt. Especially the alkali feldspar residues are often corroded until nearly complete resorption.

The euhedral habit of the phenocrysts seems to indicate unimpeded crystallisation in the melt, maybe due to high charge potential. The hexagonal habit of the zoning $(\beta$-quartz) indicates that the phenocrysts crystallised at about $750{ }^{\circ} \mathrm{C}(7 \mathrm{kbar}$; Yoder, 1950) and that the melt shows a $\mathrm{H}_{2} \mathrm{O}$-content of $<2.5 \mathrm{wt} \%$ (Johannes and Holtz, 1996). Evidence for possible maximum depths of first nucleation for crystallisation of Erzgebirge tin granites is provided by microthermometric studies of silicate melt inclusions in quartz phenocrysts (Thomas, 
1992), which indicate the depth of magma formation of up to $21 \mathrm{~km}$ (Fig. 7.13). The results of melt inclusion studies (Thomas, 1994) on granitic quartz form a p-T-t path that tracks the entrapment of melt during quartz growth in different stages of magma uprise at various crust levels. This synoptical information based on a few hundreds of inclusion data reflects the stages of melt evolution. To reconstruct in detail from which defined growth zone of a single quartz phenocryst an individual melt inclusion was measured requires application of more sophisticated methods (oriented sections, CL, SIMS).
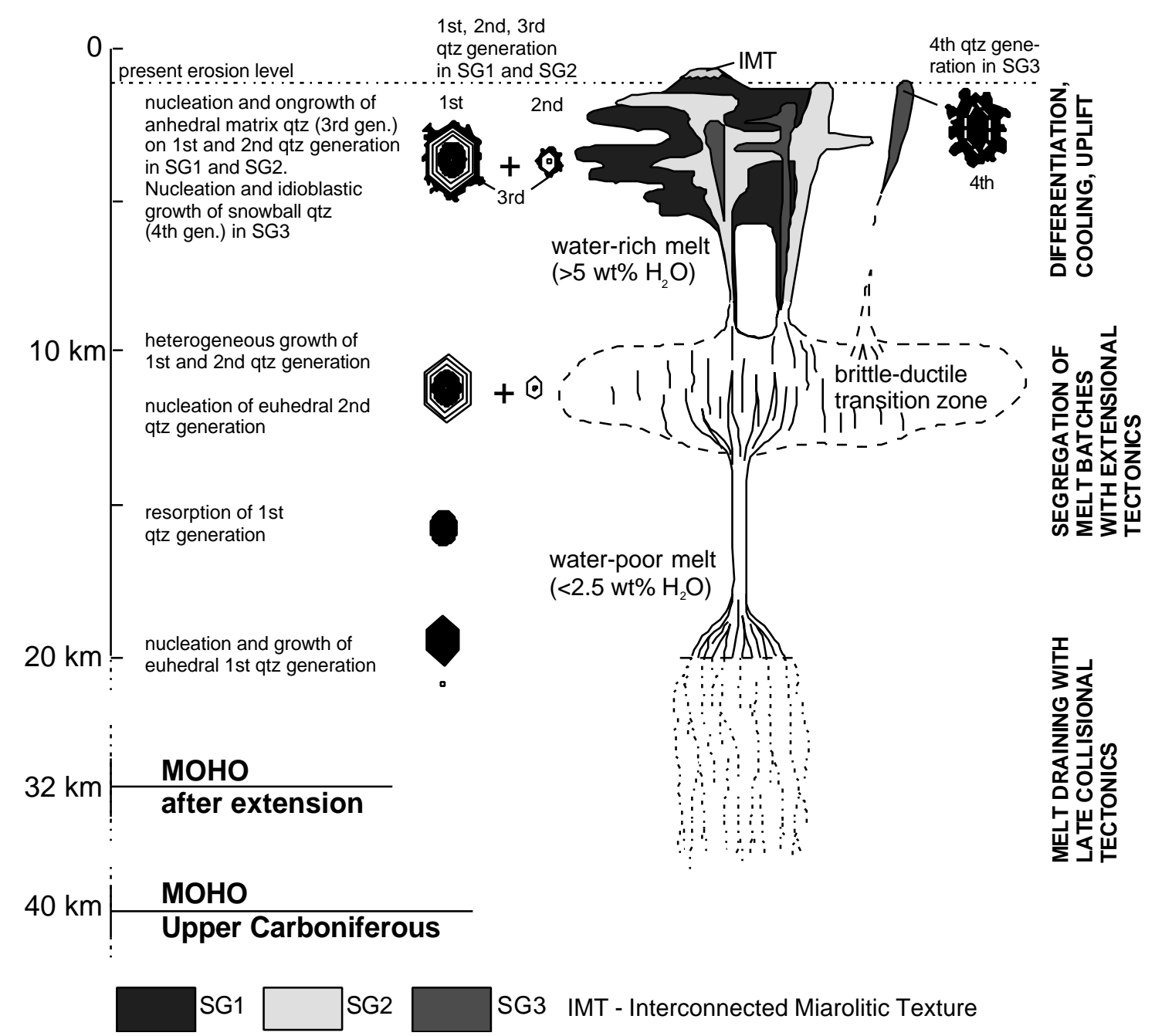

Fig. 7.13 The quartz crystallisation model of the Schellerhau granites. Scheme shows nucleation, growth and resorption of four different quartz generations at its formation depths and resulting growth patterns. The evolution scheme of the SGC considers melt generation from the lower crust under decompressional, late collisional tectonics of the Variscan orogen in the Upper Carboniferous. Extensional tectonics control the segregation of melt batches and multiphase intrusion of SG1, SG2 and SG3 into a subvolcanic level. 
Weakly CL contrasted growth zones developed only during the final stage of initial growth (red-brown luminescent core zone 1, Fig. 7.7). These may be either self-organised (oscillative) growth zones or zones disturbed by disequilibrium with the melt. The growth of zone 1 ended abruptly by strong resorption of the initial crystallisation stage. Rapid, isothermal ascent of the magma into higher crust levels explains the resorption that produced rounded crystals (Holtz and Johannes, 1994). There is no evidence for magma mixing, neither from the chemical evolution of the intrusion sequence nor from the element profiles in the feldspars (authors' unpubl. data).

The growth of the blue luminescent zone begins (zone 2) in a higher crust level, at weaklyundercooled melt conditions (Fig. 7.13). The euhedral unimpeded growth continues, with the distinction, that periodic, fine laminae, $5-20 \mu \mathrm{m}$ broad oscillatory zones form in the 300 to $1000 \mu \mathrm{m}$ broad zone 2.

Cyclic, self-organising oscillation growth is only possible when the melt cannot convect and the chemical bulk composition remains constant. Despite the obvious homogeneity of the blue growth zone a number of events are documented that possibly reflect changes of the melt conditions (Figs. 7.9 and 7.13):

1. Within zone 2 occurs three times the gradual change from bright blue to violet. These subzones ( $2 \mathrm{a}, \mathrm{b}$ and $\mathrm{c})$ stop abruptly and the next zone starts growing with bright blue CL.

2. A second nucleation stage, that begins with the growth of zone $2 b$ in the phenocrysts occurs. Crystallisation of the $2^{\text {nd }}$ euhedral quartz generation (microphenocrysts) starts (Fig. 7.7, 7.13). The second nucleation stage requires a change in temperature/pressure conditions (Sibley et al., 1976).

3. Furthermore, up to three subordinated resorption stages develop. Only one of them coincides with the abrupt change of violet to blue luminescence (border of zone $2 b$ to $2 c$ ). The other two resorptions are situated within the zones $2 \mathrm{a}$ and $2 \mathrm{~b}$, respectively. The latter resorption stages are more clearly developed in the microphenocrysts than in the phenocrysts.

4. Also obvious are frequent lobate impediments occurring in the zone $2 \mathrm{c}$, especially of the microphenocrysts (Fig. 7.8). The impediments may be caused by vapour bubbles which stuck to the crystal surface and hindered growth. The bubble formation may be explained by depressurisation (degassing) and related foaming ( $1^{\text {st }}$ boiling of melt) prior to the main intrusion. 
The equilibrium of the bulk melt in the reservoirs, that is responsible for the blue luminescent zones, occurred for a long time, and was only slightly disturbed. Stepwise ascent along short distances or convection may be the cause of weak undercooling in the melt. The initiation of growth of the microphenocrysts of zone $2 \mathrm{~b}$ caused two different euhedral quartz generations that continue to grow simultaneously. The nuclei of the microphenocrysts surrounding one and the same crystallisation centre unify themselves during continued growth to one single crystal which contrasts with the nucleation behaviour of the $1^{\text {st }}$ quartz generation. This may be due to lower charge potential of the $2^{\text {nd }}$ quartz generation.

\section{Melt separation, intrusion, and main crystallisation of SG1, SG2 and SG3}

Generally, the $1^{\text {st }}$ and $2^{\text {nd }}$ quartz generations of the SG1 and SG2 have a common crystallisation history as outlined above. Only during the growth of zone $2 b$, the SG1 melt separated from deeper located melt reservoir and intruded at a subvolcanic level. The microgranophyric and aplitic matrix quartz, both of which crystallised in the intrusion level, represent as $3^{\text {rd }}$ generation (zone 3 ) the final crystallisation. The textures indicate extreme nucleation, low growth rates and that the melt was strongly undercooled (Swanson and Fenn, 1986). MacLellan and Trembath (1991) show, that porphyritic textures in which quartz occurs as unit of phenocrysts and aplitic matrix grains (Kirkham and Sinclair, 1988) are textures of rapid cooling. Granophyric intergrowths in the groundmass and matrix quartz overgrowing the phenocrysts are common. Consequently, the quartz phenocrysts were already present, when the matrix and granophyric quartz crystallised. In addition to the textures, the geomorphological and stratigraphic considerations of Spengler (1949) and Schust (1980), who concluded a ca. 1,000 m thick cover at the time of intrusion, support the subvolcanic nature. Geothermobarometric data give a paleo-intrusion level of the various tin granites of the Erzgebirge between 200 and 3,000 m (Seltmann et al., 1992).

The locality Pöbelknochen $(833 \mathrm{~m})$ represents the roof of the Schellerhau massif. There are diffuse contacts between "normal" SG1 rocks (with 15\% phenocrysts) and local zones of SG1 variations with extremely variable phenocryst content. We interpret the latter rocks as result of highly dynamic magma near the intrusion centre. Possible interpretations include mixing of forerunner marginal and main phase magma in the immediate roof parts of the intrusion, or magma schlieres with variable phenocryst content, or melt batches intruding subsequently to the normal SG1 emplacement. Except for the marginal intrusive endocontacts, only at Pöbelknochen few xenoliths of the metamorphic cover are incorporated in the granite body. The interconnected miarolitic texture (IMT) found at Pöbelknochen 
clearly developed in the granite variety with microgranophyric matrix quartz of SG1 (0.01 - 1 $\mathrm{mm})$. It represents a snapshot of a special type of volatile-phase permeability that occurs in the upper part of granite complexes (Candela and Blevin, 1995). The volatile phase was enriched beneath the impermeable roof of the intrusive body, infiltrated earlier crystallised marginal granite intrusion phases and reacted with the crystallising magma itself. The roof impermeability was formed through rapid cooling (and pressure release quenching, resp.) when the granite melt intruded zones of sharp thermal gradient that is developed best at subvolcanic crustal levels (Seltmann, 1994). The IMT disappears beneath the top of the Pöbelknochen and merges into aplitic texture. Towards deeper parts of this elevation, the IMT is developed only along a few joints that were used after their opening as fluid pathways. Feldspar phenocrysts are surrounded by granophyric intergrowths with quartz caused by undercooling due to degassing of magmatic vapour phase and related pressure release. The locality might represent according to gravity data (Tischendorf, 1964), the central part of the NNW striking intrusion axis and, moreover, the fluid-enriched carapace above the intrusion centre.

Because the $1^{\text {st }}$ and $2^{\text {nd }}$ quartz generations were resorbed in SG2 but not in SG1 (Figs. 7.7 and 7.8), we conclude that the melt/crystal ratio remained nearly constant in SG1. The resulting slope of the P-T path of the SG1 melt ascent should run along the liquidus curve or be more flat in response to the water content of the melt (Holtz and Johannes, 1994; Johannes and Holtz, 1996).

After the SG1 melt portion separated from the deeper reservoir, the remaining phenocrysts continued to grow to another 10 to $15 \mathrm{vol} . \%$ and the microphenocrysts of the 2 nd generation increase their volume by 100 vol.\% until the SG2 melt separated from the reservoir and intruded the subvolcanic level that was earlier reached from the SG1 portion. Based on the extreme degree of phenocryst rounding, the melt/crystal ratio must have increased and the ascent was nearly isothermal. The anhedral matrix crystals are in comparison to the SG1 less but larger $(0.08-0.6 \mathrm{~mm})$, and indicate medium to low undercooling (Swanson and Fenn, 1986). The SG2 could use the intrusion path of the SG1 as is indicated by the spatial distribution of the SG2 along the SG1 flanks and that at depth the SG2 is situated parallel to the SG1 intrusion axis. Because the magma of the SG1 intrusion pre-heated the intrusion level and formed a thermal barrier by rapid cooling of its roof, the cooling of SG2 occurred more slowly as indicated by the seriate to equigranular textures of the latter. Chilled margins at some contacts and sharp borders of SG1 fragments within SG2 provide evidence that the SG1 was already fully crystallised when the SG2 intruded. It is postulated that the intrusion of both 
granites occurred in the period of crustal uplift and rapid erosion so that the crystallisation process happened within changing $\mathrm{p}$ - $\mathrm{T}$ gradients.

The SG3 represents the end member of the geochemical differentiation of the Schellerhau granite massif. Despite its geochemical and genetical relations with SG1 and SG2, the SG3 does not show textural similarities. Geochemical evidence (REE patterns, $\mathrm{Zr} / \mathrm{Hf}$ ) indicates that the melt originated from the same reservoir. But, texturally, the phenocrysts of the $1^{\text {st }}$ and $2^{\text {nd }}$ generations are missing as expected. The sealed amoebic grain boundaries of snowball quartz $\left(4^{\text {th }}\right.$ generation) show replacement and idioblastic growth with entrapment of numerous matrix crystals. The crystallisation of this phenoblastic quartz type occured in the last stage of crystallisation representing the fluid-saturated, highly-evolved alkali feldspar-rich residual melt. Oscillations of rapidly increased velocity of quartz growth enabled zonal entrapment of albite. At slow growth velocity quartz "snowplowed" the albite tablets in the melt and albite-free zones of quartz were developed. This crystallisation stage is representing the magma-hydrothermal transition when the melt is becoming highly viscous after releasing its magmatic vapour phase (magma degassing due to hydraulic fracturing).

The trigonal habit of the zoning ( $\alpha$-quartz) indicates that the phenoblasts crystallised at $<600^{\circ} \mathrm{C}(<1 \mathrm{kbar})$. The phenoblasts which crystallised in the subvolcanic level indicate a latestage $\mathrm{H}_{2} \mathrm{O}$-content of $>5 \mathrm{wt} \%$ in the melt (Yoder, 1950; Thomas, 1994; Johannes and Holtz, 1996).

The quartz phenoblasts and hydrothermal greisen quartz cannibalised more or less the older quartz generations, thus reflecting the intense late- to post-magmatic fluid-rock reactions that are closely related to tin mineralisation and deuteric alteration.

\subsection{Summary}

The application of cathodoluminescence combined with grain texture and grain size analysis facilitates the identification of four quartz generations in the SG1, SG2 and SG3: (1) large $(\varnothing=2.3 \mathrm{~mm})$ euhedral hexagonal dipyramidal zoned phenocrysts ( ${ }^{\text {st }}$ generation); (2) hexagonal dipyramidal zoned microphenocrysts ( $2^{\text {nd }}$ generation) $\varnothing=0.2 \mathrm{~mm}$ ); (3) matrix quartz $\left(3^{\text {rd }}\right.$ generation) developed aplitic and miarolitic $(\varnothing=0.1 \mathrm{~mm})$ in the SG1 and anhedral $(\varnothing=0.3 \mathrm{~mm})$ in the SG2; and (4) zoned, micropoikilitic, amoebic and snowball-like quartz phenoblasts $(0.3-5 \mathrm{~mm})\left(4^{\text {th }}\right.$ generation $)$ in the $\mathrm{SG}$. One maximum of a grain size 
distribution plot represents one quartz generation and indicates a burst of nucleation which was caused by a melt undercooling event.

The same grain size, grain habit and the correlatable growth textures of the phenocrysts and microphenocrysts in the different granite varieties give proof of a common crystallisation history until the melts of the three granite varieties SG1, SG2 and SG3 were separated and intruded. Four nucleation events occurred during crystallisation at different crustal levels between about 20 and $1 \mathrm{~km}$ depth.

The stable blue CL of the phenocrysts correlates with high Ti concentrations. The unstable blue as well as the unstable red $\mathrm{CL}$ are controlled by aqua complexes in the form of $2 \mathrm{SiO}_{3}-$ $\mathrm{H}_{2} \mathrm{O}-\mathrm{M}^{\mathrm{n}+} 2 \mathrm{M}^{3+} \mathrm{O}_{4}$, where $\mathrm{M}^{3+}$ is mostly $\mathrm{Al}^{3+}$ and $\mathrm{M}^{\mathrm{n}+}$ mostly $\mathrm{H}^{+}, \mathrm{Li}^{+}$and $\mathrm{Na}^{+}$. The slight increase of the red emission intensity during electron bombardment reflects dry conditions during the nucleation and the early crystallisation stage. The steep increase reflects more wet conditions during the granite emplacement and crystallisation of the $3^{\text {rd }}$ generation. The Schellerhauer granite melt is interpreted as one with a dry „rhyolitic“ early stage, due to the euhedral zoned $\beta$-quartz phenocrysts formed in water-poor conditions with $<2.5 \mathrm{wt} \% \mathrm{H}_{2} \mathrm{O}$ in the melt and at temperatures about $750^{\circ} \mathrm{C}$. The water content of the melt increases during the further development until the melt assumes granitic properties. The $4^{\text {th }}$ quartz generation (snowball quartz) which crystallised in the subvolcanic level indicates a $\mathrm{H}_{2} \mathrm{O}$-content of $>5$ wt $\%$ in the melt and temperatures $<600^{\circ} \mathrm{C}$. Due to the highly-reactive fluids exsolved in late magmatic stages from the melt, the quartz and feldspar phenocrysts of $1^{\text {st }}$ and $2^{\text {nd }}$ generations were cannibalised and only a few relics of $\mathrm{K}$ feldspar remained.

The application of CL is a very helpful and irreplaceable tool for the reconstruction of the crystallisation history of granitoid melts in connection with other methods such as traceelement geochemistry, grain texture and grain size analysis. 


\section{The genetic significance of snowball quartz in highly fractionated tin granites of the Krušne Hory/Erzgebirge}

(this chapter has been published in "Mineral Deposits: Processes to Processing" edited by Stanley et al., Balkema, pp. 409-412, 1999, co-author: R. Seltmann)

\subsection{Abstract}

Snowball-textured quartz phenoblasts are magmatic-hydrothermal fluid saturation textures and occur widespread in highly evolved alkali feldspar and topaz-bearing granites. They are characterised by zonal arrangement of entrapped matrix minerals (albite, K-feldspar, mica) alternating with inclusion-free zones. Case studies from the Schellerhau and Podlesi granites (Erzgebirge/Krušne Hory) showed a crystallisation sequence albite - K-feldspar - Li-mica snowball quartz. If the growth velocity increased rapidly, beside silicate melt drops also predating and simultaneously formed matrix minerals were overgrown and trapped in the quartz. CL and growth zoning studies indicate a kinetically caused increase of the growth velocity with crystal size in a nearly non-convecting crystal mush. Wavy zones of snowball quartz are interpreted as products of small scale diffusion fronts which lead to the change of $\mathrm{CL}$ properties developed during the crystal growth and caused by rapid variation of the melt conditions.

\subsection{Introduction}

Snowball-textured quartzes in granitic rocks are ellipsoidal phenoblasts up to $1 \mathrm{~cm}$ in size. They are characterised by zonal arrangement of entrapped matrix minerals (albite, K-feldspar, mica) alternating with inclusion-free zones (Figs. 8.1 - 8.2a). 


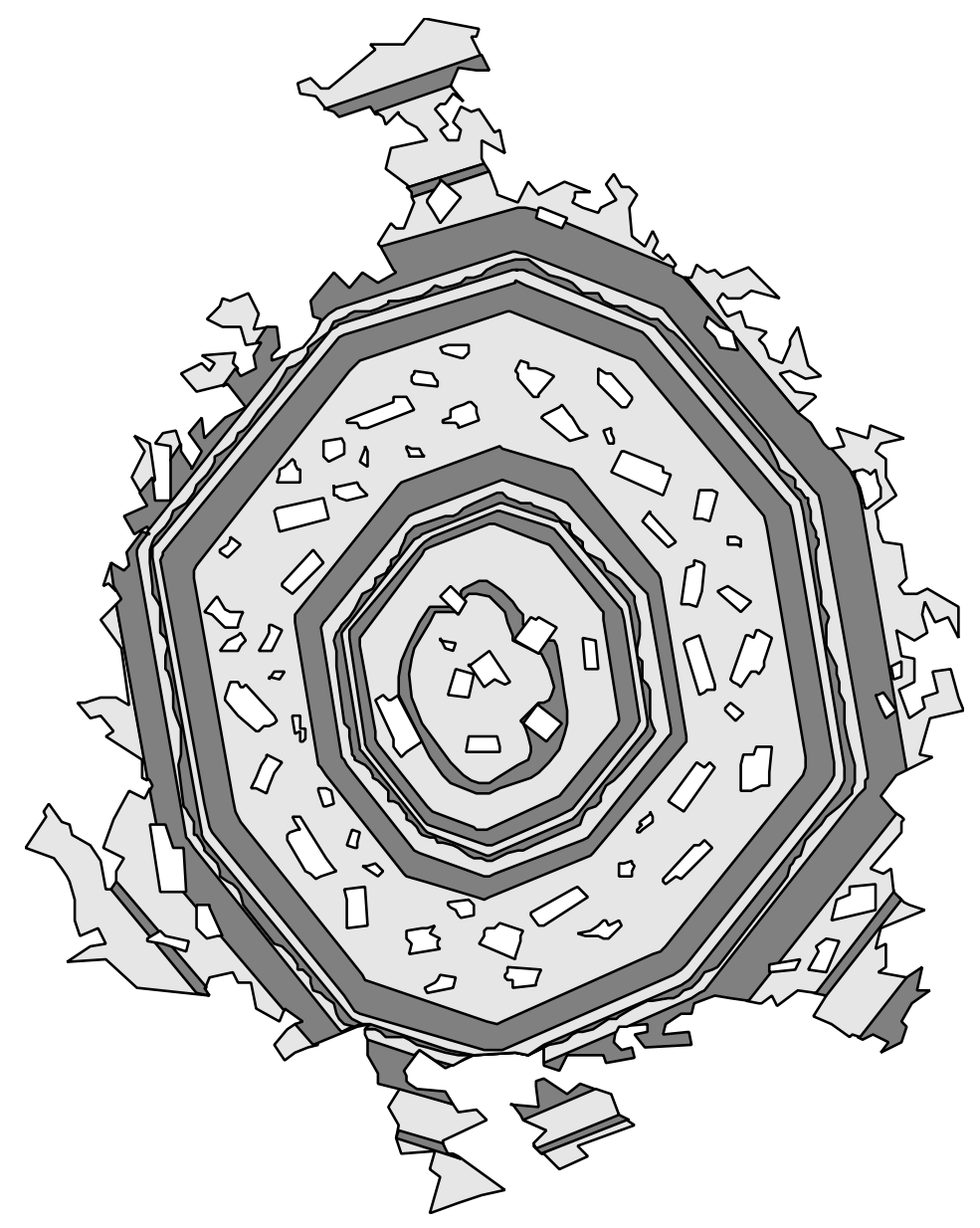

Fig. 8.1 Synoptical scheme of CL-contrasted growth textures in snowball quartz as observed in the Schellerhau SG3 granite and in the Podlesi dyke granite. Quartz crystal size is usually $1 \mathrm{~mm}$ up to $1 \mathrm{~cm}$.

Regardless the genetically totally different formation mechanism, these late-magmatic textures have some phenomenological similarities to metamorphic blastesis products also called snowball texture for which the term was first used when crystals grow under shear stress and other minerals were entrapped during rotational deformation.

The snowball texture is typical for highly evolved alkali feldspar and topaz-bearing granites world-wide and its origin is controversially discussed. It is considered to be either metasomatic (e.g. Beus et al., 1962; Sonyushkin et al., 1991), or magmatic in origin (Kovalenko, 1977; Renno, 1997; Poutiainen and Scherbakova, 1998).

Snowball-textured quartz occurs also in the roof of late Variscan tin-bearing alkali feldspar granite stocks of the Krušne Hory/Erzgebirge. For textural, cathodoluminescence (CL) and trace element studies on snowball quartz were chosen the third intrusion stage SG3 of the Schellerhau granite complex (Eastern Erzgebirge/Germany; Müller et al., 1999) and the Podlesí dyke granite (Western Krušne Hory/Czech Republic; Breiter et al., 1997). These 
highly evolved, Li-F-enriched alkali feldspar leucogranites belong to the younger granite group and are connected with the $\mathrm{Sn}-\mathrm{W}$ mineralization of the Krušne Hory/Erzgebirge (Seltmann, 1994). The rocks are emplaced as small stocks, sills and dykes at shallow crustal levels (formation pressure <1kbar).

\subsection{Petrography and texture}

The texture of the alkali feldspar granites is characterized by porphyritic snowball quartz and K-feldspar, and fine-grained euhedral albite tablets which form the main portion of the matrix. The quartz are between $2-5 \mathrm{~mm}$ and $0.2-1.5 \mathrm{~mm}$ in diameter in the Schellerhau SG3 granite and Podlesi dyke granite, respectively. In the Podlesi dyke granite, where snowball quartz and K-feldspar have nearly the same size as the matrix albite, the porphyritic texture shifts into a fine-grained one. The snowball quartz shows continuous growth into the matrix quartz, recognizable by the ramified, amoeboic grain boundaries, and penetrates the matrix. Up to 90 vol.\% of the modal quartz is accumulated in the snowballs. The crystals contain zonally enriched inclusions of the matrix minerals, such as corroded K-feldspar, mica, metamictic zircon, apatite and above all albite. Furthermore, in many cases fluid and melt nclusions occur. The entrapped albite tablets are often arranged with their long axis parallel to the zoning. Large number of albite tablets envelope the phenoblast edge indicating that the quartz put off the albite tablets during the growth. If the growth velocity increased rapidly the albite and other matrix minerals were overgrown and trapped in the quartz. The general crystallisation sequence is: albite - K-feldspar - mica - snowball quartz.

\subsection{CL and growth zoning}

The investigated snowball quartz have a red-brown luminescence with weak intensity. The CL spectra show a dominance of the red emission centred at $1.96 \mathrm{eV}$ and low intensity of the blue emission centred at $2.79 \mathrm{eV}$. During the electron radiation the red emission increases whereas the blue emission decreases visible by the blue "flash" at the first seconds of radiation.

The phenoblasts contain CL-contrasted growth zoning which is visible by using the SEM-CL with $15 \mathrm{kV}$ and a current of $15 \mathrm{~mA}$ (Figs. 8.1-8.2). The first growth zones show spherical 
shape which changes during the subsequent growth into rectilinear bordered zones with $\alpha$ quartz habit. The zones have variable width from 2 to $200 \mu \mathrm{m}$. Growth impediments around albite inclusions are recognizable as the zoning fits the shape of the obstruction (Fig. 8.2b).
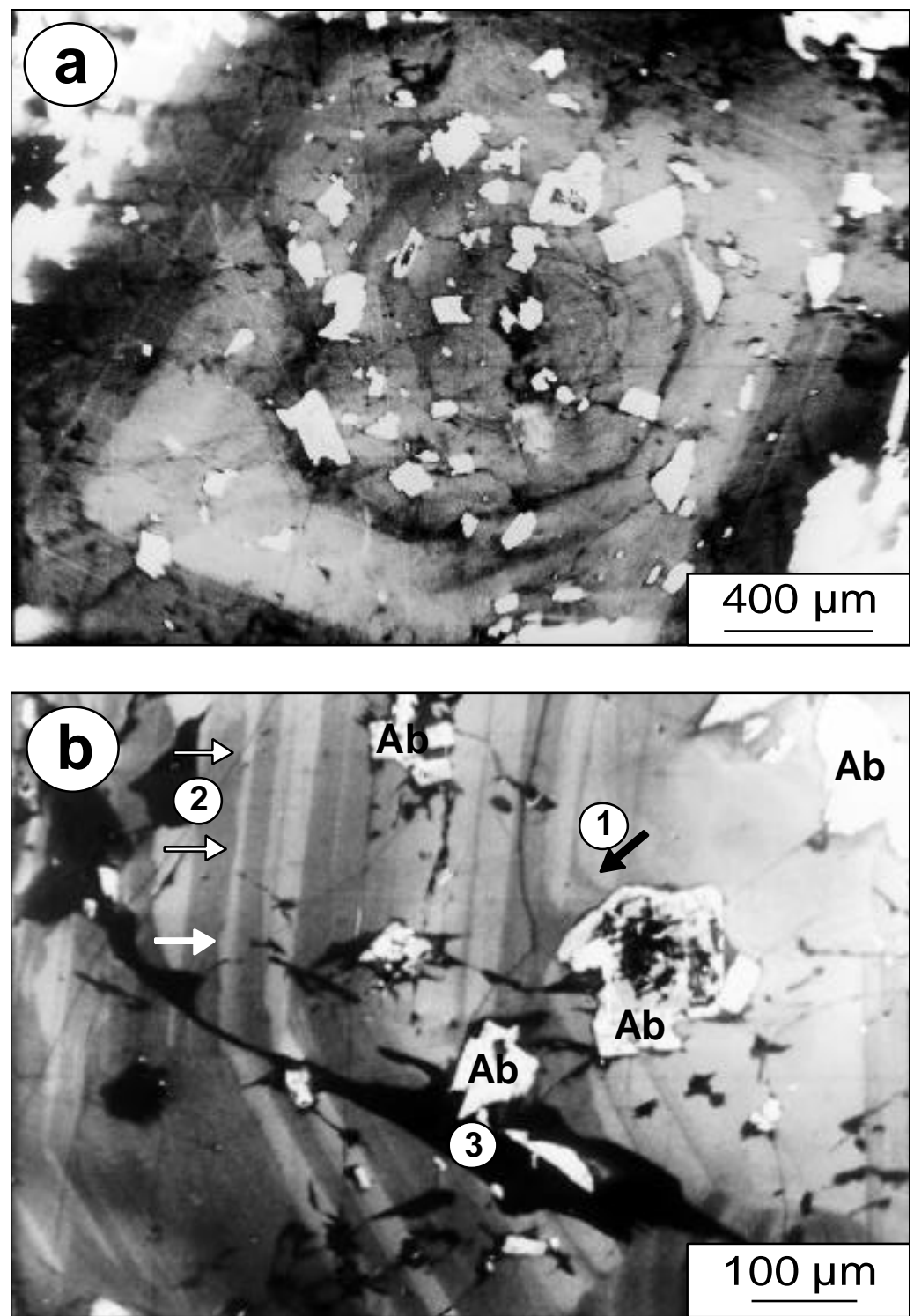

Fig. 8.2 SEM-CL images of snowball quartz of the Schellerhau SG3 granite. a) Snowball quartz with a large number of albite inclusions (white); b) Detail of a snowball quartz showing growth impediments around albite (Ab) inclusions (1), wavy zoning (2), and stress-induced recrystallised quartz (black) around mineral inclusions (3). 
These impediments are well developed in the crystal core and are smaller and indistinct in the direction to the crystal edge. This indicates a general increase of the growth velocity with growing crystal size. Between the straight bordered growth zones wavy surfaces occur. They are characterized by convex inlets which are opposed to the growth direction. In contrast to resorption surfaces which are resulted in sharp truncation of the regular zoning and rounded crystal corners (e.g. Shore and Fowler, 1996) the inlets of the wavy surface are much smaller and extend maximal $20 \mu \mathrm{m}$ in the growth zones and do not cut older zones or round-off corners. The subsequent growth zones are rectilinear bordered again and parallel to the euhedral crystal habit. This feature is in contrast to the wavy zoning which is described in plagioclase by Pearce and Kolisnik (1990) were the subsequent growth keeps the wavy texture. The wavy zones of snowball quartz are interpreted as a small scale diffusion front which lead to the change of CL properties developed during the crystal growth and caused by rapid variation of the melt conditions. The zoning continues into the amoebic crystal margin and into the matrix quartz without changes of the CL properties. Consequently, at least the rims of snowball quartz and the matrix quartz represent one and the same quartz generation. The zoning pattern indicates that the snowball quartz crystallised in-situ without significant magma movement. The tension anisotropy of quartz caused the stress-induced recrystallisation of non-luminescent secondary quartz around albite inclusions (Fig. 8.2b).

\subsection{Trace elements}

The CL of quartz results from substitutional and interstitial incorporation of trace elements like $\mathrm{Al}, \mathrm{Fe}$ and $\mathrm{Ti}$ and from different types of intrinsic and extrinsic defect centres in the quartz lattice. $\mathrm{K}$ and $\mathrm{Na}$ were measured to distinguish the $\mathrm{Al}$ originated from mineral inclusions from that of the host quartz.

Both, the Schellerhau and the Podlesi snowball quartz, are characterised by in average low Ti concentration of 20 ppm (Figs. 8.3a - 3b). In contrast, the quartz has a variable and mostly high $\mathrm{Al}$ content. Near the contact to albite the $\mathrm{Al}, \mathrm{Fe}$ and $\mathrm{Ti}$ content increases caused by diffusion (Fig. 8.3b).

The measured trace elements show no correlation with CL zoning. This is in contrast to rhyolitic phenocrysts where $\mathrm{Ti}$ is mainly responsible for the contrasting of the magmatic zoning (Müller et al., 1999). The dominance of red luminescence centered at $1.96 \mathrm{eV}$ 
associated with a steep increase during electron radiation indicates high content of $\mathrm{Si}-\mathrm{OH}$ bonds and molecular water in the quartz lattice (Kalceff and Phillips, 1995).
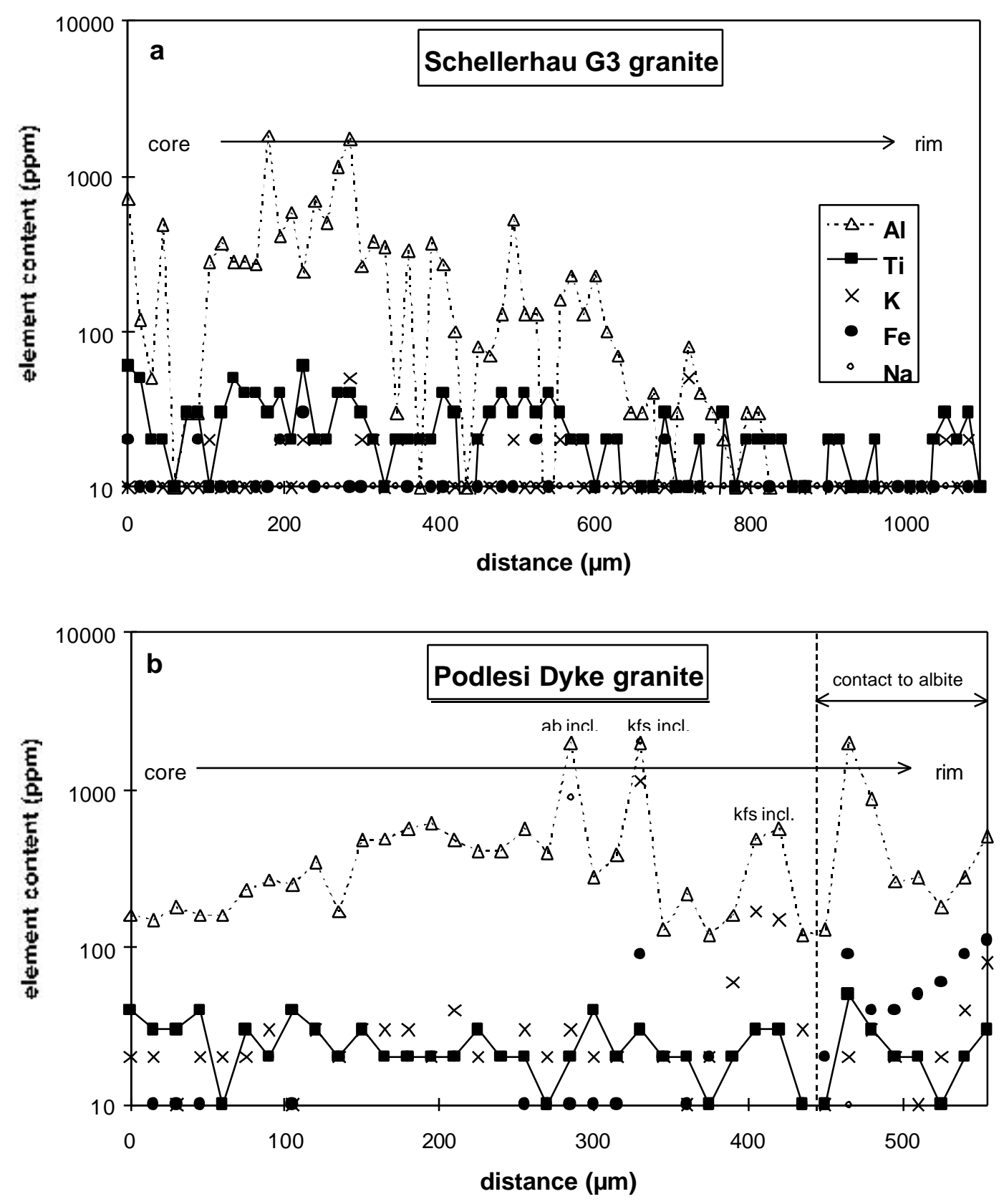

Fig. 8.3 Trace element profiles of snowball quartz of the Schellerhau SG3 granite (a) and the Podlesi dyke granite (b) using electron microprobe. 


\subsection{Conclusions}

The habit and zoning pattern, the arrangement of the enclosed and neighbouring albites and the occurrence of melt inclusions indicate a growth of the snowball quartz in a nearly nonconvecting crystal mush. On the other hand, the trigonal habit of the zoning indicates crystallisation temperature of $<600^{\circ} \mathrm{C}$ (at $<1 \mathrm{kbar}$ ). The zoning and $\mathrm{CL}$ properties of the snowball quartz show magmatic as well as hydrothermal features.

According to Holten et al. (1997) the observed zoning texture of the snowball quartz mostly reflects an external fluctuation in open systems and is not a product of self-organising growth. The irregular zoning is explained due to periodic degassing during melt cooling in the granite roof (Plimer, 1987).

Due to the highly reactive fluids exsolved in late magmatic stages from the melt, obviously the quartz and feldspar phenocrysts of the early crystallisation stages were cannibalised and mainly resolved.

Consequently, snowball quartz is a textural indicator for fluid-saturated, F-Li-enriched melts of alkali feldspar granites with subvolcanic (shallow) emplacement (Pitfield et al., 1990). Furthermore, it serves as indirect indicator for tin-tungsten mineralisation related to such melts. 


\section{Cathodoluminescence (CL) of magmatic quartz: Applications to topaz granites from the Hub Stock (Slavkovský Les Mts., Czech Republic)}

(this chapter has been submitted to Terra Nova, co-author: M. René and H.-J. Behr)

\subsection{Abstract}

Topaz-bearing granites from the Hub Stock, hosting the Sn-W deposit Krásno (Slavkovský Les Mountains, Czech Republic), form a stock structure in the SW part of the Krušné Hory/Erzgebirge Batholith. CL facilitates the discrimination of three magmatic quartz generations within these granites, which has given new insights into the textural evolution of felsic igneous rocks. Two phenocryst generations exhibit complex growth zoning with dominant blue CL, similar to those generally found in phenocrysts from rhyolites. They represent a water-poor $\left(<2.5 \mathrm{wt} \% \mathrm{H}_{2} \mathrm{O}\right)$ "rhyolitic" crystallisation environment in the lower and middle crust. Variation of $\mathrm{Ti}$ is mainly responsible for the contrasting magmatic zoning pattern in quartz phenocrysts. Furthermore, the Al/Ti ratio measured by EPMA can be used to distinguish quartz phenocrysts from different magma sources. Unzoned matrix quartz crystallised during and after subvolcanic melt emplacement and overgrew the older phenocryst generations. From the high $\mathrm{Al}$ content and the dominance of the unstable red 1.96 $\mathrm{eV}$ CL emission, which is associated with hydroxyl defects and adsorbed $\mathrm{H}_{2} \mathrm{O}$ in the lattice, it is suggested that the matrix quartz grew in a residual "granitic" melt with higher water content.

\subsection{Introduction}

Electron-excited luminescence, or cathodoluminescence (CL), is a sensitive method for revealing growth zoning, alteration patterns, grain shapes and different generations of quartz, which are not distinguishable in transmitted or polarised light (e.g. D'Lemos et al., 1997; Watt et al., 1997; Müller et al., 2000). CL colour and intensity in quartz are generally 
controlled by activator and sensitise elements (extrinsic lattice defects) like $\mathrm{Al}, \mathrm{Ti}, \mathrm{Fe}, \mathrm{Mn}$, $\mathrm{Ge}, \mathrm{Li}, \mathrm{Na}$, and $\mathrm{H}$ and intrinsic defects (e.g. oxygen and silicon vacancies) (e.g. Sprunt, 1981; Waychunas, 1988; Perny et al., 1992; D’Lemos et al., 1997; Pagel et al., 2000). $\mathrm{AP}^{3+}, \mathrm{Ti}^{4+}$, $\mathrm{Fe}^{3+}$, and $\mathrm{Ge}^{4+}$ substitute for $\mathrm{Si}^{4+}$ and the cations $\mathrm{H}^{+}, \mathrm{Li}^{+}, \mathrm{Na}^{+}, \mathrm{Fe}^{2+}$, and $\mathrm{Mn}^{2+}$ function as compensators of the electric charge at interstitial positions (e.g. Bambauer, 1961; Lehmann, 1975; Lehmann and Bambauer, 1973; Maschmeyer and Lehmann, 1983; Weil, 1984). Earlier studies showed a large variation in the trace element content within quartz crystals as well as of quartz crystals from different environments (e.g. Stuttner and Leininger, 1972; Schrön et al., 1988; Blankenburg et al., 1994; Müller, 2000). Spatial variations of CL properties reflect structural and chemical variations within crystals, which are related to crystal growth zones. These variations are caused by fluctuations in growth and diffusion rates in the melt through the crystal-melt boundary layer. Growth and diffusion rate are controlled either by selforganising intrinsic mechanism or an extrinsic mechanism involving physical or chemical changes within the bulk system, such as crystal settling, large-scale convection, magma mixing, ascent velocity and related temperature and pressure changes (e.g. Sibley et al., 1976; Shore and Fowler, 1996), but the problem is to relate the different patterns of zoning to specific genetic processes.

Despite considerable benefits of the phenomenological investigation of the CL of quartz, the relationship between CL properties, trace elements, and petrogenesis is far from being solved. This study is focused on magmatic quartz from the topaz-bearing granites of the Hub Stock hosting the Krásno Sn-W deposit (Slavkovský Les Mountains, Czech Republic). The aim of this study is to explain the causes of the CL of magmatic quartz and to determine the petrological significance of trace element distribution, quartz CL, and of textures visible in CL. Combination and comparison of the CL studies with micro-analytical results (EPMA) has been given new insights into the origin, emplacement, crystallisation, and textural evolution of fractionated Li-F-enriched melts and provide an information link between simplified systems of theory and experiment, and the complexities of natural processes. 


\subsection{Geological setting}

The Krušné Hory/Erzgebirge batholith that extends over an area of about $6000 \mathrm{~km}^{2}$, belongs to the largest Variscan granite bodies in the Bohemian Massif (Fig. 9.1). Topaz-albite granites that usually form granite stocks are traditionally related to the younger intrusive complex (YIC) of the Krušné Hory/Erzgebirge batholith (Lange et al., 1972; Fiala 1968). However, the topaz-albite granites of the Hub Stock form part of a complicated stock structure of topazalbite granites, which are associated with the upper part of the Krásno Sn-W ore deposit (Jarchovský et al., 1994; René, 1998). Topaz-albite granites in this part of the Slavkovský les Mts. are part of the Krudum massif that forms a relatively independent magmatic body on the SW margin of the Karlovy Vary pluton. The emplacement of the granite stock was associated with intensive tectonic deformation of slightly migmatized biotite paragneisses in the overlying pre-Variscan basement. Intrusion breccias described in detail by Jarchovský and Pavlu (1991) and Seltmann et al. (1992) occur in the upper part of the Hub stock and are cemented by topaz-albite microgranites.

Topaz-albite granites of the Hub stock are mostly medium-grained varieties locally accompanied by fine-grained porphyritic topaz-albite granites with characteristic quartz and K-feldspar phenocrysts. The temporal relationship between the medium-grained and finegrained porphyritic granites cannot be interpreted unambiguously. The contact of both varieties has a tectonic character in some cases and an intrusive character in the other, either gradually passing from one variety to another or linked with the origin of a small coarsegrained zone on the contact of both varieties. The two textural varieties may represent different granitic facies of approximately the same age, the origin of which was controlled by local pressure conditions during emplacement and crystallization (René, 1998) 


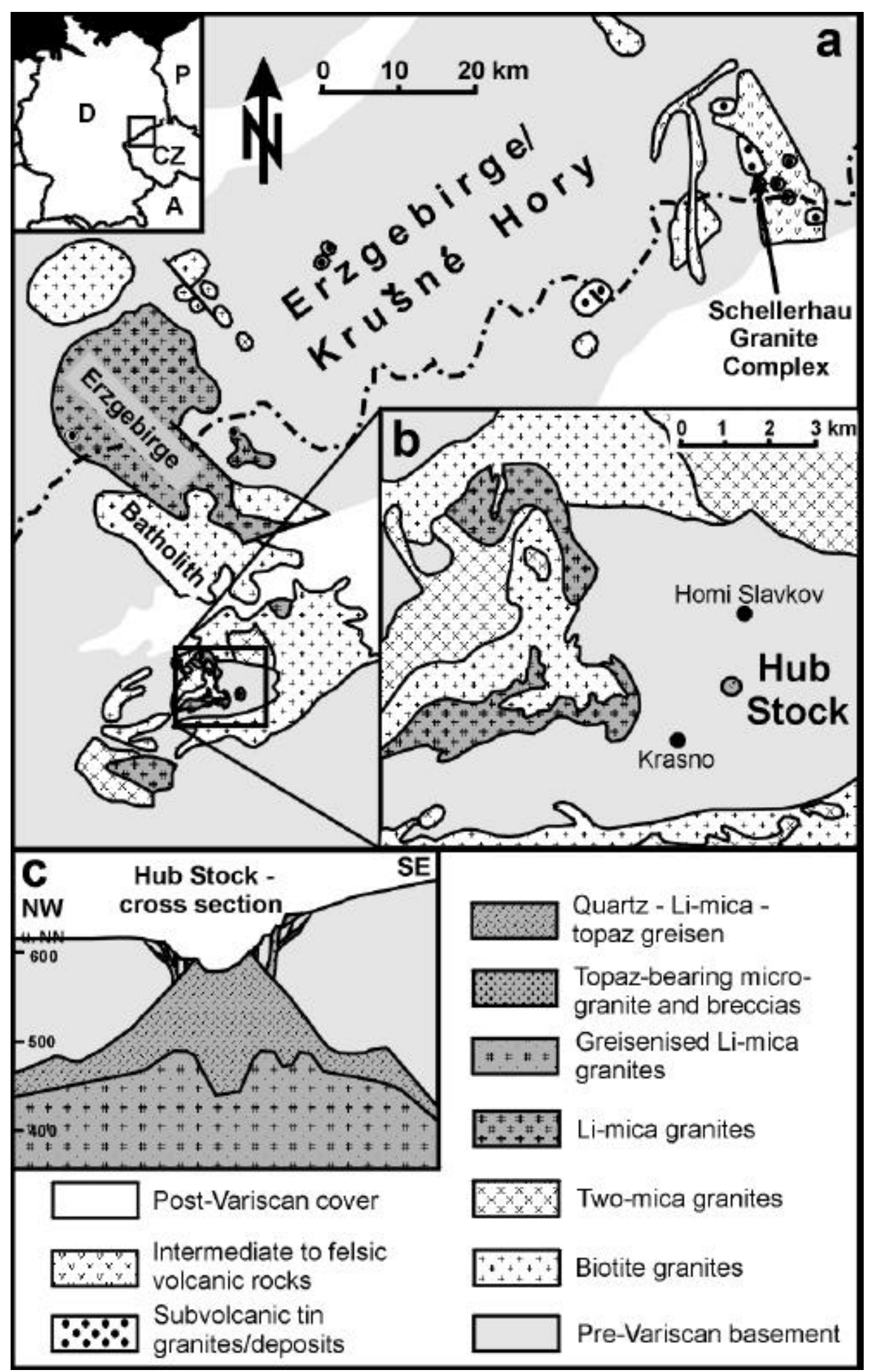

Fig. 9.1 Geological setting of the Hub stock. (a), (b) Geological map of the Krušné Hory/Erzgebirge with the distribution of granite types and the position the Hub stock. (c) Simplified cross-section through the Hub stock according to Jarchovský (1998). 


\subsection{Petrography}

The porphyritic topaz-albite granitic rocks (sample Ju-10) have a fine-grained equigranular groundmass $(50-100 \mu \mathrm{m})$ of anhedral quartz, albite (An03-05), K-feldspar, Li-mica, topaz, muscovite, and accessory minerals (fluorite, cassiterite, apatite, zircon, hematite, sulphides). The megacryst population is dominated by bipyramidal quartz $(1.5-3 \mathrm{~mm})$, platy Li-mica, and sparse K-feldspar up to two centimetres in size.

Topaz-albite microgranites (sample Ju-20) found in the upper part of the Hub stock, that form the matrix of the intrusion breccias, are aplitic (grain size: 200-500 $\mu \mathrm{m}$ ) and rarely porphyritic. The microgranitic rocks include K-feldspars several millimetres in size as well as bipyramidal quartz $(1.5-3 \mathrm{~mm})$. The groundmass of the microgranitic rocks is composed of anhedral quartz, albite, Li-mica, K-feldspar, and primary topaz.

The application of CL facilitates the identification of a third magmatic quartz population beside the large phenocrysts (qz1) and the matrix quartz (qz3) in both granite varieties (Fig. 9.2a, b). Like the large phenocrysts, this population is $300-700 \mu \mathrm{m}$ in size and exhibits a dipyramidal B-quartz habit and growth zoning. Each phenocryst population forms a maximum in the grain size distribution plot: qz1 at $2 \mathrm{~mm}$ and qz2 at $0.4 \mathrm{~mm}$. In the following we call this population microphenocryst (qz2). Both the phenocrysts and microphenocrysts are overgrown by younger matrix quartz.

\subsection{Methodology}

CL investigations were carried out using a hot-cathodoluminescence-microscope (Neuser et al., 1995) with $14 \mathrm{keV}$ energy and filament current of $0.18 \mu \mathrm{A}$. CL spectra were recorded with a triple-grating (100, 1200, and 1800 lines/mm) spectrograph TRIAX 320 provided with a liquid $\mathrm{N}_{2}$-cooled Charge Coupled Device (CCD) camera. The system is well suited to applications with very low signals such as the CL of quartz. The 100-lines/mm grating was used to detect the emitted spectra between 400 and $950 \mathrm{~nm}(3.1$ and $1.4 \mathrm{eV})$, whereas the 1200 lines/mm grating provided high-resolution spectra of $70 \mathrm{~nm}$ width sectors. The latter allowed the determination of the exact position of the single CL emission bands. For the quantification of the CL spectra were resolved by best fitting with Gaussian curves.

The application of a microprobe (EPMA) equipped with a CL detector (SEM-CL) facilitates the analysis of trace element distribution in relation to the CL textures. Trace element abundances of $\mathrm{Al}, \mathrm{Ti}, \mathrm{K}$ and $\mathrm{Fe}$ in quartz were determined using a JEOL JXA 8900 electron 
microprobe fitted with a wavelength dispersive detector and with a CL detector (CLD40 R712). Raw analysis were converted into concentrations, after making appropriate matrix corrections using the phi-rho-z method of Armstrong (1991). The main advantages of the EPMA are the high spatial resolution of $\sim 5 \mu \mathrm{m}$ and the capability of combining microanalytical analysis with CL and BSE imaging on the same area. The CL detector provided monochromatic (grey scale) images of the growth zones and alteration patterns within individual quartz crystals. Trace element measurements were carried out as line scans yielding distribution profiles. CL imaging was performed prior to and after EPMA analysis. In this way the measurement points in relation to the CL textures can be exactly located. The grey scale profiles along measured trace element profiles within quartz crystals are processed from the SEM-CL images using the software Optimas 6.0. Dark contrasted areas of quartz SEM-CL images correspond to red to reddish brown CL-colours and bright areas correspond to blue to violet colours. Quartz contains trace elements of very low concentrations so that quantification by EPMA poses a major difficulty. For high precision and sensitivity, a high beam current of $120 \mathrm{nA}$, beam diameter of $7 \mu \mathrm{m}$, and a counting rate of $10 \mathrm{~min}$ per analysis (i.e. $180 \mathrm{~s}$ per element) were chosen. Detection limits were calculated for each trace element profile with a confidence level of $95 \%$ on the basis of the standard deviation obtained from 12 background measurements (Plesch, 1982). Detection limits are $56 \mathrm{ppm}$ for Al, 9-16 ppm for Ti, 8 ppm for K, and 11-18 ppm for Fe.

There are several reasons why the concentrations of $\mathrm{Al}, \mathrm{Ti}, \mathrm{K}$ and $\mathrm{Fe}$ were determined. $\mathrm{Al}^{3+}$ and $\mathrm{T}_{1}^{4+}$ are the most frequent trace elements in quartz, which substitute for $\mathrm{Si}_{1}^{4+}$ (e.g. Bambauer, 1961; Dennen, 1965; Weil, 1984; Blankenburg et al., 1994) and may have a strong influence of the CL of quartz (e.g. Ramseyer and Mullis, 1990; Perny et al., 1992; Müller et al., 2000). $\mathrm{K}^{+}$was chosen as representative of the interstitial ions, because the detection limit of $\mathrm{Na}(\sim 80 \mathrm{ppm})$ was higher than the concentration and the ultra-light element Li cannot be measured by EPMA. Fe and Mn are important CL activators and quenchers in silicates and enter interstitial $\left(\mathrm{Fe}^{2+}\right.$ and $\left.\mathrm{Mn}^{2+}\right)$ and substitutional $\left(\mathrm{Fe}^{3+}\right.$ and $\left.\mathrm{Mn}^{3+}\right)$ positions (Marshall, 1988). However, the concentration of Mn was far below the detection limit ( $12 \mathrm{pm}$ ). 


\subsection{Quartz CL colours and growth patterns}

The application of CL facilitates the identification of three magmatic quartz generations in the two granite varieties: euhedral zoned phenocrysts (qz1), euhedral zoned microphenocrysts (qz2), and anhedral unzoned matrix quartz (Fig. 9.2a and b). The growth zoning in the phenocrysts (qz1 and qz2) is contrasted by different shades of blue, violet, and red-brown CL and include stepped (compositional) and oscillatory zoning with ß-quartz habit, resorption surfaces, and growth impediments (Kozlowski, 1981; Schneider, 1993; Müller et al., 2000; Fig. 9.2c, $d$ and e). Characteristic is the presence of fine-scale oscillatory zoning (2 - $20 \mu \mathrm{m}$ width) within super-ordinate stepped zoning (50 - $1000 \mu \mathrm{m}$ width). The analysis of the growth zoning shows, that the nucleation and growth of the microphenocrysts (qz2) begins with the growth of the outer step zone of qz1 (Fig. 9.2a, b).

The existence of euhedral quartz phenocrysts in granites showing CL-contrasted growth zoning is currently not known to be common and was described in only a few cases (Seltmann, 1994; D’Lemos et al., 1997; Müller et al., 2000). Furthermore, the growth zoning of these granitic phenocrysts is similar to growth zoning of phenocrysts observed in PermianCarboniferous rhyolites of the Erzgebirge (Fig. 9.2f). In contrast the matrix quartz (qz3) overgrowing qz1 and qz2 is free of growth zoning and exhibits a red-brown CL.

Quartz formed during post-magmatic or late-magmatic alteration is easily distinguishable from the above-described magmatic quartz. Based on postsolidus recrystallisation textures (fluid saturation textures, grain blasteses, cannibalising; e.g. Müller and Seltmann, 1999), and dark red-brown luminescence, those metasomatic quartz textures formed by hydrothermal processes could be excluded from this study.

\subsection{Quartz CL spectroscopy and trace element distribution}

The spectral response of the CL of quartz in the range of visible light is characterised by 9 emission bands between $1.7-2.2 \mathrm{eV}$ (red) and $2.4-3.1 \mathrm{eV}$ (blue) (Fig. 9.3, Table 9.1). The intensity of the emission bands changes with the exposure time of electron radiation, whereby the blue emission decreases and the red emission increases, indicating the decay and creation of luminescence centres, 

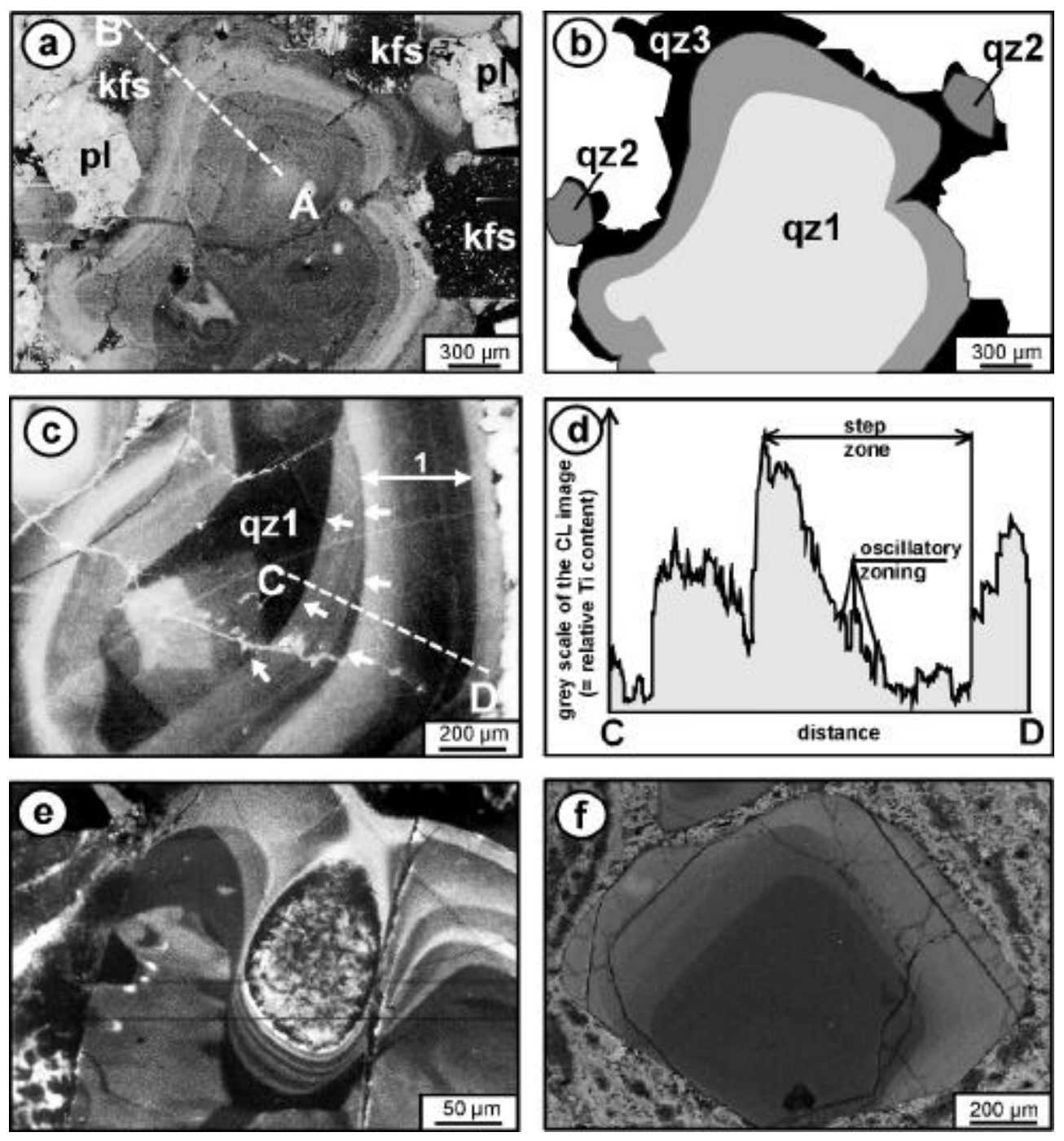

Fig. 9.2 SEM-CL images of quartz phenocrysts from the Hub stock topaz-bearing granites (Slavkovský Les Mts.). (a) Zoned quartz phenocryst (qz1, Ju-20). The line A-B shows the position of the trace element profile in figure 9.4a, c, and e. (b) Scheme of the three quartz generations, which are distinguishable in the SEM-CL image (a): zoned phenocryst (qz1), zoned microphenocrysts (qz2), and the matrix quartz (qz3) developed as ongrowths on qz1 and qz2. The nucleation and growth of qz2 begins with the growth of the outer step zone of qz1. (c) Zoned quartz phenocryst (qz1, Ju-20). The stepped zones (1) are truncated by resorption surfaces (arrowed) and overlain by the sub-ordinate oscillatory zoning. Three large scale resorption events are recorded in the zoning pattern. (d) Grey scale profile through the quartz phenocryst in figure 3c. High grey scale corresponds to blue CL and low grey scale to red-brown CL. Within a stepped zone the grey scale (blue CL) tendentiously decreases in the growth direction. The grey scale correlates with the Ti distribution (see Fig. 9.5a). (e) Quartz phenocryst showing growth impediments. The zoning fits the shape of the impediment caused by immiscible melt, vapour phases or minerals which stick onto the crystal surface during growth. During further growth the impediment becomes enclosed. (f) Zoned quartz phenocryst from the Wachtelberg Rhyolite (Eastern Erzgebirge). The zoning pattern of rhyolitic phenocrysts is similar to the zoning occurring in the phenocrysts of the Hub stock granites. 

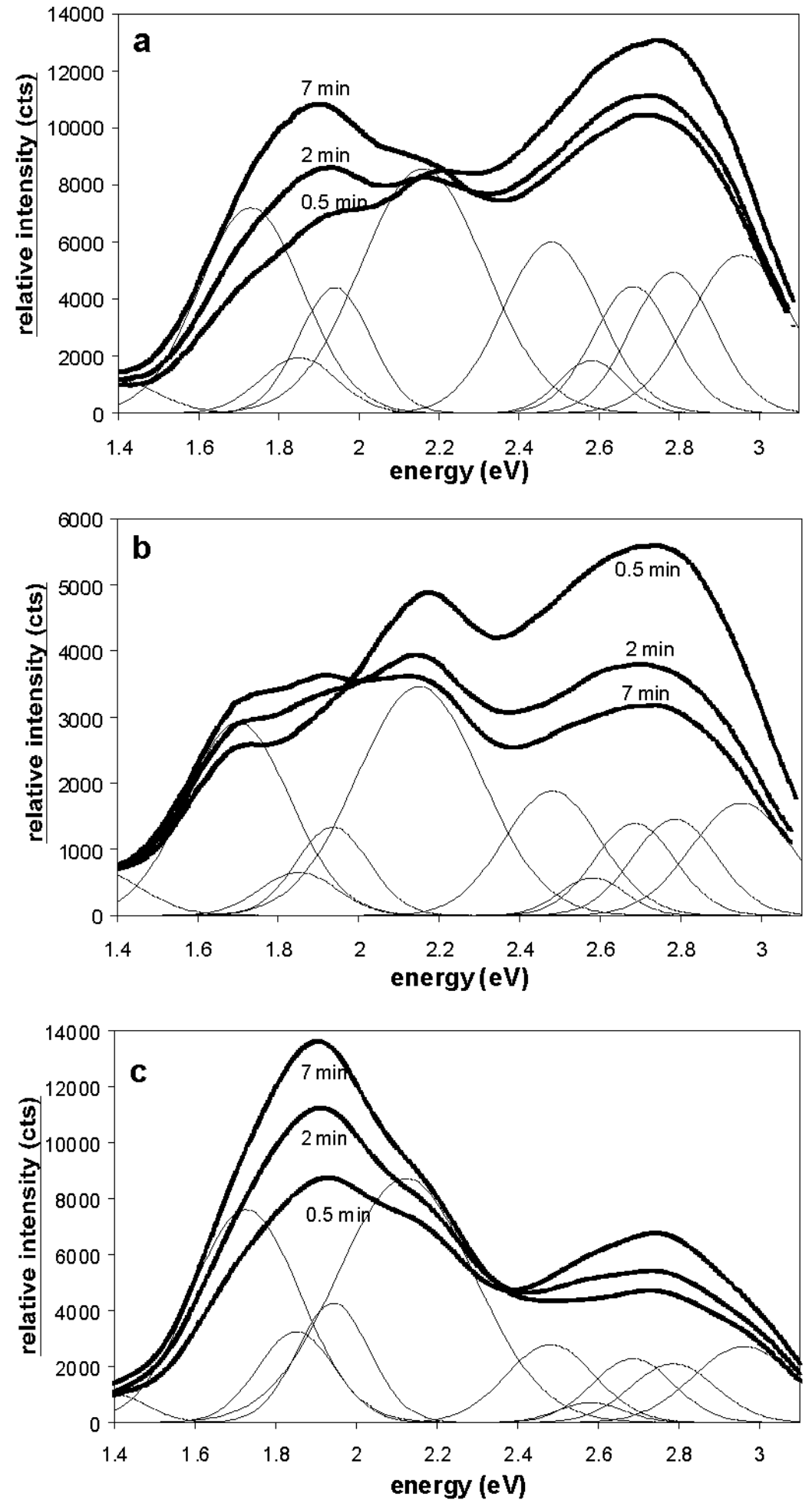

Fig. 9.3 CL spectra of (a) violet luminescent phenocryst quartz of sample Ju-10, (b) violet luminescent phenocryst quartz of sample Ju-20, and (c) red-brown luminescent matrix quartz (Ju 10). The spectra were recorded after 30 s, 2 min, and 7 min electron radiation. The 7-min-spectra are fitted with Gaussian curves. Each Gaussian curve represents a single emission band. 
Table 9.1 CL emission bands between 1.4 and $3.1 \mathrm{eV}$ observed in the magmatic quartz of the topaz-bearing granites from the Hub stock and their identification (NBOHC - non-bridging oxygen hole centre; STE - selftrapped exciton)

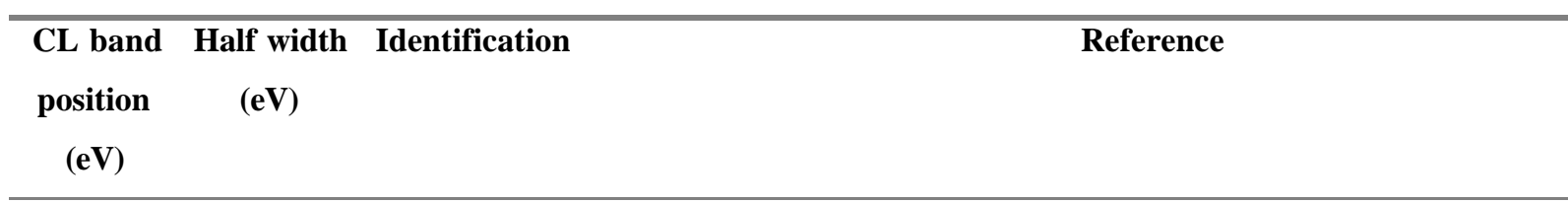
$1.73 \pm 0.02 \quad 0.3 \pm 0.02 \quad$ substitutional $\mathrm{Fe}^{3+}$
Pott and McNicol (1971)

$1.84 \pm 0.01 \quad 0.22 \pm 0.01$ Associated with NBOHC with Si--O and

Stevens Kalceff and Phillips (1995) peroxy linkage precursor or $\equiv \mathrm{Si}$ : centre

$1.96 \pm 0.02 \quad 0.22 \pm 0.02 \quad$ Associated NBOHC with $-\mathrm{OH}$ precursor

Stevens Kalceff and Phillips (1995)

$2.15 \pm 0.02 \quad 0.38 \pm 0.01 \quad$ STE associated with Ge

Luff and Townsend (1990)

$2.47 \pm 0.02 \quad 0.3 \pm 0.03 \quad$ Impurity

Itoh et al. (1988)

$2.58 \pm 0.01 \quad 0.18 \pm 0.005$ Associated with $\mathrm{Al}^{3+}$-defect structures

Nassau and Prescott (1975)

STE

Remond et al. (1992)

$2.68 \pm 0.01 \quad 0.23 \pm 0.01 \quad \mathrm{STE}$

Stevens Kalceff and Phillips (1995)

Associated with Ti-defect structures

Marfunin (1979)

$2.79 \pm 0.01 \quad 0.26 \pm 0.01 \quad$ Oxygen related centre

Hagni (1987)

$2.96 \pm 0.02 \quad 0.3 \pm 0.02 \quad$ Associated with Ti-defect structures

This study

respectively. The CL colours are more unstable in the matrix quartz than in the phenocrysts. The CL signal obtained from phenocrysts within both granitic varieties is similar, whereas the CL spectra of the matrix quartz show a dominance of the red emission (Fig. 9.3).

The comparison of CL emission band and trace elements revealed the following:

- Growth zones with blue CL show high Ti concentrations up to 70 ppm (Fig. 9.4a and b). We found that the blue CL emission at $2.96 \mathrm{eV}$ is associated with Ti (Fig. 9.5a). From this observation we conclude, that variations in $\mathrm{Ti}$ are mainly responsible for the magmatic zoning pattern within these quartz phenocrysts. The $2.96 \mathrm{eV}$ band is beside the $2.47,2.58$, 2.68, and $2.79 \mathrm{eV}$ one of five bands of the blue emission range. Generally, crystallisation 
temperatures $>500^{\circ} \mathrm{C}$ are necessary for the substitution of $\mathrm{Si}^{4+}$ through $\mathrm{Ti}^{4+}$ caused by the high field strength of $\mathrm{Ti}^{4+}(\mathrm{F}=1.04$; Blankenburg et al., 1994). However, it is generally not clear whether Ti is a CL activator or sensitizer (Marshall 1988, Götze 2000).

- Phenocryst quartz (qz1 and 2) shows an $\mathrm{Al}$ content between 170 and 270 ppm, whereas matrix quartz (qz3) has higher concentrations between 250 and 370 ppm (Fig. 9.4c and d). Al concentrations $>400 \mathrm{ppm}$ correlate with $\mathrm{K}$ concentrations $>30 \mathrm{ppm}$ indicating the contamination of the analysis by feldspar microinclusions. Al generally behaves in an opposite way to $\mathrm{Ti}$ with abundances being low in the blue and higher in the red-brown luminescent quartz especially in the matrix quartz (qz3; Fig. 9.5b). In contrast Ramseyer and Mullis (1990) and Perny et al. (1992) assume that the high Al and Li concentrations are the cause of the blue CL of hydrothermal quartz. According to Siegel and Marrone (1981), Griscom (1985), and Stevens Kalceff and Phillips (1995) the red CL emission around $1.96 \mathrm{eV}$ is related to $\mathrm{OH}^{-}$and/or adsorbed $\mathrm{H}_{2} \mathrm{O}$. The increase of the emission during electron radiation is explained by radiolysis of hydroxyl groups and/or adsorbed $\mathrm{H}_{2} \mathrm{O}$ of the quartz lattice, which leads to the formation of non-bridging oxygen hole centres (NBOHC). Hydroxyl groups and adsorbed $\mathrm{H}_{2} \mathrm{O}$ acting as charge compensator of $\mathrm{Al}^{3+}$ forming $\left[2 \mathrm{SiO}_{3}-\mathrm{H}_{2} \mathrm{O}-\mathrm{M}^{+} 2 \mathrm{AlO}_{4}\right]$ defects, where $\mathrm{M}^{+}$is a combination of $\mathrm{Li}, \mathrm{K}$, and $\mathrm{Na}$ ions (Bambauer et al., 1963; Maschmeyer and Lehmann, 1983; Kronenberg et al., 1986; Stenina, 1995). This association of $\mathrm{Al}$ and hydroxyl groups and/or adsorbed $\mathrm{H}_{2} \mathrm{O}$ may explain the weak correlation of $\mathrm{Al}$ with the red emission.

- The Fe content varies predominantly between 10 and 30 ppm (Fig. 9.4e and f). It was observed that $\mathrm{Fe}$ increases towards the grain boundary up to $260 \mathrm{ppm}$ indicating a high diffusion rate of $\mathrm{Fe}$ in the quartz lattice. This grain rim shows no change in CL properties. Pott and McNicol (1971) and Kempe et al. (1999) found that high $\mathrm{Fe}^{3+}$ causes the $1.73 \mathrm{eV}$ $\mathrm{CL}$ emission. However, in our samples we found no correlation between the $\mathrm{Fe}$ concentration and the $1.73 \mathrm{eV}$ band intensity. The lack of correlation may be explained by the fact that Fe occurs as divalent and trivalent ions.

- Weak to non-luminescent, post-magmatic (secondary) quartz is depleted in $\mathrm{Ti}, \mathrm{Al}, \mathrm{Fe}$ and K (Fig. 9.5a and b). 
Sample Ju-20
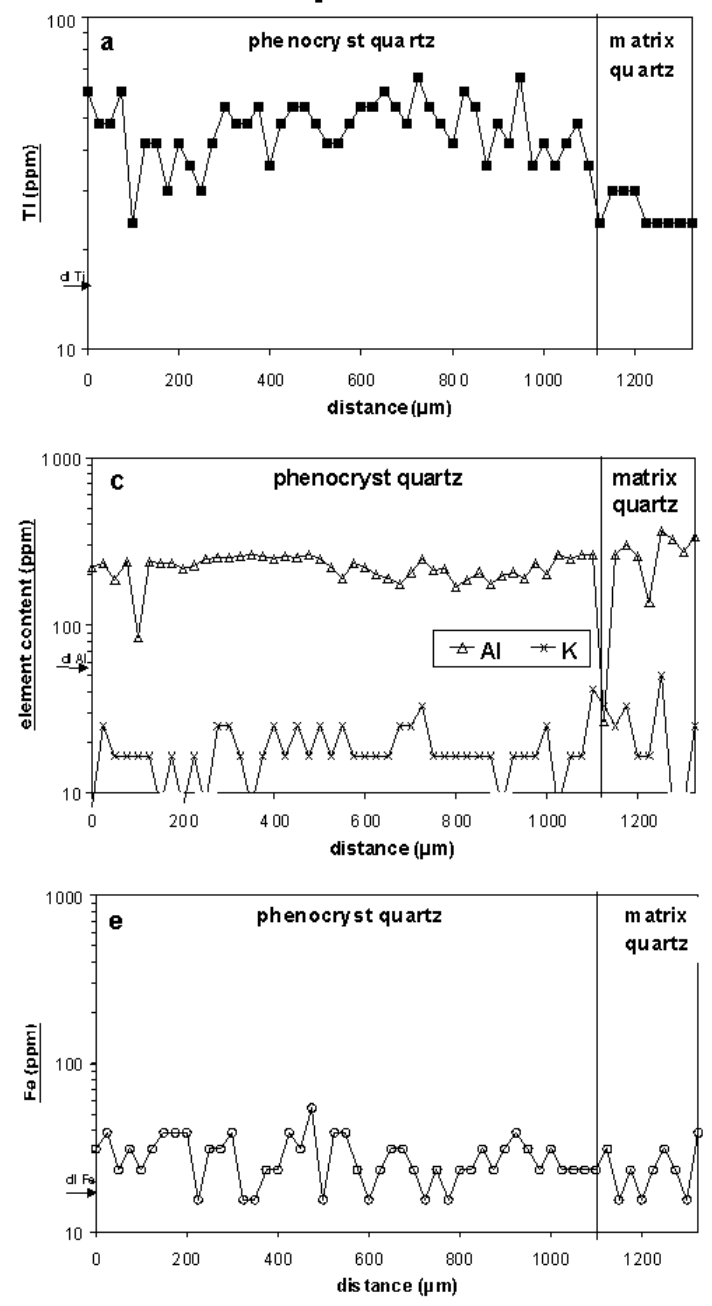

Sample Ju-10
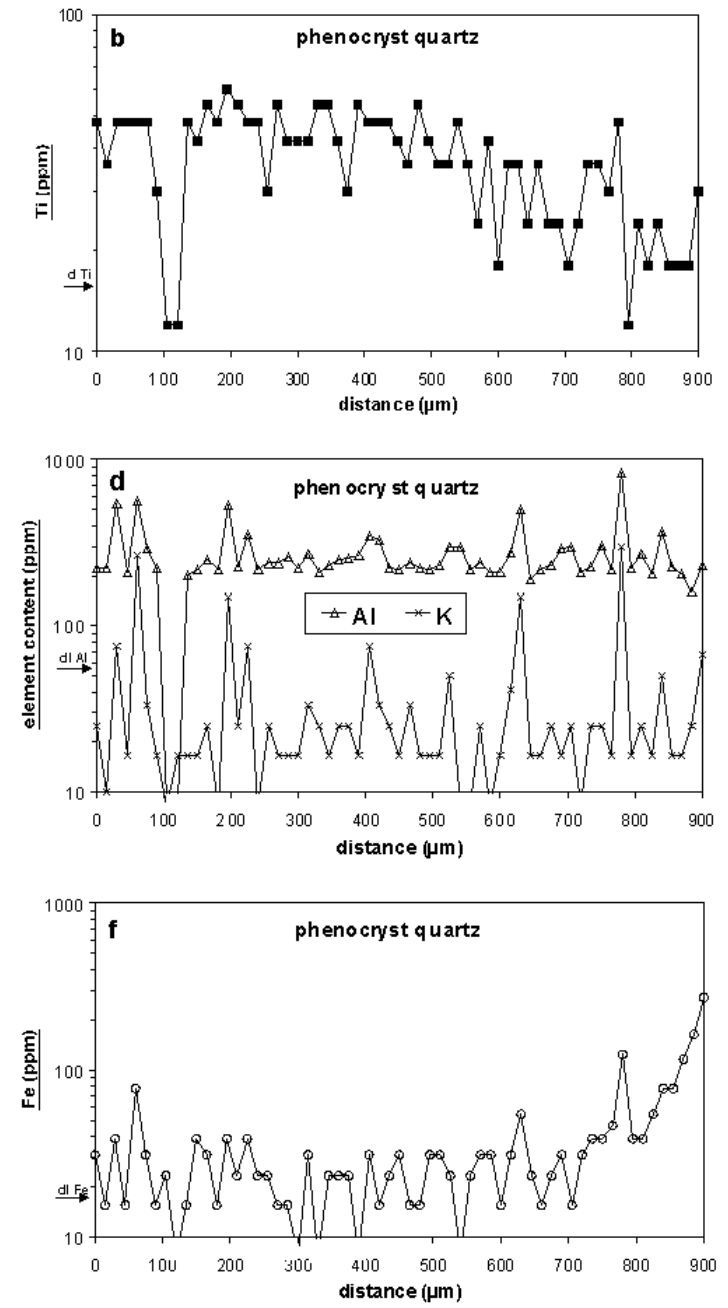

Fig. 9.4 Trace element profiles of quartz of the topaz granites from the Hub stock. Lower Ti and higher $\mathrm{Al}$ are characteristic for the matrix quartz. High $\mathrm{Al}(>400 \mathrm{ppm})$ correlates with $\mathrm{K}$ indicating analysed micro-inclusions of feldspar. The steep increase of Fe near the grain boundary to plagioclase demonstrates the high diffusion rate of $\mathrm{Fe}$ in the quartz lattice. Secondary (post-magmatic) quartz between 100 and $130 \mu \mathrm{m}$ in (b), (d), and (f) is depleted in $\mathrm{Ti}, \mathrm{Al}, \mathrm{Fe}$ and $\mathrm{K}$. The arrows at the axis of ordinates mark the detection limits (dl).

\subsection{Discussion}

Topaz-bearing granites of the Hub stock hosting the Krásno Sn-W ore deposit contain three generations of magmatic quartz represented by phenocrysts (qz1), microphenocrysts (qz2), and matrix quartz (qz3) indicating multiple crystallisation and contrasting crystallisation environments. 

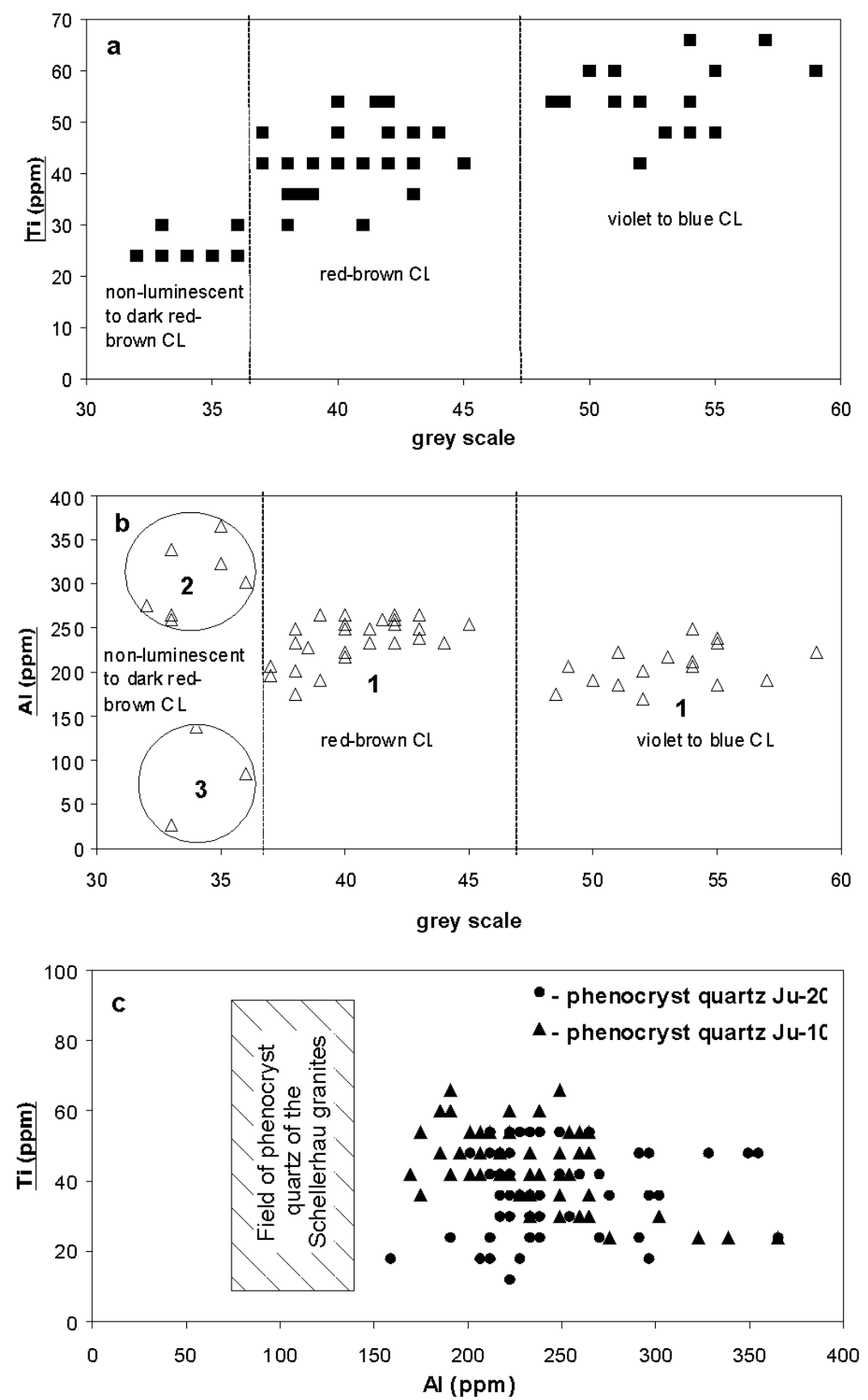

Fig. 9.5 (a) Correlation of Ti and CL signal plotted as grey scale within a zoned quartz phenocryst (qu1, Ju-10). The grey scale reflects the intensity ratio of red $(1.7-2.2 \mathrm{eV})$ versus blue emission $(2.4-3.1 \mathrm{eV})$. The higher the blue emission intensity the greater the amount of the grey scale. Quartz with high Ti shows violet to blue CL. (b) Al concentration of phenocryst quartz (1), matrix quartz (2), and secondary (post-magmatic) quartz (3). The matrix quartz (2) has high $\mathrm{Al}$ in contrast to the secondary quartz (3). (c) Comparison of the Ti-Al ratio of quartz phenocrysts from the Hub stock topaz-bearing granites and of Schellerhau tin granites (Eastern Erzgebirge). The phenocrysts of the different topaz-bearing granite varieties of the Hub stock show a similar trace element signature indicating a common magma source, whereas the phenocryst quartz of the Schellerhau tin granites has a lower Al concentration. 
To understand the $\mathrm{Ti}$ variation of growth zones in the phenocrysts (qz1 and qz2) it is necessary to distinguish between zoning caused by self-organised growth and zoning caused by physico-chemical changes of external factors such as temperature, pressure and magma composition (e.g. Allegre et al., 1981; Anderson, 1984; Fowler, 1990; Shore and Fowler, 1996). The fine-scale oscillatory zoning observed arises from self-organised growth without the intervention of externally imposed periodicities in the state (pressure, temperature, or composition) of the melt from which the crystal grew (e.g. Sibley et al., 1976; Allegre et al., 1981; Ortoleva, 1990; Shore and Fowler, 1996). Self-organisation of the growth is controlled by cyclic competition of the crystal growth rate and the diffusion rate of silica and elements such as $\mathrm{Ti}$ within the crystal-melt reaction zone and boundary layer. In contrast, stepped zoning and resorption surfaces are zoning patterns typically caused by external factors (e.g. Allegre et al., 1981; Müller et al., 2000). The stepped zones are often truncated by resorption surfaces, which results in rounding of the crystals (Fig. 9.2c). Resorption (melting) of crystal surfaces indicates local $\mathrm{SiO}_{2}$-undersaturation of the melt, which may be caused by an increase in temperature, isothermal decompression, or magma mixing. The continuous fractionation trend of the granite varieties of the Hub Stock and Krásno area (e.g. Jarchovský and Pavlu, 1991) gives no indications for magma mixing which may cause the multiple resorption events. Furthermore, the crystal settling effects in a magma chamber are small for viscous silicate melts (e.g. Dowty, 1989) and do not result in large-scale resorption of crystals.

Therefore, we favour isothermal decompression during adiabatic melt ascent as the cause of large-scale resorption. Adiabatic conditions are only possible by rapid magma ascent in dykes. Resorption drastically lowers the amount of suspended solids in the melt. The flow rate is elevated by reduction of the effective viscosity. This process may be initiated by brittle deformation during extension or shear in the upper crust. The occurrence of resorption surfaces is in accordance with the rapid ascent of granitic melts by dyke formation as found by Clemens and Mawer (1992), Petford et al. (1993), Petford (1996) and Johannes and Holtz (1996). After a resorption event (melt ascent), the subsequent growth of a new stepped zone begins with high $\mathrm{Ti}$ (blue CL) indicating a change of the crystallisation conditions. The Ti content decreases tendentiously across the stepped zones during further growth and is overlain by a sub-ordinate oscillatory $\mathrm{Ti}$ variation. If the oscillatory $\mathrm{Ti}$ variation is controlled by the rate of $\mathrm{Ti}$ diffusion in the melt (self-organised growth), then the tendentious decrease in $\mathrm{Ti}$ within the stepped zone should have other causes. After a resorption event, here explained by adiabatic melt ascent, Ti incorporation is likely to be high as a result of rapid growth rates since the melt moved into cooler surroundings. We draw this conclusion from textural 
observations. There may be some additional effects such as pressure and melt composition, which favour incorporation of Ti into the quartz lattice.

The growth zoning and CL properties of the phenocrysts of the granites (qz1 and qz2) are similar to those observed in phenocrysts of Permian-Carboniferous rhyolites of the German Variscides (Schneider, 1993; Müller, 2000) and may indicate similar crystallisation conditions. Thomas (1992) calculated the depth of quartz phenocryst crystallisation of tin granites of the Krušné Hory/Erzgebirge of up to $21 \mathrm{~km}$ provided by microthermometric studies of silicate melt inclusions. This is in accordance with the crystallisation depth of quartz phenocrysts of the Permian-Carboniferous rhyolites of the Erzgebirge, which was estimated at about $25 \mathrm{~km}$ (Thomas, 1992). Our observations and the calculations of the crystallisation depth by Thomas (1992) show that zoned quartz phenocrysts in granites with dominant blue CL represent a water-poor $\left(<2.5 \mathrm{wt} \% \quad \mathrm{H}_{2} \mathrm{O}\right)$ "rhyolitic" crystallisation environment in the lower and middle crust. Such phenocrysts contained in granites exhibit early stages of magma evolution and show features similar to rhyolite magmas, thus may represent the capability of erupting magmas. The matrix quartz (qz3) is interpreted as the product of the last magmatic crystallisation stage during and after the subvolcanic melt emplacement taking place at ca. $1.5 \mathrm{~km}$ (Thomas, 1994). Derivable from the high Al incorporated in $\left[2 \mathrm{SiO}_{3} \mathrm{H}_{2} \mathrm{OM}^{+} 2 \mathrm{AlO}_{4}\right]$ defects $\left(\mathrm{M}^{+}=\mathrm{Li}^{+}, \mathrm{Na}^{+}, \mathrm{K}^{+}\right)$and from the dominance of the unstable red $1.96 \mathrm{eV}$ CL emission, which is associated with hydroxyl defects and adsorbed $\mathrm{H}_{2} \mathrm{O}$ in the lattice the matrix quartz grew in a residual "granitic" melt with higher water content.

Quartz phenocrysts in both topaz-bearing granites of the Hub stock exhibit a similar Al/Ti ratio (Fig. 9.5c). However, this differs from quartz phenocrysts of other topaz-bearing granites of the Krušné Hory/Erzgebirge like the Schellerhau granite (Müller et al., 2000). Similar observations have been made by Stuttner and Leininger (1972) who showed that Ti content is different for quartz derived from different batholiths. Thus, quartz phenocrysts formed from different magma sources have various $\mathrm{Al} / \mathrm{Ti}$ ratios. We conclude that the two quartz phenocryst generations of the topaz-bearing granite varieties of the Hub stock represent the same crystallisation history and are derived from one-magma chamber. However, the rock textures, quartz generations, and growth patterns observed in CL are very similar for a number of topaz-bearing granites of the Krušné Hory/Erzgebirge (Müller et al., 2000; Müller, 2000). These similarities suggest that the quartz textures in the granite and the phenocryst growth patterns found in the Krušne Hory/Erzgebirge province are typical for Li-F-enriched melts, which are related to $\mathrm{Sn}-\mathrm{W}$-mineralizations. 


\section{Crystallisation, emplacement and deformation of S- and I- type granites in the Eastern Lachlan Fold Belt (SE Australia) indicated by quartz texture, cathodoluminescence, and Al-in- hornblende barometry}

(this chapter has been submitted to Mineralogy and Petrology, co-authors: P. Lennox and R. Trzebski)

\subsection{Abstract}

The I-type Carcoar and Barry Granodiorites and the S-type Sunset Hills Granite were intruded in the Late Ordovician-Early Silurian into Early Ordovician greywacke and volcaniclastic pile at different levels and subsequently repeatedly deformed in the Lachlan Fold Belt, SE Australia. Whereas the Carcoar Granodiorite has one generation of anhedral quartz, the Barry Granodiorite consists of unzoned subhedral quartz phenocrysts and anhedral matrix quartz, which crystallised at or near the emplacement level. Both granodiorites are considered to have been derived from the same magma source and have experienced a continuous and rapid ascent to depths of 4 to $6 \mathrm{~km}$ as determined by Al-in-hornblende barometry. The Sunset Hills Granite has three generations of quartz, and is geochemically related and spatially linked to the adjacent Wyangala Batholith. It was intruded at depths of 10-12 km. The magma of the Sunset Hills Granite ascended in a stepwise fashion, causing multiple quartz nucleation, episodes of slow crystal growth, and resorption events. The Carcoar and Barry granodiorites both show syn- and post-magmatic foliations, whereas the Sunset Hills Granite only has a post-magmatic foliation. The post-magmatic, solid-state foliations were produced during regional transpression and transtension during two subsequent deformation events. The earlier deformation is related to the Early Devonian Bowning event which caused east-west compression accompanied by regional transpression and transtension and vertical uplift and contraction in the Eastern Lachlan Fold Belt. During the Bowning event, the granodiorites were deformed under brittle conditions at temperatures of 250 to $400^{\circ} \mathrm{C}$; whereas the Sunset Hills Granite experienced ductile deformation at temperatures of around $550^{\circ} \mathrm{C}$. The second deformation recorded in the quartz is the late Middle Devonian Tabberabberan event, which is not apparent in the granodiorites, whereas the Sunset Hills Granite was further deformed, uplifted and experienced transpression during this event. The multiple deformation of quartz 
result in redistribution of $\mathrm{Ti}, \mathrm{Al}$ and structurally bound water in the quartz lattice and the formation of muscovite $(<0.5 \mu \mathrm{m})$ along slip planes in quartz.

\subsection{Introduction}

Structural analysis of granites with a polyphase deformation history often faces the difficulty of discriminating between generations of magmatic and deformation fabrics. In this paper, we present an method that combines microstructural, petrological and geochemical data to reconstruct the conditions of magma crystallisation, emplacement and deformation.

In recent years, cathodoluminescence (CL) of quartz has been increasingly applied to describe the processes of magma genesis, transport and deformation (Behr, 1989; Watt et al., 1997; Müller et al., 2000). In this study, CL was applied to characterise the conditions of magma crystallisation, emplacement and deformation of the Carcoar and Barry granodiorites and the Sunset Hills Granite in the Eastern Lachlan Fold Belt (SE Australia). Special emphasis was placed on the macro- and microtexture, trace element distribution in quartz, Al-in-hornblende barometry, and whole-rock geochemistry. We show how the CL behaviour of quartz and its textures at the microscale reflect the conditions and sequences of magma crystallisation and deformation. This is a complimentary study to previous structural and gravity modelling, which revealed the pluton shape at depth and the tectonic setting during emplacement of these granites (Trzebski et al., 1999).

\subsection{Geological Setting}

The northern part of the eastern Lachlan Fold Belt evolved in an island-arc setting during the lower Palaeozoic (Powell, 1984; Coney, 1992; Collins and Vernon, 1992; Gray et al., 1997). The Molong-Wyangala-Jerangle-Kuark Zone (abbreviated as Molong-Wyangala Zone) within the northern Lachlan Fold Belt may represent a fragment of a former Ordovician island arc and lies adjacent to the Hill End-Barradine Zone (abbreviated as Hill End Zone) a MidSilurian turbidite-filled trough (Glen et al., 1998; Scheibner, 1998). 


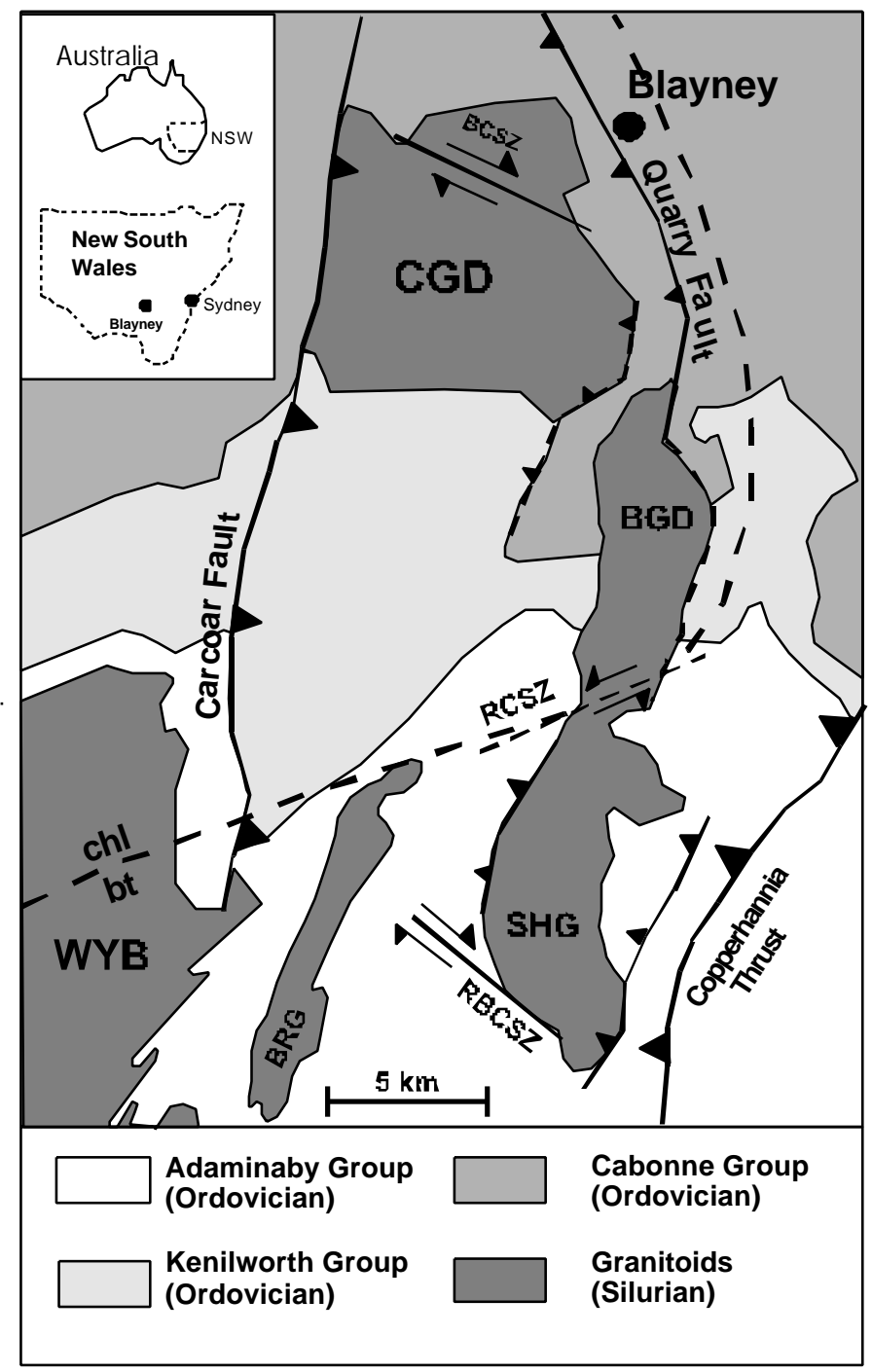

Fig. 10.1 Locality map and geological sketch map of the study area where CGD $=$ Carcoar Granodiorite, BCSZ = Browns Creek Shear Zone, BGD = Barry Granodiorite, RCSZ = Reedy Creek Shear Zone, SHG = Sunset Hills Granite, RBCSZ = Rocky Bridge Creek Shear Zone, BRG = Bugs Ridge Granite, WYB $=$ Wyangala Batholith and regional metamorphic zones in pelites from Smith (1969) are $\mathrm{chl}=$ chlorite and $\mathrm{bt}=$ biotite.

The Carcoar, Barry and Sunset Hills granites intruded the multiply deformed MolongWyangala Zone. This zone consists of Ordovician metasedimentary and volcaniclastic rocks, which were metamorphosed from prehnite-pumpellyite to greenschist conditions and deformed during the Late Ordovician/Early Silurian Benambran event (Smith, 1969). This event was followed by extensional and transcurrent deformation from the mid-Silurian to the mid-Devonian, which led to the formation of sedimentary basins (Hill End Zone) and emplacement of granitoids (Collins and Vernon, 1992; Glen, 1998).

The Carcoar Granodiorite is a roughly equant $(10 \times 10 \mathrm{~km})$ pluton bound by the Carcoar Fault on the west and the Quarry Fault on the east. It is composed of fine- to medium-grained, enclave-bearing, hornblende-biotite granodiorite to tonalite, similar to other I-type granites in the area, and minor intrusions of diorite (Long Hill Diorite), monzonite, aplite and pegmatite. The Barry Granodiorite is a meridionally elongated body $(5 \times 12 \mathrm{~km})$, consisting mainly of 
hornblende and biotite granodiorite of tonalitic composition with minor microtonalite enclaves (Lennox et al., 1998). The Sunset Hills Granite crops out as a north-south elongated body (6 x $13 \mathrm{~km}$ ) bound in part by a possible extension of the Quarry Fault in the west and the Copperhannia Thrust in the east (Fig. 10.1). It is mainly composed of a biotite granite intruded in places by aplite and muscovite-leucogranite dykes. Metasedimentary xenoliths of up to $5 \mathrm{~m}$ in length and $0.3-0.5 \mathrm{~m}$ in width represent stoped blocks of the host rocks (Adaminaby Group) and show a foliation oblique to the foliation in the granite, indicating deformation prior to granite emplacement (Lennox et al., 1998).

All three granites show poorly developed magmatic flow fabrics, and a poor to moderately pervasive tectonic fabric. The main solid-state fabric $(\mathrm{Sg})$ in all granites consists of aligned biotite books, opaque grains, fractured feldspars, rarely aligned hornblende crystals and elongated muscovite aggregates. Cross-cutting mylonite zones, S-C microstructures and shear zones are better developed south of and adjacent to the Sunset Hills Granite. New zircon SHRIMP and published Ar-Ar, Rb-Sr and K-Ar dating studies (Lennox et al., 1998) indicate that the granites intruded about the same time, during the Early Silurian following the Benambran event. All three granites were multiply deformed during the Early Devonian Bowning, late Middle Devonian Tabberabberan and Early Carboniferous Kanimblan events (Lennox et al., 1998; Trzebski et al., 1999).

\subsection{Methods}

The CL emission of quartz was analysed using a hot-cathodoluminescence-microscope (Neuser et al., 1995) at an energy of $14 \mathrm{keV}$ and a filament current of $0.18 \mathrm{~mA}$. CL is generated by the emission of photons of ultra violet (UV) to infrared (IR) wavelength from activated electrons of the sample during electron bombardment. The spectral response of the CL was recorded with the grating (100 lines/mm and 1200 lines/mm) spectrograph TRIAX 320 and a $\mathrm{LN}_{2}$-cooled CCD-detector, and corrected for the total instrument response. The high-resolution spectrograph was used to determine the energy of individual emission bands, which usually have a Gaussian shape if plotted in energy space. The position, width, and height of the Gaussian curves were calculated and adjusted in such a way that the sum of the individual components corresponds to the recorded CL spectra. The areas of the Gaussian curves were used to determine the percentage of the individual emission bands of the total 
spectra between 1.4 and $3.1 \mathrm{eV}$. The peak area portions were correlated with the recorded trace elements.

The scanning electron microscope cathodoluminescence (SEM-CL) generates a high degree of spatial resolution of CL textures, and enables visualisation of magmatic growth zoning and deformation fabrics in quartz. A Geoscan 250-MK3, with a CL detector operating at an energy of $15 \mathrm{keV}$ and a filament current of 8-12 nA was used for black-and-white images of the primary (growth) CL textures and secondary (post-magmatic) CL structures in quartz. Typical primary CL textures in magmatic quartz, as revealed by variations in CL, include (1) stepped zoning (50-1000 $\mu \mathrm{m}$ width) with subordinate oscillatory zoning (2-20 $\mu \mathrm{m}$ width), (2) resorption surfaces, (3) growth impediments, and (4) skeletal growth (Müller et al., 2000). Secondary CL structures, such as healed microcracks and recrystallised domains are also clearly detectable with CL (Behr, 1989).

Additional information about the nature and evolution of the magma can be obtained by analysing the grain size distribution of quartz and its framework. The application of the lacquer peel method (Behr 1966; see Fig. 10.3) enables detailed analyses of the quartz framework. Grain size analysis were carried out in thin sections and hand specimens. The length and width of quartz grains $(\in 1 \mathrm{~mm})$ in thin sections. Quartz grains $>1 \mathrm{~mm}$ were measured by micrometer on polished hand specimen $(15 \times 15 \mathrm{~cm})$. The grain size of each grain was calculated from the average of its length and width.

The high-resolution spectral analysis of CL was combined with Electron Probe Micro Analysis (EPMA) to establish a correlation between the CL emission bands and $\mathrm{Al}, \mathrm{Ti}, \mathrm{K}$, and $\mathrm{Fe}$, which may act as CL activators in quartz. The element concentrations in quartz and of $\mathrm{Na}$, $\mathrm{Si}, \mathrm{Ti}, \mathrm{Ca}, \mathrm{Fe}, \mathrm{Mg}, \mathrm{Al}, \mathrm{Cr}, \mathrm{K}$, and $\mathrm{Mn}$ in hornblende were determined using the JEOL JXA 8900 electron probe micro analyser (EPMA) operating at $15 \mathrm{kV}$. To minimize the excitation volume during the measurements of the hornblende crystals the beam was set to $40 \mathrm{nA}$ and to a diameter of $5 \mu \mathrm{m}$. For high precision and sensitivity of the trace element determination in quartz, the a beam current of $120 \mathrm{nA}$, a beam diameter of $7 \mu \mathrm{m}$, and a counting rate of $10 \mathrm{~min}$ per shot means $180 \mathrm{~s}$ per element were chosen. Detection limits were calculated for each trace element profile with a confidence level of $95 \%$ on the base of the standard deviation obtained from 12 background measurements (Plesch, 1982). Detection limits are $32 \mathrm{ppm}$ for Al, 20 ppm for Ti, 13 ppm for K, and 15 ppm for Fe. 


\subsection{Geochemistry}

The three granites show similarities in their geochemical composition and can be subdivided into two groups: the metaluminous I-type Carcoar and Barry granodiorites, with $\mathrm{SiO}_{2}$ contents of 63-67wt.\%, and the meta- to peraluminous Sunset Hills Granite and Wyangala Batholith with S-type affinity and with $\mathrm{S} \mathrm{SiO}_{2}$ content of 69-74wt.\% (Fig. 10.2).
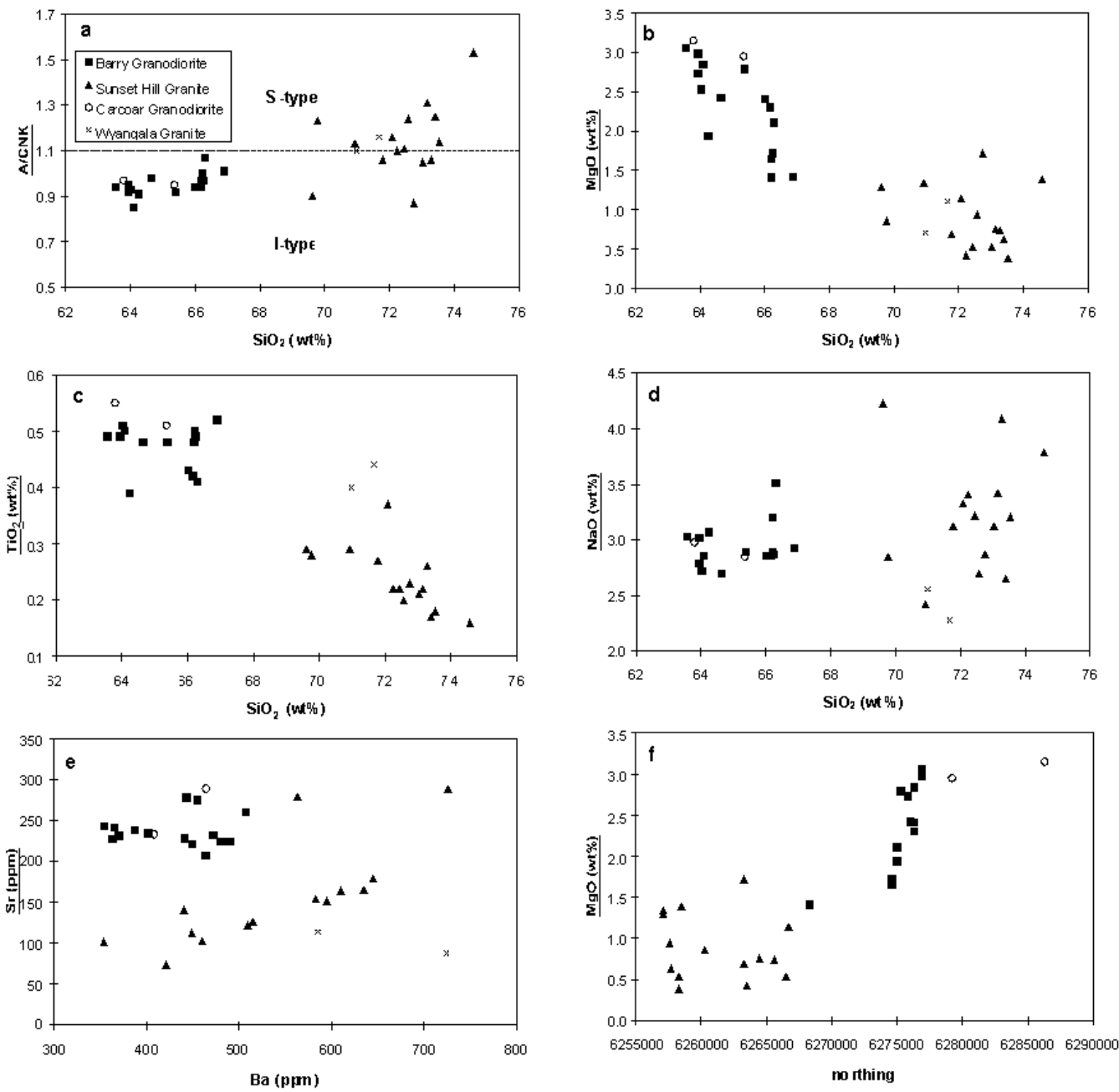

Fig. 10.2 Representative variation diagrams of whole rock samples of the Carcoar Granodiorite, Barry Granodiorite, Sunset Hills Granite and Wyangala Batholith. a - The Carcoar and Barry granodiorites are metaluminous I-type granites and the Sunset Hills Granite and Wyangala Batholith are meta- to peraluminous Stype granites. $\mathrm{b}$ - The decrease of $\mathrm{MgO}, \mathrm{FeO}^{\mathrm{T}}$ and $\mathrm{CaO}$ in the Barry Granodiorite with increasing $\mathrm{SiO}_{2}$ indicates that melt differentiation occurred by fractionation (gravity settling) of hornblende. The Carcoar Granodiorite represents a primitive melt. $\mathrm{c}$ - The differentiation trend by decreasing $\mathrm{TiO}_{2}$ is characterised by a gap which clearly separates the two granite groups. $\mathrm{d}$ - The variation of Sr indicates fractionation of plagioclase in the Barry Granodiorite, whereas the decrease of Ba concomitant with $\mathrm{Sr}$ shows that both K-feldspar and plagioclase were removed during differentiation of the Sunset Hills Granite. 
The $\mathrm{TiO}_{2}, \mathrm{Al}_{2} \mathrm{O}_{3}, \mathrm{~K}_{2} \mathrm{O}$ and $\mathrm{Na}_{2} \mathrm{O}$ contents of the Barry Granodiorite are constant, whereas the $\mathrm{MgO}, \mathrm{FeO}^{\mathrm{T}}$ and $\mathrm{CaO}$ contents decrease with increasing $\mathrm{SiO}_{2}$. The distribution of the major elements, the constant $\mathrm{Sr}$ content and the minor variation of the $\mathrm{Ba}$ content indicate that differentiation occurred by fractionation (gravity settling) of hornblende. The Barry Granodiorite shows a progressive differentiation of major and trace elements from north to south, which is shown by the decrease of hornblende and the increase of quartz to the south. The geochemistry of the Carcoar Granodiorite shows similarities with the Barry Granodiorite, except that the Barry Granodiorite shows a higher degree of fractionation, as indicated by the depletion of hornblende.

In the Sunset Hills Granite, the $\mathrm{MgO}, \mathrm{FeO}^{\mathrm{T}}, \mathrm{TiO}_{2}, \mathrm{Al}_{2} \mathrm{O}_{3}$, and $\mathrm{CaO}$ contents decrease with increasing $\mathrm{SiO}_{2}$. The $\mathrm{Na}_{2} \mathrm{O}$ and $\mathrm{K}_{2} \mathrm{O}$ contents vary between 2.4-4.2wt.\% and 0.6-4.7 wt.\%, respectively. The decrease of $\mathrm{Ba}$ concomitant with $\mathrm{Sr}$ shows that both $\mathrm{K}$-feldspar and plagioclase were removed during differentiation. In contrast to the Barry Granodiorite, the distribution of the major and trace elements shows an east-west trend in the Sunset Hills Granite. The highest fractionation was recorded at the western margin of the pluton.

\subsection{Quartz texture and foliation development}

\section{Carcoar Granodiorite}

The magmatic quartz of the Carcoar Granodiorite is represented by one anhedral generation, which forms irregular grain aggregates between the subhedral to euhedral feldspar and the hornblende grains (Fig. 10.3a). The grain size distribution of the weakly deformed samples shows one main peak around $650 \mu \mathrm{m}$, which indicates one nucleation event during magmatic crystallisation (Dowty, 1989) (Fig 10.4a).

The weak, post-magmatic deformation of the Carcoar Granodiorite is reflected in thin section by undulatory extinction of quartz, and by new grains at grain boundaries as a result of rotation recrystallisation (Fig. 10.3b). The degree of deformation in quartz generally increases with the proximity to shear zones. Measurements of the orientation of the subgrain boundaries of deformed quartz showed that the dominant feature are prismatic subgrain boundaries parallel to the c-axis. During the dynamic recrystallisation, bulges at grain boundaries formed where some new grains ( $\sim 12 \mu$ m diameter) developed due to progressive rotation of subgrains (Fig. 10.3b, 10.4a). Biotite formed 'fish' and hornblende crystals were rigidly rotated into a post-magmatic foliation. Simple, open kink-bands associated with slip on the basal plane were 

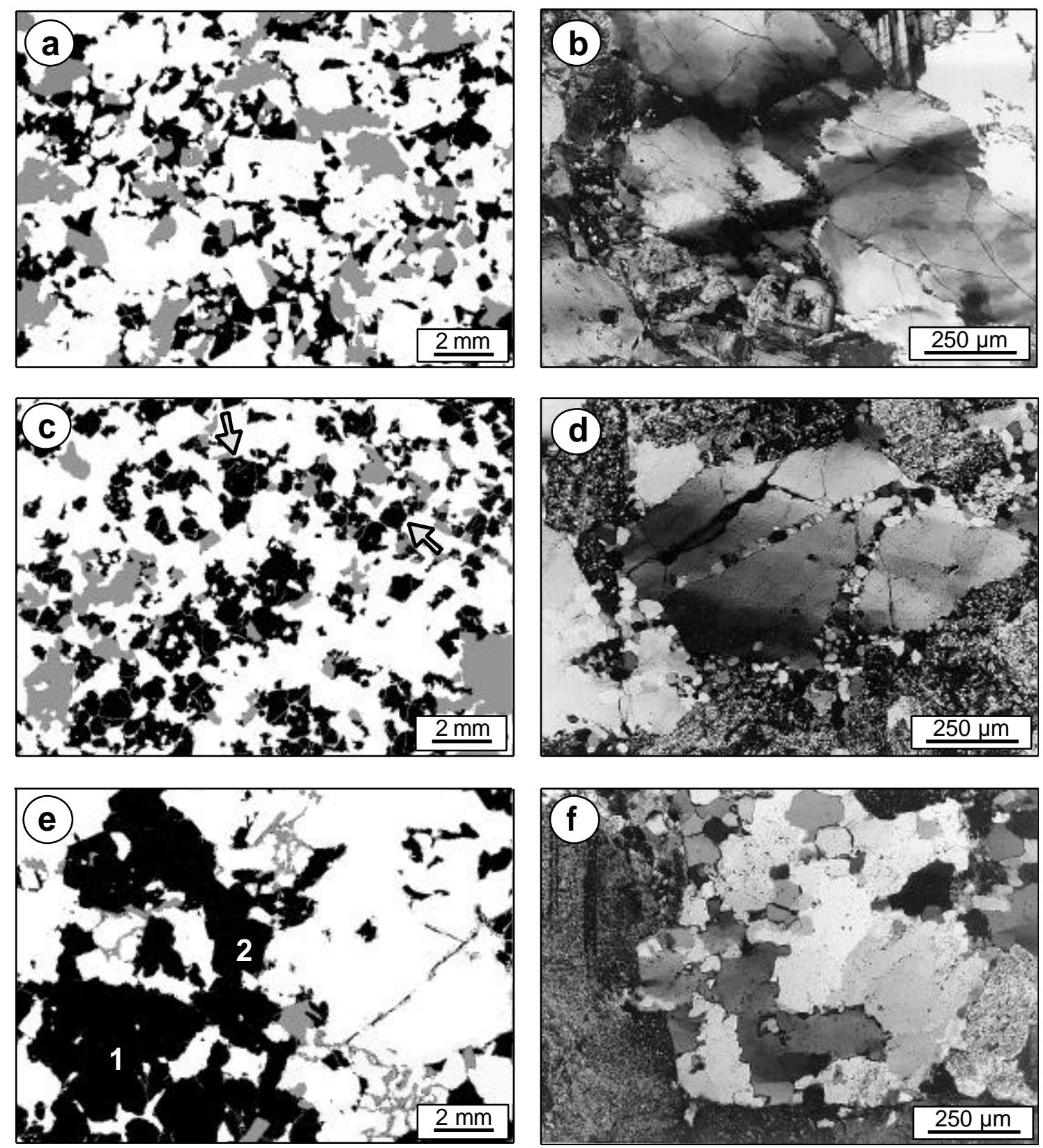

Fig. 10.3 The quartz framework of the Carcoar Granodiorite, Barry Granodiorite, and the Sunset Hills Granite. a - The anhedral quartz of the fine-grained Carcoar Granodiorite filled the irregular cavities between the subhedral to euhedral feldspar (white), biotite and hornblende crystals (grey) (contrasted lacquer peel). b Deformed quartz of the Carcoar Granodiorite contains elongated subgrains and small recrystallized grains at the edges. c - The Barry Granodiorite contains subeuhedral quartz phenocrysts (arrows) overgrown by anhedral to aplitic matrix quartz. d - Elongated phenocryst of the Barry Granodiorite with subparallel contrasted subgrains cross-cut by trails of recrystallized quartz. e - The fine- to medium-grained, porphyritic magmatic texture of the Sunset Hills Granite with two euhedral zoned phenocryst generations (first and second) which are embedded in anhedral matrix quartz. f - Deformed phenocryst (first generation) of the Sunset Hills Granite entirely converted to new grains with high-angle boundary during recovery of subgrains. 
developed in biotite, whereas hornblende reacted by intragranular, brittle displacement along the cleavage planes. The foliation within the shear zones is not parallel with the magmatic foliation marked by aligned hornblende and biotite. Muscovite occurs as fringes within strain shadows of feldspar.

\section{Barry Granodiorite}

The grain size distribution of quartz in the equigranular to weakly porphyritic Barry Granodiorite shows two maxima (Fig. 10.4). It contains sub-euhedral quartz phenocrysts with diameters between 800 and $900 \mu \mathrm{m}$ (Fig. 10.3c, d), which are embedded in the anhedral matrix quartz with an average diameter of $\sim 300 \mu \mathrm{m}$ (Fig. 10.4b). In the southern part of the Barry Granodiorite, the isometric matrix quartz has an average diameter of about $100 \mu \mathrm{m}$, whereas the size of the phenocrysts remains constant at 800 to $900 \mu \mathrm{m}$.

The deformed quartz of the Barry Granodiorite shows elongate subgrains marked by ribbons and rims of polygonal, recrystallised quartz with high-angle grain boundaries formed by rotation recrystallisation (Fig. 10.3d). Prismatic subgrain boundaries parallel to the C-axis are dominant. The non-elongated recrystallised grains with an average grain size of $40 \mu \mathrm{m}$ show straight boundaries and $120^{\circ}$ triple junctions (Fig. 10.4b). The recrystallised quartz ribbons are similar to the Type 2 polycrystalline quartz ribbons after Boullier and Bouchez (1978). The feldspars within the post-magmatic shear zones are often entirely sericitised. Plagioclase is weakly recrystallised along microcracks. Likewise in the Carcoar Granodiorite, the magmatic foliation is marked by aligned hornblende and biotite. The post-magmatic deformation of biotite and hornblende caused slip along the cleavage planes, rigid body rotation, boudinage, and recrystallisation at the crystal edges.

\section{Sunset Hills Granite}

The porphyritic Sunset Hills Granite contains two generations of euhedral quartz phenocrysts embedded in anhedral matrix quartz (third generation) as shown in Fig. 10.4c. The quartz phenocrysts and aggregates were almost entirely converted to new grains with high-angle boundaries, due to rotation recrystallisation. The new grains with an average diameter of 100 $\mu \mathrm{m}$ are either microscopically strain-free or internally deformed (Fig. 10.4c). In deformed quartz, basal subgrain boundaries normal to the c-axis occur in addition to the prismatic subgrain boundaries, forming typically rectangular ("chessboard") patterns. A number of the larger grains of the quartz aggregates shows strongly curved, sutured grain boundaries formed due to grain boundary migration recrystallisation. Recrystallised, polycrystalline quartz 

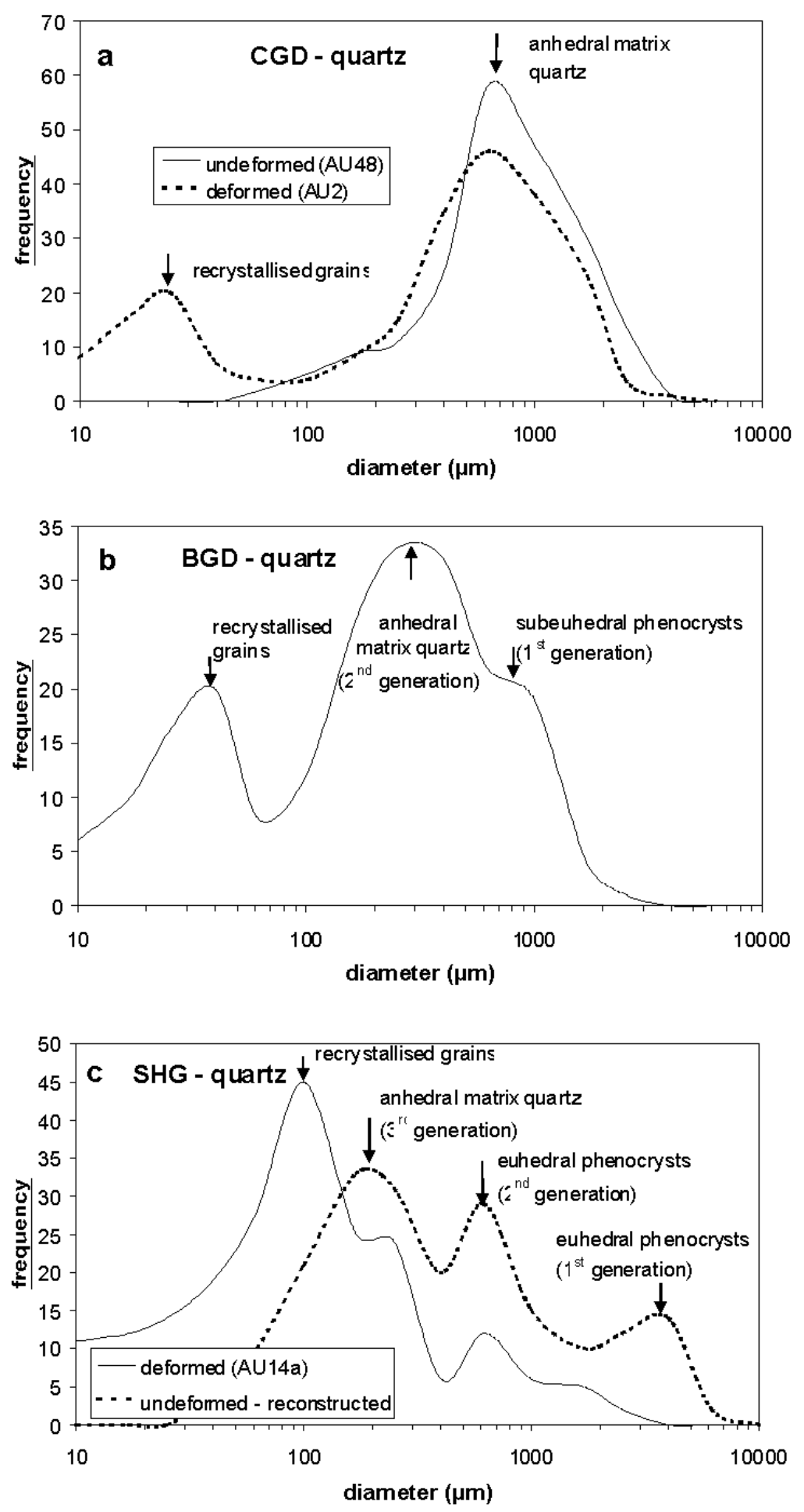

Fig. 10.4 Grain size distribution of quartz. a - of the Carcoar Granodiorite, b - of the Barry Granodiorite, c - of the Sunset Hills Granite. The original grain size maximum of $3.5 \mathrm{~mm}$ (reconstructed) of the large, first generation phenocrysts is reduced by deformation. This diagram shows that the maximum frequency of the matrix quartz is overlapped by the maximum frequency of grains modified by the post-magmatic rotation recrystallisation. 

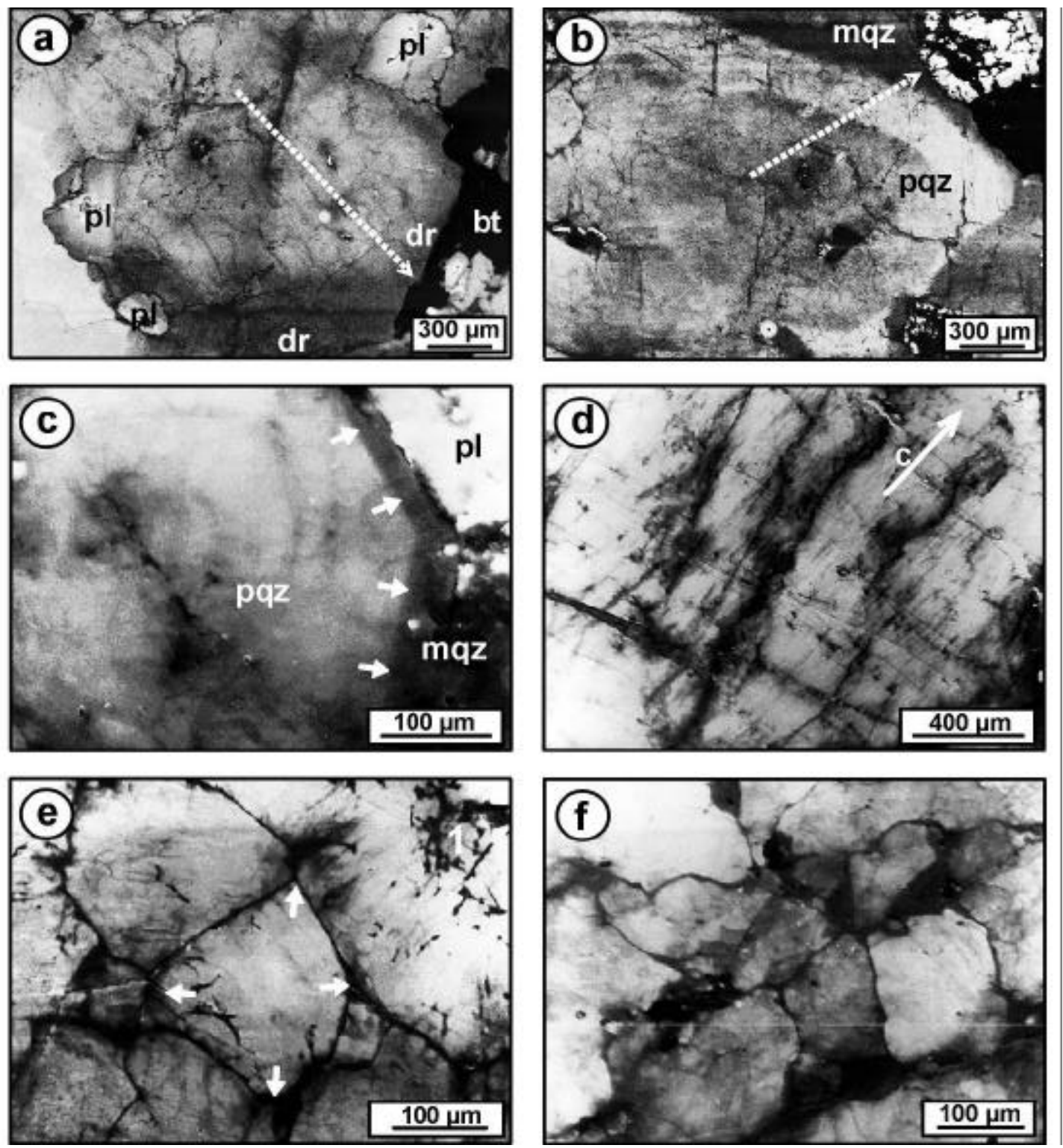

Fig. 10.5 SEM-CL images of quartz. a - Quartz grain of the Carcoar Granodiorite with a bright core and dark grey diffusion rim (dr) depleted in Ti and enriched in Fe. The high Fe concentration of the diffusion rim is derived from the neighbouring biotite $(\mathrm{bt})$ (dashed line $=$ position of the electron microprobe profile in Fig. 10.8a). b - Zoned quartz phenocryst (pqz) of the Sunset Hills Granite with magmatic growth zoning which is weakened and partly destroyed during deformation. It is overgrown by dark contrasted, unzoned matrix quartz (mqz). The brighter the CL of the zone the higher is the Ti concentration (dashed line = position of the electron microprobe profile in Fig. 10.8c). c - Euhedral quartz phenocryst of the Barry Granodiorite (pqz) overgrown by dark red-brown luminescent, anhedral matrix quartz (mqz). The arrows mark the border between the two generations. $d$ - The subgrains in the deformed quartz of the Barry Granodiorite are bordered by dark recrystallized quartz depleted in trace elements. The development of stress-induced Si-OH bonds along microsliding planes leads to this lamellate textures. Along the thin healed cracks at right angles to $\mathrm{c}$ are small star-like halos. e - Rotation recrystallization in the quartz of the Carcoar Granodiorite results in first stage starlike textures at the grain edges, as shown by the arrows. f - Advanced rotation crystallization in the quartz of the Sunset Hills Granite. The volume of newly crystallized (secondary), non-luminescent quartz (black) grows with the increase in the intensity of deformation. 
ribbons (Type 2 and Type 4 ribbons after Boullier and Bouchez, 1978) cross-cut quartz aggregates and cataclastic feldspar. Biotite is entirely recrystallised with its (001) planes subparallel to the S-C fabrics. Feldspar is entirely sericitised in some samples and shows pressure-solution phenomena, particularly at contacts with muscovite layers or where crosscut by muscovite layers. Indications of pre-existing magmatic foliation were not found.

\subsection{Cathodoluminescence of quartz}

\section{Primary magmatic CL textures}

Quartz phenocrysts of the Sunset Hills Granite (first and second generation) show weakly contrasted, relict growth zones typical of rhyolitic phenocrysts (Laemmlein 1930; Schneider 1993; Watt et al. 1997). Growth pattern, formed by oscillatory zoning (2-20 $\mu \mathrm{m}$ width), superordinate stepped zoning (50-1000 $\mu \mathrm{m}$ width) and resorption surfaces, is preserved in less deformed phenocrysts. However, these growth zones were largely erased due to hightemperature, post-magmatic deformation (Fig. 10.5b). On the other hand, experiments with zoned, rhyolitic quartz phenocrysts also show that the contrast of the CL growth zones weakens after several hours of heating at temperatures over $500^{\circ} \mathrm{C}$. In contrast, the subhedral, quartz phenocrysts of the Barry Granodiorite are non-rhyolitic, do not show growth zoning. The red-brown luminescent quartz phenocrysts are overgrown in optical continuity by dark red-brown luminescent, anhedral matrix quartz (Fig. 10.5c). In all three granites, the anhedral matrix quartz shows no zoning.

\section{Secondary CL structures}

In all three granites, quartz shows fine, transgranular ruptures, which are healed by dark redbrown, nearly non-luminescent quartz. Star-like halos around fluid inclusions are arranged along these ruptures (Fig. 10.5d).

The deformed quartz of the Carcoar and Barry granodiorites exhibits lamellae, which are not detectable using polarisation microscopy (Fig. 10.5d, e). In contrast, quartz of the Sunset Hills Granite is free of lamellae as such lamellae (Fig. 10.5f). The subgrain boundaries are coated by dark red-brown luminescent, newly crystallised quartz (Fig. 10.5d). Rotation recrystallisation mainly produced star-like structures at grain edges (Fig. 10.5e). With progressive rotation recrystallisation, the new rotated grains become more rounded, and the volume of the newly crystallised quartz (secondary quartz; Fig. 10.5f) increases in the Barry 
Granodiorite and Sunset Hills Granite. Transgranular, up to $200 \mu \mathrm{m}$ wide diffusion rims along thin, open micro-cracks indicate circulation of fluids along these cracks. These structures are abundant in the Sunset Hills Granite and relatively rare in the Barry Granodiorite.

\section{CL patterns and properties linked to trace elements in the quartz}

The quartz of the Carcoar Granodiorite and Sunset Hills Granite luminescences blue to violet/red-brown; whereas the quartz of the Barry Granodiorite luminescences red-brown to dark red-brown. The emission spectra of quartz between 1.4 and $3.1 \mathrm{eV}$ are composed of two broad emission ranges; blue (2.6-3.1 eV) and red (1.75-2.1 eV) resulting in blue, violet, and red-brown CL colours (Fig. 10.6). The blue range consists of five emission bands at 2.47, 2.58, 2.68, 2.79, $2.96 \mathrm{eV}$ (Fig. 10.7), and the red range consists of four bands at 1.73, 1.84, 1.96, and $2.15 \mathrm{eV}$. The blue emission range is generally characterised by a decrease of the intensity during electron radiation, and is caused by the destruction of luminescent defects through electron radiation and partly through sample warming (Ramseyer et al. 1988; Ramseyer and Mullis 1990). Cathodoluminescence resulting from defect centres is partly due to the effect of interstitially or substitutionally incorporated trace elements. Electron microprobe profiling of quartz grains was used to determine the relationship between the CL properties and the distribution of trace elements. The profiles and the $\mathrm{Ti}, \mathrm{Al}, \mathrm{K}$ and $\mathrm{Fe}$ concentrations are shown in Fig. 10.8.

The Ti concentration of quartz correlates with the intensity of the blue $2.97 \mathrm{eV}$ emission band. The quartz of the Carcoar Granodiorite with the highest average Ti content ( $85 \mathrm{ppm})$ shows the highest intensity of the $2.96 \mathrm{eV}$ emission. The intensity of this band and the Ti content decrease from the Sunset Hills Granite ( $75 \mathrm{ppm})$, to the Barry Granodiorite ( 45 ppm) to the new crystallised quartz ( $15 \mathrm{ppm})$. Furthermore, the intensity of the $2.96 \mathrm{eV}$ emission and the Ti vary within the zoned phenocrysts of the Sunset Hills Granite; blue luminescent zones show a higher intensity and $\mathrm{Ti}$ content than the violet and red zones. Similar observations have been made by Kerkhof et al. (1996) and Müller et al. (2000), who showed that blue to violet luminescent growth zones in high-temperature quartz have high Ti concentrations. With increasing degrees of deformation the primary magmatic Ti distribution is more and more overprinted, resulting in weakening of the growth zoning. The dark red-brown to nonluminescent, secondary CL patterns, such as star-like halos around fluid inclusions, diffusion rims along open micro-cracks, lamellae and domains of newly crystallised (secondary) quartz along healed micro-cracks (e.g. black areas of the quartz in Fig. 10.5d, e, f), are depleted in Ti (Fig. 10.9). Depletion of Ti occurs near grain boundary in all three granitoids. 

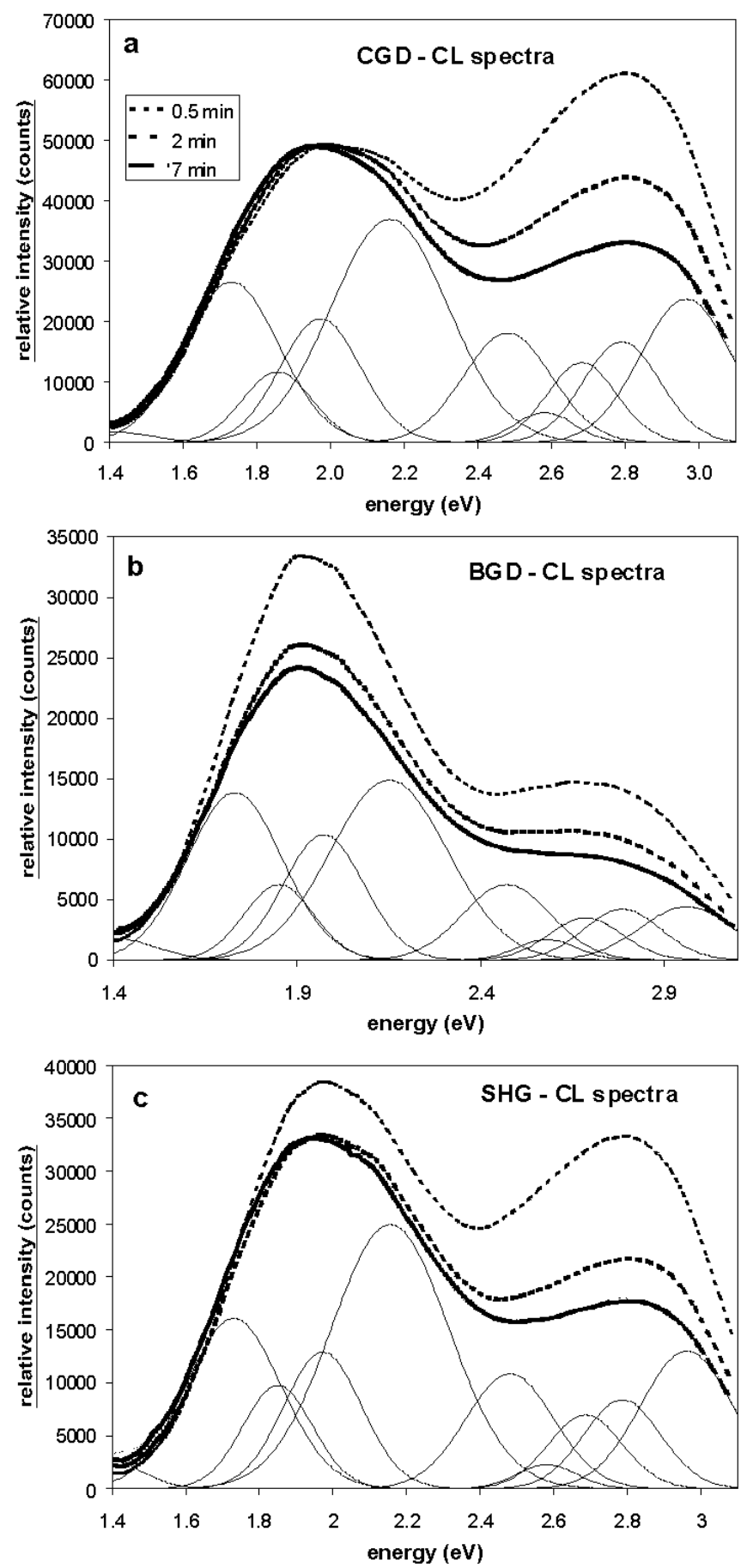

Fig. 10.6 CL spectra of quartz $(1.4-3.1 \mathrm{eV})$ recorded with the 100 lines/mm grating after $30 \mathrm{~s}, 2 \mathrm{~min}$, and 7 min of electron bombardment. The 7-min-spectra are fitted with Gaussian curves. Each Gaussian curve represents a single emission band. a - Carcoar Granodiorite (CGD). b - Barry Granodiorite (BGD). c - Sunset Hills Granite (SHG). 
The $\mathrm{Al}$ distribution in all three granites is heterogeneous and the $\mathrm{Al}$ content is mostly below 32 ppm. At Al contents above the detection limit of 32 ppm, Al correlates with K (Fig. 10.10). The regression line corresponds to the $\mathrm{Al} / \mathrm{K}$ weight ratio of an average muscovite composition. The muscovite flakes of up to $0.5 \mu \mathrm{m}$ in diameter are finely dispersed in the quartz of all three granites, probably on slide planes and we assume they are the products of deformation.

The average Fe content of the three granites amounts approximately to the detection limit of $15 \mathrm{ppm}$. Despite the low Fe concentration, the spectra show the $1.73 \mathrm{eV}$ emission band caused by $\mathrm{Fe}^{3+}$ defect structures (Pott and McNicol, 1971). The Fe content in quartz increases at the grain contacts with plagioclase, and particularly with biotite (Fig. 10.8), which indicates a high diffusion mobility of $\mathrm{Fe}$ in the quartz lattice.

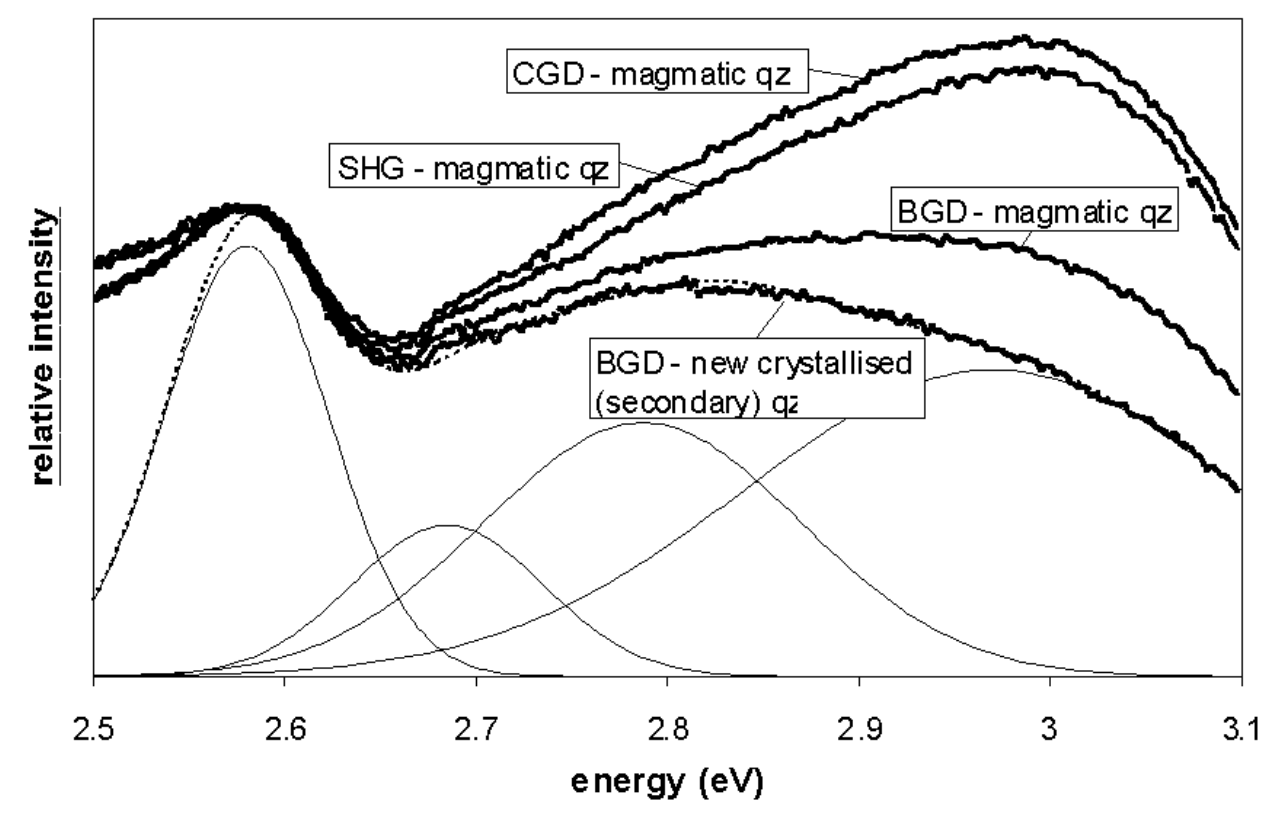

Fig. 10.7 Quartz CL spectra sections of the blue spectrum range $(2.5-3.1 \mathrm{eV})$ recorded with the 1200 lines/mm grating after $7 \mathrm{~min}$ of electron bombardment where CGD = Carcoar Granodiorite, BGD = Barry Granodiorite and SHG = Sunset Hills Granite. The spectrum of BGD - new crystallised quartz is fitted with Gaussian curves.

The intensity of the $1.96 \mathrm{eV}$ emission is constant during electron radiation in the quartz of the Carcoar Granodiorite, and decreases in the quartz of the Barry Granodiorite and Sunset Hills Granite. According to Siegel and Marrone (1981), Griscom (1985), and Stevens Kalceff and Phillips (1995), the red CL emission around $1.96 \mathrm{eV}$ is related to $\mathrm{OH}^{-}$and/or adsorbed $\mathrm{H}_{\mathbf{L}} \mathrm{O}$. In undeformed quartz the $1.96 \mathrm{eV}$ emission increases during electron radiation. This increase is explained by radiolysis of hydroxyl groups and/or adsorbed $\mathrm{H}_{2} \mathrm{O}$ of quartz lattice, which 

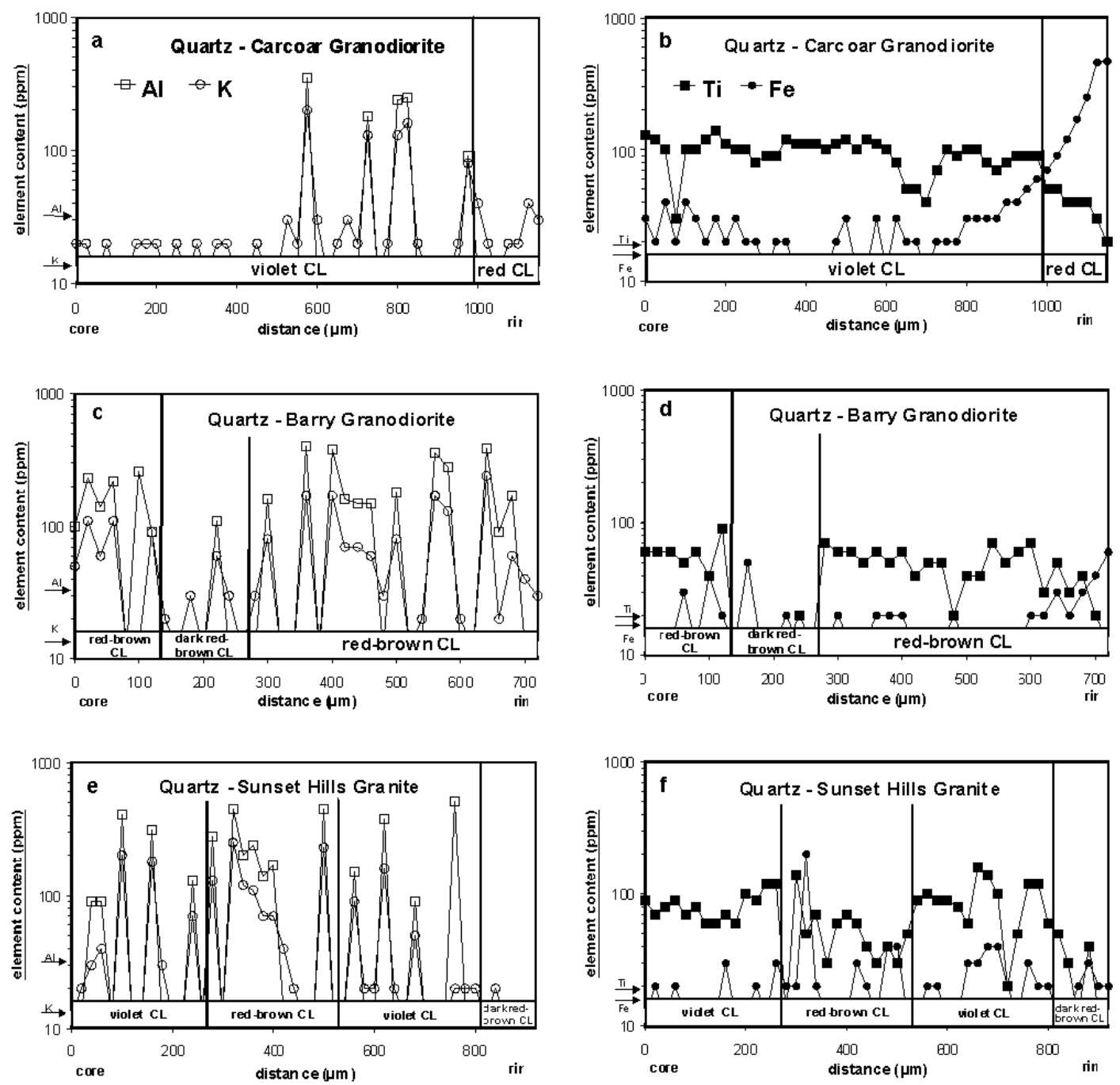

Fig. 10.8 Trace element profiles of quartz. a, b Carcoar Granodiorite. The position of the profile is shown in Figure 7a. c, d Barry Granodiorite. e, f Sunset Hills Granite. The position of the profile in the Sunset Hills Granite is shown in Figure $7 b$.

leads to the formation of non-bridging oxygen hole centres (NBOHC; Kalceff and Phillips, 1995). Hydroxyl groups and adsorbed $\mathrm{H}_{2} \mathrm{O}$ act as charge compensators for $\left[2 \mathrm{AlO}_{4} / \mathrm{M}^{+}\right]^{-}$ defects, where $\mathrm{M}^{+}$is a combination of $\mathrm{Li}, \mathrm{K}$, and $\mathrm{Na}$ ions (Bambauer et al., 1963; Maschmeyer and Lehmann, 1983; Kronenberg et al., 1986; Stenina 1995). As discussed above, the $\mathrm{Al}$ of the deformed quartz of the granites is removed from the quartz lattice and may be incorporated into the muscovite flakes. A similar process is assumed for the hydroxyl groups and adsorbed $\mathrm{H}_{2} \mathrm{O}$ of the quartz lattice. Both bound water types may also be removed during deformation. This process explains the constant or slightly decreasing $1.96 \mathrm{eV}$ emission, because no NBOHC is created during electron radiation, due to the absence of hydroxyl groups and adsorbed $\mathrm{H}_{2} \mathrm{O}$ in the quartz lattice. 


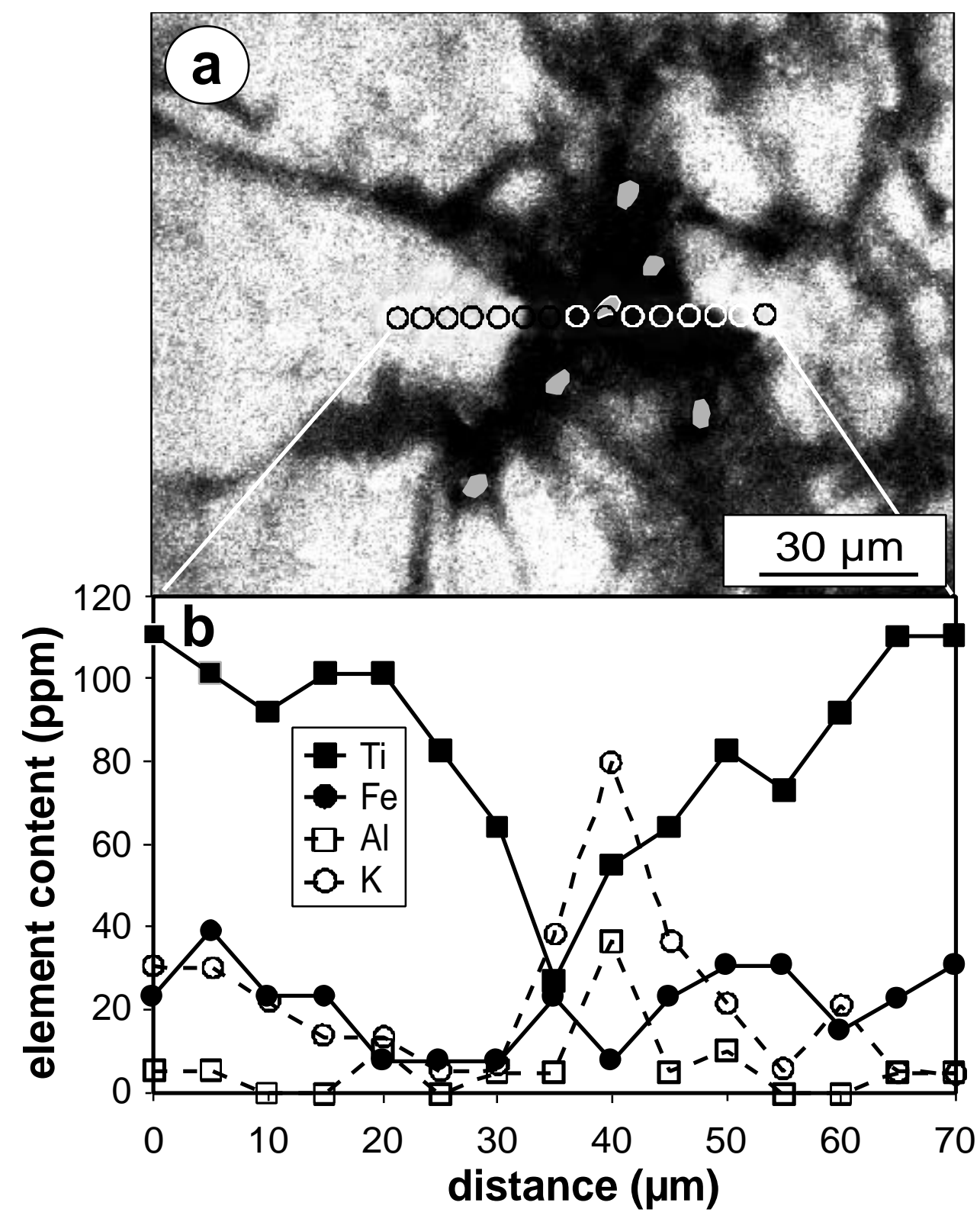

Fig. 10.9 a - SEM-CL image of quartz from the Carcoar Granodiorite. The black areas are dark red-brown to non-luminescent quartz around fluid inclusions. The residual porosity of the destroyed fluid inclusions at the sample surface are marked by grey dots. b - Trace element profile of the same quartz. The non-luminescent quartz is depleted in Ti. The high $\mathrm{Al}$ and $\mathrm{K}$ of the $40-\mu \mathrm{m}$ point is caused by impurities in the fluid inclusion hole (grey). 


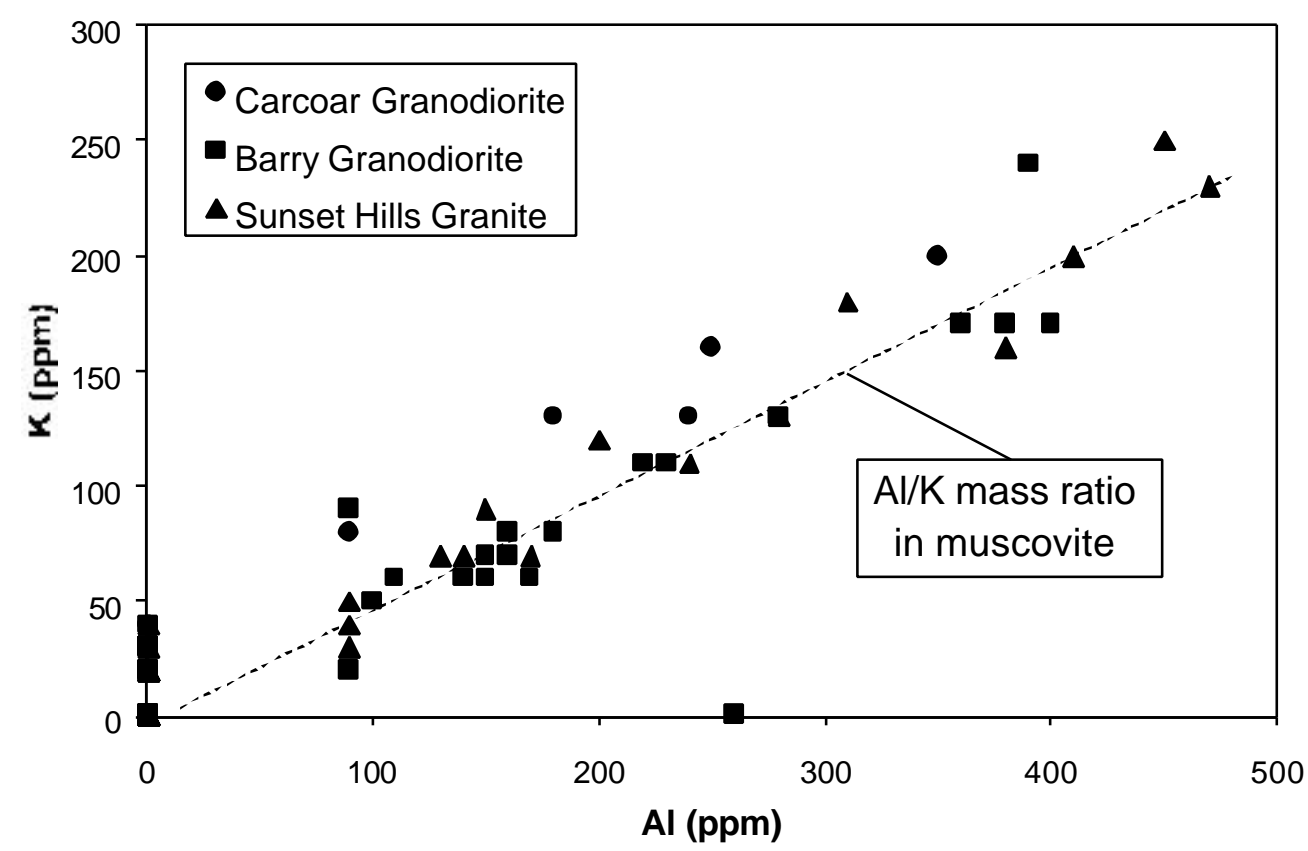

Fig. 10.10 Al versus $\mathrm{K}$ concentrations of the investigated quartz of the three granites. The regression line of the data above $50 \mathrm{ppm}$ corresponds with the $\mathrm{Al} / \mathrm{K}$ ratio of the average muscovite composition (dashed line). The deformation of magmatic quartz caused the development of submicroscopic muscovite flakes $(<0.5 \mu \mathrm{m})$ along slip planes.

\subsection{Al-in-hornblende geobarometery on the Carcoar and Barry granodiorites}

The Al-in-hornblende barometer helps to estimate the crystallisation pressure of granites. The empirical correlation between the pressure of emplacement of calcalkaline granites, and the total $\mathrm{Al}$ content of hornblende equilibrated with quartz was proposed by Hammarstrom and Zen (1986) and Hollister et al. (1987). Experimental calibrations of the barometer were carried out by numerous workers (Johnson and Rutherford, 1989; Thomas and Ernst, 1990; Schmidt, 1992; Anderson and Smith, 1995). The barometer applies if the magmatic rocks (1) have the assemblage $\mathrm{pl}+\mathrm{ksp}+\mathrm{qtz}+\mathrm{hb}+\mathrm{bt}+\mathrm{tnt}+\mathrm{Fe}-\mathrm{Ti}$; and (2) plagioclase has a constant rim composition in the range of $\mathrm{An}^{25}$ and $\mathrm{An}^{35}$; (3) the analysis is limited only to the rim composition of hornblende; (4) the hornblende $\mathrm{Fe}^{\mathrm{T}} /\left(\mathrm{Fe}^{\mathrm{T}}+\mathrm{Mg}\right.$ ) ratios are in the range of 0.40 0.65 , to exclude low $\mathrm{fO}_{2}$, and (5) the pressure of crystallisation is above $1 \mathrm{kbar}$ (Hammarstrom and Zen, 1986; Hollister et al., 1987; Anderson and Smith, 1995).

The Carcoar and Barry granodiorites have the appropriate mineral assemblage, with a plagioclase composition between $\mathrm{An}^{29}$ and $\mathrm{An}^{34}$, and hornblende with $\mathrm{Fe}^{\mathrm{T}} /\left(\mathrm{Fe}^{\mathrm{T}}+\mathrm{Mg}\right)$ ratios 
in the range of $0.42-0.53$. The pressures during mineral growth were calculated using the calibration of Anderson and Smith (1995), including the effect of temperature, as the barometer is sensitive to variations in temperature. The temperatures were determined using the amphibole-plagioclase geothermometer after Blundy and Holland (1990) with the modified pressure term after Schmidt (1992).

Al-in-hornblende barometry on the Carcoar Granodiorite yields pressures of $1.7 \pm 0.7 \mathrm{kbar}$ (30 analyses) at $756 \pm 12$ C. Amphiboles of the Barry Granodiorite yield pressures of $1.8 \pm$ $0.8 \mathrm{kbar}$ (37 analyses) at $753 \pm 22 \mathrm{C}$. No differences in the $\mathrm{Al}^{\mathrm{T}}$-content were detected between the core and the rim of hornblende in the Carcoar and Barry granodiorites. Consequently, the crystallisation depth of the hornblende of the Carcoar and Barry granodiorites is $6.0 \pm 2.6 \mathrm{~km}$. These results are consistent with the estimated intrusion depths of 4-6 km for the Carcoar and Barry granodiorites based on the extent and nature of the contact aureole as calculated by Lennox and Fowler (pers. comm.)

\subsection{Discussion and conclusions}

\section{Quartz cathodoluminescence}

Three main conclusions can be made from CL analysis:

(1) Magmatic quartz with high Ti content shows blue to violet CL, and with low Ti content red to red-brown $\mathrm{CL}$. The variation of $\mathrm{Ti}$ in the quartz lattice relates with contrasts in the growth zoning of quartz phenocrysts referred to as the primary magmatic CL textures. With increasing deformation the homogeneity of Ti distribution decreases.

(2) Dark red-brown to non-luminescent, secondary CL textures show low $\mathrm{Al}, \mathrm{Fe}$ and $\mathrm{Ti}$ concentrations. The low trace element concentration of the star-like halos and the lamellae are due to systematic recovery of the defect centres of trace element, which was initiated by local stress around fluid inclusions and along slip planes (Kerkhof and Müller, 1999). The annealing of intragranular micro-shear zones led to formation of secondary quartz, depleted in trace elements.

(3) In contrast to undeformed, natural quartz, interstitial water is absent from deformed quartz. We suggest that a large portion of the interstitial water, which was originally incorporated in the quartz lattice during magmatic crystallisation, was absorbed in the submicroscopical muscovite flakes during the post-magmatic deformation. The residual interstitial water reacted with silica due to pressure solution during deformation, and 
formed Si-OH bonds along intragranular cracks caused by sliding (e.g. Michalske and Freiman, 1982).

\section{Magmatic quartz textures}

The analysis of the magmatic quartz texture, grain size distribution, and CL contrasted growth zoning of the phenocrysts leads to the following four conclusions:-

(1) The Carcoar Granodiorite has one generation of anhedral quartz, which crystallised in cavities between feldspar and mafic minerals during and after emplacement.

(2) The Barry Granodiorite formed one generation of unzoned, subeuhedral quartz phenocrysts overgrown by a second generation of anhedral matrix quartz. The homogeneous distribution of $\mathrm{Al}^{\mathrm{T}}$ in hornblende indicates one main crystallisation stage. Therefore, both quartz generations must have crystallised at or near the emplacement level. First, quartz grew in a crystal mush, which facilitated a relatively unhindered growth and formation of planar crystal faces. Their growth may have been interrupted by magma degassing or magma pulsing. As a result, quartz with contrasting CL properties crystallised filling the residual space between the crystals. The grain size of the matrix quartz of the Barry Granodiorite is smaller in comparison to the Carcoar Granodiorite. In the south, the Barry Granodiorite shows aplitic textures and the grain size of the matrix quartz decreases to $\sim 100 \mu \mathrm{m}$ indicating faster cooling rates of the melt. Both features indicate that a higher level of the Barry pluton is exposed in the south.

(3) In contrast to the Carcoar and Barry granodiorites, the Sunset Hills Granite has three generations of quartz. The first two generations are phenocrysts of variable size, showing oscillatory and superordinate stepped zoning, and resorption surfaces. The stepped zoning and the resorption surfaces both indicate a change in melt composition, pressure and temperature during the early stage of magma ascent. The properties of these phenocrysts show similarities with rhyolitic phenocrysts. The third magmatic generation is represented by the homogeneous matrix quartz, which crystallised at the intrusion level, overgrowing the phenocrysts.

(4) The melt of both granodiorites underwent a relatively continuous and rapid ascent; whereas the melt of the Sunset Hills Granite experienced a stepwise ascent that caused multiphase nucleation, episodes of slow crystal growth, and resorption events. 


\section{Geochemistry and Al-in-hornblende geobarometry}

The similarities in chemical composition of the Carcoar and Barry granodiorites indicate derivation from one magma source. The geochemical difference between both granodiorites is documented by fractionation of hornblende within the Barry Granodiorite. The most fractionated, uppermost part of the Barry Granodiorite is exposed at the contact with the Sunset Hills Granite in the south. The intrusion depth is in the lower error range of the hornblende crystallisation depth between 3 and $6 \mathrm{~km}$. This depth is consistent with estimations of 4-6 km for the emplacement depth of the Barry Granodiorite by Lennox and Fowler (pers. comm.), which are based on the extent and nature of the contact aureole. The intrusion depth of the Carcoar Granodiorite is in the upper error range of the hornblende crystallisation depth between 6 and $9 \mathrm{~km}$, as also inferred by lower cooling rates and a wider contact aureole. Consequently, the northern part of the Carcoar Granodiorite represents a deeper part of the pluton compared with the southern part of the Barry Granodiorite, which is consistent with 3D gravity modelling of the pluton (Trzebski et al., 1999).

In contrast to the I-type Carcoar and Barry granodiorites, the Sunset Hills Granite shows Stype affinity. The magma of the Sunset Hills Granite we interprete as fractionation product derived from the magma of the Wyangala Batholith. Besides the compositional similarities of both granites, the Sunset Hills Granite occurs at the northeastern extremity of the negative gravity anomaly due to the Wyangala Batholith (Trzebski et al., 1999). Three-dimensional gravity modelling and re-interpretation of aeromagnetics suggest a subsurface connection and therefore a possible genetic link in magma genesis between both granites.

\section{Deformation fabrics}

The Carcoar and Barry granodiorites both show magmatic and post-magmatic foliation, whereas in the Sunset Hill Granite an intense post-magmatic foliation was developed, which may have possibly overprinted a pre-existing magmatic foliation. The magmatic foliation of the Carcoar and Barry granodiorites are marked by aligned biotite and hornblende and are cross-cut by the post-magmatic, solid-state foliation. This later foliation in all granitoids is post-magmatic, because it is (1) marked by secondary minerals, such as muscovite and chlorite, (2) is locally at high angles to pluton-host rock contacts, (3) is continuous with the regionally developed cleavage, and (4) cross-cuts aligned igneous minerals. In addition, the contact aureole of these granitoids overprints the earlier metamorphic fabrics (Lennox et al, 1991; Lennox and Fowler, 1994; McKinlay, 1993; Lennox et al., 1998). The post-magmatic deformation fabrics are probably related to regional shear zones. 
The dominance of prismatic subgrain boundaries of quartz in the Carcoar and Barry granodiorites indicates slip along the basal plane, which is limited to the stability field of lowquartz (Blumenfeld et al., 1986; Kruhl, 1996). The beginning of quartz recrystallisation in the Carcoar Granodiorite indicates deformation temperatures of $=290^{\circ} \mathrm{C}$ (Voll 1976, 1980). The increase in size of the dynamically recrystallised quartz grains in the Barry Granodiorite, in comparison with that of the quartz in the Carcoar Granodiorite, is due to both increasing temperature and differential stress. Secondly, the new crystallised quartz grains with highangle boundaries developed during the recovery of subgrains at moderate to high temperatures in the Barry Granodiorite (Hull and Bacon, 1984; Hirth and Tullis, 1992). The Barry Granodiorite was deformed at higher temperature than the Carcoar Granodiorite. The abscence of widespread boundary migration recrystallisation indicates a maximum deformation temperature of $400^{\circ} \mathrm{C}$ (Guillopé and Poirier, 1979; Urai and Humphreys, 1981; Urai, 1983; Paschier and Trouw, 1998). Using the closure temperature of the Ar-Ar system in biotite, the likely temperatures during the post-magmatic Bowning deformation (405-410 Ma) are estimated to $\sim 350^{\circ} \mathrm{C}$ for the Carcoar Granodiorite and to $350-400^{\circ} \mathrm{C}$ for the Barry Granodiorite.

The boundary migration recrystallisation during dynamic recrystallisation in the quartz of the Sunset Hills Granite is a typical process at high temperatures of $400-700^{\circ} \mathrm{C}$ (Guillopé and Poirier, 1979; Urai and Humphreys, 1981; Urai, 1983; Paschier and Trouw, 1998). The development of basal and prismatic subgrain boundaries in deformed quartz indicates prism slip of quartz, which is restricted to the stability field of high-quartz at temperatures around 550 C (Blacic and Christie, 1984; Blumenfeld et al., 1986; Kruhl, 1996). The increase of dynamically recrystallised grain size from the Barry Granodiorite to the Sunset Hills Granite is interpreted to be a result of the dominance of annealing recrystallisation over dynamic recrystallisation at temperatures around $550 \mathrm{C}$. This is consistent with the estimated deformation temperatures of $550^{\circ} \mathrm{C}$ for the adjacent Wyangala Batholith (Morand, unpubl. data in Paterson et al., 1990).

\subsection{Geological implications}

This study has quantified the conditions of magma crystallisation, emplacement and deformation of the Carcoar, Barry and Sunset Hills granites. Our previous work revealed the structural framework of these granites and their host rocks, the three-dimensional shape of the 
plutons, their spatial relationship with faults and their distribution at depth (Lennox et al., 1998; Trzebski et al., 1999). New and published radiometric dating differentiated three events that indicate the timing of emplacement of the granites and their subsequent deformation (Lennox et al., 1998). These events are coeval with regional orogenic events in the Lachlan Fold Belt (e.g., Gray and Forster, 1997). The first event (Benambran), dated at approximately $430 \mathrm{Ma}$ (Lower Silurian) by the zircon SHRIMP U-Pb method and by U-Pb dating of zircon fractions, indicates the emplacement time of all three granites (Lennox, unpublished data). Both subsequent events, dated to $\sim 410 \mathrm{Ma}$ (Bowning) and $\sim 375 \mathrm{Ma}$ (Tabberabberan) using the $\mathrm{Rb}$-Sr-, Ar-Ar- and K-Ar-methods on biotite and hornblende, document two deformation stages following granite emplacement (Lennox et al, 1998; Glen et al., in press).

All three granites intruded synchronously, but at different crustal levels. The Carcoar and Barry granodiorites were emplaced at a depth of $₫ 2.6 \mathrm{~km}$ under brittle to locally weakly ductile conditions. The elongate shape of the Barry Granodiorite is subparallel to the regional structural strain. In contrast, the almost square geometry of the Carcoar Granodiorite suggests emplacement in a brittle fashion which was structurally controlled by extensional faults and fractures at shallow crustal depths. Although the intrusion depth of the Sunset Hills Granite could not be determined, we assume that the magma accumulated at deeper levels on the basis of the upper greenshist facies and the ductile structures of the surrounding host rocks (Lennox and Fowler, 1994). The grain boundary migration recrystallisation and larger average size of recrystallised quartz grains $(\sim 100 \mu \mathrm{m})$ with high-angle boundaries further indicate that the Sunset Hills Granite remained in a hotter environment over a considerably longer period of time after emplacement. The concordance in structural development between the Sunset Hills Granite and the host-rocks, the geometry of foliation trends around the pluton and its elongated shape additionally indicate emplacement into host rocks at greater depth under ductile conditions. This is also supported by the fact that during the first post-magmatic Bowning event the Sunset Hills Granite was deformed at temperatures of $\sim 550^{\circ} \mathrm{C}$ and at depths of 10-12 km when applying a likely geothermal gradient of $45-55^{\circ} \mathrm{C} / \mathrm{km}$ (Packham, 1999). Similar intrusion depths were obtained by pressure data of 3-4 kbar for the adjacent and genetically related Wyangala Batholith (Morand quoted in Paterson et al., 1990). In contrast, during the same event both I-type granodiorites were deformed at temperatures of $350-400^{\circ} \mathrm{C}$ due to their higher emplacement level in the crust. The east-west contraction during the Upper Silurian/Lower Devonian causes uplift of both granodiorites and cooled through the closure temperature of biotite $\left(\sim 350^{\circ} \mathrm{C}\right)$ at around $412 \mathrm{Ma}$; whereas the deeper seated Sunset Hills Granite was synchronously cooled through the closure temperature of 
hornblende $\left(\sim 550^{\circ} \mathrm{C}\right)$. The second post-magmatic deformation (Tabberabberan event), caused by regional east-west contraction, only weakly deformed the near-surface located more resistant granodiorites in a brittle fashion because the granodiorites were at upper crustal levels (Vernon and Flood, 1988). The Sunset Hills Granite experienced further vertical uplift due to east-vergent thrusting and cooling through the closure temperature of biotite $\left(\sim 350^{\circ} \mathrm{C}\right)$ at around $380 \mathrm{Ma}$ (Paterson et al., 1990; Glen and Watkins, 1999). The youngest event around $340 \mathrm{Ma}$, which correlates with the Early Carboniferous Kanimblan deformation (Gray and Forster, 1997), was associated with north-south contraction and resulted in mega-kinking at a regional scale (Powell et al., 1985). North-south oriented thrusting may have further exposed all three granites along north-vergent ramps. This is supported by the fact that both granodiorites show deeper exposure levels in the north of the plutons. 


\section{References}

Agel A. (1992): Paramagnetische Defektzentren in polykristallinem Quarz granitischer und metamorpher Herkunft. Thesis, Univ. Marburg, 109 p.

Agel A. and Petrov I. (1990): Im Quarzgitter substituiertes Aluminium als Indikator für dessen Bildungstemperatur. Ber. Dtsch. Min. Ges., Beih. Eur. J. Mineral., 2/1: 144.

Allègre C.J., Provost A., Jaupart C. (1981): Oscillatory zoning: A pathological case of crystal growth. Nature, 294: 223-228.

Aines R.D. and Rossman G.R. (1984): Water in minerals? A peak in the infrared. J. Geophys. Res., 89/B6: 40594071.

Alonso P.J., Halliburton L.E., Kohnke E.E. and Bossoli R.B. (1983): X-ray-induced luminescence in crystalline $\mathrm{SiO}_{2}$. J.Appl.Phys., 54/9: 5369-5375.

Anderson A.T. (1984): Probable relations between plagioclase zoning and magma dynamics, Fuego Volcano, Guatemala. Amer. Mineral., 69: 660-676.

Anderson J.H. and Wickersheim K.A. (1964): Near infrared characterisation of water and hydroxyl groups on silica surfaces. Surf. Sci., 2: 252-260.

Anderson J.L. and Smith D.R. (1995): The effects of temperature and $f \mathrm{O}_{2}$ on the Al-in-hornblende barometer. American Mineralogist, 80: 549-559.

Arikas K. (1964): Geochemie und Petrologie der permischen Rhyolite in SW-Deutschland. Fortschritte d. Mineral., Bh. 1, 64: 9-10.

Armstrong J.T. (1991): Quantitative elemental analysis of individual microparticles with electron beam instruments. In: Heinrich K.F.J. and Newbury D.E. (eds.): Electron probe quantification. Plenum Press, New York, London, 261-315.

Audétat A. and Günther D. (1999): Mobility and H2O loss from fluid inclusions in natural quartz crystals. Contrib. Mineral. Petrol., 137: 1-14.

Baker B.G. and Sexton B.A. (1975): Electron beam effects in Auger analysis of physisorbed xenon. Surf. Sc., 52: 353-364.

Bambauer H.U. (1961): Spurenelementgehalt und -Farbzentren in Quarzen aus Zerrklüften der Schweizer Alpen. Schweiz. Mineral. Petrogr. Mitt., 41:335-369.

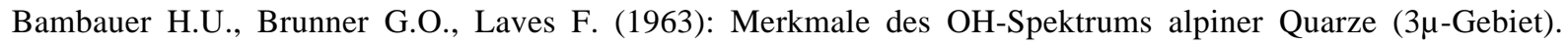
Schweiz. Mineral. Petrogr. Mitt., 43: 259-268.

Bard J.P. (1986): Microtextures of igneous and metamorphic rocks. - D. Reidel Publishing Company Dordrecht, Boston, Lancaster, 264 pp.

Behr H.J. (1966): Die Verwendung von Lackfilmen (Ätzbildern) zur Strukturuntersuchung von metamorphen und magmatischen Gesteinen. Monatsber. Dt. Akad. Wiss., 8/12: 897-904.

Behr H.J. (1989): Die geologische Aktivität von Krustenfluiden. In: Gesteinsfluide - Ihre Herkunft und Bedeutung für geologische Prozesse. Nds. Akad. Geowiss. Veröfftl. 1, Hannover, pp. 7-42.

Behr H.-J. and Frentzel-Beyme K. (1989): Permeability and paleoporosity in crystalline bedrocks of the Central European basement-studies of cathodoluminescence. In: Boden A. and Eriksson K.G. (eds.): Exploration of the deep continental crust. Deep drilling in crystalline bedrock, volume 2. Springer, pp. 477-497.

Behr H.-J. and Horn E.E. (1982): Fluid inclusion systems in metaplaya deposits and their relationship to mineralization and tectonics. Chem. Geol., 37: 173-189.

Behr H.-J., Horn E.E., Porada H. (1983): Fluid inclusions and genetic aspects of the Damara Orogen. In: Martin H. and Eder F.W.: Intracontinental Fold Belts. Springer, pp. 611-654.

Behr H.-J. and Schmidt-Mumm A. (1987): The role of sedimentary and tectonic brines in the Damara Orogen, Namibia. Appl. Geochemistry, 2: 535-542.

Bershov L.V., Krylova M.D. and Speranskij A.V. (1978): The electron holes centres O-Al and Ti3+ as indicator for temperature conditions during regional metamorphosis (in Russ.). Izv. Akad. Nauk SSSR, Ser. geol., 113-117.

Beskin S.M., Larin V.N., Marin Yu.B. (1994): Physiographic types of granitic rocks of Kazakhstan and their metallogenic significance. In: Shatov V., Seltmann R., Kremenetsky A., Lehmann B., Popov V., Ermolov P. (eds.): Granite-related ore deposits of Central Kazakhstan and adjacent areas. Glagol St. Petersburg 1996, pp 259-268.

Beus A.A., Severov E.A., Sitnin A.A., Subbotin K.D. (1962): Albitized and greisenized granites (apogranites). Izdat. Akad. Nauk SSSR, Moscow, 196 p. (in Russian).

Blacic J.D. and Christie J.M. (1984): Plasticity and hydrolytic weakening of quartz single crystals. J. Geophys. Res., 89: 4223-4239. 
Blankenburg H.-J., Götze J. and Schulz J. (1994): Quarzrohstoffe. Deutscher Verlag für Grundstoffindustrie, Leipzig-Stuttgart, $296 \mathrm{pp}$.

Blumenfeld P., Mainprice D. and Bouchez J.L. (1986): C-slip in quartz from subsolidus deformed granite. Tectonophysics, 127: 97-115.

Blundy J.D. and Holland J.B. (1990): Calcic amphibole equilibria and a new amphibole-plagioclase geothermometer. Contrib. Mineral. Petrol., 104: 208-24.

Blundy J.D. and Holland J.B. (1994): Non-ideal interactions in calcic amphiboles and their bearing on amphibole-plagioclase thermometry. Contrib. Mineral. Petrol., 116: 433-47.

Boiron M.C., Essarraj S., Sellier E., Cathelineau M., Lespinasse M. and Poty B (1992): Identification of fluid inclusions in relation to their host microstructural domains in quartz by cathodoluminsecence. Geochim. Cosmochim. Acta, 56: 175-185.

Bottinga Y., Kudo A., Weill D. (1966): Some observations on oszillatory zoning and crystallisation of magmatic plagioclase. Amer. Mineral., 51: 792-806.

Boullier A.M. and Bouchez J.L. (1978): Le quartz en rubans dans les mylonites. Bull. Soc. geol. France, 7/3: 253-262.

Breiter K., Sokolova M., Sokol A. (1991): Geochemical specialisation of the tin bearing granitoid massif of NW Bohemia. Mineral. Deposita 26: 298-306.

Breiter K., Förster H.J., Seltmann R. (1999): Variscan silicic magmatism and related tin-tungsten mineralization in the Erzgebirge-Slavkovsky les metallogenic province. Mineralium Deposita, 34: 505-521.

Breiter K., Fryda J., Seltmann R., Thomas R. (1997): Mineralogical evidence for two magmatic stages in the evolution of an extremely fractionated P-rich rare-metal granite: the Podlesi stock, Krušné Hory, Czech Republic. J. Petrol., 38/12: 1723-1739.

Brown C. and Thomas L. (1960): The effect of impurities on the growth of synthetic quartz. J. Phys. Chem. Solids, 13: 337.

Bruckschen P., Neuser R.D., Richter D.K. (1992): Cement stratigraphy in Triassic and Jurassic limestones of the Weserbergland (northwest Germany). Sedimentary Geology, 81: 195-214.

Bruhn F., Bruckschen P., Meijer J., Stephan A., Richter D.K., Veizer J. (1996): Cathodoluminescence investigations and trace-element analysis of quartz by micro-PIXE: implications for diagenetic and provenance studies in sandstone. Canadian Mineralogist 34: 1223-1232

Brunner G.O., Wondratschek H. and Laves F. (1961): Ultrarotuntersuchung über den Einbau von H in natürlichen Quarz. Z. Elektrochem. 56: 735-750.

Candela P.A., Blevin P.L. (1995): Do some miarolitic granites preserve evidence of magmatic volatile phase permeability? Economic Geology, 90: 2310-2316.

Castaing R. (1951): Application des sondes électroniques à une méthode d'analyse ponctuelle chimique et cristallographique. (Electron beam based techniques for spatially resolved chemical and crystallographical analyses.) - Thèse, Université de Paris, France.

Cobbing E.J., Pitfield P.E.J., Darbyshire D.P.F., Mallick D.I.J. (1992): The granites of the South-East Asian tin belt. British Geological Survey Overseas Memoir 10, London, 369 p.

Cohen A.J. (1960): Substitutional and interstitial aluminium impurity in quartz, structure, and color centre interrelationships. J. Phys. Chem. Solids, 13: 321-325.

Collins P.J. and Vernon R.H. (1992): Paleazoic arc growth, deformation and migration across the Lachlan Fold Belt, southeastern Australia. Tectonophysics, 214: 381-400.

Coney P.J. (1992): The Lachlan Fold Belt of eastern Australia and Circum Pacific tectonic evolution. Tectonophysics, 214: 381-400.

Crookes W. (1879): Contributions to molecular physics in high vacuo. Phil. Trans., 170: 641-662.

Demars C., Pagel M., Deloule E., Blanc P. (1996): Cathodoluminescence of quartz from sandstones: Interpretation of the UV range by determination of trace element distributions and fluid-inclusion P-T-X properties in authigenic quartz. Amer. Mineral., 81: 891-901.

Dennen W.H. (1965): Stoichiometric substitution in natural quartz. Geochimica et Cosmochimica Acta, 30: 1235-1241.

Dennen W.H., Blackburn W.H., Quesada A. (1970): Aluminium in quartz as a geothermometer. Contr. Mineral. and Petrol., 27: 332-342.

D’Lemos R.S., Kearsley A.T., Pembroke J.W., Watt G.R., Wright P. (1997): Complex quartz growth histories in granite revealed by scanning cathodoluminescence techniques. Geol. Mag., 134/4: 549-552.

Donaldson C.H., Henderson C.M.B. (1988): A new interpretation of round embayments in quartz crystals. Mineral. Mag., 52: 27-33.

Dowty E. (1989): Crystal growth and nucleation theory and the numerical simulation of igneous crystallization. In: Hargraves R.B. (ed.): Physics of magmatic processes. New Jersey, pp 419-485.

Dudek H.J. (1970): Zeitlicher und räumlicher Temperaturverlauf im Material bei fokussierter Elektronenbestrahlung. Optik 30/5: 453-460.

Dudley R.J. (1976): The use of cathodoluminscence in the identification of soil materials. J. Soil Sci., 27: 487491. 
Evans J., Hogg A.J., Hopkins M.S., Howarth R.J. (1994): Quantification of quartz cements using combined SEM CL and image analysis. J. Sed. Res., 64A: 334-338.

Fiala F. (1968): Granitoids of the Slavkovský (Císaøský) Les Mountains. Sbor. geol. Vìd, G, 14: 93-160.

Flick H. (1984): Kristallisation des Quarzes in kieselsäurereichen Schmelzen - Möglichkeiten seiner Verwendung als geologisches Thermometer und Barometer. Habilitation, University Heidelberg, 133 pp.

Flick H. (1987): Geotektonische Verknüpfung von Plutonismus und Vulkanismus im südwestdeutschen Variscicum. Geol. Rdsch. 76/3: 699-707.

Flicstein J. and Schieber M. (1974): Microsegregation of impurities in hydrothermally-grown quartz crystals. $J$. Cryst. Growth 24/25: 603-609.

Förster H.J., Tischendorf G. (1994): The western Erzgebirge-Vogtland granites: Implications to the Hercynian magmatism in the Erzgebirge-Fichtelgebirge anticlinorium. In: Seltmann R., Möller P., Kämpf H. (eds.): Metallogeny of Collisional Orogens. Czech Geological Survey Prague, pp 35-48.

Förster H.J., Seltmann R., Tischendorf G. (1995): High-fluorine, low phosphorus A-type (post-collision) silicic magmatism in the Erzgebirge. In: $2^{\text {nd }}$ Symp. Permocarboniferous Igneous Rocks. Terra Nostra, 7: pp 32-35.

Förster H.J., Seltmann R., Tischendorf G. (1996): Post-collisional A-type silicic magmatism in the Variscan Erzgebirge. Journ. Confer. Abstracts, 1: p. 174.

Fowler A.D. (1990): Self-organized mineral textures of igneous rocks: the fractal approach. Earth-Science Reviews 29: 47-55

Frentzel-Beyme K. (1989): REM-Kathodolumineszenz-Strukturen im Quarzteilgefüge von Metamorphiten: Bestandsaufnahme und geologische Interpretation. Dissertation University Göttingen, Photodruck Göttingen, $78 \mathrm{p}$.

Friebele E.J., Griscom D.L. and Marrone M.J. (1985): The optical absorption and luminescence bands near $2 \mathrm{eV}$ in irradiated and drawn synthetic silica. J. Non-Cryst. Solids, 71: 133-144.

Friskney C.A. and Haworth C.W. (1967): Heat-flow problems in electron-probe microanalysis. J. Appl. Phys. 38: $3796-3798$.

Fuchs, H. and Götze, J. (1996): Origin of volcanic agate - evidence from cathodoluminescence, EPR and geochemical studies. Intern. Conf. CL Rel. Techn. Geosci. Geomat., Nancy, Abstracts, pp. 49-50.

Gallei E. and Parks G.A. (1972): Evidence for surface hydroxyl groups in attenuated total reflectance spectra of crystalline quartz. J. Colloid Interface Sci., 38: 650-651.

Gerler J. (1990): Geochemische Untersuchungen an hydrothermalen, metamorphen, granitischen und pegmatitischen Quarzen und deren Flüssigkeitseinschlüssen. Thesis, Georg-August-Universität Göttingen, Germany, 169 pp.

Glen R.A. (1998): The Eastern Belt of the Lachlan Orogen. In: Finlayson, D.M. and Jones, L.E.A. (eds.): Mineral Systems and the crust-upper mantle of southeast Australia. Australian Geological Survey Organisation Record, 2 : 80-82.

Glen R.A., Walshe J.L., Barron L.M., Watkins J.J. (1998): Ordovician convergent-margin volcanism and tectonism in the Lachlan sector of east Gondwana. Geology, 26: 751-754.

Glen, R.A. and Walshe J.L. (1999): Cross-structures in the Lachlan Orogen: the Lachlan Transverse Zone example. Australian Journal of Earth Science, 46: 641-658.

Glen, R.A., Lennox, P.G. and Forster, D.A. (in press): 40Ar-39Ar dating of deformation west of the Hill End Through, Lachlan Orogen, New South Wales. Quarterly Note, Geological Survey of New South Wales.

Goldstein E. (1907): Über das Auftreten roten Phosphoreszenzlichtes an Geissler'schen Röhren: Bericht der Deutschen Physikalischen Gesellschaft, 598-605.

Gorobets B.S., Graft M.L., Podolskiy A.M. (1989): Luminescence of minerals and ores. Ministry of Geology USSR, Moscow, 53 pp., (in Russian).

Gorton N.T., Walker G., Burley, S.D. (1996): Experimental analysis of the composite blue CL emission in quartz - is this related to aluminium content? In: Abstracts SLMS International Conference on Cathodoluminescence, Nancy, Sept 1996, p 59.

Gottstein G. and Mecking H. (1985): Recrystallization. In: Wenk H.R. (ed.): Preferred orientation in deformed metals and rocks - an introduction to modern texture analysis. Academic Press, New York, pp. 183-218.

Götze J. (2000): Cathodoluminescence microscopy and spectroscopy in applied mineralogy. Habilitation, TU Bergakademie Freiberg, 128pp.

Götze J. and Plötze M. (1997): Investigation of trace element distribution in detrital quartz by electron paramagnetic resonance (EPR). Eur. J. Mineral. 9: 529-537.

Götze J., Plötze M., Fuchs H. and Habermann D. (1999): Defect structure and luminescence behaviour of agate results of electron paramagnetic resonance (EPR) and cathodoluminescence (CL) studies. Min. Mag. 63/2: 149-163.

Grant P. (1978): The role of scanning electron microscope in cathodoluminescence petrology. In: Whalley B. (ed): Scanning Electron Microscopy in the Study of Sediments. Geo Abstracts, pp. 1-11.

Grant P.R. and White S.H. (1978): Cathodoluminscence and microstructure of quartz overgrowths on quartz. Scan. Electr. Micr., 1978/I: 789-794. 
Gray D.R., Forster D.A., Bucher M. (1997): Recognition and definition of orogenic events in the Lachlan Fold Belt. Australian Journal of Earth Sciences, 44: 489-501.

Gray D.R. and Forster D.M. (1997): Orogenic concepts - applications and definition: Lachlan fold belt, eastern Australia. American Journal of Science, 297: 859-891.

Greenwood H.J., McTaggart K.C. (1957): Correlation of zones in plagioclase. Amer J Sci 255: 656-666.

Griggs D.T. (1967): Hydrolytic weakening of quartz and other silicates. Geophys. J. R. Astron. Soc. 14: 19-32.

Griggs D.T. and Blacic J.D. (1965): Quartz: Anomalous weakness of synthetic crystals. Science, 147: 292-295.

Griscom D.L. (1985): Defect structure of glass. - J. Non-Cryst. Solids 73, 51-77.

Griscom D.L. (1991): Optical properties and structure of defects in silica glass. J. Cer. Soc. Japan, $99: 923$.

Gritsenko B.P. and Lisitsyn V.M. (1985): Intrinsic short-lived defects in quartz. Sov. Phys. Solid State, 27/7: 1330-1331.

Grün R., Tani A., Gurbanov A., Koshchug D., Williams I., Braun J. (2000): A new method for the estimation of cooling and denudation rates using paramagnetic centres in quartz: A case study on the Eldzhurtinsky Granite, Caucasus. J. Geophys. Research (in review).

Guillopè M. and Poirier J.P. (1979): Dynamic recrystallization during creep of single crystalline halite: an experimental study. J. Geophys. Res., 4: 5557-5567.

Guzzi M., Martini M., Mattaini M., Pio F., Spenolo G. (1987): Luminescence of fused silica: observation of the $\mathrm{O}_{2}{ }^{-}$emission band. Phys. Rev. B, 35: 9407-9409.

Haapala I. (1997): Magmatic and postmagmatic processes in tin-mineralized granites: Topaz-bearing leucogranite in the Eurajoki Rapakivi granite stock, Finland. J. Petrol., 38/12: 1645-1659.

Haase C.S., Chandam J., Feinn D., Ortoleva P. (1980): Oscillatory zoning in plagioclase feldspar. Science, 209: $272-274$

Habermann D., Neuser R.D., Richter D.K. (2000): Quantitative high-resolution spectral analysis of Mn2+ activated CL in sedimentary calcite. In: Pagel M., Barbin V., Blanc P., Ohnenstetter D. (eds.): Cathodoluminescence in Geosciences. Springer, Berlin Heidelberg New York, pp. 331-358.

Hagni R.D. (1984): Cathodoluminescence microscopy applied to mineral exploration and benefication. In: Park W.C., Hausen D.M., Hagni R.D. (eds.): Applied mineralogy. Proceedings of the Second International Congress on Applied Mineralogy, AIME, New York, p. 41-66.

Hagni R.D. (1987): Industrial applications of cathodoluminescence microscopy. In: Hagni R.D. (ed.): Process Mineralogy IV: Applications to precious metal deposits, industrial minerals, coal, liberation, mineral processing, agglomeration, metallurgical products, and refractories, with special emphasis on cathodoluminescence microscopy. TMS, Warrendale, Pennsylvania, p. 37-52.

Hammarstrom J.M. and Zen E-An (1986): Aluminium in hornblende: An empirical igneous geobarometer. Am. Mineral., 71: 1297-1313.

Hanusiak W.M. (1975): Low temperature cathodoluminescence of crystalline silica for use in the characterisation of respirable dusts. MSc Thesis, State College, Penn State University.

Hanusiak W.M. and White E.M. (1975): SEM cathodoluminescence for characterisation of damaged and undamaged alpha-quartz in respirable dusts. In: Johari O., Corvin I. (eds.): Proceedings of the $8^{\text {th }}$ annual Scanning Electron Microscope Symposium, pp. 125-132.

Harris D.W., Anderson A.T. (1984): Volatiles $\mathrm{H}_{2} \mathrm{O}, \mathrm{CO}_{2}$ and $\mathrm{Cl}$ in a subduction related basalt. Contrib. Mineral. Petrol., 87: 120-128.

Hartmann P. (1978): Sur la morphologie des cristaux. Bull. Mineral., 101: 195.

Hashimoto T., Sakaue S., Aoki H., Ichino M. (1994): Dependence of TL-property changes of natural quartzes on aluminium contents accombined by thermal annealing treatment. Radiat. Meas., 23: 293-299.

Hay R.S. and Evans B. (1987a): Chemically induced grain boundary migration in calcite: temperature dependence, phenomenology, and possible applications to geologic systems. Contrib. Mineral. Petrol., 97: 127-141.

Hay R.S. and Evans B. (1987b): Chemically induced grain boundary migration in low and high angle calcite grain boundaries. Acta Metal., 135: 2049-2062.

Hayes W., Kane M.J., Salminen O., Wood R.L. and Doherty S.P. (1984): ODMR of recombination centers in crystalline quartz. J. Phys. C, 17: 2943-2951.

Heggie M.I. (1992): A molecular water pump in quartz dislocations. Nature, 355/23: 337-339.

Helbig C., Beyer F. (1970): Zur relativen Alterstellung und petrotektonischen Analyse des Schellerhauer Granits. Jb. Geol., 3/1967, Berlin, pp. 217-242.

Hess P.C. (1989): Origin of igneous rocks. Harvard University Press, 336 pp.

Hirth G. and Tullis J. (1992): Dislocation creep regimes in quartz aggregates. J. Struct. Geol., 14: 145-160.

Hollister L.S., Grissom G.C., Peters E.K., Stowell H.H., and Sisson V.B. (1987): Confirmation of the empirical correlation of $\mathrm{Al}$ in hornblende with pressure of solidification of calc-alkaline plutons. Am. Mineral., 72: 231-239.

Holt D.B. (1992): New directions in scanning electron microscopy cathodoluminecence microcharacterisation. Scanning Microscopy, 6: 1-21. 
Holt D.B. and Saba F.M. (1985): The cathodoluminescence mode of the scanning electron microscope: a powerful microcharacterisation technique. Scanning Electron Microscopy, 1985/III: 1023-1045.

Holten T., Jamtveit B., Meakin P., Cortini M., Blundy J., Austrheim H. (1997): Statistical characteristics and origin of oscillatory zoning in crystals. Amer. Min., 82: 596-606.

Holtz F., Johannes W. (1994): Maximum and minimum water contents of granitic melts: implications for chemical and physical properties of ascending magmas. Lithos, 32: 149-159.

Hull D. and Bacon D.S. (1984): Introduction to dislocation. Pergamon Press, New York, 251p.

Isoya J., Bowman M.K., Norris J.R., Weil J.A. (1983): An electron spin echo envelope modulation study of lithium hyperfine and quadropole coupling in the $\mathrm{Al}$ (Ti-Li) center of a-quartz. J.Chem.Phys., 78: 17351746.

Itoh C., Suzuki T., Itoh N. (1990): Luminescence and defect formation in undensified and densified amorphous $\mathrm{SiO}_{2}$. Phys. Rev. B, 41/6: 3794-3799.

Jackson K. (1979): Theory of crystal growth. Treatise on solid Chemistry Vol. 5, Hannay N. (ed.), Plenum Press, New York.

Jani M., Halliburton L.E., Kohnke E.E. (1983): Point defects in crystalline SiO2: thermally stimulated luminescence above room temperature. J. Appl. Phys., 54: 6321.

Jarchovský T. and Pavlù D. (1991): Albite-topaz microgranite from Horní Slavkov (Slavkovský Les Mts.) North Bohemia. Vist. Ústф. úst. geol., 66: 13-22.

Jarchovský T., Pavlù D., Morysek J., Najman K., Kozubek P. (1994): Li-F granite cupolas and Sn-W mineralization in the Slavkovský les Mts., Czech Republic. Monograph Series on Mineral Deposits, 31: 131148.

Johannes W., Holtz F. (1996): Petrogenesis and experimental petrology of granitic rocks. Springer, Berlin Heidelberg New York, 335 p.

Johnson, M.C. and Rutherford, M.J. (1989): Experimental calibration of the aluminium-in-hornblende geobarometer with application to Long valley caldera (California) volcanic rocks. Geology, 17: 837-841.

Jones C.E. and Embree D. (1976): Correlations of the 4.77-4.28-eV luminescence band in silicon dioxide with the oxygen vacancy. J. Appl. Phys., 47/12: 5365-5371.

Just G., Schilka W., Seltmann R. (1987): INAA investigations in tin-bearing granites of the Altenberg and Sadisdorf ore deposits. In: Proc. $4^{\text {th }}$ Meeting on Nuclear Analytical Methods, Vol. 1, pp. 242-251.

Kalceff S.M.A. and Phillips M.R. (1995): Cathodoluminescence microcharacterization of the defect structure of quartz. Phys. Review B, 52/5: 3122-3134.

Kalceff S.M.A., Phillips M.R., Moon A.R. (1997): Cathodoluminescence microcharacterisation of the irradiation sensitive defect structure of amorphous silicon dioxide. Microscopy and Microanalysis, 3: 751.

Kalceff S.M.A., Phillips M.R., Moon A.R., Kalceff W. (2000): Cathodoluminescence microcharacterisation of silicon dioxide polymorphs. In: Pagel M., Barbin V., Blanc P., Ohnenstetter D.: Cathodoluminescence in Geosciences. Springer, Berlin Heidelberg New York, pp. 193-224.

Kats A. (1962): Hydrogen in alpha-quartz. Philips Res. Repts, 17: 133-279.

Kempe U., Götze J., Dandar, S., Habermann, D. (1999): Magmatic and metasomatic processes during formation of the Nb-Zr-REE deposits from Khaldzan Buregte (Mongolian Altai): Indications from a combined CLSEM study. Miner. Mag., 63: 165-177.

Kennedy S.K. and Arikan F. (1990): Spalled quartz overgrowths as a potential source of silt. J. Sed. Petrol., 60: 438-444.

Kerkhof A.M. van den, Scherer T., Riganti A. (1996): Cathodoluminescence and EPR analysis of Archean quarzites from the Nondweni Greenstone Belt, South Africa. In: Abstracts SLMS International Conference on Cathodoluminescence, Nancy, Sept 1996, p. 75.

Kerkhof A.M. van den, Behr H.-J., and Müller A. (1999): Charakterisierung von Defektstrukturen in Quarz mit Kathodolumineszenz. SFB 468 Wechselwirkungen an geologischen Grenzflächen, Arbeits- und Ergebnisbericht, Universität Göttingen.

Kerkhof A.M. van den and Müller A. (1999): Fluid inclusion re-equilibration and trace element redistribution in quartz: observations by cathodoluminescence microscopy. ECROFI XV 1999 Abstracts and Program, Potsdam, Terra Nostra, 99/6: 161-162.

Khanlary M.R., Townsend P.D., Townsend J.E. (1993): Luminescence spectra of germanosilicate optical fibres. 1: radioluminescence and cathodoluminescence. J. Phys. D, 26: 371.

Kirkham R.V., Sinclair W.D. (1988): Comb quartz layers in felsic intrusions and their relationship to porphyry deposits. In: Taylor R.P., Strong D.F. (eds.): Canadian Institute of Mining and Metallurgy. Special Volume 39: pp 50-71.

Kirkpatrick R.J. (1975): Crystal growth from the melt: A review. Amer. Mineral., 60: 798-814.

Kirkpatrick R.J. (1981): Kinetics of crystallization of igneous rocks. Mineral. Soc. Amer., Rev. Mineral., 8: 321398.

Kostov R.I. and Bershov L.V. (1987): Systematics of paramagnetic electron-hole centres in natural quartz (in Russian). Izvest. AN SSSR, ser. geol., 7: 80-87. 
Kovalenko V.I. (1977): Petrology and geochemistry of rare-metal granitoids. Novosibirsk: Nauka, 225 p. (in Russian).

Kozlowski A. (1981): Melt inclusions in pyroclastic quartz from the Carboniferous deposits of the Holy Cross Mts, and the problem of magmatic corrosion. Acta Geologica Polonica, 31/3-4: 273-283.

Koyama H. (1980): Cathodoluminescence study of $\mathrm{SiO}_{2}$. J. Appl. Phys., 51: 2228-2235.

Krbetschek M.R., Götze J., Dietrich A., Trautmann T. (1997): Spectral information from minerals relevant for luminescence dating. Radiat. Meas. 27/5,6: 695-748.

Kronenberg A.K., Kirby S.H., Aines R.D., Rossmann G.R. (1986): Solubility and diffusional uptake of hydrogen in quartz at high water pressures: implications for hydrolytic weakening in the laboratory and within the earth. Tectonophysics 172: 255-271.

Kruhl J.H. (1996): Prism- and basal-plane parallel subgrain boundaries in quartz: a microstructural geothermobarometer. J. metam. Geol., 14: 581-589.

Kuznetov V. and Lobachev A. (1973): Hydrothermal method for the growth of crystals. Sov. Phys. Crystallography, 17: 775 .

Laemmlein G. (1930): Korrosion und Regeneration der Porphyr-Quarze. Z Kristallogr. 75: 109-127.

Lange H., Tischendorf G., Pälchen W., Klemm I., Ossenkopf W. (1972): Fortschritte der Metallogenie im Erzgebirge. B. Zur Petrographie und Geochemie der Granite des Erzgebirges. Geologie, 21/4-5: 457-493.

Laubach S.E. (1997): Method to detect natural fracture strike in sandstones. AAPG Bulletin, 81/4: 640-623.

Lehmann G. and Bambauer H.V. (1973): Quarzkristalle und ihre Farben. Angew. Chem. 7 : 281-289.

Lehmann G. (1975): On the colour centres of iron in amethyst and synthetic quartz: a discussion. Amer. Mineral. 60: $335-337$.

Lennox P.G., Hawley S., Fowler T.J. (1991): Intraorogenic Barry Granite - two granites in one! Lachlan Fold Belt Conference, Abstracts, 29: 17.

Lennox P.G. and Fowler T.J. (1994): Tectonism, deformation gradients and intrusion styles. $7^{\text {th }}$ Specialist Group in Tectonics and Structural Geology, Field Conference, Jindabyne. Geological Society of Australia, Abstracts, 36: 93-94.

Lennox P.G., Fowler T. and Foster D. (1998): Barry Granodiorite and Sunset Hill Granite: Wyangala-style intrusion at the margin of a regional ductile shear zone, northern Lachlan Fold Belt, New South Wales. Australian Journal of Earth Sciences, 45: 849-863.

Lennox P.G., Trzebski R.C., Siebel W., Armstrong R. (in prep.): Crustal architecture in the eastern Lachlan Fold Belt, Australia.

Lobin M. (1983): Pflanzenfunde aus den Tuffiten des Teplicer Quarzporphyrs. Exk. Führ. U. Kurzref. "Fortschr. Paläont. Stratigr. Rotl.”, Ges. Geol. Wiss. DDR, Berlin, p. 31.

Long J.V.P. and Agrell S.O. (1965): The cathodoluminescence of minerals in thin section. Miner. Mag., 34: 318326.

Loomis T.P. (1982): Numerical simulations of crystallization processes of plagioclase in complex melts: the origin of major and oszillatory zoning of plagioclase. Contr. Miner. Petr., 81: 219-229.

Lowenstern J.B. (1995): Applications of silicate-melt inclusions to the of magmatic volatiles. In: Thompson J.F.H. (ed.): Magmas, fluids and ore deposits. Mineralogical Association of Canada Short Course, 23: 71-99.

Luff B.J. and Townsend P.D. (1990): Cathodoluminescence of synthetic quartz. J. Phys. Condens. Matter, 2: 8089-8097.

Lysakov V.S. (1978): Luminescence of quartz activated with manganese ions. Sov. Phys. J., 21: 946-947.

MacLellan H.E., Trembath T.T. (1991): The role of quartz crystallization in the development and preservation of igneous texture in granitic rocks: Experimental evidence at 1 kbar. Amer. Mineral., 76: 1291-1305.

Magnus M. and Götze (1998): Mineral composition of Lower Turonian sandstones of the Elbe Zone (Germany): evidence from combined CL and image analysis. Zbl. Geol. Paläont. Teil 1, 11/12: 1255-1262.

Marfunin A.S. (1979a): Physics of Minerals and Inorganic materials. Springer, Berlin.

Marfunin A.S. (1979b): Spectroscopy, luminescence and radiation centres in minerals. Translated from Russian by V.V. Schiffer, Springer, Berlin, $352 \mathrm{pp}$.

Marfunin A.S. (1995): Advanced Mineralogy. Vol.2 - Methods and instrumentations: Results and recent developments. Springer, Berlin Heidelberg New York.

Martin J. and Armington A. (1983): Effect of growth rate on quartz defects. J. Cryst. Growth, 62: 203.

Maschmeyer D. and Lehmann G. (1983a): New hole centres in natural quartz. Phys. Chem. Minerals, 10: 84-88.

Maschmeyer D. and Lehmann G. (1983b): A trapped-hole centre causing rose coloration of natural quartz. $Z$. Kristallogr. 163: 181-196.

Marshall D.J. (1988): Cathodoluminescence of geological materials. Allen \& Unwin Inc., Winchester/Mass., $146 \mathrm{pp}$.

Matter A. and Ramseyer K. (1985): Cathodoluminescence microscopy as a tool for provenance studies of sandstones. In: Zuffa G.G. (ed.): Provenance of arenites. Dordrecht Reidel, pp. 191-212.

McKinlay S. (1993): Geology of the Carcoar Granite, Blayney. BSc(Hons) thesis, The University of New South Wales, Sydney (unpubl.). 
McLaren A.C., Phakey P.P. (1966): Transmission electron microscope study of bubbles and dislocations in amethyst and citrine quartz. Aust. J. Phys., 19: 19-24.

McLaren A.C., Cook R.F., Hyde S.T., Tobin R.C. (1983): The mechanisms of the formation and growth of water bubbles and associated dislocation loops in synthetic quartz. Phys. Chem. Minerals, 9: 79-94.

Medlin W.L. (1964): Trapping centers in thermoluminescent calcite. Phys. Rev. 135: 1770-1779.

Merino E., Harvey C., and Murray H.H. (1989): Aqueous-chemical control of the tetrahedral-Aluminium content of quartz, halloysite, and other low-temperature silicates. Clays and Clay Minerals 37/2: 135-142.

Merlet C. and Bodinier J.-L. (1990): Electron microprobe determination of minor and trace transition elements in silicate minerals: A method and its application to mineral zoning in the peridotite nodule PHN 1611. Chemical Geol. 83: 55-69.

Michalske A. and Freiman W. (1982): A molecular interpretation of stress corrosion in silica. Nature 295: 511 512.

Miller J.C. and Miller J.N. (1988): Basic statistical methods for analytical chemistry: Part I: Statistics of repeated measurements. A review. Analyst, 113: 1351-1356.

Miller J.N. (1991): Basic statistical methods for analytical chemistry: Part 2: Calibration and regression methods. Analyst, 116: 3-14.

Milliken K.L. (1994): Cathodoluminescent textures and the origin of quartz silt in Oligocene mudrocks South Texas. J. Sed. Res., 64A: 567-571.

Müller A. (1995): Untersuchung magmatischer, metamorpher und hydrothermaler Quarze aus der Oberpfalz mit thermischer Schallemissionsanalyse. Diploma, Universität Göttingen, 61 pp.

Müller A. and Behr H.J. (1997): The lacquer peels method and cathodoluminescence applied to quartz in granites and rhyolites. IAVCEI Abstracts, Puerto Vallarta, Mexico, p 101.

Müller A. and Seltmann R. (1999): The genetic significance of snowball quartz in high fractionated tin granites of the Krušne Hory/Erzgebirge. In: Stanley et al.: Mineral deposits: processes to processing. Volume 1, Balkema, Rotterdam, pp. 409-412.

Müller A., Seltmann R. and Behr H.-J. (2000a): Application of cathodoluminescence to magmatic quartz in a tin granite - case study from the Schellerhau Granite Complex, Eastern Erzgebirge, Germany. Mineralium Deposita, 35/2-3: 169-189.

Müller A., Trzebski, R. and Lennox P. (2000b): Magma crystallisation, emplacement and deformation of S- and I-type granitoids in the Eastern Lachlan Fold (SE Australia) as constrained by quartz cathodoluminescence and Al-in-hornblende barometry. (in prep.).

Müller A. and René M. (2000): Cathodoluminescence microcharaterization of magmatic quartz of the topazbearing granites from the tin ore deposit Krásno (Slavkovský Les Mts., Czech Republic). Terra Nova (in review).

Nassau K. and Prescott B.E. (1975): A reinterpretation of smoky quartz. Phys. Stat. Sol. (A) 29: 659-663.

Neuser R. D. (1988): Zementstratigraphie und Kathodolumineszenz des Korallenoolith (Malm) imSüdniedersächsischen Bergland. Bochumer geol. u. geotechn. Arb. 32: 172.

Neuser R. D., Bruhn F., Götze J., Habermann D. and Richter D. K. (1995): Kathodolumineszenz: Methodik und Anwendung. Zbl. Geol. Paläont. Teil 1, 1/2: 287-306.

Neuser R.D., Richter D.K., Vollbrecht A. (1988): Natural quartz with brown/violet cathodoluminescence Genetic aspects evident from spectral analysis. Zbl. Geol. Paläont. Teil 1, 7/8: 919-930.

Nicolas A. and Poirier J.P. (1976): Crystalline plasticity and solid state flow in metamorphic rocks. Wiley London, 444 pp.

Nishikawa H., Shiroyama Y., Nakamura R., Ohki Y., Nagasawa K., Hama Y. (1992): Photoluminescence from defect centers in high-purity silica glasses oberserved under 7.9-eV excitation. Phys. Rev. B 45/2: 586-591.

Nuttall R.H.D. and Weil J.A. (1980): Two hydrogenic trapped-hole species in $\alpha$-quartz. Solid State Commun. 33: 99-102.

Nuttall R.H.D., Weil J.A. (1981): The magnetic properties of the oxygen-hole aluminium centers in crystalline $\mathrm{SiO}_{2}$. I. $\left[\mathrm{Al}_{4} \mathrm{O}\right]^{0}$. Canad. J. Phys. 59: 1696-1708.

O'Keeffe M. and Hyde B.G. (1978): On Si-O-Si configurations in silicates. Acta Crystallogr. B34: 27-32.

O'Reilly E.P. and Robertson J. (1983): Theory of defects in vitreous silicon dioxide. Phys. Rev. B 27: 37803795 .

Owen M.R. (1984): Southern source of the Jackford sandstone determined by petrography, cathodoluminescence of quartz, and hafnium content of zircons. Abstracts with Programs 16, Boulder, Co: Geol. Soc. Amer., p. 616.

Owen M.R. (1988): Radiation-damage halos in quartz. Geology, 16: 529-532.

Owen M.R. (1991): Application of cathodoluminescence to sandstone provenance. In: Barker E., Kopp O.C. (eds.): Luminescence microscopy and spectroscopy. Quantitative and qualitative applications. Soc. Sed. Geol., Tulska Oklahoma, p. 67-75.

Packham G.H. (1999): Radiometric evidence for Middle Devonian inversion of the Hill End Trough, northeast Lachlan Fold Belt. Australian Journal of Earth Sciences, 46: 23-33. 
Pagel M., Barbin V., Blanc P., Ohnenstetter D. (2000): Cathodoluminescence in Geosciences. Springer, Berlin Heidelberg New York, 514 pp.

Pälchen W. (1968): Zur Geochemie und Petrologie der postorogenen variszischen Magmatite des sächsischen Osterzgebirges. Thesis, TU Bergakademie Freiberg, 142 pp.

Pälchen W., Ossenkopf P. (1967): Über das relative Alter des Schellerhauer Granitmassivs und seiner Varietäten. Ber deutsch Ges geol Wiss B, Miner. Lagerstättenf., 12/4: 359-371.

Pankrath R. (1988): Spurenelementeinbau in Tief-Quarz als Funktion der Wachstumsbedingungen und Umprägungen unter trockenen und hydrothermalen Bedingungen. Thesis, Ruhr-Universität Bochum, Germany.

Parks G.A. (1984): Surface and interfacial free energies of quartz J. Geophys. Res., 89/B6: 3997-4008.

Passchier C.W. and Trouw R.A.J. (1998): Microtectonics. Springer Verlag, Berlin Heidelberg New York.

Paterson S.R., Tobisch O.T., Morand V.J. (1990): The influence of large ductile shear zones on the emplacement and deformation of the Wyangala Batholith, SE Australia. J. Struct. Geol., 12: 639-650.

Paterson S.R., Vernon R.H., Tobisch O.T. (1989): A review of criteria for determining magmatic and solid-state foliations in granitoids. J. Struct. Geol., 11:349-363.

Pearce T.H. (1993): A simple deterministic model of oscillatory zoning in magmatic plagioclase. Geol. Assoc. Can. - Mineral. Assoc. Can., Program Abstr. 18, p. A-81.

Pearce T.H. and Kolisnik A.M. (1990): Observations of plagioclase zoning using interference imaging. EarthScience Reviews, 29: 9-26.

Perny B., Eberhardt P., Ramseyer K., Mullis J., Pankrath R. (1992): Microdistribution of aluminium, lithium and sodium in a quartz: possible causes and correlation with shored lived cathodoluminescence. Amer. Mineral., 77: 534-544.

Pfenninger H. (1961): Diffusion von Kationen und Abscheidung von Metallen in Quarz unter elektrischer Feldeinwirkung. Thesis, Universität Zürich, Switzerland.

Picouet P.A. (1999): Cathodoluminecence spectroscopy and the orientation of a hydrothermal quartz crystal. Schweiz. Mineral. Petrol. Mitt., 79: 455-460.

Pitfield P.E.J., Teoh L.H., Cobbing E.J. (1990): Textural variation and tin mineralization in granites from the Main Range Province of the Southeastern Asian Tin Belt. Geol. J., 25: 419-429.

Plesch R. (1982): Auswerten und Prüfen in der Röntgenspektrometrie. G-I-T Verlag Ernst Giebeler, Darmstadt, $147 \mathrm{pp}$.

Plimer I.R. (1987): Fundamental parameters for the formation of granite-related tin deposits. Geol. Rundschau, 76/1: 23-40.

Plötze M. (1995): Investigation of quartz, scheelite and fluorite from hydrothermal rare-metal deposits by EPR (in German). Thesis, TU Bergakademie Freiberg, 141 pp.

Poirier J.P. and Guillope M. (1979): Deformation-induced recrystallisation of minerals. Bull. Mineral., 102: 6774.

Pott G.T. and McNicol B.D. (1971): Spectroscopy study of the coordination and valence of Fe and Mn ions in and on the surface of aluminas and silicas. Disc. Faraday Soc. 52: 121-131.

Potts P.J., Bowles J.F.W., Reed S.J.B., and Cave M.R. (1995): Microprobe techniques in the earth sciences. The Mineralogy Society Series, vol. 6, Chapman and Hall, London, 419 pp.

Poty B. (1969): La croissance des cristaux de quartz dans les filons sur l'exemble du filon de la Gardette (Bourg d'Oisans) et des filons du massif du Mont-Blanc. Thesis, University of Nancy, France, 162 pp.

Poutiainen M., Scherbakova T.F. (1998): Fluid and melt inclusion evidence for the origin of idiomorphic quartz crystals in topaz-bearing granite from the Salmi batholith, Karelia, Russia. Lithos, 44: 141-151.

Powell C.McA. (1984): Ordovician to earliest Silurian: marginal sea and island arc. In: Veevers J.J. (ed.): Phanerozoic Earth History of Australia. Oxford University Press, Oxford, 29-309.

Powell C.McA., Cole J.P., Cudahy T.J. (1985): Megakinking in the Lachlan Fold Belt, Australia. In: Hancock P.L. and Powell C.McA. (eds.): Multiple Deformation in Ductile and Brittle Rocks. J. Struct. Geology, 7: 281-300.

Rakov L.T., Kuvshinova K.A., Moiseev B.M., Pleskova M.A., Kandinov M.N. (1991): Typomorphic properties of Ti centres in quartz (in Russian). Dokl. Akad. Nauk SSSR, 317: 181-185.

Ramseyer K., Baumann J., Matter A., and Mullis J. (1988): Cathodoluminescence colours of a-quartz. Miner. Magazine, 52: 669-677.

Ramseyer K. and Mullis J. (1990): Factors influencing short-lived blue cathodoluminescence of a-quartz. Amer. Miner., 75: 791-800.

Reed S.J.B. (1996): Electron microprobe analysis and scanning electron microscopy in geology. Cambridge University Press, Cambridge, $201 \mathrm{pp}$.

Reimer L. (1985): “SEM” - Physics of image formation of microanalysis. Springer Verlag, Berlin-HeidelbergNew York-Tokyo.

Remond G. (1977): Applications of cathodoluminscence in mineralogy. J. Luminescence, 15/2: 121-155. 
Remond G., Le Gressus C., Okuzumi H. (1979): Electron beam effects observed in cathodoluminescence and Auger electron spectroscopy in natural minerals: Evidence for ionic diffusion. Scanning Electron Microsc., 1: 237-244.

Remond G., Cesbron F., Chapoulie R., Ohnenstetter D., Rouques-Carmes C. and Schvoerer M. (1992): Cathodoluminescence applied to the microcharacterization of mineral materials: a present status in experimentation and interpretation. Scanning Microsc., 6/1:23-69.

René M. (1998): Development of topaz-bearing granites of the Krudum massif (Karlovy Vary pluton). Acta Univ. Carolinae, Geol., 42/1: 103-109.

Renno A. (1997): Zur Petrogenese der Albitgranite von Abu Dabbab und Nuweibi. Thesis. Berlin: Techn. Univ., Logos-Verl. D 83.

Richter D.K. and Zinkernagel U. (1975): Petrographie des „Permoskyth“ der Jaggl-Plawen-Einheit (Südtirol) und Diskussion der Detritusherkunft mit Hilfe von Kathoden-Lumineszenz-Untersuchungen. Geol. Rdsch., 64: 783-807.

Rink W.J., Rendell H., Marseglia E.A., Luff B.J., and Townsend P.D. (1993): Thermoluminescence Spectra of igneous quartz and hydrothermal quartz. Phys. Chem. Minerals, 20: 353-361.

Rinneberg H., Weil J.A. (1972): EPR studies of $\mathrm{Ti}^{3+}-\mathrm{H}^{+}$centers in X-irradiated -quartz. J. Chem. Phys., 56: 2019-2028.

Rovetta M.R., Blacic J.D., Hervig R.L. and Holloway J.R. (1989): An experimental study of hydroxyl in quartz using infrared spectroscopy and ion microprobe techniques. J. Geophys. Res., 94: 5840-5850.

Rub M.G., Stemprok M., Rub M.G. (1997): On the tantalum mineralization in the rare metal granites of the Cinovec massif (Czechia). Dokl. Akad. Nauk ., 352: 795-798 (in Russian).

Rumyantsev V. and Novozhilov A. (1980): Dependence on concentration of aluminium centres and anomalous pleochroism on certain crystallisation parameters in synthetic quartz. Sov. Phys. Crystallography, 25: 75.

Ruppert L.F. (1987): Applications of cathodoluminescence of quartz and feldspar to sedimentary petrology. Scanning Microscopy, 1: 63.

Scala C.M. and Hutton D.R. (1976): Site assignment of $\mathrm{Fe}^{3+}$ in $\alpha$-quartz. Physica Status Solidi, B73: K115K117.

Scheibner E. (1998): In: Basden H. (ed.): Geology of New South Wales - Synthesis. Volume 2. - Geological Survey of New South Wales, Memoirs in Geology 13.

Schilka W., Baumann L. (1996): Metasomatische Prozesse im Schellerhauer Granitmassiv (Osterzgebirge). Freib. Forsch.-H., C467: 151-175.

Schmidt W. (1992): Amphibole composition in tonalite as a function of pressure: an experimental calibration of the Al-in-hornblende barometer. Contrib. Mineral. Petrol., 110: 304-310.

Schmidt-Mumm A. (1991): Low frequency acoustic emission from quartz upon heating from 90-610 ${ }^{\circ} \mathrm{C}$. Phys. Chem. Minerals, 17: 545-553.

Schmidt-Mumm A. and Behr H.-J. (1987): Fluid systems in metaplaya sequences in the Damara Orogen (Namibia): Evidence for sulphur-rich brines - general evolution and first results. Chem. Geol., 61: 135-145.

Schneider N. (1993): Das lumineszenzaktive Strukturinventar von Quarzphänokristen in Rhyolithen. Göttinger Arb. Geol. Paläont., 60: 81 pp.

Schrön W., Schmädicke E., Thomas R., Schmidt W. (1988): Geochemische Untersuchungen an Pegmatitquarzen. Z. geol. Wiss., 16: 229-244.

Schust F. (1980): Zum Zusammenhang zwischen der paläogeographischen Entwicklung und der Intrusionstiefe der Granite im Osterzgebirge. Z. angew. Geol. 26/8: 405-411.

Schust F., Thomas U., Schwandke E. (1991): Erkenntnisfortschritte zur Geologie des Harzes. Z. geol. Wiss. 19/6: 625-635.

Schwartz M.O. (1992): Geochemical criteria for distinguishing magmatic and metasomatic albite-enrichment in granitoids - examples from the Ta-Li granite Yichun (China) and the Sn-W deposit Tikus (Indonesia). Mineralium Deposita, 27: 101-108.

Seim R., Eidam J., Korich D. (1982): Zur Elementverteilung in einem Zinngranit (Schellerhauer Massiv/Osterzgebirge). Chem Erde, 41: 219-235.

Seltmann R. (1994): Sub-volcanic minor intrusions in the Altenberg caldera and their metallogeny. In: Seltmann R., Möller P., Kämpf H. (eds.): Metallogeny of Collisional Orogens. Czech Geological Survey Prague, pp 198-206.

Seltmann R., Bankwitz P., Frischbutter A., Thomas R. (1992): Metallogenic position of breccia-related granite bodies and tin ore deposits at the north-western border of the Bohemian Massif (Krusne Hory - Krasny Les area). In: Kukal Z. (ed.): Proceed $1^{\text {st }}$ Internat Conf Bohemian Massif in Prague 1988. Czech Geol Survey Prague: pp 257-268.

Seltmann R., Stemprok M. (1994): Textural evidence for the existence of two-phase granites in the younger intrusive complex granites of the Krusne Hory/Erzgebirge Province. J. of the Czech Geol. Soc., 39/1: 103104.

Seltmann R., Stemprok M., Müller A. (2000): Textures of rare-metal granites as exploration tool. Extended Abstract. Proceed. $31^{\text {st }}$ IGC, Rio de Janeiro (in print). 
Serebrennikov A.I., Valter A.A., Mashkovtsev R.I., Shscherbakova M.Ya. (1982): The investigation of defects in shock-metamorphosed quartz. Phys. Chem. Minerals, 8: 153-157.

Shore M., Fowler A.D. (1996): Oscillatory zoning in minerals: a common phenomenon. Canadian Mineral. 34: 1111-1126.

Sibley D.F., Vogel T.A., Walker B.M., Byerly G. (1976): The origin of oszillatory zoning in plagioclase: A diffusion and growth controlled model. Amer. J. Sci. 276: 275-284.

Siebel W., Trzebski R., Stettner G., Hecht L., Casten U., Höhndorf A., Müller P. (1997): Granitoid magmatism of the NW Bohemian massif relealed: gravity data, composition, age relations and phase concept. Geol. Rdsch., Suppl., 86:45-63.

Siebers F.B., Giese U., Flörke O.W. (1984): Growth of doped quartz and the anisotropy of impurity distribution. Zeitschrift für Kristallographie, 167: 189-190.

Siebers F.B. and Klapper H. (1984): Zelluläres Wachstum und Verunreinigungsverteilung im Zuchtquarz, aufgezeigt mit Röntgentopographie. Zeitschrift für Kristallographie, 167: 177-178.

Siebers F.B. (1986): Inhomogene Verteilung von Verunreinigungen in gezüchteten und natürlichen Quarzen als Funktion der Wachstumsbedingungen und ihr Einfluß auf kristallphysikalische Eigenschaften. Thesis, RuhrUniversität Bochum, Germany, 133 pp.

Siegel G.H. and Marrone M.J. (1981): Photoluminescence in as-drawn and irradiated silica optical fibers: An assessment of the role of nonbridging oxygen defect centres. J. Non-Cryst. Solids 45: 235-247.

Simakin A.G. (1984): A simple quantitive model of rhythmic zoning in crystals. Geochem. Int., 21: 13-26.

Simpson C. (1985): Deformation of granitic rocks across the brittle-ductile transition. J. Struct. Geol., 7: 503511.

Singer B.S., Dunger M.A., Layne G.D. (1995): Textures and Sr, Ba, Mg, Fe, K, and Ti compositional profiles in volcanic plagioclase: Clues to the dynamics of calc-alkaline magma chambers. American Mineralogist, $\mathbf{8 0}$ : 776-798.

Sippel R.F. (1965): Simple device for luminescence petrography. Rev. Sci. Instrum., 36: 1556-1558.

Sippel R.F. (1968): Sandstone petrology. Evidence from luminescence petrography. J. Sed. Petrol., 38: 530-554.

Skuja L. and Trukhin A. (1989): Comment on the "Luminescence of fused silica: Observation of the O2emission band". Phys. Rev. B, 39: 3909.

Smith J.V. and Stenstrom R.C. (1965): Electron-excited luminescence as a petrologic tool. J. Geol., 73: 627-635.

Smith R.E. (1969): Zones of progressive regional burial metamorphism in part of the Tasman Geosyncline, Eastern Australia. J. Petrol., 10: 144-163.

Sonyushkin V.E., Sukhorukov Y.T., Scherbakova T.F. (1991): P-T enviroment of crystallization of quartz in granites of the Salmi batholith, Russian Karelia. In: Haapala I. and Rämö O.T. (eds.): Symposium on Rapakivi Granites and Related Rocks, p. 47. Geol. Surv. Finland Guide, vol. 34.

Spengler E. (1949): Über die Abtragung des variszischen Gebirges in Sachsen. Abh. Geol. Landesanst., Berlin, $212 \mathrm{p}$.

Sprunt E. (1979): Microcracking and healing in granites: New evidence from cathodoluminescence. Science, 205: 495-497.

Sprunt E. (1981): Causes of quartz cathodoluminescence colors. Scan. Electron Micr., 1981: 525-535.

Spry A. (1969): Metamorphic textures. Pergamon Press, Oxford, 352 pp.

Stemprok M. (1986): Petrology and geochemistry of the Czechoslovak part of the Krusne hory Mts. granite pluton. Sbor. geol. ved. L GM, 27: 111-156.

Stemprok M. (1993): Magmatic evolution of the Krusne Hory-Erzgebirge batholith. Z. geol. Wiss., 21/1-2: 237245.

Stemprok M., Novak J.K., David J. (1994): The association between granites and tin-tungsten mineralization in the eastern Krusne hory (Erzgebirge), Czech Republic. In: von Gehlen K., Klemm D.D. (eds.): Monograph Series on Mineral Deposits 31. Gebr. Boerntraeger, Berlin Stuttgart, pp. 97-129.

Stemprok M., Sulcek Z. (1969): Geochemical profile through an ore-bearing lithium granite. Econ. Geol., 64: 392-404.

Stenina N.G., Bazarov L.S., Shcherbakova M.Y., Mashkovtsev R.I. (1984): Structural state and diffusion of impurities in natural quartz of different genesis. Phys. Chem. Minerals, 10: 180-186.

Stenina N.G., Sotnikov V.I., Korolyuk V.N., Kovaleva L.T. (1988): Microstructural features of hydrothermal vein quartz as an indicator of mineralization. Geokhimiya, 5: 641-653, (English translation).

Stenina N.G. (1995): Energy aspect in the formation of granitic magma and ore deposits. In: Pašava J., Kribek B. and Zák K. (eds): Mineral deposits: from their origin to their environmental impacts. Balkema, Rotterdam, pp. 539-542.

Sterner S.M. and Bodnar R.J. (1989): Synthetic fluid inclusions - VII. Re-equilibration of fluid inclusions in quartz during laboratory-simulated metamorphic burial and uplift. J. Metamorphic Geol., 7: 243-260.

Stoecklein W. and Gobel R. (1992): Application of cathodoluminescence in paint analysis. Scanning Microscopy, 6: 669-678.

Stünitz H. (1998): Syndeformational recrystallisation - dynamic or compositionally induced? Contrib. Mineral. Petrol., 131: 219-236. 
Suttner L.J. and Leininger R.K. (1972): Comparison of the trace element content of plutonic, volcanic, and metamorphic quartz from southwestern Montana. Geol. Soc. Am. Bull., 83: 1855-1862.

Swanson S.E. (1977): Relation of nucleation and crystal-growth rate to the development of granitic textures. Amer. Mineral., 62: 966-978.

Swanson S.E. and Fenn P.M. (1986): Quartz crystallization in igneous rocks. Amer. Mineral., 71: 331-342.

Thomas R. (1992): Results of investigations on melt inclusions in various magmatic rocks from the northern border of the Bohemian Massif. In: Kukal Z. (ed.) Proceed 1st Internat Conf Bohemian Massif in Prague 1988, Czech Geol Surv Prague, pp 298-306.

Thomas R. (1994a): Fluid evolution to the emplacement of the Variscan granites in the Erzgebirge region: a review of the melt and fluid inclusion evidence. In: Seltmann R, Möller P, Kämpf H (eds.): Metallogeny of Collisional Orogens. Czech Geological Survey Prague, pp 70-82.

Thomas R (1994b) Estimation of water content of granitic melts from inclusion data. In: Seltmann R, Möller P, Kämpf H (eds.): Metallogeny of Collisional Orogens. Czech Geological Survey Prague, pp 224-229.

Thomas W.M. and Ernst W.G. (1990): The aluminium content of hornblende in calc-alkaline granitic rocks: A mineralogic barometer calibrated experimentally to 12 kbars. - In: Spencer R.J. and I-Ming Chou (eds.): Fluid-mineral interactions: A tribute to H.P. Eugster. The Geochemical Society, Special Publication 2, 5963.

Tischendorf G (1964) Stand der Kenntnisse bei der Suche nach Zinnlagerstätten im Osterzgebirge. Zeitschrift für Angewandte Geologie 10/5: 225-238

Tischendorf G., Förster H.J. (1990): Acid magmatism and related metallogenesis in the Erzgebirge. Geol. J., 25: 443-454.

Tobisch O.T. and Paterson S.R. (1990): The Yarra granite: An intradeformational pluton associated with ductile thrusting, Lachlan Fold Belt, southeastern Australia. Geol. Soc. Am. Bull., 102: 693-703.

Toramaru A. (1991): Model of nucleation and growth of crystla in cooling magmas. Contrib. Mineral. Petrol., 108: $106-117$.

Tovey N.K. and Krinsley D.H. (1980): A cathodoluminescent study of quartz sand grains. J. Microscopy, 120: 279-289.

Townsend P.D. and Rowlands A.P. (2000): Information encoded in cathodoluminescence emission spectra. In: Pagel M., Barbin V., Blanc P., Ohnenstetter D. (eds.): Cathodoluminescence in Geosciences. Springer, Berlin Heidelberg New York, pp. 41-57.

Trukhin A.N. and Plaudis A.E. (1979): Investigation of intrinsic luminescence of $\mathrm{SiO}_{2}$. Sov. Phys. Solid State, 21/4: 644-646.

Trzebski R., Lennox P., Palmer D. (1999): Contrasts in morphogenesis and tectonic setting during contemporaneous emplacement of S- and I-type granitoids in the Eastern Lachlan Fold Belt, southeastern Australia. In: Castro A., Fernandez C., Vigneresse J.L. (eds.): Understanding Granites: Integrating New and Classical Techniques. Geol. Soc., London, Sp. Publ., 158: 123-140.

Tsinober L. and Kamentsev I. (1964): Effect of growth rate on the concentration of centers of smoky color and on the unit cell parameters of synthetic quartz crystals. Sov. Phys. Crystallography, 9: 374.

Urai J.L. (1983): Water assisted dynamic recrystallization and weakening in polycrystalline bischofite. Tectonophysics, 96: 125-127.

Urai J.L. and Humphreys F.J. (1981): The development of shear zones in polycrystalline camphor. Tectonophysics, 78: 677-685.

Valley J.W. and Graham C.M. (1996): Ion microprobe analysis of oxygen isotope ratios in quartz from Skye granite: healed micro-cracks, fluid flow, and hydrothermal exchange. Contrib. Mineral. Petrol., 124: 225234.

Vernon R.H. and Flood R.H. (1988): Contrasting deformation of S- and I-type granitoids in the Lachlan Fold Belt, eastern Australia. Tectonophysics, 147: 127-144.

Voll G. (1976): Recrystallization of quartz, biotite and feldspars from Erstfeld to the Leventina Nappe, Swiss Alps, and ist geological significance. Schweiz. mineral. Petrogr. Mitt., 56: 641-47.

Voll G. (1980): Ein Querprofil durch die Schweizer Alpen vom Vierwaldstätter See zur Wurzelzone Strukturen und ihre Entwicklung durch Deformationsmechanismen wichtiger Minerale. N. Jb. Geol. Pal. Abh., 160: 321-335.

Walker G. (1985): Mineralogical applications of luminescence technique. In: Berry F.J., Vaughan D.J. (eds.): Chemical bonding and spectroscopy in mineral chemistry. Chapman and Hall, London, 103-140.

Watt G.R., Wright P., Galloway S., McLean C. (1997): Cathodoluminescence and trace element zoning in quartz phenocrysts and xenocrysts. Geochim Cosmochim Acta, 61: 4337-4348.

Waychunas G.A. (1988): Luminescence, X-ray emission and new spectroscopies. In: Hawthorne F.C. (ed.) Spectroscopic methods in mineralogy and geology. Rev. Miner. 18: 639-698.

Weeks R.A: (1994): The many varieties of E'centres: a review. J. Non-Cryst. Solids, 179: 1-9.

Weil J.A: (1984): A review of electron spin spectroscopy and its application to the study of paramagnetic defects in crystalline quartz. Phys. Chem. Minerals, 10: 149-165. 
Wiebe R.A. (1968): Plagioclase stratigraphy: A record of magmatic conditions and events in a granite stock. Am. J. Sci., 266: 690-703.

Wilkins C. and Smart G. (1997): Browns Creek gold-copper deposit. In: Berkmann D.A. and Mackenzie D.H. (eds.): Geology of Australian and Papua New Guinean Mineral Deposits. The Australian Institute of Mining and Metallurgy, Melbourne, 575-580.

Williamson B.J., Stanley C.J., Wilkinson J.J. (1997): Implications from inclusions in topaz for greisenisation and mineralisation in the Hensbarrow topaz granite, Cornwall, England. Contrib. Mineral. Petrol., 127: 119-128.

Winslow D.M., Bodnar R.J., and Tracy R.J. (1994): Fluid inclusion evidence for an anticlockwise metamorphic P-T path in central Massachusetts. J. Metamorphic Geology, 12: 361-371.

Wyborn D. and Henderson G.A.M. (1996): Notes to accompany geological map Blayney 1 : 100000 sheet area. Australian Geol. Surv. Organisation Report, 56.

Yang X.H. and McKeever S.W.S. (1990): The pre-dose effect in crystalline quartz. J. Phys. D: Appl. Physics, 23: $237-244$.

Yang X.H., Townsend P.D., Holgate S.A. (1994): Cathodoluminescence and depth profiles of tin in float glass. J. Phys. D, 27: 1757.

Yin L., Pollard P.J., Hu Shouxi, Taylor R.G. (1995): Geologic and geochemical characteristics of the Yichun TaNb-Li deposit, Jiangxi Province, South China. Economic Geology, 90/3: 577-585.

Yoder H.S. (1950): High-low quartz inversion up to 10,000 bars. Transactions Amer Geophys Union, $31: 827$.

Ziebold T.O. (1967): Precision and sensitivity in electron microprobe analysis. Anal. Chem., 39: 858-861.

Zinkernagel U. (1978): Cathodoluminescence of quartz and its application to sandstone petrology. Contrib. Sedimentology, 8: 1-69. 


\section{Appendix A}

\section{List of CL emission band parameters of quartz}

\begin{tabular}{|c|c|c|c|c|c|c|c|c|c|c|}
\hline \multirow[t]{2}{*}{ Sample } & \multicolumn{5}{|l|}{$1.73 \mathrm{eV}-$} & \multicolumn{5}{|c|}{$1.84 \mathrm{eV}-\quad$ Band } \\
\hline & $\begin{array}{c}\text { Position } \\
(\mathrm{eV})\end{array}$ & $\begin{array}{c}\text { Sigma } \\
(\mathrm{eV})\end{array}$ & $\begin{array}{c}\text { Half-width } \\
(\mathrm{eV})\end{array}$ & If & If $(\%)$ & $\begin{array}{c}\text { Position } \\
(\mathrm{eV})\end{array}$ & $\begin{array}{c}\text { Sigma } \\
(\mathrm{eV})\end{array}$ & $\begin{array}{c}\text { Half-width } \\
(\mathrm{eV})\end{array}$ & If & If $(\%)$ \\
\hline \multirow[t]{3}{*}{1 Megaquartz } & 1.74 & 0.13 & 0.3 & 5000 & 4.3 & 1.84 & 0.095 & 0.22 & 3500 & 3.0 \\
\hline & 1.74 & 0.13 & 0.3 & 8600 & 13.0 & 1.84 & 0.095 & 0.22 & 5000 & 7.6 \\
\hline & 1.73 & 0.13 & 0.3 & 10500 & 17.5 & 1.84 & 0.095 & 0.22 & 8000 & 13.4 \\
\hline \multirow{3}{*}{2 Fissile Quartz } & 1.74 & 0.14 & 0.32 & 5500 & 9.0 & 1.84 & 0.095 & 0.22 & 3000 & 4.9 \\
\hline & 1.74 & 0.14 & 0.32 & 7700 & 12.3 & 1.84 & 0.095 & 0.22 & 3700 & 5.9 \\
\hline & 1.74 & 0.13 & 0.3 & 11500 & 16.5 & 1.84 & 0.095 & 0.22 & 5000 & 7.2 \\
\hline \multirow{3}{*}{$\begin{array}{l}3 \text { Oil-bearing } \\
\text { Quartz }\end{array}$} & 1.735 & 0.13 & 0.31 & 6500 & 7.5 & 1.84 & 0.095 & 0.22 & 3500 & 4.1 \\
\hline & 1.735 & 0.13 & 0.31 & 13000 & 15.7 & 1.84 & 0.095 & 0.22 & 6000 & 7.3 \\
\hline & 1.735 & 0.13 & 0.31 & 17000 & 22.7 & 1.84 & 0.095 & 0.22 & 8000 & 10.7 \\
\hline \multirow{3}{*}{$\begin{array}{l}4 \text { Schoenfeld } \\
\text { Rhyolite }\end{array}$} & 1.73 & 0.13 & 0.3 & 5000 & 4.6 & 1.845 & 0.095 & 0.23 & 8000 & 7.3 \\
\hline & 1.73 & 0.13 & 0.3 & 7500 & 7.4 & 1.845 & 0.095 & 0.23 & 9000 & 8.8 \\
\hline & 1.73 & 0.13 & 0.3 & 11000 & 10.8 & 1.845 & 0.095 & 0.23 & 9600 & 9.5 \\
\hline \multirow{3}{*}{$\begin{array}{l}5 \text { Teplice Rhyolite } \\
\text { blue CL/ } \\
\text { phenocryst }\end{array}$} & 1.73 & 0.13 & 0.3 & 3714 & 7.2 & 1.84 & 0.095 & 0.22 & 1864 & 3.6 \\
\hline & 1.73 & 0.13 & 0.3 & 5200 & 10.6 & 1.84 & 0.095 & 0.22 & 2200 & 4.5 \\
\hline & 1.73 & 0.13 & 0.3 & 7000 & 13.5 & 1.84 & 0.095 & 0.22 & 3000 & 5.8 \\
\hline \multirow{3}{*}{$\begin{array}{l}\text { Teplice Rhyolite } \\
\text { red CL/ } \\
\text { phenocryst }\end{array}$} & 1.73 & 0.125 & 0.3 & 39600 & 36.1 & 1.835 & 0.095 & 0.23 & 8500 & 7.7 \\
\hline & 1.735 & 0.125 & 0.29 & 38000 & 34.9 & 1.835 & 0.095 & 0.23 & 9600 & 8.8 \\
\hline & 1.73 & 0.13 & 0.3 & 36000 & 31.1 & 1.835 & 0.095 & 0.23 & 14000 & 12.1 \\
\hline \multirow{3}{*}{$\begin{array}{l}6 \text { Schellerhau Granite } \\
\text { blue CL/ } \\
\text { phenocryst }\end{array}$} & 1.735 & 0.125 & 0.29 & 9000 & 7.0 & 1.837 & 0.095 & 0.23 & 5000 & 3.9 \\
\hline & 1.735 & 0.125 & 0.29 & 12000 & 10.1 & 1.837 & 0.095 & 0.23 & 6000 & 5.0 \\
\hline & 1.735 & 0.13 & 0.31 & 15500 & 14.3 & 1.84 & 0.095 & 0.22 & 7700 & 7.1 \\
\hline \multirow{3}{*}{$\begin{array}{l}6 \text { Schellerhau Granite } \\
\text { red CL/ } \\
\text { phenocryst }\end{array}$} & 1.734 & 0.125 & 0.28 & 12000 & 14.3 & 1.84 & 0.095 & 0.22 & 5300 & 6.3 \\
\hline & 1.734 & 0.125 & 0.28 & 17000 & 19.1 & 1.84 & 0.095 & 0.22 & 7000 & 7.9 \\
\hline & 1.735 & 0.13 & 0.31 & 20000 & 22.2 & 1.84 & 0.095 & 0.22 & 8800 & 9.8 \\
\hline \multirow{3}{*}{$\begin{array}{l}6 \text { Schellerhau Granite } \\
\text { red CL/ } \\
\text { matrix quartz }\end{array}$} & 1.735 & 0.13 & 0.31 & 5500 & 7.9 & 1.836 & 0.095 & 0.23 & 6400 & 9.2 \\
\hline & 1.735 & 0.13 & 0.31 & 10300 & 13.4 & 1.836 & 0.095 & 0.23 & 7500 & 9.7 \\
\hline & 1.735 & 0.13 & 0.31 & 13500 & 17.2 & 1.84 & 0.095 & 0.22 & 8000 & 10.2 \\
\hline \multirow[t]{3}{*}{7 Eibenstock Granite } & 1.725 & 0.135 & 0.31 & 4500 & 17.2 & 1.85 & 0.095 & 0.22 & 1350 & 5.2 \\
\hline & 1.73 & 0.14 & 0.32 & 6000 & 21.0 & 1.835 & 0.09 & 0.21 & 1600 & 5.6 \\
\hline & 1.725 & 0.135 & 0.31 & 7000 & 22.8 & 1.85 & 0.095 & 0.22 & 2500 & 8.1 \\
\hline \multirow[t]{3}{*}{8 Aue Granite } & 1.73 & 0.12 & 0.28 & 8620 & 5.9 & 1.85 & 0.095 & 0.22 & 3080 & 2.1 \\
\hline & 1.73 & 0.12 & 0.28 & 12500 & 9.1 & 1.85 & 0.095 & 0.22 & 4000 & 2.9 \\
\hline & 1.73 & 0.13 & 0.31 & 13000 & 10.9 & 1.85 & 0.095 & 0.22 & 5000 & 4.2 \\
\hline \multirow[t]{3}{*}{9 Vein Quartz } & 1.7 & 0.15 & 0.36 & 2200 & 2.8 & 1.84 & 0.095 & 0.22 & 1 & 0.0 \\
\hline & 1.71 & 0.15 & 0.36 & 2400 & 5.8 & 1.84 & 0.095 & 0.22 & 1 & 0.0 \\
\hline & 1.7 & 0.15 & 0.36 & 2420 & 13.9 & 1.84 & 0.095 & 0.22 & 1 & 0.0 \\
\hline \multirow{3}{*}{$\begin{array}{l}10 \text { Wachtelberg } \\
\text { Rhyolite } \\
\text { blue CL }\end{array}$} & 1.73 & 0.13 & 0.3 & 4190 & 6.1 & 1.84 & 0.095 & 0.22 & 4325 & 6.3 \\
\hline & 1.73 & 0.13 & 0.3 & 4630 & 7.4 & 1.84 & 0.095 & 0.22 & 4780 & 7.7 \\
\hline & 1.73 & 0.13 & 0.3 & 4960 & 8.3 & 1.84 & 0.095 & 0.22 & 5120 & 8.5 \\
\hline \multirow{3}{*}{$\begin{array}{l}10 \text { Wachtelberg } \\
\text { Rhyolite } \\
\text { red CL }\end{array}$} & 1.723 & 0.125 & 0.29 & 5000 & 9.4 & 1.84 & 0.095 & 0.22 & 5500 & 10.3 \\
\hline & 1.723 & 0.125 & 0.29 & 6000 & 12.0 & 1.84 & 0.095 & 0.22 & 5500 & 11.0 \\
\hline & 1.73 & 0.13 & 0.3 & 6200 & 12.7 & 1.84 & 0.095 & 0.22 & 6400 & 13.1 \\
\hline \multirow{3}{*}{$\begin{array}{l}11 \text { Beucha Rhyolite } \\
\text { blue CL }\end{array}$} & 1.73 & 0.13 & 0.3 & 6384 & 7.6 & 1.85 & 0.095 & 0.22 & 4910 & 5.8 \\
\hline & 1.73 & 0.13 & 0.3 & 8300 & 10.8 & 1.85 & 0.095 & 0.22 & 5400 & 7.0 \\
\hline & 1.73 & 0.13 & 0.3 & 10000 & 13.2 & 1.85 & 0.095 & 0.22 & 5300 & 7.0 \\
\hline \multirow{3}{*}{$\begin{array}{l}11 \text { Beucha Rhyolite } \\
\text { red CL }\end{array}$} & 1.73 & 0.13 & 0.3 & 6375 & 10.6 & 1.84 & 0.095 & 0.22 & 3312 & 5.5 \\
\hline & 1.73 & 0.13 & 0.3 & 8287 & 13.9 & 1.84 & 0.095 & 0.22 & 3810 & 6.4 \\
\hline & 1.73 & 0.13 & 0.3 & 10200 & 15.9 & 1.84 & 0.095 & 0.22 & 5300 & 8.3 \\
\hline
\end{tabular}




\section{List of CL emission band parameters of quartz (continued)}

\begin{tabular}{|c|c|c|c|c|c|c|c|c|c|c|}
\hline \multirow[t]{2}{*}{ Sample } & \multicolumn{5}{|c|}{$1.73 \mathrm{eV}-\quad$ Band } & \multicolumn{5}{|c|}{$1.84 \mathrm{eV}-\quad$ Band } \\
\hline & $\begin{array}{c}\text { Position } \\
(\mathrm{eV})\end{array}$ & $\begin{array}{c}\text { Sigma } \\
(\mathrm{eV})\end{array}$ & $\begin{array}{c}\text { Half-width } \\
(\mathrm{eV})\end{array}$ & If & If $(\%)$ & $\begin{array}{c}\text { Position } \\
(\mathrm{eV})\end{array}$ & $\begin{array}{c}\text { Sigma } \\
(\mathrm{eV})\end{array}$ & $\begin{array}{c}\text { Half-width } \\
(\mathrm{eV})\end{array}$ & If & If $(\%)$ \\
\hline \multirow{3}{*}{$\begin{array}{l}12 \text { Flossenbuerg } \\
\text { Granite }\end{array}$} & 1.73 & 0.135 & 0.31 & 12000 & 8.0 & 1.84 & 0.095 & 0.22 & 3500 & 2.3 \\
\hline & 1.73 & 0.135 & 0.31 & 8500 & 6.1 & 1.832 & 0.095 & 0.22 & 7000 & 5.0 \\
\hline & 1.735 & 0.13 & 0.3 & 15000 & 10.4 & 1.84 & 0.095 & 0.22 & 10000 & 7.0 \\
\hline \multirow{3}{*}{$\begin{array}{l}13 \text { Leucosome } \\
\text { Quartz }\end{array}$} & 1.74 & 0.13 & 0.3 & 5000 & 6.7 & 1.84 & 0.095 & 0.22 & 4000 & 5.4 \\
\hline & 1.74 & 0.13 & 0.3 & 7000 & 8.3 & 1.84 & 0.095 & 0.22 & 5700 & 6.8 \\
\hline & 1.74 & 0.13 & 0.3 & 11500 & 11.4 & 1.84 & 0.095 & 0.22 & 8800 & 8.7 \\
\hline \multirow[t]{3}{*}{14 Ramberg Granite } & 1.735 & 0.13 & 0.31 & 7000 & 6.6 & 1.84 & 0.09 & 0.22 & 5500 & 5.2 \\
\hline & 1.735 & 0.13 & 0.31 & 11000 & 11.3 & 1.84 & 0.09 & 0.22 & 7500 & 7.7 \\
\hline & 1.735 & 0.13 & 0.31 & 15000 & 10.4 & 1.84 & 0.095 & 0.22 & 10000 & 7.0 \\
\hline \multirow{3}{*}{$\begin{array}{l}15 \text { Weinheim } \\
\text { Rhyolite } \\
\text { blue CL }\end{array}$} & 1.735 & 0.125 & 0.29 & 9800 & 5.1 & 1.845 & 0.095 & 0.22 & 13000 & 6.8 \\
\hline & 1.735 & 0.125 & 0.29 & 12000 & 6.6 & 1.845 & 0.095 & 0.22 & 15000 & 8.3 \\
\hline & 1.73 & 0.13 & 0.31 & 14300 & 8.5 & 1.845 & 0.095 & 0.22 & 15000 & 8.9 \\
\hline \multirow{3}{*}{$\begin{array}{l}15 \text { Weinheim } \\
\text { Rhyolite } \\
\text { red CL }\end{array}$} & 1.73 & 0.13 & 0.31 & 12575 & 14.9 & 1.84 & 0.095 & 0.22 & 9494 & 11.3 \\
\hline & 1.73 & 0.13 & 0.31 & 19400 & 18.4 & 1.84 & 0.095 & 0.22 & 14160 & 13.4 \\
\hline & 1.73 & 0.13 & 0.31 & 21000 & 20.1 & 1.84 & 0.095 & 0.22 & 15000 & 14.4 \\
\hline
\end{tabular}

\begin{tabular}{|c|c|c|c|c|c|c|c|c|c|c|}
\hline Sample & $1.96 \mathrm{eV}-$ & Band & & & & $2.15 \mathrm{eV}-$ & Band & & & \\
\hline & $\begin{array}{c}\text { Position } \\
(\mathrm{eV})\end{array}$ & $\begin{array}{c}\text { Sigma } \\
(\mathrm{eV})\end{array}$ & $\begin{array}{c}\text { Half-width } \\
(\mathrm{eV})\end{array}$ & If & If $(\%)$ & $\begin{array}{c}\text { Position } \\
(\mathrm{eV})\end{array}$ & $\begin{array}{c}\text { Sigma } \\
(\mathrm{eV})\end{array}$ & $\begin{array}{c}\text { Half-width } \\
(\mathrm{eV})\end{array}$ & If & If $(\%)$ \\
\hline \multirow[t]{3}{*}{1 Megaquartz } & 1.96 & 0.1 & 0.24 & 4100 & 3.5 & 2.16 & 0.16 & 0.38 & 30000 & 25.6 \\
\hline & 1.96 & 0.1 & 0.24 & 9000 & 13.6 & 2.16 & 0.16 & 0.38 & 19500 & 29.5 \\
\hline & 1.96 & 0.1 & 0.24 & 9800 & 16.4 & 2.15 & 0.16 & 0.38 & 20300 & 33.9 \\
\hline \multirow[t]{3}{*}{2 Fissile Quartz } & 1.955 & 0.1 & 0.23 & 5000 & 8.2 & 2.155 & 0.16 & 0.37 & 12600 & 20.6 \\
\hline & 1.955 & 0.1 & 0.23 & 7000 & 11.1 & 2.15 & 0.16 & 0.38 & 14000 & 22.3 \\
\hline & 1.955 & 0.1 & 0.23 & 11000 & 15.8 & 2.145 & 0.16 & 0.37 & 16000 & 22.9 \\
\hline \multirow{3}{*}{$\begin{array}{l}3 \text { Oil-bearing } \\
\text { Quartz }\end{array}$} & 1.96 & 0.1 & 0.24 & 5300 & 6.1 & 2.155 & 0.175 & 0.41 & 22000 & 25.5 \\
\hline & 1.956 & 0.1 & 0.24 & 12400 & 15.0 & 2.15 & 0.155 & 0.36 & 21000 & 25.4 \\
\hline & 1.96 & 0.1 & 0.24 & 14500 & 19.4 & 2.14 & 0.16 & 0.38 & 20300 & 27.1 \\
\hline \multirow{3}{*}{$\begin{array}{l}4 \text { Schoenfeld } \\
\text { Rhyolite }\end{array}$} & 1.972 & 0.087 & 0.2 & 13700 & 12.5 & 2.15 & 0.16 & 0.38 & 17000 & 15.5 \\
\hline & 1.972 & 0.095 & 0.22 & 16000 & 15.7 & 2.15 & 0.16 & 0.38 & 17000 & 16.7 \\
\hline & 1.967 & 0.1 & 0.24 & 19000 & 18.7 & 2.15 & 0.16 & 0.38 & 19000 & 18.7 \\
\hline \multirow{3}{*}{$\begin{array}{l}5 \text { Teplice Rhyolite } \\
\text { blue CL/ } \\
\text { phenocryst }\end{array}$} & 1.956 & 0.09 & 0.22 & 3076 & 5.9 & 2.15 & 0.16 & 0.38 & 6863 & 13.2 \\
\hline & 1.956 & 0.09 & 0.22 & 4000 & 8.2 & 2.15 & 0.16 & 0.38 & 7000 & 14.3 \\
\hline & 1.956 & 0.1 & 0.24 & 7000 & 13.5 & 2.16 & 0.16 & 0.38 & 8300 & 16.0 \\
\hline \multirow{3}{*}{$\begin{array}{l}5 \text { Teplice Rhyolite } \\
\text { red CL/ } \\
\text { phenocryst }\end{array}$} & 1.976 & 0.085 & 0.21 & 18000 & 16.4 & 2.14 & 0.16 & 0.38 & 20000 & 18.2 \\
\hline & 1.97 & 0.085 & 0.2 & 20800 & 19.1 & 2.14 & 0.16 & 0.38 & 19800 & 18.2 \\
\hline & 1.972 & 0.1 & 0.24 & 25500 & 22.0 & 2.13 & 0.16 & 0.38 & 25000 & 21.6 \\
\hline \multirow{3}{*}{$\begin{array}{l}6 \text { Schellerhau Granite } \\
\text { blue CL/ } \\
\text { phenocryst }\end{array}$} & 1.957 & 0.093 & 0.22 & 8500 & 6.6 & 2.155 & 0.16 & 0.37 & 21000 & 16.3 \\
\hline & 1.957 & 0.1 & 0.24 & 13000 & 10.9 & 2.15 & 0.16 & 0.38 & 22000 & 18.5 \\
\hline & 1.957 & 0.105 & 0.26 & 17300 & 16.0 & 2.15 & 0.16 & 0.38 & 23300 & 21.5 \\
\hline \multirow{3}{*}{$\begin{array}{l}6 \text { Schellerhau Granite } \\
\text { red CL/ } \\
\text { phenocryst } \\
\end{array}$} & 1.955 & 0.095 & 0.23 & 9400 & 11.2 & 2.15 & 0.16 & 0.38 & 19500 & 23.3 \\
\hline & 1.954 & 0.105 & 0.24 & 17500 & 19.7 & 2.145 & 0.155 & 0.37 & 22000 & 24.7 \\
\hline & 1.957 & 0.11 & 0.26 & 20500 & 22.7 & 2.14 & 0.16 & 0.38 & 23800 & 26.4 \\
\hline \multirow{3}{*}{$\begin{array}{l}6 \text { Schellerhau Granite } \\
\text { red CL/ } \\
\text { matrix quartz }\end{array}$} & 1.968 & 0.095 & 0.22 & 8500 & 12.2 & 2.143 & 0.16 & 0.37 & 13800 & 19.8 \\
\hline & 1.96 & 0.105 & 0.24 & 15300 & 19.9 & 2.143 & 0.16 & 0.37 & 17400 & 22.6 \\
\hline & 1.962 & 0.11 & 0.26 & 18300 & 23.3 & 2.14 & 0.16 & 0.38 & 19000 & 24.2 \\
\hline \multirow[t]{3}{*}{7 Eibenstock Granite } & 1.942 & 0.09 & 0.2 & 1500 & 5.7 & 2.136 & 0.17 & 0.4 & 8200 & 31.4 \\
\hline & 1.942 & 0.09 & 0.2 & 2400 & 8.4 & 2.136 & 0.17 & 0.4 & 9300 & 32.6 \\
\hline & 1.942 & 0.09 & 0.2 & 2700 & 8.8 & 2.122 & 0.17 & 0.4 & 10500 & 34.1 \\
\hline \multirow[t]{3}{*}{8 Aue Granite } & 1.935 & 0.09 & 0.21 & 5140 & 3.5 & 2.19 & 0.152 & 0.36 & 53000 & 36.2 \\
\hline & 1.935 & 0.09 & 0.21 & 7200 & 5.2 & 2.19 & 0.152 & 0.36 & 48000 & 35.0 \\
\hline & 1.935 & 0.09 & 0.21 & 7700 & 6.4 & 2.185 & 0.155 & 0.36 & 46500 & 38.8 \\
\hline
\end{tabular}




\section{List of CL emission band parameters of quartz (continued)}

\begin{tabular}{|c|c|c|c|c|c|c|c|c|c|c|}
\hline \multirow[t]{2}{*}{ Sample } & \multirow{2}{*}{$\begin{array}{c}1.96 \mathrm{eV}- \\
\text { Position } \\
(\mathrm{eV})\end{array}$} & \multicolumn{4}{|l|}{ Band } & \multicolumn{5}{|c|}{$2.15 \mathrm{eV}-\quad$ Band } \\
\hline & & $\begin{array}{c}\text { Sigma } \\
(\mathrm{eV})\end{array}$ & $\begin{array}{c}\text { Half-width } \\
(\mathrm{eV})\end{array}$ & If & If $(\%)$ & $\begin{array}{c}\text { Position } \\
(\mathrm{eV})\end{array}$ & $\begin{array}{c}\text { Sigma } \\
(\mathrm{eV})\end{array}$ & $\begin{array}{c}\text { Half-width } \\
(\mathrm{eV})\end{array}$ & If & If $(\%)$ \\
\hline \multirow[t]{3}{*}{9 Vein Quartz } & 1.95 & 0.11 & 0.26 & 600 & 0.8 & 2.17 & 0.175 & 0.44 & 7000 & 9.0 \\
\hline & 1.95 & 0.11 & 0.26 & 600 & 1.4 & 2.17 & 0.175 & 0.44 & 5000 & 12.1 \\
\hline & 1.95 & 0.11 & 0.26 & 600 & 3.4 & 2.167 & 0.18 & 0.41 & 3150 & 18.1 \\
\hline \multirow{3}{*}{$\begin{array}{l}10 \text { Wachtelberg } \\
\text { Rhyolite } \\
\text { blue CL }\end{array}$} & 1.962 & 0.095 & 0.22 & 9200 & 13.4 & 2.173 & 0.16 & 0.38 & 10500 & 15.3 \\
\hline & 1.962 & 0.095 & 0.22 & 10800 & 17.4 & 2.173 & 0.16 & 0.38 & 9500 & 15.3 \\
\hline & 1.962 & 0.1 & 0.24 & 12144 & 20.2 & 2.17 & 0.16 & 0.38 & 9000 & 15.0 \\
\hline \multirow{3}{*}{$\begin{array}{l}10 \text { Wachtelberg } \\
\text { Rhyolite } \\
\text { red CL }\end{array}$} & 1.967 & 0.089 & 0.22 & 13200 & 24.7 & 2.163 & 0.16 & 0.37 & 6350 & 11.9 \\
\hline & 1.963 & 0.089 & 0.22 & 14200 & 28.5 & 2.163 & 0.155 & 0.36 & 5900 & 11.8 \\
\hline & 1.962 & 0.1 & 0.23 & 15180 & 31.1 & 2.16 & 0.16 & 0.38 & 5700 & 11.7 \\
\hline \multirow{3}{*}{$\begin{array}{l}11 \text { Beucha Rhyolite } \\
\text { blue CL }\end{array}$} & 1.95 & 0.1 & 0.24 & 10760 & 12.8 & 2.165 & 0.16 & 0.38 & 14020 & 16.7 \\
\hline & 1.95 & 0.1 & 0.24 & 11300 & 14.7 & 2.165 & 0.16 & 0.38 & 13600 & 17.7 \\
\hline & 1.95 & 0.1 & 0.24 & 14100 & 18.6 & 2.16 & 0.16 & 0.38 & 14000 & 18.5 \\
\hline \multirow{3}{*}{$\begin{array}{l}11 \text { Beucha Rhyolite } \\
\text { red CL }\end{array}$} & 1.956 & 0.1 & 0.24 & 8542 & 14.2 & 2.16 & 0.16 & 0.38 & 7777 & 12.9 \\
\hline & 1.956 & 0.1 & 0.24 & 10250 & 17.2 & 2.16 & 0.16 & 0.38 & 8555 & 14.3 \\
\hline & 1.956 & 0.1 & 0.24 & 14950 & 23.4 & 2.16 & 0.16 & 0.38 & 10500 & 16.4 \\
\hline \multirow{3}{*}{$\begin{array}{l}12 \text { Flossenbuerg } \\
\text { Granite }\end{array}$} & 1.95 & 0.09 & 0.22 & 8000 & 5.3 & 2.155 & 0.16 & 0.37 & 29700 & 19.8 \\
\hline & 1.95 & 0.09 & 0.22 & 9000 & 6.5 & 2.145 & 0.16 & 0.37 & 28700 & 20.7 \\
\hline & 1.956 & 0.1 & 0.24 & 15000 & 10.4 & 2.14 & 0.16 & 0.38 & 33000 & 23.0 \\
\hline \multirow{3}{*}{$\begin{array}{l}13 \text { Leucosome } \\
\text { Quartz }\end{array}$} & 1.96 & 0.1 & 0.24 & 7000 & 9.4 & 2.155 & 0.16 & 0.37 & 13200 & 17.8 \\
\hline & 1.96 & 0.1 & 0.24 & 10700 & 12.7 & 2.155 & 0.16 & 0.37 & 15300 & 18.1 \\
\hline & 1.96 & 0.1 & 0.24 & 15500 & 15.3 & 2.14 & 0.16 & 0.38 & 20600 & 20.4 \\
\hline \multirow[t]{3}{*}{14 Ramberg Granite } & 1.958 & 0.085 & 0.2 & 12600 & 12.0 & 2.16 & 0.16 & 0.38 & 17400 & 16.5 \\
\hline & 1.962 & 0.09 & 0.22 & 16000 & 16.4 & 2.15 & 0.16 & 0.38 & 18500 & 18.9 \\
\hline & 1.956 & 0.1 & 0.24 & 15000 & 10.4 & 2.14 & 0.16 & 0.38 & 33000 & 23.0 \\
\hline \multirow{3}{*}{$\begin{array}{l}15 \text { Weinheim } \\
\text { Rhyolite } \\
\text { blue CL }\end{array}$} & 1.96 & 0.085 & 0.2 & 25500 & 13.3 & 2.16 & 0.16 & 0.38 & 19000 & 9.9 \\
\hline & 1.96 & 0.085 & 0.2 & 27000 & 14.9 & 2.16 & 0.16 & 0.38 & 19000 & 10.5 \\
\hline & 1.955 & 0.09 & 0.22 & 28000 & 16.6 & 2.16 & 0.16 & 0.38 & 19000 & 11.2 \\
\hline \multirow{3}{*}{$\begin{array}{l}15 \text { Weinheim } \\
\text { Rhyolite } \\
\text { red CL }\end{array}$} & 1.958 & 0.1 & 0.24 & 24333 & 28.8 & 2.165 & 0.16 & 0.38 & 9383 & 11.1 \\
\hline & 1.958 & 0.1 & 0.24 & 40200 & 38.2 & 2.165 & 0.16 & 0.38 & 12000 & 11.4 \\
\hline & 1.958 & 0.1 & 0.24 & 43800 & 42.0 & 2.165 & 0.16 & 0.38 & 12200 & 11.7 \\
\hline
\end{tabular}

\begin{tabular}{|c|c|c|c|c|c|c|c|c|c|c|}
\hline \multirow[t]{2}{*}{ Sample } & \multirow{2}{*}{$\begin{array}{c}2.47 \mathrm{eV} \text { - } \\
\text { Position } \\
(\mathrm{eV})\end{array}$} & \multicolumn{4}{|l|}{ Band } & \multicolumn{5}{|c|}{$2.58 \mathrm{eV}$ Band } \\
\hline & & $\begin{array}{c}\text { Sigma } \\
(\mathrm{eV})\end{array}$ & $\begin{array}{c}\text { Half-width } \\
(\mathrm{eV})\end{array}$ & If & If $(\%)$ & $\begin{array}{c}\text { Position } \\
(\mathrm{eV})\end{array}$ & $\begin{array}{c}\text { Sigma } \\
(\mathrm{eV})\end{array}$ & $\begin{array}{c}\text { Half-width } \\
(\mathrm{eV})\end{array}$ & If & If $(\%)$ \\
\hline \multirow[t]{3}{*}{1 Megaquartz } & 2.44 & 0.15 & 0.36 & 48300 & 41.2 & 2.58 & 0.08 & 0.18 & 3400 & 2.9 \\
\hline & 2.445 & 0.14 & 0.32 & 16400 & 24.8 & 2.58 & 0.08 & 0.18 & 2300 & 3.5 \\
\hline & 2.465 & 0.125 & 0.29 & 11000 & 18.4 & 2.58 & 0.08 & 0.18 & 750 & 1.3 \\
\hline \multirow[t]{3}{*}{2 Fissile Quartz } & 2.46 & 0.137 & 0.32 & 14600 & 23.9 & 2.58 & 0.08 & 0.18 & 2500 & 4.1 \\
\hline & 2.46 & 0.13 & 0.3 & 12300 & 19.6 & 2.58 & 0.08 & 0.18 & 2500 & 4.0 \\
\hline & 2.465 & 0.125 & 0.29 & 11000 & 15.8 & 2.58 & 0.08 & 0.18 & 2100 & 3.0 \\
\hline \multirow{3}{*}{$\begin{array}{l}3 \text { Oil-bearing } \\
\text { Quartz }\end{array}$} & 2.455 & 0.15 & 0.35 & 25000 & 29.0 & 2.58 & 0.08 & 0.18 & 2900 & 3.4 \\
\hline & 2.455 & 0.13 & 0.31 & 15100 & 18.3 & 2.58 & 0.08 & 0.18 & 2400 & 2.9 \\
\hline & 2.465 & 0.125 & 0.29 & 9400 & 12.6 & 2.58 & 0.08 & 0.18 & 1200 & 1.6 \\
\hline \multirow{3}{*}{$\begin{array}{l}4 \text { Schoenfeld } \\
\text { Rhyolite }\end{array}$} & 2.46 & 0.122 & 0.28 & 18800 & 17.1 & 2.58 & 0.08 & 0.18 & 5000 & $\overline{4.6}$ \\
\hline & 2.46 & 0.122 & 0.28 & 15000 & 14.7 & 2.58 & 0.08 & 0.18 & 4700 & 4.6 \\
\hline & 2.47 & 0.12 & 0.28 & 13800 & 13.6 & 2.58 & 0.08 & 0.18 & 3100 & 3.1 \\
\hline \multirow{3}{*}{$\begin{array}{l}5 \text { Teplice Rhyolite } \\
\text { blue CL/ } \\
\text { phenocryst }\end{array}$} & 2.465 & 0.13 & 0.31 & 10715 & 20.6 & 2.58 & 0.08 & 0.18 & 1790 & 3.4 \\
\hline & 2.465 & 0.13 & 0.31 & 9000 & 18.4 & 2.58 & 0.08 & 0.18 & 1700 & 3.5 \\
\hline & 2.47 & 0.125 & 0.3 & 7900 & 15.2 & 2.58 & 0.08 & 0.18 & 1500 & 2.9 \\
\hline \multirow{3}{*}{$\begin{array}{l}\text { Teplice Rhyolite } \\
\text { red CL/ } \\
\text { phenocryst }\end{array}$} & 2.465 & 0.125 & 0.29 & 11000 & 10.0 & 2.58 & 0.08 & 0.18 & 1900 & 1.7 \\
\hline & 2.465 & 0.125 & 0.29 & 10000 & 9.2 & 2.58 & 0.08 & 0.18 & 1900 & 1.7 \\
\hline & 2.47 & 0.125 & 0.3 & 9500 & 8.2 & 2.58 & 0.08 & 0.18 & 1600 & 1.4 \\
\hline
\end{tabular}




\section{List of CL emission band parameters of quartz (continued)}

\begin{tabular}{|c|c|c|c|c|c|c|c|c|c|c|}
\hline \multirow[t]{2}{*}{ Sample } & \multicolumn{5}{|c|}{$2.47 \mathrm{eV}$ - Band } & \multicolumn{5}{|c|}{$2.58 \mathrm{eV} \quad$ Band } \\
\hline & $\begin{array}{c}\text { Position } \\
(\mathrm{eV})\end{array}$ & $\begin{array}{c}\text { Sigma } \\
(\mathrm{eV})\end{array}$ & $\begin{array}{c}\text { Half-width } \\
(\mathrm{eV})\end{array}$ & If & If $(\%)$ & $\begin{array}{c}\text { Position } \\
(\mathrm{eV})\end{array}$ & $\begin{array}{c}\text { Sigma } \\
(\mathrm{eV})\end{array}$ & $\begin{array}{c}\text { Half-width } \\
(\mathrm{eV})\end{array}$ & If & If $(\%)$ \\
\hline \multirow{3}{*}{$\begin{array}{l}\text { 6 Schellerhau Granite } \\
\text { blue CL/ } \\
\text { phenocryst }\end{array}$} & 2.463 & 0.135 & 0.32 & 25000 & 19.4 & 2.58 & 0.08 & 0.18 & 4500 & 3.5 \\
\hline & 2.463 & 0.135 & 0.32 & 20000 & 16.8 & 2.58 & 0.08 & 0.18 & 3800 & 3.2 \\
\hline & 2.47 & 0.125 & 0.3 & 14000 & 12.9 & 2.58 & 0.08 & 0.18 & 3000 & 2.8 \\
\hline \multirow{3}{*}{$\begin{array}{l}6 \text { Schellerhau Granite } \\
\text { red CL/ } \\
\text { phenocryst }\end{array}$} & 2.462 & 0.13 & 0.3 & 14300 & 17.1 & 2.58 & 0.08 & 0.18 & 2500 & 3.0 \\
\hline & 2.462 & 0.13 & 0.3 & 11000 & 12.4 & 2.58 & 0.08 & 0.18 & 2200 & 2.5 \\
\hline & 2.47 & 0.125 & 0.3 & 8700 & 9.6 & 2.58 & 0.08 & 0.18 & 1500 & 1.7 \\
\hline \multirow{3}{*}{$\begin{array}{l}6 \text { Schellerhau Granite } \\
\text { red CL/ } \\
\text { matrix quartz }\end{array}$} & 2.465 & 0.13 & 0.31 & 11300 & 16.2 & 2.58 & 0.08 & 0.18 & 2700 & 3.9 \\
\hline & 2.465 & 0.13 & 0.31 & 9300 & 12.1 & 2.58 & 0.08 & 0.18 & 2050 & 2.7 \\
\hline & 2.47 & 0.125 & 0.3 & 7700 & 9.8 & 2.58 & 0.08 & 0.18 & 1500 & 1.9 \\
\hline \multirow[t]{3}{*}{7 Eibenstock Granite } & 2.48 & 0.11 & 0.26 & 2700 & 10.3 & 2.58 & 0.08 & 0.18 & 850 & 3.3 \\
\hline & 2.48 & 0.11 & 0.26 & 2400 & 8.4 & 2.58 & 0.08 & 0.18 & 820 & 2.9 \\
\hline & 2.48 & 0.11 & 0.26 & 2600 & 8.5 & 2.58 & 0.08 & 0.18 & 600 & 2.0 \\
\hline \multirow[t]{3}{*}{8 Aue Granite } & 2.48 & 0.11 & 0.26 & 18000 & 12.3 & 2.58 & 0.08 & 0.18 & 6525 & 4.5 \\
\hline & 2.48 & 0.11 & 0.26 & 15300 & 11.2 & 2.58 & 0.08 & 0.18 & 6200 & 4.5 \\
\hline & 2.48 & 0.11 & 0.26 & 10500 & 8.8 & 2.58 & 0.08 & 0.18 & 5500 & 4.6 \\
\hline \multirow[t]{3}{*}{9 Vein Quartz } & 2.47 & 0.145 & 0.34 & 17000 & 21.9 & 2.58 & 0.08 & 0.18 & 4000 & 5.1 \\
\hline & 2.47 & 0.145 & 0.34 & 8500 & 20.5 & 2.58 & 0.08 & 0.18 & 2000 & 4.8 \\
\hline & 2.47 & 0.125 & 0.3 & 2700 & 15.5 & 2.58 & 0.08 & 0.18 & 700 & 4.0 \\
\hline \multirow{3}{*}{$\begin{array}{l}10 \text { Wachtelberg } \\
\text { Rhyolite } \\
\text { blue CL }\end{array}$} & 2.465 & 0.13 & 0.31 & 11770 & 17.1 & 2.58 & 0.08 & 0.18 & 2500 & 3.6 \\
\hline & 2.465 & 0.13 & 0.31 & 9800 & 15.8 & 2.58 & 0.08 & 0.18 & 1900 & 3.1 \\
\hline & 2.465 & 0.13 & 0.31 & 9000 & 15.0 & 2.58 & 0.08 & 0.18 & 1580 & 2.6 \\
\hline \multirow{3}{*}{$\begin{array}{l}10 \text { Wachtelberg } \\
\text { Rhyolite } \\
\text { red CL }\end{array}$} & 2.457 & 0.137 & 0.33 & 7900 & 14.8 & 2.58 & 0.08 & 0.18 & 1750 & 3.3 \\
\hline & 2.457 & 0.137 & 0.33 & 6500 & 13.0 & 2.58 & 0.08 & 0.18 & 1500 & 3.0 \\
\hline & 2.465 & 0.125 & 0.28 & 5800 & 11.9 & 2.58 & 0.08 & 0.18 & 1000 & 2.1 \\
\hline \multirow{3}{*}{$\begin{array}{l}11 \text { Beucha Rhyolite } \\
\text { blue CL }\end{array}$} & 2.485 & 0.12 & 0.29 & 11585 & 13.8 & 2.58 & 0.08 & 0.18 & 3043 & 3.6 \\
\hline & 2.485 & 0.12 & 0.29 & 9500 & 12.3 & 2.58 & 0.08 & 0.18 & 2800 & 3.6 \\
\hline & 2.48 & 0.12 & 0.28 & 9500 & 12.5 & 2.58 & 0.08 & 0.18 & 1800 & 2.4 \\
\hline \multirow{3}{*}{$\begin{array}{l}11 \text { Beucha Rhyolite } \\
\text { red CL }\end{array}$} & 2.48 & 0.125 & 0.3 & 10416 & 17.3 & 2.58 & 0.08 & 0.18 & 1733 & 2.9 \\
\hline & 2.48 & 0.125 & 0.3 & 9166 & 15.4 & 2.58 & 0.08 & 0.18 & 1698 & 2.8 \\
\hline & 2.48 & 0.125 & 0.3 & 7500 & 11.7 & 2.58 & 0.08 & 0.18 & 1300 & 2.0 \\
\hline \multirow{3}{*}{$\begin{array}{l}12 \text { Flossenbuerg } \\
\text { Granite }\end{array}$} & 2.47 & 0.13 & 0.3 & 29700 & 19.8 & 2.58 & 0.08 & 0.18 & 5000 & 3.3 \\
\hline & 2.47 & 0.13 & 0.3 & 25000 & 18.0 & 2.58 & 0.08 & 0.18 & 5000 & 3.6 \\
\hline & 2.48 & 0.125 & 0.3 & 22500 & 15.7 & 2.58 & 0.08 & 0.18 & 3000 & 2.1 \\
\hline \multirow{3}{*}{$\begin{array}{l}13 \text { Leucosome } \\
\text { Quartz }\end{array}$} & 2.47 & 0.127 & 0.29 & 14600 & 19.7 & 2.58 & 0.08 & 0.18 & 2500 & 3.4 \\
\hline & 2.47 & 0.13 & 0.3 & 14600 & 17.3 & 2.58 & 0.08 & 0.18 & 2700 & 3.2 \\
\hline & 2.47 & 0.125 & 0.28 & 15200 & 15.0 & 2.58 & 0.08 & 0.18 & 3100 & 3.1 \\
\hline \multirow[t]{3}{*}{14 Ramberg Granite } & 2.465 & 0.13 & 0.31 & 19000 & 18.0 & 2.58 & 0.08 & 0.18 & 4000 & 3.8 \\
\hline & 2.465 & 0.125 & 0.28 & 14700 & 15.0 & 2.58 & 0.08 & 0.18 & 3200 & 3.3 \\
\hline & 2.48 & 0.125 & 0.3 & 22500 & 15.7 & 2.58 & 0.08 & 0.18 & 3000 & 2.1 \\
\hline \multirow[t]{3}{*}{15 Weinheim } & 2.45 & 0.138 & 0.32 & 36000 & 18.8 & 2.571 & 0.08 & 0.18 & $\begin{array}{c}1080 \\
0\end{array}$ & 5.6 \\
\hline & 2.45 & 0.138 & 0.32 & 31400 & 17.4 & 2.571 & 0.08 & 0.18 & $\begin{array}{c}1040 \\
0\end{array}$ & 5.8 \\
\hline & 2.46 & 0.135 & 0.32 & 28000 & 16.6 & 2.58 & 0.08 & 0.18 & 7600 & 4.5 \\
\hline \multirow{3}{*}{$\begin{array}{l}15 \text { Weinheim } \\
\text { Rhyolite } \\
\text { red CL }\end{array}$} & 2.46 & 0.125 & 0.3 & 11875 & 14.1 & 2.58 & 0.08 & 0.18 & 2717 & 3.2 \\
\hline & 2.46 & 0.125 & 0.3 & 10000 & 9.5 & 2.58 & 0.08 & 0.18 & 2420 & 2.3 \\
\hline & 2.46 & 0.125 & 0.3 & 8200 & 7.9 & 2.58 & 0.08 & 0.18 & 1900 & 1.8 \\
\hline
\end{tabular}




\section{List of CL emission band parameters of quartz (continued)}

\begin{tabular}{|c|c|c|c|c|c|c|c|c|c|c|}
\hline \multirow[t]{2}{*}{ Sample } & \multirow{2}{*}{$\begin{array}{c}2.68 \mathrm{eV}- \\
\text { Position } \\
(\mathrm{eV})\end{array}$} & \multicolumn{4}{|l|}{ Band } & \multicolumn{5}{|c|}{$2.79 \mathrm{eV}-\quad$ Band } \\
\hline & & $\begin{array}{c}\text { Sigma } \\
(\mathrm{eV})\end{array}$ & $\begin{array}{c}\text { Half-width } \\
(\mathrm{eV})\end{array}$ & If & If $(\%)$ & $\begin{array}{c}\begin{array}{c}\text { Position } \\
(\mathrm{eV})\end{array} \\
\end{array}$ & $\begin{array}{c}\text { Sigma } \\
(\mathrm{eV})\end{array}$ & $\begin{array}{c}\text { Half-width } \\
(\mathrm{eV})\end{array}$ & If & If $(\%)$ \\
\hline \multirow[t]{3}{*}{1 Megaquartz } & 2.685 & 0.1 & 0.23 & 11000 & 9.4 & 2.79 & 0.11 & 0.26 & 10200 & 8.7 \\
\hline & 2.685 & 0.1 & 0.23 & 4000 & 6.1 & 2.79 & 0.11 & 0.26 & 4100 & 6.2 \\
\hline & 2.685 & 0.1 & 0.23 & 3500 & 5.8 & 2.79 & 0.11 & 0.26 & 2500 & 4.2 \\
\hline \multirow[t]{3}{*}{2 Fissile Quartz } & 2.685 & 0.1 & 0.23 & 6700 & 10.9 & 2.792 & 0.11 & 0.26 & 7300 & 11.9 \\
\hline & 2.685 & 0.1 & 0.23 & 6500 & 10.4 & 2.792 & 0.11 & 0.26 & 6800 & 10.8 \\
\hline & 2.685 & 0.1 & 0.23 & 6150 & 8.8 & 2.795 & 0.11 & 0.26 & 6200 & 8.9 \\
\hline \multirow{3}{*}{$\begin{array}{l}3 \text { Oil-bearing } \\
\text { Quartz }\end{array}$} & 2.685 & 0.1 & 0.23 & 7200 & 8.3 & 2.79 & 0.11 & 0.26 & 8700 & 10.1 \\
\hline & 2.685 & 0.1 & 0.23 & 6000 & 7.3 & 2.79 & 0.11 & 0.26 & 6000 & 7.3 \\
\hline & 2.685 & 0.1 & 0.23 & 4500 & 6.0 & 2.79 & 0.11 & 0.26 & 3500 & 4.7 \\
\hline \multirow{3}{*}{$\begin{array}{l}4 \text { Schoenfeld } \\
\text { Rhyolite }\end{array}$} & 2.685 & 0.1 & 0.23 & 13100 & 11.9 & 2.79 & 0.11 & 0.26 & 15200 & 13.8 \\
\hline & 2.685 & 0.1 & 0.23 & 11200 & 11.0 & 2.79 & 0.11 & 0.26 & 12700 & 12.5 \\
\hline & 2.685 & 0.1 & 0.23 & 9800 & 9.7 & 2.79 & 0.11 & 0.26 & 10800 & 10.6 \\
\hline \multirow{3}{*}{$\begin{array}{l}5 \text { Teplice Rhyolite } \\
\text { blue CL/ } \\
\text { phenocryst }\end{array}$} & 2.68 & 0.1 & 0.24 & 7060 & 13.6 & 2.8 & 0.11 & 0.26 & 8700 & 16.8 \\
\hline & 2.68 & 0.1 & 0.24 & 6000 & 12.2 & 2.8 & 0.11 & 0.26 & 7100 & 14.5 \\
\hline & 2.68 & 0.1 & 0.24 & 5700 & 11.0 & 2.8 & 0.11 & 0.26 & 6300 & 12.1 \\
\hline \multirow{3}{*}{$\begin{array}{l}5 \text { Teplice Rhyolite } \\
\text { red CL/ } \\
\text { phenocryst } \\
\end{array}$} & 2.685 & 0.1 & 0.23 & 6000 & 5.5 & 2.8 & 0.11 & 0.26 & 5800 & 5.3 \\
\hline & 2.685 & 0.1 & 0.23 & 6000 & 5.5 & 2.8 & 0.11 & 0.26 & 5000 & 4.6 \\
\hline & 2.685 & 0.1 & 0.23 & 5300 & 4.6 & 2.8 & 0.11 & 0.26 & 5500 & 4.8 \\
\hline \multirow{3}{*}{$\begin{array}{l}6 \text { Schellerhau Granite } \\
\text { blue CL/ } \\
\text { phenocryst }\end{array}$} & 2.68 & 0.1 & 0.24 & 15000 & 11.6 & 2.8 & 0.11 & 0.26 & 18500 & 14.3 \\
\hline & 2.68 & 0.1 & 0.24 & 12100 & 10.2 & 2.8 & 0.11 & 0.26 & 14200 & 11.9 \\
\hline & 2.68 & 0.1 & 0.24 & 9000 & 8.3 & 2.8 & 0.11 & 0.26 & 10800 & 10.0 \\
\hline \multirow{3}{*}{$\begin{array}{l}6 \text { Schellerhau Granite } \\
\text { red CL/ } \\
\text { phenocryst }\end{array}$} & 2.68 & 0.1 & 0.24 & 8000 & 9.6 & 2.8 & 0.11 & 0.26 & 8000 & 9.6 \\
\hline & 2.68 & 0.1 & 0.24 & 5500 & 6.2 & 2.8 & 0.11 & 0.26 & 6300 & 7.1 \\
\hline & 2.68 & 0.1 & 0.24 & 5000 & 5.5 & 2.8 & 0.11 & 0.26 & 5000 & 5.5 \\
\hline \multirow{3}{*}{$\begin{array}{l}6 \text { Schellerhau Granite } \\
\text { red CL/ } \\
\text { matrix quartz }\end{array}$} & 2.68 & 0.1 & 0.24 & 6700 & 9.6 & 2.8 & 0.11 & 0.26 & 8600 & 12.4 \\
\hline & 2.68 & 0.1 & 0.24 & 6000 & 7.8 & 2.8 & 0.11 & 0.26 & 6700 & 8.7 \\
\hline & 2.68 & 0.1 & 0.24 & 4900 & 6.2 & 2.8 & 0.11 & 0.26 & 5600 & 7.1 \\
\hline \multirow[t]{3}{*}{7 Eibenstock Granite } & 2.685 & 0.1 & 0.23 & 2200 & 8.4 & 2.79 & 0.105 & 0.24 & 2300 & 8.8 \\
\hline & 2.685 & 0.1 & 0.23 & 1980 & 6.9 & 2.79 & 0.105 & 0.24 & 2050 & 7.2 \\
\hline & 2.685 & 0.1 & 0.23 & 2000 & 6.5 & 2.79 & 0.105 & 0.24 & 1850 & 6.0 \\
\hline \multirow[t]{3}{*}{8 Aue Granite } & 2.685 & 0.1 & 0.23 & 15568 & 10.6 & 2.785 & 0.105 & 0.24 & 16436 & 11.2 \\
\hline & 2.685 & 0.1 & 0.23 & 13700 & 10.0 & 2.785 & 0.105 & 0.24 & 14300 & 10.4 \\
\hline & 2.685 & 0.1 & 0.23 & 9650 & 8.1 & 2.785 & 0.105 & 0.24 & 11200 & 9.4 \\
\hline \multirow[t]{3}{*}{9 Vein Quartz } & 2.685 & 0.1 & 0.23 & 10500 & 13.5 & 2.8 & 0.11 & 0.26 & 18000 & 23.1 \\
\hline & 2.685 & 0.1 & 0.23 & 5500 & 13.3 & 2.8 & 0.11 & 0.26 & 8500 & 20.5 \\
\hline & 2.685 & 0.1 & 0.23 & 2250 & 12.9 & 2.8 & 0.11 & 0.26 & 2600 & 14.9 \\
\hline 10 Wachtelberg & 2.685 & 0.1 & 0.23 & 8100 & 11.8 & 2.8 & 0.11 & 0.26 & 8100 & 11.8 \\
\hline Rhyolite & 2.685 & 0.1 & 0.23 & 6735 & 10.8 & 2.8 & 0.11 & 0.26 & 6745 & 10.9 \\
\hline blue CL & 2.685 & 0.1 & 0.23 & 6150 & 10.3 & 2.8 & 0.11 & 0.26 & 6160 & 10.3 \\
\hline 10 Wachtelberg & 2.685 & 0.1 & 0.23 & 4700 & 8.8 & 2.8 & 0.11 & 0.26 & 5400 & 10.1 \\
\hline Rhyolite & 2.685 & 0.1 & 0.23 & 3800 & 7.6 & 2.8 & 0.11 & 0.26 & 4400 & 8.8 \\
\hline $\operatorname{red} \mathrm{CL}$ & 2.685 & 0.1 & 0.23 & 4000 & 8.2 & 2.8 & 0.11 & 0.26 & 3900 & 8.0 \\
\hline 11 Beucha Rhyolite & 2.685 & 0.1 & 0.23 & 9195 & 10.9 & 2.79 & 0.11 & 0.26 & 11850 & 14.1 \\
\hline blue CL & 2.685 & 0.1 & 0.23 & 8000 & 10.4 & 2.79 & 0.11 & 0.26 & 9000 & 11.7 \\
\hline & 2.685 & 0.1 & 0.23 & 6500 & 8.6 & 2.79 & 0.11 & 0.26 & 7600 & 10.0 \\
\hline 11 Beucha Rhyolite & 2.685 & 0.1 & 0.23 & 6050 & 10.1 & 2.79 & 0.11 & 0.26 & 7073 & 11.8 \\
\hline $\operatorname{red} \mathrm{CL}$ & 2.685 & 0.1 & 0.23 & 5444 & 9.1 & 2.79 & 0.11 & 0.26 & 6295 & 10.5 \\
\hline & 2.685 & 0.1 & 0.23 & 4900 & 7.7 & 2.79 & 0.11 & 0.26 & 5600 & 8.8 \\
\hline 12 Flossenbuerg & 2.68 & 0.1 & 0.24 & 17000 & 11.4 & 2.79 & 0.11 & 0.26 & 19300 & 12.9 \\
\hline & 2.68 & 0.1 & 0.24 & 15900 & 11.4 & 2.795 & 0.11 & 0.26 & 18800 & 13.5 \\
\hline & 2.68 & 0.1 & 0.24 & 14500 & 10.1 & 2.79 & 0.11 & 0.26 & 16100 & 11.2 \\
\hline 13 Leucosome & 2.685 & 0.1 & 0.23 & 9000 & 12.1 & 2.79 & 0.11 & 0.26 & 9000 & 12.1 \\
\hline Quartz & 2.685 & 0.1 & 0.23 & 9800 & 11.6 & 2.79 & 0.11 & 0.26 & 9200 & 10.9 \\
\hline & 2.685 & 0.1 & 0.23 & 10200 & 10.1 & 2.79 & 0.11 & 0.26 & 10000 & 9.9 \\
\hline
\end{tabular}




\section{List of CL emission band parameters of quartz (continued)}

\begin{tabular}{|c|c|c|c|c|c|c|c|c|c|c|}
\hline \multirow[t]{2}{*}{ Sample } & \multicolumn{5}{|c|}{$2.68 \mathrm{eV}-\quad$ Band } & \multicolumn{5}{|c|}{$2.79 \mathrm{eV}-\quad$ Band } \\
\hline & $\begin{array}{c}\text { Position } \\
(\mathrm{eV})\end{array}$ & $\begin{array}{c}\text { Sigma } \\
(\mathrm{eV})\end{array}$ & $\begin{array}{c}\text { Half-width } \\
(\mathrm{eV})\end{array}$ & If & If $(\%)$ & $\begin{array}{c}\text { Position } \\
(\mathrm{eV})\end{array}$ & $\begin{array}{c}\text { Sigma } \\
(\mathrm{eV})\end{array}$ & $\begin{array}{c}\text { Half-width } \\
(\mathrm{eV})\end{array}$ & If & If $(\%)$ \\
\hline 14 Ramberg Granite & 2.68 & 0.1 & 0.24 & 11800 & 11.2 & 2.8 & 0.11 & 0.26 & 13500 & 12.8 \\
\hline & 2.68 & 0.1 & 0.24 & 9300 & 9.5 & 2.8 & 0.11 & 0.26 & 10500 & 10.7 \\
\hline & 2.68 & 0.1 & 0.24 & 14500 & 10.1 & 2.79 & 0.11 & 0.26 & 16100 & 11.2 \\
\hline 15 Weinheim & 2.685 & 0.095 & 0.22 & 22300 & 11.6 & 2.79 & 0.11 & 0.26 & 26500 & 13.8 \\
\hline Rhyolite & 2.685 & 0.095 & 0.22 & 19000 & 10.5 & 2.79 & 0.11 & 0.26 & 25000 & 13.8 \\
\hline blue CL & 2.685 & 0.1 & 0.23 & 17400 & 10.3 & 2.79 & 0.11 & 0.26 & 23600 & 14.0 \\
\hline 15 Weinheim & 2.685 & 0.1 & 0.23 & 6704 & 7.9 & 2.8 & 0.11 & 0.26 & 7800 & 9.2 \\
\hline Rhyolite & 2.685 & 0.1 & 0.23 & 6750 & 6.4 & 2.8 & 0.11 & 0.26 & 7000 & 6.6 \\
\hline $\operatorname{red} C L$ & 2.685 & 0.1 & 0.23 & 5300 & 5.1 & 2.8 & 0.11 & 0.26 & 5500 & 5.3 \\
\hline
\end{tabular}

\begin{tabular}{|c|c|c|c|c|c|}
\hline \multirow[t]{2}{*}{ Sample } & \multicolumn{5}{|c|}{$2.96 \mathrm{eV}-\quad$ Band } \\
\hline & $\begin{array}{c}\text { Position } \\
(\text { eV })\end{array}$ & $\begin{array}{c}\text { Sigma } \\
(\mathrm{eV})\end{array}$ & $\begin{array}{c}\text { Half-width } \\
(\mathrm{eV})\end{array}$ & If & If $(\%)$ \\
\hline \multirow[t]{3}{*}{1 Megaquartz } & 2.955 & 0.125 & 0.28 & 5200 & 4.4 \\
\hline & 2.96 & 0.125 & 0.3 & 2200 & 3.3 \\
\hline & 2.96 & 0.125 & 0.3 & 1500 & 2.5 \\
\hline \multirow[t]{3}{*}{2 Fissile Quartz } & 2.96 & 0.12 & 0.28 & 7000 & 11.4 \\
\hline & 2.96 & 0.12 & 0.28 & 6000 & 9.6 \\
\hline & 2.96 & 0.12 & 0.28 & 5800 & 8.3 \\
\hline \multirow{3}{*}{$\begin{array}{l}3 \text { Oil-bearing } \\
\text { Quartz }\end{array}$} & 2.96 & 0.127 & 0.3 & 8700 & 10.1 \\
\hline & 2.965 & 0.125 & 0.29 & 6700 & 8.1 \\
\hline & 2.96 & 0.125 & 0.3 & 4500 & 6.0 \\
\hline \multirow{3}{*}{$\begin{array}{l}4 \text { Schoenfeld } \\
\text { Rhyolite }\end{array}$} & 2.96 & 0.13 & 0.3 & 22000 & 20.0 \\
\hline & 2.96 & 0.13 & 0.3 & 17800 & 17.5 \\
\hline & 2.96 & 0.13 & 0.3 & 15000 & 14.8 \\
\hline \multirow{3}{*}{$\begin{array}{l}5 \text { Teplice Rhyolite } \\
\text { blue CL/ } \\
\text { phenocryst }\end{array}$} & 2.96 & 0.128 & 0.3 & 10000 & 19.3 \\
\hline & 2.96 & 0.128 & 0.3 & 9000 & 18.4 \\
\hline & 2.96 & 0.128 & 0.3 & 8200 & 15.8 \\
\hline \multirow{3}{*}{$\begin{array}{l}5 \text { Teplice Rhyolite } \\
\text { red CL/ } \\
\text { phenocryst }\end{array}$} & 2.97 & 0.13 & 0.3 & 7500 & 6.8 \\
\hline & 2.97 & 0.13 & 0.3 & 7500 & 6.9 \\
\hline & 2.97 & 0.13 & 0.3 & 7300 & 6.3 \\
\hline \multirow{3}{*}{$\begin{array}{l}6 \text { Schellerhau Granite } \\
\text { blue CL/ } \\
\text { phenocryst }\end{array}$} & 2.965 & 0.135 & 0.31 & 27500 & 21.3 \\
\hline & 2.965 & 0.135 & 0.31 & 22000 & 18.5 \\
\hline & 2.965 & 0.135 & 0.31 & 15500 & 14.3 \\
\hline \multirow{3}{*}{$\begin{array}{l}6 \text { Schellerhau Granite } \\
\text { red CL/ } \\
\text { phenocryst }\end{array}$} & 2.965 & 0.135 & 0.31 & 10000 & 11.9 \\
\hline & 2.965 & 0.135 & 0.31 & 7500 & 8.4 \\
\hline & 2.965 & 0.135 & 0.31 & 5700 & 6.3 \\
\hline \multirow{3}{*}{$\begin{array}{l}6 \text { Schellerhau Granite } \\
\text { red CL/ } \\
\text { matrix quartz }\end{array}$} & 2.97 & 0.135 & 0.32 & 12500 & 18.0 \\
\hline & 2.97 & 0.135 & 0.32 & 10000 & 13.0 \\
\hline & 2.97 & 0.135 & 0.32 & 8000 & 10.2 \\
\hline \multirow[t]{3}{*}{7 Eibenstock Granite } & 2.965 & 0.13 & 0.31 & 3900 & 14.9 \\
\hline & 2.965 & 0.13 & 0.31 & 3600 & 12.6 \\
\hline & 2.96 & 0.13 & 0.3 & 3500 & 11.4 \\
\hline \multirow[t]{3}{*}{8 Aue Granite } & 2.96 & 0.125 & 0.3 & 23000 & 15.7 \\
\hline & 2.96 & 0.125 & 0.3 & 20000 & 14.6 \\
\hline & 2.96 & 0.125 & 0.3 & 15700 & 13.1 \\
\hline \multirow[t]{3}{*}{9 Vein Quartz } & 2.96 & 0.125 & 0.3 & 18500 & 23.8 \\
\hline & 2.96 & 0.125 & 0.3 & 8900 & 21.5 \\
\hline & 2.96 & 0.125 & 0.3 & 3000 & 17.2 \\
\hline \multirow{3}{*}{$\begin{array}{l}10 \text { Wachtelberg } \\
\text { Rhyolite } \\
\text { blue CL }\end{array}$} & 2.965 & 0.135 & 0.31 & 14470 & 21.0 \\
\hline & 2.965 & 0.135 & 0.31 & 12045 & 19.4 \\
\hline & 2.965 & 0.135 & 0.31 & 11000 & 18.3 \\
\hline
\end{tabular}


List of CL emission band parameters of quartz (continued)

\begin{tabular}{|l|ccccc|}
\hline Sample & $\mathbf{2 . 9 6}$ eV - & Band & & & \\
\hline & Position & Sigma & Half-width & If & If (\%) \\
& $(\mathbf{e V})$ & $\mathbf{( e V )}$ & $\mathbf{( e V})$ & & \\
\hline 10 Wachtelberg & 2.965 & 0.135 & 0.31 & 9100 & 17.0 \\
Rhyolite & 2.965 & 0.135 & 0.31 & 7600 & 15.2 \\
red CL & 2.965 & 0.135 & 0.31 & 7000 & 14.4 \\
\hline 11 Beucha Rhyolite & 2.962 & 0.135 & 0.32 & 17300 & 20.6 \\
blue CL & 2.962 & 0.135 & 0.32 & 14500 & 18.8 \\
& 2.962 & 0.135 & 0.32 & 12300 & 16.2 \\
\hline 11 Beucha Rhyolite & 2.965 & 0.135 & 0.31 & 12100 & 20.1 \\
red CL & 2.965 & 0.135 & 0.31 & 10000 & 16.8 \\
& 2.965 & 0.135 & 0.31 & 9000 & 14.1 \\
\hline 12 Flossenbuerg & 2.957 & 0.13 & 0.3 & 29000 & 19.4 \\
Granite & 2.957 & 0.13 & 0.3 & 28000 & 20.2 \\
& 2.957 & 0.13 & 0.3 & 24500 & 17.1 \\
\hline 13 Leucosome & 2.965 & 0.135 & 0.31 & 14000 & 18.8 \\
Quartz & 2.96 & 0.135 & 0.31 & 15000 & 17.8 \\
& 2.965 & 0.135 & 0.31 & 15000 & 14.8 \\
\hline 14 Ramberg Granite & 2.965 & 0.135 & 0.31 & 20000 & 19.0 \\
& 2.965 & 0.135 & 0.31 & 14500 & 14.8 \\
& 2.957 & 0.13 & 0.3 & 24500 & 17.1 \\
\hline 15 Weinheim & 2.955 & 0.135 & 0.31 & 42000 & 21.9 \\
Rhyolite & 2.955 & 0.135 & 0.31 & 37000 & 20.5 \\
blue CL & 2.96 & 0.125 & 0.3 & 31000 & 18.4 \\
\hline 15 Weinheim & 2.96 & 0.125 & 0.3 & 9000 & 10.7 \\
Rhyolite & 2.96 & 0.125 & 0.3 & 7600 & 7.2 \\
red CL & 2.96 & 0.125 & 0.3 & 6500 & 6.2 \\
\hline
\end{tabular}




\section{Appendix B}

\section{List of kinetic law parameters of $C L$ intensity change for the 1.96 and $2.79 \mathrm{eV}$ emission}

Function of the $1.96 \mathrm{eV}$ emission increase $\left(\right.$ and $\left.^{\mathrm{b}}\right)$ : $\mathrm{I}_{\mathrm{r}}=\mathrm{I}_{\mathrm{rs}}-\mathrm{I}_{\mathrm{r} 1} * \exp \left(-\mathrm{t} / \mathrm{k}_{\mathrm{r} 1}\right)-\mathrm{I}_{\mathrm{r} 2} * \exp \left(-\mathrm{t} / \mathrm{k}_{\mathrm{r} 2}\right)$ where $\mathrm{I}_{\mathrm{r}}=$ intensity of red $\mathrm{CL}$ at the radiation time $\mathrm{t} ; \mathrm{I}_{\mathrm{rs}}=$ intensity of red $\mathrm{CL}$ for $\mathrm{t}$ ? $8 ; \mathrm{I}_{\mathrm{r} 1}=$ intensity of the slow increasing $\mathrm{CL}$ component for $\mathrm{t}$ ? $8 ; \mathrm{k}_{\mathrm{r} 1}=$ velocity constant of the slow increasing CL component; $\mathrm{I}_{\mathrm{r} 2}=$ intensity of the fast increasing CL component for $\mathrm{t}$ ? $8 ; \mathrm{k}_{\mathrm{r} 2}=$ velocity constant of the fast increasing $\mathrm{CL}$ component; $\mathrm{t}=$ radiation time.

Function of the $2.79 \mathrm{eV}$ emission decay $\left(\mathrm{and}^{\mathrm{a}}\right): \mathrm{I}_{\mathrm{b}}=\mathrm{I}_{\mathrm{bs}}+\mathrm{I}_{\mathrm{b} 1} * \exp \left(-\mathrm{t} / \mathrm{k}_{\mathrm{b} 1}\right)+\mathrm{I}_{\mathrm{b} 2} * \exp \left(-\mathrm{t} / \mathrm{k}_{\mathrm{b} 2}\right)$ where $\mathrm{I}_{\mathrm{b}}=$ intensity of blue $\mathrm{CL}$ at the radiation time $\mathrm{t}$; $\mathrm{I}_{\mathrm{bs}}=$ intensity of stable blue $\mathrm{CL} ; \mathrm{b}_{1}=$ intensity of the slow decreasing $\mathrm{CL}$ component at $\mathrm{t}=0 ; \mathrm{k}_{\mathrm{b} 1}=$ velocity constant of the slow decreasing CL component; $\mathrm{I}_{\mathrm{b} 2}=$ intensity of the fast decreasing CL component at $\mathrm{t}=0 ; \mathrm{k}_{\mathrm{b} 2}=$ velocity constant of the fast decreasing CL component; $\mathrm{t}=$ radiation time. Intensities are normalised for the highest measured intensity ( $\mathrm{I}_{\mathrm{rs}}$ of sample 15). The reproducibility of the parameters lies in the error range of $10-20 \%$.

\begin{tabular}{|c|c|c|c|c|c|c|c|c|c|c|c|}
\hline \multirow[t]{2}{*}{ No. } & \multirow[t]{2}{*}{ Sample name } & \multicolumn{5}{|c|}{$1.96 \mathrm{eV}$ emission } & \multicolumn{5}{|c|}{2.79 eV emission } \\
\hline & & $\mathbf{I}_{\mathrm{rs}}(\%)$ & $I_{r 1}(\%)$ & $\mathbf{k}_{\mathbf{r} 1}$ & $I_{r 2}(\%)$ & $\mathbf{k}_{\mathrm{r} 2}$ & $\mathbf{I}_{\mathrm{bs}}(\%)$ & $\mathbf{I}_{\mathbf{b} 1}(\%)$ & $\mathbf{k}_{\mathbf{b} \mathbf{1}}$ & $\mathbf{I}_{\mathrm{b} 2}(\%)$ & $\mathbf{k}_{\mathbf{b} 2}$ \\
\hline 1 & Megaquartz & 46.2 & 16.1 & 512 & 3.0 & 7 & 4.5 & 4.5 & 254 & 72.2 & 14 \\
\hline 2 & Fissile Quartz & 49.8 & 30.2 & 498 & 7.2 & 10 & 12.1 & 3.5 & 234 & 25.7 & 7 \\
\hline 3 & Oil quartz & 55.0 & 15.6 & 470 & 29.2 & 36 & 6.9 & 10.2 & 248 & 37.8 & 10 \\
\hline 4 & Schoenfeld Rhyolite & 61.6 & 18.1 & 502 & 4.4 & 36 & 23.0 & 9.9 & 259 & 17.9 & 16 \\
\hline 5 & $\begin{array}{l}\text { Teplice rhyolite - blue } \\
\text { CL }\end{array}$ & 23.1 & 6.6 & 513 & 4.9 & 18 & 13.0 & 4.5 & 250 & 16.8 & 8 \\
\hline 5 & Teplice Rhyolite- red CL & 95.6 & 37.2 & 522 & 3.8 & 11 & 12.0 & 0.9 & 245 & 4.7 & 8 \\
\hline 6 & $\begin{array}{l}\text { Schellerhau Granite - } \\
\text { blue CL/phenocryst }\end{array}$ & 64.2 & 26.0 & 489 & 11.0 & 42 & 21.0 & 19.3 & 261 & 33.0 & 15 \\
\hline 6 & $\begin{array}{l}\text { Schellerhau Granite - } \\
\text { red CL/Phenocryst }\end{array}$ & 72.7 & 26.9 & 495 & 23.8 & 45 & 9.3 & 6.4 & 256 & 9.8 & 22 \\
\hline 6 & $\begin{array}{l}\text { Schellerhau Granite - } \\
\text { red CL/matrix quartz }\end{array}$ & 59.2 & 17.2 & 504 & 36.9 & 33 & 11.2 & 6.8 & 252 & 14.7 & 15 \\
\hline 7 & Eibenstock Granite & 21.1 & 9.3 & 521 & 5.6 & 23 & 4.8 & 6.8 & 243 & 6.2 & 10 \\
\hline 8 & Aue Granite & 47.0 & 8.1 & 506 & 9.9 & 16 & 22.0 & 0.6 & 245 & 22.5 & 10 \\
\hline 9 & Vein Quartz & $30.1^{\mathrm{a}}$ & $3.5^{\mathrm{a}}$ & $244^{\mathrm{a}}$ & $1.3^{\mathrm{a}}$ & $8^{\mathrm{a}}$ & 2.2 & 22.8 & 257 & 74.6 & 16 \\
\hline 10 & $\begin{array}{l}\text { Wachtelberg Rhyolite - } \\
\text { blue CL }\end{array}$ & 31.8 & 5.6 & 491 & 3.2 & 26 & 15.1 & 24.7 & 271 & 11.3 & 20 \\
\hline 10 & $\begin{array}{l}\text { Wachtelberg Rhyolite - } \\
\text { red CL }\end{array}$ & 35.8 & 3.3 & 509 & 2.4 & 26 & 9.4 & 3.7 & 240 & 11.4 & 20 \\
\hline 11 & $\begin{array}{l}\text { Beucha Rhyolite- blue } \\
\text { CL }\end{array}$ & 44.2 & 13.6 & 531 & 0.5 & 18 & 16.7 & 6.6 & 255 & 11.4 & 20 \\
\hline 11 & $\begin{array}{l}\text { Beucha Rhyolite - red } \\
\text { CL }\end{array}$ & 40.1 & 6.2 & 485 & 2.7 & 24 & 12.7 & 8.2 & 247 & 9.0 & 20 \\
\hline 12 & Flossenbuerg Granite & 80.1 & 47.3 & 492 & 25.4 & 12 & 35.2 & 2.7 & 254 & 51.1 & 8 \\
\hline 13 & Leucosome Quartz & 68.4 & 44.6 & 479 & 6.0 & 27 & $24.4^{\mathrm{b}}$ & $11.9^{\mathrm{b}}$ & $495^{\mathrm{b}}$ & $3.9^{\mathrm{b}}$ & $24^{\mathrm{b}}$ \\
\hline 14 & Ramberg Granite & 60.4 & 16.0 & 488 & 22.6 & 24 & 21.6 & 1.4 & 263 & 45.3 & 17 \\
\hline 15 & $\begin{array}{l}\text { Weinheim Rhyolite - } \\
\text { blue CL }\end{array}$ & 78.0 & 8.0 & 504 & 7.1 & 20 & 47.5 & 2.3 & 254 & 23.5 & 10 \\
\hline 15 & $\begin{array}{l}\text { Weinheim Rhyolite - red } \\
\text { CL }\end{array}$ & 100.0 & 15.6 & 521 & 6.8 & 26 & 10.4 & 16.5 & 247 & 11.1 & 8 \\
\hline
\end{tabular}




\section{Appendix C}

\section{List of trace element analysis of quartz (LA ICP-MS)}

1 Megaquartz

\begin{tabular}{crrrrrrrrr}
\hline Sample & \multicolumn{1}{c}{$\mathbf{L i}$} & Na & \multicolumn{1}{c}{ Al } & \multicolumn{1}{c}{ Ca } & \multicolumn{1}{c}{ Ti } & Cr & Mn & Fe & \multicolumn{1}{c}{ Ge } \\
\hline hakos01 1 & 36.5 & 108.8 & 229.5 & 1506.6 & 14.3 & 39.8 & 2.2 & 44.9 & 15.7 \\
hakos02 1 & 29.5 & 348.1 & 168.8 & 1286.5 & 16.2 & 42.4 & 4.4 & 72.1 & 11.7 \\
hakos03 1 & 33.4 & 378.9 & 238 & 1787.9 & 14.8 & 35.7 & 3.0 & 57.7 & 12.8 \\
hakos04 1 & 27.2 & 225.3 & 156.4 & 991 & 20 & 30.3 & 1.8 & 29.8 & 14.4 \\
hakos05 1 & 38.7 & 309.5 & 204.8 & 1371.7 & 22.2 & 37.6 & 2.3 & 38.3 & 20.2 \\
hakos06 1 & 45.8 & 357.4 & 217.6 & 1273.3 & 12.1 & 34.2 & 2.4 & 43.6 & 12.4 \\
hakos07 1 & 34.8 & 246.2 & 237.1 & 893.4 & 14.2 & 43.2 & 1.2 & 50.0 & 11.2 \\
hakos08 1 & 25.8 & 217.6 & 178.7 & 1391.2 & 18.1 & 34.2 & 2.2 & 44.4 & 9.8 \\
hakos09 1 & 36.9 & 253.9 & 216.1 & 1123.1 & 14.2 & 37.5 & 2.4 & 53.2 & 12.2 \\
hakos10 1 & 29.7 & 264.3 & 181.1 & 1023.3 & 15.3 & 30.2 & 1.8 & 40.3 & 13.8 \\
\hline
\end{tabular}

\section{Fissile quartz}

\begin{tabular}{cccccrrrrr}
\hline Sample & \multicolumn{1}{c}{ Li } & Na & Al & \multicolumn{1}{l}{ Ca } & \multicolumn{1}{c}{ Ti } & Cr & Mn & Fe & Ge \\
\hline spalt01 1 & 2.8 & 241.4 & 125.6 & 464.5 & 14.4 & 0.1 & 4.1 & 90.3 & 2.6 \\
spalt02 1 & 2.7 & 250.3 & 144.4 & 378.2 & 26.3 & 2.0 & 2.1 & 51.9 & 0.1 \\
spalt03 1 & 2.5 & 241.7 & 168.3 & 280.4 & 20.0 & 0.9 & 1.8 & 63.9 & 1.1 \\
spalt04 1 & 2.1 & 251.4 & 170.4 & 7.1 & 12.2 & 0.1 & 1.9 & 74.7 & 0.4 \\
spalt05 1 & 2.2 & 154.7 & 103.3 & 0.1 & 9.4 & 0.1 & 1.5 & 77.5 & 0.9 \\
spalt06 1 & 2.7 & 247.5 & 157.9 & 345.3 & 11.1 & 0.8 & 1.8 & 72.0 & 1.2 \\
spalt07 1 & 2.4 & 249.2 & 162.4 & 0.1 & 13.6 & 0.1 & 1.5 & 51.6 & 0.4 \\
spalt08 1 & 2.3 & 258.3 & 167.0 & 293.2 & 9.0 & 0.1 & 2.0 & 61.3 & 1.2 \\
spalt09 1 & 2.2 & 138.2 & 126.8 & 397.4 & 12.9 & 1.7 & 3.0 & 77.6 & 2.1 \\
spalt10 1 & 2.7 & 263.9 & 149.2 & 0.1 & 11.2 & 0.1 & 3.2 & 86.5 & 0.1 \\
\hline
\end{tabular}

\section{Oil-bearing quartz}

\begin{tabular}{clllllllll}
\hline Sample & Li & Na & Al & Ca & Ti & Cr & Mn & Fe & Ge \\
\hline oel01 1 & 134.3 & 1788.2 & 410.4 & 200.8 & 16.8 & 0.1 & 0.4 & 76.4 & 7.2 \\
oel02 1 & 118.8 & 2416.2 & 472.4 & 256.5 & 14.9 & 0.1 & 0.2 & 36.7 & 6.7 \\
oel03 1 & 131.2 & 3458.0 & 630.3 & 215.4 & 15.0 & 0.1 & 0.6 & 60.5 & 5.5 \\
oel04 1 & 118.6 & 3375.5 & 487.7 & 125.7 & 14.6 & 2.7 & 0.8 & 63.6 & 2.9 \\
oel05 1 & 119.1 & 1288.4 & 597.9 & 152.1 & 9.3 & 0.1 & 1.7 & 92.0 & 7.0 \\
oel06 1 & 112.8 & 3921.5 & 493.7 & 234.8 & 10.1 & 0.1 & 0.2 & 44.1 & 5.4 \\
oel07 1 & 123.8 & 3545.2 & 417.1 & 176.4 & 8.2 & 0.1 & 0.6 & 58.6 & 6.3 \\
oel08 1 & 109.6 & 3455.0 & 518.2 & 349.2 & 12.5 & 0.1 & 0.8 & 63.3 & 3.2 \\
oel09 1 & 116.3 & 2392.2 & 483.7 & 281.8 & 13.2 & 0.1 & 0.2 & 36.3 & 7.3 \\
oel010 1 & 121.0 & 1823.3 & 417.1 & 175.8 & 14.5 & 0.1 & 1.4 & 75.5 & 2.9 \\
\hline
\end{tabular}

\section{Teplice Rhyolite}

\begin{tabular}{|c|c|c|c|c|c|c|c|c|c|}
\hline Sample & $\mathbf{L i}$ & $\mathbf{N a}$ & Al & $\mathbf{C a}$ & Ti & $\mathrm{Cr}$ & Mn & $\mathrm{Fe}$ & Ge \\
\hline lug102 1 & 32.4 & 89.9 & 157.4 & 452.9 & 99.2 & 1.8 & 0.8 & 61.9 & 2.2 \\
\hline $\operatorname{lug} 1031$ & 29.5 & 79.6 & 152.7 & 0.1 & 124.1 & 0.1 & 0.9 & 81.0 & 1.3 \\
\hline $\operatorname{lug} 1041$ & 34.8 & 75.4 & 149.3 & 116.1 & 167.4 & 0.1 & 1.3 & 57.1 & 1.9 \\
\hline $\operatorname{lug} 1051$ & 34.0 & 0.1 & 157.6 & 154.0 & 93.1 & 0.1 & 0.5 & 0.1 & 0.4 \\
\hline lug106 1 & 28.0 & 0.1 & 159.2 & 0.1 & 107.8 & 0.1 & 0.1 & 0.1 & 1.5 \\
\hline $\operatorname{lug} 1071$ & 28.6 & 6.4 & 149.9 & 149.0 & 124.3 & 0.1 & 0.9 & 0.1 & 2.4 \\
\hline lug108 1 & 27.1 & 88.3 & 140.6 & 761.0 & 85.1 & 0.1 & 0.1 & 8.4 & 1.6 \\
\hline $\operatorname{lug} 1091$ & 25.7 & 424.1 & 171.2 & 0.1 & 60.1 & 0.1 & 12.6 & 17.4 & 1.2 \\
\hline lug110 1 & 18.3 & 393.1 & 175.1 & 141.3 & 35.3 & 0.1 & 5.4 & 0.1 & 1.3 \\
\hline $\operatorname{lug} 1111$ & 17.5 & 70.7 & 170.4 & 0.1 & 50.7 & 0.1 & 2.0 & 0.1 & 1.4 \\
\hline $\operatorname{lug} 1131$ & 29.3 & 0.1 & 160.2 & 0.1 & 54.2 & 0.1 & 1.2 & 0.1 & 1.0 \\
\hline
\end{tabular}


List of trace element analysis of quartz (LA ICP-MS) (continued)

5 Teplice Rhyolite

\begin{tabular}{|c|c|c|c|c|c|c|c|c|c|}
\hline Sample & $\mathbf{L i}$ & $\mathrm{Na}$ & Al & $\mathbf{C a}$ & Ti & $\mathrm{Cr}$ & Mn & $\mathrm{Fe}$ & Ge \\
\hline $\operatorname{lug} 1141$ & 29.5 & 0.1 & 155.1 & 0.1 & 74.5 & 0.1 & 0.3 & 0.1 & 1.2 \\
\hline $\operatorname{lug} 1151$ & 23.5 & 26.5 & 178.1 & 0.1 & 69.2 & 0.1 & 0.2 & 6.5 & 1.3 \\
\hline $\operatorname{lug} 1161$ & 32.4 & 0.1 & 170.0 & 2180.3 & 136.2 & 0.1 & 0.5 & 0.1 & 0.9 \\
\hline $\operatorname{lug} 1191$ & 27.0 & 121.6 & 161.6 & 133.5 & 98.6 & 1.3 & 3.6 & 9.0 & 0.8 \\
\hline $\operatorname{lug} 1201$ & 30.1 & 113.8 & 163.2 & 363.7 & 89.1 & 0.1 & 1.0 & 21.8 & 0.5 \\
\hline $\operatorname{lug} 2011$ & 31.9 & 354.8 & 123.2 & 453.1 & 149.4 & 0.9 & 3.8 & 14.4 & 2.5 \\
\hline $\operatorname{lug} 2021$ & 34.2 & 0.1 & 134.4 & 260.3 & 124.9 & 0.1 & 0.6 & 2.2 & 2.8 \\
\hline $\operatorname{lug} 2031$ & 35.9 & 0.1 & 159.6 & 0.1 & 176.6 & 0.1 & 1.4 & 13.1 & 1.2 \\
\hline $\operatorname{lug} 2041$ & 37.8 & 144.9 & 134.9 & 0.1 & 80.6 & 0.1 & 11.1 & 8.8 & 0.8 \\
\hline $\operatorname{lug} 2051$ & 26.8 & 104.1 & 129.0 & 0.1 & 60.7 & 2.7 & 16.0 & 5.1 & 0.7 \\
\hline $\operatorname{lug} 2061$ & 33.6 & 194.4 & 122.1 & 491.2 & 70.1 & 2.2 & 1.0 & 4.0 & 0.4 \\
\hline $\operatorname{lug} 2071$ & 33.4 & 0.1 & 129.0 & 0.1 & 55.0 & 0.1 & 0.2 & 2.1 & 1.8 \\
\hline $\operatorname{lug} 2081$ & 31.1 & 0.1 & 125.1 & 70.7 & 60.4 & 0.1 & 0.9 & 1.7 & 3.2 \\
\hline $\operatorname{lug} 2091$ & 39.9 & 0.1 & 177.4 & 0.1 & 107.9 & 0.1 & 2.2 & 7.3 & 0.8 \\
\hline $\operatorname{lug} 2101$ & 30.8 & 0.1 & 161.1 & 290.2 & 144.3 & 0.1 & 1.4 & 6.3 & 1.6 \\
\hline $\operatorname{lug} 2111$ & 34.1 & 0.1 & 147.1 & 0.1 & 165.1 & 0.1 & 0.4 & 10.8 & 1.5 \\
\hline $\operatorname{lug} 2121$ & 38.2 & 0.1 & 142.6 & 0.1 & 169.9 & 0.1 & 0.4 & 7.0 & 0.2 \\
\hline $\operatorname{lug} 2131$ & 28.9 & 0.1 & 155.6 & 0.1 & 199.8 & 4.5 & 0.1 & 22.9 & 0.1 \\
\hline $\operatorname{lug} 3011$ & 30.4 & 0.1 & 133.9 & 0.1 & 87.0 & 0.1 & 1.5 & 31.0 & 0.1 \\
\hline $\operatorname{lug} 3021$ & 32.6 & 0.1 & 144.2 & 179.7 & 86.2 & 0.1 & 4.3 & 26.9 & 0.1 \\
\hline $\operatorname{lug304} 1$ & 35.7 & 94.9 & 144.3 & 475.8 & 103.2 & 3.6 & 1.5 & 29.8 & 1.4 \\
\hline $\operatorname{lug} 3051$ & 33.0 & 0.1 & 140.5 & 162.4 & 120.2 & 0.1 & 0.1 & 25.1 & 1.1 \\
\hline $\operatorname{lug} 3061$ & 30.1 & 0.1 & 146.5 & 240.8 & 146.7 & 2.5 & 0.3 & 19.3 & 1.4 \\
\hline $\operatorname{lug} 3071$ & 32.7 & 0.1 & 144.4 & 0.1 & 102.5 & 0.1 & 0.5 & 10.8 & 0.8 \\
\hline $\operatorname{lug} 3081$ & 26.9 & 0.1 & 134.5 & 0.1 & 51.6 & 0.1 & 0.2 & 17.1 & 1.1 \\
\hline $\operatorname{lug} 3091$ & 22.6 & 0.1 & 117.8 & 224.4 & 63.0 & 0.8 & 0.1 & 20.1 & 1.0 \\
\hline $\operatorname{lug} 3101$ & 24.9 & 0.1 & 115.4 & 105.0 & 57.3 & 0.1 & 0.1 & 16.6 & 0.1 \\
\hline $\operatorname{lug} 3111$ & 22.8 & 0.1 & 119.0 & 185.5 & 47.2 & 0.1 & 0.1 & 5.0 & 0.4 \\
\hline $\operatorname{lug} 3121$ & 25.2 & 0.1 & 112.5 & 196.9 & 58.3 & 0.1 & 0.1 & 3.1 & 0.1 \\
\hline $\operatorname{lug} 5011$ & 26.3 & 1368.4 & 183.6 & 45.6 & 58.4 & 14.9 & 5.0 & 49.2 & 1.0 \\
\hline $\operatorname{lug} 5021$ & 20.1 & 1110.3 & 174.5 & 0.1 & 64.1 & 5.3 & 1.0 & 41.4 & 0.2 \\
\hline $\operatorname{lug} 5031$ & 20.8 & 1128.7 & 170.2 & 0.1 & 57.3 & 6.3 & 2.7 & 53.8 & 1.7 \\
\hline $\operatorname{lug5041}$ & 22.8 & 899.5 & 163.0 & 135.5 & 51.4 & 5.1 & 0.4 & 68.5 & 2.4 \\
\hline $\operatorname{lug} 5051$ & 20.9 & 903.4 & 145.8 & 0.1 & 41.7 & 1.1 & 0.1 & 38.8 & 1.5 \\
\hline $\operatorname{lug506} 1$ & 19.8 & 911.1 & 151.8 & 224.9 & 26.6 & 3.3 & 0.5 & 58.7 & 1.1 \\
\hline $\operatorname{lug5071}$ & 20.9 & 795.1 & 155.8 & 29.3 & 15.4 & 3.0 & 0.2 & 24.8 & 1.5 \\
\hline $\operatorname{lug508} 1$ & 20.7 & 835.5 & 149.3 & 26.3 & 36.2 & 5.8 & 0.1 & 21.1 & 2.1 \\
\hline $\operatorname{lug5091}$ & 19.2 & 918.8 & 141.2 & 41.4 & 44.6 & 3.4 & 0.2 & 24.2 & 2.4 \\
\hline $\operatorname{lug5101}$ & 16.8 & 1059.0 & 141.4 & 0.1 & 42.4 & 7.1 & 1.8 & 34.0 & 0.7 \\
\hline $\operatorname{lug} 5111$ & 18.7 & 999.0 & 150.1 & 0.1 & 59.2 & 4.3 & 0.1 & 13.7 & 1.5 \\
\hline $\operatorname{lug} 5121$ & 17.3 & 878.0 & 151.7 & 0.1 & 40.3 & 6.2 & 0.1 & 18.4 & 2.0 \\
\hline $\operatorname{lug5} 5131$ & 17.8 & 1034.4 & 160.2 & 0.1 & 20.3 & 8.0 & 0.1 & 12.1 & 0.9 \\
\hline $\operatorname{lug5141}$ & 16.0 & 1031.9 & 157.1 & 0.1 & 46.8 & 10.8 & 0.1 & 22.9 & 1.9 \\
\hline $\operatorname{lug} 5151$ & 14.7 & 1223.0 & 158.8 & 271.4 & 39.6 & 5.8 & 0.2 & 55.8 & 1.5 \\
\hline $\operatorname{lug5161}$ & 16.4 & 1202.4 & 156.4 & 0.1 & 46.7 & 3.8 & 0.1 & 48.5 & 2.1 \\
\hline
\end{tabular}

6 Schellerhau Granite

\begin{tabular}{|c|c|c|c|c|c|c|c|c|c|}
\hline Sample & $\mathbf{L i}$ & $\mathbf{N a}$ & Al & Ca & Ti & $\mathrm{Cr}$ & Mn & $\mathbf{F e}$ & Ge \\
\hline sh69101 & 29.2 & 136.3 & 300.7 & 3156.9 & 26.1 & 17.5 & & 23.0 & 5.8 \\
\hline sh69102 & 27.3 & 19.0 & 119.0 & 3043.8 & 100.7 & 9.8 & & 7.1 & 0.1 \\
\hline sh69103 & 24.5 & 32.2 & 87.0 & 3434.3 & 83.1 & 1.7 & & 2.3 & 7.5 \\
\hline sh69105 & 20.2 & 13.3 & 114.6 & 2823.5 & 24.9 & 5.7 & & 0.1 & 2.1 \\
\hline sh69106 & 30.6 & 282.0 & 124.2 & 3345.0 & 25.6 & 11.3 & & 0.1 & 4.1 \\
\hline sh69107 & 20.4 & 64.9 & 96.4 & 2864.5 & 10.5 & 21.9 & & 0.1 & 1.2 \\
\hline sh69108 & 29.0 & 71.9 & 140.5 & 2709.6 & 86.9 & 13.3 & & 2.2 & 0.1 \\
\hline sh69109 & 27.0 & 1.6 & 88.5 & 2706.3 & 102.0 & 4.9 & & 0.1 & 7.8 \\
\hline sh69110 & 44.8 & 44.1 & 444.0 & 2157.2 & 123.7 & 0.1 & & 12.5 & 0.1 \\
\hline $\operatorname{sh} 69111$ & 43.6 & 110.0 & 454.1 & 2174.7 & 100.1 & 4.7 & & 0.1 & 0.7 \\
\hline sh69112 & 38.7 & 14.9 & 124.5 & 3641.5 & 76.0 & 0.1 & & 0.1 & 0.1 \\
\hline sh69113 & 15.2 & 55.8 & 183.0 & 3353.2 & 30.8 & 11.9 & & 16.0 & 0.6 \\
\hline
\end{tabular}


List of trace element analysis of quartz (LA ICP-MS) (continued)

6 Schellerhau Granite

\begin{tabular}{|c|c|c|c|c|c|c|c|c|c|}
\hline Sample & $\mathbf{L i}$ & $\mathbf{N a}$ & Al & $\mathbf{C a}$ & $\mathbf{T i}$ & $\mathrm{Cr}$ & Mn & $\mathrm{Fe}$ & Ge \\
\hline sh69201 & 35.1 & 1.8 & 108.8 & 3047.9 & 73.0 & 0.1 & & 8.8 & 1.5 \\
\hline $\operatorname{sh} 69202$ & 33.2 & 2.3 & 116.8 & 2786.4 & 83.6 & 0.1 & & 63.1 & 0.1 \\
\hline sh69204 & 27.7 & 0.1 & 138.5 & 2940.4 & 57.8 & 0.8 & & 0.1 & 2.9 \\
\hline sh69205 & 35.3 & 0.1 & 110.7 & 3273.3 & 73.8 & 0.1 & & 0.1 & 8.6 \\
\hline sh69206 & 40.8 & 0.1 & 99.4 & 3757.0 & 150.3 & 0.1 & & 32.2 & 3.3 \\
\hline $\operatorname{sh} 69207$ & 24.5 & 0.1 & 108.4 & 3706.7 & 9.9 & 0.1 & & 0.1 & 0.1 \\
\hline sh69209 & 37.6 & 98.7 & 117.7 & 3254.6 & 22.5 & 0.1 & & 26.4 & 1.2 \\
\hline $\operatorname{sh} 69210$ & 27.1 & 0.1 & 101.4 & 3442.2 & 45.2 & 0.3 & & 0.1 & 0.1 \\
\hline sh69211 & 21.9 & 110.6 & 124.9 & 2523.5 & 62.9 & 0.1 & & 0.1 & 0.1 \\
\hline $\operatorname{sh} 69212$ & 20.2 & 0.1 & 175.3 & 2696.9 & 34.3 & 0.1 & & 68.3 & 0.1 \\
\hline $\operatorname{sh} 69401$ & 25.0 & & 423.7 & 0.1 & 20.9 & 24.7 & & 130.9 & 0.9 \\
\hline sh69402 & 25.3 & & 216.2 & 1958.7 & 15.4 & 12.9 & & 110.6 & 2.4 \\
\hline sh69403 & 26.5 & & 92.2 & 0.1 & 13.8 & 14.3 & & 136.2 & 0.1 \\
\hline $\operatorname{sh} 69404$ & 29.9 & & 104.8 & 0.1 & 21.1 & 11.9 & & 20.5 & 0.1 \\
\hline sh69405 & 33.6 & & 149.4 & 0.1 & 20.1 & 14.3 & & 11.1 & 0.1 \\
\hline sh69406 & 34.5 & & 124.0 & 0.1 & 20.9 & 15.4 & & 34.4 & 28.3 \\
\hline sh69407 & 24.6 & & 106.1 & 2230.8 & 16.1 & 16.3 & & 73.8 & 1.4 \\
\hline $\operatorname{sh} 69408$ & 32.2 & & 85.2 & 1550.0 & 18.1 & 10.8 & & 188.7 & 7.7 \\
\hline sh69409 & 17.5 & & 106.2 & 455.6 & 16.7 & 19.0 & & 130.9 & 0.1 \\
\hline $\operatorname{sh} 69410$ & 23.0 & & 79.0 & 415.1 & 20.3 & 14.6 & & 130.5 & 0.1 \\
\hline sh69411 & 26.0 & & 263.7 & 6309.7 & 18.2 & 15.5 & & 104.8 & 0.1 \\
\hline $\operatorname{sh} 70101$ & 21.6 & & 261.3 & 0.1 & 16.6 & 15.8 & & 81.7 & 51.7 \\
\hline $\operatorname{sh} 70102$ & 31.1 & & 257.0 & 494.1 & 16.3 & 12.8 & & 19.9 & 28.3 \\
\hline $\operatorname{sh} 70103$ & 40.2 & & 258.8 & 1761.7 & 15.9 & 13.7 & & 0.1 & 15.3 \\
\hline sh70104 & 35.7 & & 269.4 & 2293.9 & 17.1 & 15.0 & & 18.9 & 0.1 \\
\hline $\operatorname{sh} 70105$ & 36.3 & & 283.9 & 0.1 & 18.0 & 13.4 & & 12.9 & 9.3 \\
\hline $\operatorname{sh} 70106$ & 32.5 & & 229.0 & 1094.8 & 15.6 & 16.5 & & 19.4 & 19.4 \\
\hline $\operatorname{sh} 70107$ & 27.8 & & 271.5 & 0.1 & 18.1 & 14.4 & & 15.9 & 0.1 \\
\hline $\operatorname{sh} 70108$ & 39.3 & & 262.5 & 0.1 & 18.9 & 14.2 & & 55.4 & 0.1 \\
\hline $\operatorname{sh} 70109$ & 23.2 & & 248.0 & 0.1 & 12.9 & 11.8 & & 83.8 & 0.8 \\
\hline $\operatorname{sh} 70110$ & 22.0 & & 166.1 & 698.1 & 23.1 & 14.2 & & 60.7 & 20.6 \\
\hline $\operatorname{sh} 70201$ & 32.0 & & 116.1 & 1418.6 & 18.7 & 11.3 & & 102.0 & 22.6 \\
\hline $\operatorname{sh} 70202$ & 30.2 & & 94.6 & 0.1 & 15.0 & 11.8 & & 99.6 & 37.5 \\
\hline sh70203 & 26.5 & & 111.0 & 1205.4 & 13.1 & 16.4 & & 139.8 & 6.0 \\
\hline $\operatorname{sh} 70204$ & 23.7 & & 104.3 & 516.9 & 17.4 & 17.8 & & 151.6 & 30.6 \\
\hline $\operatorname{sh} 70205$ & 16.1 & & 96.4 & 0.1 & 14.2 & 14.0 & & 208.4 & 2.8 \\
\hline $\operatorname{sh} 70206$ & 19.3 & & 126.6 & 1450.1 & 19.4 & 17.8 & & 86.0 & 0.1 \\
\hline $\operatorname{sh} 70207$ & 29.2 & & 135.6 & 526.8 & 12.4 & 14.3 & & 138.1 & 49.0 \\
\hline $\operatorname{sh} 70209$ & 29.3 & & 162.6 & 1005.9 & 22.3 & 15.2 & & 56.3 & 29.5 \\
\hline $\operatorname{sh} 70210$ & 33.7 & & 138.3 & 293.0 & 21.8 & 14.7 & & 30.4 & 0.1 \\
\hline $\operatorname{sh} 70211$ & 22.8 & & 122.3 & 541.2 & 19.3 & 18.8 & & 4.5 & 48.5 \\
\hline $\operatorname{sh} 70212$ & 19.8 & & 113.7 & 1589.9 & 14.3 & 11.9 & & 218.2 & 28.5 \\
\hline sh70213 & 17.5 & & 91.9 & 647.8 & 13.9 & 13.5 & & 294.0 & 0.1 \\
\hline $\operatorname{sh} 70214$ & 13.8 & & 110.7 & 468.4 & 18.4 & 18.2 & & 113.0 & 18.6 \\
\hline $\operatorname{sh} 70215$ & 18.1 & & 108.5 & 167.3 & 19.1 & 12.6 & & 225.6 & 28.1 \\
\hline $\operatorname{sh} 70303$ & 27.6 & & 261.5 & 0.1 & 11.9 & 13.8 & & 266.7 & 0.1 \\
\hline $\operatorname{sh} 70304$ & 38.8 & & 189.4 & 1795.5 & 12.4 & 10.5 & & 11.1 & 0.1 \\
\hline $\operatorname{sh} 70305$ & 39.3 & & 242.9 & 510.5 & 21.7 & 17.9 & & 26.1 & 0.1 \\
\hline $\operatorname{sh} 70306$ & 28.2 & & 176.6 & 737.0 & 18.1 & 12.8 & & 58.0 & 48.7 \\
\hline $\operatorname{sh} 70307$ & 33.2 & & 206.3 & 732.8 & 16.9 & 12.1 & & 36.9 & 0.1 \\
\hline sh70308 & 28.8 & & 267.7 & 1266.7 & 14.4 & 16.9 & & 41.1 & 7.3 \\
\hline sh70309 & 27.7 & & 298.9 & 0.1 & 14.7 & 15.2 & & 42.3 & 31.2 \\
\hline $\operatorname{sh} 70310$ & 24.9 & & 158.8 & 456.5 & 14.6 & 13.1 & & 31.2 & 0.1 \\
\hline $\operatorname{sh} 70311$ & 33.8 & & 114.3 & 2930.2 & 19.9 & 18.3 & & 33.8 & 0.1 \\
\hline $\operatorname{sh} 70312$ & 11.9 & & 125.1 & 0.1 & 17.2 & 16.1 & & 185.7 & 0.1 \\
\hline $\operatorname{sh} 70313$ & 21.6 & & 235.8 & 527.7 & 21.0 & 15.7 & & 68.8 & 10.7 \\
\hline $\operatorname{sh} 70314$ & 25.3 & & 192.4 & 675.2 & 12.9 & 19.7 & & 203.8 & 49.0 \\
\hline $\operatorname{sh} 70315$ & 28.0 & & 176.4 & 1028.7 & 19.2 & 14.4 & & 67.3 & 0.1 \\
\hline $\operatorname{sh} 70316$ & 22.3 & & 239.6 & 33.0 & 13.6 & 13.4 & & 75.1 & 17.8 \\
\hline $\operatorname{sh} 72101$ & 23.7 & & 119.6 & 0.1 & 13.7 & 15.6 & & 40.6 & 0.1 \\
\hline $\operatorname{sh} 72102$ & 20.3 & & 108.0 & 43.8 & 13.5 & 10.0 & & 323.0 & 0.1 \\
\hline $\operatorname{sh} 72103$ & 25.8 & & 118.4 & 0.1 & 15.0 & 13.9 & & 112.5 & 0.1 \\
\hline
\end{tabular}


List of trace element analysis of quartz (LA ICP-MS) (continued)

\section{Schellerhau Granite}

\begin{tabular}{|c|c|c|c|c|c|c|c|c|c|}
\hline Sample & $\mathbf{L i}$ & $\mathbf{N a}$ & Al & $\mathbf{C a}$ & Ti & $\mathrm{Cr}$ & Mn & $\mathrm{Fe}$ & Ge \\
\hline $\operatorname{sh} 72104$ & 29.8 & & 118.8 & 527.3 & 17.9 & 13.0 & & 11.9 & 0.1 \\
\hline $\operatorname{sh} 72105$ & 24.3 & & 141.6 & 943.7 & 18.8 & 15.1 & & 61.1 & 0.1 \\
\hline sh72106 & 26.0 & & 116.0 & 2011.4 & 17.3 & 11.4 & & 58.9 & 0.1 \\
\hline sh72107 & 29.9 & & 101.7 & 204.1 & 15.3 & 17.4 & & 81.9 & 0.1 \\
\hline $\operatorname{sh} 72108$ & 25.7 & & 179.2 & 0.1 & 16.6 & 20.1 & & 168.1 & 0.1 \\
\hline $\operatorname{sh} 72109$ & 32.5 & & 123.2 & 636.8 & 16.9 & 13.8 & & 90.5 & 6.8 \\
\hline $\operatorname{sh} 72110$ & 16.2 & & 110.2 & 1175.5 & 18.8 & 13.2 & & 120.2 & 0.1 \\
\hline sh72111 & 16.7 & & 109.4 & 800.6 & 18.5 & 12.6 & & 139.7 & 0.1 \\
\hline $\operatorname{sh} 72112$ & 25.8 & & 98.1 & 238.1 & 15.8 & 15.1 & & 78.3 & 0.1 \\
\hline $\operatorname{sh} 72113$ & 29.5 & & 103.1 & 0.1 & 11.8 & 13.3 & & 120.7 & 0.1 \\
\hline $\operatorname{sh} 72114$ & 25.4 & & 98.3 & 456.9 & 16.4 & 13.1 & & 140.5 & 0.1 \\
\hline $\operatorname{sh} 72115$ & 27.8 & & 91.0 & 218.0 & 16.3 & 12.6 & & 146.1 & 0.1 \\
\hline $\operatorname{sh} 72116$ & 28.9 & & 133.5 & 782.9 & 16.9 & 13.5 & & 146.5 & 0.1 \\
\hline $\operatorname{sh} 72117$ & 24.0 & & 114.6 & 769.8 & 17.0 & 15.7 & & 153.9 & 3.5 \\
\hline sh72201 & 25.7 & & 185.1 & 1096.1 & 15.4 & 16.6 & & 10.3 & 3.4 \\
\hline $\operatorname{sh} 72202$ & 30.9 & & 136.1 & 3925.0 & 19.7 & 9.9 & & 41.7 & 10.2 \\
\hline $\operatorname{sh} 72203$ & 28.3 & & 99.0 & 115.8 & 14.8 & 13.1 & & 148.6 & 17.0 \\
\hline sh72204 & 30.2 & & 125.5 & 1238.7 & 13.8 & 13.5 & & 136.1 & 5.2 \\
\hline $\operatorname{sh} 72205$ & 27.9 & & 83.5 & 344.5 & 12.6 & 15.3 & & 47.9 & 0.1 \\
\hline $\operatorname{sh} 72206$ & 16.6 & & 66.3 & 736.8 & 15.0 & 13.2 & & 55.4 & 7.9 \\
\hline sh72208 & 20.4 & & 141.2 & 0.1 & 17.6 & 16.0 & & 11.4 & 0.1 \\
\hline $\operatorname{sh} 72209$ & 22.4 & & 120.6 & 1278.3 & 16.9 & 12.6 & & 5.6 & 44.6 \\
\hline $\operatorname{sh} 72210$ & 23.7 & & 192.7 & 5354.0 & 15.1 & 14.5 & & 9.7 & 39.1 \\
\hline $\operatorname{sh} 72211$ & 24.5 & & 200.3 & 407.2 & 14.2 & 14.6 & & 7.9 & 12.2 \\
\hline sh72212 & 23.3 & & 100.3 & 138.7 & 13.9 & 13.5 & & 34.5 & 0.1 \\
\hline $\operatorname{sh} 72213$ & 16.2 & & 98.6 & 1441.2 & 15.1 & 6.5 & & 219.4 & 61.3 \\
\hline $\operatorname{sh} 72214$ & 17.7 & & 109.5 & 1537.8 & 16.1 & 10.8 & & 215.9 & 12.6 \\
\hline sh72302 & 28.1 & & 114.3 & 2848.6 & 14.1 & 14.4 & & 24.2 & 0.1 \\
\hline $\operatorname{sh} 72303$ & 27.9 & & 85.5 & 4205.8 & 17.8 & 11.6 & & 115.1 & 0.1 \\
\hline sh72304 & 48.7 & & 259.7 & 5011.6 & 7.0 & 13.2 & & 27.8 & 92.6 \\
\hline $\operatorname{sh} 72305$ & 29.7 & & 144.1 & 0.1 & 18.8 & 16.9 & & 23.0 & 0.1 \\
\hline $\operatorname{sh} 72306$ & 33.7 & & 112.8 & 6278.7 & 13.2 & 11.5 & & 26.1 & 0.1 \\
\hline $\operatorname{sh} 72307$ & 27.2 & & 65.3 & 2568.9 & 12.2 & 12.4 & & 0.1 & 0.1 \\
\hline sh72308 & 27.1 & & 93.1 & 1448.1 & 18.3 & 11.0 & & 0.1 & 0.1 \\
\hline $\operatorname{sh} 72309$ & 25.4 & & 42.5 & 0.1 & 13.8 & 13.3 & & 29.9 & 1.9 \\
\hline $\operatorname{sh} 72310$ & 21.4 & & 68.8 & 3507.5 & 11.6 & 7.5 & & 65.4 & 0.1 \\
\hline $\operatorname{sh} 72311$ & 24.4 & & 103.8 & 1566.7 & 11.8 & 6.4 & & 0.1 & 0.1 \\
\hline $\operatorname{sh} 72312$ & 29.8 & & 103.7 & 1693.1 & 15.9 & 12.9 & & 20.7 & 0.1 \\
\hline $\operatorname{sh} 72315$ & 31.1 & & 51.4 & 5600.9 & 21.9 & 11.9 & & 97.0 & 2.5 \\
\hline $\operatorname{sh} 72316$ & 25.7 & & 86.3 & 4696.6 & 17.0 & 14.2 & & 90.0 & 0.9 \\
\hline
\end{tabular}

7 Eibenstock Granite

\begin{tabular}{crllrrrrrr}
\hline Sample & \multicolumn{1}{c}{$\mathbf{L i}$} & \multicolumn{1}{c}{$\mathbf{N a}$} & $\mathbf{A l}$ & $\mathbf{C a}$ & $\mathbf{T i}$ & $\mathbf{C r}$ & $\mathbf{M n}$ & $\mathbf{F e}$ & $\mathbf{G e}$ \\
\hline eiben01 1 & 25.98 & 4654.1 & 696.6 & 66.3 & 54.0 & 1.7 & 5.2 & 59.9 & 2.1 \\
eiben02 1 & 33.66 & 3454.4 & 625.3 & 83.1 & 48.3 & 0.1 & 5.5 & 30.2 & 2.3 \\
eiben03 1 & 30.36 & 3815.6 & 701.7 & 0.1 & 52.6 & 0.9 & 5.1 & 50.1 & 1.9 \\
eiben04 1 & 32.82 & 1974.8 & 726.0 & 89.0 & 67.4 & 2.1 & 3.8 & 32.4 & 1.2 \\
eiben05 1 & 35.76 & 1128.3 & 627.0 & 0.1 & 66.2 & 3.7 & 0.1 & 24.6 & 2.2 \\
eiben06 1 & 30.3 & 3954.3 & 714.2 & 0.1 & 55.5 & 0.7 & 5.6 & 43.7 & 1.8 \\
eiben07 1 & 26.76 & 2596.3 & 635.2 & 0.1 & 70.2 & 2.3 & 6.3 & 58.5 & 2.7 \\
eiben08 1 & 34.02 & 4294.4 & 734.2 & 112.1 & 65.4 & 3.1 & 5.3 & 23.7 & 1.3 \\
eiben09 1 & 35.04 & 3867.4 & 678.5 & 67.4 & 68.4 & 2.3 & 5.7 & 51.7 & 2.1 \\
eiben10 1 & 33 & 3444.3 & 658.4 & 0.1 & 53.2 & 2.1 & 3.9 & 32.1 & 1.9 \\
\hline
\end{tabular}


List of trace element analysis of quartz (LA ICP-MS) (continued)

\section{Aue Granite}

\begin{tabular}{cccccccccr}
\hline Sample & Li & Na & Al & Ca & Ti & Cr & Mn & Fe & Ge \\
\hline auer101 1 & 49.2 & 491.4 & 231.0 & 0.0 & 46.9 & 0.0 & 3.5 & 33.5 & 0.0 \\
auer102 1 & 48.8 & 403.4 & 222.7 & 0.0 & 75.1 & 0.5 & 1.7 & 24.2 & 0.1 \\
auer103 1 & 33.4 & 386.4 & 281.4 & 0.0 & 62.2 & 0.0 & 4.2 & 52.2 & 0.1 \\
auer104 1 & 31.6 & 578.9 & 152.4 & 0.0 & 71.6 & 0.0 & 4.5 & 49.3 & 2.0 \\
auer105 1 & 28.7 & 427.1 & 207.4 & 0.0 & 80.2 & 0.4 & 2.4 & 27.3 & 0.4 \\
auer106 1 & 40.8 & 552.6 & 247.7 & 0.0 & 53.0 & 0.0 & 5.1 & 54.8 & 1.4 \\
auer107 1 & 50.2 & 545.5 & 276.5 & 0.0 & 78.1 & 3.5 & 2.7 & 38.4 & 0.6 \\
auer108 1 & 38.4 & 511.8 & 180.8 & 0.0 & 59.7 & 0.0 & 2.5 & 24.9 & 1.4 \\
auer109 1 & 27.2 & 308.9 & 153.9 & 0.0 & 44.7 & 3.5 & 1.1 & 17.8 & 1.1 \\
auer110 1 & 33.1 & 643.9 & 162.8 & 0.0 & 67.6 & 3.8 & 3.1 & 26.5 & 0.5 \\
auer111 1 & 43.2 & 466.8 & 169.8 & 0.0 & 80.2 & 0.0 & 3.1 & 34.6 & 0.2 \\
auer112 1 & 52.0 & 379.3 & 211.8 & 0.0 & 63.2 & 2.4 & 4.5 & 48.5 & 0.7 \\
\hline
\end{tabular}

10 Wachtelberg Rhyolite

\begin{tabular}{|c|c|c|c|c|c|c|c|c|c|}
\hline Sample & $\overline{\mathbf{L i}}$ & $\mathrm{Na}$ & Al & $\overline{\mathrm{Ca}}$ & Ti & $\mathrm{Cr}$ & Mn & $\mathrm{Fe}$ & $\overline{\text { Ge }}$ \\
\hline wacht1011 & 25.9 & 922.8 & 164.6 & 0.1 & 90.7 & 0.1 & 4.9 & 40.2 & 0.2 \\
\hline wacht102 1 & 25.0 & 520.6 & 177.5 & 0.1 & 69.4 & 0.1 & 0.1 & 21.8 & 1.4 \\
\hline wacht1031 & 20.4 & 387.6 & 154.5 & 0.1 & 50.1 & 0.1 & 0.1 & 23.1 & 0.5 \\
\hline wacht104 1 & 21.2 & 622.5 & 150.4 & 89.9 & 55.2 & 0.1 & 5.0 & 42.4 & 1.8 \\
\hline wacht105 1 & 21.3 & 458.8 & 157.0 & 161.2 & 41.1 & 0.1 & 1.4 & 28.5 & 0.1 \\
\hline wacht108 1 & 22.6 & 607.5 & 158.8 & 31.3 & 38.2 & 0.1 & 0.5 & 23.2 & 0.3 \\
\hline wacht109 1 & 21.0 & 796.1 & 152.2 & 6.4 & 28.4 & 3.2 & 0.1 & 37.6 & 1.5 \\
\hline wacht110 1 & 20.5 & 373.3 & 163.2 & 53.9 & 72.0 & 1.2 & 3.7 & 45.8 & 1.5 \\
\hline wacht111 1 & 20.9 & 374.3 & 175.8 & 27.9 & 58.6 & 0.1 & 0.1 & 71.5 & 1.4 \\
\hline wacht112 1 & 19.6 & 293.1 & 160.1 & 0.1 & 74.5 & 0.1 & 0.1 & 39.2 & 1.7 \\
\hline wacht 4021 & 24.5 & 75.1 & 147.9 & 41.3 & 40.8 & 0.1 & 0.4 & 23.3 & 1.5 \\
\hline wacht4031 & 24.4 & 78.6 & 127.6 & 332.9 & 24.1 & 5.3 & 0.1 & 28.1 & 1.4 \\
\hline wacht404 1 & 25.9 & 111.6 & 132.6 & 159.3 & 12.7 & 9.2 & 0.5 & 21.3 & 1.5 \\
\hline wacht405 1 & 29.3 & 28.3 & 148.1 & 173.6 & 9.1 & 1.1 & 0.1 & 11.6 & 0.7 \\
\hline wacht406 1 & 24.7 & 162.0 & 135.9 & 545.8 & 5.9 & 4.9 & 0.1 & 13.2 & 1.3 \\
\hline wacht407 1 & 22.1 & 10.2 & 134.4 & 107.4 & 11.4 & 1.9 & 0.1 & 24.9 & 0.8 \\
\hline wacht 4081 & 21.2 & 305.8 & 133.2 & 0.1 & 25.5 & 3.0 & 7.2 & 15.3 & 1.2 \\
\hline wacht409 1 & 22.5 & 114.6 & 134.3 & 0.1 & 40.7 & 0.1 & 1.3 & 18.8 & 2.5 \\
\hline wacht 4101 & 24.8 & 163.9 & 140.3 & 0.1 & 98.4 & 0.1 & 0.1 & 21.0 & 1.6 \\
\hline wacht411 1 & 22.0 & 117.3 & 144.7 & 0.1 & 98.4 & 8.4 & 0.1 & 25.1 & 0.7 \\
\hline wacht501 1 & 26.4 & 231.0 & 186.1 & 38.0 & 90.7 & 0.1 & 7.3 & 63.4 & 2.3 \\
\hline wacht502 1 & 28.6 & 526.8 & 141.7 & 210.4 & 108.0 & 3.2 & 0.5 & 58.5 & 0.7 \\
\hline wacht503 1 & 22.7 & 554.3 & 119.9 & 271.5 & 14.2 & 8.9 & 0.8 & 26.0 & 0.1 \\
\hline wacht504 1 & 22.2 & 464.3 & 124.0 & 0.1 & 23.5 & 0.1 & 0.1 & 22.8 & 2.3 \\
\hline wacht505 1 & 21.6 & 290.6 & 119.2 & 116.8 & 22.3 & 5.7 & 0.3 & 26.1 & 0.8 \\
\hline wacht506 1 & 22.1 & 397.7 & 129.8 & 0.1 & 25.2 & 0.1 & 0.2 & 46.9 & 2.7 \\
\hline wacht507 1 & 21.5 & 418.8 & 141.6 & 0.1 & 9.2 & 7.6 & 0.1 & 34.9 & 0.8 \\
\hline wacht508 1 & 22.4 & 365.4 & 140.1 & 0.1 & 80.4 & 3.9 & 0.1 & 32.9 & 1.3 \\
\hline wacht201 1 & 23.4 & 658.5 & 145.4 & 0.1 & 99.0 & 9.5 & 4.2 & 71.8 & 0.5 \\
\hline wacht 2021 & 32.0 & 82.8 & 149.7 & 427.3 & 132.1 & 1.8 & 4.0 & 49.0 & 0.9 \\
\hline wacht203 1 & 27.4 & 0.1 & 137.8 & 0.1 & 108.0 & 6.7 & 1.5 & 40.6 & 1.9 \\
\hline wacht204 1 & 23.8 & 0.1 & 116.4 & 0.1 & 58.0 & 7.8 & 0.3 & 20.7 & 1.3 \\
\hline wacht205 1 & 26.0 & 0.1 & 114.8 & 90.1 & 16.6 & 3.2 & 0.3 & 0.1 & 0.1 \\
\hline wacht206 1 & 23.0 & 0.1 & 109.5 & 0.1 & 30.7 & 2.8 & 0.2 & 4.4 & 2.9 \\
\hline wacht207 1 & 27.8 & 0.1 & 123.2 & 0.1 & 83.5 & 5.3 & 0.5 & 8.2 & 0.1 \\
\hline wacht 2081 & 24.6 & 0.1 & 118.0 & 0.1 & 32.3 & 0.1 & 0.1 & 16.8 & 1.9 \\
\hline wacht209 1 & 27.5 & 0.1 & 114.5 & 0.1 & 21.9 & 4.4 & 5.3 & 21.8 & 1.6 \\
\hline wacht 2111 & 22.3 & 121.3 & 109.2 & 0.1 & 20.2 & 0.1 & 2.3 & 1.0 & 0.6 \\
\hline wacht 2121 & 37.1 & 388.8 & 112.8 & 0.1 & 32.1 & 0.1 & 4.5 & 0.1 & 0.8 \\
\hline wacht213 1 & 22.6 & 328.2 & 120.6 & 891.5 & 23.1 & 1.6 & 4.1 & 25.6 & 2.0 \\
\hline wacht214 1 & 36.0 & 219.4 & 135.1 & 0.1 & 108.4 & 0.7 & 3.9 & 40.9 & 1.1 \\
\hline wacht 2151 & 46.8 & 235.4 & 153.8 & 0.1 & 93.9 & 0.1 & 1.5 & 84.8 & 0.1 \\
\hline wacht302 1 & 27.3 & 0.1 & 141.3 & 0.1 & 113.5 & 0.1 & 17.0 & 68.5 & 2.0 \\
\hline wacht3031 & 26.7 & 116.9 & 155.1 & 0.1 & 78.0 & 0.1 & 14.2 & 76.9 & 1.1 \\
\hline
\end{tabular}


List of trace element analysis of quartz (LA ICP-MS) (continued)

10 Wachtelberg Rhyolite

\begin{tabular}{ccrlrrrrrr}
\hline Sample & \multicolumn{1}{c}{$\mathbf{L i}$} & \multicolumn{1}{c}{ Na } & \multicolumn{1}{c}{ Al } & \multicolumn{1}{c}{ Ca } & \multicolumn{1}{c}{ Ti } & Cr & \multicolumn{1}{c}{ Mn } & \multicolumn{1}{c}{ Fe } & Ge \\
\hline wacht304 1 & 22.2 & 197.2 & 161.5 & 582.7 & 57.9 & 3.9 & 28.0 & 71.1 & 0.7 \\
wacht305 1 & 22.5 & 0.1 & 123.2 & 0.1 & 39.4 & 0.1 & 5.8 & 54.1 & 0.8 \\
wacht306 1 & 28.4 & 0.1 & 146.5 & 591.5 & 110.7 & 2.6 & 1.0 & 51.6 & 1.4 \\
wacht307 1 & 24.5 & 0.1 & 126.4 & 416.9 & 78.1 & 2.5 & 0.1 & 12.8 & 1.0 \\
wacht308 1 & 27.3 & 0.1 & 131.8 & 0.1 & 93.4 & 2.4 & 0.5 & 10.1 & 0.2 \\
wacht309 1 & 23.8 & 30.7 & 172.2 & 0.1 & 73.1 & 0.1 & 0.1 & 13.0 & 2.9 \\
wacht310 1 & 23.8 & 29.7 & 154.5 & 0.1 & 27.2 & 0.1 & 0.1 & 15.1 & 0.7 \\
wacht311 1 & 24.0 & 0.1 & 121.6 & 0.1 & 44.8 & 0.1 & 0.6 & 21.8 & 0.4 \\
wacht312 1 & 29.3 & 0.1 & 137.9 & 0.1 & 122.3 & 0.1 & 0.1 & 30.1 & 0.8 \\
\hline
\end{tabular}

11 Beucha Rhyolite

\begin{tabular}{rrrrrrrrrr}
\hline Sample & $\mathbf{L i}$ & \multicolumn{1}{c}{$\mathbf{N a}$} & \multicolumn{1}{l}{$\mathbf{A l}$} & $\mathbf{C a}$ & $\mathbf{T}$ & $\mathbf{C r}$ & $\mathbf{M n}$ & $\mathbf{F e}$ & $\mathbf{G e}$ \\
\hline beuch101 & 21.78 & 1486.3 & 197.5 & 0.1 & 79.0 & 15.7 & 4.2 & 32.1 & 1.5 \\
beuch102 & 18.54 & 1178.9 & 195.0 & 258.4 & 71.1 & 10.9 & 0.1 & 45.1 & 2.0 \\
beuch103 & 18.18 & 759.2 & 190.0 & 63.2 & 77.4 & 7.7 & 5.1 & 31.8 & 2.0 \\
beuch104 & 18.66 & 1017.8 & 186.2 & 0.1 & 73.2 & 10.3 & 0.1 & 29.2 & 1.3 \\
beuch105 & 19.08 & 1081.5 & 211.8 & 0.1 & 112.5 & 4.8 & 0.1 & 54.8 & 1.2 \\
beuch201 & 22.38 & 948.9 & 186.2 & 164.1 & 95.7 & 5.8 & 0.8 & 39.9 & 2.2 \\
beuch202 & 16.44 & 958.5 & 179.7 & 121.0 & 80.2 & 2.2 & 0.9 & 42.5 & 1.9 \\
beuch203 & 19.74 & 800.1 & 178.1 & 260.8 & 85.6 & 7.9 & 0.3 & 25.6 & 0.5 \\
beuch204 & 18.84 & 803.9 & 182.7 & 151.1 & 82.0 & 8.0 & 0.1 & 17.6 & 1.3 \\
beuch205 & 19.2 & 971.4 & 178.0 & 0.1 & 83.4 & 8.4 & 0.1 & 29.1 & 1.5 \\
beuch206 & 19.44 & 727.3 & 188.4 & 0.1 & 91.4 & 1.7 & 0.1 & 58.0 & 1.0 \\
\hline
\end{tabular}

12 Flossenbürg Granite

\begin{tabular}{cccrrrrrrr}
\hline Sample & \multicolumn{1}{c}{$\mathbf{L i}$} & Na & \multicolumn{1}{c}{ Al } & \multicolumn{1}{c}{ Ca } & Ti & Cr & Mn & \multicolumn{1}{c}{ Fe } & Ge \\
\hline floss01 1 & 11.3 & 833.3 & 49.4 & 0.1 & 13.5 & 0.1 & 0.1 & 13.1 & 1.9 \\
floss02 1 & 12.5 & 279.7 & 71.3 & 147.2 & 36.4 & 0.2 & 0.1 & 4.9 & 2.6 \\
floss03 1 & 12.7 & 357.1 & 84.1 & 257.2 & 34.8 & 0.1 & 0.1 & 7.5 & 2.2 \\
floss04 1 & 23.1 & 512.9 & 145.9 & 0.1 & 37.5 & 0.4 & 0.1 & 0.1 & 0.3 \\
floss05 1 & 16.9 & 498.5 & 116.9 & 110.4 & 33.1 & 0.1 & 0.1 & 20.9 & 1.9 \\
floss06 1 & 17.9 & 372.2 & 138.1 & 211.2 & 37.0 & 0.1 & 0.1 & 0.1 & 2.0 \\
floss07 1 & 12.0 & 467.2 & 68.1 & 16.6 & 28.5 & 1.1 & 0.1 & 16.7 & 1.5 \\
floss08 1 & 12.3 & 456.3 & 85.3 & 201.4 & 34.2 & 0.5 & 0.1 & 8.3 & 1.9 \\
floss09 1 & 16.4 & 546.4 & 72.1 & 0.1 & 32.1 & 0.1 & 0.1 & 0.1 & 2.2 \\
floss10 1 & 12.5 & 438.4 & 110.2 & 174.2 & 35.4 & 0.1 & 0.1 & 12.1 & 1.9 \\
\hline
\end{tabular}

13 Leucosome quartz

\begin{tabular}{lrllllllll}
\hline \multicolumn{1}{c}{ Sample } & \multicolumn{1}{c}{$\mathbf{L i}$} & $\mathbf{N a}$ & $\mathbf{A l}$ & $\mathbf{C a}$ & $\mathbf{T i}$ & $\mathbf{C r}$ & $\mathbf{M n}$ & \multicolumn{1}{l}{$\mathbf{F e}$} & $\mathbf{G e}$ \\
\hline exsud01 1 & 9.3 & 273.2 & 229.6 & 234.9 & 27.3 & 7.9 & 1.8 & 140.1 & 1.1 \\
exsud02 1 & 12.0 & 409.5 & 210.8 & 306.1 & 15.4 & 9.1 & 1.6 & 82.0 & 1.0 \\
exsud03 1 & 8.5 & 359.3 & 234.6 & 287.6 & 22.3 & 7.8 & 1.9 & 127.2 & 1.2 \\
exsud04 1 & 6.2 & 346.1 & 246.5 & 264.8 & 23.3 & 8.0 & 4.4 & 100.7 & 1.6 \\
exsud05 1 & 5.7 & 276.0 & 232.2 & 192.1 & 21.8 & 3.4 & 3.1 & 45.5 & 2.1 \\
exsud06 1 & 10.3 & 439.2 & 243.8 & 304.7 & 18.8 & 7.6 & 2.1 & 60.5 & 1.2 \\
exsud07 1 & 9.4 & 297.3 & 227.5 & 293.5 & 25.3 & 8.1 & 1.8 & 58.7 & 2.1 \\
exsud08 1 & 6.4 & 321.2 & 212.0 & 253.9 & 22.6 & 5.6 & 3.0 & 114.2 & 1.3 \\
exsud09 1 & 9.2 & 482.1 & 250.6 & 304.5 & 21.3 & 9.0 & 3.3 & 128.2 & 3.5 \\
exsud10 2 & 8.3 & 403.2 & 237.9 & 295.4 & 22.6 & 8.9 & 2.7 & 94.0 & 2.0 \\
\hline
\end{tabular}


List of trace element analysis of quartz (LA ICP-MS) (continued)

14 Ramberg Granite

\begin{tabular}{llllllrrrr}
\hline Sample & $\mathbf{L i}$ & $\mathbf{N a}$ & $\mathbf{A l}$ & $\mathbf{C a}$ & $\mathbf{T i}$ & $\mathbf{C r}$ & $\mathbf{M n}$ & $\mathbf{F e}$ & $\mathbf{G e}$ \\
\hline ram01 1 & 13.7 & 650.5 & 389.4 & 880.8 & 42.8 & 19.4 & 2.4 & 85.6 & 3.0 \\
ram02 1 & 13.8 & 494.0 & 421.9 & 483.8 & 28.3 & 6.6 & 1.3 & 56.6 & 2.0 \\
ram03 1 & 19.5 & 505.4 & 428.9 & 282.5 & 23.1 & 8.1 & 0.6 & 46.2 & 1.2 \\
ram04 1 & 14.2 & 870.5 & 378.9 & 1056.0 & 36.5 & 5.3 & 1.3 & 73.1 & 2.3 \\
ram05 1 & 14.7 & 764.4 & 471.9 & 545.3 & 35.7 & 14.3 & 1.0 & 71.5 & 2.1 \\
ram06 1 & 15.6 & 647.5 & 479.7 & 657.4 & 34.4 & 6.5 & 1.4 & 68.9 & 2.1 \\
ram07 1 & 18.5 & 530.3 & 398.7 & 943.2 & 25.2 & 8.3 & 0.8 & 50.3 & 3.2 \\
ram08 1 & 15.3 & 732.2 & 456.9 & 456.3 & 35.9 & 11.2 & 1.6 & 71.9 & 2.4 \\
ram09 1 & 16.5 & 842.5 & 498.0 & 645.3 & 36.8 & 9.4 & 1.3 & 73.6 & 2.0 \\
ram10 1 & 14.3 & 653.9 & 423.8 & 899.7 & 37.8 & 6.4 & 1.7 & 75.5 & 1.9 \\
\hline
\end{tabular}

15 Weinheim Rhyolite

\begin{tabular}{|c|c|c|c|c|c|c|c|c|c|}
\hline Sample & $\mathbf{L i}$ & $\mathbf{N a}$ & $\overline{A l}$ & $\mathrm{Ca}$ & Ti & $\mathrm{Cr}$ & Mn & $\mathrm{Fe}$ & Ge \\
\hline wein101 1 & 29.2 & 746.2 & 185.7 & 0.1 & 24.9 & 1.0 & 1.7 & 0.1 & 1.6 \\
\hline wein102 1 & 46.5 & 55.5 & 179.8 & 0.1 & 44.1 & 0.1 & 1.3 & 0.1 & 2.5 \\
\hline wein103 1 & 56.2 & 123.7 & 171.0 & 331.4 & 75.4 & 6.8 & 1.2 & 4.6 & 5.6 \\
\hline wein104 1 & 43.7 & 0.1 & 169.1 & 0.1 & 99.5 & 6.4 & 0.4 & 0.1 & 3.7 \\
\hline wein105 1 & 34.8 & 0.1 & 169.2 & 0.1 & 98.0 & 0.1 & 0.3 & 0.1 & 1.6 \\
\hline wein106 1 & 25.9 & 309.6 & 170.6 & 97.2 & 79.0 & 0.1 & 0.4 & 0.1 & 1.0 \\
\hline wein107 1 & 30.8 & 5474.6 & 170.3 & 0.1 & 87.6 & 5.8 & 5.5 & 0.1 & 1.3 \\
\hline wein108 1 & 33.0 & 1307.6 & 172.7 & 0.1 & 51.7 & 0.1 & 9.7 & 0.1 & 0.8 \\
\hline wein109 1 & 24.8 & 445.5 & 184.9 & 268.6 & 44.3 & 0.5 & 1.3 & 0.1 & 0.9 \\
\hline wein110 1 & 22.6 & 350.8 & 173.9 & 283.8 & 33.7 & 0.1 & 0.1 & 0.1 & 2.0 \\
\hline wein201 1 & 31.1 & 449.4 & 155.3 & 547.6 & 62.3 & 0.1 & 0.5 & 30.7 & 2.3 \\
\hline wein202 1 & 37.1 & 0.1 & 184.0 & 247.6 & 60.1 & 1.8 & 1.3 & 11.3 & 0.9 \\
\hline wein203 1 & 34.7 & 6474.0 & 214.7 & 208.3 & 178.8 & 10.4 & 1.7 & 45.2 & 3.3 \\
\hline wein204 1 & 31.0 & 563.6 & 192.6 & 0.1 & 84.3 & 0.4 & 1.5 & 0.1 & 2.0 \\
\hline wein206 1 & 39.4 & 245.1 & 196.3 & 249.2 & 162.6 & 10.5 & 2.2 & 49.2 & 0.7 \\
\hline wein207 1 & 39.7 & 181.3 & 189.3 & 40.5 & 123.8 & 0.1 & 1.4 & 0.1 & 1.8 \\
\hline wein208 1 & 37.9 & 211.1 & 170.5 & 270.9 & 52.7 & 0.1 & 1.2 & 54.6 & 1.3 \\
\hline wein209 1 & 24.8 & 80.9 & 162.2 & 239.4 & 40.5 & 4.3 & 0.1 & 22.9 & 2.0 \\
\hline wein301 1 & 35.9 & 540.4 & 152.6 & 307.9 & 35.7 & 1.7 & 4.8 & 0.1 & 1.2 \\
\hline wein302 1 & 42.8 & 0.1 & 154.3 & 454.1 & 13.7 & 0.1 & 0.5 & 0.1 & 0.1 \\
\hline wein303 1 & 50.6 & 0.1 & 162.5 & 637.3 & 58.7 & 0.1 & 1.5 & 0.1 & 3.2 \\
\hline wein304 1 & 44.8 & 0.1 & 165.3 & 326.3 & 105.3 & 2.7 & 0.7 & 36.8 & 2.8 \\
\hline wein305 1 & 34.7 & 0.1 & 172.4 & 0.1 & 132.9 & 0.1 & 0.7 & 24.5 & 0.8 \\
\hline wein308 1 & 32.1 & 3122.5 & 170.2 & 787.0 & 186.6 & 0.1 & 2.5 & 28.2 & 7.6 \\
\hline wein309 1 & 33.3 & 1289.3 & 174.7 & 0.1 & 122.0 & 7.6 & 6.1 & 26.4 & 1.6 \\
\hline wein310 1 & 32.5 & 502.6 & 165.5 & 344.7 & 165.6 & 1.0 & 8.5 & 38.2 & 0.8 \\
\hline wein401 1 & 28.3 & 185.2 & 171.2 & 246.5 & 38.5 & 0.1 & 0.5 & 0.1 & 0.6 \\
\hline wein402 1 & 27.3 & 191.7 & 194.4 & 77.0 & 45.5 & 0.4 & 0.4 & 0.1 & 1.5 \\
\hline wein403 1 & 31.4 & 152.8 & 195.7 & 281.6 & 75.8 & 1.7 & 0.1 & 0.1 & 2.2 \\
\hline wein404 1 & 34.0 & 241.9 & 202.6 & 314.0 & 69.4 & 0.1 & 0.5 & 0.1 & 0.5 \\
\hline wein405 1 & 32.6 & 109.1 & 199.2 & 4.0 & 71.1 & 1.1 & 0.1 & 0.1 & 0.7 \\
\hline wein406 1 & 27.4 & 145.4 & 189.9 & 239.6 & 62.8 & 0.1 & 0.5 & 0.1 & 1.3 \\
\hline wein407 1 & 26.3 & 1104.7 & 189.2 & 364.0 & 36.1 & 0.1 & 0.8 & 0.1 & 1.0 \\
\hline wein408 1 & 28.1 & 1611.2 & 176.9 & 402.9 & 26.0 & 5.2 & 1.4 & 0.1 & 1.5 \\
\hline wein501 1 & 28.5 & 544.5 & 173.7 & 0.1 & 66.0 & 0.6 & 3.8 & 19.6 & 2.5 \\
\hline wein502 1 & 41.6 & 556.1 & 179.2 & 0.1 & 113.9 & 2.5 & 0.2 & 32.2 & 0.1 \\
\hline wein503 1 & 46.3 & 776.2 & 195.7 & 0.1 & 241.7 & 14.4 & 7.6 & 30.0 & 2.1 \\
\hline wein504 1 & 54.1 & 899.0 & 196.2 & 0.1 & 305.7 & 1.5 & 0.1 & 55.1 & 2.5 \\
\hline wein505 1 & 48.1 & 1065.4 & 204.8 & 0.1 & 267.0 & 44.7 & 0.1 & 44.0 & 2.8 \\
\hline wein506 1 & 42.7 & 1026.0 & 223.0 & 0.1 & 221.8 & 1.3 & 2.2 & 24.0 & 0.7 \\
\hline wein507 1 & 46.7 & 1289.3 & 225.7 & 0.1 & 259.9 & 1.3 & 0.4 & 38.4 & 1.7 \\
\hline wein508 1 & 51.4 & 909.6 & 215.5 & 0.1 & 203.6 & 7.2 & 0.4 & 23.7 & 2.2 \\
\hline wein509 1 & 35.4 & 944.0 & 167.8 & 0.1 & 50.7 & 7.9 & 0.1 & 19.2 & 2.8 \\
\hline
\end{tabular}




\section{Appendix D}

\section{List of trace element analysis of quartz (EPMA)}

\section{Megaquartz}

\begin{tabular}{crrrr}
\hline Sample & Al & \multicolumn{1}{c}{ Ti } & \multicolumn{1}{c}{ K } & \multicolumn{1}{c}{ Fe } \\
\hline Megaquartz & 158.8 & 0.0 & 33.2 & 15.5 \\
Megaquartz & 142.9 & 0.0 & 24.9 & 7.8 \\
Megaquartz & 153.5 & 0.0 & 8.3 & 15.5 \\
Megaquartz & 127.1 & 12.0 & 16.6 & 15.5 \\
Megaquartz & 5.3 & 6.0 & 8.3 & 7.8 \\
Megaquartz & 5.3 & 12.0 & 16.6 & 15.5 \\
Megaquartz & 5.3 & 6.0 & 16.6 & 0.0 \\
Megaquartz & 5.3 & 0.0 & 0.0 & 0.0 \\
Megaquartz & 5.3 & 0.0 & 24.9 & 0.0 \\
Megaquartz & 5.3 & 0.0 & 24.9 & 7.8 \\
\hline
\end{tabular}

\section{Fissile quartz}

\begin{tabular}{lrrrr}
\hline \multicolumn{1}{c}{ Sample } & Al & \multicolumn{1}{c}{ Ti } & \multicolumn{1}{c}{ K } & \multicolumn{1}{c}{ Fe } \\
\hline Fissile & 21.2 & 18.0 & 33.2 & 7.8 \\
Fissile & 15.9 & 0.0 & 58.1 & 23.3 \\
Fissile & 21.2 & 18.0 & 41.5 & 0.0 \\
Fissile & 15.9 & 0.0 & 49.8 & 7.8 \\
Fissile & 21.2 & 6.0 & 66.4 & 15.5 \\
Fissile & 26.5 & 18.0 & 99.6 & 15.5 \\
Fissile & 10.6 & 12.0 & 66.4 & 7.8 \\
Fissile & 21.2 & 6.0 & 49.8 & 7.8 \\
Fissile & 21.2 & 0.0 & 83.0 & 0.0 \\
Fissile & 21.2 & 30.0 & 58.1 & 0.0 \\
\hline
\end{tabular}

\section{Oil-bearing quartz}

\begin{tabular}{ccrrr}
\hline Sample & Al & \multicolumn{1}{c}{ Ti } & \multicolumn{1}{c}{ K } & \multicolumn{1}{c}{ Fe } \\
\hline Oil & 455.3 & 0.0 & 41.5 & 0.0 \\
Oil & 465.9 & 0.0 & 33.2 & 7.8 \\
Oil & 460.6 & 0.0 & 33.2 & 31.1 \\
Oil & 471.2 & 18.0 & 24.9 & 0.0 \\
Oil & 434.1 & 18.0 & 41.5 & 15.5 \\
Oil & 434.1 & 18.0 & 49.8 & 0.0 \\
Oil & 476.5 & 0.0 & 58.1 & 0.0 \\
Oil & 476.5 & 6.0 & 41.5 & 15.5 \\
\hline
\end{tabular}

\section{Schellerhau Granite}

\begin{tabular}{lrrrr}
\hline Sample & \multicolumn{1}{c}{ Al } & \multicolumn{1}{l}{ Ti } & \multicolumn{1}{c}{ K } \\
\hline Schel matrix & 199.0 & 0.0 & 7.8 \\
Schel matrix & 273.2 & 0.0 & 15.5 \\
Schel matrix & 214.9 & 21.0 & 15.5 \\
Schel matrix & 199.0 & 17.0 & 0.0 \\
Schel matrix & 214.9 & 19.0 & 0.0 \\
Schel matrix & 199.0 & 25.0 & 15.5 \\
Schel matrix & 225.5 & 24.0 & 15.5 \\
Schel matrix & 183.1 & 27.0 & 15.5 \\
Schel matrix & 156.6 & 30.0 & 23.3 \\
Schel matrix & 209.6 & 30.0 & 15.5 \\
Schel matrix & 193.7 & 30.0 & 15.5 \\
Schel matrix & 206.2 & 36.0 & 23.3 \\
Schell red CL & 98.3 & 11.0 & 0.0 \\
Schell red CL & 124.8 & 12.0 & 23.3 \\
Schell red CL & 98.3 & 14.0 & 0.0 \\
\hline
\end{tabular}

6 Schellerhau Granite

\begin{tabular}{|c|c|c|c|c|}
\hline Sample & Al & Ti & $\mathbf{K}$ & $\mathrm{Fe}$ \\
\hline Schell red CL & 108.9 & 16.0 & & 0.0 \\
\hline Schell red CL & 103.6 & 18.0 & & 0.0 \\
\hline Schell red CL & 114.2 & 18.0 & & 23.3 \\
\hline Schell red CL & 93.0 & 18.0 & & 31.1 \\
\hline Schell red CL & 124.8 & 18.0 & & 15.5 \\
\hline Schell red CL & 135.4 & 16.0 & & 0.0 \\
\hline Schell red CL & 135.4 & 18.0 & & 7.8 \\
\hline Schell red CL & 188.4 & 29.0 & & 0.0 \\
\hline Schell red CL & 119.5 & 24.0 & & 7.8 \\
\hline Schell red CL & 130.1 & 21.0 & & 0.0 \\
\hline Schell red CL & 93.0 & 24.0 & & 0.0 \\
\hline Schell red CL & 93.0 & 25.0 & & 0.0 \\
\hline Schell red CL & 114.2 & 24.0 & & 15.5 \\
\hline Schell red CL & 103.6 & 26.0 & & 23.3 \\
\hline Schell red CL & 108.9 & 27.0 & & 0.0 \\
\hline Schell red CL & 82.4 & 31.0 & & 23.3 \\
\hline Schell red CL & 119.5 & 29.0 & & 15.5 \\
\hline Schell red CL & 98.3 & 33.0 & & 0.0 \\
\hline Schell red CL & 103.6 & 35.0 & & 7.8 \\
\hline Schell red CL & 135.4 & 32.0 & & 0.0 \\
\hline Schell red CL & 114.2 & 28.0 & & 0.0 \\
\hline Schell red CL & 103.6 & 30.0 & & 15.5 \\
\hline Schell red CL & 93.0 & 36.0 & & 23.3 \\
\hline Schell red CL & 98.3 & 36.0 & & 15.5 \\
\hline Schell red CL & 130.1 & 36.0 & & 15.5 \\
\hline Schell red CL & 103.6 & 38.0 & & 15.5 \\
\hline Schell red CL & 87.7 & 48.0 & & 7.8 \\
\hline Schell blue CL & 87.7 & 36.0 & & 7.8 \\
\hline Schell blue CL & 124.8 & 42.0 & & 7.8 \\
\hline Schell blue CL & 108.9 & 42.0 & & 7.8 \\
\hline Schell blue CL & 93.0 & 42.0 & & 0.0 \\
\hline Schell blue CL & 93.0 & 42.0 & & 15.5 \\
\hline Schell blue CL & 93.0 & 48.0 & & 7.8 \\
\hline Schell blue CL & 93.0 & 50.0 & & 0.0 \\
\hline Schell blue CL & 77.1 & 46.0 & & 0.0 \\
\hline Schell blue CL & 124.8 & 51.0 & & 0.0 \\
\hline Schell blue CL & 103.6 & 54.0 & & 15.5 \\
\hline Schell blue CL & 82.4 & 54.0 & & 7.8 \\
\hline Schell blue CL & 98.3 & 55.0 & & 7.8 \\
\hline Schell blue CL & 87.7 & 57.0 & & 15.5 \\
\hline Schell blue CL & 98.3 & 58.0 & & 15.5 \\
\hline Schell blue CL & 98.3 & 62.0 & & 0.0 \\
\hline
\end{tabular}

8 Aue Granite

\begin{tabular}{lrrrr}
\hline Sample & Al & \multicolumn{1}{l}{ Ti } & K & Fe \\
\hline aue & 58.2 & 60.0 & 41.5 & 23.3 \\
aue & 42.4 & 60.0 & 49.8 & 31.1 \\
aue & 63.5 & 60.0 & 41.5 & 15.5 \\
aue & 68.8 & 65.9 & 49.8 & 38.9 \\
aue & 79.4 & 65.9 & 33.2 & 23.3 \\
aue & 58.2 & 65.9 & 33.2 & 7.8 \\
aue & 74.1 & 71.9 & 83.0 & 23.3 \\
\hline
\end{tabular}




\section{List of trace element analysis of quartz (EPMA) (continued)}

9 Vein quartz

\begin{tabular}{|c|c|c|c|c|}
\hline Sample & Al & $\mathbf{T i}$ & $\mathbf{K}$ & $\mathbf{F e}$ \\
\hline Vein & 3377.6 & 30.0 & 33.2 & 31.1 \\
\hline Vein & 3488.7 & 36.0 & 41.5 & 31.1 \\
\hline Vein & 4155.8 & 24.0 & 58.1 & 15.5 \\
\hline Vein & 4214.0 & 30.0 & 66.4 & 31.1 \\
\hline Vein & 3769.3 & 24.0 & 41.5 & 15.5 \\
\hline Vein & 2779.4 & 30.0 & 24.9 & 23.3 \\
\hline Vein & 3044.1 & 18.0 & 24.9 & 31.1 \\
\hline Vein & 2567.6 & 18.0 & 33.2 & 38.9 \\
\hline Vein & 2721.1 & 30.0 & 33.2 & 23.3 \\
\hline Vein & 2832.3 & 24.0 & 24.9 & 31.1 \\
\hline Vein & 2212.9 & 18.0 & 24.9 & 15.5 \\
\hline Vein & 2408.8 & 24.0 & 16.6 & 15.5 \\
\hline Vein & 4351.7 & 18.0 & 356.9 & 31.1 \\
\hline Vein & 3282.3 & 18.0 & 33.2 & 15.5 \\
\hline Vein & 3165.8 & 24.0 & 16.6 & 23.3 \\
\hline Vein & 3102.3 & 36.0 & 41.5 & 23.3 \\
\hline Vein & 3049.3 & 18.0 & 33.2 & 23.3 \\
\hline Vein & 2954.1 & 24.0 & 33.2 & 31.1 \\
\hline Vein & 3991.7 & 18.0 & 16.6 & 15.5 \\
\hline Vein & 4383.4 & 18.0 & 16.6 & 23.3 \\
\hline Vein & 4277.6 & 36.0 & 24.9 & 31.1 \\
\hline Vein & 4886.4 & 36.0 & 24.9 & 23.3 \\
\hline Vein & 4886.4 & 24.0 & 16.6 & 31.1 \\
\hline Vein & 3022.9 & 24.0 & 24.9 & 15.5 \\
\hline Vein & 3245.2 & 30.0 & 41.5 & 31.1 \\
\hline Vein & 3123.5 & 36.0 & 33.2 & 23.3 \\
\hline Vein & 3277.0 & 30.0 & 33.2 & 23.3 \\
\hline Vein & 3377.6 & 18.0 & 33.2 & 23.3 \\
\hline
\end{tabular}

10 Wachtelberg Rhyolite

\begin{tabular}{lrrrr}
\hline Sample & Al & Ti & K & Fe \\
\hline wachtel1 & 26.5 & 42.0 & 16.6 & 38.9 \\
wachtel1 & 21.2 & 42.0 & 24.9 & 38.9 \\
wachtel1 & 21.2 & 42.0 & 16.6 & 15.5 \\
wachtel1 & 26.5 & 42.0 & 16.6 & 31.1 \\
wachtel1 & 26.5 & 48.0 & 16.6 & 15.5 \\
wachtel1 & 15.9 & 48.0 & 16.6 & 23.3 \\
wachtel1 & 21.2 & 54.0 & 16.6 & 15.5 \\
wachtel1 & 31.8 & 54.0 & 8.3 & 31.1 \\
wachtel1 & 26.5 & 54.0 & 8.3 & 31.1 \\
wachtel1 & 26.5 & 60.0 & 8.3 & 31.1 \\
wachtel1 & 26.5 & 60.0 & 16.6 & 31.1 \\
wachtel1 & 31.8 & 60.0 & 8.3 & 31.1 \\
wachtel1 & 15.9 & 65.9 & 16.6 & 23.3 \\
wachtel1 & 26.5 & 65.9 & 16.6 & 31.1 \\
wachtel1 & 21.2 & 65.9 & 16.6 & 23.3 \\
wachtel1 & 15.9 & 65.9 & 16.6 & 31.1 \\
wachtel1 & 37.1 & 65.9 & 8.3 & 31.1 \\
wachtel1 & 21.2 & 71.9 & 16.6 & 23.3 \\
wachtel1 & 31.8 & 71.9 & 8.3 & 31.1 \\
wachtel1 & 26.5 & 71.9 & 16.6 & 31.1 \\
wachtel1 & 26.5 & 71.9 & 16.6 & 38.9 \\
wachtel1 & 26.5 & 77.9 & 16.6 & 31.1 \\
\hline
\end{tabular}

11 Beucha Rhyolite

\begin{tabular}{lrrrr}
\hline \multicolumn{1}{c}{ Sample } & \multicolumn{1}{c}{ Al } & \multicolumn{1}{l}{ Ti } & \multicolumn{1}{c}{ K } & \multicolumn{1}{c}{ Fe } \\
\hline beuch red CL & 142.9 & 18.0 & 16.6 & 15.5 \\
beuch red CL & 153.5 & 18.0 & 8.3 & 31.1 \\
beuch red CL & 148.2 & 18.0 & 33.2 & 15.5 \\
beuch red CL & 37.1 & 24.0 & 16.6 & 15.5 \\
beuch red CL & 52.9 & 30.0 & 8.3 & 7.8 \\
beuch red CL & 201.2 & 30.0 & 24.9 & 31.1 \\
beuch red CL & 153.5 & 30.0 & 8.3 & 38.9 \\
beuch red CL & 15.9 & 36.0 & 24.9 & 31.1 \\
beuch red CL & 137.6 & 36.0 & 8.3 & 31.1 \\
beuch red CL & 132.4 & 42.0 & 8.3 & 15.5 \\
beuch blue CL & 37.1 & 48.0 & 8.3 & 38.9 \\
beuch blue CL & 37.1 & 48.0 & 16.6 & 23.3 \\
beuch blue CL & 58.2 & 54.0 & 8.3 & 23.3 \\
beuch blue CL & 148.2 & 54.0 & 8.3 & 46.6 \\
beuch blue CL & 42.4 & 65.9 & 24.9 & 31.1 \\
beuch blue CL & 37.1 & 65.9 & 16.6 & 38.9 \\
beuch blue CL & 158.8 & 65.9 & 8.3 & 46.6 \\
beuch blue CL & 31.8 & 65.9 & 24.9 & 46.6 \\
beuch blue CL & 42.4 & 71.9 & 8.3 & 38.9 \\
beuch blue CL & 58.2 & 71.9 & 8.3 & 46.6 \\
beuch blue CL & 31.8 & 77.9 & 24.9 & 101.0 \\
beuch blue CL & 153.5 & 83.9 & 0.0 & 62.2 \\
beuch blue CL & 164.1 & 95.9 & 8.3 & 70.0 \\
beuch blue CL & 164.1 & 95.9 & 8.3 & 46.6 \\
beuch blue CL & 174.7 & 95.9 & 0.0 & 62.2 \\
beuch blue CL & 42.4 & 95.9 & 16.6 & 38.9 \\
beuch blue CL & 153.5 & 95.9 & 8.3 & 62.2 \\
beuch blue CL & 58.2 & 101.9 & 33.2 & 70.0 \\
beuch blue CL & 164.1 & 101.9 & 8.3 & 70.0 \\
beuch blue CL & 164.1 & 101.9 & 8.3 & 70.0 \\
beuch blue CL & 158.8 & 101.9 & 16.6 & 93.3 \\
beuch blue CL & 116.5 & 113.9 & 16.6 & 108.8 \\
beuch blue CL & 42.4 & 113.9 & 24.9 & 101.0 \\
beuch blue CL & 42.4 & 119.9 & 8.3 & 147.7 \\
beuch blue CL & 52.9 & 119.9 & 16.6 & 155.5 \\
beuch blue CL & 42.4 & 125.9 & 16.6 & 241.0 \\
beuch blue CL & 74.1 & 125.9 & 24.9 & 349.8 \\
\hline
\end{tabular}

\section{Flossenbürg Granite}

\begin{tabular}{lrrrr}
\hline \multicolumn{1}{c}{ Sample } & Al & \multicolumn{1}{l}{ Ti } & K & \multicolumn{1}{l}{ F } \\
\hline Floss_1 & 5.3 & 24.0 & 8.3 & 15.5 \\
Floss_1 & 5.3 & 24.0 & 8.3 & 15.5 \\
Floss_2 & 5.3 & 24.0 & 8.3 & 7.8 \\
Floss_2 & 5.3 & 30.0 & 8.3 & 23.3 \\
Floss_2 & 5.3 & 30.0 & 8.3 & 15.5 \\
Floss_2 & 5.3 & 30.0 & 8.3 & 15.5 \\
Floss_2 & 5.3 & 30.0 & 8.3 & 23.3 \\
Floss_2 & 5.3 & 36.0 & 8.3 & 15.5 \\
Floss_2 & 15.9 & 42.0 & 8.3 & 15.5 \\
Floss_2 & 5.3 & 42.0 & 0.0 & 23.3 \\
Floss_2 & 5.3 & 42.0 & 8.3 & 7.8 \\
\hline
\end{tabular}




\section{List of trace element analysis of quartz (EPMA) (continued)}

13 Leucosome quartz

\begin{tabular}{rrrrr}
\hline Sample & \multicolumn{1}{c}{ Al } & \multicolumn{1}{c}{ Ti } & \multicolumn{1}{c}{ K } & \multicolumn{1}{c}{ Fe } \\
\hline Leucosome & 84.7 & 24.0 & 49.8 & 7.8 \\
Leucosome & 100.6 & 30.0 & 83.0 & 15.5 \\
Leucosome & 84.7 & 30.0 & 74.7 & 7.8 \\
Leucosome & 95.3 & 18.0 & 107.9 & 7.8 \\
Leucosome & 95.3 & 0.0 & 74.7 & 0.0 \\
Leucosome & 100.6 & 12.0 & 132.8 & 0.0 \\
Leucosome & 90.0 & 18.0 & 74.7 & 0.0 \\
Leucosome & 116.5 & 12.0 & 33.2 & 23.3 \\
Leucosome & 84.7 & 12.0 & 33.2 & 7.8 \\
Leucosome & 84.7 & 24.0 & 24.9 & 15.5 \\
\hline
\end{tabular}

14 Ramberg Granite

\begin{tabular}{lrrrr}
\hline \multicolumn{1}{c}{ Sample } & \multicolumn{1}{c}{ Al } & \multicolumn{1}{l}{ Ti } & \multicolumn{1}{l}{ K } & Fe \\
\hline ramb & 5.3 & 36.0 & 16.6 & 15.5 \\
ramb & 5.3 & 42.0 & 33.2 & 23.3 \\
ramb & 47.6 & 42.0 & 16.6 & 15.5 \\
ramb & 127.1 & 48.0 & 33.2 & 23.3 \\
ramb & 111.2 & 60.0 & 16.6 & 38.9 \\
ramb & 47.6 & 60.0 & 24.9 & 31.1 \\
ramb & 95.3 & 60.0 & 8.3 & 7.8 \\
ramb & 153.5 & 77.9 & 49.8 & 23.3 \\
ramb & 5.3 & 42.0 & 8.3 & 15.5 \\
\hline
\end{tabular}

15 Weinheim Rhyolite

\begin{tabular}{lrrrr}
\hline \multicolumn{1}{c}{ Sample } & \multicolumn{1}{c}{ Al } & Ti & \multicolumn{1}{c}{ K } & \multicolumn{1}{c}{ Fe } \\
\hline wein red CL & 180.0 & 24.0 & 8.3 & 23.3 \\
wein red CL & 169.4 & 24.0 & 24.9 & 31.1 \\
wein red CL & 142.9 & 24.0 & 16.6 & 23.3 \\
wein red CL & 142.9 & 24.0 & 16.6 & 31.1 \\
wein red CL & 142.9 & 36.0 & 8.3 & 15.5 \\
wein red CL & 142.9 & 36.0 & 16.6 & 23.3 \\
wein red CL & 148.2 & 42.0 & 8.3 & 15.5 \\
wein red CL & 180.0 & 42.0 & 8.3 & 7.8 \\
wein red CL & 180.0 & 42.0 & 8.3 & 7.8 \\
wein red CL & 180.0 & 42.0 & 8.3 & 15.5 \\
wein red CL & 158.8 & 42.0 & 8.3 & 23.3 \\
wein blue CL & 185.3 & 42.0 & 8.3 & 7.8 \\
wein blue CL & 52.9 & 42.0 & 16.6 & 23.3 \\
wein blue CL & 68.8 & 42.0 & 33.2 & 46.6 \\
wein blue CL & 153.5 & 48.0 & 16.6 & 15.5 \\
wein blue CL & 185.3 & 48.0 & 16.6 & 7.8 \\
wein blue CL & 148.2 & 48.0 & 16.6 & 15.5 \\
wein blue CL & 169.4 & 48.0 & 16.6 & 23.3 \\
wein blue CL & 158.8 & 54.0 & 16.6 & 7.8 \\
wein blue CL & 158.8 & 54.0 & 8.3 & 15.5 \\
wein blue CL & 74.1 & 54.0 & 16.6 & 31.1 \\
wein blue CL & 153.5 & 54.0 & 16.6 & 7.8 \\
wein blue CL & 148.2 & 54.0 & 8.3 & 15.5 \\
wein blue CL & 169.4 & 54.0 & 8.3 & 15.5 \\
wein blue CL & 158.8 & 54.0 & 8.3 & 7.8 \\
wein blue CL & 164.1 & 60.0 & 16.6 & 7.8 \\
wein blue CL & 169.4 & 60.0 & 8.3 & 31.1 \\
wein blue CL & 68.8 & 60.0 & 16.6 & 31.1 \\
wein blue CL & 164.1 & 60.0 & 24.9 & 23.3 \\
wein blue CL & 137.6 & 65.9 & 16.6 & 7.8 \\
wein blue CL & 158.8 & 65.9 & 16.6 & 23.3 \\
wein blue CL & 153.5 & 65.9 & 16.6 & 15.5 \\
wein blue CL & 185.3 & 65.9 & 16.6 & 7.8 \\
wein blue CL & 169.4 & 65.9 & 16.6 & 7.8 \\
\hline & & & &
\end{tabular}

15 Weinheim Rhyolite

\begin{tabular}{lrrrr}
\hline \multicolumn{1}{c}{ Sample } & \multicolumn{1}{c}{ Al } & \multicolumn{1}{l}{ Ti } & \multicolumn{1}{c}{ K } & \multicolumn{1}{l}{ Fe } \\
\hline wein blue CL & 169.4 & 71.9 & 16.6 & 15.5 \\
wein blue CL & 52.9 & 71.9 & 24.9 & 31.1 \\
wein blue CL & 58.2 & 89.9 & 24.9 & 23.3 \\
wein red CL & 158.8 & 18.0 & 8.3 & 15.5 \\
wein red CL & 127.1 & 18.0 & 16.6 & 15.5 \\
wein red CL & 142.9 & 18.0 & 8.3 & 31.1 \\
wein red CL & 132.4 & 18.0 & 16.6 & 46.6 \\
wein red CL & 142.9 & 18.0 & 58.1 & 70.0 \\
\hline
\end{tabular}

Carcoar Granodiorite

\begin{tabular}{|c|c|c|c|c|}
\hline Sample & Al & Ti & $\mathbf{K}$ & $\mathbf{F e}$ \\
\hline carcor & 350 & 110 & 200 & 30 \\
\hline carcor & 0 & 100 & 30 & 0 \\
\hline carcor & 0 & 80 & 0 & 30 \\
\hline carcor & 0 & 50 & 20 & 20 \\
\hline carcor & 0 & 50 & 30 & 20 \\
\hline carcor & 0 & 40 & 20 & 0 \\
\hline carcor & 180 & 70 & 130 & 20 \\
\hline carcor & 0 & 100 & 0 & 20 \\
\hline carcor & 0 & 90 & 20 & 20 \\
\hline carcor & 240 & 100 & 130 & 30 \\
\hline carcor & 250 & 100 & 160 & 30 \\
\hline carcor & 0 & 80 & 20 & 30 \\
\hline carcor & 0 & 70 & 0 & 30 \\
\hline carcor & 0 & 80 & 0 & 40 \\
\hline carcor & 0 & 90 & 0 & 40 \\
\hline carcor & 0 & 90 & 20 & 50 \\
\hline carcor & 90 & 90 & 80 & 60 \\
\hline carcor & 0 & 50 & 40 & 70 \\
\hline carcor & 0 & 50 & 20 & 90 \\
\hline carcor & 0 & 40 & 0 & 120 \\
\hline carcor & 0 & 40 & 20 & 170 \\
\hline carcor & 0 & 40 & 20 & 250 \\
\hline carcor & 0 & 30 & 40 & 460 \\
\hline carcor & 0 & 20 & 30 & 470 \\
\hline carcor & 0 & 130 & 20 & 30 \\
\hline carcor & 0 & 120 & 20 & 20 \\
\hline carcor & 0 & 100 & 0 & 40 \\
\hline carcor & 0 & 30 & 20 & 20 \\
\hline carcor & 0 & 100 & 0 & 40 \\
\hline carcor & 0 & 100 & 0 & 30 \\
\hline carcor & 0 & 120 & 20 & 20 \\
\hline carcor & 0 & 140 & 20 & 30 \\
\hline carcor & 0 & 110 & 20 & 20 \\
\hline carcor & 0 & 100 & 0 & 30 \\
\hline carcor & 0 & 100 & 20 & 20 \\
\hline carcor & 0 & 80 & 0 & 20 \\
\hline carcor & 0 & 90 & 20 & 0 \\
\hline carcor & 0 & 90 & 0 & 20 \\
\hline carcor & 0 & 120 & 20 & 20 \\
\hline carcor & 0 & 110 & 20 & 0 \\
\hline carcor & 0 & 110 & 0 & 0 \\
\hline carcor & 0 & 110 & 0 & 0 \\
\hline carcor & 0 & 100 & 20 & 0 \\
\hline carcor & 0 & 110 & 0 & 20 \\
\hline carcor & 0 & 120 & 0 & 30 \\
\hline carcor & 0 & 100 & 30 & 0 \\
\hline carcor & 0 & 120 & 20 & 0 \\
\hline
\end{tabular}




\section{List of trace element analysis of quartz (EPMA) (continued)}

Barry Granodiorite

\begin{tabular}{lrrrr}
\hline Sample & Al & Ti & K & Fe \\
\hline bary & 100 & 60 & 50 & 0 \\
bary & 230 & 60 & 110 & 0 \\
bary & 140 & 60 & 60 & 0 \\
bary & 220 & 50 & 110 & 30 \\
bary & 0 & 60 & 0 & 0 \\
bary & 260 & 40 & 0 & 40 \\
bary & 90 & 90 & 90 & 20 \\
bary & 0 & 0 & 20 & 12 \\
bary & 0 & 0 & 0 & 50 \\
bary & 0 & 0 & 30 & 0 \\
bary & 0 & 0 & 0 & 0 \\
bary & 110 & 0 & 60 & 20 \\
bary & 12 & 20 & 30 & 0 \\
bary & 12 & 12 & 12 & 0 \\
bary & 12 & 70 & 30 & 0 \\
bary & 160 & 60 & 80 & 20 \\
bary & 0 & 60 & 0 & 0 \\
bary & 0 & 50 & 0 & 0 \\
bary & 400 & 60 & 170 & 20 \\
bary & 0 & 50 & 0 & 20 \\
bary & 380 & 60 & 170 & 20 \\
bary & 160 & 40 & 70 & 0 \\
bary & 150 & 50 & 70 & 0 \\
bary & 150 & 50 & 60 & 0 \\
bary & 0 & 20 & 30 & 20 \\
bary & 180 & 40 & 80 & 0 \\
bary & 0 & 40 & 0 & 0 \\
bary & 0 & 70 & 20 & 0 \\
bary & 360 & 50 & 170 & 0 \\
bary & 280 & 60 & 130 & 0 \\
bary & 0 & 70 & 20 & 20 \\
bary & 0 & 30 & 0 & 20 \\
bary & 390 & 50 & 240 & 30 \\
bary & 90 & 30 & 20 & 20 \\
bary & 170 & 40 & 60 & 30 \\
bary & 0 & 20 & 40 & 40 \\
bary & 0 & 0 & 30 & 60 \\
\hline & & & &
\end{tabular}

Sunset Hills Granite

\begin{tabular}{lrrrr}
\hline Sample & Al & Ti & K & Fe \\
\hline sunset & 0 & 90 & 0 & 0 \\
sunset & 0 & 70 & 20 & 20 \\
sunset & 90 & 80 & 30 & 0 \\
sunset & 90 & 90 & 40 & 20 \\
sunset & 0 & 70 & 0 & 0 \\
sunset & 410 & 80 & 200 & 0 \\
sunset & 0 & 60 & 0 & 0 \\
sunset & 0 & 60 & 0 & 0 \\
sunset & 310 & 70 & 180 & 30 \\
sunset & 0 & 60 & 30 & 0 \\
sunset & 0 & 100 & 0 & 0 \\
sunset & 0 & 90 & 0 & 20 \\
sunset & 130 & 120 & 70 & 0 \\
sunset & 0 & 120 & 0 & 30 \\
sunset & 280 & 0 & 130 & 20 \\
sunset & 0 & 140 & 0 & 20 \\
sunset & 450 & 50 & 250 & 200 \\
sunset & 200 & 70 & 120 & 20 \\
sunset & 240 & 30 & 110 & 0 \\
sunset & 140 & 60 & 70 & 0 \\
sunset & 170 & 70 & 70 & 0 \\
\hline & & & &
\end{tabular}

Sunset Hills Granite

\begin{tabular}{lrrrr}
\hline Sample & Al & \multicolumn{1}{c}{ Ti } & \multicolumn{1}{c}{ K } & Fe \\
\hline sunset & 0 & 60 & 40 & 30 \\
sunset & 0 & 40 & 20 & 20 \\
sunset & 0 & 30 & 0 & 0 \\
sunset & 0 & 40 & 0 & 40 \\
sunset & 470 & 30 & 230 & 40 \\
sunset & 0 & 50 & 0 & 0 \\
sunset & 0 & 90 & 0 & 0 \\
sunset & 150 & 100 & 90 & 20 \\
sunset & 12 & 90 & 20 & 20 \\
sunset & 12 & 90 & 20 & 0 \\
sunset & 380 & 80 & 160 & 0 \\
sunset & 12 & 60 & 20 & 30 \\
sunset & 12 & 160 & 0 & 30 \\
sunset & 90 & 140 & 50 & 40 \\
sunset & 0 & 100 & 0 & 40 \\
sunset & 0 & 20 & 0 & 20 \\
sunset & 0 & 50 & 0 & 0 \\
sunset & 510 & 120 & 20 & 30 \\
sunset & 0 & 120 & 20 & 20 \\
sunset & 0 & 60 & 20 & 20 \\
sunset & 0 & 50 & 0 & 0 \\
sunset & 0 & 30 & 20 & 0 \\
sunset & 0 & 0 & 0 & 20 \\
sunset & 0 & 40 & 0 & 30 \\
sunset & 0 & 0 & 0 & 20 \\
sunset & 0 & 0 & 0 & 20 \\
\hline & & & &
\end{tabular}

Porphyritic topaz-albite granite (Ju 10)

\begin{tabular}{lrrrr}
\hline Sample & \multicolumn{1}{l}{ Al } & \multicolumn{1}{l}{ Ti } & \multicolumn{1}{l}{ K } & Fe \\
\hline Ju_10_1 & 222.3 & 60.0 & 8.3 & 31.1 \\
Ju_10_1 & 232.9 & 48.0 & 24.9 & 38.9 \\
Ju_10_1 & 185.3 & 48.0 & 16.6 & 23.3 \\
Ju_10_1 & 238.2 & 60.0 & 16.6 & 31.1 \\
Ju_10_1 & 84.7 & 24.0 & 16.6 & 23.3 \\
Ju_10_1 & 238.2 & 42.0 & 16.6 & 31.1 \\
Ju_10_1 & 232.9 & 42.0 & 8.3 & 38.9 \\
Ju_10_1 & 232.9 & 30.0 & 16.6 & 38.9 \\
Ju_10_1 & 217.1 & 42.0 & 8.3 & 38.9 \\
Ju_10_1 & 227.6 & 36.0 & 16.6 & 15.5 \\
Ju_10_1 & 248.8 & 30.0 & 8.3 & 31.1 \\
Ju_10_1 & 254.1 & 42.0 & 24.9 & 31.1 \\
Ju_10_1 & 254.1 & 54.0 & 24.9 & 38.9 \\
Ju_10_1 & 259.4 & 48.0 & 16.6 & 15.5 \\
Ju_10_1 & 264.7 & 48.0 & 8.3 & 15.5 \\
Ju_10_1 & 259.4 & 54.0 & 16.6 & 23.3 \\
Ju_10_1 & 248.8 & 36.0 & 24.9 & 23.3 \\
Ju_10_1 & 259.4 & 48.0 & 16.6 & 38.9 \\
Ju_10_1 & 254.1 & 54.0 & 24.9 & 31.1 \\
Ju_10_1 & 264.7 & 54.0 & 16.6 & 54.4 \\
Ju_10_1 & 248.8 & 48.0 & 24.9 & 15.5 \\
Ju_10_1 & 222.3 & 42.0 & 16.6 & 38.9 \\
Ju_10_1 & 190.6 & 42.0 & 24.9 & 38.9 \\
Ju_10_1 & 232.9 & 48.0 & 16.6 & 23.3 \\
Ju_10_1 & 222.3 & 54.0 & 16.6 & 15.5 \\
Ju_10_1 & 201.2 & 54.0 & 16.6 & 23.3 \\
Ju_10_1 & 190.6 & 60.0 & 16.6 & 31.1 \\
Ju_10_1 & 174.7 & 54.0 & 24.9 & 31.1 \\
Ju_10_1 & 206.5 & 48.0 & 24.9 & 23.3 \\
Ju_10_1 & 248.8 & 65.9 & 33.2 & 15.5 \\
Ju_10_1 & 211.8 & 54.0 & 16.6 & 23.3 \\
Ju_10_1 & 217.1 & 48.0 & 16.6 & 15.5 \\
\hline & & & &
\end{tabular}




\section{List of trace element analysis of quartz (EPMA) (continued)}

Porphyritic topaz-albite granite (Ju 10)

\begin{tabular}{lrrrr}
\hline Sample & Al & Ti & K & Fe \\
\hline Ju_10_1 & 169.4 & 42.0 & 16.6 & 23.3 \\
Ju_10_1 & 185.3 & 60.0 & 16.6 & 23.3 \\
Ju_10_1 & 206.5 & 54.0 & 16.6 & 31.1 \\
Ju_10_1 & 174.7 & 36.0 & 16.6 & 23.3 \\
Ju_10_1 & 195.9 & 48.0 & 8.3 & 31.1 \\
Ju_10_1 & 206.5 & 42.0 & 16.6 & 38.9 \\
Ju_10_1 & 190.6 & 65.9 & 16.6 & 31.1 \\
Ju_10_1 & 232.9 & 36.0 & 16.6 & 23.3 \\
Ju_10_1 & 201.2 & 42.0 & 24.9 & 31.1 \\
Ju_10_1 & 264.7 & 36.0 & 8.3 & 23.3 \\
Ju_10_1 & 248.8 & 42.0 & 16.6 & 23.3 \\
Ju_10_1 & 264.7 & 48.0 & 16.6 & 23.3 \\
Ju_10_1 & 264.7 & 36.0 & 41.5 & 23.3 \\
Ju_10_1 & 26.5 & 24.0 & 33.2 & 31.1 \\
Ju_10_1 & 264.7 & 30.0 & 24.9 & 15.5 \\
Ju_10_1 & 301.8 & 30.0 & 33.2 & 23.3 \\
Ju_10_1 & 259.4 & 30.0 & 16.6 & 15.5 \\
Ju_10_1 & 137.6 & 24.0 & 16.6 & 23.3 \\
Ju_10_1 & 365.3 & 24.0 & 49.8 & 31.1 \\
Ju_10_1 & 322.9 & 24.0 & 8.3 & 23.3 \\
Ju_10_1 & 275.3 & 24.0 & 8.3 & 15.5 \\
Ju_10_1 & 338.8 & 24.0 & 24.9 & 38.9 \\
\hline
\end{tabular}

Topaz-albite microgranite (Ju 20)

\begin{tabular}{|c|c|c|c|c|}
\hline Sample & Al & Ti & $\mathbf{K}$ & $\mathrm{Fe}$ \\
\hline Ju_20_1 & 222.3 & 48.0 & 24.9 & 31.1 \\
\hline Ju_20_1 & 222.3 & 36.0 & 10.0 & 15.5 \\
\hline Ju_20_1 & 545.3 & 48.0 & 74.7 & 38.9 \\
\hline Ju_20_1 & 211.8 & 48.0 & 16.6 & 15.5 \\
\hline Ju_20_1 & 561.2 & 48.0 & 265.6 & 77.7 \\
\hline Ju_20_1 & 291.2 & 48.0 & 33.2 & 31.1 \\
\hline Ju_20_1 & 222.3 & 30.0 & 16.6 & 15.5 \\
\hline Ju_20_1 & 9.0 & 12.0 & 8.3 & 23.3 \\
\hline Ju_20_1 & 9.0 & 12.0 & 16.6 & 7.8 \\
\hline Ju_20_1 & 201.2 & 48.0 & 16.6 & 15.5 \\
\hline Ju_20_1 & 217.1 & 42.0 & 16.6 & 38.9 \\
\hline Ju_20_1 & 248.8 & 54.0 & 24.9 & 31.1 \\
\hline Ju_20_1 & 217.1 & 48.0 & 8.3 & 15.5 \\
\hline Ju_20_1 & 534.7 & 60.0 & 149.4 & 38.9 \\
\hline Ju_20_1 & 227.6 & 54.0 & 24.9 & 23.3 \\
\hline Ju_20_1 & 354.7 & 48.0 & 74.7 & 38.9 \\
\hline Ju_20_1 & 217.1 & 48.0 & 8.3 & 23.3 \\
\hline Ju_20_1 & 238.2 & 30.0 & 24.9 & 23.3 \\
\hline Ju_20_1 & 238.2 & 54.0 & 16.6 & 15.5 \\
\hline Ju_20_1 & 259.4 & 42.0 & 16.6 & 15.5 \\
\hline Ju_20_1 & 222.3 & 42.0 & 16.6 & 7.8 \\
\hline Ju_20_1 & 270.0 & 42.0 & 33.2 & 31.1 \\
\hline Ju_20_1 & 211.8 & 54.0 & 24.9 & 7.8 \\
\hline Ju_20_1 & 232.9 & 54.0 & 16.6 & 23.3 \\
\hline Ju_20_1 & 248.8 & 42.0 & 24.9 & 23.3 \\
\hline Ju_20_1 & 254.1 & 30.0 & 24.9 & 23.3 \\
\hline Ju_20_1 & 264.7 & 54.0 & 16.6 & 7.8 \\
\hline Ju_20_1 & 349.4 & 48.0 & 74.7 & 31.1 \\
\hline Ju_20_1 & 328.2 & 48.0 & 33.2 & 15.5 \\
\hline Ju_20_1 & 222.3 & 48.0 & 24.9 & 23.3 \\
\hline Ju_20_1 & 217.1 & 42.0 & 16.6 & 31.1 \\
\hline Ju_20_1 & 238.2 & 36.0 & 33.2 & 15.5 \\
\hline Ju_20_1 & 222.3 & 54.0 & 16.6 & 15.5 \\
\hline
\end{tabular}

Topaz-albite microgranite (Ju 20)

\begin{tabular}{|c|c|c|c|c|}
\hline Sample & Al & Ti & $\mathbf{K}$ & $\mathrm{Fe}$ \\
\hline$\overline{J u} \_20 \_1$ & 217.1 & 42.0 & 16.6 & 31.1 \\
\hline Ju_20_1 & 232.9 & 36.0 & 16.6 & 31.1 \\
\hline Ju_20_1 & 296.5 & 36.0 & 49.8 & 23.3 \\
\hline Ju_20_1 & 296.5 & 48.0 & 8.3 & 7.8 \\
\hline Ju_20_1 & 217.1 & 36.0 & 8.3 & 23.3 \\
\hline Ju_20_1 & 238.2 & 24.0 & 24.9 & 31.1 \\
\hline Ju_20_1 & 211.8 & 42.0 & 8.3 & 31.1 \\
\hline Ju_20_1 & 211.8 & 18.0 & 16.6 & 15.5 \\
\hline Ju_20_1 & 275.3 & 36.0 & 41.5 & 31.1 \\
\hline Ju_20_1 & 502.9 & 36.0 & 149.4 & 54.4 \\
\hline Ju_20_1 & 190.6 & 24.0 & 16.6 & 23.3 \\
\hline Ju_20_1 & 217.1 & 36.0 & 16.6 & 15.5 \\
\hline Ju_20_1 & 232.9 & 24.0 & 24.9 & 23.3 \\
\hline Ju_20_1 & 291.2 & 24.0 & 16.6 & 31.1 \\
\hline Ju_20_1 & 296.5 & 18.0 & 24.9 & 15.5 \\
\hline Ju_20_1 & 211.8 & 24.0 & 8.3 & 31.1 \\
\hline Ju_20_1 & 227.6 & 36.0 & 24.9 & 38.9 \\
\hline Ju_20_1 & 301.8 & 36.0 & 24.9 & 38.9 \\
\hline Ju_20_1 & 217.1 & 30.0 & 16.6 & 46.6 \\
\hline Ju_20_1 & 836.5 & 48.0 & 298.8 & 124.4 \\
\hline Ju_20_1 & 222.3 & 12.0 & 16.6 & 38.9 \\
\hline Ju_20_1 & 270.0 & 24.0 & 24.9 & 38.9 \\
\hline Ju_20_1 & 206.5 & 18.0 & 16.6 & 54.4 \\
\hline Ju_20_1 & 365.3 & 24.0 & 49.8 & 77.7 \\
\hline Ju_20_1 & 227.6 & 18.0 & 16.6 & 77.7 \\
\hline Ju_20_1 & 206.5 & 18.0 & 16.6 & 116.6 \\
\hline Ju_20_1 & 158.8 & 18.0 & 24.9 & 163.2 \\
\hline Ju_20_1 & 232.9 & 30.0 & 66.4 & 272.1 \\
\hline Ju_20_2 & 301.8 & 30.0 & 49.8 & 38.9 \\
\hline Ju_20_2 & 206.5 & 48.0 & 16.6 & 31.1 \\
\hline Ju_20_2 & 248.8 & 42.0 & 24.9 & 31.1 \\
\hline Ju_20_2 & 481.8 & 36.0 & 141.1 & 54.4 \\
\hline Ju_20_2 & 741.2 & 36.0 & 215.8 & 93.3 \\
\hline Ju_20_2 & 232.9 & 30.0 & 8.3 & 23.3 \\
\hline Ju_20_2 & 206.5 & 48.0 & 16.6 & 15.5 \\
\hline Ju_20_2 & 291.2 & 42.0 & 8.3 & 23.3 \\
\hline Ju_20_2 & 217.1 & 42.0 & 8.3 & 15.5 \\
\hline Ju_20_2 & 211.8 & 30.0 & 16.6 & 23.3 \\
\hline
\end{tabular}

Podlesi dyke granite

\begin{tabular}{cccrr}
\hline Sample & Al & Ti & K & Fe \\
\hline Podlesi & 160 & 40 & 20 & 0 \\
Podlesi & 150 & 30 & 20 & 10 \\
Podlesi & 180 & 30 & 10 & 10 \\
Podlesi & 160 & 40 & 20 & 10 \\
Podlesi & 160 & 10 & 20 & 0 \\
Podlesi & 230 & 30 & 20 & 0 \\
Podlesi & 270 & 20 & 30 & 20 \\
Podlesi & 250 & 40 & 10 & 10 \\
Podlesi & 350 & 30 & 30 & 0 \\
Podlesi & 170 & 20 & 20 & 20 \\
Podlesi & 480 & 30 & 30 & 0 \\
Podlesi & 490 & 20 & 30 & 0 \\
Podlesi & 570 & 20 & 30 & 20 \\
Podlesi & 620 & 20 & 20 & 20 \\
Podlesi & 480 & 20 & 40 & 20 \\
Podlesi & 410 & 30 & 20 & 0 \\
\hline
\end{tabular}




\section{List of trace element analysis of quartz (EPMA) (continued)}

Podlesi dyke granite

\begin{tabular}{crrrr}
\hline Sample & Al & Ti & K & Fe \\
\hline Podlesi & 410 & 20 & 0 & 0 \\
Podlesi & 570 & 20 & 30 & 10 \\
Podlesi & 400 & 10 & 20 & 10 \\
Podlesi & 2000 & 20 & 30 & 10 \\
Podlesi & 280 & 40 & 20 & 10 \\
Podlesi & 390 & 20 & 20 & 10 \\
Podlesi & 2000 & 30 & 1140 & 90 \\
Podlesi & 130 & 20 & 20 & 20 \\
Podlesi & 220 & 20 & 10 & 10 \\
Podlesi & 120 & 10 & 20 & 20 \\
Podlesi & 160 & 20 & 60 & 0 \\
Podlesi & 490 & 30 & 170 & 0 \\
Podlesi & 570 & 30 & 150 & 0 \\
Podlesi & 120 & 10 & 30 & 10 \\
Podlesi & 130 & 10 & 10 & 20 \\
Podlesi & 2000 & 50 & 20 & 90 \\
Podlesi & 880 & 30 & 30 & 40 \\
Podlesi & 260 & 20 & 20 & 40 \\
Podlesi & 280 & 20 & 10 & 50 \\
Podlesi & 180 & 10 & 20 & 60 \\
Podlesi & 280 & 20 & 40 & 90 \\
Podlesi & 510 & 30 & 80 & 110 \\
\hline
\end{tabular}

Schellerhau SG3

\begin{tabular}{lrrrr}
\hline \multicolumn{1}{c}{ Sample } & \multicolumn{1}{c}{ Al } & Ti & K & Fe \\
\hline Schell G3 & 720 & 60 & 10 & 20 \\
Schell G4 & 120 & 50 & 10 & 10 \\
Schell G5 & 50 & 20 & 0 & 10 \\
Schell G6 & 490 & 20 & 10 & 0 \\
Schell G7 & 10 & 10 & 10 & 0 \\
Schell G8 & 30 & 30 & 10 & 0 \\
Schell G9 & 30 & 30 & 10 & 20 \\
Schell G10 & 280 & 10 & 20 & 10 \\
Schell G11 & 370 & 30 & 10 & 10 \\
Schell G12 & 280 & 50 & 10 & 10 \\
Schell G13 & 280 & 40 & 10 & 0 \\
Schell G14 & 270 & 40 & 10 & 10 \\
Schell G15 & 1810 & 30 & 0 & 10 \\
Schell G16 & 410 & 40 & 20 & 20 \\
Schell G17 & 580 & 20 & 10 & 0 \\
Schell G18 & 240 & 60 & 20 & 30 \\
Schell G19 & 690 & 20 & 20 & 10 \\
Schell G20 & 500 & 20 & 0 & 0 \\
Schell G21 & 1150 & 40 & 0 & 0 \\
Schell G22 & 1740 & 40 & 50 & 10 \\
Schell G23 & 260 & 30 & 20 & 10 \\
Schell G24 & 380 & 20 & 20 & 0 \\
Schell G25 & 350 & 10 & 10 & 0 \\
Schell G26 & 30 & 20 & 20 & 0 \\
\hline
\end{tabular}

Schellerhau SG3

\begin{tabular}{|c|c|c|c|c|}
\hline Sample & $\mathbf{A l}$ & $\mathbf{T i}$ & $\mathbf{K}$ & $\mathrm{Fe}$ \\
\hline Schell G27 & 330 & 20 & $\overline{0}$ & 10 \\
\hline Schell G28 & 10 & 20 & 20 & 0 \\
\hline Schell G29 & 370 & 20 & 0 & 10 \\
\hline Schell G30 & 270 & 40 & 10 & 10 \\
\hline Schell G31 & 100 & 30 & 10 & 0 \\
\hline Schell G32 & 10 & 0 & 10 & 0 \\
\hline Schell G33 & 80 & 20 & 20 & 10 \\
\hline Schell G34 & 70 & 30 & 10 & 0 \\
\hline Schell G35 & 130 & 40 & 0 & 10 \\
\hline Schell G36 & 520 & 30 & 20 & 10 \\
\hline Schell G37 & 130 & 40 & 10 & 0 \\
\hline Schell G38 & 130 & 30 & 10 & 20 \\
\hline Schell G39 & 0 & 40 & 10 & 10 \\
\hline Schell G40 & 160 & 30 & 20 & 0 \\
\hline Schell G41 & 230 & 20 & 20 & 0 \\
\hline Schell G42 & 130 & 20 & 10 & 0 \\
\hline Schell G43 & 230 & 10 & 0 & 10 \\
\hline Schell G44 & 100 & 20 & 0 & 0 \\
\hline Schell G45 & 70 & 20 & 10 & 0 \\
\hline Schell G46 & 30 & 0 & 10 & 0 \\
\hline Schell G47 & 30 & 10 & 0 & 0 \\
\hline Schell G48 & 40 & 10 & 10 & 10 \\
\hline Schell G49 & 0 & 30 & 10 & 20 \\
\hline Schell G50 & 30 & 10 & 0 & 10 \\
\hline Schell G51 & 80 & 10 & 50 & 10 \\
\hline Schell G52 & 40 & 20 & 10 & 10 \\
\hline Schell G53 & 30 & 0 & 0 & 0 \\
\hline Schell G54 & 20 & 30 & 0 & 0 \\
\hline Schell G55 & 10 & 10 & 10 & 0 \\
\hline Schell G56 & 30 & 20 & 10 & 0 \\
\hline Schell G57 & 30 & 20 & 0 & 0 \\
\hline Schell G58 & 10 & 20 & 0 & 10 \\
\hline Schell G59 & 0 & 20 & 0 & 0 \\
\hline Schell G60 & 0 & 10 & 0 & 0 \\
\hline Schell G61 & 0 & 10 & 10 & 10 \\
\hline Schell G62 & 0 & 0 & 0 & 0 \\
\hline Schell G63 & 0 & 20 & 20 & 10 \\
\hline Schell G64 & 0 & 20 & 10 & 0 \\
\hline Schell G65 & 0 & 10 & 10 & 10 \\
\hline Schell G66 & 0 & 10 & 0 & 10 \\
\hline Schell G67 & 0 & 20 & 10 & 10 \\
\hline Schell G68 & 0 & 0 & 10 & 0 \\
\hline Schell G69 & 0 & 0 & 0 & 10 \\
\hline Schell G70 & 0 & 10 & 0 & 0 \\
\hline Schell G71 & 0 & 0 & 10 & 10 \\
\hline Schell G72 & 0 & 20 & 0 & 10 \\
\hline Schell G73 & 0 & 30 & 20 & 0 \\
\hline Schell G74 & 0 & 20 & 10 & 0 \\
\hline Schell G75 & 0 & 30 & 20 & 10 \\
\hline Schell G76 & 0 & 10 & 0 & 0 \\
\hline
\end{tabular}




\section{Appendix E}

List of trace element analysis of quartz (SIMS) given in relative concentrations $\left(\mathrm{X} /{ }^{30} \mathrm{Si}\right)$

1 Megaquartz

\begin{tabular}{lrrrrrr}
\hline \multicolumn{1}{c}{ Sample } & $\mathbf{6 L i} / \mathbf{3 0 S i}$ & \multicolumn{1}{c|}{ 23Na/30Si } & \multicolumn{1}{c|}{ 27Al/30Si } & \multicolumn{1}{c}{ 39K/30Si } & \multicolumn{1}{c|}{ 48Ti/30Si } & 54Fe/30Si \\
\hline Hak01 & $2.16 \mathrm{E}-04$ & $3.78 \mathrm{E}-05$ & $1.54 \mathrm{E}-02$ & $2.12 \mathrm{E}-05$ & $2.52 \mathrm{E}-06$ & $2.88 \mathrm{E}-06$ \\
Hak02 & $1.06 \mathrm{E}-05$ & $1.51 \mathrm{E}-05$ & $3.10 \mathrm{E}-03$ & $1.72 \mathrm{E}-05$ & $1.14 \mathrm{E}-06$ & $2.67 \mathrm{E}-07$ \\
Hak03 & $2.84 \mathrm{E}-04$ & $2.39 \mathrm{E}-05$ & $1.50 \mathrm{E}-02$ & $9.12 \mathrm{E}-06$ & $2.07 \mathrm{E}-06$ & $2.75 \mathrm{E}-06$ \\
Hak04 & $2.21 \mathrm{E}-04$ & $1.69 \mathrm{E}-05$ & $1.03 \mathrm{E}-02$ & $5.36 \mathrm{E}-06$ & $1.82 \mathrm{E}-06$ & $2.15 \mathrm{E}-06$ \\
Hak05 & $3.02 \mathrm{E}-04$ & $1.92 \mathrm{E}-05$ & $1.53 \mathrm{E}-02$ & $6.55 \mathrm{E}-06$ & $1.66 \mathrm{E}-06$ & $3.48 \mathrm{E}-06$ \\
Hak06 & $7.17 \mathrm{E}-06$ & $1.93 \mathrm{E}-05$ & $7.87 \mathrm{E}-04$ & $1.09 \mathrm{E}-05$ & $8.76 \mathrm{E}-12$ & $1.47 \mathrm{E}-07$ \\
\hline
\end{tabular}

8 Aue Granite

\begin{tabular}{|c|c|c|c|c|c|c|}
\hline Sample & $6 \mathrm{Li} / 30 \mathrm{Si}$ & $23 \mathrm{Na} / 30 \mathrm{Si}$ & $27 \mathrm{Al} / 30 \mathrm{Si}$ & $39 \mathrm{~K} / 30 \mathrm{Si}$ & 48Ti/30Si & $54 \mathrm{Fe} / 30 \mathrm{Si}$ \\
\hline AUE01 & $5.20 \mathrm{E}-04$ & $3.86 \mathrm{E}-04$ & $2.80 \mathrm{E}-02$ & $6.64 \mathrm{E}-04$ & $1.82 \mathrm{E}-04$ & $1.40 \mathrm{E}-05$ \\
\hline AUE02 & $5.25 \mathrm{E}-04$ & $1.43 \mathrm{E}-04$ & $2.56 \mathrm{E}-02$ & $1.27 \mathrm{E}-04$ & $1.77 \mathrm{E}-04$ & $1.13 \mathrm{E}-05$ \\
\hline AUE03 & $4.90 \mathrm{E}-04$ & $1.79 \mathrm{E}-04$ & $2.53 \mathrm{E}-02$ & $1.30 \mathrm{E}-04$ & $1.90 \mathrm{E}-04$ & $1.28 \mathrm{E}-05$ \\
\hline AUE04 & $3.90 \mathrm{E}-04$ & $1.70 \mathrm{E}-04$ & $2.10 \mathrm{E}-02$ & $1.23 \mathrm{E}-04$ & 2.04E-04 & $1.20 \mathrm{E}-05$ \\
\hline AUE05 & $4.16 \mathrm{E}-04$ & $1.06 \mathrm{E}-04$ & $2.05 \mathrm{E}-02$ & $6.77 \mathrm{E}-05$ & $1.92 \mathrm{E}-04$ & $9.15 \mathrm{E}-06$ \\
\hline AUE06 & $3.04 \mathrm{E}-04$ & $1.06 \mathrm{E}-04$ & $1.56 \mathrm{E}-02$ & 7.66E-05 & 2.22E-04 & 7.41E-06 \\
\hline AUE07 & $2.89 \mathrm{E}-04$ & $1.51 \mathrm{E}-04$ & $1.60 \mathrm{E}-02$ & $9.13 \mathrm{E}-05$ & $2.24 \mathrm{E}-04$ & $8.69 \mathrm{E}-06$ \\
\hline AUE08 & $1.29 \mathrm{E}-04$ & $1.92 \mathrm{E}-04$ & $1.16 \mathrm{E}-02$ & 1.49E-04 & 2.70E-05 & $6.15 \mathrm{E}-06$ \\
\hline AUE10 & $3.25 \mathrm{E}-04$ & 2.81E-04 & 2.14E-02 & 2.36E-04 & 2.02E-04 & $1.26 \mathrm{E}-05$ \\
\hline AUE11 & $1.23 \mathrm{E}-04$ & $9.85 \mathrm{E}-04$ & $1.47 \mathrm{E}-02$ & $4.32 \mathrm{E}-04$ & 1.33E-04 & 9.44E-06 \\
\hline AUE12 & $1.79 \mathrm{E}-04$ & $4.69 \mathrm{E}-04$ & $1.77 \mathrm{E}-02$ & $1.97 \mathrm{E}-04$ & 2.07E-04 & $1.08 \mathrm{E}-05$ \\
\hline AUE14 & $1.87 \mathrm{E}-04$ & $3.08 \mathrm{E}-04$ & $1.53 \mathrm{E}-02$ & $1.54 \mathrm{E}-04$ & 2.10E-04 & $9.91 \mathrm{E}-06$ \\
\hline AUE15 & $1.89 \mathrm{E}-04$ & $3.70 \mathrm{E}-04$ & $1.62 \mathrm{E}-02$ & $1.96 \mathrm{E}-04$ & 2.06E-04 & $1.15 \mathrm{E}-05$ \\
\hline AUE17 & $1.73 \mathrm{E}-04$ & 2.24E-04 & $1.50 \mathrm{E}-02$ & $1.46 \mathrm{E}-04$ & $1.89 \mathrm{E}-04$ & $1.10 \mathrm{E}-05$ \\
\hline AUE18 & 2.23E-04 & $1.80 \mathrm{E}-04$ & $1.60 \mathrm{E}-02$ & $1.28 \mathrm{E}-04$ & $1.92 \mathrm{E}-04$ & $1.07 \mathrm{E}-05$ \\
\hline AUE19 & 2.33E-04 & $1.77 \mathrm{E}-04$ & $1.67 \mathrm{E}-02$ & $1.29 \mathrm{E}-04$ & 2.01E-04 & 1.11E-05 \\
\hline AUE20 & $3.23 \mathrm{E}-04$ & $1.87 \mathrm{E}-04$ & 2.31E-02 & $1.47 \mathrm{E}-04$ & 2.31E-04 & $1.83 \mathrm{E}-05$ \\
\hline AUE21 & $3.26 \mathrm{E}-04$ & $1.48 \mathrm{E}-04$ & $1.67 \mathrm{E}-02$ & $9.06 \mathrm{E}-05$ & 2.26E-04 & $8.31 \mathrm{E}-06$ \\
\hline AUE24 & $2.26 \mathrm{E}-04$ & $1.49 \mathrm{E}-04$ & $1.67 \mathrm{E}-02$ & $1.10 \mathrm{E}-04$ & 2.23E-04 & $1.60 \mathrm{E}-05$ \\
\hline AUE25 & 2.79E-04 & 2.32E-04 & $2.14 \mathrm{E}-02$ & $1.49 \mathrm{E}-04$ & $1.39 \mathrm{E}-04$ & 2.94E-05 \\
\hline AUE27 & $1.17 \mathrm{E}-04$ & $3.38 \mathrm{E}-04$ & $1.38 \mathrm{E}-02$ & $1.85 \mathrm{E}-04$ & 8.42E-06 & $5.52 \mathrm{E}-05$ \\
\hline AUE28 & $1.90 \mathrm{E}-04$ & $1.44 \mathrm{E}-03$ & 2.93E-02 & $3.74 \mathrm{E}-04$ & $1.28 \mathrm{E}-04$ & 3.01E-05 \\
\hline AUE29 & $1.89 \mathrm{E}-04$ & $6.53 \mathrm{E}-04$ & $1.98 \mathrm{E}-02$ & 4.89E-04 & 0.000129 & $2.78 \mathrm{E}-05$ \\
\hline AUE30 & $2.26 \mathrm{E}-04$ & 2.94E-04 & $2.08 \mathrm{E}-02$ & 2.15E-04 & $1.27 \mathrm{E}-04$ & 2.23E-05 \\
\hline AUE31 & $2.89 \mathrm{E}-04$ & $3.28 \mathrm{E}-04$ & $2.37 \mathrm{E}-02$ & 2.71E-04 & $1.27 \mathrm{E}-04$ & 2.35E-05 \\
\hline AUE32 & $2.46 \mathrm{E}-04$ & $5.01 \mathrm{E}-04$ & $2.21 \mathrm{E}-02$ & $3.28 \mathrm{E}-04$ & $1.37 \mathrm{E}-04$ & 2.02E-05 \\
\hline AUE33 & 2.22E-04 & 4.98E-04 & $2.15 \mathrm{E}-02$ & 3.52E-04 & $1.59 \mathrm{E}-04$ & $2.20 \mathrm{E}-05$ \\
\hline AUE35 & 1.49E-04 & 4.71E-04 & $1.74 \mathrm{E}-02$ & $3.85 \mathrm{E}-04$ & 2.06E-04 & $1.82 \mathrm{E}-05$ \\
\hline AUE36 & $1.63 \mathrm{E}-04$ & 3.99E-04 & $1.78 \mathrm{E}-02$ & 2.12E-04 & 2.03E-04 & $1.61 \mathrm{E}-05$ \\
\hline AUE38 & $2.90 \mathrm{E}-04$ & 4.33E-04 & $2.78 \mathrm{E}-02$ & $3.14 \mathrm{E}-04$ & $9.90 \mathrm{E}-05$ & $2.98 \mathrm{E}-05$ \\
\hline AUE39 & $1.31 \mathrm{E}-04$ & 8.14E-04 & $1.64 \mathrm{E}-02$ & $5.72 \mathrm{E}-04$ & $1.64 \mathrm{E}-04$ & $1.85 \mathrm{E}-05$ \\
\hline AUE40 & $2.54 \mathrm{E}-04$ & $2.80 \mathrm{E}-04$ & $1.87 \mathrm{E}-02$ & $2.00 \mathrm{E}-04$ & $2.00 \mathrm{E}-04$ & $1.91 \mathrm{E}-05$ \\
\hline
\end{tabular}

15 Weinheim Rhyolite

\begin{tabular}{|c|c|c|c|c|c|c|}
\hline Sample & $6 \mathrm{Li} / 30 \mathrm{Si}$ & $23 \mathrm{Na} / 30 \mathrm{Si}$ & $27 \mathrm{Al} / 30 \mathrm{Si}$ & 39K/30Si & $48 \mathrm{Ti} / 30 \mathrm{Si}$ & $54 \mathrm{Fe} / 30 \mathrm{Si}$ \\
\hline Rhy01 & $2.32 \mathrm{E}-04$ & $2.05 \mathrm{E}-04$ & $1.83 \mathrm{E}-02$ & $1.87 \mathrm{E}-04$ & $1.76 \mathrm{E}-04$ & $2.26 \mathrm{E}-05$ \\
\hline Rhy02 & $2.18 \mathrm{E}-04$ & 2.16E-04 & $1.61 \mathrm{E}-02$ & 1.94E-04 & $2.26 \mathrm{E}-04$ & $1.90 \mathrm{E}-05$ \\
\hline Rhy04 & $9.44 \mathrm{E}-05$ & 2.43E-04 & $1.66 \mathrm{E}-02$ & $2.11 \mathrm{E}-04$ & 2.44E-04 & $1.91 \mathrm{E}-05$ \\
\hline Rhy05 & $1.10 \mathrm{E}-04$ & 2.39E-04 & $1.63 \mathrm{E}-02$ & $2.15 \mathrm{E}-04$ & 2.37E-04 & $2.02 \mathrm{E}-05$ \\
\hline Rhy06 & $9.01 \mathrm{E}-05$ & 2.19E-04 & 1.61E-02 & $1.98 \mathrm{E}-04$ & $2.38 \mathrm{E}-04$ & $1.89 \mathrm{E}-05$ \\
\hline Rhy07 & $9.22 \mathrm{E}-05$ & $2.52 \mathrm{E}-04$ & $1.53 \mathrm{E}-02$ & 2.18E-04 & $2.28 \mathrm{E}-04$ & $1.87 \mathrm{E}-05$ \\
\hline Rhy08 & $1.34 \mathrm{E}-04$ & $2.66 \mathrm{E}-04$ & $1.75 \mathrm{E}-02$ & 2.53E-04 & $1.86 \mathrm{E}-04$ & 2.09E-05 \\
\hline Rhy09 & $2.46 \mathrm{E}-04$ & $1.35 \mathrm{E}-03$ & $3.20 \mathrm{E}-02$ & 3.04E-03 & 2.97E-04 & 4.04E-05 \\
\hline Rhy10 & 2.91E-04 & $2.60 \mathrm{E}-03$ & $3.38 \mathrm{E}-02$ & 3.34E-03 & 3.07E-04 & $4.31 \mathrm{E}-05$ \\
\hline Rhy11 & $3.66 \mathrm{E}-04$ & $6.38 \mathrm{E}-04$ & 2.29E-02 & $7.56 \mathrm{E}-04$ & $2.41 \mathrm{E}-04$ & $3.06 \mathrm{E}-05$ \\
\hline Rhy13 & 2.79E-04 & $2.70 \mathrm{E}-04$ & 1.64E-02 & 2.31E-04 & 7.65E-05 & $1.93 \mathrm{E}-05$ \\
\hline Rhy14 & $2.18 \mathrm{E}-04$ & 2.47E-04 & $1.40 \mathrm{E}-02$ & $1.98 \mathrm{E}-04$ & 4.64E-05 & $1.80 \mathrm{E}-05$ \\
\hline Rhy15 & $1.55 \mathrm{E}-04$ & $1.53 \mathrm{E}-03$ & $1.94 \mathrm{E}-02$ & $1.03 \mathrm{E}-03$ & $1.29 \mathrm{E}-04$ & $5.97 \mathrm{E}-05$ \\
\hline
\end{tabular}




\section{Curriculum vitae}

Date \& place of birth:

Education:
2 June 1970, Dresden, Germany

1977-1983 Polytechnische Oberschule, Dresden

1983-1987 Polytechnische Oberschule, Leipzig

1987-1989 Abitur, Halle

1989-1990 Civil Service

1990-1993; Mining Academy Freiberg

1993-1996; University Göttingen

Diploma in Geology/Paleontology

Advisor: H.-J. Behr

Co-advisor: D. Helmcke

Thesis: Part I - Investigation of magmatic, metamorphic and hydrothermal quartz from the Oberpfalz/Germany with thermal acoustic emission analysis [in German];

Part II - Geological mapping SE of the Flossenbürg Granite Massif, Oberpfalz, Germany [in German]

1996-1997; University Göttingen

Work on DEKORP-Project: Development and application of gravimetric methods for the evidence of steep dipping structures in seismic profiles

1997-2000; University Göttingen

Ph.D. Studies in Earth Sciences

Advisor: H.-J. Behr

Co-advisor: K. Weber

Thesis: Cathodoluminescence and characterisation of defect structures in quartz with applications to the study of granitic rocks 